Monatsschr Kinderheilkd 2017 · 165

(Suppl 1):S1-S111

DOI 10.1007/s00112-017-0301-5

๑) Springer Medizin Verlag GmbH 2017

CrossMark

\section{Abstracts 2017 der GNPI und DGPI}

\author{
43. Jahrestagung der Gesellschaft \\ für Neonatologie und Pädiatrische \\ Intensivmedizin und 25. Jahrestagung der \\ Deutschen Gesellschaft für Pädiatrische \\ Infektiologie, 8.-10. Juni 2017, Dresden
}

\author{
Tagungsleitung der GNPI: \\ Prof. Dr. Mario Rüdiger, PD Dr. Jürgen Dinger, Dresden \\ Tagungsleitung der DGPI: \\ Prof. Dr. Reinhard Berner, Dresden
}

\section{Freie Vorträge GNPI}

\section{GNPI-V01 \\ "Studenten werden Paten“ - praxisorientiertes, individuelles Lehrprojektes in der Neonatologie}

S. Poralla, T. Dresbach, A. Müller

Universitätsklinikum Bonn, Neonatologie und Pädiatrische Intensivmedizin, Bonn, Deutschland

Projekt: Ein seit fünf Jahren etabliertes Lehrprojekt der Abteilung für Neonatologie am Universitätsklinikum Bonn ermöglicht Medizinstudenten ein gesundes Kind von der Geburt an bis zum Ende des zweiten Lebensjahres zu begleiten. Die Studenten lernen ihr „Patenkind“ direkt nach der Geburt kennen und begleiten die Familie in den ersten zwei Jahren zu allen Kinderarztbesuchen, insbesondere den Vorsorgeuntersuchungen. So erleben die „Paten“ hautnah und aktiv, wie sich ein Kind normal entwickelt unter motorischen, sprachlichen und psychosozialen Aspekten.

Ablauf: Das erste Kennenlernen findet im Rahmen der U2 statt. Ab diesem Zeitpunkt erfolgt die regelmäßige Kontaktaufnahme zwischen Paten und Patenfamilien in Eigenverantwortung, die jeweiligen Arzttermine werden individuell untereinander abgesprochen. Die Studenten haben einen Arzt als Ansprechpartner, der sie in Kleingruppen in Seminaren auf die jeweils bevorstehende Vorsorgeuntersuchung vorbereitet. Durch gute Kooperation mit den niedergelassenen Kinderärzten wird eine ebenso intensive Betreuung in den Praxen gewährleistet.

Ziel: Das Projekt ermöglicht Studenten bereits in den überwiegend theoretisch ausgerichteten vorklinischen und ersten klinischen Semestern erste Patientenkontakte, ein „Miterleben“ der frühkindlichen Entwicklung, somit erste Kontakte mit dem pädiatrischen Berufsfeld. Nach dem Grundsatz „nur wer ein gesundes Kind kennt, kann auch Krankheiten erkennen“ legen die Studenten mit ihren gesammelten praktischen Erfahrungen einen wichtigen Grundstein für ihr späteres Berufsleben.

Bisherige Erfahrungen: Das Projekt stößt bei Eltern und Studenten auf außerordentlich gute Resonanz. Jedes Semester bewerben sich deutlich mehr Studenten als Plätze zur Verfügung stehen. Die Studenten sind sehr motiviert und engagiert. Aus einigen Patenschaften wird mehr: Besuche zu Hause, Paten als Babysitter, regelmäßiger Kontakt auch zwischen den Terminen der U-Untersuchungen und über die geplanten zwei Jahre. Die
Evaluationen zeigen, dass Studenten durch ein solches Projekt einen intensiveren Einblick in die Pädiatrie erhalten und ihr Interesse für diesen Fachbereich geweckt werden kann. Um das Gelingen des Projektes und die Zufriedenheit aller beteiligten Personen zu gewährleisten, ist ein hoher personeller Betreuungsaufwand notwendig, der aber insgesamt mehr als gerechtfertigt ist und durch das positive Feedback belohnt wird.

Ausblick: Das Konzept des Projektes lässt sich auch auf andere Bereiche der Pädiatrie anwenden und ermöglicht Studenten Lernen durch aktives Erleben. Fähigkeiten, die so erworben werden können, sind nur schwer durch traditionelle Lehrformen vermittelbar. Profitieren würden Studenten auch von Lehrprojekten in den Fachbereichen Allgemeinpädiatrie, Kardiologie und Onkologie, bei denen Studenten die Möglichkeit erhalten, einen einzelnen Patienten über längere Zeit zu begleiten. Um eine adäquate Umsetzung zu ermöglichen, sind weitere personelle Ressourcen erforderlich.

\section{GNPI-V02}

Effect of different volume expansion strategies on return of spontaneous circulation (ROSC) in a newbornpiglet model of asphyxia and hemorrhage

M. R. Mendler', L. Hechenrieder', S. Kurth', S. Schwarz', B. Mayer', H. Hummler ${ }^{1}$

'Klinik für Kinder- und Jugendmedizin, Universitätsklinikum Ulm, Sektion Neonatologie und pädiatrische Intensivmedizin, Ulm, Deutschland, 2Universität Ulm, Institut für Epidemiologie und Medizinische Biometrie, Ulm, Deutschland

Background: Immediately after birth approximately $5 \%$ of newborn infants need respiratory support and very few need chest compressions (CC). Current ILCOR guidelines suggest volume replacement when blood loss is known or suspected and the infant"s heart rate remains less than $60 / \mathrm{min}$ despite adequate ventilation with $100 \%$ oxygen and CC. However, it is not clear whether early blood transfusion improves outcome as compared to isotonic crystalloid solution.

Objective: To test the hypothesis that early blood transfusion reduces time to ROSC as compared to isotonic crystalloid during resuscitation in a newborn piglet model of asphyxia and hemorrhagic shock.

Design/Methods: Forty-four asphyxiated newborn piglets with controlled hemorrhage with cardiac arrest undergoing cardio-pulmonary resuscita- 
tion according to ILCOR 2015 guidelines were randomized into an early transfusion and an crystalloid replacement group.

Results: Average blood extraction was in median (IQR) 30.7 (22.3-39.6) $\mathrm{ml} / \mathrm{kg}$ in the crystalloid and $34.6(25.2-44.7) \mathrm{ml} / \mathrm{kg}$ in the blood group. 33 animals received volume expansion. 16 in the crystalloid group and 17 in the blood group. We found no significant difference in time to ROSC between groups (Crystalloid: $164(129-198)$ s; Blood: 163 (162-199) s; Median (IQR)). There was no difference in use of epinephrine. Immediately after ROSC there was a significant higher potassium and lactate in the blood group and a significant higher $\mathrm{PaO}_{2}$ in the crystalloid group.

Conclusions: Our hypothesis that early blood transfusion reduces time to ROSC during resuscitation compared to using a crystalloid solution was not confirmed. However, our model is limited by the fact that ROSC occurred already at a time when only 12 (7-21) \% (Median (IQR) of depleted blood volume was re-transfused suggesting that hemorrhagic shock not severe enough to limit resuscitation success substantially.

\section{GNPI-V03}

Diskrepanz bei der Bewertung der Atmung beim Apgar-Score bei reifen Neugeborenen

\section{Konstantelos', J. Dinger ${ }^{1}$, N. Braun ${ }^{2}$, M. Rüdiger'}

'Medizinische Fakultät Carl Gustav Carus an der TU Dresden, Fachbereich Neonatologie und Pädiatrische Intensivmedizin, Dresden, Deutschland, ${ }^{2}$ Vivantes Auguste-Viktoria-Klinikum, Chirurgie, Viszeral- und Gefäßchirurgie, Berlin, Deutschland

Hintergrund: Der Apgar-Score wird seit 1953 weltweit für die Evaluation der postnatalen Anpassung der Neugeborenen genutzt. Allerdings haben sich seit dieser Zeit nicht nur die technischen Möglichkeiten bei der Erstversorgung verändert sondern auch das Patientenklientel. Bisher fehlt Einigkeit, wie Neugeborene mit Atemunterstützung im Apgar-Score beurteilt werden sollen.

Fragestellung: Wie wird aktuell die Atmung der reifen Neugeborenen im Apgar-Score von den Erstversorgern bewertet, wenn eine Atemunterstützung notwendig ist?

Material und Methoden: Prospektiv untersucht wurden alle reifen Neugeborenen, die im Zeitraum vom 01/2010 bis 12/2014 mit einer verzögerten postnatalen Adaptation eine Unterstützung im Kreißsaal erhielten und anschließend auf die neonatologische Intensivstation verlegt wurden. $\mathrm{Zu}-$ sätzliches Einschlusskriterium war die Notwendigkeit einer Intervention (CPAP, Ventilation, Intubation und Ventilation, Thoraxkompression oder Epinephrin-Verabreichung) für die Unterstützung der postnatalen Anpassung zur ersten, fünften oder 10. Lebensminute.

Ergebnisse: In dem Zeitraum wurden 407 Fälle von reifen Neugeborenen, die eine der oben genannten Interventionen zur ersten, fünften oder 10. Minute brauchten, erfasst. Von den 272 mit CPAP versorgten Neugeborenen erhielten $10 \%$ null, $79 \%$ einen und $11 \%$ zwei Punkte für die Atmung. 98 wurden beatmet, davon erhielten $20 \%, 79 \%$ und $10 \%$ null, einen bzw. zwei Punkte. Von den 22 intubierten Kindern hatten $27 \%$, 68 bzw. $5 \%$ eine entsprechend Punktzahl. Ähnliche Variationen fanden sich auch für andere Parameter des Apgar-Scores.

Schlussfolgerung: Die Auswertung der Daten zeigt eine Diskrepanz bei der Bewertung der Atmung im Apgar-Score bei reifen Neugeborenen mit Anpassungsstörungen. Die hier dokumentierten Variationen beruhen auf einer unscharfen Definition im klassischen Apgar-Score und lassen sich durch den COMBINED-APGAR vermeiden.

\section{GNPI-V04}

Hohe Expression von Low Density Lipoprotein Receptor-related Protein 1 (LRP-1/CD91) prädiktiert Seneszenz und eingeschränkte Funktionalität von mesenchymalen Stromazellen aus humanem Nabelschnurgewebe (hUCMSC)

M. C. Clouth', S. Klempien', J. Marzahn', S. Koss', D. Freund', B. Thébaud ${ }^{3,4}$, M. Rüdiger ${ }^{2,1}$, M. A. Möbius ${ }^{2,1,3}$

"Universitätsklinikum „Carl Gustav Carus" TU Dresden, Neonatologie und pädiatrische Intensivmedizin, Dresden, Deutschland, ${ }^{2}$ DFG Research Centre and Cluster of Excellence for Regenerative Therapies (CRTD), Dresden, Deutschland, ${ }^{3}$ Ottawa Hospital Research Institute, University of Ottawa, Sinclair Centre for Regenerative Medicine, Sprott Centre for Stem Cell Research, Ontario, Canada, ${ }^{4}$ Children's Hospital of Eastern Ontario, University of Ottawa, Division of Neonatology, Department of Pediatrics, Ontario, Canada

Hintergrund: MSC zeigen sich in aktuellen klinischen Studien als vielversprechende Zelltherapeutika. Die diesen Zellpopulationen inhärente Heterogenität, sowie das Fehlen standardisierter Methoden zur eindeutigen Charakterisierung, Qualitätskontrolle und Prädiktion therapeutischer Potenz stehen jedoch einer breiten klinischen Anwendung im Wege. Die Analyse von Oberflächenmarkern könnte eine einfache und schnelle Methode darstellen, um die Qualität und das therapeutische Potenzial einer Zellpräparation vor deren Anwendung einzuschätzen. Oberflächenmarkerscreenings (eigene, unveröffentlichte Daten) erbrachten den Nachweis einer global vermehrten Expression von LRP-1/CD91 in alten und/oder funktionell eingeschränkten MSC Populationen.

Fragestellung: Wir prüften die Hypothese, dass verschiedene Subpopulationen innerhalb einer hUCMSC Präparation basierend auf ihrer CD91 Expression identifiziert werden können.

Material und Methoden: Aus den Nabelschnüren reifer Neugeborener isolierte hUCMSC wurden zur 3. Passage PE/anti-CD91 gelabelt und mittels FACS analysiert. Zellen aus der 5.-95. (CD91lo) und aus der 85.-95. Perzentile (CD91hi) wurden gesammelt und mittels membranbasierter Arrays hinsichtlich der Konzentration Zellstress-assoziierter Proteine im Zelllysat, der Sekretion von pro- und antiinflammatorischen Zytokinen sowie Angiogenesefaktoren verglichen. Seneszenz wurde mittels $\beta$-Galactosidase Färbung sowie der Analyse von Prelamin-A/C (Progerin), einem essentiell in Pfadwegen vorzeitiger Alterung involvierten Protein, untersucht.

Ergebnisse: Im Vergleich zu CD91lo hUCMSC zeigen CD91hi Zellen eine eingeschränkte Sekretion von pro-angiogenetischen Faktoren. In den Überständen von den MSC, welche für eine hohe Expression von CD91 sortiert wurden, finden sich im Vergleich zu CD91lo MSC aus der gleichen Präparation 30-fach reduzierte Level von VEGF, sowie 13-fach reduzierte Level von PDGF-AA. Darüberhinaus zeigten CD91hi MSC - verglichen mit CD91lo Zellen - höhere Level an proinflammatoischem IL-6 und durch oxidativen Stress induziertem Thioredoxin-1. Weiterhin zeigten CD91hi MSC vermehrt Zeichen von Seneszenz im Sinne einer ausgeprägten $\beta$-Galactosidase Färbung, sowie höheren Konzentrationen von Progerin. Im Gegensatz hierzu haben CD91lo Zellen höhere Level von Sirtuin-2, einem wesentlich an der Regulierung des Zellzyklus, sowie dem Schutz der genomischen Integrität beteiligten Proteins.

Diskussion und Schlussfolgerung: Eine hohe Expression von CD91 auf der Zelloberfläche von hUCMSC ist mit vermehrter Seneszenz, oxidativem Stress und der Sekretion von pro-inflammatorischen Proteinen, sowie niedriger Produktion von pro-angiogenischen Faktoren assoziiert. Insbesondere für VEGF und PDGF-AA zeigt sich eine deutlich negative Korrelation mit der Expression von CD91. Beide Faktoren sind essentiell in der normalen Gefäßentwicklung und werden für die therapeutischen Effekte von MSC in Erkrankungen mit vaskulären Pathologien wie z. B. der Bronchopulmonalen Dysplasie (BPD) oder pulmonalen Hypertonie verantwortlich gemacht. CD91 könnte daher ein nützlicher Marker sein, um die Qualität von MSC-basierten Zellprodukten vor deren therapeutischer Anwendung zu beurteilen. Die genaue Rolle von LRP-1/CD91 in der Zellbiologie der MSCs bleibt jedoch unklar. Weiterhin muss analysiert werden, in wie fern diese in vitro Ergebnisse auch mit einem tatsächlich erhöhten therapeutischen Potenzial der MSC in vivo korrelieren. 


\section{GNPI-V05}

Fluoreszenzbasierte Analyse des mitochondrialen

Membranpotenzials $(\Delta \Psi)$ zur Identifizierung funktionell unterschiedlicher Subpopulationen mesenchymaler Stromazellen aus humanem Nabelschnurgewebe (hUCMSC)

S. Klempien', M. C. Clouth', J. Marzahn', S. Koss', D. Freund ', M. Rüdiger 1,2, B. Thébaud ${ }^{3,4}$, M. A. Möbius 1,2,3

'Fachbereich Neonatologie und pädiatrische Intensivmedizin, Klinik und Poliklinik für Kinder- und Jugendmedizin, Medizinische Fakultät und Universitätsklinikum „Carl Gustav Carus" der Technischen Universität Dresden, Dresden, Deutschland, ${ }^{2}$ DFG Research Center and Cluster of Excellence for Regenerative Therapies (CRTD), Technische Universität Dresden, Dresden, Deutschland, ${ }^{3}$ Sinclair Centre for Regenerative Medicine, Sprott Centre for Stem Cell Research, Ottawa Hospital Research Institute, University of Ottawa, Ontario, Canada, ${ }^{4}$ Division of Neonatology, Department of Pediatrics, Children's Hospital of Eastern Ontario, University of Ottawa, Ontario, Canada

Hintergrund: Zellbasierte Therapeutika, insbesondere auf der Basis von MSC, werden derzeit in verschiedenen klinischen Studien für pädiatrische und adulte Indikationen eingesetzt. Die den verwendeten Zellpopulationen inhärente Heterogenität sowie das Fehlen standardisierter Methoden zur eindeutigen Charakterisierung, Qualitätskontrolle und Prädiktion therapeutischer Potenz stehen jedoch einer breiteren klinischen Anwendung im Wege und erschweren die Interpretation der in den Studien gewonnenen klinischen Daten. Es ist bekannt, dass der Transfer von Mitochondrien von MSC zu Zielzellen eine Rolle in deren therapeutischer Aktivität spielen könnte. Zudem prädiktieren die mitochondrialen Aktivitätslevel von z. B. hämatopoietischen Stammzellen deren therapeutische Effizienz. TMRM, ein protonensensitiver, nicht toxischer Farbstoff akkumuliert in Mitochondrien mit hohem Transmembranpotenzial und kann mittels FACS analysiert werden.

Fragestellung: Das mitochondriale Membranpotenzial $\Delta \Psi$ prädiktiert unterschiedliche funktionelle Eigenschaften von hUCMSC in vitro.

Methoden: Passage 3 - hUCMSC von reifgeborenen Kindern wurden mit dem $\Delta \Psi$-sensitiven Farbstoff TMRM gefärbt und mittels FACS in zwei Gruppen (7.-10. $\left(\Delta \Psi^{\mathrm{lo}}\right)$ und 90.-93. $\left(\Delta \Psi^{\mathrm{hi}}\right)$ Perzentile) sortiert. Mittels single-cell plating wurden Morphologie sowie die Effizienz Kolonien zu bilden untersucht. Membranbasierte Arrays wurden zur Analyse der Sekretion therapeutisch aktiver Faktoren genutzt. Die Gesamtmenge an mitochondrialen Proteinen wurde durch Western Blots bestimmt und die Seneszenz mittels $\beta$-Galactosidase Färbung.

Ergebnisse: Innerhalb beider Populationen wurden gleiche Mengen an mitochondrialen Proteinen gemessen. $\Delta \Psi^{\mathrm{lo}}$-MSC waren kleiner, bildeten mehr und größere Kolonien und zeigten eine längere Lebensdauer in Einzelzell-Kultur. Außerdem implizierten Morphologie und $\beta$-Galactosidase Färbung weniger Seneszenz in der Gruppe der $\Delta \Psi^{\mathrm{lo}}$-MSC. Höhere Level von VEGF und Activin-A wurden in den Kulturüberständen der $\Delta \Psi^{\text {lo }}$ MSC Population gemessen. Im Gegensatz dazu sezernierten $\Delta \Psi^{\text {hi }}$-MSC mehr immunaktivierende Zytokine, höhere Level an Stressproteinen und anti-angiogene Faktoren wie Thrombospondin-1. Des Weiteren produzierten $\Delta \Psi^{\text {hi }}$-MSC große Mengen an potenten Antioxidantien wie FABP-1, Thioredoxin-1, Superoxiddismutase-1 und sezernierten im Gegensatz zu $\Delta \Psi^{\mathrm{lo}}$-MSC auch PDGF-AA und GM-CSF.

Schlussfolgerung: Wir demonstrierten, dass $\Delta \Psi^{\mathrm{lo}}-\mathrm{MSC}$ mit geringerer Seneszenz, Zeichen gesteigerter Stammzellaktivität und der Sekretion von pro-angiogenen Faktoren in vitro assoziiert sind. Im Gegensatz dazu produzierten $\Delta \Psi^{\text {hi }}$-MSC potente Antioxidantien und wichtige Wachstumsfaktoren. Die TMRM-Färbung mit anschließender Durchflusszytometrie ist geeignet, um die mitochondriale Gesamtfunktion von MSC-Gruppen zu untersuchen. Inwiefern diese unterschiedlichen mitochondrialen Funktionen auch mit dem therapeutischen Potenzial von MSC in vivo korrelieren wird in derzeit andauernden Experimenten untersucht.

\section{GNPI-V06}

\section{Durchflusszytometrische Analyse von Muttermilchzellen in} Abhängigkeit vom Gestationsalter

T. Keller', L. Wengenroth', D. Smorra', B. Brachvogel' ${ }^{2}$ A. Kribs ${ }^{1}$

'Uniklinik Köln, Neonatologie und Pädiatrische Intensivmedizin, Köln, Deutschland, ${ }^{2}$ Uniklinik Köln, Experimentelle Neonatologie, Köln, Deutschland

Hintergrund: Frühgeborene, die auf der NICU mit Muttermilch ernährt wurden, zeigen ein besseres neurokognitives Outcome als Formula-ernährte Frühgeborene (Vohr 2007, Rozé 2012). Muttermilch ist eine komplexe Flüssigkeit, die lebende Zellen einschließlich Stammzellen enthält (Hassiotou 2012). Der monoklonale Antikörper TRA-1-81, der zur Detektion pluripotenter humaner embryonaler Stammzellen verwendet wird, bindet an ein Epitop auf dem Zelladhäsionsmolekül Podocalyxin, das eine erhöhte Microvillusformation und Migrationsfähigkeit bedingt (Schopperle 2007, Nielsen 2009). CD11b wird auf vielen Leukozyten exprimiert einschließlich Monozyten, Makrophagen, Neutrophilen Granuloyzten. Ob sich die Milch Frühgeborener in ihrer Zellzusammensetzung von der Milch Reifgeborener unterscheidet, ist bisher nicht bekannt.

Fragestellung: Welchen Einfluss hat das Gestationsalter auf den zellulären Anteil der Muttermilch? Material und Methoden: Nach schriftlichem Einverständnis der Eltern erfolgte der Einschluss von 45 in der Neonatologie der Uniklinik Köln betreuten Mutter-Kind-Paaren (ELGAN $n=16$, Preterm $n=15$, Term $n=13$ ). Frische Muttermilchproben (5-20 ml) wurden in jeder Laktationsphase (Colostrum, Übergangsmilch, Reife Milch) gewonnen. Es wurden zu jeder Probe die klinischen Daten zum MutterKind-Paar gesammelt, sowie der Creamatokrit bestimmt. Nach Isolation der Zellen aus der frischen Milch erfolgte die Bestimmung des Zellgehalts in der Neubauer-Zählkammer. Zur sicheren durchflusszytometrischen Identifikation von kernhaltigen Zellen wurde DRAQ5 ${ }^{\text {tw }}$ verwendet, zum Ausschluss toter Zellen Sytox Blue ${ }^{\oplus}$, es folgte die Analyse der viablen Zellen auf Oberflächenmarker CD11b und TRA-1-81. Zur statistischen Überprüfung wurde der Mann-Whitney-U Test für kontinuierliche Variablen angewandt. Die Studie wurde von der Ethikkommission der Uniklinik Köln genehmigt.

Ergebnisse: Es wurden 81 Milchproben von drei Gestationsgruppen (GA1 ELGAN $=$ FG $<28$ SSW, GA2 FG $>=28$ SSW, GA3 Reifgeborene) durchflusszytometrisch untersucht (GA1: $n=44$, GA2 $n=22$, GA3 $n=15 ; 11$ Kolostrum, 23 Übergangsmilch, 48 Reife Milch). Die Zellzahl lag bei (MW \pm SD) 1.079.281 $\pm 1.277 .015 / \mathrm{ml}$. Die Viabilität 26 $\pm 15 \%$. Der Anteil CD11b+ Leukozyten lag bei $60 \pm 25 \%$. Der Anteil CD11b-/TRA-1-81+ Zellen war $20 \pm 20 \%$. Über die Gestationsgruppen zeigte sich ein Anstieg der CD11b+ Leukozyten (GA1 53 $\pm 25 \%$, GA2 $71 \pm 22 \%$, GA3 $78 \pm 15 \%$ ), GA1 vs. GA3 $p=0,027$. Der Anteil der CD11b-/TRA-1-81+ Zellen nahm $\mathrm{ab}(23 \pm 22 \% ; 17 \pm 17 \% ; 8 \pm 7 \%)$, GA1 vs. GA3 $p=0,117$. Über die Laktationsphasen Colostrum/Übergangsmilch/Reife Milch zeigte sich ein Absinken der CD11b+ Zellen $(76 \pm 16 \%, 60 \pm 25 \%, 56 \pm 26 \%), p=0,026$ für Colostrum vs. Reife Milch, sowie ein Anstieg für CD11b-/TRA-1-81+ Zellen $(p=0,013)$.

Schlussfolgerung: Mit niedrigerem Gestationsalter bei Geburt war in unserer Studie ein geringerer Leukozytenanteil und ein Trend für einen höheren Anteil TRA-1-81 positiver Zellen in der Muttermilch zu detektieren.

\section{GNPI-V07}

\section{Chorioamnionitis induziert A20 in der fetalen Lunge}

S. Kunzmann', M. Fehrholz², M. Hütten ${ }^{3}$, B. Ottensmeier' ${ }^{2}$, C. P. Speer², B. W. Kramer

${ }^{1}$ Klinik für Neonatologie und päd. Intensivmedizin, Bürgerhospital Frankfurt am Main, Frankfurt, Deutschland, ${ }^{2}$ Universitäts-Kinderklinik Würzburg, Würzburg, Deutschland, ${ }^{3}$ Universitäts-Kinderklinik, Neonatologie, Maastricht, Niederlande

Hintergrund: Das Protein A20 (TNFAIP3) übernimmt eine wichtige Rolle bei der Regulation verschiedener Signaltransduktionswege wie dem NF$\mathrm{kB}$ - und dem Smad-Signalweg. Letztere sind in Inflammations- und Re- 
modelling-Prozesse der Lunge involviert; beide spielen auch eine wichtige Rolle in der Pathogenese der bronchopulmonalen Dysplasie (BPD) Frühgeborener. Über die Bedeutung von A20 für neonatologische Erkrankungen ist bisher wenig bekannt.

Fragestellung: Ziel dieser Studie war es daher, eine potentielle Regulation von A20 durch proinflammatorische Zytokine in vitro, sowie Chorioamnionitis, eine der häufigsten Ursachen von Frühgeburtlichkeit und Trigger vieler neonataler Morbiditäten, in vivo zu charakterisieren.

Material und Methoden: Hierfür wurden A20 Genexpressions-Analysen in Lungenepithelzellen (A549), Lungenfibroblasten (IMR-90) und Lungenendothelzellen (HPMEC), welche mit LPS, IL- $1 \beta$ oder TNF- $\alpha$ inkubiert wurden, durchgeführt. Zusätzlich wurden in einem etablierten Tiermodell für Chorioamnionitis nach intraamniotischer Gabe (IA) von LPS Entzündungsmediatoren (IL-6, IL-8, TNF- $\alpha$ ) sowie die Expression von A20 mittels real-time PCR und Western-Blot in der fetalen Lunge untersucht. Ergebnisse: In vitro Genexpressionsstudien mit LPS, IL- $1 \beta$ oder TNF- $\alpha$ zeigten eine Hochregulation von A20 in Lungenepithelzellen $(p<0,05)$, Lungenfibroblasten $(p<0,05)$, sowie Lungenendothelzellen $(p<0,05)$. In vivo zeigte sich, dass IA-LPS zu einer Hochregulation der pro-inflammatorischen Zytokine in der fetalen Lunge führte, wobei ein Maximum der IL-6 (23-fach), IL-8 (29-fach) und TNF- $\alpha$ (5-fach) mRNA Expression in der 2d IA-LPS Gruppe beobachtet wurde $(p<0,05)$. Damit verbunden fand sich zusätzlich eine erhöhte A20 mRNA (12-fach) und Protein Expression $(p<0,05)$

Schlussfolgerung: In dieser Studie konnte eine Induktion von A20 durch LPS und proinflammatorische Zytokine in Lungenepithelzellen, Lungenfibroblasten und Lungenendothelzellen, sowie erstmalig auch durch Chorioamnionitis in einem Tiermodell in der fetalen Lunge gezeigt werden. Um eine mögliche Bedeutung von A20 bei verschiedenen Lungenerkrankungen Frühgeborener näher zu charakterisieren sind weiterführende funktionelle Studien in verschiedenen Lungenzellen geplant.

\section{GNPI-V08 \\ Die Depletion peripherer T-Zellen durch Fingolimod ist mit einer verstärkten hypoxisch-ischämischen Gehirnschädigung der neonatalen Maus assoziiert.}

I. Bendix' , M. Crasmöller', C. Köster', M. Serdar', U. Felderhoff-Müser², J. Herz' 'Universitätsklinik Essen, Universität Duisburg-Essen, Klinik für Kinderheilkunde I, Experimentelle perinatale Neurowissenschaften, Essen, Deutschland, ${ }^{2}$ Universitätsklinikum Essen, Universität Duisburg-Essen, Klinik für Kinderheilkunde I, Zentrum für Kinder- und Jugendmedizin, Essen, Deutschland

Hintergrund: Trotz zunehmender Kenntnisse über die pathophysiologische Rolle der Inflammation in adulter und neonataler ischämischer Gehirnschädigung sind bisher kaum therapeutisch-wirksame Ansätze verfügbar. Beide Entwicklungsstadien haben eine anhaltende Ischämieinduzierte Entzündungsreaktion gemein, die eine zerebrale Infiltration peripherer Immunzellen beinhaltet und in einem sekundären Läsionswachstum sowie in einer verschlechterten neurologischen Entwicklung mündet. Die immunmodulatorische Substanz Fingolimod (FTY720), ein Sphingosin-1-Phosphat-Rezeptor-Modulator, zeigte im adulten Schlaganfallmodell bereits neuroprotektive Effekte, die auf die lymphopene Wirkung von FTY720 zurückzuführen sind. Trotz dieser vielversprechenden Erkenntnisse, sind die Zielmechanismen immunmodulatorischer Therapien höchstwahrscheinlich abhängig von der Entwicklungsstufe des Gehirns und des Immunsystems und können daher nicht ohne Weiteres übertragen werden.

Fragestellung: Welche Auswirkungen hat die Behandlung mit FTY720 im Modell der Hypoxisch-Ischämischen Enzephalopathie (HIE) in neonatalen Nagern?

Material und Methoden: Zur Modellierung der HIE wurde das ursprünglich in neonatalen Ratten entwickelte Rice-Vannucci-Modell der Hypoxie-Ischämie (HI) für die Maus adaptiert. Dazu wurde in 9 Tage alten C57BL/6 Mäusen die rechte Arteria Carotis Communis ligiert und nach einer einstündigen Erholung bei den Muttertieren eine einstündige Hypoxie bei $10 \%$ Sauerstoff angeschlossen. Unmittelbar nach der Hypoxie erhielten die Tiere eine intraperitoneale Injektion von $1 \mathrm{mg} / \mathrm{kg}$ Körpergewicht FTY720 $(n=29)$ oder Phosphat-gepufferte Salzlösung (Kontrolle, $n=24)$. Das Ausmaß der Gewebeschädigung sowie die zerebrale Immunzellinfiltration wurde mittels Histologie, Western Blot und Durchflusszytometrie an Tag 7 nach Schädigung charakterisiert. In einem weiteren Ansatz mit naïven Mäusen wurde die Anzahl zirkulierender, peripherer Lymphozyten an Tag 1, 3 und 7 nach einmaliger FTY720-Injektion durchflusszytometrisch bestimmt $(n=5-7)$.

Ergebnisse: Die einmalige Behandlung mit FTY720 unmittelbar nach der HI führte zu einem signifikanten Anstieg der neuropathologischen Gewebeschädigung und einer reduzierten Expression des neuronal/axonalen Markerproteins Mikrotubuli-assoziiertes Protein-1. Die beobachtete anhaltende FTY720-induzierte Lymphopenie, die insbesondere T-Zellen betraf, resultierte in einer signifikanten Reduktion der zerebralen Infiltration von CD4 und CD8 T-Zellen, die jedoch mit einer erhöhten Einwanderung von Immunzellen des angeborenen Immunsystems einherging. Diskussion und Schlussfolgerung: Im Gegensatz zur ischämischen Hirnschädigung im Erwachsenen deuten die bisherigen Ergebnisse auf eine protektive Rolle von T-Zellen oder bestimmten T-Zell-Subpopulationen in der neonatalen hypoxisch-ischämischen Hirnschädigung hin. Diese Untersuchungen zeigen, dass Unterschiede zwischen adulten und neonatalen neuro-inflammatorischen Antworten wesentlich Einfluss auf die Entwicklung des ischämischen Gewebeschadens haben, sodass neuartige Therapieansätze nicht unmittelbar übertragbar sind.

\section{GNPI-V09}

\section{Negative Interaktion zwischen akuter therapeutischer Hypothermie und verzögerter mesenchymaler Stammzelltherapie nach neonataler Hypoxie-Ischämie}

J. Herz, C. Köster, B. S. Reinboth, M. Dzietko, I. Bendix, U. Felderhoff-Müser

Universitätsklinikum Essen, Universität Duisburg-Essen, Klinik für

Kinderheilkunde 1/Neonatologie, Essen, Deutschland

Hintergrund: Die hypoxisch-ischämische Enzephalopathie (HIE) als Folge von perinataler Asphyxie ist die häufigste Ursache für Mortalität und neurologische Entwicklungsstörungen im Kindesalter. Eins bis zwei von 1000 Reifgeborenen sind betroffen. Die Hypothermie (HT) ist bisher die einzige empfohlene und standardmäßig angewandte Therapiemöglichkeit. Dennoch bleiben 40-50 \% der gekühlten Kinder mit langfristigen neurologischen Problemen zurück. Daher sind neue und potentiell kombinierbare Behandlungsoptionen, die endogene Regenerations- und Entwicklungsprozesse fördern, dringend notwendig. In diesem Zusammenhang haben vor allem mesenchymale Stammzellen (MSZ) in der jüngeren Vergangenheit besonderes Interesse erlangt.

Fragestellung: Welche kurz- und langfristigen Therapieeffekte ergeben sich nach einer Kombinationstherapie von HT mit MSZ im experimentellen Modell der neonatalen HIE?

Material und Methoden: Zur Modellierung der HIE wurde das ursprünglich in neonatalen Ratten entwickelte Rice-Vannucci-Modell der Hypoxie-Ischämie (HI) für die Maus adaptiert. Dazu wurde in 9 Tage alten C57BL/6 Mäusen die rechte Arteria Carotis Communis ligiert und nach einer einstündigen Erholung bei den Muttertieren eine einstündige Hypoxie bei $10 \%$ Sauerstoff unter Aufrechterhaltung der physiologischen Körpertemperatur $\left(\mathrm{T}_{\text {rektal }} 35^{\circ} \mathrm{C}\right)$ angeschlossen. In direktem Anschluss folgte eine 4-stündige $\mathrm{HT}\left(\mathrm{T}_{\text {rektal }} 32^{\circ} \mathrm{C}\right)$. Kontrolltiere wurden bei physiologischer Körpertemperatur gehalten. Die Applikation muriner, aus dem Knochenmark 6-Wochen alter C57BL/6 Mäuse isolierter und expandierter, MSZ erfolgte intranasal am 12. Lebenstag $\left(1 \times 10^{6}\right.$ Zellen/Tier, Kontrolle: 0,9\% $\mathrm{NaCl})$. An Tag sieben nach HI wurde die Gewebeschädigung, Mikrogliaaktivierung, die Expression des vaskulären Adhäsionsmolküls-1 (VCAM1) und die zerebrale Immunzellinfiltration mittels Immunhistochemie und Western Blot evaluiert ( $n=14-16 /$ Gruppe). Die Analyse der motorischen und kognitiven Langzeitentwicklung erfolgte anhand der Aufrichtungsaktivität und mittels Novel Object Recognition-Test in einer Open Field-Arena fünf Wochen nach Schädigung ( $n=16-18 /$ Gruppe). 
Ergebnisse: Die Einzeltherapie mit einer HT oder MSZ reduzierte kurzfristige histopathologische Veränderungen, Mikrogliaaktivierung, VCAM-1-Expression und zerebrale Immunzellinfiltration. Die Kombination beider Behandlungen zeigte jedoch im Vergleich zu den Einzeltherapien keine neuroprotektiven Effekte. Darüber hinaus war sowohl die HT-vermittelte Verbesserung mortorischer Fähigkeiten als auch die MSZvermittelte Protektion kognitiver Langzeitdefizite durch eine Kombinationstherapie beider Behandlungen nicht mehr nachweisbar.

Diskussion und Schlussfolgerung: Unsere Untersuchungen in einem klinisch relevanten HIE/HT Modell der neonatalen Maus weisen auf einen negativen Interaktionseffekt einer MSZ-Therapie mit einer akuten Kühlungstherapie hin, der vermutlich durch eine Interaktion der injizierten Zellen mit der veränderten Gewebeumgebung infolge der Kühlung hervorgerufen wird. Für das vertiefte Verständnis der Wechselwirkung zwischen MSZ und der vorliegenden Mikroumgebung unter Berücksichtigung der einzigartigen Pathophysiologie der hypoxisch-ischämischen Enzephalopathie und obligater Therapien sind weitere Untersuchungen dringend erforderlich.

\section{GNPI-V10 \\ Hohe Mengen an S100-Alarminen in Muttermilch schützen Neugeborene vor schwerer Sepsis}

S. Pirr', M. Richter', J. Pagel', C. Härtel', B. Fehlhaber', A. S. Heinemann', S. Pfeifer', F. Reuner', M. von Köckritz-Blickwede', L. Völlger', J. Roth' ${ }^{5}$, T. Vogl', D. Viemann ${ }^{1}$

${ }^{1}$ Medizinische Hochschule Hannover, Pädiatrische Pneumologie, Allergologie und Neonatologie, Hannover, Deutschland, ${ }^{2}$ Kinderklinik Auf der Bult, Hannover, Deutschland, ${ }^{3}$ Universität Lübeck, Lübeck, Deutschland, ${ }^{4}$ Tierärztliche Hochschule Hannover, Hannover, Deutschland, ${ }^{5}$ Universität Münster, Münster, Deutschland

Hintergrund: Muttermilch (MM) ist der Goldstandard der Neugeborenenund Säuglingsernährung. Sie hat förderliche Effekte auf die Abwehr von Infektionskrankheiten. Die zugrundeliegenden Mechanismen sind bisher aber nur zum Teil verstanden. Wir konnten den endogenen Toll-like Rezeptor 4 (TLR4)-Liganden S100A8 und S100A9 eine wichtige Rolle bei der Regulation neonataler angeborener Immunantworten zuweisen. Frühgeborene mit postpartal niedrigen S100A8/A9 Serumspiegeln haben ein signifikant erhöhtes Risiko, an einer Sepsis zu erkranken. In experimentellen neonatalen Sepsismodellen verhindert die systemische Applikation von S100A8/A9 fatale Sepsisverläufe. In sehr hohen Konzentrationen wurden direkte antimikrobielle Effekte für S100A8/A9 nachgewiesen.

Fragestellung: In dieser Studie haben wir untersucht, ob MM S100-Alarmine enthält, die über direkte antibakterielle und/oder regulatorische Effekte von klinischer Relevanz für die Pathogenese der neonatalen Sepsis sind.

Material und Methoden: Die Konzentration von S100A8/A9 wurde in 97 MM-Proben bestimmt. Antimikrobielle und immunregulatorische Effekte wurden mittels Hemmtests des Wachstums relevanter Sepsiserreger, Analyse der Darmbesiedlung von Wildtyp- (wt-) und S100A9 knock-out (ko)Mäusen und enteraler Applikation von S100-Alarminen in einem neonatalen Sepsismodell untersucht.

Ergebnisse: S100A8/A9 Spiegel in MM waren nach Geburt massiv erhöht, 5-6-fach höher als die im Vergleich zu Erwachsenen bereits erhöhten Serumspiegel Neugeborener. Die höchsten S100A8/A9-Werte fanden sich in MM nach Spontangeburten reifer Kinder. Das Heterodimer S100A8/A9, nicht aber das Homodimer S100A8 übte direkte bakteriostatische Effekte auf Sepsis-relevante Keime wie Staphylococcus (S.) aureus und Escherichia (E.) coli aus, während das Wachstum von Streptokokken der Gruppe B nicht beeinflusst wurde. Die S100A9 ko-Maus wurde nach Geburt intestinal stärker mit fakultativen Anaerobiern wie S. aureus und E. coli besiedelt als die wt-Maus. Enteral zugeführte S100-Alarmine ließen sich systemisch nachweisen und schützten S100A9 ko Neugeborene vor fatalen Sepsisverläufen.

Diskussion und Schlussfolgerung: Neugeborene erhalten über die MM hohe Mengen an S100A8/A9. Antibakterielle und immunregulierende
Effekte der S100-Alarmine senken das Sepsisrisiko von Neugeborenen und beeinflussen offenbar die Darmbesiedelung. Unsere Daten liefern den ersten Hinweis, dass die Supplementierung von Säuglingsnahrungen mit S100-Alarminen eine neue Strategie in der Behandlung von Neugeborenen mit erhöhtem Risiko für das Erleiden einer Sepsis oder nekrotisierenden Enterokolitis sein könnte.

\section{GNPI-V11}

\section{Beeinträchtigung des assoziativen zerebellären Lernverhaltens} bei Frühgeborenen im Vorschul- und jungen Erwachsenenalter

L. Tran', B. Hüning' ' U. Felderhoff-Müser', O. Kaiser', D. Timmann'2, S. Sirin', B. Schweiger ${ }^{3}, H$. Quick ${ }^{4}$

'Universitätsklinikum Essen, Klinik für Kinderheilkunde I, Essen, Deutschland, ${ }^{2}$ Universitätsklinikum Essen, Klinik für Neurologie, Essen, Deutschland, ${ }^{3}$ Universitätsklinikum Essen, Institut für Diagnostische und Interventionelle Radiologie und Neuroradiologie, Essen, Deutschland, ${ }^{4}$ Erwin L. Hahn Institut für MR Bildgebung, Essen, Deutschland

Hintergrund: Bei Frühgeburtlichkeit besteht sowohl ein erhöhtes Risiko für fokale Kleinhirnläsionen, möglicherweise aber auch für eine Entwicklungsstörung des Kleinhirns. Es wird postuliert, dass zerebelläre Entwicklungsstörungen zu motorischen und kognitiven Auffälligkeiten bei frühgeborenen Kindern beitragen. Der experimentelle Nachweis einer Kleinhirndysfunktion bei frühgeborenen Kindern und jungen Erwachsenen steht bisher weitestgehend aus. In der vorliegenden Studie wurde die klassische Blinkreflexkonditionierung als Marker für eine mögliche Kleinhirndysfunktion genutzt, da diese einfache Form des assoziativen motorischen Lernens wesentlich von der Integrität des Kleinhirns abhängt.

Material und Methoden: Die Blinkreflexkonditionierung wurde mit einem Delay-Paradigma an 20 extrem frühgeborenen jungen Erwachsenen und 32 extrem frühgeborenen Kindern im Vorschulalter untersucht. Fokal zerebelläre und zerebrale Läsionen wurden vorher anhand von MRTUntersuchungen ausgeschlossen. Die erwachsenen Probanden erhielten ein zerebrales MRT zur Zeit der Testung und die Kinder zum errechneten Geburtstermin. Zum Vergleich wurden dem Alter und Geschlecht entsprechende reifgeborene Kontrollprobanden getestet. Eine Untergruppe von 12 frühgeborenen Kindern und deren Kontrollen wurden ein zweites Mal drei Monate nach der ersten Sitzung getestet.

Ergebnisse: Frühgeborene junge Erwachsene erzielten im Vergleich zu den entsprechenden Kontrollen eine signifikant geringere Anzahl an konditionierten Antworten und zeigten eine geringere Lernrate (Gruppeneffekt, $p<0,001$, Block- und Gruppeninteraktion, $p=0,02$; Varianzanalyse mit Messwiederholung). Die frühgeborenen Kinder unterschieden sich in der ersten Sitzung nicht von den Kontrollen. Dieses spiegelt eine generell niedrige Konditionierungsrate in dem jungen Schulalter wider. Nach einer Konsolidierungsphase zeigte die Untergruppe der erneut untersuchten Frühgeborenen eine signifikant geringere Anzahl an konditionierten Antworten im Vergleich zu den Kontrollen (Gruppeneffekt, $p=0,018$ ). Des Weiteren zeigten die frühgeborenen Kinder nicht die gleiche Größenzunahme der konditionierten Antwort zwischen den Sitzungen wie ihre Kontrollen (Interaktion zwischen Sitzung und Gruppe, $p=0,002$ ).

Schlussfolgerung: Die vorliegenden Daten zeigen, dass die Frühgeburtlichkeit das kleinhirnabhängige assoziative Lernen auch bei fehlenden fokalen Kleinhirnläsionen beeinträchtigt. Diese Kleinhirndysfunktionen existieren in der Kindheit und bestehen bis ins frühe Jugendalter. Die Ergebnisse sprechen dafür, dass eine extreme Frühgeburtlichkeit mit einer Entwicklungsstörung des Kleinhirns einhergeht. 


\section{GNPI-V12}

Untersuchung der Anwendbarkeit der magnetischen Induktionsmessung zur kontaktlosen Detektion der Atemtätigkeit und Lungenbelüftung Früh- und Neugeborener - Erste Ergebnisse einer Pilotstudie

\section{K. Heimann', C. Platen', P. Vetter', K. Scherer ${ }^{3}$, S. Leonhardt ${ }^{2}$, T. Orlikowsky' \\ ${ }^{1} K$ linik für Kinder- und Jugendmedizin, Universitätsklinikum Aachen, Sektion Neonatologie, Aachen, Deutschland, ${ }^{2}$ Helmholtz Institut RWTH Aachen, Lehrstuhl für Medizinische Informationstechnik, Aachen, Deutschland, ${ }^{3}$ Universitätsklinikum Aachen, Institut für Versuchstierkunde, Aachen, Deutschland}

Hintergrund: Die Magnetische Induktionsmessung (MIM) ermöglicht die Bestimmung des Widerstandes in biologischem Gewebe mit Hilfe von magnetischen Wechselfeldern, d.h. sich zeitlich ändernden Magnetfeldern auf Basis von Verschiebungen gut leitender (Blut) bzw. schlecht leitender (Luft) Stoffe. Mittels einer Spule, die in ihrer Größe variabel ist und in der Nähe des zu messenden Areales (z. B. auf Höhe der Thoraxwand im Inkubatorboden) platziert werden muss, werden nun diese Veränderungen kontaktlos ohne Anbringung von Überwachungselektroden registriert und aufgezeichnet. Nach ersten Untersuchungen mit ausgewachsenen Schweinen, konnte gezeigt werden, dass u. a. eine detailliertere kontaktlose Erfassung Atemtätigkeit mittels MIM auch bei neugeborenen Ferkeln möglich ist [1]. Akute pulmonale Probleme können bei Frühgeborenen negative Determinanten für ein neurologisches und psychomotorisches Outcome sein.

Fragestellung/Ziel: Ziel dieser Untersuchung ist, inwieweit die kontaktlose Messung der Magnetischen Induktion bei Früh- und Neugeborenen zur Erfassung von akut auftretenden pulmonalen Belüftungsstörungen herangezogen werden kann. Zu diesem Zweck soll das etablierte NeugeborenenTiermodell (1-2 Tage alte Ferkel im Inkubator) um verschiedene Formen von Belüftungsstörungen (Apnoe, Tubusfehllage im rechten Hauptbronchus, Pneumothorax, Aspiration) erweitert werden, die mit klassischen Techniken wie Atemtätigkeit am Überwachungsmonitor (EKG, Pulsoxymetrie) und/oder Röntgen erfasst werden. Die Ergebnisse sollen als Grundlage für Vergleichsmessungen mit der MIM zu ihrer Validierung z.B. in Form der topographischen Erfassung der Art der Belüftungsstörung herangezogen werden. Diese Erfassung topographischer Veränderungen im Bereich bestimmter Lungenabschnitte könnte frühzeitig Rückschlüsse über präventive therapeutische Maßnahmen geben.

Material und Methoden: Mit 3 Erreger- und 3 Mess-Spulen wurde simultan die Veränderung der Magnetischen Induktion in Abhängigkeit Belüftungszustand der Lunge gemessen. Als Goldstandard wurden simultan die Referenzsignale eines Pulsoxymeters und eines Atemfluss-Messers (Strömungswiderstand + Differenzdrucksensor) aufgezeichnet und mit einem Röntgenbild verifiziert. Dies am konventionell beatmeten Ferkel unter Induktion von Apnoe, Tubusfehllage rechts, Pneumothorax und Aspiration. Ergebnisse: Bisher wurden 10 Tiere untersucht. Bei allen Tieren konnten die akuten Belüftungsstörungen induziert und mittels Goldstandard (Monitorüberwachung, Röntgen) verifiziert werden. Erfassung der Apnoe insgesamt bei allen-, Tubusfehllage rechts bei 2-, Pneumothorax bei 5- und Aspiration bei 6 Tieren.

Schlussfolgerung: Bis zum jetzigen Zeitpunkt ist es gelungen, die topographischen Veränderungen akuter Belüftungsstörungen in Form von Apnoe, Pneumothorax und Aspiration mittels MIM in über $50 \%$ non-invasiv im Neugeborenen-Tiermodell zu erfassen. Die Erfassung im klinischen Alltag z. T. mit sehr unterschiedlichem Ausprägungsgrad auftretende Tubusfehllage im rechten Hauptbronchus kann jedoch als noch nicht ausgereift bezeichnet werden.

Förderung: DFG LE 817/8-1; HE 6890/2-1

\section{Literatur}

1. Heimann K, Steffen M, Bernstein N et al (2009) Non-contact monitoring of heart and lung activity using magnetic induction measurement in a neonatal animal model. Biomed Tech (Berl) 54:337-345

\section{GNPI-V13}

Intrauterine Wachstumsrestriktion (IUGR) mit Aufholwachstum hemmt die Bildung elastischer Fasern und Angiogenese in Lungen neugeborener Ratten

C. Kuiper ${ }^{1,2}$, K. Dinger ${ }^{2}$, C. Klaudt ${ }^{2}$, D. Hirani ${ }^{2}$, C. Vohlen ${ }^{2,3}$, M. Odenthal ${ }^{4}$, S. v. Koningsbruggen-Rietschel ${ }^{5}$, J. Dötsch ${ }^{3}$, M. A. Alejandre Alcazar ${ }^{2}$

${ }^{1}$ Klinik- und Poliklinik für Kinder- und Jugendmedizin, Uniklinik Köln, Neonatologie, Köln, Deutschland, ${ }^{2}$ Klinik und Poliklinik für Kinder- und Jugendmedizin, Uniklinik Köln, Translationale Experimentelle Pädiatrie, Experimentelle Pneumologie, Köln, Deutschland, ${ }^{3}$ Klinik- und Poliklinik für Kinder- und Jugendmedizin, Uniklinik Köln, Köln, Deutschland, ${ }^{4}$ Institut für Pathologie, Uniklinik Köln, Köln, Deutschland, ${ }^{5}$ Klinik und Poliklinik für Kinder- und Jugendmedizin, Uniklinik zu Köln, Pädiatrische Pneumologie, Köln, Deutschland

Hintergrund: Intrauterine Wachstumsrestriktion (IUGR) ist ein Risikofaktor für Bronchopulmonale Dysplasie (BPD) und chronische Lungenerkrankungen. Lungen mit BPD zeigen neben fibrotischen Veränderungen eine reduzierte Ausbildung von Gefäßen und Alveolen. Unsere Studien zeigen, dass IUGR molekulare Signalwege dysreguliert und zu Fibrose mit reduzierter Lungenfunktion führt.

Fragestellung: Diese Vorarbeiten ließen uns die Hypothese untersuchen, dass IUGR als Risikofaktor für BPD 1) angiogenetische Signalwege und Endothelmarker in der frühen Alveolarisation dysreguliert und dies 2) die Mikrogefäß- und Kapillarbildung sowie ECM nachteilig beeinflusst. Material und Methoden: Induktion einer IUGR in Wistar Ratten durch eine Proteinmangel-Diät (8\% Casein; IUGR) während der Gestation; die Kontrolltiere erhielten Normal-Protein-Diät (17\% Casein; Co). Am embryonalen Tag 21 (E21), postnatalen Tag 3 (P3) und P23 wurden die Nachkommen getötet und die Lungen für molekularbiologische Untersuchungen asserviert.

Ergebnisse: 1) IUGR reduzierte das Körpergewicht (KG) an E21. Zeitgleich war die Genexpression endothelialer Marker (CD31, vWF, VECadherin) und angiogenetischer Faktoren (VEGF-A, VEGF-R2, EphA1, BMPR2, Apelin, Klf2) signifikant erniedrigt. Dem folgte an P3 eine Verminderung von CD31-Protein als Endothelmarker und eine postnatale Aktivierung von SMAD1/5/8 (BMPR-Signalweg) in IUGR-Lungen. Postnatal zeigten die IUGR Tiere ein Aufholwachstum und ihr KG war an P23 gleich dem der Kontrollgruppe. Während an P23 Genexpression sowie Aktivierung des pSmad1/5/8 Signalweges in IUGR- und Co-Lungen gleich war, fanden wir ein deutlich reduziertes phosphoryliertes Erk1/2 (proliferativ). 2) Histomorphometrisch zeigten die IUGR-Lungen an P3 eine Tendenz zur Zunahme von Mikrogefäßen (20-100 $\mu \mathrm{m})$; an P23 war zwar kein Unterschied in Mikrogefäßen, aber die Kapillaranzahl $(<20 \mu \mathrm{m})$ in den IUGR-Lungen war signifikant erniedrigt. Weiterhin zeigte sich histologisch eine um mehr als $50 \%$ reduzierte Menge an elastischen Fasern an P3 und P23, die mit einer signifikant verminderten Ablagerung von Kollagen an P23 einherging.

Schlussfolgerung: Unsere Studie zeigt a) eine frühe Hemmung pro-angiogenetischer Signalwege und b) reduzierte Bildung elastischer Fasern und perivaskulärer ECM als Mechanismen reduzierten Lungenwachstums infolge von IUGR. Diese Ergebnisse zeigen nicht nur, dass IUGR die Ausbildung von Lungengefäßen hemmt, sondern identifiziert IUGR auch als einen möglichen Risikofaktor für pulmonale Gefäßerkrankungen. 


\section{GNPI-V14}

Novel functional role of GH/IGF1 axis in neonatal lung fibroblasts is linked to lung growth after intrauterine growth restriction

J. Nawabi', C. Vohlen ${ }^{1,2}$, K. Dinger ', C. Kuiper ${ }^{3,1}$, C. Klaudt',

C. Thangaratnarajah', E. Lopez Garcia', K.D. Nüsken²,

S. v. Koningsbruggen-Rietschel ${ }^{4}$, J. Dötsch ${ }^{2}$, M. A. Alejandre Alcazar ${ }^{1}$

${ }^{1}$ Klinik und Poliklinik für Kinder- und Jugendmedizin, Uniklinik Köln, Translationale Experimentelle Pädiatrie, Experimentelle Pneumologie, Köln, Deutschland, ${ }^{2}$ Klinik- und Poliklinik für Kinder- und Jugendmedizin, Uniklinik Köln, Köln, Deutschland, ${ }^{3}$ Klinik- und Poliklinik für Kinder- und Jugendmedizin, Uniklinik Köln, Neonatologie, Köln, Deutschland, ${ }^{4}$ Klinik und Poliklinik für Kinder- und Jugendmedizin, Uniklinik zu Köln, Pädiatrische Pneumologie, Köln, Deutschland

Background: Intrauterine growth restriction (IUGR) is a risk factor for bronchopulmonary dysplasia, characterized by reduced alveoli and fibrosis. Prior studies of our group showed fibrosis in rat lungs after IUGR. Growth Hormone (GH) and Insulin-like growth factor 1 (IGF1) are important in development and dysregulated in cord blood of infants with IUGR.

Aims: To investigate if (1) lung growth after IUGR is related to dysregulated lung GH/IGF1 signaling; and if (2) GH/IGF1 signaling is linked to neonatal lung fibroblast function.

Material and Methods: (1) IUGR in Wistar rats was induced by isocaloric low protein diet during gestation. Lungs were obtained on embryonic day (E)21, postnatal day (P)3, and P23. (2) cell culture: primary neonatal rat fibroblasts $(\mathrm{PnF})$ were isolated from lungs of Control $(\mathrm{Co}-\mathrm{PnF})$ and IUGR (IUGR-PnF).

Results: (1) E21: lung GH mRNA was increased, GH-Receptor (GH-R) protein and Stat5 signaling were reduced; and lung IGF1 mRNA and IGF1-R signaling (Akt) were decreased in IUGR lungs. At P23: increment of GH-R/IGF1-R protein was linked to active Akt and Stat5 in lungs after IUGR. Increased septal thickness after IUGR was related to higher PCNA/ CyclinD1 protein (proliferation) and collal, elastin and aSMA mRNA. Serum IGF1, however, was reduced after IUGR. (2) GH/pStat5 signaling, PCNA and CyclinD1 protein were increased in IUGR-pnF. Both GH and IGF1 induced proliferation and migration of Control-pnF; only IGF1 had these effects on IUGR-pnF.

Conclusions: Our study shows a novel mechanism by which GH/IGF1 axis in lung fibroblasts could account for lung growth after IUGR. Those new insights offer potential innovative strategies to enable lung growth.

\section{GNPI-V15 \\ Frühgeborene bilden im Vergleich zu Neugeborenen und Erwachsenen weniger Neutrophil Extracellular Traps}

I. Hegge ', J. Ruhnau' ${ }^{2}$, A. Lange ${ }^{1}$, A. Vogelgesang ${ }^{2}$, D. Olbertz ${ }^{2,3}$, M. Heckmann ${ }^{1}$

'Universitätsmedizin Greifswald, Neonatologie und Pädiatrische

Intensivmedizin, Greifswald, Deutschland, 2Universitätsmedizin, Neurologie, Greifswald, Deutschland, ${ }^{3}$ Südstadt Klinikum, Neonatologie und

Neonatologische Intensivmedizin, Rostock, Deutschland

Hintergrund: Neonatale Infektionen sind mit einer erhöhten Mortalität und teilweise mit schweren neurologischen Langzeitschäden assoziiert. Neutrophil extracellular traps (NET) sind gegen Pathogene gerichtete Strukturen aus Chromatin und antimikrobiellen Proteinen, die von neutrophilen Granulozyten gebildet werden. Vorläufige Untersuchungen lassen eine fehlende oder verzögerte neonatale NET-Bildung vermuten. Unsere Arbeitsgruppe konnte bei reifen Neugeborenen eine im Vergleich zum Erwachsenen deutlich reduzierte NET-Aktivität messen. Bei sehr unreifen Frühgeborenen, die besonders vulnerabel für Infektionen sind, könnte die NET-Bildung noch weiter vermindert sein.

Fragestellung: Ist die Kapazität, NETs zu bilden, mit zunehmender Unreife weiter reduziert? Zusätzlich soll der Einfluss perinataler Faktoren auf die NET-Bildung untersucht werden.

Material und Methoden: Aus Nabelschnurblut von 17 unreifen (Angaben als Median (Min-Max): 34+1 $(27+6-36+6)$ Gestationswochen, Ge- burtsgewicht: $2110 \mathrm{~g}(1040-2610 \mathrm{~g}))$ und 4 reifen gesunden Neugeborenen und venösem Blut einer gesunden, adulten Kontrollgruppe $(n=7)$ wurden die neutrophilen Granulozyten mittels Dichtegradienten-Zentrifugation isoliert und die Bildung von NETs durch Stimulation mit Phorbol-Myristol-Acetat (PMA) induziert. Die NETs wurden immunhistochemisch dargestellt und hinsichtlich Anzahl (Verhältnis NET-bildende zu Gesamt-Neutrophilen in \%) und Größe analysiert. Für die Studie lagen die Zustimmung der Ethikkommission und die Einwilligung der Eltern vor. Die Analyse erfolgte mittels Anova (Angabe der Daten als Mittelwert \pm Standardabweichung).

Ergebnisse: Es fand sich ein erniedrigter Anteil NET-bildender neutrophiler Granulozyten nach Stimulation mit PMA bei Frühgeborenen (FG) im Vergleich zu reifen Neugeborenen (NG) und Erwachsenen (AD): FG: $2,49 \% \pm 1,65 \%$ vs. NG: $8,92 \% \pm 3,65 \%$ vs. AD: $13,07 \% \pm 4,25 \% ; p<0,0001$. Kein Unterschied fand sich bei der NET-Größe: Fläche FG: $559,6 \mu^{2} \pm$ $177,6 \mu \mathrm{m}^{2}$ vs. NG: $533,6 \mu \mathrm{m}^{2} \pm 72,63 \mu \mathrm{m}^{2}$ vs. AD: $655,5 \mu \mathrm{m}^{2} \pm 132,5 \mu \mathrm{m}^{2}$; $p=0,008$ (post-hoc Test mittels Bonferroni ergab keine Signifikanz). In der Gruppe der Frühgeborenen zeigten das Geschlecht, der Geburtsmodus und das Gestationsalter ( $<32$ Gestationswochen vs. $>32-<37$ Gestationswochen) keinen signifikanten Effekt auf die NET-Bildung (t-Test).

Schlussfolgerung/Ausblick: Die NET-Bildung war bei Frühgeborenen im Vergleich zu reifen Neugeborenen und Erwachsenen weiter vermindert. Dies könnte zu dem erhöhten Infektionsrisiko Frühgeborener beitragen. Welche Signalalterationen zu diesem Defekt führen ist bislang unbekannt, weitere Untersuchungen hierzu sind notwendig.

\section{GNPI-V16}

\section{Entscheidungsfindung an der Grenze zur Lebensfähigkeit}

\section{K. Schneider, N. Hepping, W. Garbe}

GFO Kliniken Bonn, Neonatologie, Bonn, Deutschland

Hintergrund: Bei Therapientscheidungen von Frühgeborenen an der Grenze zur Lebensfähigkeit hat sich sowohl prä- als auch postnatal die Devise der geteilten Entscheidungsfindung zwischen Ärzten und Eltern („shared decision making“) etabliert. Der vermeintliche Patientenwillen soll stellvertretend durch die Eltern wiedergegeben werden. Nur eine umfassende Aufklärung der Eltern rückt die Autonomie des Patienten in einen möglichen Bereich. Dieses führt oftmals für das Behandlungsteam zu einer Gratwanderung zwischen Akzeptanz des Patientenwillens, persönlichen Vorstellungen und Verantwortung dem Kindeswohl gegenüber [1]. Fallbeispiele: Anhand von 3 Fallbeispielen, bei denen die Eltern jeweils „eine Maximaltherapie um jeden Preis wünschten“, soll gezeigt und diskutiert werden, wie komplex und heterogen die Entscheidungsfindung im Einzelfall sein kann.

1. Noah: $23+2$ SSW, Geburtsgewicht 560 g; Wechsel auf palliative Behandlung am 42. Lebenstag mit nachfolgendem Tod; Eltern fühlen sich schuldig, dem Kind ein so langes Leid zugemutet zu haben

2. Yasin: $22+5$ SSW, Geburtsgewicht 480 g; Kind ist tetraspastisch, blind und schwer entwicklungsretardiert; Mutter versorgt das Kind aufopferungsvoll und ist zufrieden und glücklich mit ihrer Lebenssituation

3. Tom: $24+0$ SSW, Geburtsgewicht: 680 g, schweres Amnioninfektionssyndrom, postnatal 20 min. kardiopulmonale Reanimation, Kind dann stabil; Behandlungsteam reflektiert kritisch, ob eine so lange Reanimation zu rechtfertigen war.

Diskussion: Die 3 Fälle beschreiben scheinbar aussichtslose („futile“) Situationen. Jedoch zeigt es sich, dass die Definition von Futility nicht allein durch evidenzbasierte Risikofaktoren gestellt werden kann [1, 2], sondern in der Kommunikation mit Eltern stets individuell neu zu bewerten ist und einer Entwicklung unterliegt. Frühgeborene Patienten haben selbst keine Möglichkeit, ihre Autonomie zu sichern. Dieses wird stellvertretend durch die Eltern übernommen. Die Eltern geben dabei oftmals ihre eigene Autonomie zugunsten der Versorgung ihres Kindes auf. Der Verzicht der eigenen Autonomie der Eltern kann über Jahrzehnte von dem Patienten eingefordert werden. „Shared decision making“ bedeutet für den Arzt, dass er dies den Eltern im intensiven Gespräch wertfrei vermittelt [3, 4]. 
Literatur

1. Orzalesi M, Cuttini M (2011) Ethical issues in neonatal intensive care. Ann Ist Super Sanita 47:273-277

2. Lipp V, Bauer D (2013) Behandlungsbegrenzung und „Futility“ aus rechtlicher Sicht. Palliativmedizin 14:121-126

3. Janvier A, Barrington K, Farlow B (2014) Communication with parents concerning withholding or withdrawing of life-sustaining interventions in neonatology. Semin Perinatol 38:38-46

4. Duont-Thibodeau A, Barrington K, Farlow B, Janvenier A (2014) End-of-life decisions for extremely low-gestational-age infants: Why simple rules for complicated decisions should be avoided. Semin Perinatol 38:31-37

\section{GNPI-V17}

Progressive kongenitale Myopathie bei einem Säugling Tracheotomie, ja oder nein?

\section{Vlajnic, V. Sittig}

GFO Kliniken Bonn, St. Marien-Hospital Bonn, Bonn, Deutschland

Hintergrund: Entscheidungen zur Tracheotomie stellen eine Herausforderung an das gesamte Team dar. Dabei gibt es wenig standardisierte Vorgehen.

Fragestellung: Knapp vier Monate alter Säugling, der mit einer progressiven kongenitalen Myopathie (ohne klare Diagnose) bisher in 3 Kliniken behandelt worden war. Dabei war er zunächst nach protrahierter Neugeborenenperiode spontan atmend entlassen worden. Nach einem Reanmiationsereignis und folgendem stationären Aufenthalt erfolgte die häusliche Versorgung durch ein häusliches High-Flow-System. Stationäre Aufnahme bei uns mit respiratorischem Versagen. Nach mehreren Tagen NIV wurde eine Intubation erfroderlich. Nach mehreren Extubationsversuchen befand sich das Kind erneut an einer NIV in schlechtem Allgemeinzustand, die Re-Intubation drohte. Das Team stand vor der Entscheidung ReIntubation, Anlage eines Tracheotomas oder palliative Versorgung. Eine Eigenbewegung des Kindes bis auf Okulomotorik ist nicht vorhanden.

Material und Methoden: Standardisiertes Vorgehen in unserer Klinik mit mehreren dokumentierten strukturierten Elterngesprächen sowie mehreren Teamgesprächen. Dann Einberufung einer ethischen Fallbesprechung des klinischen Ethik-Komittees. Das Votum der Besprechung wurde Grundlage des weiteren Procedere.

Ergebnisse: Moderierte Fallbesprechung mit sechs Teilnehmern des klinischen Teams (Chefarzt, drei Oberärzte, zwei Pflegekräfte) sowie zwei Moderatoren des klinischen Ethik-Komittees. Konsens bestand zur einer familienzentrierten Versorgung. Konsekutiv ergab sich die Empfehlung zur Anlage eines Tracheostomas und einer PEG unter drei „Auflagen“:

Erneutes Gespräch mit den Eltern über Diagnose und mögliche Prognose

- Schriftliche Vereinbarung über Verzicht von Reanimationsmaßnahem und weiteren Empfehlungen

- Vereinbarung zur Re-Evaluation in unserer Klinik in regelmäßigen Abständen bezüglich Lebensqualität, Fortschreiten der Erkrankung. Bei völlig fehlendem Atemantrieb soll eine erneute ethische Fallbesprechung erfolgen.

Die Fallbesprechung hat dem klinischen Team sehr geholfen und wurde gemeinsam mit den Eltern getragen. Das Kind wurde tracheotomiert und mit 24-h-Beatmung, Anbindung an häusliche Pflege und an ein Kinderpalliativteam nach Hause entlassen. Molekulargenetisch konnte in der Zwischenzeit eine ACTA1-Mutation nachgewiesen werden. Erfreulicherweise bessert sich der klinische Zustand des Kindes in der häuslichen Betreuung zusehends, so dass nach 8 Monaten deutlich mehr Eigenbewegung vorhanden ist. Das Kind atmet $12 \mathrm{~h}$ ohne Atemunterstützung an der feuchten Nase, es efolgt nur nächtliche Betamung.

Schlussfolgerung: Entscheidungen zur Trachetomie im Kindesalter sollten generell strukturiert erfolgen. Unserer Ansicht ist bei solchen Entscheidungen eine moderierte ethische Fallbesprechung mit interprofessionellen Beteiligung und unter Einbindung eines klinischen Ethik-Komittees zwingend erforderlich.

\section{GNPI-V18 \\ Wunsch der Eltern auf Therapiebeendigung bei infauster Prognose}

\section{Vlajnic, K. Schneider}

GFO Kliniken Bonn, St. Marien-Hospital Bonn, Pädiatrie, Bonn, Deutschland

Fragestellung: 1-jähriges Mädchen nach peripartaler Asphyxie mit nachfolgender schwerster Entwicklungsstörung, Tetraspastik und bulbärem Syndrom. Rezidivierende Aspirationspneumonien und häufige Phasen schwerster Luftnot bei Sekretverhalt. Trotz Betreuung durch ambulantes Palliativteam und einmaligem stationären Aufenthalt in einer palliativmedizinischen Einrichtung kaum Linderung der Symptome, Kind lebt in ständiger Unruhe.

Für die Eltern bestand das Kind aus einem einzigen „Leiden“. Auch für das Behandlungsteam und insbesondere die Pflege stellte die Betreuung eine große Belastung dar. Die Eltern forderten uns als Team offen auf, das Leiden zu beenden und eine terminale Sedierung einzuleiten.

Material und Methoden: Aufgrund dieses ethischen und forensischen Konfliktes wurde eine ethische Fallbesprechung mit unserem klinischen EthikKomittee anberaumt.

Das Votum der ethischen Fallbesprechung lautete:

- Optimierung der palliativen Betreuung und Unterbringung in einem speziellen Kinderhaus. Das Kind soll dort eine Heimat finden und sein Leben mit entsprechender palliativer Behandlung und Symptomkontrolle in geschütztem Rahmen leben und beenden.

- Nach Möglichkeit soll das Kind auch in einer Notfallsituation in dem Kinderhaus bleiben und alle Formen der Leidenslinderung erhalten bis hin zur palliativen Sedierung. Für eine Notfallsituation soll die bereits existierende DNR-Order reevaluiert und effektiv dokumentiert werden; bei allen diesen Aufgaben unterstützt das Kinder-PalliativTeam aktiv nach Möglichkeit das Kinderhaus.

- Die Intention des therapeutischen Handelns ist bei diesem Kind ausschließlich die Linderung des Leids, unter Umständen auch in Form einer palliativen Sedierung, aber nicht die Verkürzung oder Beendigung des Lebens.

- Dem Anliegen der Eltern nach einer aktiven Beendigung des Lebens durch medizinische Maßnahmen wird aus ethischen und juristischen Gründen nicht entsprochen.

Ergebnisse: Unter höchstem Engagement der Betreuung im Kinderhaus sowie des ambulanten Palliativteams hat sich der Zustand stabilisiert und eine sichtbare Leidenslinderung und Symptomkontrolle hat sich ergeben. Stationäre Aufenthalte waren nicht mehr erforderlich. Das Kind ist 9 Monate später friedlich in den Armen der Eltern im Kinderhaus verstorben. 


\section{GNPI-V19}

\section{Der Einfluss des $\mathrm{PCO}_{2}$ auf das klinische und} entwicklungsneurologische Outcome invasiv beatmeter sehr kleiner Frühgeborener

U. Thome', J. Dreyhaupt ${ }^{2}$, O. Genzel-Boroviczeny' ${ }^{3}$, B. Bohnhorst ${ }^{4}$, M. Schmid ${ }^{5}$, H. Fuchs ${ }^{6}$, O. Rohde ${ }^{7}$, S. Avenarius ${ }^{8}$, H. G. Topf ${ }^{9}$, A. Zimmermann ${ }^{10}$, D. Faas ${ }^{11}$, K. Timme ${ }^{12}$, B. Kleinlein ${ }^{13}$, H. Buxmann ${ }^{14}$, W. Schenk ${ }^{15}$, H. Segerer ${ }^{16}$, N. Teig ${ }^{17}$, F. Pulzer ${ }^{1}$, R. Hentschel', M. Heckmann ${ }^{18}$, R. Schlösser ${ }^{14}$, J. Peters ${ }^{13}$, R. Rossi ${ }^{12}$, W. Rascher ${ }^{9}$, R. Böttger ${ }^{8}$, J. Seidenberg ${ }^{7}$, G. Hansen ${ }^{4}$, M. Zernickel ${ }^{19}$, R. Muche ${ }^{2}$, H.D. Hummler ${ }^{19}$

'Universitätsklinikum Leipzig, Neonatologie, Leipzig, Deutschland, ${ }^{2}$ Universität Ulm, Institut für Epidemiologie und Medizinische Biometrie, Ulm, Deutschland, ${ }^{3}$ Dr. von Haunersches Kinderspital, Neonatologie, München, Deutschland, ${ }^{4}$ Medizinische Hochschule Hannover, Neonatologie, Hannover, Deutschland, ${ }^{5}$ UniversitätsSpital Zürich, Klinik für Neonatologie, Zürich, Schweiz, ${ }^{6}$ Universitätsklinikum Freiburg, Pädiatrische Intensivmedizin, Freiburg, Deutschland, ${ }^{7}$ Klinikum Oldenburg, Neonatologie und Intensivmedizin, Oldenburg, Deutschland, ${ }^{8}$ Universitätsklinikum Magdeburg, Experimentelle Pädiatrie und Neonatologie, Magdeburg, Deutschland, 'Universitätsklinikum Erlangen, Neonatologie, Erlangen, Deutschland, ${ }^{10} \mathrm{~K}$ linikum rechts der Isar, Technische Universität, MutterKind-Zentrum, München, Deutschland, "'Justus-LiebigUniversität Gießen, Allgemeine Pädiatrie und Neonatologie, Gießen, Deutschland, ${ }^{12}$ Vivantes Klinikum Neukölln, Neonatologie, Berlin, Deutschland, ${ }^{13}$ Klinikum Dritter Orden, Kinder- und Jugendmedizin/Neonatologie, München, Deutschland, ${ }^{14}$ Universitätsklinikum Frankfurt, Neonatologie, Frankfurt/Main, Deutschland, ${ }^{15}$ Klinikum Augsburg, Neonatologie, Augsburg, Deutschland, ${ }^{16}$ Krankenhaus Barmherzige Brüder - Klinik St. Hedwig, Neonatologie, Regensburg, Deutschland, ${ }^{17}$ Katholisches Klinikum Bochum, Neonatologie, Bochum, Deutschland, ${ }^{18}$ Universitätsmedizin Greifswald, Abteilung für Neonatologie und Pädiatrische Intensivmedizin, Greifswald, Deutschland, ${ }^{19}$ Universitätsklinikum Ulm, Sektion Neonatologie und Pädiatrische Intensivmedizin, Ulm, Deutschland

Hintergrund: Extreme Werte oder starke Schwankungen des $\mathrm{PCO}_{2}$ könnten gemäß mehrerer retrospektiver Studien die Behandlungsergebnisse bei kleinen Frühgeborenen beeinflussen. Randomisierte Studien mit verschiedenen $\mathrm{PCO}_{2}$ Zielbereichen konnten keine wesentlichen Unterschiede der Behandlungsergebnisse zeigen. Allerdings führten häufige große Schwankungen des $\mathrm{PCO}_{2}$ zu einer starken Überlappung der erzielten $\mathrm{PCO}_{2}$-Werte der Behandlungsgruppen in diesen Studien.

Fragestellung: Sind hohe, niedrige oder schwankende $\mathrm{PCO}_{2}$-Werte unabhängige Risikofaktoren für die Behandlungsergebnisse bei sehr kleinen Frühgeborenen?

Material und Methoden: Sekundäranalyse der Daten aus der PHELBIStudie, an der 359 Frühgeborene 2 ( $\mathrm{CO}_{2}$-Exposition) sowie das Produkt aus inspiratorischem Sauerstoffanteil $\left(\mathrm{FiO}_{2}\right) *$ mittlerem Atemwegsdruck (MAP) bestimmt. Außerdem wurden die Kinder je nach ihren $\mathrm{pCO}_{2-}$ Werten in vier Gruppen eingeteilt: Tendenz zu Hyperkapnie, Hypokapnie, Normokapnie oder starke Fluktuationen des $\mathrm{pCO}_{2}$. Letztere waren definiert als Kinder, deren maximaler $\mathrm{PCO}_{2}$ im obersten Quartil der Maxima und minimaler $\mathrm{PCO}_{2}$ im untersten Quartil der Minima lag. Die statistischen Vergleiche erfolgten mit Kruskal Wallis und Fishers exakten Tests sowie multiplen logistischen Regressionsanalysen.

Ergebnisse: Die Kinder der vier Gruppen unterschieden sich nur geringfügig in ihrem Gestationsalter und Geburtsgewicht. Beim klinischen Outcome zeigte sich jedoch eine deutliche Häufung von moderater oder schwerer BPD bei Kindern aus der hyperkapnischen Gruppe (33\% vs. $20 \%$ in den anderen 3 Gruppen, $p=0,05)$. Kinder mit starken Fluktuationen des $\mathrm{pCO}_{2}$ neigten vermehrt zu Hirnblutungen aller Schweregrade ( $39 \%$ vs. $16 \%$ in den andren 3 Gruppen, $p<0,01$ ) und auch zu schweren Hirnblutungen Grad 3 oder 4 (17\% vs. $8 \%, p=0,04)$. Kinder mit fluktuierendem $\mathrm{pCO}_{2}$ hatten auch signifikant schlechtere Ergebnisse im Bayley-IITest im Alter von zwei Jahren (Median, 1.-3. Quartil): MDI 74 (52-88) vs 91 (66-102), $p<0,01$; PDI 80 (52-92) vs. 90 (57-103), p2*MAP auf BPD oder Tod, sowie von $\mathrm{CO}_{2}$ Exposition auf IVH Grad 3/4 oder Tod und Ent- wicklungsverzögerung oder Tod, die nicht über Unterschiede im Gestationsalter oder Geburtsgewicht erklärbar waren.

Diskussion und Schlussfolgerung: Hohe $\mathrm{PCO}_{2}$ Werte, hohe $\mathrm{CO}_{2}$ Exposition und hohe Werte für $\mathrm{FiO}_{2}{ }^{\star} \mathrm{MAP}$ waren Risikofaktoren für die BPD, was auf eine zusätzliche Gewebeschädigung hindeuten könnte, oder aber auch nur anzeigen könnte, dass diese Kinder einen insgesamt schwereren Verlauf der Lungenerkrankung (höheres $\mathrm{FiO}_{2}{ }^{*} \mathrm{MAP}$ ) hatten. Schwankende $\mathrm{PCO}_{2}$ Werte sowie eine hohe $\mathrm{CO}_{2}$ Exposition waren mit Hirnblutungen sowie einem schlechteren neurologischen Outcome assoziiert.

\section{GNPI-V20}

\section{Neuronal gesteuerte Beatmung (NAVA) bei Frühgeborenen}

S. Demirakca, R. Koch, T. Doniga, T. Jung, T. Schaible

Universitätsmedizin Mannheim, Neonatologie, Mannheim, Deutschland

Hintergrund: Die Asynchronie stellt ein wesentliches Problem bei der Beatmung Frühgeborener dar. Nicht selten kämpfen diese Patienten gegen jedwede Beatmungsform massiv an. Dies kann in einigen Fällen zu schwerer Lungentraumatisierung mit Emphysembildung und bullösen Veränderungen führen.

Fragestellung: Kann NAVA als ultima ratio Beatmungsform für Frühgeborene dienen, die sich weder durch konventionelle Beatmung noch durch Hochfrequenzoszillation beatmen lassen.

Material und Methoden: Retrospektive Untersuchung der Beatmungsdaten von $n=30$ Frühgeborenen aus 2012-2016 nach Beatmung mittels NAVA. Vergleich mittels gepaartem T-Test.

Ergebnisse: Gruppe 1: $N=20$ Frühgeborene (mittlere SSW 25,3 $\pm 2,1$; GG $728 \pm 343 \mathrm{~g}$ ) wurden nach erfolgloser konventioneller Beatmung und Hochfrequenzoszillation mit NAVA beatmet (Dauer $25 \pm 24$ d). Die Zufriedenheit der Kinder besserte sich unter NAVA deutlich. NEO COMFORT Score vor NAVA $14,4 \pm 3,2$ unter NAVA $11,4 \pm 1,2 p=0,001$. Das $\Delta \mathrm{P}$ der Beatmungsdrücke sank von 14,3 $\pm 2,5$ auf $10,1 \pm 2,8$ mbar $p=0,01$; der $\mathrm{pCO} 2$ von $56,4 \pm 14,1$ auf $49,0 \pm 9,5 \mathrm{mmHg} ; p=0,01$. Die S/F ratio (SO2/FiO2) stieg von $235 \pm 94$ auf $323 \pm 104 p<0,001$. $N=16$ Kinder wurden anschließend erfolgreich extubiert, 4 mussten mit einem Tracheostoma versorgt werden. Gruppe 2: $N=10$ Frühgeborene (mittlere SSW 25,0 $\pm 2,7$; GG $747 \pm 331 \mathrm{~g}$ ) wurden nach erfolglosen konventionellen Extubationsversuchen unter NIV NAVA extubiert und weiter beatmet (Dauer $25 \pm 21 \mathrm{~d}$ ) und mussten nicht reintubiert werden. PCO2 und S/F ratio blieben stabil, der NEO COMFORT Score verbesserte sich von $14,8 \pm 2,5$ auf $11,5 \pm 0,8 ; p=0,028$.

Schlussfolgerung: Frühgeborene, die unter konventioneller Beatmung nicht ausreichend synchronisiert werden können, profitieren von NAVA. Damit kann die Zufriedenheit der Kinder unter Beatmung erhöht und die Beatmungsparameter abgemildert werden. Mittels NIV NAVA konnten die Erfolgschancen der Extubation erhöht werden. Weitergehende Untersuchungen zum Stellenwert der NAVA bei Frühgeborenen sind damit gerechtfertigt.

\section{GNPI-V21}

\section{Einfluss adaptiver Backup-Beatmung auf das Sättigungsprofil von Frühgeborenen unter nicht-invasiver Beatmung mit automatisierter Sauerstoffkontrolle}

\section{S. Herber-Jonat ', M. Waitz' ${ }^{2}$ W. Braun ${ }^{3}$, H. Hummler ${ }^{2}$, A. W. Flemmer',} M. Gadjos ${ }^{2}$

'Dr. von Haunersches Kinderspital, Ludwig-Maximilians-Universität, Perinatalzentrum Großhadern, München, Deutschland, ${ }^{2}$ Klinik für Kinderund Jugendmedizin am Universitätsklinikum Ulm, Sektion für Pädiatrische Intensivmedizin und Neonatologie, Ulm, Deutschland, ${ }^{3}$ Fritz Stephan GmbH, Medizintechnik, Gackenbach, Deutschland

Hintergrund: Extrem unreife Frühgeborene zeigen unter nicht-invasiver Beatmung häufig Schwankungen der arteriellen Sauerstoffsättigung $\left(\mathrm{SpO}_{2}\right)$ und einen fluktuierenden Sauerstoffbedarf. Eine automatisierte Steuerung der inspiratorischen Sauerstofffraktion $\left(\mathrm{FiO}_{2}\right)$, aber auch eine 
adaptive Backup-Beatmung gelten als sicher und effektiv im Hinblick auf die Reduktion von $\mathrm{SpO}_{2}$-Schwankungen. Die Kombination beider Methoden der automatisierten Beatmungsadaptation wurde bisher jedoch noch nicht untersucht.

Ziel: Beurteilung der Wirksamkeit einer neu entwickelten Kombination von adaptiver Backup Beatmung (ABV) mit automatisierter $\mathrm{FiO}_{2}$-Steuerung (SPO2C) auf die Häufigkeit von $\mathrm{SpO}_{2}$-Schwankungen bei Frühgeborenen unter nicht-invasiver Beatmung.

Methoden: Wir untersuchten Frühgeborene $(<32$ SSW $)>72 \mathrm{~h}$ mit $\geq 4$ Phasen mit einer $\mathrm{SpO}_{2}<80 \%$ innerhalb von 8 Stunden in den $24 \mathrm{~h}$ vor Studienbeginn unter nicht-invasiver Atemunterstützung (Stratum 1: NCPAP; $n=12$, Stratum 2: NIPPV; $n=12$; Sophie ${ }^{\oplus}$ Säuglingsbeatmungsgerät, Fritz Stephan $\mathrm{GmbH}$, Gackenbach, Deutschland. Vergleich der automatisierten $\mathrm{FiO}_{2}$-Anpassung allein (SPO2C) und dem kombinierten Ansatz aus $\mathrm{SPO} 2 \mathrm{C}$ und adaptiver, apnoe-sensitiver, synchronisierter Backup-Beatmung (ABV-SPO2C) in einem randomisierten Crossover-Design von zweimal 24 Stunden. Primäres Zielkriterium war der Zeitanteil der $\mathrm{SpO}_{2}$ im Zielbereich (88-95\%).

Ergebnisse (vorläufig): Wir fanden in beiden Studienstrata bisher keinen signifikanten Einfluss der ABV auf die Dauer der $\mathrm{SpO}_{2}$ im vorgesehenen Zielbereich (NCPAP: $75,0 \% \pm 8,5 \%$ vs. $72,3 \% \pm 8,0 \%$; $p=0,43$; NIPPV: $81,3 \pm 6,6 \%$ vs. $78,4 \% \pm 7,2 \% ; p=0,33$ [Mittelwert \pm SD; ABV-SPO2C vs. SPO2C]. Bei Kinder unter NCPAP zeigt sich unter ABV-SPOC ein Trend in Richtung einer Reduktion des Zeitanteils mit einer $\mathrm{SpO}_{2}<88 \%$ $(14,6 \% \pm 5,2 \%$ vs. $18,8 \% \pm 5,4 \% ; p=0,065)$. In beiden Studienstrata führt die Kombination aus ABV und SPO2C tendenziell zu weniger prolongierten Hypoxämieepisoden mit einer $\mathrm{SpO}_{2}<88 \%$ mit $>60$ s Dauer (NCPAP: $23 \pm 21$ vs. $31 \pm 26, p=0,39$; NIPPV: $26 \pm 20$ vs. $30 \pm 26, p=0,70$ ). Wir fanden keinen signifikanten Unterschied im Zeitanteil einer $\mathrm{SpO}_{2}>97 \%$, der mittleren $\mathrm{SpO}_{2}$ und der mittleren $\mathrm{FiO}_{2}$ in beiden Messintervallen und Studienstrata.

Zusammenfassung: Der Einsatz adaptiver Backup Beatmung zusätzlich zu automatisierter $\mathrm{FiO}_{2}$-Anpassung führt bei VLBWI unter nicht-invasiver Atemunterstützung in der bisherigen Analyse nicht zu einer zusätzlichen signifikanten Stabilisierung der $\mathrm{SPO}_{2}$ im vorgegeben Zielbereich. Tendenziell scheint die Kombination aus adaptiver Backup Beatmung und SPOC die Dauer unterhalb des Sättigungszielbereichs und Rate prolongierter und tiefer Hypoxämieepisoden zu verringern.

\section{GNPI-V22}

\section{Molekulare Mechanismen der Koffein-vermittelten Reduktion Steroid-induzierter Expression von CTGF in Lungenepithelzellen und Fibroblasten}

\section{Fehrholz', K. Glaser', C. P. Speer', S. Kunzmann ${ }^{1,2}$}

'Universität Würzburg, Universitäts-Kinderklinik, Würzburg, Deutschland, ${ }^{2}$ Bürgerhospital Frankfurt am Main, Klinik für Neonatologie, Frankfurt am Main, Deutschland

Hintergrund: Koffein und Steroide werden zur Behandlung und Prophylaxe der bronchopulmonalen Dysplasie (BPD) Frühgeborener eingesetzt; potentielle Interaktionen beider Substanzen sind jedoch weitestgehend unbekannt. Positive Effekte auf inflammatorische sowie remodeling-Prozesse der Lunge durch Koffein wurden bereits beschrieben, der Einfluss von Steroiden auf remodeling-Vorgänge der Lunge ist jedoch weniger gut charakterisiert. Connective tissue growth factor (CTGF) spielt eine Schlüsselrolle bei der Initiierung von airway-remodeling und wird als bedeutend für die Pathogenese der BPD angesehen. Wir konnten bereits zeigen, dass Koffein die stimulatorische Wirkung von Steroiden auf die Expression von CTGF in Lungenepithelzellen hemmt.

Fragestellung: In dieser weiterführenden Studie wurde untersucht, inwieweit fetale Lungenfibroblasten von diesem Effekt betroffen sind, ob Koffein hier ebenfalls entgegenwirken kann und was mögliche molekulare Grundlagen für diese Effekte in Lungenzellen sind.

Material und Methoden: Die Expression von CTGF wurde mittels realtime PCR und Immunoblotting in Anwesenheit verschiedener Steroide (Dexamethason, Budesonid, u. a.) sowie Koffein in fetalen Lungenfibro- blasten (IMR 90) sowie Lungenepithelzellen (H441) quantifiziert. Zusätzlich wurden die Zellmodelle mit cAMP, TNF- $\alpha$, Antikörpern gegen TNF- $\alpha$, dem Adenylylcyclase Aktivator Forskolin, sowie dem selektiven Phosphodiesterase (PDE)-4 Inhibitor Cilomilast behandelt, um potentielle Koffein-vermittelte Mechanismen zu simulieren.

Ergebnisse: Steroide $(1 \mu \mathrm{M})$ führten auch in IMR-90 Zellen zu einer Induktion von CTGF mRNA $(p<0,001)$ sowie Protein $(p<0,01)$, die bei gleichzeitiger Anwesenheit von Koffein $(10 \mathrm{mM})$ signifikant reduziert werden konnte $(p<0,001)$. Koffein allein bewirkte eine signifikante Reduktion der basalen Expression von CTGF mRNA und Protein. Die Verminderung der CTGF Expression war unabhängig von cAMP Niveaus, Aktivierung der Adenylylcyclase oder einer PDE-4 Inhibition. Dexamethason und Koffein hatten keinen Einfluss auf TGF- $\beta 1$ oder TGF- $\beta 2$ mRNA in H441 Zellen, jedoch auf TGF- $\beta 3$ mRNA $(p<0,01)$. TNF- $\alpha$ mRNA wurde in H441 Zellen durch Koffein signifikant induziert $(6,5 \pm 2,2$-fach, $p<0,05)$. Die Gabe von TNF- $\alpha$, welches als Inhibitor der CTGF Expression beschrieben ist, konnte die beobachtete Reduktion der Dexamethason-induzierten Induktion von CTGF durch Koffein simulieren und wurde durch Antikörper gegen TNF- $\alpha$ wieder aufgehoben.

Schlussfolgerung: Zusätzlich zu den bereits gut charakterisierten anti-inflammatorischen Eigenschaften von Steroiden könnten durch die Induktion von CTGF auch nachteilige Effekte auf remodeling-Vorgänge der Lunge bestehen. Eine Co-Medikation mit Koffein könnte einer steroid-induzierten Expression von CTGF entgegenwirken und so zu einer verbesserten Lungenphysiologie beitragen.

\section{GNPI-V23}

\section{Review of vascular and non-vascular accesses during neonatal} resuscitation

M. Wagner', M. Olischar', M. O'Reilly' ${ }^{2}$ K. Goeral', A. Berger', P. Y. Cheung', G. Schmölzer ${ }^{2}$

'Medical University of Vienna, Division of Neonatology, Pediatric Intensive Care Unit and Neuropediatrics, Vienna, Austria, ${ }^{2}$ Centre for the Studies of Asphyxia and Resuscitation, Neonatal Research Unit, Royal Alexandra Hospital, Edmonton, Canada

Background: In the rare case of extensive neonatal cardiopulmonary resuscitation (CPR), establishing an immediate vascular access is crucial. Intravenous access for administration of medications remains the mainstay in neonatal resuscitation, alternative accesses include intraosseous (IOA) and endotracheal (ETT) routes.

Aim: We aimed to review current evidence regarding different accesses for the administration of medications during neonatal resuscitation.

Material and Methods: We reviewed PubMed, EMBASE, and Google Scholar using search terms catheterization, umbilical cord, delivery room, catecholamine, resuscitation, simulation, newborn, and infant.

Results: No randomised controlled trials comparing IOA vs. peripheral intravascular access (PIV) vs. umbilical venous catheter (UVC) vs. ETT vs. laryngeal mask airway (LMA) during neonatal resuscitation in the delivery room regarding success rate, application time and plasma catecholamine levels were identified. Animal studies suggest that a higher dose of adrenaline (epinephrine) for ETT is required compared to intravenous administration. Adrenaline via LMA showed similar plasma levels compared to ETT and could be a non-invasive alternative for drug delivery.

Discussion and Conclusions: It is vital to establish a quick access for drug administration during neonatal resuscitation. Based on animal studies, ETT administration of medications requires a higher dose than that by PIV or UVC. Although establishing an IOA could be faster and more successful compared to ETT, LMA, UVC, or PIV with a low complication rate, little information is available on the required medication dosage. IOA should be considered in situations with difficulties in establishing other accesses. Randomised controlled clinical trials in neonates are required to compare all access possibilities described above. 


\section{GNPI-V24}

\section{Reifung der Thrombozytenfunktion in vivo im Verlauf der fetalen}

\section{Entwicklung}

C. Nussbaum ${ }^{1,2}$, A. Margraf2, , I. Rohwedder', S. Klapproth' ${ }^{2}$, A. R. M. Kurz ${ }^{2}$,

A. Florian 1,2, V. Wiebking' ', J. Plrcher 2,4 M. Pruenster', R. Immler' ', S. Dietzel',

L. Kremer ${ }^{5}$, F. Kiefer', M. Moser ${ }^{2,6}$, A. W. Flemmer', E. Quackenbush',

U. H. von Andrian ${ }^{8}$, M. Sperandio ${ }^{2}$

'Dr. von Haunersches Kinderspital, Abteilung für Neonatologie, München, Deutschland, ${ }^{2}$ Ludwig-Maximilians-Universität, Walter-Brendel-Zentrum

für Experimentelle Medizin, München, Deutschland, ${ }^{3}$ Universitätsklinikum

Münster, Klinik für Anästhesiologie, operative Intensivmedizin und

Schmerztherapie, Münster, Deutschland, ${ }^{4}$ Klinikum der Ludwig-MaximiliansUniversität, Medizinische Klinik und Poliklinik, München, Deutschland, ${ }^{5}$ MaxPlanck-Institut für Molekulare Biomedizin, Münster, Deutschland, ${ }^{6}$ Max-

Planck-Institut für Biochemie, Molekulare Medizin, München, Deutschland, ${ }^{7}$ Roche Inc., New York, USA, ${ }^{8}$ Harvard Medical School, Dep. of Microbiology and Immunobiology, Boston, USA

Hintergrund: Thrombozyten spielen eine zentrale Rolle bei der primären Hämostase. Störungen der Thrombozytenfunktion können daher zu schweren Blutungskomplikationen führen. In vitro Untersuchungen offenbarten eine Hyporeaktivität der Thrombozyten von früh- und reifgeborene Neonaten und deuten auf eine ontogenetische Regulation der primären Hämostase hin.

Fragestellung: Ziel war es die Thrombozytenfunktion in vivo im sich entwickelnden Fetus zu untersuchen, um ein besseres Verständnis über die ontogenetische Regulation der primären Hämostase zu erlangen.

Methoden: Die Thrombozytenfunktion wurde anhand eines neu entwickelten intravitalmikroskopischen Thrombosemodells an murinen Feten zu verschiedenen Gestationszeitpunkten untersucht. Zur weiteren Charakterisierung wurde die Expression wichtiger Adhäsionsmoleküle auf Thrombozyten mittels Durchflusszytometrie und Westernblot analysiert. Ergebnisse: Die in vivo Untersuchungen zeigen eine stark reduzierte Fähigkeit zur Ausbildung eines stabilen Thrombus bei E13.5 Feten (d.h. an Tag 13,5 von 21 Tagen Gestation) im Vergleich zu E17.5 Feten. Zudem finden sich bei jungen Feten signifikant niedrigere Thrombozytenzahlen. In vitro zeigen fetale Thrombozyten im Vergleich zu adulten Kontrollen ein vermindertes Ansprechen auf verschiedene Agonisten und eine signifikant niedrigere Expression von Kindlin-3, Talin-1 und Rap1, welche für die Integrinaktivierung essentiell sind. Interessanterweise kommt es nach Transfusion adulter Thrombozyten in die fetale Zirkulation zu einer akuten Thrombusbildung selbst in E14.5 Feten. Eine retrospektive Datenanalyse aus einem Perinatalzentrum ergab jedoch keinen Hinweis auf einen Vorteil einer Thromboyztentransfusion auf die medikamentöse Verschlussrate eines persistierenden PDA bei Frühgeborenen mit Thrombozytopenie. Schlussfolgerung: Unsere Studie zeigt erstmalig eine verminderte Funktion fetaler Thrombozyten in vivo in Abhängigkeit vom Gestationsalter. Hierfür scheinen neben Unterschieden in der Thrombozytenzahl eine reduzierte Aktivierbarkeit fetaler Plättchen und Störungen in der Funktion thrombozytärer Integrine verantwortlich zu sein. Während eine Thrombusbildung in utero für die fetale Entwicklung entbehrlich erscheint, stellt die verminderte Funktion fetaler Plättchen bei extremer Frühgeburtlichkeit möglicherweise ein Problem dar.

\section{GNPI-V25 \\ ChyloBEST - Chylothorax in Infants and Nutrition with Low Fat Breast Milk - Pilotstudie - Chylothorax bei Neugeborenen - Ernährung mit fettarmer Muttermilch}

\section{T. Springer ${ }^{1}, K_{\text {. Nieschke }}{ }^{1}$, M. Abedini' ${ }^{2}$, M. Kostelka ${ }^{3}$, I. Dähnert ${ }^{1}$}

${ }^{1}$ Herzzentrum Leipzig GmbH, Kinderkardiologie, Leipzig, Deutschland, ${ }^{2}$ Asklepios Klinik St. Augustin, Kinderherzzentrum, St. Augustin, Deutschland, ${ }^{3}$ Herzzentrum Leipzig $\mathrm{GmbH}$, Klinik für Herzchirurgie, Leipzig, Deutschland

Hintergrund: Die Inzidenz eines postoperativen Chylothorax bei Herzchirurgie im Neugeborenenalter liegt nach Literaturangaben bei 5-9,2\%
(10\% im Herzzentrum Leipzig). Ein Zusammenhang zwischen steigender Komplexität der herzchirurgischen Eingriffe bei Neugeborenen und dem Auftreten eines Chylothorax liegt nahe. Die bisherige Standardtherapie besteht neben der Drainage der chylösen Ergüsse in der Nahrungsumstellung auf fettfreie Formula (Basic-f) für sechs Wochen. Die Gabe von Muttermilch wäre ein Fortschritt in der Therapie im Zeitalter der individuellen patientenbezogenen Behandlung.

Fragestellung: Ist eine Diät mit fettarmer Muttermilch (lfBM) bei Chylothorax eine sichere und effektive Therapie des postoperativen Chylothorax?

Methoden: Neugeborene mit angeborenem Herzfehler und postoperativem Chylothorax $(n=17)$ wurden in die prospektive, nicht randomisierte, multizentrische (Hauptprüfzentrum Herzzentrum Leipzig, Nebenprüfzentrum Kinderherzzentrum St. Augustin) Pilotstudie eingeschlossen. Durch 15-minütige Kühlzentrifugation kann lfBM gewonnen werden, wobei die fettreiche Schicht von der fettarmen Muttermilch getrennt wird. Eine ausreichende Nährstoffversorgung wird durch Zugabe von MCT-Öl und Muttermilchsupplement gewährleistet. Neben dem Fettgehalt wurden mit einem geeigneten Messgerät auch der Kohlenhydrat-, Energieund Proteingehalt der lfBM bestimmt. Um den Erfolg der Diät mit lfBM zu überprüfen, wurden der Rückgang der Ergussmenge, das Rezidiv eines Chylothorax und die körperliche Entwicklung beobachtet.

Bisherige Ergebnisse: Durch Kühlzentrifugation der Muttermilch bleibt der Gehalt der Hauptnährstoffe bis auf den Fettgehalt unverändert (meanFat: $0,36 \%^{\star}$, meanProtein: $1,5 \%$, meanCarbohydrate: $7,1 \%$, meanEnergy: $39,3 \mathrm{kcal} / 100 \mathrm{ml}$ ). Bisher erhielten 17 Patienten ( $n=5$ Norwood-1, $n=6$ Arterieller Switch, $n=1$ TAPVD-Redir., $n=1$ Glenn, $n=1$ TAC-Korrektur, $n=1$ ISTA-Resektion, $n=2$ komplexer VSD-Verschluss) angereicherte lfBM. Bei allen Patienten wurde mit Beginn der lfBM Diät ein deutlicher Rückgang der Drainageverluste beobachtet. Kein Patient hatte ein Chylothorax-Rezidiv. Nach Beendigung der lfBM Diät wurden 11 von $16(68,7 \%)$ der Patienten gestillt. Alle Patienten zeigten eine positive Gewichtsentwicklung.

Schlussfolgerung: Fettarme Muttermilch kann schnell und unkompliziert gewonnen werden. Die Ernährung mit angereicherter lfBM scheint eine sichere Form der Diät bei Chylothorax zu sein, ohne auf die Vorteile der Muttermilchernährung zu verzichten.

\section{GNPI-V26}

Less Invasive Surfactant Administration (LISA) verbessert nicht nur die Mortalität und Morbidität Frühgeborener sondern auch deren neurologisches Langzeitoutcome

K. Klebermass-Schrehof, A. Grill, M. Hayde, N. Haiden, A. Flunt, R. Fuiko, S. Brandstetter, A. Berger

Medizinische Universität Wien, Abteilung für Neonatologie, Pädiatrische Intensivmedizin und Neuropädiatrie, Universitätsklinik für Kinder- und Jugendheilkunde, Wien, Österreich

Hintergrund: In aktuellen Metaanalysen wird LISA (less invasive surfactant administration) als effektivste non-invasive Ventilationsstrategie beschrieben, mit der niedrigsten Assoziation zu Mortalität und $\operatorname{BPD}(1,2)$. Somit ist der Kurzzeitbenefit dieser Methode bereits bekannt, unklar bleibt aber noch, ob diese Methode auch eine Verbesserung des Langzeitoutcomes von Frühgeborenen bewirken kann.

Fragestellung: Daher war das Ziel unserer Studie das entwicklungsneurologische Outcome mit 2 Jahren von Frühgeborenen aus unserer Abteilung, die mittels LISA behandelt wurden mit einer historischen Kontrollgruppe zu vergleichen.

Material und Methoden: Alle Kinder die zwischen 01/2009-12/2014 $(n=546)$ mit einem Gestationsalter von $23+0-27+6$ SSW an der medizinischen Universität Wien (MUW) geboren wurden, wurden mittels LISA behandelt und mit Kindern desselben Gestationsalters die zwischen 01/2003-12/2008 $(n=402)$ an der MUW geboren wurden verglichen (=historische Kontrollgruppe). Das entwicklungsneurologische Outcome im Alter von 2 Jahren wurde mittels Bayley Scales of Infant Development erhoben. 
Ergebnisse: In der mittels LISA behandelten Gruppe 2009-2014 überlebten $82,3 \%$ aller Frühgeborener $<28$ SSW, im Vergleich zu 59,3\% aller Kinder der historischen Kontrollgruppe $(p=<0,001) .49,7 \%$ der LISA-Kohorte zeigten eine normales Outcome oder nur eine milde Beeinträchtigung (MDI/PDI > 70) im Alter von 2 Jahren im Vergleich zu 24,8\% der Kontrollgruppe ( $p=>0,001) .18,0 \%$ zeigten ein moderat bis schwer beeinträchtigtes Outcome (MDI/PDI > 70) im Vergleich zu 11,3\% der Kontrollgruppe ( $p=0,03)$. 37,3\% der LISA-Kohorte überlebten ohne Morbidität (=IVH>II, NEC, ROP >II, CLD) im Vergleich zu 22,7\% in der Kontrollgruppe $(p=0,012)$.

Schlussfolgerung und Diskussion: Mittels LISA behandelte Frühgeborene zeigen an unserer Abteilung nicht nur ein verbessertes Kurzzeitoutcome, sondern auch ein signifikant verbessertes entwicklungsneurologisches Outcome. Neben deutlich verbesserter Überlebensraten stieg auch der Anteil an Kindern mit unauffälligem Outcome an. Als Limitation unserer Studie muss der Vergleich mit einer historischen Vergleichsgruppe angesehen werden, da sich Outcomedaten über die Jahre bekanntermassen kontinuierlich verbessern; als großen Vorteil unserer Studie sehen wir die hohe Patientenzahl und Daten aus einem singulärem Center.

\section{Literatur}

1. Isayama JT, Iwami H, McDonald S, Beyene J (2016) Association of noninvasive ventilation strategies with mortality and bronchopulmonary dysplasia among preterm infants: a systematic review and meta-analysis. JAMA 316:611-624

2. Aldana-Aguirre JC, Pinto M, Featherstone RM, Kumar M (2017) Less invasive surfactant administration versus intubation for surfactant delivery in preterm infants with respiratory distress syndrome: a systematic review and meta-analysis. Arch Dis Child Fetal Neonatal Ed 102:F17-F23

\section{GNPI-V27}

\section{Telomerlänge von frühgeborenen Kindern -Biomarker neben Gestationsalter und Geburtsgewicht}

N. T. Siebert', M. Hütten', S. Dreschers', F. Beier², T. Brümmendorf', T. Orlikowsky'

'Universitätsklinik Aachen, Neonatologie, Aachen, Deutschland, ${ }^{2}$ Universitätsklinik Aachen, Hämatologie und Onkologie, Aachen, Deutschland

Hintergrund: Aktuelle Studien unterstreichen den Zusammenhang zwischen Frühgeburtlichkeit und einem beschleunigten zellularem Alterungsprozess der betroffenen Kinder. Telomere sind am Ende jedes Chromosoms lokalisiert und verkürzen sich mit jeder Zellteilung. Biochemisch kann somatische Zellalterung als eine Telomerlängenverkürzung aufgefasst werden. So sind sie in der Stammzellbiologie ein etabliertes Instrument, um das Replikationsverhalten einer Zelle zu analysieren.

Fragestellung: Gegenstand unsere Untersuchung ist die Frage nach einem Zusammenhang zwischen der durchschnittlichen Telomerlänge und dem Gestationsalter bzw. dem Geburtsgewicht von früh- und reifgeborenen Neonaten. Dabei wird die Telomerlänge in einem zweiten Schritt auf ihre Eignung als prognostischer Biomarker für das Outcome von Frühgeburtlichkeit analysiert.

Material und Methoden: Die durchschnittliche Telomerlänge von Granulozyten und Lymphozyten wurde aus Nabelschnurblut von 46 Neonaten (33 früh- und 11 reif geborene Kinder) mithilfe von flow-FISH (Fluoreszenz-in-situ-Hybridisation) bestimmt. In einem follow-up-Setting wurde der Zusammenhang zwischen der durchschnittlichen Telomerlänge zur Geburt und der Gewichtsentwicklung von neun moderat frühgeborenen Kindern (32-37. SSW) während ihres ersten Lebensjahres untersucht. Ergebnisse: Es konnte ein signifikanter Rückgang der durchschnittlichen Telomerlänge bei zunehmendem Gestationsalter und bei steigendem $\mathrm{Ge}$ burtsgewicht festgestellt werden. Dabei verkürzen sich die Telomere pro Woche um 125,7 Basenpaare (bp) bei Granulozyten und 186,2 bp bei Lymphozyten. Darüber hinaus scheinen moderat frühgeborene Kinder mit längeren Telomeren ein größeres Wachstumspotential vorweisen zu können als Kinder mit kürzeren Telomeren.

Schlussfolgerung: Zellulare Alterungsprozesse von Frühgeborenen können anhand der durchschnittlichen Telomerlänge untersucht werden. Da- bei unterstreichen unsere Ergebnisse die prognostische Relevanz dieser. Aufgrund dessen schlagen wir die durchschnittliche Telomerlänge als einen möglichen prognostischen Biomarker für Frühgeburtlichkeit neben dem Gestationsalter und dem Geburtsgewicht vor.

\section{GNPI-V28}

\section{Sustained high pressure CPAP therapy for primary resusciation of} VLBW infants using the Benveniste valve

C. Kirchgäßner, B. Kühne, A. Kribs, A. Oberthür

Klinik für Kinder und Jugendmedizin, Universität Köln, Neonatologie, Köln, Deutschland

Background: Primary CPAP therapy for stabilization of preterm infants helps to avoid invasive mechanical ventilation and results in improved outcome. It is usually applied with pressure levels of 5-8 cmH2O. In addition, sustained inflation manoeuvres $(20-25 \mathrm{cmH} 2 \mathrm{O}$ for $10-20 \mathrm{~s})$ have been shown to improve lung aeration during resuscitation. Using the Benveniste device, a gas jet-CPAP generator with low exspiratory resistance, we support preterm infants with sustained high CPAP pressure levels, but exact CPAP levels were not known. We used a respiratory function monitor to analyze CPAP pressure levels generated by the Benveniste device in combination with a face mask or nasopharyngeal tube in a series of 30 VLBW infants and assessed the effects on neonatal outcome parameters. Methods: 30 preterm infants with a birth weight below $1500 \mathrm{~g}$ (VLBW infants) were included in the study. Mean gestational age was $26+4$ weeks (range: $23+1$ to $31+3$ weeks) and average birthweight was 820,7 gramm (range $450 \mathrm{~g}$ to $1475 \mathrm{~g}$ ). Using the Benveniste device, CPAP pressure levels were increased by increasing the gas flow that is applied to the system using a standardized step-wise increasing PEEP approach for primary resuscitation: starting with a gas flow of $14 \mathrm{l} / \mathrm{min}$ the flow was increased in steps of $2 \mathrm{l} / \mathrm{min}$ in case of insufficient heart rate or oxygenation. Using a respiratory function monitor, the over-time applied pressure levels during the first 60 minutes of life were recorded and both basic patient data and neonatal outcome parameters were collected.

Results: All infants in the analysis commenced breathing after birth with CPAP support and no infant required positive pressure ventilation or intubation during stabilization in the delivery room. The constantly applied pressure levels ranged from $10 \mathrm{cmH} 2 \mathrm{O}$ to $36 \mathrm{cmH} 2 \mathrm{O}$. Resuscitation was started with an average pressure of $16.4 \mathrm{cmH} 2 \mathrm{O}$ (SD 2.26), followed by increasing CPAP levels up to an average maximum of $29.4 \mathrm{cmH} 2 \mathrm{O}$ (SD 3.21). The overall average CPAP-pressure for the full primary stabilization procedure (approx. 45-60 minutes) was $26.2 \mathrm{cmH} 2 \mathrm{O}$ (SD 3.9). All infants received surfactant via the less invasive surfactant application (LISA) technique. During the first 72 hours of life, $8 / 30$ infants (26.6\%) required invasive mechanical ventilation. Pneumothorax occurred in 7/30 infants (23\%), however no pneumothorax was observed in the first 12 hours of life. $4 / 30(13.8 \%)$ developed a mild or moderate BPD, $3 / 30(10 \%)$ had focal intestinal perforation and 5/30 (16.6\%) had intraventricular hemorrhage (IVH) ${ }^{\circ}$ II or higher. No PIE or ROP requiring treatment were observed in the study cohort and all infants survived until discharge.

Conclusions: Using the Benveniste device, sustained high CPAP pressure levels up to $>30 \mathrm{cmH} 2 \mathrm{O}$ were applied to VLBW infants for $>30$ minutes during resuscitation with good clinical outcome (low rate of complications or need for mechanical ventilation $<72$ hours). Thus, a continuous high pressure CPAP procedure might be an effective approach for lung aeration during resuscitation without putting premature infants at an increased risk of lung injury. 


\section{GNPI-V29}

Kann eine einfache qualitative und quantitative Analyse des MRT am errechneten Geburtstermin das Outcome sehr kleiner Frühgeborener mit korrigiert $\mathbf{2 4}$ Monaten vorhersagen?

M. V. Dewan', R. Herrmann', H. Müller', T. Storbeck', F. Dransfeld', J. Hobrecht', S. Sirin', B. Schweiger', U. Felderhoff-Müser', B. Hüning'

'Universitätsklinikum Essen, Kinderklinik I, Essen, Deutschland,

${ }^{2}$ Universitätsklinikum Essen, Institut für Diagnostische und Interventionelle Radiologie und Neuroradiologie, Essen, Deutschland

Hintergrund: Die Geburt eines sehr unreifen Frühgeborenen (FG) fällt in die vulnerable Phase der Hirnentwicklung und geht mit einem hohen Risiko für eine eingeschränkte neurologische Entwicklung einher. Im klinischen Alltag werden einfach zugängliche Biomarker zur Vorhersage des neurologischen Outcomes benötigt um Kinder mit einem erhöhten Risiko für eine langfristige neurokognitive Beeinträchtigung frühzeitig zu erfassen, die betroffenen Eltern angemessen zu beraten sowie neuroprotektive Maßnahmen kurzfristig zu bewerten.

Fragestellung: Kann die Anwendung metrischer Parameter zur Erfassung des Hirnwachstums sowie die Bewertung zerebraler Schädigungsmuster und der Hirnentwicklung in Form eines Scoring-Systems die neurologische Langzeitentwicklung sehr kleiner FG im Alter von korr. 24 Monaten vorhersagen?

Methoden: In dieser Studie wurden 134 FG (67 Mädchen und 67 Jungen), die zwischen 01/2009 und 06/2014 geboren wurden, untersucht. Das Gestationsalter betrug im Median 28+1 SSW (Min: 23+5; Max: 33+0) und das Geburtsgewicht lag im Median bei $982 \mathrm{~g}$ (Min: $450 \mathrm{~g}$; Max: $1730 \mathrm{~g}$ ). Im MRT am errechneten Geburtstermin wurde für die quantitative Analyse das Hirnwachstum durch Messung der Biparietalweite (BPW) und des Transzerebellardiameters (TCD) erfasst. Die qualitative Analyse beinhaltete 1. die Bewertung der zerebralen Schädigung durch Erfassung des Grades an periventrikulärer Leukomalazie, intraventrikulärer Hämorrhagie und Kleinhirnblutung sowie 2. die Hirnentwicklung, bewertet durch einen modifizierten Score nach Kidokoro et al. [1] und zusammengefasst zum Total Abnormality Score (TAS). Als Parameter für die Hirnentwicklung wurden Gyrierung, Myelinisierung und Ventrikelweite betrachtet. Die neurologische Entwicklung wurde mit korr. 24 Monaten mittels Mental Developmental Index (MDI) und dem Psychomotor Developmental Index (PDI) im Rahmen des Bayley Scales of Infant Development II erhoben. Das Untersuchungsalter betrug im Median 24,55 Monate (Min: 15,97; Max: 36,57). Bei nicht normverteilten Daten erfolgte die Korrelationsanalyse mittels Spearman-Test.

Ergebnisse: Ein MDI konnte bei 134 FG, ein PDI bei 122 FG erhoben werden. Der Median des MDI betrug 92 (Min: <50; Max: 124), der des PDI 84 (Min: $<50$; Max: 125). Der TAS konnte bei 74 Kindern erhoben werden und ergab im Median 2 (Min: 0; Max: 19). Der BPW war nicht signifikant mit dem MDI $(\mathrm{r}=0,10 ; p=0,2393)$ oder dem PDI $(\mathrm{r}=0,16 ; p=0,0856)$ assoziiert. Ebenfalls nicht signifikant war der TCD weder mit dem MDI $(r=0,17$; $p=0,0545)$ noch mit dem PDI $(r=0,2 ; p=0,0362)$ korreliert. Auch der TAS korrelierte nicht signifikant mit dem MDI $(\mathrm{r}=-0,15 ; p=0,2005)$ und dem PDI ( $\mathrm{r}=-0,2 ; p=0,1122)$.

Schlussfolgerung: Die einfache quantitative und qualitative Analyse des MRT am errechneten Geburtstermin sehr kleiner FG konnte in unserem Kollektiv keine ausreichende Korrelation mit dem Outcome im Alter von korrigiert 24 Monaten zeigen, so dass sie für eine Aussage zur Prognose ungeeignet erscheint.

\section{Literatur}

1. Kidokoro H, Anderson PJ, Doyle LW, Woodward LJ, Neil JJ, Inder TE (2014) Brain injury and altered brain growth in preterm infants: predictors and prognosis. Pediatrics 134:E444-E453

\section{GNPI-V30}

Episodes of hypo - and hypercapnia in a cohort of mechanically ventilated VLBW infants: the role of adequate staffing

\section{S. Meyer, M. Röhr, M. Poryo, J. Bay, L. Gortner}

Universität des Saarlandes, NICU, Homburg, Deutschland

Background and Study purpose: The aim of this prospective audit was to examine the frequency of episodes of hypo - and/or hyperventilation in a cohort of VLBW infants whether a positive correlation existed between the number of physicians on duty (day vs. night shift, week days vs. weekend) and the occurrence rate of inadequate ventilation, and whether a positive association existed between common complications of prematurity. Patients and Methods: After ethics approval VLBWI and ELBW neonates who were born between $01 / 2012$ and 12/2013 at the University Hospital of Saarland, and who had to be invasively ventilated during the first 72 hours after birth were included. All arterial blood gas analyses were aspirated from an umbilical or radial artery catheter. $\mathrm{CO} 2$ partial pressure data were divided into 4 categories: $<35 \mathrm{mmHg}=$ hypocapnia; $35-45.9 \mathrm{~mm}$ $\mathrm{Hg}=$ normocapnia, $46-49.9 \mathrm{mmHg}=$ mild hypercapnia; $>50 \mathrm{mmHg}$ severe hypercapnia.

Results: The study cohort consisted of 63 VLBWI/ELBW infants with a median gestational age of 26 weeks of gestation (range: $23+4 / 32+1$ ) and a median birth weight of $852 \mathrm{~g}$ (range: $330-1490 \mathrm{~g}$ ). In $79.4 \%$ of cases, antenatal steroids were given. Median APGAR scores at 1,5 , and 10 minutes were: 5,7 , and 8 . The most common indication for mechanical ventilation ( $>95 \%$ of infants) was RDS. 2408 blood gas analyses were performed in total (mean: $38.8 \pm 39.4$ blood gas analyses per patient). 1280 arterial blood gas analyses were performed during hours of regular staffing (53.2\%). In 1383 of blood gas analyses (57.3\%), pathological CO2 values were seen. In $48.4 \%$ of infants transient hypocapnic episodes were noted while in $22.7 \%$ of infants mild hypercapnia was observed and in $28.5 \%$ severe hypercapnia was diagnosed. Regarding the quality of the blood gas analyses during work periods with reduced staff (night shift) compared to regular staff presence (day shift), a statistically significant increase of $9.8 \%$ in abnormal blood gas analyses ( $\mathrm{p}$ value $<0.001$ ) was seen. At weekends and holidays, a $5.0 \%$ rise in pathological blood gas analyses was noted ( $\mathrm{p}$ value $<0.001$ ). The typical complications of prematurity (IVH, PVL, ROP) demonstrated a positive, albeit non-significant association with abnormal blood gas analyses whereas BPD was significantly associated with the number of hypocapnic episodes $(p<0.05)$.

Conclusions: Our study shows that a large portion of mechanically ventilated VLBW/ELBW neonates experience episodes of hyper- and hypoventilation. The rate of hypocapnic episodes was substantially higher when compared to results from previous reports. This may be attributable to differences in cut-off valuesa. Conversely, the relatively high rate of hypercapnic episodes may be reflective of changing patterns in ventilation strategies. A reduced presence of medical staff at night and weekends was associated with a significant aggravation of inadequate ventilatory support. The realization of adequate staffing will require further organizational steps - both on a local (eg, improved neonatal training) and political scale (eg. allocation of adequate funding).

\section{GNPI-V31}

Reden statt handeln? Kommunikation im klinischen Alltag von Neonatologen

N. Börner', S. Mache ${ }^{1,2}$, C. Bührer ${ }^{1}$

${ }^{1}$ Charité Universitätsmedizin Berlin, Neonatologie, Berlin, Deutschland, ${ }^{2}$ Universitätsklinik Hamburg-Eppendorf, Zentrum für Psychosoziale Medizin Universitätsprofessur für Arbeitsmedizin, Hamburg, Deutschland

Hintergrund: Kommunikation ist essentieller Bestandteil klinischer Arbeit - bei Austausch, Bewertung von Informationen sowie Therapieentscheidungen. Das gilt auch für die Neonatologie mit fragilen, lang hospitalisierten Patienten betreut von interdisziplinären Team mit überlappenden Aufgabenbereichen, häufigen Personalwechseln und von Notfällen geprägten Unterbrechungen. Kommunikationsprobleme und resultierende Behand- 
lungsfehler sind in der Literatur beschrieben. Wieviel mit wem kommuniziert wird und wo Potential zur Verbesserung liegt, ist weniger untersucht Ziel dieser Arbeit ist eine erste objektive Erhebung ärztlicher Kommunikation auf einer neonatologischen Intensivstation.

Methoden: Die Ergebnisse sind Teil einer objektiven Tätigkeitsuntersuchung an zwei Standorten eines Level-1 Perinatalzentrum in Deutschland. Mittels Schattentechnik wurden alle durchgeführten Tätigkeiten von 15 ärztlichen Probanden über 60 Wochentage in je 2 Früh- und Spätdiensten dokumentiert. Erfasst werden konnten bis zu zwei Tätigkeiten gleichzeitig aus einer der 13 Oberkategorien wie z. B. Besprechungen oder direkte Patiententätigkeiten und bis zu 12 Unterkategorien.

Ergebnisse: Insgesamt wurden ca. $550 \mathrm{~h}$ Tätigkeiten erfasst. Von den täglich durchschnittlich gearbeiteten 9 h 10 min entfielen ca. $31 \%$ auf Besprechungen als Haupttätigkeit (174 min), der Anteil lag signifikant über dem der direkten Patiententätigkeiten (145 min, 15,43\%, $p=0,001$ ). Auch die zweithäufigste Kategorie, indirekte Patientenbehandlung/Administration, wurde mit $131 \mathrm{~min}$ signifikant häufiger ausgeübt als die direkte Arbeit am Patienten $(p=0,002)$. Besprechungen bestanden vor allem aus $\mathrm{Ge}-$ sprächen unter ärztlichen Kollegen, unterteilt in Gespräche in Visiten (21 min), Übergaben (46 min), Früh- und Mittagsbesprechungen (10 min) und weitere ärztliche Gespräche (38 min). Zwischen Früh- und Spätdienst ließ sich für die Kommunikation unter ärztlichen Kollegen $(p=0,394)$ kein signifikanter Unterschied nachweisen, aber bei weiterer Aufteilung eine Dominanz der Visiten im Frühdienst (42 min) sowie der Übergaben im Spätdienst ( $70 \mathrm{~min} ; p=0,012$ ). Mit dem Pflege- und weiterem Personal der Abteilung wurde durchschnittlich ca. 34 min kommuniziert, in der Visite anteilig ca. 4 min. Es ließ sich ein signifikanter Unterschied der Kommunikation zugunsten des Spätdienstes nachweisen mit fast 40 min versus 29 min im Frühdienst $(p=0,002)$.

Diskussion: Die Arbeit bestätigte den großen Anteil von Kommunikation, v. a. untereinander, im klinischen Alltag, der von Erwachsenen-Intensivstationen beschrieben wurde. Inwieweit diese Kommunikation effektiv ist, kann mit diesen Daten nicht bewertet werden. Bei aller Länge an ärztlichen Besprechungen sind Ausbildungs- und sozialer Charakter der Kommunikation nicht zu vernachlässigen. Auffällig bleibt der geringe Anteil an Kommunikation mit pflegerischem Personal, v. a. in Visiten, die nachweislich die Zufriedenheit der Pflege reduziert. Auch bei unzureichender Studienlage zum Patientenoutcome bei insuffizienter Kommunikation scheinen einige Empfehlungen zur Verbesserung von Kommunikation und Teamarbeit sinnvoll. V. a. für Übergaben wird die Reduktion des menschlichen Faktors durch Standards, Nutzung vorhandener Technologien, Training und Reduktion des Umgebungseinflusses vorschlagen. Schlussfolgerung: Weitere Untersuchungen zur Qualität der Kommunikation und z.B. deren Unterbrechung sind nötig.

\section{GNPI-V32}

\section{Kinderanalgosedierung am Beispiel UKE: Maximale Patientensicherheit bei minimaler Kostenabbildung im bestehenden DRG-Abrechnungssystem}

\section{K. Röher', C. Zöllner' , G. Schön², H. Müller ${ }^{3}$, D. Singer', S. Apostolidou ${ }^{4}$}

'Universitätsklinikum Hamburg-Eppendorf, Zentrum für Anästhesiologie und Intensivmedizin, Hamburg, Deutschland, ${ }^{2}$ Universitätsklinikum Hamburg-Eppendorf, Institut für Medizinische Biometrie und Epidemiologie, Hamburg, Deutschland, ${ }^{3}$ Universitätsklinikum HamburgEppendorf, Zentrum für Geburtshilfe, Kinder- und Jugendmedizin, Hamburg, Deutschland, ${ }^{4}$ Universitätsklinikum Hamburg-Eppendorf, Sektion Neonatologie und Pädiatrische Intensivmedizin, Hamburg, Deutschland

Hintergrund und Fragestellung: Am Universitätsklinikum Hamburg-Eppendorf wurde im August 2014 ein spezialisiertes interdisziplinäres Kinderanalgosedierungsteam (KAST) aus 5 Fachärzten der Anästhesiologie sowie der Neonatologie und pädiatrischen Intensivmedizin eingerichtet, welches alle Analgosedierungen für diagnostische Maßnahmen und kleine Eingriffe bei Kindern durchführt. Neben der Erfassung von Prävalenz und Prädiktoren von Komplikationen bei Analgosedierungen durch unser interdisziplinäres Team soll in dieser Untersuchung außerdem die Vergütung der Analgosedierungen durch die Kostenträger betrachtet werden. Material und Methoden: Es erfolgte für den Zeitraum August 2014 bis August 2015 eine retrospektive Auswertung der Sedierungsprotokolle. Mittels multifaktorieller Varianzanalyse wurden Risikofaktoren für das Auftreten von Komplikationen ermittelt. Dabei wurden als unabhängige Variablen Alter, Geschlecht, ASA-Klassifikation, Art und Dosierung des Hypnotikums, Verwendung eines Analgetikums sowie Erfahrung des Arztes untersucht. Zur Evaluation der wirtschaftlichen Effizienz des KAST erfolgte eine Gegenüberstellung von Kosten und DRG-Erlösen.

Ergebnisse und Diskussion: Innerhalb eines Jahres wurde bei 784 Kindern eine Analgosedierung durchgeführt, davon $30 \%$ ambulant oder im tagesklinischen Bereich. Der Anteil von Patienten mit einer ASA-Klassifikation von 3 oder 4 lag bei $53 \%$. Insgesamt traten bei 6,5\% der Sedierungen unerwünschte Ereignisse auf, am häufigsten Apnoe (1,7\%), Atemwegsobstruktion $(1,0 \%)$ und Probleme mit dem intravenösen Zugang (1,0\%). Es gab keine schwerwiegenden Komplikationen wie Herz-Kreislaufstillstand oder Aspiration. In der Varianzanalyse war mit jedem Quartal mehr an Behandlungserfahrung des KAST eine signifikante Verringerung des Komplikationsrisikos festzustellen (OR 0,61; $95 \%$-CI 0,44-0,83). Die Gesamtkosten pro Fall (Personal- und Sachkosten) belaufen sich bei einer mittleren periinterventionellen Zeit von 38 min und einer Rüstzeit von 45 min auf $€ 174,48$. Die DRG-Erlöse für die entsprechenden Fälle sind nicht ausreichend, um die zusätzlichen Kosten für das KAST zu decken. Dies gilt insbesondere für die $30 \%$ ambulanten und tagesklinischen Fälle. Trotz des hohen Anteils komplex kranker Kinder in unserem Kollektiv liegen die beobachteten Komplikationsraten in der Größenordnung vergleichbarer Literaturangaben. Eine geringere Erfahrung in der Durchführung von Analgosedierungen bei Kindern hat sich als unabhängiger Risikofaktor für Komplikationen erwiesen. Der Einsatz eines spezialisierten Teams aus Fachärzten wird durch die Kostenträger nicht ausreichend finanziert. Schlussfolgerung: Da eine entsprechende Expertise im Bereich der Analgosedierung komplex kranker Kinder einen wesentlichen Faktor für die Sicherheit darstellt, wäre eine Anpassung der Finanzierung für diese Leistungen bei diagnostischen Maßnahmen und kleinen Eingriffen bei Kindern im DRG-System dringend erforderlich.

\section{Literatur}

1. Cravero JP, Beach ML, Blike GT et al (2009) The incidence and nature of adverse events during pediatric sedation/anesthesia with propofol for procedures outside the operating room: a report from the Pediatric Sedation Research Consortium. Anesth Analg 108:795-804

\section{GNPI-V33}

\section{Neurologisches Outcome nach akuter Niereninsuffizienz bei Frühgeborenen: Eine retrospektive Kohortenstudie}

F. Cardona, M. Röttger, D. Csaicsich, L. Unterasinger, R. Fuiko, A. Berger Medizinische Universität Wien, Wien, Österreich

Hintergrund: Eine akute Niereninsuffizienz ist eine häufige Komplikation bei Frühgeborenen und tritt je nach Patientenkollektiv bei 5-55\% dieser Patientengruppe auf. Eine Schwierigkeit bei der Erfassung ist dabei die Vielzahl an Kriterien, die zur Erfassung dafür verwendet werden. Die meisten Studien verwendeten dabei ausschließlich Serum-Kreatinin zur Definition. Eine Assoziation zwischen Niereninsuffizienz und Mortalität bei Frühgeborenen wurde bereits mehrfach in Studien nachgewiesen, allerdings ist ein Zusammenhang mit einer erhöhten Morbidität bislang noch nicht untersucht worden.

Fragestellung: Ist das Auftreten einer akuten Niereninsuffizienz ein unabhängiger Risikofaktor für ein kombiniert negatives Outcome mit 2 Jahren? Material und Methoden: Die retrospektive Kohortenanalyse umfasste alle Frühgeborenen unter der vollendeten 33 . Schwangerschaftswoche, die zwischen 2007 und 2010 an der Neonatologie im AKH Wien (Österreich) behandelt wurden. Zur Definition für das Auftreten einer Niereninsuffizienz wurden die vom internationalen Acute Kidney Injury Network (AKIN) vorgeschlagenen Kriterien verwendet. Diese verwenden sowohl Harnmenge als auch Serumkreatininwerte und teilen die Niereninsuffizi- 
enz nach Schweregrad in 3 Stadien (1). Negatives Outcome war entweder Versterben oder eine Kombination aus mental development index (MDI) oder psychomotor development index (PDI) (Bayley II-Score) $<70$ oder eingeschränktes Seh- oder Hörvermögen. Ein logistisches Regressionsmodell wurde berechnet um die Rolle von Confoundern zu bewerten. Faktoren umfassten pränatale Faktoren als auch Morbiditäten wie PDA, PVL, NEC, Kreislaufinsuffizienz, NEC, BPD und ROP. Das Studienprotokoll wurde von der verantwortlichen Ethikkommission genehmigt.

Ergebnisse: In die Studie wurden 398 Frühgeborene eingeschlossen. Bei $28,6 \%(n=114)$ kam es zu einer akuten Niereninsuffizienz. In 34,7\% der Gesamtpopulation trat das kombiniert negative Outcome mit 2 Jahren auf. Die adjusted Odds Ratio (aOR) betreffend akuter Niereninsuffizienz auf das negative Outcome betrug 3,59 (95\% CI: 2,14-6,02), die Mortalität war dabei der bestimmende Faktor. Das Auftreten eines $\mathrm{MDI}<70$ oder PDI $<70$ bei Überlebenden war nach akuter Niereninsuffizienz um $50 \%$ bzw. 70 \% erhöht. In der Analyse der Stadien zeigte das schwerste Stadium der Niereninsuffizienz ein 12 fach erhöhtes Risiko für ein negatives Outcome (aOR 12,1 [95\% CI: 4,2-34,8], allerdings zeigte bereits die mildeste Form der Niereninsuffizienz ein 2,6fach erhöhtes Risiko (aOR 2,7 [95\% CI: 1,4-5,1]. In der prädefinierten Sekundäranalyse konnte gezeigt werden, dass sowohl der MDI als auch PDI bei ehemaligen Frühgeborenen mit 2 Jahren nach durchgemachter akuter Niereninsuffizienz statistisch signifikant niedriger war (PDI $83,8( \pm 1,7)$ vs. $88,7( \pm 0,8)$ und MDI $83,5( \pm 2,3)$ vs $89,2( \pm 1,1), p<0,05)$.

Diskussion: In unserer Studie konnten wir nachweisen, dass das Auftreten einer akuten Niereninsuffizienz bei Frühgeborenen zu einer schlechteren Prognose führt. Diese ist nicht nur auf die erhöhte Mortalität zurückzuführen, da überlebende Frühgeborene auch ein schlechteres neurologisches Outcome mit 2 Jahren nach durchgemachter Niereninsuffizienz zeigen.

\section{Literatur}

1. Mehta RL, Kellum JA, Shah SV et al. (2007) Acute Kidney Injury Network: report of an initiative to improve outcomes in acute kidney injury. Crit Care 11: R31

\section{GNPI-V34}

Neue Biomarker im Urin zur frühzeitigen und sensitiven Detektion einer akuten Nierenschädigung bei Very Low Birth Weight (VLBW) Frühgeborenen unter Indometacin-Therapie zum Verschluss eines persistierenden Ductus arteriosus Botalli

\section{S. Waldherr', A. Fichtner', B. Beedgen', T. H. Westhoff, F. Schaefer',} B. Tönshoff', J. Pöschl', J. H. Westhoff ${ }^{2}$

'Zentrum für Kinder- und Jugendmedizin, Universitätsklinikum Heidelberg, Klinik für Neonatologie, Heidelberg, Deutschland, ${ }^{2}$ Zentrum für Kinder- und Jugendmedizin, Universitätsklinikum Heidelberg, Klinik Kinderheilkunde I, Heidelberg, Deutschland, ${ }^{3}$ Marien Hospital Herne, Universitätsklinikum der Ruhr-Universität Bochum, Medizinische Klinik I, Herne, Deutschland

Hintergrund: Kleine Frühgeborene (FG) mit noch fortwährender Nephrogenese werden regelhaft mit potenziell nephrotoxischen Medikamenten behandelt. Hierzu gehören nicht-steroidale Antiphlogistika zum Verschluss eines persistierenden Ductus arteriosus Botalli (PDA). Aufgrund des transplazentaren Transfers von maternalem Kreatinin, variierender tubulärer Rückresorption und einer sich dynamisch entwickelnden glomerulären Filtrationsrate in den ersten Lebenstagen sind Serumkreatininund Urinausscheidungs-basierte Definitionen der akuten Nierenschädigung (AKI) bei diesen Patienten problematisch. Neue Biomarker im Urin ermöglichen potenziell eine frühzeitigere und sensitivere AKI-Detektion. Fragestellung: Ziel der Studie war es, den prädiktiven Stellenwert der Biomarker Neutrophilen Gelatinase-assoziiertes Lipocalin (NGAL), Kidney Injury Molecule-1 (KIM-1), Calprotectin und dem Produkt aus Tissue Inhibitor of Metalloproteinases (TIMP)-2 und Insulin-like Growth Factor Binding Protein 7 (IGFBP7) für das Auftreten einer AKI bei VLBW FG unter Indometacin-Therapie zu untersuchen.

Material und Methoden: Es wurden 32 VLBW FG im Alter von 2-3 Tagen in diese prospektive kontrollierte Kohortenstudie eingeschlossen, darunter 18 Patienten mit Indometacin-Therapie (Schema: $3 \times 0,2 \mathrm{mg} / \mathrm{kg}$ in 12 -Stunden (h)- gefolgt von $2 \times 0,2 \mathrm{mg} / \mathrm{kg}$ in 24 -h-Intervallen) und 14 vergleichbare Patienten ohne PDA. Serum und Urin wurden unmittelbar vor erster Indometacin-Gabe sowie 6, 12, 36, 84 und $120 \mathrm{~h}$ und 7, 14 und 28 Tage nach Therapiebeginn gewonnen. Die [TIMP-2]•[IGFBP7]Bestimmung erfolgte mittels NephroCheck ${ }^{\circledR}$ (Astute Medical), die Bestimmung von NGAL im Immunoassay am ARCHITECT Analyzer (Abbott Diagnostics), jene von Calprotectin und KIM-1 mittels ELISA (PhiCal ${ }^{\circ}$ Calprotectin, Immundiagnostik AG, Bensheim; KIM-1 human ELISA kit, Enzo Life Sciences, Lörrach).

Ergebnisse: Während das Serumkreatinin bei den unbehandelten FG rasch abfiel, persistierte es unter Indometacin-Therapie länger auf dem initial hohen Niveau ( $p<0,05$ ab 36 h). Drei der 14 (21\%) Indometacin-behandelten FG entwickelten im Verlauf eine AKI gemäß der neonatalen Kidney Disease: Improving Global Outcomes (KDIGO) Klassifikation. Cystatin C im Serum unterschied sich nicht zwischen behandelten und unbehandelten FG. [TIMP-2]•[IGFBP7] im Urin war bei Indometacin-behandelten FG, welche nach $36 \mathrm{~h}$ eine AKI entwickelten, bereits nach $12 \mathrm{~h}$ signifikant erhöht. NGAL hingegen war bei Indometacin-behandelten FG, unabhängig von der Erfüllung der AKI-Kriterien, ab $12 \mathrm{~h}$ nach erster Indometacin-Gabe signifikant erhöht. Signifikant erhöhte Urinkonzentrationen bei Indometacin-behandelten FG fanden sich auch für Calprotectin nach 12 und 36 h. KIM-1 im Urin zeigte nach $12 \mathrm{~h}$ nicht signifikant erhöhte Werte bei FG mit AKI. Schlussfolgerung: [TIMP-2]•[IGFBP7] im Urin ermöglicht bei VLBW FG unter Indomethacin-Therapie eine frühzeitigere Detektion einer AKI als herkömmliche Marker. NGAL und Calprotectin im Urin sind zusätzlich bei Indometacin-behandelten FG, welche die KDIGO AKI-Kriterien nicht erfüllen, erhöht. Dies könnte ein Hinweis auf subklinische Nierenschädigungen sein, welche der gegenwärtigen Diagnostik entgehen. Ob die Detektion subklinischer Nierenschäden prognostisch relevant ist, muss in einer prospektiven Langzeitbeobachtung untersucht werden.

\section{GNPI-V35}

\section{Vergleich der Auswirkungen des Opiat- vs. Methamphetamin-} Abusus Schwangerer auf die Neugeborenen

A. Gebauer, E. Robel-Tillig

Klinkum St. Georg Leipzig, Leipzig, Deutschland

Hintergrund: Substanzabusus bei schwangeren Frauen ist in den letzten Jahren zu einem immensen Problem auch für die Betreuung der geborenen Kinder geworden. Dabei spielt zunehmend der Methamphetamin (Crystal-Meth) Missbrauch eine Rolle. Ziel der Studie war die Beurteilung der postnatalen Adaptation und neurologischen Entwicklung der Kinder im Vergleich des pränatalen Substanzmissbrauches der Mutter.

Methode: Retrospektiv wurden von 2010 bis 201533 Neugeborene (NG) mit Opiat- und 53 mit Methamphetamin-Abusus der Mutter in die Studie integriert.

Ergebnisse: Die postnatale Adaptation gestaltete sich in beiden Gruppen problemlos. Auffällig war ein hoher Anteil (32\%) an Frühgeburten in der Crystal-Gruppe. NG beider Gruppen lagen mit Gewicht, Länge und Kopfumfang unter der Norm. Während die NG der Opiat-Gruppe ein Aufholwachstum aufwiesen, blieben die NG der Crystal-Gruppe im Verlauf zu klein und zu leicht. Bei einem hohen Prozentsatz der NG beider Gruppen gestaltete sich der Nahrungsaufbau schwierig. Eine Mitaufnahme der Mütter auf die neonatologische Nachsorgestation gelang in der Opiat-Gruppe zu $76 \%$, in der Methamphetamin-Gruppe nur zu $26 \%$, entsprechend konnten $64 \%$ der NG der Opiat-Gruppe und nur $42 \%$ der NG der Crystal-Gruppe zur Mutter entlassen werden. Die neurologische Nachuntersuchung ergab deutliche Auffälligkeiten in beiden Gruppen. Bei $42 \%$ der Kinder der Opiat- und $70 \%$ der Crystalgruppe zeigten sich ausgeprägte Tonusstörungen und motorische Defizite. Ebenso ließen sich besonders in der Crystalgruppe schwere Defizite im Sozialverhalten aufzeigen.

Schlussfolgerung: Kinder nach maternalem Drogenabusus stellen eine große Risikogruppe dar. Besonders nach Methamphetaminabusus ist mit schwerwiegenden Folgestörungen zu rechnen, sodass langfristig regelmäßige Kontrollen zur Früherkennung und Intervention durchgeführt werden sollten. 


\section{GNPI-V36}

Kommensalen oder relevante Pathogene? Ureaplasmen induzieren und modulieren eine pro-inflammatorische Zytokinantwort in neonatalen und adulten Monozyten

K. Glaser', C. Silwedel', M. Fehrholz', B. Henrich'², H. Claus ${ }^{3}$, C. P. Speer ${ }^{1}$ 'Julius-Maximilians-Universität Würzburg, Universitäts-Kinderklinik, Würzburg, Deutschland, ${ }^{2}$ Universitätsklinikum der Heinrich-HeineUniversität Düsseldorf, Institut für Medizinische Mikrobiologie und Krankenhaushygiene, Düsseldorf, Deutschland, ${ }^{3}$ Julius-MaximiliansUniversität Würzburg, Institut für Hygiene und Mikrobiologie, Würzburg, Deutschland

Hintergrund: Die Ureaplasmen-Infektion ist mit Chorioamnionitis, vorzeitiger Wehentätigkeit und Frühgeburt assoziiert. Bei Früh- und Neugeborenen sind Ureaplasmen als pathogene Erreger invasiver Erkrankungen wie neonataler Pneumonie und Sepsis beschrieben, und ein Zusammenhang zwischen perinataler Ureaplasmen-Infektion und der bronchopulmonalen Dysplasie wird vermutet. Angesichts der geringen Pathogenität der Erreger bei Kindern und Erwachsenen werden Prävalenz und Relevanz der neonatalen Ureaplasmen-Infektion und Ureaplasmen-vermittelten Inflammation dennoch kontrovers diskutiert.

Fragestellung: In der vorliegenden Arbeit wurde die pro-inflammatorische Potenz von Ureaplasmen auf primäre humane Monozyten untersucht. Material und Methoden: Positiv selektionierte neonatale und adulte CD14+ Monozyten, nativ oder LPS-aktiviert, wurden mit Ureaplasma (U.) urealyticum Serovar 8 (Uu8) und U. parvum Serovar 3 (Up3) stimuliert. Die Expression von Tumornekrosefaktor (TNF-) $\alpha$, Interleukin (IL-) $1 \beta$, IL-8, Toll-like Rezeptor (TLR) 2 und TLR4 sowie Matrix-Metalloproteinase (MMP-) 9 wurde auf mRNA- und Proteinebene mittels quantitativer Real-time PCR, Durchflusszytometrie und Bead-basierter MultiplexAnalyse analysiert

Ergebnisse: Beide Isolate induzierten IL- $1 \beta$ und IL- 8 in neonatalen und adulten Monozyten ( $p<0,05$; vs. unstimulierte Kontrolle) sowie TNF- $\alpha$ mRNA in adulten CD14+Zellen $(p<0,05)$. Die Stimulation mit Up3 führte zusätzlich zu einer signifikanten Erhöhung des sezernierten TNF- $\alpha$ in neonatalen und adulten Zellen (pE. coli LPS führte zu einer signifikanten Reduktion der intrazellulären IL-1 $\beta$ (Uu8: $p<0,001$, Up3: $p<0,05$ ) und IL-8 $(p<0,05)$ Synthese in adulten Monozyten, während die Pro-Inflammation in ko-stimulierten neonatalen Zellen auf dem LPS-induzierten Niveau konstant blieb.

Diskussion: Unsere Daten bestätigen eine relevante pro-inflammatorische Kapazität von Ureaplasmen-Isolaten in neonatalen und adulten Monozyten mit Induktion pro-inflammatorischer Zytokine und MMP-9. Daneben weisen die Ergebnisse auf relevante immunmodulatorische Effekte von Ureaplasmen hin. Diese äußern sich in Induktion von TLR2 und Suppression von TLR4 mRNA sowie Inhibition der LPS-induzierten IL$1 \beta$ und IL-8-Antwort in adulten Monozyten, aber Persistenz derselben in neonatalen Zellen.

\section{GNPI-V37}

\section{Retrospektive Datenanalyse zum enteralen Nahrungsaufbau bei Frühgeborenen unter $1250 \mathrm{~g}$ Geburtsgewicht}

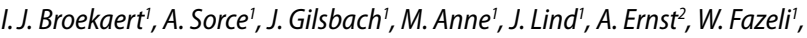
T. Keller', B. Hero', C. Hünseler', A. Kribs'

'Universitätskinderklinik Köln, Universität zu Köln, Medizinische Fakultät, Köln, Deutschland, ${ }^{2} I M S I E$, Universität zu Köln, Köln, Deutschland

Hintergrund: Die Zeit bis zum Erreichen des enteralen Nahrungsaufbaus ist ein etablierter Outcomeparameter in klinischen Studien zur Ernährung Frühgeborener. Die Daten dieser Studie wurden erhoben zur Fallzahlberechnung für eine multizentrische Studie bei Extrem Frühgeborenen, welche den enteralen Nahrungsaufbau und das neurologische Outcome untersucht.

Methode: Daten von 237 Frühgeborenen unter $1250 \mathrm{~g}$ Geburtsgewicht, die in den Jahren 2010-2015 an der Universitätskinderklinik Köln geboren wurden, wurden retrospektiv ausgewertet. Zur statistischen Auswertung wurde der X2-Test angewendet ( $\alpha=5 \%$ ).

Ergebnisse: Der Abschluss des enteralen Nahrungsaufbaus wurde nach $18,6 \pm 9,1$ Tagen erreicht. Bei Entlassung wurden 156 Kinder ausschließlich mit Muttermilch ernährt und 81 mit Formula \pm Muttermilch. In der Muttermilch-Gruppe war der enterale Nahrungsaufbau tendenziell schneller erreicht (18,3 $\pm 8,0$ vs. 19,2 $\pm 10,8$ Tage). Das Geburtsgewicht war tendenziell höher ( $929 \pm 239$ vs. $835 \pm 263 \mathrm{~g})$ und das Entlassungsgewicht tendenziell niedriger ( $2006 \pm 274$ vs. $2243 \pm 640$ g). Die NEC-/FIP- (5,8 vs. $8,6 \%)$ sowie die Sepsisrate (18,0 vs. $30,9 \%$ ) waren relativ niedriger.

Wenn die Frühgeborenen eingeteilt wurden in 3 gleich große Gruppen je nach Zeitpunkt der ersten oralen Muttermilchgabe (A: 1.-9. Lebensstunde $(n=80)$; B: 10.-25. Lebensstunde $(n=78)$; C: nach der 25. Lebensstunde $(n=76))$ zeigte sich folgendes: in Gruppe A war tendenziell ein höheres Geburtsgewicht (914 (A) vs. 881 (B) vs. 898 (C) g) und ein niedrigeres Entlassungsgewicht (2039 (A) vs. 2115 (B) vs. 2104 (C) g) auffällig. In Gruppe A war die relative Häufigkeit für das Auftreten einer NEC/FIP 8/16 vs. 4/16 (B) vs. 4/16 (C). Die relative Häufigkeit des Auftretens einer Sepsis war unverändert (17/53 (A) vs. 19/53 (B) vs. 17/53 (C)). Der Abschluss des enteralen Nahrungsaufbaus wurde tendenziell schneller erreicht (17,66 (A) vs. 18,54 (B) vs. 19,56 (C) Tage). In Gruppe A (72\%) und B (74\%) wurde tendenziell häufiger ausschließlich Muttermilch bei Entlassung verabreicht als in Gruppe C (54\%).

Diskussion: Frühgeborene mit einem höheren Geburtsgewicht haben tendenziell einen schnelleren enteralen Nahrungsaufbau. Der schnelle enterale Nahrungsaufbau ist assoziiert mit einem frühen Start von Muttermilchgaben, welcher wiederum für eine hohe Rate ausschließlicher Muttermilchnahrung bei Entlassung prädisponiert. Die ausschließliche Ernährung mit Muttermilch bei Entlassung ist assoziiert mit einer tendenziell niedrigeren Rate von Sepsis und NEC/FIP. Ziel der geplanten prospektiven Studie ist es, den enteralen Nahrungsaufbau bei extremen Frühgeborenen zu optimieren und den Einfluss auf das neurologische Outcome zu untersuchen.

\section{GNPI-V38}

Auswirkungen einer erhöhten enteralen Proteinzufuhr auf die Harnstoffkonzentration in Urin und Plasma bei Frühgeborenen $<32$ Wochen Gestationsalter und $<1500 \mathrm{~g}$ Geburtsgewicht in einer randomisierten, kontrollierten Interventionsstudie

M. Mathes', C. Maas' , C. Bleeker', J. Vek', W. Bernhard', A. Peter', C. Poets', A. Franz ${ }^{1,3}$

${ }^{1}$ Universitätsklinikum für Kinder- und Jugendmedizin, Neonatologie, Tübingen, Deutschland, ${ }^{2}$ Universitätsklinikum, Innere Medizin IV, Bereich Endokrinologie, Diabetologie, Angiologie, Nephrologie und klinische Chemie, Tübingen, Deutschland, ${ }^{3}$ Univeristätsklinikum für Kinder- und Jugendmedizin, Center for Pediatric Clinical Studies, Tübingen, Deutschland

Hintergrund: Muttermilch wird als die beste Nahrung für Früh (FG)und Neugeborene angesehen. Aufgrund des schnellen Wachstums und daher hohen Nährstoffbedarfs von FG wird die Frauenmilch standardisiert mit Nährstoffen angereichert. Da der Nährstoffgehalt der Muttermilch Schwankungen unterliegt, birgt standardisierte Supplementierung die Gefahr einer Unterversorgung, v. a. in Hinblick auf die Proteinversorgung. Harnstoff ist Endprodukt der Proteinoxidation. Die Harnstoffkonzentration in Plasma (HCP) und Urin (HCU) könnte daher Hinweise auf eine Proteinüber- bzw. unterversorgung der FG bieten.

Fragestellung: Das Ziel dieser a-priori geplanten, sekundären Analyse ist die Hypothese zu prüfen, ob die HCU ein geeigneter Parameter zur Abschätzung der HCP und der enteralen Proteinzufuhr ist.

Patienten und Methoden: Randomisiert kontrollierte Interventions-Studie (60 FG, $<32$ Wochen Gestationsalter/<1500 g Geburtsgewicht, mittlerer Lebenstag bei Einschluss: 7, Okt. 2012 bis Okt. 2014, Neonatologie Tübingen). Primäres Ziel war die Untersuchung der Auswirkungen erhöhter enteraler Eiweißzufuhr auf das Wachstum sehr unreifer, überwiegend muttermilchernährter FG [1]. Die FG wurden in drei Parallelgruppen randomisiert: Gruppe 1: Standardproteingruppe (SPG), Gruppe 2: Hochpro- 
teingruppe (HPG) mit standardisierter (2a) und individualisierter Anreicherung (2b) [1]. Der Muttermilchproteingehalt wurde $2 \times$ wöchentlich ermittelt. Zwei venöse Blutentnahmen (BE) zur Messung der HCP wurden durchgeführt, HCU wurden wöchentlich gemessen, die zeitlich am nächsten gelegene Urinprobe wurde den BEs zugeordnet (max. +/-3 Tage(d)). Die mittlere tägliche Proteinzufuhr wurde über einen Zeitraum von $5 \mathrm{~d}$ vor den jeweiligen BE ermittelt. Die Daten sind als Median (IQR) dargestellt. Ergebnisse: Die HPG hatte eine höhere Proteinzufuhr an den $5 \mathrm{~d}$ vor den BE (BE1: 4,69(4,34-5,01) g/kg/d vs. 4,02(3,72-4,42) g/kg/d, $p<0,001 ; \mathrm{BE} 2$ : $4,19(3,92-4,38) \mathrm{g} / \mathrm{kg} / \mathrm{d}$ vs. $3,49(3,30-3,99) \mathrm{g} / \mathrm{kg} / \mathrm{d}, p<0,0001)$. Dies war mit einer signifikant höheren HCP assoziiert. Die HCU unterschied sich nicht zwischen den Gruppen in Lebenswoche 2, war jedoch signifikant höher in der HPG in Lebenswoche 3-6. HCP- und HCU-Werte zeigten eine positive Korrelation $(\rho=0,63 ; p<0,0001)$. Die tatsächliche Proteinaufnahme korrelierte ebenfalls positiv mit der $\operatorname{HCP}(\rho=0,59 ; p<0,0001)$ und der HCU $(\rho=0,34 ; p=0,0006)$. Ein Zusammenhang zwischen Gewichtszunahme und HCP $(\rho=-0,03 ; p=0,7)$ bzw. HCU; $(\rho=-0,18 ; p=0,08)$ bestand in dieser gut wachsenden Kohorte nicht. In dieser Studie, mit perzentilen-parallelem Gedeihen (SDS-Diff. Gewicht Geburt-Interventionsende 0,18 (-0,165-0,59) und tatsächlicher Proteinzufuhr von 4,0 $(3,8-$ 4,3)g/kg/d), war die 2,5. Perzentile der HCU $105 \mathrm{mg} / \mathrm{dl}$.

Schlussfolgerung: Die Messung der HCU bei sehr unreifen FG stellt einen vielversprechenden Ansatz zur nicht-invasiven Abschätzung der tatsächlichen Proteinverfügbarkeit dar, da im vorliegenden Studienkollektiv die HCU hochsignifikant positiv mit der HCP und der verabreichten Proteinmenge korrelierte. Bei Kindern mit unzureichendem Gedeihen sollte bei einer HCU $<100 \mathrm{mg} / \mathrm{dl}$ eine ungenügende Proteinzufuhr in Betracht gezogen werden.

\section{Literatur}

1. Maas CM, Mathes C, Bleeker J et al (2017) Effect of increased enteral protein intake on growth in human milk-fed preterm infants: a randomized clinical trial. JAMA Pediatr 171:16-22

\section{GNPI-V39}

\section{Zu frühe Einführung von Beikost bei Frühgeborenen in Salzburg}

\section{Köttstorfer, M. Wald, E. Hofstätter}

Universitätsklinik für Kinder- und Jugendheilkunde der PMU, Division für Neonatologie, Salzburg, Österreich

Hintergrund: Die Optimierung der Ernährung ist ein wesentlicher Faktor für ein verbessertes Outcome von Frühgeborenen (FG). Die Umsetzung von Leitlinien für die parenterale und enterale Ernährung während des Klinikaufenthaltes ist heutzutage Standard. Spezielle Formulanahrungen nach der Entlassung decken den erhöhten Bedarf an Energie, Proteinen und Mikronährstoffen von FG zumindest in der ersten Zeit. Während es für Reifgeborene klare Richtlinien zur Einführung von Beikost gibt, wurde dieses bei FG bisher nur wenig untersucht und die Richtlinien dazu sind weniger eindeutig. Entgegen nationaler als auch internationaler Empfehlungen, zeigen zumindest 4 Studien, dass ein wesentlicher Prozentsatz aller FG Beikost vor den empfohlenen korrigierten 17 Wochen bekommt. Ziel dieser Studie war einen Einblick in die derzeitige Praxis der Beikosteinführung bei Frühgeborenen in Salzburg zu bekommen und Einflussfaktoren bzw. Gründe für einen möglichen verfrühten Start zu ermitteln. Studiendesign: Es wurde eine prospektive Fragebogenstudie durchgeführt. 68 FG (<36 6/7 SSW) wurden über einen 4-monatigen Zeitraum rekrutiert und im korrigierten Alter von 17 Wochen ( \pm 1 Woche) wurde eine detaillierte telefonische Befragung der Eltern durchgeführt. Es wurden sowohl Daten zur Ernährung der FG als auch soziodemographische Informationen zu Mutter und Kind erfragt.

Ergebnisse: 51,5\% aller FG bekommen ihre erste Beikost vor korr. 17 Wochen. Die zu frühe Beikosteinführung korreliert signifikant mit ausschließlicher und früher Formulagabe, niedrigem Haushaltseinkommen, maternalem nicht-insulinpflichtigem Gestationsdiabetes, höherer Gewichtsperzentile zum Zeitpunkt der Beikosteinführung und Zwillingsgeburt. Ausschließliches und längeres Stillen ist positiv mit einer späteren Einführung der Beikost korreliert. Alle Kinder erhielten entweder Gemü- se oder Obst als erste feste Nahrung. 31,4\% der FG erhielten zum Befragungszeitpunkt mit korr. 17 Wochen immer noch Obst oder Gemüse als einzige Beikost. In 34,3\% der Fälle war der Grund für einen verfrühten Beikostbeginn die Empfehlung von niedergelassenen Pädiatern, knappe $10 \%$ der Mütter fühlten sich von ihrem Umfeld unter Druck gesetzt.

Diskussion: Internationalen Studien zufolge erhalten 61-95\% aller FG Beikost vor den empfohlenen korr. 17 Wochen. In der vorliegenden Studie erhielten mehr als die Hälfte der FG Beikost vor den empfohlenen korr. 17 Wochen, knapp ein Viertel sogar vor korr. 12 Wochen und sind Studien zufolge damit einem wesentlich höherem Risiko ausgesetzt, später an Zöliakie, Adipositas und Diabetes Mellitus zu erkranken. Die Studie zeigt die Notwendigkeit klarer Richtlinien für die Beikosteinführung bei FG und die Umsetzung dieser durch die Kinderärzte. Vor allem im niedergelassenen Bereich ist die Weitergabe der Empfehlungen an die Mütter extrem wichtig, da insbesondere bei late preterms die Frühgeburtlichkeit bis zum Beikostalter für die Eltern oft nicht mehr relevant ist.

\section{GNPI-V40}

\section{Förderung oraler Nahrungsaufnahme bei Frühgeborenen durch olfaktorische Stimulation}

\section{J. Gellrich', N. Rocher', T. Hummel', M. Rüdiger ', V. A. Schriever ${ }^{1}$}

${ }^{1}$ Klinik und Poliklinik für Kinder- und Jugendmedizin, Uniklinikum Dresden, Neuropädiatrie, Dresden, Deutschland, ${ }^{2}$ Klink für Hals-, Nasen- und Ohrenheilkunde, Uniklinikum Dresden, Interdisziplinäres Zentrum für Riechen- und Schmecken, Dresden, Deutschland, ${ }^{3}$ Klinik und Poliklinik für Kinder- und Jugendmedizin, Uniklinikum Dresden, Neonatologie und pädiatrische Intensivmedizin, Dresden, Deutschland

Hintergrund: Bedingt durch die Unreife müssen viele zu früh geborene Kinder zunächst mittels Magensonde ernährt werden. Es wird angestrebt eine möglichst schnelle eigenständige orale Ernährung der Frühgeborenen zu erreichen. Der Geruchssinn ist auch bei Frühgeborenen schon vor der Geburt vollständig entwickelt und es konnte gezeigt werden, dass Gerüche eine erhebliche Rolle bei der Nahrungsaufnahme spielen.

Hypothese: Bei Frühgeborenen reduziert die Geruchsstimulation vor der Nahrungsaufnahme die Dauer der Sonden-Ernährung.

Material und Methoden: Eingeschlossen werden Frühgeborene mit einem Gestationsalter $>27$ Wochen, kompletter oder teilweiser Ernährung mittels Magensonde, stabilen Vitalparametern und ohne Beatmung. Vor jeder Nahrungsaufnahme erfolgt eine Geruchspräsentation mittels Riechstiften. Die Kinder werden in folgende Geruchsgruppen randomisiert: Rose (nicht-nahrungsassoziiert), Vanille (nahrungsassoziiert) bzw. ohne Geruch (Kontrolle). Primärer Endpunkt ist der Zeitpunkt der vollständigen oralen Ernährung.

Ergebnisse: Eingeschlossen wurden insgesamt 142 Kinder mit einem mittleren Gestationsalter von $33 \pm 2,4$ SSW und einem mittleren postnatalen Alter von 9,4 \pm 7,5 Tagen. Es gab keine Unterschiede bezüglich dieser $\mathrm{Pa}$ rameter zwischen den Therapiegruppen. Die Dauer bis zum Erreichen der kompletten oralen Nahrung nach Studienbeginn war wie folgt: 12,0 $\pm 7,8$ (Vanille), 12,1 $\pm 7,9$ (Rose), 13,0 $\pm 9,1$ (Kontrolle) Tage. Es konnte kein signifikanter Unterschied festgestellt werden. Bei einer Mindestpräsentationsfrequenz der Riechstifte von $50 \%$ aller Fütterungen zeigten sich jedoch für die Vanille-Gruppe eine signifikante Reduktion der Dauer der Sondenernährung um durchschnittlich 4,6 Tage $(p=0,036)$.

Schlussfolgerung: Die Ergebnisse zeigen, dass die Geruchsstimulation mit Vanille die Länge der Fütterung mittels Magensonde signifikant reduzieren konnte. Dieser Effekt war nur festzustellen, wenn die Riechstifte regelmäßig präsentiert wurden.

Förderung: Die Studie wurde durch die Else Kröner-Fresenius-Stiftung finanziert. 


\section{GNPI-V41}

Handhabung von Muttermilch in neonatologischen Abteilungen Erste Ergebnisse einer bundesweiten Erhebung

\section{S. Jansen', C. Gebauer', H. Fuchs', D. Klotz'}

'Zentrum für Kinder- und Jugendmedizin, Universitätsklinikum Freiburg, Funktionsbereich Neonatologie und Pädiatrische Intensivmedizin, Freiburg, Deutschland, ${ }^{2}$ Universitätsklinikum Leipzig, Abteilung für Neonatologie, Leipzig, Deutschland

Hintergrund: Die Evidenz bezüglich vieler Aspekte der Aufbereitung von Muttermilch ist gering. Es gibt keine Leitlinien und große Unterschiede in der Behandlung von Muttermilch zwischen den neonatologischen Zentren.

Fragestellung: Darstellung der unterschiedlichen Vorgehensweisen neonatologischer Abteilungen in der Muttermilchaufbereitung für Früh- und Reifgeborene.

Methoden: Onlinebasierte, deutschlandweite Umfrage mittels eines stratifizierten Fragebogens an neonatologischen Abteilungen (Level I-III) von Juni 2016 bis Februar 2017. Erfragt wurden pro Abteilung u. a. Angaben zu den Themenkomplexen Zytomegalievirus (CMV)-Screening, Screening auf Keimbesiedelung der Milch/bakterielle Grenzwerte, Pasteurisierung, Frauenmilchspende, Nährstoffmessung und -anreicherung, räumliche und personelle Infrastruktur, sowie Still- und Laktationsförderung. Ergebnisse: 253 Abteilungen wurden kontaktiert, 131 nahmen an der Befragung teil (52\%). Zentrumsverteilung: $70 \%$ Level I, $23 \%$ Level II und $7 \%$ Level III. Ein Screening der Mutter auf CMV findet in 74\% der Abteilungen statt. 76/132 (58\%) führen eine CMV-Inaktivierung der Milch durch, davon 22/75 Abteilungen mittels Gefrierlagerung (Median 1 Tag), $9 / 75$ mittels Kurzzeitpasteurisierung $\left(5 \mathrm{~s}, 62^{\circ} \mathrm{C}\right)$ und die übrigen Abteilungen nutzen Holder-Pasteurisierung. 56/128 (43\%) der Abteilungen untersuchen Muttermilch auf eine bakterielle Besiedelung. Von diesen würden $40 \%$ eine Pasteurisierung zur Reduktion der Keimzahl durchführen, die zugrunde gelegten Grenzwerte sind aber sehr verschieden. Gespendete Muttermilch wird in 15/122 Abteilungen (12\%) regelmäßig als Teil eines schriftlichen Ernährungsstandard eingesetzt, in 85/122 Abteilungen $(70 \%)$ wird nie Spendermilch eingesetzt. 61/84 Umfrageteilnehmer (73\%) würden Spendermilch verfüttern, wenn diese zur Verfügung stünde. In 64/114 Abteilungen findet die Lagerung und Aufbereitung der Milch auf der neonatologischen Station statt. Personal, welches ausschließlich für die Milchaufbereitung zuständig ist, steht in 68/120 der Abteilungen (41\%) zur Verfügung, ansonsten übernimmt dies das Pflegepersonal. Die Leitung der Muttermilchaufbereitung liegt überwiegend in pflegerischer Hand (59\%), in 17\% der Abteilungen gibt es keine explizite zugeordnete Verantwortlichkeit. Eine Muttermilchnährstoffmessung wird in 9 Abteilungen regelmäßig durchgeführt, 109/120 Abteilungen fügen der Milch über die Standardanreicherung hinausgehende Nährstoffe zu. 119/120 Abteilungen haben Zugriff eine eine/n Still- und Laktationsberater/in. 76/100 Abteilungen berichten über das Vorkommen von Muttermilchverwechslung, teilweise häufiger als 10x/Jahr.

Diskussion: Die Verschiedenheit des Vorgehens hinsichtlich der Handhabung von Muttermilch betrifft viele Aspekte. Teilweise sind Maßnahmen, deren Nutzen unsicher ist, auch mit hohen Kosten und Qualitätseinbußen der Muttermilch assoziiert. Bedenklich stimmt die hohe Rate an Muttermilchverwechselungen. Die Aussagekraft unserer Erhebung wird durch eine Beteiligung von nur 52\% limitiert, dennoch stellen wir einen breiten, aktuellen Querschnitt aus der täglichen Praxis der Muttermilchbehandlung in deutschen neonatologischen Abteilungen vor. Evidenzbasierte Handlungsempfehlungen zur Muttermilchbehandlung und Maßnahmen, die zu einer Reduktion von Muttermilchverwechselungen führen, scheinen geboten.

\section{GNPI-V42}

\section{Mixed lipid emulsion rich in omega-3 LC-PUFAs and its effect on brain maturation in extremely low birth weight infants}

C. Binder', A. Repa' , V. Giordano ', A. Kreissl ' ', M. Thanhaeuser ', N. Haiden', A. Berger ' ${ }^{\prime}$ N. Longford ${ }^{2}$, K. Klebermass-Schrehof ${ }^{1}$

'Medizinische Universität Wien, Neonatologie, Vienna, Austria, ${ }^{2}$ Imperial College London, London, UK

Background: Omega-3 long-chain polyunsaturated fatty acids (LC-PUFAs) are an essential functional component of cell membranes in the central nervous system and key factors for neonatal brain maturation [1]. Supplementation with LC-PUFAs during lactation has been shown to improve cognitive performance in ex-premature infants [2]. Bedside amplitude-integrated electroencephalography ( $\mathrm{aEEG})$ is a valuable tool for assessing brain maturation and a good predictor for the long-term neurological outcome in preterm infants [3]. The aim of this study was to evaluate the effect of a mixed lipid emulsion - rich in omega-3 LC-PUFAs - (SMOFlipid $\left.{ }^{\circ}\right)$ on brain maturation as measured by EEG.

Methods: In a double-blind randomized controlled trial (Preventing Cholestasis Using SMOFlipid, NCT01585935) performed at the Neonatal Intensive Care Unit of the Medical University Vienna between 2012-2015 extremely low birth weight infants received either SMOFlipid ${ }^{\star}$ (30\% soybean oil, $20 \%$ MCTs, $25 \%$ olive oil, $15 \%$ fish oil, group A) or Intralipid ${ }^{\circ}$ (100\% soybean oil, group B) for parenteral nutrition. Brain maturation measured by aEEG4 was analysed as a secondary outcome using measurements generated as part of routine examinations in ELBW infants. Amplitude-integrated EEG records were performed on a bi-weekly basis from birth until discharge, transfer or death. Infants with IVH grade $>$ II and/or PVL were excluded as well as those aEEG sequences that were recorded while infants were on sedative drugs.

Results: 317 aEEG records (group A: $n=152$ and group B: $n=165$ ) of 121 infants (group A: $n=58$ and group B: $n=63$ ) between the gestational ages (GA) of 24 to 41 weeks were analyzed. Demographic and baseline characteristics of the two study groups were well balanced. Brain maturational scores 4 and background activities (percentage of continuous pattern) were significantly higher in group B, starting from a GA after 27 weeks. Infants in group $B$ reached the maximum maturational score (median GA: 36.4 weeks) significantly earlier than infants in group A (median GA: 38.4 weeks) $(p<0.001)$. Sleep-wake cycles did not show significant differences between the groups at any GA.

Conclusions: Brain maturational scores, measured by serial aEEG records were significantly higher in preterm infants who received a mixed lipid emulsion -rich in omega-3 LC-PUFAs- in comparison to a pure soybean oil lipid emulsion. These results support the hypothesis that omega-3 LC-PUFAs have a positive effect on brain maturation. Follow up of study infants will show whether these findings translate into improved neurodevelopmental outcome.

\section{References}

1. Scott BL, Bazan NG (1989) Membrane docosahexaenoate is supplied to the developing brain and retina by the liver. Proc Natl Acad Sci 86:2903-2907

2. Wang Q, Cui Q, Yan C (2016) The effect of supplementation of long-chain polyunsaturated fatty acids during lactation on neurodevelopmental outcomes of preterm infant from infancy to school age: Systematic Review and Meta-analysis. Pediatr Neurol 59(51):54-61e

3. Klebermass K, Olischar M, Waldhoer T et al (2011) Amplitude-integrated EEG pattern predicts further outcome in preterm infants. Pediatr Res 70:102-108

4. Burdjalov VF, Baumgart S, Spitzer AR (2003) Cerebral function monitoring: a new scoring system for the evaluation of brain maturation in neonates. Pediatrics 112:855-861 


\section{GNPI-V43}

\section{Stillraten von Früh- und Neugeborenen in der Neonatologie}

\section{Schöpping, L. Beroll, T. Keller, A. Kribs}

\section{Uniklinik Köln, Neonatologie, Köln, Deutschland}

Hintergrund: Insbesondere Frühgeborene und kranke Neugeborene profitieren von Muttermilchernährung und Stillen. Jedoch ist Stillen in einer neonatologischen Abteilung eine Herausforderung für Mutter und Kind sowie das unterstützende Team.

Fragestellung: Welchen Effekt hatte die räumliche Verbesserung mit mehr Privatsphäre und Rooming-In Möglichkeit in der Neonatologie auf den Stillerfolg während des stationären Aufenthaltes?

Methoden: Für Neugeborene, die zwischen dem 1.3.-31.07.2015 (Phase $1, n=260$ ) und dem 1.4.-30.06.2016 (Phase 2, $n=190$ ) geboren und stationär in der Neonatologie der Uniklinik Köln behandelt wurden, erfolgte die tägliche Dokumentation des Stillerfolges mithilfe eines dafür entworfenen 6 Punkte Scores. Phase 1 wurde erhoben während sich die NICU und die Frühgeborenenstation in provisorischen Räumlichkeiten mit fehlender Privatsphäre befanden. Phase 2 erfolgte nach Umzug in Räumlichkeiten mit zwei bis maximal drei Kindern pro Zimmer und Roomin-In-Möglichkeit auf der Frühgeborenenstation.

Ergebnisse: Insgesamt wurde für 450 Kinder der Stillerfolg erhoben. Bei Entlassung waren $78 \%$ der Kinder gestillt, davon die Hälfte vollgestillt. Muttermilch erhielten $86 \%$, davon $72 \%$ ausschließlich. Primär abgestillt hatten 29 Mütter. Phase 1 ließ einen Förderbedarf insbesondere der FG vor der 29.SSW und ab der 34.SSW im Hinblick auf die Stillrate erkennen. In Phase 2 zeigte sich ein Anstieg der Gesamtstillrate mit $+9 \%$, insbesondere in der Gruppe der FG $<28+0$ mit $+27 \%$, sowie der FG ab der 34 .SSW mit $+9 \%$. Die Rate der voll Muttermilch ernährten Kinder verbesserte sich in Phase 2 in allen Gestationsgruppen $(+27 \% /+10 \% /+5 \% /+18 \% /+5 \%$ für $\mathrm{FG}<28+0 / 28+0-31+6 / 32+0-33+6 / 34+0-36+6 />=37+0)$.

In beiden Erhebungszeiträumen korrelierte der Score am 5. LT bereits gut mit dem Entlassungsscore. Wurde bei FG $<32$ SSW am 5. Lebenstag ein Score von 5 dokumentiert (voll Muttermilch, teilgestillt), so wurde bei Entlassung ein Score erreicht von im Mittel 5,6 (95\% CI 5,2-6,0). Bei einem Score von 3 am 5. LT resultierte in einem Entlassungsscore von 4,1 (95\%CI 3,6-4,6).

Diskussion: Eine Verbesserung der Räumlichkeiten wirkte sich positiv auf die Stillrate und Muttermilchernährungsrate aus, insbesondere auf die Frühgeborenen vor der 29. SSW und ab der 34. SSW. Dennoch besteht weiter Förderbedarf im Hinblick auf die Stillrate insbesondere der genannten Gestationsgruppen, da die Reifgeborenen sowie die FG der 28.-32. SSW deutlich bessere Raten erreichen. Der Stillerfolg bei Entlassung zeichnet sich auch bei FG $<32$ SSW bereits am 5 . LT. ab. Daher sollte das erste Anlegen frühzeitig erfolgen und auf die Etablierung mindestens des Teilstillens innerhalb der ersten 5 Tage abzielen.

\section{GNPI-V44}

Target fortification of breast milk with protein, carbohydrate and fat for preterm infants improves growth outcomes: a double blind randomized controlled trial

N. Rochow', G. Fusch', A. Bhatia', A. Ali', S. Ahmad', A. Nguyen', L. Chessel', S. el Helou', C. Fusch ${ }^{2,1}$

'McMaster University, Pediatrics, Hamilton, Canada, ${ }^{2}$ Paracelsus Medizinische Privatuniversität Klinikum Nürnberg, Klinik für Neugeborene, Kinder und Jugendliche, Nürnberg, Deutschland

Background: The natural variation of breast milk (BM) composition makes it difficult to provide recommended macronutrient $(\mathrm{MN})$ intakes for preterm infants with standard fortification (SF). There is evidence that this increases the risk for poor postnatal growth. Target Fortification (TFO) is a novel approach that individually adjusts $\mathrm{MN}$ content using bedside milk analysis and was shown to be feasible in a pilot trial.

Objective: To investigate the impact of TFO on growth outcomes of preterm infants in a double-blind randomized controlled trial (RCT).
Design/Methods: Single center RCT, infants born $<30$ gestational weeks on BM or donor milk; intervention (INTVN) group received SF+TFO, control (CTL) group only SF. SF was provided using Enfamil HMF. For TFO, modular fortifier products (Beneprotein, Microlipids, Polycose) were added after BM content was measured 3x/week using a validated near-IR spectrometer (Spectrastar) to achieve ESPGHAN recommended intakes $[\mathrm{g} / \mathrm{kg} / \mathrm{d}]$ of $4.5,13.2$ and 6.6 for protein, $\mathrm{CHO}$ and fat, respectively. For final MN analysis all native BM samples $(n=2810)$ were reanalyzed; nearIR for protein and fat and UPLC-MS/MS for CHO (lactose). SF intakes were defined as deficient when they fell below the lower limit of ESPGHAN guidelines. Nutritional efficiency (NE) was defined as weight gain per fluid intake $[\mathrm{g} / \mathrm{dL}]$. Body composition was measured by Air Displacement Plethysmography (PeaPod). The primary outcome was weight at 36 weeks. Results: For analysis, 103 infants were included with mean time in the study at 27 and 28 days for INTVN and CTL, respectively. Baseline characteristics and total fluid intake were similar between groups. After applying SF, $n=55(53 \%)$ and $n=91$ (88\%) of all infants were deficient in protein or CHO, respectively. In INTVN, infants had higher intakes of MN. The INTVN group had higher weight at 36 weeks, higher growth rate and higher NE. Sub-group analysis, stratified for protein intake below the median $(<3.5 \mathrm{~g} / \mathrm{kg} / \mathrm{d}$ after SF), showed INTVN infants had higher change in length $\mathrm{z}$-scores compared to the CTL group. Fat-free mass at term age was also higher for the INTVN group (not statistically significant).

Conclusions: This RCT shows that TFO leads to improved growth outcomes in a group of extremely preterm infants. In addition to TFO enhancing the quality of nutrition, these results provide further evidence of the positive effect of nutritional intake on growth. Neurodevelopmental follow-up is in progress.

\section{GNPI-V45}

Reducing variability in macronutrient intakes improves growth in preterm infants: Analysis from a Double-Blind Randomized Controlled Trial

A. Bhatia', N. Rochow', G. Fusch', A. Ali', A. Nguyen', A. Bahonjic', C. Fusch',

${ }^{1}$ McMaster University, Pediatrics, Hamilton, Canada, ${ }^{2}$ Paracelsus

Medizinische Privatuniversität Klinikum Nürnberg, Klinik für Neugeborene, Kinder und Jugendliche, Nürnberg, Deutschland

Background: A recent RCT investigated the effects of optimizing the macronutrient (MN) intakes with individualized Target Fortification (TFO) of breast milk (BM) on growth outcomes. In this study, all native BM samples were used for their $\mathrm{MN}$ content to determine true daily nutritional intake. This provides a unique opportunity to explore the effect of dayto-day variability in MN intake on growth. From adult data, it could be speculated that a larger variation of the $\mathrm{MN}$ intakes could influence metabolism and growth.

Objective: To examine the impact of MN intakes, and their variability, on growth rates of preterm infants.

Methods: Secondary analysis of a singlecenter, doubleblind RCT in 103 infants $<30$ gestational weeks fed $\mathrm{BM}$ or donor milk receiving either standard fortification (SF) in control or SF+TFO in intervention. All native BM samples $(n=2810)$ used to make feeds were reanalyzed; fat and protein with near-IR spectrometer (SpectraStar) and CHO (lactose) with UPLC-MS/ MS. Daily MN intakes and average growth rates were calculated for a 21day observation period. The variability of $\mathrm{MN}$ intakes was calculated as the average of day-to-day changes (absolute value) divided by the average $\mathrm{MN}$ intake. Correlation and regression analysis was used to assess the impact of MN intakes and their variability on growth rates.

Results: Protein and $\mathrm{CHO}$ intakes are positively correlated with growth velocity. However, when combined in a multiple linear regression model $\left(r^{2}=0.102, p=0.013\right)$, these intakes are not significant predictors of infants growth rate. The variability of the average $\mathrm{MN}$ intake indicates that larger day-to-day changes in $\mathrm{CHO}$ and fat intakes were negatively correlated with growth velocity. The variability of the $\mathrm{CHO}$ intake is also a negative predictor $(p=0.008)$ of growth rate in a multiple regression model including $\mathrm{MN}$ intakes and variability $\left(\mathrm{r}^{2}=0.207, p=0.001\right)$. The data show that 
growth rates decrease by $0.23 \mathrm{~g} / \mathrm{kg} / \mathrm{d}$ for each percentage increase in average $\mathrm{CHO}$ variability. The trend of increasing $\mathrm{CHO}$ intake variability related to decreasing growth rates is independent of an infants mean protein intake during the study period.

Conclusions: This study provides evidence of the variability of MN. These findings are supported by the intrauterine physiology where a constant flux of nutrients is provided by the placenta to allow high fetal growth rates.

\section{GNPI-V46 \\ Milk Analysis using Milk Analyzers in a standardized Setting (MAMAS) Study}

G. Fusch', C. Kwan', N. Rochow', C. Fusch ${ }^{2,1}$, . MAMAS Study Group ${ }^{1}$

${ }^{1}$ McMaster University, Pediatrics, Hamilton, Canada, ${ }^{2}$ Paracelsus

Medizinische Privatuniversität Klinikum Nürnberg, Klinik für Neugeborene, Kinder und Jugendliche, Nürnberg, Deutschland

Background: Human milk analyzers (MA) are increasingly used to rapidly measure the macronutrient content in breast milk for target fortification, to reduce the risk of postnatal growth restriction. However, many MA are used without quality assurance, validation or calibration. Hence, we have launched the MAMAS study, a multicenter international quality initiative, to implement standard procedures following good laboratory and clinical practice (GLCP) for MA.

Objective: To investigate the quality of measurements between different MA, test whether the accuracy and precision of devices can be improved by establishing individual calibration curves, and assess the long-term stability of measurements, following the GLCP guidelines.

Design/Methods: Breast milk samples prepared at McMaster University were sent out to 13 participating centers in North America and Europe for measurement purposes, for a total of 15 devices. The study included 3 sets of samples: A) initial assessment of the devices performance consisting of 10 calibration samples with random replicates; B) long term stability and quality control (LQC) consisting of 2 batches of 100 samples to be measured every time before the device is used, over 6 months; C) ring trial consisting of 2 samples to be measured monthly. The devices tested were Unity SpectraStar $(n=5)$ and MIRIS Human Milk Analyzer $(n=10)$. Results: We report data from sample sets A and B. Fat, protein and carbohydrate measurements vary significantly, independent of the device used. The range of protein variation was $>1 \mathrm{~g} / \mathrm{dL}$. Correction of the devices using the validation data significantly improved the accuracy for fat and protein measurements, as shown by LQC data.

Conclusions: This is the first trial to compare MA measurements in a multicenter setting. The observed variations in measurements between centers are clinically significant and would impact the outcomes of clinical trials assessing the adjustment of nutrient intake in human milk fed babies. This study shows that GLCP must be introduced to bedside milk analysis to avoid confusing results in breast milk research.

Acknowledgement: The other members of the MAMAS study group are: $\mathrm{D}$ OConnor (Toronto, Canada), A. Hair (Texas, USA), A. Wesolowska (Warsaw, Poland), J. Festival (Calgary, Canada), M. Nelle (Bern, Switzerland), B. Urlesberger (Graz, Austria), J.-M. Hascoet (Nancy, France), T. Kuehn (Berlin, Germany), G. Pelligra (Victoria, Canada), M. Belfort (Boston, USA), MIRIS (Uppsala, Sweden), B. Poindexter (Cincinnati, USA).

\section{GNPI-V47 \\ Querschnitts-Kohortenstudie zur motorischen und neurokognitiven Entwicklung von Kindern mit Schädeldeformitäten}

\section{Schwertel, geb. Fritz' ', H. P. Howaldt', A. Hahn'2, J. F. Wilbrand'}

'Justus-Liebig-Universität Gießen, Mund-, Kiefer- und Gesichtschirurgie, Gießen, Deutschland, 'Justus-Liebig-Universität Gießen, Neuropädiatrie, Gießen, Deutschland

Hintergrund: Kindliche Schädeldeformitäten können synostotischer und nicht-synostotischer Genese sein. In der aktuell verfügbaren Literatur sind
Hinweise für kognitive Einschränkungen bei Kindern mit Schädeldeformitäten bislang nicht sicher untersucht. Lediglich Entwicklungsverzögerungen im Zusammenhang mit nicht-synostotischen Schädeldeformitäten finden vereinzelt Erwähnung.

Fragestellung: Hauptfragestellung ist, ob Kinder mit synostotischen und nicht-synostotischen Schädeldeformitäten einen statistisch relevant niedrigeren IQ als gesunde Kinder haben und ob Kinder mit Schädeldeformitäten häufiger als Gesunde fein- und grobmotorische Störungen aufweisen, ob diese Patienten öfter und wenn ja, in welcher Stärke Verhaltensprobleme zeigen.

Patienten und Methode: Für die Studie werden jeweils 30 Kinder mit nicht-synostotischen und 30 Kinder mit synostotischen Schädeldeformitäten im Alter von 5;6 bis 6;11 Jahren untersucht. Das allg. Intelligenzniveau wird mittles CFT-1 erfasst, der sich in 5 Untertests gliedert (Substitutionen, Labyrinthe, Klassifikationen, Ähnlichkeiten, Matrizen). Die fein- und grobmotorischen Koordinationsfähigkeiten wird durch den Movement - ABC (Handgeschicklichkeit, Ballfertigkeiten, Balance) ermittelt. Die Verhaltensmerkmale werden aus Sicht der Eltern mittels CBCLFragebogen erfasst.

\section{Bisherige Ergebnisse:}

- Kinder mit synostotischer Schädeldeformität: In dieser Gruppe zeigte sich in $20 \%$ eine Einschränkung der motorischen Fähigkeiten, weitere $10 \%$ erzielen Ergebnisse im Grenzbereich zur Auffälligkeit und 10\% haben ein unterdurchschnittliches Intelligenzniveau. Bei $10 \%$ ist eine gesonderte Förderung aufgrund von Hochbegabung nötig, weitere $30 \%$ haben ein hohes/sehr hohes Intelligenzniveau. $30 \%$ der Kinder zeigen Verhaltensauffälligkeiten, weitere $10 \%$ zeigen Werte im Grenzbereich zur Auffälligkeit.

- Kinder mit nicht-synostotischer Schädeldeformität: Nur 5\% der Kinder dieser Gruppe sind motorisch therapiebedürftig, wobei die Mädchen keinerlei motorische Einschränkung haben. Ebenso $5 \%$ haben ein etwas unterdurchschnittliches Intelligenzniveau. $45 \%$ erzielen einen hohen/ sehr hohen IQ Wert. 5\% zeigen Verhaltensauffälligkeiten, weitere 25\% liegen im Grenzbereich zur Auffälligkeit.

Diskussion: Die bisherigen Ergebnisse zeigen erstmals, dass Kinder mit Craniosynostosen schlechtere motorische Fähigkeiten haben als gleichaltrige Kinder mit nicht-synostotischer Schädeldeformitäten. Die Jungen haben vor allem Schwierigkeiten bei der Handgeschicklichkeit, die Mädchen eher bei den Ballfertigkeiten. Auch das Intelligenzniveau der Kinder mit nicht-synostotischen Schädeldeformitäten ist insgesamt höher als das derer mit Craniosynostosen. Probleme treten meist bei Wahrnehmungsumfang und -geschwindigkeit auf. Kinder mit synostotischen Schädeldeformitäten zeigen häufiger ein externalisierendes Verhalten, hauptsächlich aggressives und dissoziales Verhalten. Andere Auffälligkeiten sind Aufmerksamkeits- und soziale Probleme, sowie körperliche Beschwerden. Auch wenn es unspezifische Abweichungen gibt, die ein schlechteres Abschneiden von Kindern mit Craniosynostosen in allen 3 Testreihen vermuten lassen, ist durch die ersten Ergebnisse noch kein eindeutiger Beweis abzuleiten, dass Kinder mit Schädeldeformitäten einen signifikanten Unterschied im Intelligenzniveau, der motorischen Entwicklung oder dem sozialen Verhalten im Vergleich zum Normkollektiv haben.

\section{GNPI-V48}

Fallvorstellungen: Ultraschall gesteuerte Lagekorrektur von Nabelvenenkathetern

P. Richter, F. Ebinger

St. Vincenz Krankenhaus, Paderborn, Deutschland

Hintergrund: Der Nabelvenenkatheter (NVK) ist auch heutzutage ein schnell und einfach zu legender, großlumiger zentraler Zugang bei intensivtherapiepflichtigen Neugeborenen auch im Kreißsaal. Einführtiefe nach Tabelle/Diagramm, federnder Widerstand, mangelnde Möglichkeit der Aspiration und ausgelöste Extrasystolen dienen neben dem Röntgenbild klassischerweise als Lagekontrolle. Komplikationen entstehen insbesondere aus der Gefahr von Fehllagen. Leider entstehen diese Fehllagen 
nicht selten ( $>50 \%$ ) und werden, zum Beispiel bei rein ventraler Fehllage, vom Unerfahrenen auch im Röntgenbild häufig nicht erkannt.

Methode: Die modernen hochauflösenden Microkonvex-Sonographiesonden erzeugen mittlerweile eine exzellente Darstellung des Nahfeldes. Damit sind bei Früh- und Neugeborenen Position und Perlauf eines NVK sehr gut zu überprüfen. Bei Kenntnis der Anatomie des Nabelgefäß-/ Portalvenenbettes können auch Lagekorrekturen unter kontinuierlicher Echtzeit-Ultraschallkontrolle durchgeführt werden. Hilfreich kann hierfür auch das Reflexverhalten von Mikrobubbles in Infusionslösungen sein. Ergebnisse: In der Fallvorstellung werden die anatomischen Verhältnisse dargestellt, die zu den bekannten Fehlpositionen führen. Anhand von Sono-Videos wird demonstriert, wie Lagekorrekturen fehlpositionierter NVK bei mehreren Kindern durchgeführt wurden. Hierfür bietet es sich an, dass eine Person die Ultraschalldokumentation durchführt und die Katheterrichtung durch leichten Druck mittels der kleinen Auflagefläche der Sonden beeinflusst und eine zweite Person den Katheter bewegt. Angewendet wurden die Ultraschallgeräte Aplio MX sowie Aplio 200 der Fa. Toshiba, jeweils mit der Microkonvexsonde (PVU-712BT Xario bzw. PVT712BT Aplio) bei $10.2 \mathrm{Mhz}$.

Schlussfolgerung: Das Vorhandensein von guten hochauflösenden Sonographiegeräten im Rahmen der Neugeborenenversorgung kann für eine schnelle Sicherung bzw. Korrektur der Katheterposition und einer Vermeidung von katheterbedingten Komplikationen und sowie der nicht unerheblichen Strahlenbelastung mehrfacher Oberbauch Röntgenaufnahmen führen.

\section{GNPI-V49 \\ Maßnahmen zur Optimierung der nichtinvasiven Maskenbeatmung von Früh- und Reifgeborenen im Rahmen der postnatalen Erstversorgung}

\section{P. Mileder, T. Derler, N. Baik-Schneditz, B. Schwaberger, B. Urlesberger, G. Pichler}

Medizinische Universität Graz, Klinische Abteilung für Neonatologie, Univ.Klinik für Kinder- und Jugendheilkunde, Graz, Österreich

Hintergrund: Bei apnoeischen oder insuffizient spontanatmenden Neugeborenen in der postnatalen Adaptationsphase stellt die Belüftung und Ventilation der Lunge mit kontinuierlichem positivem Atemwegsdruck (continuous positive airway pressure - CPAP) und/oder die manuelle Überdruckbeatmung (positive pressure ventilation - PPV) appliziert mit Beatmungsmaske die primär wichtigste Intervention dar. Zur Optimierung der respiratorischen Unterstützung werden in der Literatur verschiedene Maßnahmen wie etwa die Neupositionierung des kindlichen Kopfes oder die Beatmung mittels der 2-Helfer-Methode genannt.

Fragestellung: Das Ziel dieser Studie war die Untersuchung der Häufigkeit von Maßnahmen zur Verbesserung der nichtinvasiven Maskenbeatmung von Früh- und Reifgeborenen in der Adaptationsphase unmittelbar nach der Geburt und von deren Effekten auf Vitalparameter.

Material und Methoden: Für diese Studie wurden Videos von Früh- und Reifgeborenen analysiert, die im Rahmen von prospektiven Beobachtungsstudien zwischen September 2009 und Januar 2015 in den ersten 15 Minuten nach ihrer Geburt gefilmt wurden. In die Analyse inkludiert wurden ausschließlich Neugeborene, die in der postnatalen Adaptationsphase Masken-CPAP und/oder Masken-PPV erhielten.

Folgende Maßnahmen wurden erhoben: Repositionierung von Beatmungsmaske oder Kopf, oropharyngeales Absaugen, Wechsel zwischen ein- und beidhändiger Beatmungsmaskenführung, Wechsel der Beatmungsmaske und Wechsel der durchführenden Person. Folgende Parameter wurden vor und nach der ersten beatmungsoptimierenden Maßnahme verglichen: Herzfrequenz und arterielle Sauerstoffsättigung gemessen mittels Pulsoxymetrie, zerebrale Gewebssauerstoffsättigung gemessen mittels Nahinfrarotspektroskopie und Beatmungsmaskenleckage gemessen mittels Atemfunktionsmonitoring.

Ergebnisse: Von insgesamt 653 Videos war bei 143 Neugeborenen $(21,9 \%)$ Masken-CPAP und/oder Masken-PPV erforderlich. Davon mussten neun Videos (6,3\%) aufgrund ungenügender Qualität exkludiert werden. Von den 134 inkludierten Videos (76 Früh- und 58 Reifgeborene) wurden in 105 (78,4\%) insgesamt 427 Maßnahmen (Median [Range]: 2 Maßnahmen [0-22]) zur Verbesserung der Beatmungssituation gesetzt. Maskenrepositionierung $(56,9 \%)$ und oropharyngeales Absaugen $(26,0 \%)$ waren die häufigsten gesetzten Maßnahmen. Beatmungsoptimierende Maßnahmen waren bei Frühgeborenen signifikant häufiger als bei Reifgeborenen ( 287 versus $140 ; p=0,006$ ). Für Herzfrequenz, Sauerstoffsättigung und Beatmungsmaskenleckage zeigten sich nach der ersten gesetzten Maßnahme keine Unterschiede, die regionale zerebrale Gewebsoxygenierung stieg nach der ersten Intervention jedoch signifikant an $(37,3 \pm 22,0 \%$ versus $45,4 \pm 21,5 \% ; p=0,001$ ).

Schlussfolgerung: Maßnahmen zur Optimierung der nichtinvasiven Maskenbeatmung von Neugeborenen wurden während der postnatalen Erstversorgung häufig durchgeführt, es bestand dabei jedoch eine hohe Streubreite. Es zeigten sich außerdem Unterschiede in der Häufigkeit der gesetzten Maßnahmen zwischen Früh- und Reifgeborenen. Die erste beatmungsoptimierende Maßnahme war mit einer Verbesserung der zerebralen Gewebsoxygenierung assoziiert.

\section{GNPI-V50}

Nichtinvasive Hochfrequenzoszillationsbeatmung versus nichtinvasiver CPAP - Eine randomisierte kontrollierte CrossoverStudie

D. Klotz, J. Baumgartner, R. Hentschel, D. Stavropoulou, H. Schneider, H. Fuchs Zentrum für Kinder- und Jugendmedizin, Universitätsklinikum Freiburg, Funktionsbereich Neonatologie und Pädiatrische Intensivmedizin, Freiburg, Deutschland

Hintergrund: Die nichtinvasive Hochfrequenzoszillationsbeatmung ( $\mathrm{nH}-$ FOV) zeigt in Fallserien und nichtrandomisierten Studien eine höhere $\mathrm{CO}_{2}$-Clearance im Vergleich zu nichtinvasivem CPAP (nCPAP).

Fragestellung: Senkt nHFOV bei Frühgeborenen $<32$ Schwangerschaftswochen (SSW) mit Notwendigkeit für nichtinvasive Atemunterstützung den $\mathrm{pCO}_{2}$ effektiver als nCPAP?

Methoden: Monozentrische prospektive randomisierte nichtverblindete Studie im $2 \times 2$ Crossover Design. Einschlusskriterien waren: Gestationsalter $<32$ SSW, Notwendigkeit einer nichtinvasiven Atemhilfe aufgrund eines Atemnotsyndroms, $<24 \mathrm{~h}$ nach Extubation oder nichtinvasiver Surfactantgabe, $\mathrm{pCO}_{2}>40 \mathrm{~mm} \mathrm{Hg}$. Fehlende elterliche Einwilligung, Therapielimitierung, intraventrikuläre Blutung (IVH) und Fehlbildungssyndrome waren Ausschlusskriterien. Die Studienphase umfasste $8 \mathrm{~h}$ Atemhilfe bestehend aus 2 Perioden ( $4 \mathrm{~h} \mathrm{nHFOV;} 4 \mathrm{~h} \mathrm{nCPAP}$ ), die randomisiert den Sequenzen (nCPAP-nHFOV; nHFOV-nCPAP) zugeordnet wurden. Der mittlere Atemwegsdruck war in beiden Perioden gleich und entsprach dem Atemwegsdruck vor Studienbeginn. nHFOV wurde mit einer Frequenz von $10 \mathrm{~Hz}$ und der Amplitude appliziert, bei der deutlich sichtbare Vibrationen des Thorax erreicht wurden. Der kapilläre oder arterielle $\mathrm{pCO}_{2}$ wurde zu Beginn und am Ende jeder Periode gemessen. Primäres Ziel-Kriterium war der $\mathrm{pCO}_{2}$ am Ende der jeweiligen Beatmungsperiode. Sekundäre Ziel-Kriterien waren: Versagen der nichtinvasiven Beatmung, Anzahl von Apnoen und Bradykardien nach vordefinierten Kriterien, mittlerer Atemwegsdruck, $\mathrm{FiO}_{2}$ um eine präduktale Sättigung von $>85 \%$ zu erreichen, Herzfrequenz, Atemfrequenz, $\mathrm{SpO}_{2}$ und Schmerzscore (EDIN-Scale). Die Fallzahlberechnung bei einem erwarteten Unterschied des pCO2 von $5 \pm 6 \mathrm{~mm}$ Hg ergab 26 einzuschließende Patienten bei einer Power von $80 \%$ und einem Signifikanzniveau von 5\%. Die Ethikkommission der Universität Freiburg stimmte der Durchführung der Studie zu. Die Studie ist im DRKS registriert (DRKS00007171).

Ergebnisse: Im Zeitraum von Juli 2014 bis September 2016 wurden 26 Frühgeborene (GA: $27 \pm 2$ SSW; GG $949 \pm 330$ g; postnatales Alter $5 \pm 5$ Tage) rekrutiert und randomisiert den beiden Sequenzen zugeordnet. Vor Studienbeginn waren mittlerer Atemwegsdruck, $\mathrm{FiO}_{2}, \mathrm{SpO}_{2}, \mathrm{Ge}-$ burtsgewicht, Gestationsalter, postnatales Alter, Rate an vollständiger Lungenreifung, Surfactanttherapie, Apgar-Werte und Nabelschnur-pH in beiden Gruppen gleich. Der mittlere Atemwegsdruck war in beiden Perioden gleich $\left(6,1 \pm 0,9 \mathrm{cmH}_{2} \mathrm{O}\right)$. Die Amplitude während der nHFOV- 
Phase war $17 \pm 10 \%$. Primäres Ziel-Kriterium: Es gab keinen Unterschied im $\mathrm{pCO}_{2}$ nach $4 \mathrm{~h}$ nCPAP oder $4 \mathrm{~h}$ nHFOV ( $48 \mathrm{~mm} \mathrm{Hg}$ versus $49,7 \mathrm{~mm}$ $\mathrm{Hg} ; p=0,14)$. Sekundäre Ziel-Kriterien: Bis auf eine höhere Atemfrequenz während nHFOV ( 50 versus $57 / \mathrm{min} ; p<0,01$ ) gab es keine Unterschiede in den sekundären Zielkriterien. Bei 5 Patienten wurde die nHFOV-Periode vorzeitig nach vordefinierten Kriterien abgebrochen $(n=3$ Hyperkapnie $>70 \mathrm{~mm} \mathrm{Hg}, n=2$ Hypoxie bei FiO2 $>0,6 ; n=1>2$ stimulationsbedürftige Apnoen/h). Bei keinem Patient wurde die nCPAP-Periode vorzeitig abgebrochen. Kein Frühgeborenes entwickelte eine IVH in der Studienphase. Schlussfolgerung: In unserem Kollektiv konnten wir keine effektivere $\mathrm{CO}_{2}$-Clearance durch nHFOV im Vergleich zu nCPAP nachweisen. Beatmung mit nHFOV führte häufiger zu einem vorzeitigem Therapieabbruch als nCPAP.

\section{GNPI-V51 \\ (Erst-)Versorgung eines Kindes mit pränatal unbekannter Trisomie 13}

\section{B. Wannenmacher 1,2, M. Heruth ${ }^{2}$, M. Reitmann'2, D. Huhle', A. Möckel ${ }^{2}$ ${ }^{1}$ Herzzentrum Leipzig $\mathrm{GmbH}$, Klinik für Kinderkardiologie, Leipzig, Deutschland, ${ }^{2}$ Sana Kliniken Leipziger Land, Klinik für Kinder- und Jugendmedizin, Borna, Deutschland, ${ }^{3}$ Genetik-Praxis Leipzig, Leipzig, Deutschland}

Hintergrund: Die Trisomie 13 (Pätau-Syndrom) ist eine seltene genetische Erkrankung mit schwerer körperlicher und geistiger Entwicklungsstörung und deutlich reduzierter Lebenserwartung. In der Regel tritt ein intrauteriner Fruchttod bis zur 20. Schwangerschaftswoche ein. Überlebt ein Fetus bis zur Geburt, beträgt das durchschnittliche Lebensalter etwa 3 Monate, in Ausnahmefällen über 10 Jahre, wenn keine schweren lebenslimitierenden Komorbiditäten vorliegen. Die Inzidenz unter Lebendgeborenen beträgt ca. 1:5000-1:14.500.

Methoden: Wir berichten über ein Mädchen mit Trisomie 13 (Karyotyp $47, X X+13$ ), welches ohne pränatale Diagnosestellung per Sectio bei mütterlichem HELLP-Syndrom in der 33+1. Schwangerschaftswoche in unserer Klinik geboren wurde. Vorangegangen war eine Fehlgeburt, sonst unauffällige Familienanamnese.

Ergebnisse: Die postnatale Anpassung war verzögert. Nach Erstversorgung und CPAP-Anlage wurde wegen hohen Sauerstoffbedarfs bei Atemnotsyndrom sekundär intubiert, Surfactant appliziert sowie über 10 Stunden nachbeatmet. Ein ausgeprägtes Apnoe-Bradykardie-Syndrom erforderte Coffein-Substitution. Das Vorliegen mehrerer typischer Dysmorphiezeichen führte zum Verdacht auf das Vorliegen einer schwerwiegenden Chromosomenabberation. Die zytogenetischen Untersuchungen bestätigten eine freie Trisomie 13 ohne Anhalt für das Vorliegen eines Mosaiks. Hiernach wurde mit der Familie ein Wechsel des Behandlungsziels auf eine primär palliative Therapie vereinbart sowie eine Anbindung an einen ambulanten Hospiz-Dienst initiiert. Generalisierte epileptische Krampfanfälle und Myoklonien wurden mit Phenobarbital, Levetiracetam und im Verlauf Clobazam behandelt. Eine Entlassung war unter Vollsondierung am 52. Lebenstag möglich. Im 7. Lebensmonat erfolgte bei dauerhafter Abhängigkeit von der Magensonde die Anlage einer PEG-Sonde. Die Patientin ist zum Publikationszeitpunkt über 2 Jahre alt. Es besteht eine enge Anbindung an unsere Klinik im Rahmen mehrerer Spezialsprechstunden. Mehrfach war eine geplante und akute stationäre Aufnahme u. a. zur Behandlung von Infektionen, komplizierten epileptischen Anfällen und aufgrund von Ernährungsschwierigkeiten erforderlich. Im Zuge dessen erfolgte eine ständige Revision und Anpassung der „Empfehlungen zum Vorgehen in Notfallsituationen" an die aktuelle klinische Situation. Schlussfolgerung: Zusammenfassend berichten wir über den Fall einer pränatal unbekannten Trisomie 13, welche trotz Frühgeburtlichkeit und typischer klinischer Fehlbildungen unter Therapie ein gutes Gedeihen zeigt. Ein besonderer Fokus wird auf die ethischen Aspekte der neonatalen Versorgung vor Kenntnis der Chromosomenabberation gelegt.

\section{GNPI-V52}

Development of a new morpho-functional MRI scoring system for neonatal chronic lung disease

K. Förster', A. Hilgendorff', S. Sass', S. Stöcklein ${ }^{3}$, F. Schöppe ${ }^{3}$, O. Dietrich ${ }^{3}$, A. Pomschar ${ }^{3}$, A. Schulze', C. Hübener , F. Theis', H. Ehrhardt ${ }^{5}$, A. W. Flemmer', B. Ertl-Wagner ${ }^{3}$

'Ludwig-Maximilian University, Dept. of Neonatology, Perinatal Center Grosshadern, Dr. von Hauner Children's Hospital, Munich, Germany, ${ }^{2}$ Helmholtz Zentrum München, Institute of Computational Biology, Munich, Germany, ${ }^{3}$ Ludwig-Maximilian University Hospital, Institute for Clinical Radiology, Munich, Germany, ${ }^{4}$ Ludwig-Maximilian University, Clinic for Gynecology and Obstetrics, Perinatal Center Grosshadern, Munich, Germany, ${ }^{5}$ Children's Hospital of the University Clinic Giessen and Marburg, Giessen, Dept. of Neonatology, Giessen, Germany

Objective: Bronchopulmonary dysplasia (BPD) is a common complication in neonates undergoing postnatal lung injury. Despite the clinical significance of the disease, the diagnostic process still lacks sensitive imaging tools to improve disease detection and characterization. We therefore aimed to develop a new morpho-functional MR-scoring system in order to allow for disease stratification based on structural changes in the diseased lung.

Methods: Thirty six preterm infants (median gestational age (GA) 28.0 weeks) were prospectively included in the study. MRI measurements were performed in spontaneously breathing, unsedated infants at the time of diagnosis (median 35.7 GA weeks) using a 3T scanner. Detailed and standardized image analysis was performed by a consensus panel using a 6-point semi-quantitative Likert scale ( 1 = normal, $6=$ maximum pathology) in regional sagittal and transverse images Scoring parameters were presence of emphysema, interstitial thickening, increased airway signal, atelectasis, and caudo-cranial as well as anterior-to-posterior gradient of signal intensities. Presence of infiltrates, pleural effusion or pneumothorax was documented. In all patients, infant lung function testing (ILFT) was performed in addition to MR imaging to correlate structural and functional findings. Results: Global scores ranged from 4 to 72 . Morpho-functional MR-scoring revealed the outcome variable BPD to be associated with a higher global score in interstitial thickening when compared to infants without BPD. A significant increase in scores for emphysematous changes were observed in infants moderate and severe disease. Furthermore, increased scores for emphysema were associated with a longer duration of mechanical ventilation, whereas interstitial thickening was found to be associated with the duration of oxygen therapy. Confirmation of the findings showed a high inter-reader reproducibility.

Conclusions: With these results, we propose a reliable, new morpho-functional MR-scoring-system that is clinically applicable for the semi-quantitative detection of the pulmonary structural changes in infants with BPD. Implementation of the MRI score into clinical routine would significantly improve the diagnostic process by allowing for individualized treatment and monitoring approaches.

\section{GNPI-V53}

\section{Die schwere bronchopulmonale Dysplasie, diagnostiziert mit 40 postmenstruellen Wochen, ist der beste Prädiktor für die Einschätzung der neurologischen Entwicklung}

A. M. Malavolti ${ }^{1,2}$, D. Bassler ${ }^{1}$, R. Arlettaz-Mieth' ${ }^{1}$, B. Latal, ${ }^{3,4}$, G. Natalucci, ${ }^{1,3}$

${ }^{1}$ Klinik für Neonatologie, UniversitätsSpital Zürich, Zürich, Schweiz, 2Dipartimento della salute della donna e del bambino, Ospedale universitario Sant'Orsola, Bologna, Italia, ${ }^{3}$ Abteilung Entwicklungspädiatrie, Kinderspital Zürich, Zürich, Schweiz, ${ }^{4}$ Forschungszentrum für das Kind, Zürich, Schweiz

Hintergrund: Beinahe die Hälfte aller Frühgeborenen mit einem Gestationsalter $<28$ Wochen leidet unter bronchopulmonaler Dysplasie (BPD). Die BPD ist ein guter Prädiktor für eine entwicklungsneurologische Beeinträchtigung (NDI) bei sehr kleinen Frühgeborenen. Allerdings ist noch 
unklar, welche Rolle der Schweregrad der BPD sowie der Zeitpunkt der Diagnosestellung bei der Vorhersage der neurologischen Entwicklung spielt. Fragestellung: Inwieweit tragen bei Frühgeborenen der Schweregrad der BPD (mild, moderat, schwer) sowie der Zeitpunkt der Diagnosestellung (mit 36 oder 40 postmenstruellen (pm) Wochen) zur Optimierung der Vorhersage der neurologischen Entwicklung im korrigierten Alter von 2 Jahren bei?

Methoden: Monozentrische retrospektive Analyse einer Kohorte von 754 frühgeborenen Kindern mit einem Gestationsalter $<30$ Wochen, die im Zeitraum von 2000 bis 2013 geboren wurden. BPD wurde definiert als FiO2 $>21 \%$ für $>28$ Tage und ihr Schweregrad folgendermassen klassifiziert: mild: $\mathrm{FiO} 2=21 \%$; moderat: $\mathrm{FiO} 2<30 \%$; und schwer: $\mathrm{FiO} 2 \geq 30 \%$ und/oder positive Druckunterstützung. Wir applizierten diese Kriterien zu 2 verschiedenen Zeitpunkten: mit 36 pm Wochen (gemäss dem 2000-NICHD-Konsens) und mit 40 pm Wochen. Multivariable Regressionsmodelle wurden verwendet, um die Assoziation (OR (95\%-CI) von BPD und ihrem an 2 unterschiedlichen Zeitpunkten diagnostizierten Schweregrad, mit dem Auftreten einer NDI einzuschätzen. (NDI wurde dabei folgendermassen definiert: kognitiver oder motorischer Entwicklungsscore $<-2 \mathrm{SD}$, schwere Zerebralparese, Taubheit oder Blindheit).

Ergebnisse: Bei 610 (81\%) der Kinder wurde eine Nachuntersuchung im Alter von 2 Jahren durchgeführt. Von diesen Kindern benötigten 357 (58\%) $\mathrm{FiO} 2>21 \%$ für $>28$ Tage und $98(16 \%)$ zeigten mit 2 Jahren eine NDI. BPD war mit NDI assoziiert $[1,5(1,1 ; 1,9)]$, allerdings ausschliesslich die schwere BPD. Der Diagnosezeitpunkt einer schweren BPD mit 40 postmenstruellen Wochen $[11,9(4,6 ; 59,9)]$ war ein besserer Prädiktor als mit 36 Wochen $[5,6(2,0 ; 15,9)]$. Kinder mit schwerer BPD hatten tiefere Entwicklungsscores als Kinder ohne BPD, und die mittlere Differenz der Werte war grösser mit 40 pm Wochen [kognitiv $-25,7(-35,9 ;-15,5)$, motorisch $-20,1(-30,7 ;-9,5)$ ] als mit 36 Wochen [kognitiv $-11,4(-18,5$; $-4,3)$, motorisch $-7,8(-14,9 ;-0,6)]$.

Schlussfolgerung: In unserer Kohorte frühgeborener Kinder war eine schwere BPD ein besserer unabhängiger Prädiktor für eine neurologische Entwicklungsbeeinträchtigung im Alter von 2 Jahren als eine milde oder moderate BPD. Die Diagnosestellung einer schweren BPD mit 40 (und nicht mit 36) postmenstruellen Wochen, erweist sich als die bessere Möglichkeit, um Kinder mit besonders hohem Risiko für eine neurologische Entwicklungs-beeinträchtigung frühzeitig identifizieren zu können.

\section{GNPI-V54}

\section{Microfluidic chip-based quantification of circulating endothelial} cells in pulmonary arterial hypertension

H. Sallmon', A. Hatch'2, B. Plouffe', S. K. Murthy' ${ }^{2}$, G. Hansmann ${ }^{3}$

${ }^{1}$ Charité - Universitätsmedizin Berlin, Klinik für Neonatologie, Berlin, Deutschland, ${ }^{2}$ Northeastern University, Chemical Engineering, Boston, USA, ${ }^{3}$ Medizinische Hochschule Hannover, Pädiatrische Kardiologie und Intensivmedizin, Hannover, Deutschland

Objective: Circulating endothelial cells (CECs) have been discussed as potential biomarkers in patients with pulmonary arterial hypertension (PAH). Current protocols for isolation and quantification of these cells are laborious and time-consuming.

Background: We recently developed a disposable microfluidic platform capable of selectively capturing and enumerating specific cell populations directly from human whole blood. The aim of this study was to apply this microfluidic chip on CECs and to test whether CECs measured by this device may serve as potential biomarker in $\mathrm{PAH}$ patients.

Methods: Human whole blood was collected and injected into polymeric microfluidic chips containing microcolumns pre-coated with anti-CD146 antibody. Captured cells were immuno-fluorescently stained for additional stem and endothelial cell markers.

Results: The CEC capture chip was validated against conventional flow cytometry $(\mathrm{r}=0.89)$. In a cohort of 66 patients with three forms of PAH (idiopathic/heritable, drug-induced, and connective tissue disease), CEC numbers are significantly increased $\approx 400 \%$ in $\mathrm{PAH}$ subjects vs. matched controls. CEC elevations were consistent between different PAH etiologies. CEC numbers were not related to body mass index or age.

Conclusions: The CEC capture chip requires $200-400 \mu \mathrm{L}$ of blood and may serve as a bedside test for the screening and monitoring of patients with $\mathrm{PAH}$ and other diseases related to vascular injury.

\section{Freie Vorträge DGPI}

\section{DGPI-V01}

Neonatale primäre dendritische Zellen zeigen im Vergleich zu aus Monozyten generierten dendritischen Zellen unterschiedliche Antworten auf Toll-like Rezeptor Stimulation - ein Stolperstein in der Entwicklung neuer Impfstoffformulierungen?

F. Borgans, M. Fichter, V. Saase, L. Pretsch, F. Zepp, S. Gehring

Universitätsmedizin Mainz, Zentrum für Kinder- und Jugendmedizin, Pädiatrische Immunologie und Infektiologie, Mainz, Deutschland

Hintergrund: Ein zentrales Anliegen in der präklinischen Impfstoffentwicklung ist die Suche nach neuen Adjuvantienkombinationen zur Induktion effektiveren Immunantworten, insbesondere im Neugeborenen- und Säuglingsalter. In viele Studien werden hierzu aus Monozyten generierte dendritische Zellen (moDCs) verwendet, deren Vorteil in einer guten Verfügbarkeit und vergleichsweise geringen Kosten liegt.

Fragestellung: Ziel der Studie war die Gewinnung und Charakterisierung von humanen primär-isolierten (neonatalen und adulten) dendritischen Zellen (DCs) und die Charakterisierung ihrer Immunantwort nach Stimulation mit Toll-like-Rezeptor-Liganden im Vergleich zu moDCs.

Material und Methoden: Humane neonatale Zellen wurden aus Nabelschnurblut nach elektiver Sectio caesara gesunder Neugeborener gewonnen und die adulten Zellen aus Leukozytenkonzentraten gesunder Blutspender. Primäre und moDCs wurden mittels Magnetzellseparation aus dem Blut isoliert und in einer 96-well-half-area-Platte mit dem TLR-4-Liganden MPLA oder mit dem TLR-7/8-Liganden R848 stimuliert. Zur Bestimmung des Aktivierungstatus der Zellen wurden diese nach $24 \mathrm{~h}$ Inkubation durchflusszytometrisch auf die Expression von CD80, CD83, CD86 und HLA-DR untersucht. Anschließend wurden die Zytokinkonzentrationen in den Überständen des Kulturmediums mittels Cytometric Bead Array quantifiziert.

Ergebnisse: Die Population der isolierten primären dendritischen Zellen setzte sich aus $\mathrm{CD} 303^{+} \mathrm{CD} 123^{+}$plasmazytoiden $\mathrm{DCs}, \mathrm{CD} 1 \mathrm{c}^{+}$myeloiden DCs, $\mathrm{CD}_{141^{+}}$myeloiden DCs und einer heterogenen Population aus $\mathrm{CD}^{-} \mathrm{c}^{-} \mathrm{CD} \mathrm{C3}^{-} \mathrm{CD}^{-} \mathrm{C3}^{-}$Zellen zusammen. Die Stimulation der moDCs mit MPLA zeigte eine starke Zunahme der Expression von CD80, CD83, CD86 und HLA-DR und der Sekretion von proinflammatorischen Zytokinen, während die Stimulation mit R848 nur einen schwachen Effekt zeigte. Die primären DCs hingegen reagierten nicht auf MPLA, zeigten aber eine starke Aktivierung und Zytokinsekretion nach Stimulation mit R848. Diskussion: Zusammenfassend zeigt sich aufgrund des unterschiedlichen Verhaltens von primären DCs und moDCs nach TLR-Liganden Stimulation, dass es notwendig ist, zukünftig primäre dendritische Zellen in der präklinischen Impfstoffentwicklung zu nutzen. 


\section{DGPI-V02}

\section{Anti-IL-6-Autoantikörper sind ein selektiver Risikofaktor für} bakterielle Infektionen mit unvollständiger Penetranz

S. Heller 1,2, U. Kölsch ${ }^{3}$, C. Tersch ${ }^{4}$, A. Knaus ${ }^{2,5}$, L. B. Rosen ${ }^{6}$, R. Döffinger? M. van der Linden ${ }^{8}$, M. Farinacci ${ }^{9}$, C. C. Schaefer ${ }^{1}$, J. Bustamante ${ }^{10,11,12 \text {, }}$ P. Kühnen ${ }^{13}$, S. Seeliger ${ }^{14}$, D. Hüseman ${ }^{15}$, H. U. Thomalla ${ }^{16}$, G. Bär17, M. S. Lionakis ${ }^{18}$, S. K. Browne ${ }^{6}$, M. Bauer', N. Unterwalder ${ }^{3}$, H. Krude ${ }^{13}$, P. Krawitz ${ }^{2,5}$, C. Bührer ${ }^{19}$, H. D. Volk ${ }^{3,2,9}$, S. M. Holland ${ }^{6}$, J. L. Casanova ${ }^{10,11,12,20,}$ A. Puel ${ }^{10,11}$, S. Rose-John ${ }^{21}$, U. Reimer', C. Meise ${ }^{3,2,9}$, H. von Bernuth ${ }^{1,3,2,22}$ ${ }^{1}$ Charité - Universitätsmedizin Berlin, Klinik für Pädiatrie mit Schwerpunkt Pneumologie und Immunologie, Berlin, Deutschland, ${ }^{2}$ Berlin Brandenburg Centrum für Regenerative Therapien, Berlin, Deutschland, ${ }^{3}$ Labor Berlin $\mathrm{GmbH}$, Fachbereich Immunologie, Berlin, Deutschland, ${ }^{4} \mathrm{JPT}$ Peptide Technologies $\mathrm{GmbH}$, Berlin, Deutschland, ${ }^{5}$ Institut für Medizinische Genetik und Humangenetik, Berlin, Deutschland, ${ }^{6} \mathrm{NIH} / \mathrm{NIAID}$, Bethesda, USA, ${ }^{7}$ Addenbrooke's Hospital, Cambridge, UK, ${ }^{8}$ Uniklinik RWTH Aachen, Nationales Referenzzentrum für Streptokokken, Aachen, Deutschland, ${ }^{9}$ Institut für Medizinische Immunologie, Berlin, Deutschland, ${ }^{10}$ Necker Enfants Malades Hospital, Paris, France, ${ }^{1}$ University Paris Descartes, Paris, France, ${ }^{12}$ Rockefeller University, New York, USA, ${ }^{13}$ Charité Universitätsmedizin Berlin, Institut für Experimentelle Pädiatrische Endokrinologie, Berlin, Deutschland, ${ }^{14}$ Kliniken Sankt Elisabeth, Neuburg an der Donau, Deutschland, ${ }^{15} \mathrm{Klinikum}$ Barnim GmbH, Werner Forßmann Krankenhaus, Eberswalde, Deutschland, ${ }^{16} \mathrm{Kreiskrankenhaus} \mathrm{Torgau}$ "J. Kentmann" gGmbH, Torgau, Deutschland, ${ }^{17}$ St. Franziskus-Hospital Ahlen, Ahlen, Deutschland, ${ }^{18} \mathrm{LCID}, \mathrm{NIH} / \mathrm{NIAID}$, Bethesda, USA, ${ }^{19} \mathrm{Charité}-$ Universitätsmedizin Berlin, Institut für Neonatologie, Berlin, Deutschland, ${ }^{20} \mathrm{How}$ ard Hughes Medical Institute, New York, USA, ${ }^{21}$ Christian-Albrechts Universität, Institut für Biochemie, Kiel, Deutschland, ${ }^{22}$ Charité Universitätsmedizin Berlin, Sozialpädiatrisches Zentrum, Berlin, Deutschland

Hintergrund: Interleukin-6 (IL-6) ist ein früher Mediator der Akut-Phase Antwort auf pyogene Infektionen. Angeborene Immundefekte, die mit eingeschränkter Produktion von IL-6 oder Abschwächung des vom IL6-Rezeptor kontrollierten Signalwegs einhergehen, führen zu einer deutlich erhöhten, selektiven Anfälligkeit für eitrige bakterielle Infektionen. Eine erhöhte Neigung zu Infektionen wurde wiederum auch im Zusammenhang mit verschiedenen anti-Zytokin-Autoantikörpern (AAk) beschrieben: aIFN-g-AAk (Mykobakterien, Salmonellen); aGM-CSF-AAk (Nocardien, Kryptokokken); aIL-17A-AAk, aIL-17F-AAk und aIL-22AAk (chronische mukokutane Candidiasis). Die Rolle dieser AAk wird als krankheitsverursachend angenommen, da sie Phänokopien der korrespondierenden Rezeptordefekte darstellen. Die Rolle von AAk gegen IL-6 (aIL-6-AAk) ist hingegen weniger klar, da bisher nur drei Patienten mit aIL-6-AAk schwere eitrige Infektionen entwickelten (S. aureus, S. intermedius und E. coli).

Fragestellung: Welche Rolle spielen neutralisierende aIL-6-AAk für die Entwicklung bakterieller Infektionen?

Material und Methoden: 348 Patienten mit bakteriellen Infektionen, 564 Patienten mit Autoimmunerkrankungen, 366 Patienten mit mykobakteriellen Infektionen und 1321 gesunde Individuen wurden mit Hilfe eines ELISAs bzw. eines Bead-basierten Assays auf spezifische aIL-6-AAk untersucht. Die neutralisierende Wirkung der aIL-6-AAk wurde durch Inhibition der STAT3-Phosphorylierung nach IL-6-Stimulation nachgewiesen. Mittels Epitop-Mapping wurden spezifische IL-6 Epitope identifiziert. Die Inhibition der klassischen (mIL-6R-abhängig) und trans (sIL-6-R-abhängig) vermittelten Signaltransduktion durch aIL-6-AAk wurde in den murinen Zelllinien $\mathrm{Ba} / \mathrm{F} 3$-gp130/IL-6Ra und $\mathrm{Ba} / \mathrm{F} 3$-gp130 untersucht.

Ergebnisse: In der Patientenkohorte mit bakteriellen Infektionen wurde ein weiterer Patient mit aIL-6-AAk identifiziert. Der zuvor gesunde 5 jährige Junge erkrankte an einer schweren nekrotisierenden Pneumokokkenpneumonie. Zwei adulte Patienten mit Autoimmunerkrankungen (APECED bzw. Autoimmunhepatitis) sowie ein jugendlicher gesunder Kontrollproband zeigten ebenfalls hohe aIL-6-AAk-Titer, entwickelten jedoch bisher keine bakterielle Infektion. Die identifizierten IL-6 Epitope befanden sich an Positionen, die für die Bildung des hexameren IL-6/gp130/
IL-6R-Komplexes entscheidend sind. Alle aIL-6-AAk inhibierten sowohl die klassisch- als auch die trans-vermittelte IL-6 Signaltransduktion. Schlussfolgerung: Anti-IL-6-Autoantikörper sind ein selektiver Risikofaktor für bakterielle Infektionen mit unvollständiger Penetranz.

\section{DGPI-V03}

Beeinflussung der Programmierung von Makrophagen im in-vitro Infektionsmodell - kann ein Signal umgeleitet werden, um einen anti-inflammatorischen Effekt zu erzielen?

\section{S. Dreschers, C. Platen, N. Hartmann, K. Ohl, T. Orlikowsky \\ Universitätsklinik Aachen, Neonatologie, Aachen, Deutschland}

Hintergrund: Vorausgehende Experimenten zeigten, dass anti-inflammatorische Makrophagen (M2c) von Neugeborenen eine geringere Aktivierung des STAT3-Polarisationstransmitters als solche von Erwachsenen aufweisen. Dies hat zur Folge, dass Rezeptoren, die u. a. an der Bindung und Eliminierung von Zelltrümmern beteiligt sind, geringer auf M2cMakrophagen Neugeborener exprimiert werden. Die Signalmediatoren mTOR und MAP2-Kinase spielen eine wesentliche Rolle bei der Phagozytose-bedingten Induktion von Apoptose und bei der Zytokinproduktion von IL-10 und TNF-alpha.

Hypothese: Werden anti-inflammatorische M2c -Makrophagen von Neugeborenen einer Infektion ausgesetzt, reagieren sie durch reduzierte Aktivität von mTOR und/oder MAP2-Kinasen mit einer geringeren Induktion von Apoptose und sezernieren Zytokine in einem Verhältnis, das die Umgebung in einen pro-inflammatorischen Zustand versetzt.

Methoden: FACS gestützte Charakterisierung von Oberfächen-Rezeptoren auf Makrophagen und Apoptose-Messung. ELISA zur Detektion von sezerniertem IL-10 und TNF-alpha. Infektion mit E. coli. Inhibition der MAP2-Kinasen und mTOR durch die Substanzen PD098059 und Rapamycin. Intrazelluläre Messung von STAT3 Phosphorylierung (FACS).

Ergebnisse: Die Phagozytose von E. coli durch M2c-Makrophagen war unter dem Einfluss von Inhibitoren unverändert mit gleichen Indices von Neugeborenen und Erwachsenen. Der STAT3 Polarisationstransmitter wurde durch Phosphorylierung nach E.coli Infektion bei M2c Makrophagen von Neugeborenen und Erwachsenen auf gleichem Niveau aktiviert. Die IL-10 Sekretion nach Infektion war bei M2c-Makrophagen Erwachsener gegenüber Neugeborenen signifikant erhöht. Die Blockierung von MAP2-Kinasen und mTOR führte zur deutlichen Reduktion der IL-10 Sekretion. Bei M2c-Makrophagen Neugeborener erniedrigte nur die Blockierung der MAP2-Kinasen die IL-10 Sekretion. Die TNF-alpha Konzentration war nach Infektion bei M2c-Makrophagen von Erwachsenen ebenfalls erhöht. Bei beiden Gruppen konnte nur der Einsatz von MAP2Kinase Inhibitoren die TNF-alpha Sekretion erniedrigen. Nach Infektion war, wie dies auch bei Blutmonozyten gezeigt wurde, die Apoptose bei M2c-Makrophagen Erwachsener gegenüber Neugeborener signifikant erhöht. Die Blockierung von MAP2-Kinasen und mTOR führte zur deutlichen Verminderung beim Erwachsenen, nicht jedoch beim Neugeborenen.

Schlussfolgerung: Die in ihrer Funktion als anti-inflammatorisch beschriebenen M2c-Makrophagen weisen nach Infektion bei Neugeborenen und Erwachsenen zwar identische Phagozytosequalitäten auf, jedoch wird beim Erwachsenen wesentlich mehr IL-10 sezerniert und beim Neugeborenen hinsichtlich der TNF-alpha/IL-10 Sekretion ein pro-inflammatorisches Zytokin-Milieu geschaffen, das, ebenfalls im Gegensatz zum Erwachsenen durch Inhibition von MAP2-Kinasen und des mTOR Komplexes nicht verändert werden kann.

\section{DGPI-V04}

Ureaplasmen steigern bei Co-Infektion mit Escherichia coli die Produktion reaktiver Sauerstoffradikale neonataler Monozyten

H. Rippel-Rex', S. Bapistella', B. Spring ${ }^{1,2}$, C. Poets', C. Gille'

'Universitätsklinikum Tübingen, Neonatologie, Tübingen, Deutschland, 2Universitätsklinikum, Kinderkardiologie, Tübingen, Deutschland 
Hintergrund: Die Bronchopulmonale Dysplasie (BPD) ist eine der Hauptkomplikationen kleiner Frühgeborener und bestimmt maßgeblich deren Langzeit-Prognose. Die BPD ist durch einen inflammatorisch bedingten Differenzierungsarrest der Lunge gekennzeichnet, der durch Granulozyten und Monozyten vermittelt wird. Eine Infektion mit Ureaplasmen wird als Risikofaktor für die Entwicklung einer BPD beschrieben, vor allem, wenn diese als Co-Infektion mit weiteren Erregern gemeinsam auftreten. Wie Ureaplasmen zum Entzündungsgeschehen beitragen ist bis heute allerdings wenig verstanden.

Fragestellung: Welchen Einfluss haben Ureaplasmen auf die Produktion reaktiver Sauerstoffradikale (ROS) von Monozyten?

Materialien und Methoden Mononukleäre Zellen aus Nabelschnurblut (cord blood mononuclear cells, CBMC) wurden isoliert. und anschlieBend mit hitzeinaktivierten Ureaplasma parvum (U. parvum, Verhältnis Bakterien zu Zellen $250 \mathrm{zu}$ 1) alleine oder mit Escherichia coli (E. coli, Verhältnis Bakterien zu Zellen 50: 1) infiziert. Nach 25 Minuten wurde die ROS-Produktion mittels Nachweis der Oxidation von Dihydrorhodamin (DHR) im Durchflusszytometer bestimmt.

Ergebnisse: Nach Infektion mit U. parvum stieg der Anteil ROS-produzierender Monozyten im Vergleich zu nicht infizierten Monozyten von $86,8 \pm 7,4 \%$ auf $94,97 \pm 3,2 \%$ an $(n=16, p<0,05)$, während die Menge an ROS pro Zelle ausgedrückt als mittlere DHR-Fluoreszenzaktivität (MFI) nicht anstieg (41,5 $\pm 9,6 \mathrm{MFI}$ vs. $43,91 \pm 8,7 \mathrm{MFI}, n=16)$. Durch Co-Infektion von $E$. coli-infizierten Monozyten mit $U$. parvum stieg der Prozentsatz ROS-produzierender Zellen im Vergleich zu Infektion mit $E$. coli alleine nicht an $(94,1 \pm 3,3 \%$ vs. $95 \pm 3,1 \%, n=16)$. Die Menge an ROS pro Zelle ausgedrückt als mittlere DHR-Fluoreszenzaktivität (MFI) stieg jedoch um $22 \%$ an, von $31,8 \pm 7,2$ MFI auf $38,6 \pm 7,1$ MFI $(n=16, p=0,0004)$.

Diskussion: Im gewählten in-vitro Modell steigerte U. parvum alleine die Anzahl an ROS-produzierenden neonataler Monozyten. Im Co-Infektionsmodell mit E. coli wurde jedoch die ROS-Produktion pro Zelle erheblich gesteigert. Die Daten weisen darauf hin, dass Ureaplasmen als pro-inflammatorischer Reiz bei bestehenden Infektionen wirken können.

\section{DGPI-V05}

\section{Der Einsatz von SeptiFast ${ }^{\oplus}$ erhöht die Häufigkeit eines Keimnachweises aus bronchoalveolärer Lavage bei Kindern mit schwerer Pneumonie}

\section{E. Tschiedel, A. Goralski, F. Stehling}

Universität Duisburg-Essen, Uniklinik Essen, Klinik für Kinderheilkunde 1, Essen, Deutschland

Hintergrund: Schwere bakterielle Infektionen müssen schnell antibiotisch behandelt werden, um die Mortalität zu senken [1]. Die initial verabreichten Antibiotika müssen empirisch ausgewählt werden. Bei Pneumonien ist Material für einen Erregernachweis nicht unmittelbar verfügbar. Bei schweren Verläufen muss eine bronchoalveoläre Lavage (BAL) mit allen damit verbundenen Risiken durchgeführt werden. Auch aus der BAL gelingt ein Keimnachweis oft nicht, insbesondere bei antibiotischer Vorbehandlung [2, 3]. Für den Erregernachweis bei Blutstrominfektionen steht zusätzlich zur Kultur ein molekulargenetisches Nachweisverfahren auf dem Boden einer Multiplex PCR (SeptiFast $\left.{ }^{\oplus}=S F\right)$ zur Verfügung. Es ermöglicht den Nachweis von DNA aus 20 verschiedenen Bakterien und Pilzen, auch wenn diese durch Antibiotikabehandlung bereits avital sind Es konnte bereits gezeigt werden, dass durch zusätzlichen Einsatz von SF in der Sepsisdiagnostik die Häufigkeit eines Keimnachweises signifikant gesteigert werden kann, dieser in kürzerer Zeit möglich ist und therapeutische Relevanz hat $[4,5,6,7]$.

Fragestellung: Ziel unserer Studie war zu untersuchen, ob der zusätzliche Einsatz von SF aus BAL auch in diesem Material einen häufigeren und therapierelevanten Keimnachweis ermöglicht.

Patienten und Methoden: Die Ergebnisse zeitgleich entnommener BALProben für Kultur und SF bei pädiatrischen Patienten mit schwerer Pneumonie wurden retrospektiv ausgewertet. 55\% der Patienten waren antibiotisch vorbehandelt.
Ergebnisse: Durch die Kombination beider Untersuchungsmethoden konnte die Häufigkeit des Keimnachweises von 16/49 (33\%) auf 37/49 $(76 \%)$ gesteigert werden $(p=0,037)$. Eine Therapieveränderung erfolgte allein aufgrund des kulturellen Ergebnisses bei 5/49 (10\%), aufgrund des molekulargenetischen Keimnachweises bei 21/49 (43\%) Patienten.

Schlussfolgerung: Durch den zusätzlichen Einsatz von SF zur mikrobiologischen Untersuchung von BAL pädiatrischer Patienten mit schwerer Pneumonie kann die Häufigkeit eines Keimnachweises erhöht werden und zieht therapeutische Konsequenzen nach sich.

\section{Literatur}

1. Dupont $\mathrm{H}$, Mentec $\mathrm{H}$, Sollet JP, Bleichner $\mathrm{G}$ (2001) Impact of appropriateness of initial antibiotic therapy on the outcome of ventilator-associated pneumonia. Intensive Care Med 27:355-362

2. Chastre J, Trouillet JL, Combes A, Luyt CE (2010) Diagnostic techniques and procedures for establishing the microbial etiology of ventilator-associated pneumonia for clinical trials: the pros for quantitative cultures. Clin Infect Dis 51(Suppl 1):88-92

3. Mandell LA, Wunderink RG, Anzueto A et al (2007) Infectious Diseases Society of America/American Thoracic Society Consensus Guidelines on the management of community-acquired pneumonia in adults. Clin Infect Dis 44(Suppl 2):27-72

4. Vince A, Lepej SZ, Barsić B et al (2008) LightCycler SF assay as a tool for the rapid diagnosis of sepsis in patients during antimicrobial therapy. J Med Microbiol 57:1306-1307

5. Tschiedel E, Steinmann J, Buer J et al (2012) Results and relevance of molecular detection of pathogens by SF - a retrospective analysis in 75 critically ill children. Klin Padiatr 224:12-16

6. von Lilienfeld-Toal M, Lehmann LE, Raadts AD et al (2009) Utility of a commercially available multiplex real-time PCR assay to detect bacterial and fungal pathogens in febrile neutropenia. J Clin Microbiol 47:2405-2410

7. Gies F, Tschiedel E, Felderhoff-Müser U et al (2016) Prospective evaluation of SF Multiplex PCR in children with systemic inflammatory response syndrome under antibiotic treatment. BMC Infect Dis 16:378

\section{DGPI-V06}

Kann Procalcitonin zwischen respiratorischer Adenovirusinfektion mit hohem CRP von bakterieller Superinfektion unterscheiden?

J.P. Streidl', W. Kunze', T. Klemm²

'Muldentalkliniken gGmbH, Kinder- und Jugendmedizin, Wurzen, Deutschland, ${ }^{2} \mathrm{MVZ}$ Labor Dr. Reising-Ackermann und Kollegen, Leipzig, Deutschland

Hintergrund: Adenoviren (ADV) stellen einen hohen Anteil an Infektionen des Respirationstraktes. Dabei sind Akute-Phase-Parameter (C-reactives Protein [CRP], Leukozyten, Interleukin-6 [IL-6]) in der Mehrzahl der Fälle erhöht. Folge davon ist eine (Fehl)Bewertung als bakterielle Infektion mit Antibiotikaverordnung.

Fragestellung: Ziel der Studie ist mittels Procalcitonin (PCT) zwischen diesen beiden Verläufen zu unterscheiden.

Patienten und Methoden: Klinische Daten und Laborbefunde wurden von 54 Patienten mittels Polymerasekettenreaktion (PCR) gesicherter ADVInfektion auf der Basis von PCT 0,5 $\mu \mathrm{g} / \mathrm{l}$ retrospektiv ausgewertet. An Daten wurden erhoben: Alter, Fieberhöhe, Fieber-, Verweildauer, Antibiotikatherapie. Laborwerte: PCT, CRP, Leukozyten mit Neutrophilen, IL-6, StrepA-Test, Blutkulturen.

Ergebnisse: Das Alter betrug (Median) 17,5 Monate, Verweildauer 4, Fieberdauer 5 Tage, -höhe $40,0^{\circ} \mathrm{C}$. Folgende Labordaten wurden erhoben (MW \pm SD, median) CRP $61,3 \pm 60,3,44,2 \mathrm{mg} / \mathrm{l}$, Leukozyten 18,2 $\pm 6,6,16,6$ Gpt/l, abs.neutrophile Leukozyten 10,6 $\pm 4,8,10,1 \mathrm{Gpt} / \mathrm{l}$, IL-6 59,2 $\pm 55,5$, $45,6 \mathrm{ng} / \mathrm{l}$. PCT wurde mit $0,75 \pm 0,9,0,35$, bestimmt. Bei PCT wurde $31 \mathrm{mal}$ $(57,4 \%)$ ein Ergebnis von $<0,5 \mu \mathrm{g} / \mathrm{l}(0,18 \pm 0,1$, median 0,17$)$ und $23 \mathrm{mal}$ $(42,6 \%)$ von $\geq 0,5 \mu \mathrm{g} / \mathrm{l}(1,49 \pm 1,0$, median 0,12$)$ ermittelt. Bezogen auf den PCT-Wert von $0,5 \mu \mathrm{g} / \mathrm{l}$ zeigt sich, dass weder bei Alter, Verweil-dauer, Fieberhöhe sowie -dauer noch bei CRP, Leukozyten und IL-6 signifikante Unterschiede bestehen. Jeweils 17 (31,8\%) Blutkulturen bzw. StrepATests waren negativ. Sieben von 8 Röntgen-Thorax-Befunden bestätigten die Diagnose Pneumonie. Untersuchungen auf Influenza- erfolgten $44 \mathrm{mal}(81,5 \%)$, auf RS-Virus $13 \mathrm{mal}(24,1 \%)$ mit jeweils negativem Ergebnis. Klinische Hinweise auf „mixed infections“ ergaben sich nicht. Bei 
einem cut-off-Wert von $0,5 \mu \mathrm{g} / \mathrm{l}$ ergab sich bzgl. einer Antibiotika-Therapie folgendes Ergebnis: PCT $\geq 0,5$ : Therapie $12 \mathrm{mal}(22,2 \%)$, keine Therapie $11 \mathrm{mal}(20,4 \%)$. PCT $<0,5 \mu \mathrm{g} / \mathrm{l}$ : Therapie $15 \mathrm{mal}(27,8 \%)$, keine Therapie $16 \mathrm{mal}(29,6 \%)$; Therapie und Nichttherapie wurden jeweils $27 \mathrm{mal}$ registriert. Bei 12 von 27 Therapien wurde diese vorzeitig $(<5$ Tagen) beendet. Somit war 39 Patienten (72,2\%) kein Antibiotikum verordnet bzw. nach Vorliegen des positiven ADV-Befundes abgesetzt worden. Von 10 Patienten mit einem PCT $\geq 100 \mu \mathrm{g} / \mathrm{l}$ blieben 4 ohne Antibiotikaverordnung ohne nachteilige Folgen.

Diskussion: PCT kann bei einem Wert von $0,5 \mu \mathrm{g} / \mathrm{l}$ abweichend von den Empfehlungen zur Antibiotikatherapie bei Infekten der Atemwege zwischen ADV- und bakteriellen (Co)-Infektionen auch unter dem Kriterium Antibiotikatherapie unterscheiden.

Schlussfolgerungen: ADV-Infektionen nehmen eine Sonderstellung bezüglich ihres Verhaltens von Akute-Phase-Parametern ein. PCT kann bei einem Wert von $<0,5 \mu \mathrm{g} / \mathrm{l}$ auch bei hohen CRP-Werten eine bakterielle Ursache ausschließen und so eine nichtindizierte Antibiotikatherapie vermeiden.

\section{DGPI-V07}

\section{Assessment of the multiplex PCR based assay Unyvero ${ }^{\mathrm{Tm}}$ Pneumonia application for detection of bacterial pathogens and antibiotic resistance genes in children and neonates}

C. Papan ${ }^{1,2}$, M. Meyer-Buehn', G. Laniado', T. Nicolai', M. Griese', J. Huebner 'Dr. von Haunersches Kinderspital, Klinikum der Universität München, München, Deutschland, ${ }^{2}$ Universität Heidelberg, Universitätsklinikum Mannheim, Pädiatrische Infektiologie, Mannheim, Deutschland

Background: Pneumonia is a major healthcare issue, especially in children with chronic diseases. Rapid diagnosis and appropriate therapy are urgently indicated, especially in hospital-acquired pneumonia. Diagnosis can be delayed due to the duration of conventional culturing, while extensive preemptive antibacterial therapy might lead to false negative culture findings and antibiotic overuse resulting in the development of antimicrobial resistance. We aim to assess the diagnostic validity of the new application Unyvero $^{\text {th }}$ based on multiplex polymerase chain reaction to detect bacterial pathogens in children and neonates.

Methods: Bronchoalveolar lavage fluid, tracheal aspirates, or pleural fluids from neonates and children were analyzed simultaneously by culture and Unyvero ${ }^{\mathrm{Tx}}$. Results were compared and performances were assessed by calculating sensitivity, specificity, positive predictive value and negative predictive value for each detected pathogen.

Results: We analyzed specimens from 79 patients with a median age of 1.8 (range .02-20.1). Of these, 43 were bronchoalveolar lavage fluids, 30 were tracheal aspirates, and six were pleural fluids. A total of 19 specimens were obtained from neonates. Overall, Unyvero ${ }^{\text {nat }}$ yielded a sensitivity of $71.4 \%$ and a specificity of $97.1 \%$. Best results were observed for non-fermenting bacteria, for which sensitivity of Unyvero ${ }^{\text {tut }}$ was $90 \%$ and specificity $97.3 \%$, while rates were substantially lower for Gram-positive bacteria $(47.1 \%$ and $91.5 \%$, respectively). Four important multi-drug resistances were not detected by Unyvero ${ }^{\mathrm{m}}$.

Conclusions: Unyvero ${ }^{\mathrm{ma}}$ Pneumonia application is a fast and feasible tool that might provide additional information relevant for clinical decision-makers. However, sensitivity of the PCR for Gram-positive bacteria and important resistance genes must be improved before this application can be widely recommended.

\section{DGPI-V08 \\ Point of Care Multiplex-PCR Diagnostik auf einer Pädiatrischen Intensivstation ermöglicht die frühzeitige Differenzierung zwischen einer neonatalen Sepsis und einer humanen Parechovirusinfektion}

L. H. Llano López, A. T. Reischl, B. Gröndahl, A. Kidszun, F. Kowalzik, C. Oetzmann von Sochaczewski, S. Gehring

Universitätsklinikum Mainz, Mainz, Deutschland
Hintergrund: Infektionen mit humanen Paraechoviren sind in den letzten Jahren auf dem Vormarsch, insbesondere Meningitiden und sepsisartige Infektionen durch den Typ 3 (Tang et al., Euro Surveill. 2016;25:31; Fischer et al., Emerg Infect Dis J. 2014;20:83). Das BioFire FilmArray ${ }^{\infty}$ Meningitis/ Encephalitis-Panels (BioFire) wurde sowohl in der Europäischen Union als auch in den Vereinigten Staaten für diagnostische Zwecke zugelassen und ermöglicht die simultane Detektion von 14 häufigen bakteriellen und viralen Erregern von Meningitiden und Encephalitiden als auch von Cryptococcus spp. Eine kürzlich veröffentliche Multicenter-Evaluation in den Vereinigten Staaten zeigte hervorragende Ergebnisse hinsichtlich Sensitivität und Spezifität (Leber et al., J Clin Microbiol. 2016;54:2251-2261). Fragestellung: Verändert der diagnostische Einsatz des BioFire als Pointof-Care-Diagnostik (POCT) in der Notaufnahme das Patientenmanagement von Paraechovirusinfektionen?

Material und Methoden: Das BioFire wurde im Juni 2016 als POCT in der Notaufnahme der Universitätskinderklinik Mainz für eine Testphase eingeführt. Eine verpflichtende Einbindung in klinische Behandlungspfade besteht derzeit nicht. Das System benötigt ein Probenvolumen von $200 \mu \mathrm{L}$ Liquor, welcher mit dem Puffervolumen vermengt wird und mit dieser Mischung das geschlossen arbeitende System beschickt wird. Die Ergebnisse stehen binnen einer Stunde zur Verfügung. Retrospektiv ausgewertet wurden 4 Meningitisfälle durch humane Paraechoviren.

Ergebnisse: Bei allen Patienten handelte es sich um reife Neugeborene im Alter zwischen 7 und 22 Tagen, die mit sepsisartigem Krankheitsbild (wenigstens 3 von 4 SIRS-Kriterien) und quantitativer Bewusstseinsstörung vorgestellt wurden. In allen Fällen wurde neben Erstversorgung und hämodynamischer Stabilisierung eine umfangreiche Diagnostik eingeleitet, die bis auf den Paraechovirusnachweis ohne pathologischen Befund blieb. Gemeinsamkeiten bestanden lediglich in einer retrospektiv nach $\mathrm{Pa}$ raechovirusnachweis erfragten viralen Erkrankung von Elternteilen. Bei allen Kindern wurde eine leitliniengerechte, empirische antibiotische Behandlung begonnen, deren Dauer mit zunehmender Familiarisierung mit dem BioFire von 5 Tagen beim ersten auf 3 Tage beim vierten Patienten reduziert wurde.

Schlussfolgerung: Das BioFire hat das Potential als frühzeitige POCT einen Beitrag zum rationalen Einsatz von Antibiotika beizutragen als auch einen Beitrag zur Verhinderung von nosokomialen Infektionen zu leisten, da Maßnahmen des Infektionsschutzes früher und gezielter möglich sind als mit herkömmlicher Diagnostik. Aufgrund der Kosten des Systems ist jedoch eine gezielte Integration in klinische Behandlungspfade notwendig.

\section{Poster GNPI}

\section{Fehlermanagement}

\section{FM-P01}

Infusoabdomen als akutes Abdomen bei Paravasat durch zentralvenöse Katheter bei extrem frühgeborenen Zwillingen zwei Fallberichte

\section{A. J. Michel', J. Brandner', S. Cotofana ${ }^{3}$, M. Ardelean', R. Metzger'}

'Paracelsus Medizinische Privatuniversität, Universitätsklinik für Kinderund Jugendchirurgie, Salzburg, Österreich, ${ }^{2}$ Paracelsus Medizinische Privatuniversität, Universitätsklinik für Kinder- und Jugendmedizin, Division für Neonatologie, Salzburg, Österreich, ${ }^{3}$ Paracelsus Medizinische Privatuniversität, Institut für Anatomie, Salzburg, Österreich

Hintergrund: Zentralvenöse Zugänge als lebenserhaltende Maßnahme sind in der Behandlung extrem Frühgeborener eine Standardprozedur. $\mathrm{Zu}$ den katheterassoziierten Komplikationen zählen Infektion, Thrombose, Blutung und Paravasat.

Patienten und Methoden: Wir präsentieren extrem frühgeborene Zwillinge der 23+5. SSW mit einem akuten Abdomen jeweils als Komplikation durch einen 1 Fr. peripher inserierten zentralvenösen Katheter (PICC). 
Ergebnisse: Zwilling 1 zeigte am 9. Lebenstag ein akutes Abdomen mit erhöhten Infektionsparametern sowie sonografisch nachgewiesener intraabdomineller Flüssigkeit. Bei kardiorespiratorischer Instabilität wurde, ausgehend von einer NEC, eine Laparotomie durchgeführt. Es fanden sich intakte Darmschlingen sowie interintestinal viel chylöses Sekret. Ein doppelläufiges Ileostoma sowie eine extraperitoneal ausgeleitete Drainage wurden angelegt. Bei rascher Stabilisierung und rückläufigem Abdomenumfang förderte die Drainage weiterhin chylöse Flüssigkeit. Die Kontrastmitteldarstellung über den PICC zeigte ein Paravasat das sich von retroperitoneal nach intraabdominal ausbreitete, retrospektiv als Ursache für eine iatrogene Komplikation.

Zwilling 2 zeigte am 26. Lebenstag ähnliche Symptome: ausgeprägte abdominelle Distension, erhöhte Entzündungsparameter und respiratorische Beeinträchtigung. Die frühzeitig angefertigte KM-Darstellung über den PICC wies ebenfalls ein Paravasat nach, dieses lediglich intraabdominell. Bei kardiorespiratorisch stabilen Verhältnissen wurde keine Laparotomie durchgeführt. Der Wechsel des PICC und die Gabe von Vancomycin und Metronidazol als therapeutische Maßnahme führten zu rascher Besserung.

Diskussion: Obwohl die Zugangssysteme radiologisch als zentral liegend kontrolliert sowie die maximal zulässige Infusionsgeschwindigkeit von $36 \mathrm{ml} / \mathrm{h}$ weit unterschritten wurden, haben extrem Frühgeborene, aufgrund der Fragilität der Gefäße und der verabreichten, oft hyperosmolaren, Flüssigkeiten, ein erhöhtes Risiko für ein Paravasat. Je nach Lage der Katheterspitze kann sich die Infusionslösung in unterschiedliche anatomische Regionen ausbreiten. Bei dieser Patientengruppe sollte bei klinischen Zeichen eines akuten Abdomens vor der Entscheidung für die chirurgische Intervention die Lage des PICC per Kontrastmittel-Röntgen überprüft werden.

\section{FM-P02 \\ latrogene Perforationen durch Polyurethan-Magensonden bei extremen Frühgeborenen - benötigen Kinder unter 25 Wochen ein eigenes Management?}

\section{Thanhäuser, C. Binder, A. Repa, A. Berger, N. Haiden}

Medizinische Universität Wien, Universitätsklinik für Kinder- und Jugendheilkunde, Abteilung für Neonatologie, pädiatrische Intensivmedizin \& Neuropädiatrie, Wien, Österreich

Hintergrund: Die Inzidenz von iatrogenen Perforationen durch Magensonden (Ösophagus oder Magen) bei Frühgeborenen ist mit 0,5\% niedrig, die Mortalität liegt bei $20-30 \%$, wobei diese meist auf Begleitmorbiditäten aufgrund der Frühgeburtlichkeit zurückzuführen ist. Das Management der Perforation erfolgt entweder operativ oder konservativ, wobei sich in den letzten Jahren ein Trend zur primär konservativen Behandlung vor allem bei Ösophagusperforationen hin abzeichnet, welcher bisher in noch keiner randomisierten Studie untersucht wurde.

Fragestellung: Ziel dieser Studie war es Inzidenz, Management, Begleitmorbidität und Mortalität von iatrogenen Perforationen durch Magensonden bei Frühgeborenen an der Medizinischen Universität Wien seit der Umstellung auf Polyurethan-Sonden im Jahr 2012 zu erheben.

Material und Methoden: Es handelt sich hier um eine retrospektive Analyse bei Frühgeborenen mit einem Geburtsgewicht unter 1000 g, die seit der Umstellung auf Polyurethan-Sonden zwischen 2012 und 2016 eine Perforation durch eine Magensonde erlitten haben. Primär wurden alle Kinder konservativ, d.h. mit parenteraler Ernährung und antibiotischer Therapie behandelt und ein Spontanremission der Perforation angestrebt Ergebnisse: Die Inzidenz an Perforationen lag bei 1,5\% $(n=7 / 471)$, das Geburtsgewicht war $563 \mathrm{~g}$ (=Median, Range: $475-755 \mathrm{~g})$, das Gestationsalter $23+3$ SSW (= Median, Range: $23+0-24+5) .57 \%(n=4 / 7)$ hatten eine Magenperforation und $43 \%(n=3 / 7)$ eine Perforation des Ösophagus. Die Perforation ereignete sich im Schnitt am dritten Lebenstag (Range: 2.-14. Lebenstag). Durchschnittlich wurden die Frühgeborenen sechs Tage (Range: 4-13 Tage) rein parenteral ernährt und erhielten für 16 Tage (Range: 8-22 Tage) eine antibiotische Therapie. Zwei Kinder mit Magenperforation mussten aufgrund konsekutiver Ileumperforation laparoto- miert werden. Die Mortalität lag bei 28,6\% $(n=2 / 7)$, wobei kein Kind aufgrund von Komplikationen durch die Perforation verstarb.

Diskussion und Schlussfolgerung: Primär waren nur die kleinsten Frühgeborenen mit einem Gestationsalter unter 25 SSW von Perforationen durch Polyurethansonden betroffen, weshalb in dieser Patientengruppe eventuell Silikonsonden in den ersten 2-3 Lebenswochen verwendet werden sollten. Das konservative Management von iatrogenen Perforationen durch Magensonden führte zu einem hohen Anteil an Spontanremissionen.

\section{FM-P03}

Frühgeborenes der 32. SSW mit schwerer Pulmonalstenose hätte man etwas anders machen können?

\section{H. Schneider', R. Hentschel', K. Reineker ${ }^{2}$}

'Zentrum für Kinder- und Jugendmedizin Uniklinikum Freiburg, Funktionsbereich Neonatologie und päd. Intensivmedizin, Freiburg, Deutschland, ${ }^{2}$ Universitätsherz-Zentrum Freiburg, Klinik für angeborene Herzfehler/Pädiatrische Kardiologie, Freiburg, Deutschland

Hintergrund: Diese Fallvorstellung soll den Verlauf und die Therapieoptionen bei einem hypotrophen Frühgeborenen mit kritischer Lungenperfusion als Folge einer schweren Pulmonalstenose darstellen.

Fallbericht: Im vorliegenden Fall bestand pränatal sonografisch der V.a. Bestehen einer Fallot-Tetralogie mit Pulmonalstenose. Bei vorzeitigem Blasensprung und pathologischem CTG wurde dann in der 31 + 5/7 SSW die Indikation zu sekundären Sectio gestellt. Im Rahmen der Erstversorgung musste das Kind bei insuffizienter Eigenatmung und anhaltender Oxygenierungsstörung intubiert werden, erhielt Surfactant und es wurde eine Therapie mit Alprostadil gestartet. Unter HFO-Beatmung mit einer $\mathrm{FiO} 2$ von $100 \%$ und einem MAP von $9 \mathrm{cmH} 2 \mathrm{O}$ betrugen die arteriell gemessenen Sättigungen (SaO2) 40-60\%. In der Echokardiografie wurde eine Fallot-Tetralogie mit Ventrikelseptumdefekt, überreitender Aorta und stenotischer Pulmonalklappe bestätigt. Ein Ductus arteriosus war nicht nachweisbar. Es bestanden zudem Hinweise auf eine persistierende pulmonale Hypertonie des Neugeborenen (PPHN). Bei nur leicht erhöhtem Laktat schien die Lungen- und Organperfusion zunächst auszureichen. Durch niedrig dosierte Katecholamintherapie und Volumengabe versuchten wir den Systemwiderstand zu erhöhen und durch inhalatives NO, Normoventilation und Sauerstoff-Zufuhr hofften wir die Lungenperfusion zu verbessern. Leider kam es sekundär, bei anhaltend niedrigen Sauerstoffsättigungswerten $(\mathrm{SaO} 2<40 \%)$, zu einer schweren Laktatazidose mit Multiorganversagen und letztlich Versterben des Kindes am 4. Lebenstag.

Diskussion und Schlussfolgerung: Zusammenfassend war die ungünstige Konstellation von einer schweren Pulmonalstenose mit unzureichender Lungenperfusion bei fehlendem Ductus arteriosus sowie dem Bestehen einer PPHN und zusätzlich Frühgeburtlichkeit mit intrauteriner Wachstumsretardierung therapiebegrenzend.

Der Vortrag soll sich an Kolleginnen und Kollegen auf neonatologischen Intensivstationen richten. Wir möchten zum einen die Therapieoptionen, insbesondere ein interventionelles Stenting des rechtsventrikulären Ausflusstraktes, und außerdem die tolerable kritische Sättigung, in derartigen Fällen diskutieren.

\section{FM-P04}

\section{Fixierungsfehler}

P. Morhart' ${ }^{1}$ N. Gratzki', O. Rompel' ${ }^{2}$, M. Besendörfer ${ }^{3}$, W. Rascher', T. Völkl'

'Universitätskinderklinik, Neonatologie, Erlangen, Deutschland, ${ }^{2}$ Universität, Kinderradiologie, Erlangen, Deutschland, ${ }^{3}$ Universität, Kinderchirurgie, Erlangen, Deutschland, ${ }^{4}$ Universität, Erlangen, Deutschland

Hintergrund: Fixierungsfehler ergeben sich aus zunächst konsistenten, aber dennoch falschen mentalen Modellen von Situationen, die im Verlauf trotz widersprechender Fakten beibehalten werden. Gerade in der Medizin führt dies zu Fehldiagnosen und falschen Therapien.

Fallbericht: Wir berichten über ein Frühgeborenes der $35+5$ SSW, Geburtsgewicht $2050 \mathrm{~g}$ mit bereits pränatal diagnostiziertem VSD und Bal- 
kenagenesie. Postnatal wurde zusätzlich eine Ösophagusatresie festgestellt. Am 1. Lebenstag erfolgten die Primäranastomose der Ösophagusatresie sowie die Resektion der ösophagotrachealen Fistel; eine Woche später Beginn der enteralen Ernährung. Zwei Wochen darauf kam es bei bereits seit mehreren Tagen bestehender CrP-Erhöhung zu blutigem Stuhlgang. Das Abdomen war gebläht und schmerzempfindlich. Radiologisch konnte eine Perforation ausgeschlossen werden, es wurde aber der V.a. einer Pneumatosis hepatis et portae dokumentiert. Sonografisch wurden Gasbläschen in der Pfortader festgestellt. Die antibakterielle Therapie wurde auf Meropenem und Vancomycin umgesetzt, die Patientin intubiert, beatmet und nüchtern belassen. Die Entzündungswerte verdoppelten sich rasch, Thrombozyten waren stabil, es kam weder zu einer met. Azidose noch zu einem relevanten Laktatanstieg, so dass primär eine konservative Therapie erfolgte. Am nächsten Tag zeigte sich sonografisch neben weiterhin bestehenden portalvenösen Gasbläschen der V.a. einer Perforation, weswegen eine operative Exploration erfolgte. Hier präsentierte sich ein Volvulus des gesamten Dünndarms mit langstreckigen Dünndarmnekrosen, so dass eine Derotation, Ileumteilresektion, Anlage zweier endständiger Ileostomata und ein temporärer Bauchdeckenverschluss mittels Tutopatch erfolgte. Es gelang, einen großen Teil des Dünndarmes zu erhalten und in einem langwierigen Verlauf die Patientin letztendlich enteral zu ernähren. Diskussion: Aufgrund mehrerer typischer Symptome einer nekrotisierende Enterokolitis wurde der eigentlich bestehende, allerdings etwas atypisch verlaufende Volvolus verspätet erkannt. Gegen eine NEC sprechen retrospektiv stabile Thrombozytenwerte, Fehlen einer met. Azidose, nicht bestehender Aszites und ein eher unspezifisches akutes Abdomen ohne Flankenrötung oder Resistenzen im rechten Unterbauch. Bis zum Absetzen des blutigen Stuhles wurde die Nahrung gut vertragen und keine Magenreste aufgebaut. Umgekehrt zeigte sich keine relevante Laktaterhöhung, was die Diagnose eines Volvulus zusätzlich erschwerte.

Schlussfolgerung: Bei abweichender Klinik sollte die Verdachtsdiagnose wiederholt hinterfragt werden und gerade ein Volvulus bei akutem Abdomen in der Neonatologie immer differentialdiagnostisch mitberücksichtigt werden.

\section{FM-P05 \\ Todesursachen auf der Neonatologie eines Schweizer Perinatalzentrums}

R. Wettstein, R. Arlettaz Mieth

Universitätsspital Zürich, Klinik für Neonatologie, Zürich, Schweiz

Hintergrund: Die Kenntnis über die aktuellen Todesursachen auf der Neonatologie ist ein wichtiger Schritt um die medizinische Betreuung der Neugeborenen zu verbessern und um einen Schwerpunkt in der Prävention festzulegen.

Fragestellung: Woran verstarben die Neugeborenen im Universitätsspital Zürich im Zeitraum zwischen 2009 und 2014?

Material und Methoden: Die Krankengeschichten aller im Zeitraum von Juli 2009 bis Juni 2014 verstorbenen Patienten wurden retrospektiv analysiert. Dabei wurden alle lebendgeborenen Neugeborenen ab einem Gestationsalter von 24 0/7 Schwangerschaftswochen, welche innert drei Monaten nach Geburt verstarben, in die Studie eingeschlossen. Wir haben die Todesursachen nach Häufigkeiten, sowie in Abhängigkeit des Todeszeitpunktes und des Gestationsalters ausgewertet. Alle Daten wurden in anonymer Form verwendet.

Ergebnisse: In den untersuchten fünf Jahren sind 179 Neugeborene lebend geboren und innert 3 Lebensmonaten verstorben. Davon waren $92(51,4 \%)$ Neugeborene extrem frühgeboren mit einem Gestationsalter zwischen 24 0/7 und 27 6/7 Schwangerschaftswochen. Insgesamt bildeten kongenitale Fehlbildungen (52; 29,1\%) die häufigste Todesursache. Ebenfalls häufige Todesursachen waren in absteigender Häufigkeit: Atemwegspathologien $(34 ; 19,0 \%)$, neurologische Pathologien $(29 ; 16,2 \%)$, Unreife (28; $15,6 \%)$ und Infektionen (21; 11,7\%). Insgesamt $52(29,1 \%)$ verstarben innert 2 Stunden nach der Geburt. Bei 43 (24,0\%) Neugeborenen wurde pränatal gemeinsam mit den Eltern der Entscheid getroffen, aufgrund von extremer Unreife oder schweren kongenitalen Fehlbildungen, das Neugeborene primär palliativ zu betreuen.

Diskussion und Schlussfolgerung: Die häufigste Todesursache war die kongenitale Fehlbildung, welche sehr beschränkt beeinflussbar ist. Schwerpunkte sollten in der Therapie von Atemwegspathologien und Infektionen, sowie in der Prävention von extremer Frühgeburtlichkeit liegen.

\section{FM-P06 \\ Vena cava Thrombosen bei Frühgeborenen mit Einschwemmkatheter (PICC) - nur Einzelfälle?}

\section{K. Schmitz, S. Tippmann, C. Whybra-Trümpler, E. Mildenberger} Universitätsmedizin Mainz, Neonatologie, Mainz, Deutschland

Hintergrund: In der Neonatologie sind peripher gelegte zentrale Einschwemmkatheter (PICC) ein häufiger Zugangsweg. Vorteile gegenüber peripheren Venenkathetern sind die reduzierte Anzahl venöser Punktionen, Möglichkeit der Verabreichung hochkonzentrierter Lösungen und die Sicherheit eines venösen Zugangswegs. Demgegenüber stehen Risiken wie Infektion, Thrombose und Fehllage. Die Inzidenz von PICC-assoziierten Thrombosen bei Frühgeborenen ist nicht bekannt. Ebenso ist unklar, welcher Zugangsweg ein geringeres Risiko einer PICC-assoziierten Thrombose birgt.

Fragestellung: Können Risikofaktoren und klinische Symptome für das Auftreten von PICC-assoziierten Thrombose identifiziert werden? Material und Methoden: In die retrospektive Analyse wurden 8 Frühgeborene eingeschlossen, bei denen zwischen 2010 und 2016 eine PICC-assoziierte Thrombose festgestellt worden war. Alle Patienten waren extrem unreif: Gestationsalter zwischen $23+4$ und $26+4$ SSW, Geburtsgewicht $330 \mathrm{~g}$ bis $1040 \mathrm{~g}$. Analysiert wurden Indikation zur PICC-Anlage, Zugangsweg obere oder untere Extremität, Lage des Katheters, Liegedauer, Osmolarität der Lösung, klinische Auffälligkeiten und Inzidenz von chirurgischen Interventionen und Infektionen während der Liegezeit des Katheters. Die Familienanamnese hinsichtlich Thromboseneigung und die jeweilige Therapie wurden erfasst.

Ergebnisse: Bei allen 8 Patienten war eine Thrombose in der V. cava inferior festgestellt worden. Bei 6/8 Patienten war die Indikation zur Anlage des PICC eine parenterale Ernährung. Bei 2/8 Patienten wurde der Katheter perioperativ etabliert. Alle 8 Patienten hatten einen PICC im Bereich der unteren Extremität erhalten. Bei allen Patienten lag die Katheterspitze zentral. Die Osmolarität der Infusion betrug bei 3/7 Fällen >1000 mosmol/l. Das Auftreten der Thrombose wurde 3 bis 28 Tagen nach Einbringen des PICC sonografisch dokumentiert. In 6 Fällen war eine persistierende Thrombozytopenie und in 2 Fällen eine Beinschwellung auffällig. Bei 7/8 Patienten waren perinatale Komplikationen aufgetreten. 2 Patienten waren innerhalb der ersten Lebenstage kardiopulmonal reanimiert worden. Chirurgische Interventionen waren bei 6 Patienten notwendig. Bei 6/8 Patienten war es während der Liegedauer des PICC zu Infektionen gekommen. Bei 3/8 Patienten könnte eine genetische Prädisposition bezüglich Thromboseneigung eine Rolle gespielt haben. 4/8 Patienten erhielten eine Antikoagulation.

Diskussion: Auffällig ist, dass bei allen Patienten eine Thrombose im Stromgebiet der V. cava inferior auftrat. Klinische Symptome gaben Anlass zur sonografischen Darstellung des einliegenden PICC. Wie viele PICCassoziierte Thrombosen subklinisch verlaufen, ist unbekannt. Anhand unserer Patienten zeigt sich, dass mehrere Risikofaktoren eine Thromboseentstehung begünstigen könnten. Ein vermehrtes Auftreten von katheterassoziierten Thrombosen bei extrem kleinen Frühgeborenen mit kompliziertem postnatalen Verlauf und operativen Eingriffen finden sich auch in der Literatur. Anhand unserer Fallbeispiele lassen sich keine Rückschlüsse auf den komplikationsloseren Zugangsweg eines PICC ziehen. Zur Beantwortung der Frage nach Inzidenz, Risikofaktoren für PICC-assoziierte Thrombosen und zu präferierendem Zugangsweg wäre eine prospektive Studie erstrebenswert. 


\section{FM-P07 \\ Letaler VACTERL-Fehlbildungskomplex mit Larynx-/ Trachealatresie und ösophagotrachealer Fistel}

\author{
D. Stavropoulou', L. Farnung' ', P. Franck', K. Werner'², S. Huber-Schumacher', \\ R. Hentschel ${ }^{1}$ \\ 'Universitätsklinikum Freiburg, Neonatologie und pädiatrische \\ Intensivmedizin, Freiburg, Deutschland, 2Universitätsklinikum Freiburg, \\ Institut für Klinische Pathologie, Freiburg, Deutschland
}

Hintergrund: Die Prävalenz der VACTERL Assoziation wird mit 1:10.0001:40.000 angegeben. Führende Fehlbildungen betreffen Herzfehler, Wirbel- und Gliedmassedefekte, ösophagotracheale Anomalien, Analatresien und Nierenfehlbildungen. Die Prognose für ein Überleben sind in der Regel sehr gut. Larynxagenesie und Trachealatresien sind keine typischen Anomalien des VACTERL-Komplexes, und auch isoliert sind diese Agenesien extrem selten und fast immer letal.

Fallbericht: Wir berichten über ein eutrophes FG der $31+6 / 7$ SSW mit einem GG von $1795 \mathrm{~g}$ und pränatalem Verdacht auf Ösophagusatresie (Polyhydramnion) und Fallot'sche Tetralogie. Geburt per eilige Sectio bei vorzeitgem Blasensprung und unaufhaltsamer Wehentätigkeit. Mittels Amniozentese waren die Trisomien 13/18/21 sowie ein Di GeorgeSyndrom ausgeschlossen worden. Es bestand ein Polyhydramnion und ein wenig gefüllter Magen. Bei der Primärversorgung schlappes, zyanotisches FG mit fehlendem Schrei und wenig Atemanstrengungen, initiale HF $>100 / \mathrm{min}$. Ab der 2. LM Abfall der HF (60/min) und schlechter werdende Perfusion und Oxygenierung trotz Maskenbatmung. Entscheidung zur Intubation im LM 3. Wiederholte Intubationsversuche blieben frustan: Arylknorpel und Epiglottis waren einsehbar, etwa $5 \mathrm{~mm}$ unterhalb der Arylknorpel bestand jedoch ein nicht zu überwindender Widerstand. Daraufhin wurde die Entscheidung zur Notconiotomie unter Hinzuziehen des Anästhesisten getroffen. Eine korrekte Platzierung einer Kanüle war jedoch nicht möglich. Deshalb wurde die Reanimation schließlich in LM 24 beendet. Die Obduktion erbrachte eine komplexe Fehlbildung aus dem VACTERL-Komplex mit kompletter Larynx- und partieller Trachealagenesie, einer tracheoösophagealen Fistel und segmentaler Ösophagusatresie, Lungenhypoplasie, Fallot'sche Pentalogie und Analatresie.

Diskussion und Schlussfolgerung: Ein „Congental high airway obstruktion"-Syndrom (CHAOS) dieser Art ist pränatal mittels Ultraschall prinzipiell diagnostizierbar. Die Mortalität der Trachealagenesie beträgt $80-100 \%$. Bei Verdacht auf diese Diagnose ist die pränatale MRT-Untersuchung sinnvoll und ermöglicht die Lokalisation der Obstruktion und die Abschätzung der Ausdehnung sowie die Planung eines möglichen EXITVerfahrens bei der Erstversorgung. Fallbeschreibungen berichten über ein erfolgreich durchgeführtes EXIT, jedoch auch mit letalem Outcome. Die typischen Symptome des CHAOS (vergrößerte, hyperechogene Lungen, flüssigkeitsgefüllte, dilatierte Trachea ohne Fluss, Herzkompression, abgeflachtes Zwerchfell) waren in unserem Fall wegen des Abflusses über die tracheao-ösophageale Fistel nicht nachweisbar, es lagen nur indirekte Hinweise, wie das Polyhydramnion vor. In Unkenntnis der Diagnose konnte in unserem Fall ein EXIT-Verfahren nicht geplant werden.

\section{FM-P08}

Neonatales Nierenversagen nach Therapie mit Angiotensin IIRezeptor-Blockern (Sartanen) während der Schwangerschaft

S. Hollenbach ${ }^{1,2}$, M. Henn ${ }^{1,2}$, U. Fleischer ${ }^{3}$, M. Rose ${ }^{3}$, G. Müller', S. Wygoda', M. Borte

${ }^{1} \mathrm{KfH}$ Nierenzentrum für Kinder-und Jugendliche am Klinikum St. Georg Leipzig, Kinderdialyse, Leipzig, Deutschland, ${ }^{2}$ Klinikum St. Georg, Kinderdialyse, Leipzig, Deutschland, ${ }^{3}$ Klinikum St. Georg, Klinik für Kinderund Jugendliche, Leipzig, Deutschland, ${ }^{4}$ Städtisches Krankenhaus DresdenNeustadt, Klinik für Kinder-und Jugendmedizin, Dresden, Deutschland

Hintergrund: Die Prävalenz der arteriellen Hypertonie ist mit 30-45\% sehr hoch. Sartane und ACE-Hemmer gehören aufgrund ihrer allgemein guten Verträglichkeit zur Standardtherapie. Für beide Substanzgruppen besteht jedoch eine relative Kontraindikation für Frauen im gebärfähigen Alter.
Sie sind ab zweitem Schwangerschaftstrimenon streng kontraindiziert, da ein hohes Risiko für die Entwicklung einer neonatalen Niereninsuffizienz wie auch extrarenaler, teils durch das Oligohydramnion bedingte, Komplikationen besteht. Auch nach Erholung der Nierenfunktion kann es zu einer sekundären Manifestation einer chronischen Niereninsuffizienz und eines renalen Hypertonus kommen.

Kasuistik: Wir berichten über zwei Neugeborene, deren Mütter mit Sartanen behandelt wurden. In beiden Fällen war die Schwangerschaft unbekannt. Postnatal entwickelten beide Neugeborenen eine dialysepflichtige Niereninsuffizienz. Bei einem Kind kam es nach zwischenzeitlicher Erholung der Nierenfunktion zu erneuter Dialysepflichtigkeit.

Schlussfolgerung: Eine Therapie mit ACE-Hemmern oder Sartanen sollte nur unter strenger Nutzen-Risiko-Abwägung erfolgen und bei Frauen im gebärfähigen Alter nur unter konsequenter Kontrazeption. Insbesondere bei älteren Frauen besteht bei vermuteter Menopause ein hohes Risiko für Schädigung des Feten bei unbekannter Schwangerschaft. Auch nach Erholung einer initial eingeschränkten Nierenfunktion ist eine langfristige kindernephrologische Betreuung notwendig.

\section{FM-P09}

24 Schwangerschaftswochen und beidseitige Lippen-KieferGaumenspalte - eine interdisziplinäre Herausforderung!

S. Pogodda' , F. Würfel', W. Beyer ${ }^{3}$, S. Armbrust ${ }^{1}$

'Dietrich-Bonhoeffer-Klinikum, Klinik für Kinder- und Jugendmedizin, Neubrandenburg, Deutschland, ${ }^{2}$ Dietrich-Bonhoeffer-Klinikum, Klinik für Mund-Kiefer-Gesichtschirurgie und Plastische Operationen, Neubrandenburg, Deutschland, ${ }^{3}$ Dietrich-Bonhoeffer-Klinikum, Klinik für Kinderchirurgie und -urologie, Neubrandenburg, Deutschland

Hintergrund: Die Inzidenz von Lippen-Kiefer-Gaumen-Spalten (LKGSpalten) in Europa beträgt etwa 1 zu 500 Geburten. Spaltbildungen im Kiefer- und Gesichtsbereich gehören damit zu den häufigsten angeborenen Erkrankungen. In der Mehrzahl betreffen sie Jungen und kommen linksseitig vor. Frühgeborene benötigen über einen längeren Zeitraum Atemwegsunterstützung. In der Literatur gibt es Einzelbeschreibungen von Frühgeborenen und LKG-Spalten, allerdings nur eine bei einem VLBWFrühgeborenen. Wir berichten über den Verlauf eines solchen Frühgeborenen in Bezug auf die multiplen Probleme des Atemwegmanagements und deren Lösungen.

Fallbericht: Zwillings-Frühgeborenes $24+5$ SSW, GG: 635 g, beidseitige ausgeprägte LKG-Spalte, initiale Intubation zur Atemwegsstabilisierung bereits erschwert, im weiteren Verlauf diverse Modi der Atemwegsunterstützung inkl. 3-D-Vermessung und des Einsatzes von individuell angefertigten Atemmasken mit Gaumenplatten (Institut für Anaplastologie, Genthin). Auch diese führten zu immer neuen Problemen in Bezug auf die Schleimhaut, das Feuchthalten der Atemwege, die Lage der Zunge, etc. Im weiteren Verlauf Einsatz einer Mund-Nase Maske, darunter aber beginnende Deformierung der Prämaxilla. Hier erneuter Einsatz einer individuellen Gaumenplatte. Entlassung mit dieser nach 5 1⁄2 Monaten mit $3090 \mathrm{~g}$. Diskussion: LKG-Spalten lassen sich heute mit den entsprechenden Konzepten erfolgreich korrigieren. Das Frühgeborene hat jedoch besondere Bedürfnisse in Bezug auf die Atemwegsunterstützung, die bei ausgeprägten Spalten mit den Standardsystemen nicht funktioniert. Insbesondere die bilateralen Spalten stellen dabei eine besondere Herausforderung, die sowohl anatomisch als auch funktionell über das reine Atemwegsmanagement hinausgeht, dar.

Schlussfolgerung: Ausgeprägte bilaterale LKG-Spalten können auch beim Extrem-Frühgeborenen erfolgreich versorgt werden. Eine interdisziplinäre Zusammenarbeit von Anfang an ist unerläßlich. Der Aufwand sowohl in pflegerischer Hinsicht als auch in Bezug auf die individuellen Lösungen für den Patienten ist dabei überdurchschnittlich hoch. 
FM-P10

\section{Durch Routine zum Verdachtsfall}

\section{Neumann, H. P. Sperling}

Johanniter Krankenhaus Stendal, Pädiatrie, Stendal, Deutschland

Hintergrund: Unter balancierter Anästhesie für Routine-HNO-OP bei einer 9-jährigen Patientin wurde bei rektaler Applikation von Schmerzmittel (Paracetamol) eine ungewöhnlich große Öffnung im Urogenitalbereich (Rektum und Vagina) durch die Anästhesistin festgestellt.

Fragestellung: Sexueller Missbrauch? Pädiatrisches und gynäkologisches Konsil unter Narkose möglich?

Methoden: Pädiatrisches Konsil im OP erfolgte, Bestätigung des o.g. Befundes incl. Fotodokumentation. Unsere Empfehlungen: Weitere Abklärung im Rahmen des postoperativen Managements in der Klinik für Kinder- und Jugendmedizin. Bei Aufnahme in unserer Klinik erfolge vorerst keine lokale Untersuchung des Urogenitalbereichs, sondern ein allgemeinpädiatrisch-internistischer Status.

Erhebung der Sozialanamnese: Eltern geschieden, Mutter neuen Lebenspartner, Sorgerecht beide Elternteile, Patientin hat gute Verhältnisse zu beiden Männern. Gespräch mit der Mutter über die Feststellung während der Operation und den V.a. Kindeswohlgefährdung. Abklärung Seitens der Mutter ebenfalls erwünscht. Daraufhin Hinzuziehen des Rechtsmediziners und gynäkologisches Konsil im Beisein der Mutter, welches durch die Kollegen unseres Hauses erfolgte.

Ergebnisse: Das gynäkologische Konsil ergab einen unauffälligen Befund, kein Anhalt für Kindeswohlgefährdung bzw. Verletzung durch Fremdeinwirkung. Daraufhin Recherche im medizinischen Bereich à V.a. außergewöhnliche Nebenwirkungen des Narkosemittels in Form von Muskelrelaxation. Durch umfangreiche Recherche Vermutung von Nebenwirkungen des Propofols à Kontaktaufnahme mit Herstellerfirma Braun, sofort in der Firma angenommen, es werden weitere gezielte Recherchen in Bezug der o.g. Nebenwirkungen durch medizinisch-wissenschaftliche Mitarbeiter der Firma durchgeführt.

Schlussfolgerung: Sexueller Missbrauch konnte ausgeschlossen werden Den Erziehungsberechtigten wurden Verhaltensmaßnahmen für eventuell spätere medizinische Behandlungen mit Propofol mitgeteilt. Ein Anästhesiepass wurde ausgestellt.

Fazit: Durch unerklärbaren Befund kann es schnell zu einer Vor- bzw. Fehlverurteilung kommen.

\section{Freie Themen}

\section{FT-P01}

Bedeutung der sonographischen Messung der Durchmesser der Aorta descendens und der Vena cava inferior zur Beurteilung des Volumenstatus von Neugeborenen

\section{S. Behnke, E. Robel-Tillig}

Klinikum St. Georg Leipzig, Neonatologie, Leipzig, Deutschland

Hintergrund: Durch die verbesserte perinatale Versorgung ist die Neugeborenenmortalität und -morbidität deutlich gesunken. Die dadurch immer unreiferen Frühgeborenen und kranken Neugeborenen bedürfen einer wenig invasiven und gut reproduzierbaren Diagnostik. Typische neonatologische Erkrankungen sind häufig mit einer Beeinträchtigung der Hämodynamik im Sinne einer behandlungsbedürftigen Hypovolämie assoziiert. Sonographische Untersuchungen haben einen festen Stellenwert in der neonatologischen Praxis. Bewährt zur Einschätzung des Volumenstatus der Neugeborenen hat sich seit Jahren die Beurteilung der Füllung der Vena cava inferior in Relation zur Aorta abdominalis. Konkrete Normwerte zum Durchmesser und der Relation beider Gefäße zueinander existieren bisher nicht.

Fragestellung: Ziel der vorliegenden Studie war die Ermittlung der Normalwerte für Vena cava inferior, der Aorta abdominalis und eines Index aus beiden bei reifen, gesunden Neugeborenen. Mit Hilfe eines solchen standardisierten Index lässt sich ein Beitrag zur Objektivierung einer behandlungsbedürftigen Hypovolämie leisten.

Methoden: Es wurden 97 termingeborene gesunde Neugeborene am Tag der Geburt und am dritten Lebenstag untersucht. Gemessen wurden die Durchmesser der Aorta descendens vor dem Abgang des Truncus coeliacus und der Vena cava inferior $2 \mathrm{~cm}$ vor ihrer Mündung in das rechte Atrium. Hierfür wurden dreimalige Messungen gemittelt. Die Messungen erfolgten direkt auf dem Bildschirm des Sonographiegerätes.

Ergebnisse: Als Normalwerte für die Durchmesser der Aorta descendens wurden für Tag 1 6,10 mm (Standardabweichung [SD] 0,76) und für Tag 3 $6,16 \mathrm{~mm}(\mathrm{SD} 0,72)$ ermittelt. Für die Vena cava inferior ergab sich für Tag $12,46 \mathrm{~mm}$ (SD 0,62) und für Tag $32,61 \mathrm{~m}$ (SD 0,59). Obwohl alle Neugeborenen zum 3. Lebenstag an Gewicht verloren hatten, kam es nicht zum Abfall des Durchmessers der Vena cava inferior. Für den Quotienten aus Vena cava inferior und Aorta descendens ergaben sich für Tag 10,40 und für Tag 3 0,42 (SD 0,03).

Schlussfolgerung: Mit Hilfe der ermittelten Normalwerte ist die beschriebene Beurteilung der Durchmesser der großen Gefäße und insbesondere des Index ein wertvoller Beitrag in der Diagnostik einer Hypovolämie, zur Einschätzung der Behandlungsbedürftigkeit und im Rahmen einer Therapiekontrolle sinnvoll anwendbar.

\section{FT-P02}

\section{Tellerrand oder Teller: Neonatologie und Komplementärmedizin}

M. Thiel ${ }^{1,2}$

'Sana-Klinikum Remscheid, Klinik für Kinder und Jugendliche, Remscheid, Deutschland, ${ }^{2}$ Universität Witten/Herdecke, Fakultät Für Gesundheit, Abteilung für Humanmedizin, Herdecke, Deutschland

Hintergrund: Die Komplementärmedizin ist in der Medizin von erheblicher praktischer Bedeutung insbesondere auch in ökonomischer Hinsicht. Fragestellung: Dieser Beitrag soll der Beurteilung dienen, inwieweit diese Verfahren in der Neonatologie von Bedeutung sind.

Material und Methoden: Literaturgestützte Evaluation komplementärmedizinischer Themen in der Neonatologie.

Ergebnisse:

- Forschungsergebnisse mit klinischen Konsequenzen beziehen sich auf elementare Phänomene der Sinneswahrnehmung, deren Verarbeitung und deren physiologische Konsequenzen. Es lassen sich zu primären sensorischen Empfindungen mittlerweile anerkannte therapeutische Nutzungen zuordnen. Dazu zählen der Geschmackssinn (Glucose als Analgetikum), Berührung (Kanguru-Pflege), der Geruchssinn (AromaTherapie) und das Gehör (Musiktherapie). Zu optischen Reizen existieren bisher keine Studien und auch keine klinisch relevanten Aspekte.

- Klinische Studien aus beiden Bereichen existieren zu den Themen Stressreduktion, Minimal Handling und Analgesie.

- Die Datenlage zu den Themen Akupunktur und Homöopathie ist dünn. In der Fläche gibt es keine klinsche Relevanz.

- Elternarbeit, seelsorgerisch und bedarfsweise psychologisch, ist in der Neonatologie Standard. Diesbezügliche Studien existieren u.a. zum Thema Spiritualität.

Diskussion: Die Neonatologie weniger invasiv und mehr zentriert auf die individuelle Situation des Kindes geworden. Hier bestehen starke Bezüge zur Komplementärmedizin. Einige Aspekte früher als alternativ bezeichneten Methoden sind Teil des „schulmedizinischen“ Standards geworden. Dabei finden die individuelle Situation des Kindes und die Bedürfnisse der Eltern besondere Beachtung.

Schlussfolgerung: Auf den ersten Blick scheint die Neonatologie für integrative Methoden ungeeignet. Bei näherem Hinsehen zeigt sich, dass viele Aspekte in den klinischen Alltag übernommen wurden und sich mit Ergebnissen schulmedizinischer Forschung decken. 


\section{FT-P03}

\section{ALTE versus BRUE- das Potenzial einer neuen Risikostratifizierung}

\section{N. Mingirulli, H. Schneider, R. Hentschel}

Uniklinik freiburg, Neonatologie und pädiatrische Intensivmedizin, Freiburg, Deutschland

Hintergrund: Plötzlich auftretende, für den Beobachter lebensbedrohlich wirkende Ereignisse im ersten Lebensjahr sind ein regelmäßiger Vorstellungsgrund in pädiatrischen Notaufnahmen. Die klinische Herausforderung besteht darin, Kinder mit medizinisch signifikanten Ereignissen bzw. einer zugrundeliegenden Erkrankung zu identifizieren, sowie unnötige Diagnostik und belastende Interventionen zu vermeiden.

Zur Beschreibung dieser Ereignisse wurde bislang der Begriff „ALTE“ (apparent life threatening event) verwendet. „ALTE“ umschreibt eine sehr heterogene Krankheitsentität, was die Optimierung von Diagnostik und Therapie erschwert. Eine neue Klassifikation der AAP (American Academy of Pediatrics) hat eine Verbesserung der Risikostratifizierung dieses inhomogenen Patientenguts zum Ziel und lanciert den Begriff „BRUE“ (brief resolved unexplained event). Dieser steht für kurze, vom Beobachter als bedrohlich erlebte, vollständig regrediente Ereignisse bei Kindern unter 1 Jahr.

Fallbricht 1:24 h altes, reifes Neugeborenes. Aufnahmegrund: 2-minütige Episode mit Zyanose, Vigilanzminderung und Tonusverlust auf der Wöchnerinnenstation ohne Residualsymptome bei Eintreffen des Kinderarztes. Diagnostik/Befunde: Laborchemische Untersuchungen, EEG, EKG, Echokardiographie, Schädelsonographie allesamt unauffällig. Therapie: Stationäre Monitorüberwachung für 5 d. Diagnose: BRUE. Spezifische Empfehlungen für die Eltern: keine.

Fallbericht 2: 2 Mo. alter Säugling. Aufnahmegrund: Z.n. respiratorischer Reanimation durch den Notarzt wegen prolongiertem Zyanoseanfall bei respiratorischem Infekt. Diagnostik/Befunde: fortbestehende Dyspnoe mit Husten. Leukozytose. Pertussis-PCR positiv. Therapie: supportive stationäre Therapie für $9 \mathrm{~d}$. Diagnose: Pertussis-assoziierte Apnoe. Spezifische Empfehlungen für die Eltern: keine.

Schlussfolgerung: Die dargestellten Fälle veranschaulichen den möglichen Benefit der Patienten bei konsequenter Anwendung der neuen Einteilung durch die Vermeidung unnötiger Maßnahmen. Gleichzeitig werden aber auch die Limitierungen in der Applikation der neuen Klassifikation deutlich, da für einen Großteil der Patienten weiterhin die Notwendigkeit individueller diagnostischer und therapeutischer Entscheidungen besteht.

\section{FT-P04}

\section{Veränderungen der lokalen Hauttemperatur am Akupunkturpunkt Dickdarm 4 bei Neugeborenen unter Anwendung von Laserakupunktur}

\section{J. Stadler ${ }^{1,2}$, W. Raith ${ }^{1,2}$, S. Kurath-Koller', E. Ziehenberger ${ }^{1}$, S. Blum ${ }^{1}$,} G. Litscher ${ }^{2}$, B. Urlesberger ${ }^{1,2}$

'Univ. Klinik für Kinder und Jugendheilkunde, Medizinische Universität Graz, Klinische Abteilung für Neonatologie, Graz, Österreich, ${ }^{2}$ Forschungseinheit für biomedizinische Technik in Anästhesie und Intensivmedizin und TCM Forschungszentrum Graz, Medizinische Universität Graz, Graz, Österreich

Hintergrund: Laserakupunktur wird immer öfter bei Neugeborenen in einem multimodalen Therapiekonzept, wie beispielsweise dem neonatalen Abstinenzsyndrom, und in klinischen Studien, zum Beispiel der infantilen Kolik, angewandt. Bereits bestehenden Untersuchungen mit demselben Laserakupunkturgerät zeigten unter Anwendung von $15 \mathrm{~mW}$ für 5 sowie für 10 min einen signifikanten Anstieg der lokalen Hauttemperatur. Fragestellung: Ziel der Studie war die Untersuchung, ob Laserakupunktur mit $20 \mathrm{~mW}$ bei Neugeborenen die Oberflächentemperatur signifikant verändert beziehungsweise ein potentielles Anwendungsrisiko darstellt. Material und Methoden: Insgesamt wurden 10 Neugeborene (6 männlich/4 weiblich, mittleres Gestationsalter (GA) 35+3 SSW und mittleres Geburtsgewicht (GG) 2494,4 g) eingeschlossen. Die Studie wurde kurz vor der stationären Entlassung im Rahmen einer Polygraphieuntersuchung durchgeführt. Während dieser Untersuchung lagen die Neugeborenen zu- gedeckt in einem Wärmebett mit $30^{\circ} \mathrm{C}$. Die Lasernadeln wurden am Akupunkturpunkt Dickdarm 4 (Di 4, chinesisch $\mathrm{He} \mathrm{Gu}$ ) beidseitig fixiert und nach einer 10 minütigen Ruhephase zur Akklimatisation bei konstanter Raumtemperatur mit einer Leistung von $20 \mathrm{~mW}$ (Laserneedle $\odot$ Glienicke/Nordbahn, Germany, $685 \mathrm{~nm}, 500 \mu \mathrm{m}$ ) für 5 Minuten durchgeführt. Mittels einer Thermokamera (Flir i5 - Flir Sytems Inc. (C), Portland, USA) wurden lokale thermographische Bilder vor Beginn sowie 1, 5 und $10 \mathrm{Mi}$ nuten nach der Laserstimulation angefertigt. Jeweils der wärmste Punkt wurde definiert und die Temperatur im Verlauf verglichen. Die statistische Auswertung erfolgte mittels Varianzanalyse für wiederholte Messungen (ANOVA).

Ergebnisse: Die Laserakupunktur wurde im Durchschnitt am 19. Lebenstag (postmenstruelles GA 38+0, mittleres Gewicht 2719,9 g) durchgeführt. Im Vergleich zur Ausgangstemperatur rechts mit $32,5^{\circ} \mathrm{C}$ und links mit $33,5^{\circ} \mathrm{C}$ konnte nach 5 min Stimulation kein signifikanter Anstieg der Hauttemperatur an der linken (mittlere Temperatur $=33,6^{\circ} \mathrm{C}, p=0,820$ ) sowie an der rechten (mittlere Temperatur $=32,2^{\circ} \mathrm{C}, p=0,752$ ) Hand festgestellt werden. Die maximal gemessene Hauttemperatur betrug $36,6^{\circ} \mathrm{C}$. Diskussion: Im Vergleich zu bereits bestehenden Untersuchungen konnte in dieser Studie kein signifikanter Anstieg der Hauttemperatur beobachtet werden. Die Neugeborenen beider Studien gleichen sich hinsichtlich dem durchschnittlichen GA (35+3 vs. $35+0)$, dem GG (2494,4 g vs. 2261,2 g) sowie des GA zum Zeitpunkt der Untersuchung (postmenstruelles GA $38+0$ vs. $38+2$ ). Ein Unterschied besteht in der sogenannten Energiedichte (energy dosage in $\mathrm{Ws} / \mathrm{cm}^{2}$ oder $\mathrm{J} / \mathrm{cm}^{2}$ ) der Laserapplikation, denn die Energiedichte nach 5 min Laserakupunktur mit $20 \mathrm{~mW}$ betrug $3,1 \mathrm{~kJ} /$ $\mathrm{cm}^{2}$ und bei Laserakupunktur mit $15 \mathrm{~mW}$ nach $5 \mathrm{~min} 2,3 \mathrm{~kJ} / \mathrm{cm}^{2}$ und nach $10 \mathrm{~min} 4,6 \mathrm{~kJ} / \mathrm{cm}^{2}$.Diese Studie konnte zeigen, dass Laserakupunktur mit $20 \mathrm{~mW}$ für 5 Minuten bei Neugeborenen zu keiner thermografisch signifikanten Erwärmung der Haut und auch zu keinen sichtbaren Nebenwirkungen führt.

\section{FT-P05}

Veränderungen der Körpertemperatur bei Neugeborenen während Laserakupunktur am Akupunkturpunkt Dickdarm 4

J.Stadler, ${ }^{1,2}$ G. Litscher ${ }^{2}$, A. Gross', E. Ziehenberger', T. Freidl', B. Urlesberger ${ }^{1,2}$, W. Raith ${ }^{1,2}$

'Univ. Klinik für Kinder und Jugendheilkunde, Medizinische Universität Graz, Klinische Abteilung für Neonatologie, Graz, Österreich, ${ }^{2}$ Forschungseinheit für biomedizinische Technik in Anästhesie und Intensivmedizin und TCM Forschungszentrum Graz, Medizinische Universität Graz, Graz, Österreich

Hintergrund: Laserakupunktur gehört zu einer sanften Methode, um Kinder und Neugeborene auf eine nicht-invasive Weise zu behandeln. Allerdings gibt es nur wenige Daten über die zentralen und peripheren Effekte der Laserakupunktur auf Kinder und Neugeborene. Mehrere Studien an Erwachsenen konnten zeigen, dass mit Akupunktur durch Veränderung der lokalen Mikrozirkulation wärmende Effekte erzielt werden konnten. Bei Neugeborenen liegen bisher nur sehr vereinzelte Daten vor.

Fragestellung: Hat lokale Laserakupunktur auch Einfluss auf die rektal gemessene Körpertemperatur?

Material und Methoden: Diese sekundäre Analyse liefert explorative Daten aus einer prospektiven Studie, durchgeführt an der Abteilung für Neonatologie, Abteilung für Kinder- und Jugendheilkunde Graz. Die Laserakupunktur wurde bei Neugeborenen kurz vor der Entlassung im Rahmen einer Polygraphieuntersuchung durchgeführt. Während dieser Untersuchung lagen die Neugeborenen zugedeckt in einem Wärmebett mit $30^{\circ} \mathrm{C}$. Lasernadeln wurden am Akupunkturpunkt Dickdarm 4 (Di 4, chinesisch $\mathrm{He} \mathrm{Gu}$ ) beidseitig fixiert und, nach einer Ruhephase zur Akklimatisation bei konstanter Raumtemperatur, mit einer Leistung von $15 \mathrm{~mW}$ (Laserneedle $\odot$ Glienicke/Nordbahn, Germany, $685 \mathrm{~nm}, 500 \mu \mathrm{m}$ ) durchgeführt. Die erste Laserstimulation dauerte 5 Minuten, darauf folgte eine 10-minütige Pause und eine zweite Stimulation für 10 Minuten. Zehn Minuten vor und nach Anwendung der Laserakupunktur wurde die Körpertemperatur rektal mit dem MED-Comfort (Digital Thermometer, Shanghai Internati- 
onal Holding Corp. GmbH, Europe, Germany) gemessen. Die statistische Auswertung erfolgte mittels abhängigem t-Test.

Ergebnisse: Insgesamt wurden 20 ehemalige Früh- sowie reife Neugeborene (12 männlich, 8 weiblich) mit einem mittleren postmenstruellen Gestationsalter (GA) zum Zeitpunkt der Untersuchung von 38+2 SSW und einem mittleren Gewicht von $2604 \mathrm{~g}(\mathrm{SD}=611,7 \mathrm{~g})$ im Durchschnitt am 23. Lebenstag $(S D=15 \mathrm{~g})$ eingeschlossen. Die anfängliche Körpertemperatur vor der Laserakupunktur betrug $36,8^{\circ} \mathrm{C}$, nach der Laserakupunktur $37,04^{\circ} \mathrm{C}$. Somit zeigte sich ein signifikanter Anstieg der rektal gemessenen Körpertemperatur $(p=0,014)$.

Diskussion: Laserakupunktur könnte nicht nur lokal wärmende, sondern auch generalisierende Effekte auf den Körper haben. Die Ursachen dafür sind noch weitestgehend unerforscht und es gibt mannigfaltige Hypothesen. Der Anstieg kann auf die lokalen Veränderungen der Mikrozirkulation am Akupunkturpunkt selbst, aber auch in weiterer Folge auf die Wirkung der Akupunktur auf den Hippocampus und somit den Parasympathikus zurück zu führen sein, welche zu einer Regulation der Körpertemperatur führen. Allerdings ist die Studie aufgrund einer fehlenden Kontrollgruppe limitiert. Alle gemessenen Werte lagen im Normalbereich, womit die klinische Relevanz des signifikanten Unterschieds klein ist. Jedoch kann die Laserakupunktur mit $15 \mathrm{~mW}$ für 5 und 10 Minuten in Bezug auf die Körpertemperatur bei Neugeborenen als sicher bezeichnet werden.

\section{FT-P06 \\ Nationale Umfrage der Klinik für Neonatologie des Universitätsklinikum Heidelberg zu: Ultraschallscreening des Gehirns bei Frühgeborenen $<32$ + 0 SSW zur Erfassung des jeweiligen Klinikstandards}

\section{S. Menne, U. Rochwalsky, C. Seitz, M. T. Dabek, N. Kuss, J. Pöschl}

Universitätsklinikum Heidelberg, Klinik für Neonatologie, Heidelberg, Deutschland

Hintergrund/Fragestellung: Das Auftreten einer peri- oder intraventrikulären Hirnblutung (IVH) stellt eine der schwersten Komplikationen der extremen Frühgeburt dar und ist sowohl mit einer hohen Mortalität, als auch einer hohen Morbidität verbunden. Jedoch gibt es in deutschen neonatologischen Abteilungen bisher keine Leitlinie zum Ultraschallscreening und den Verlaufskontrollen der peri- oder intraventrikulären Hirnblutung (PVH/IVH), des posthämorrhagischen Hydrozephalus (PHH) und der periventrikulären Leukomalazie (PVL) des Gehirns bei Frühgeborenen $<32+0$ Schwangerschaftswochen (SSW). Deshalb führten wir eine Erhebung der Zeitpunkte von Routine-Ultraschall, das jeweilige Vorgehen, sowie Verlaufskontrollen bei statt gehabter intraventrikuläre Blutung in deutschen neonatologischen Abteilungen durch.

Methoden: Von Juni 2016 bis August 2016 führten wir eine Online-Befragung 222 deutscher neonatologischer Abteilungen durch. Eingeschlossen wurden Abteilungen mit einer Versorgung von Frühgeborenen $<32+0$ SSW. Zur Gestaltung und Abwicklung der Befragung wurde die kommerzielle Online-Umfrage-Plattform SurveyMonkey (SurveyMonkey Inc., Palo Alto, Kalifornien, USA, www.surveymonkey.com) verwendet.

Ergebnis: Von 137 angenommenen Anfragen nahmen 103 an der Umfrage teil, die zur Auswertung verwendet werden konnten. Davon stammen 77 (75\%) Teilnehmer aus einem Level 1 Schwerpunktzentrum, 22 (21\%) aus einem Level 2 und 4 (4\%) aus einem perinatalen Schwerpunkt. Wir konnten zeigen, dass die Routineschädelsonographie zu 65,2\% durch den Assistenzarzt, zu 21,7\% durch einen Facharzt und/oder einen Facharzt mit der Zusatzqualifikation Neonatologe durchgeführt wurde. Darüber hinaus zeigten wir, dass die Dokumentation in $85,9 \%$ nach den empfohlenen Standardschnitten der DEGUM (mindestens 3 Koronarschnitte und mindestens 3 Sagittalschnitte) erfolgte, in $12 \%$ nach eigenem Klinik-Standard. Wobei die Sonographiebilder zu 59,8\% digital gespeichert wurden, in $18,5 \%$ lediglich in ausgedruckter Form vorlagen und in $9,8 \%$ nur im Sonographiegerät abrufbar waren. In 41,3\% erfolgte die Befundung/Validierung durch einen zweiten, unabhängigen ärztlichen Mitarbeiter (z.B. Radiologe). In Bezug auf die zeitliche Abfolge fanden wir heraus, dass es bei der Routinesonographie in $87,9 \%$ der Fälle einen schriftlich festgelegten internen Standard gibt. Hier zeigte sich, dass bei 16,5\% der Fälle die 1. Routine Schädelsonographie bei FG $<32+0$ SSW innerhalb der ersten 6 Lebensstunden durchgeführt wurde. In 17,6\% innerhalb der ersten 12 Lebensstunden, in 53,8\% innerhalb der ersten 24 Stunden. Die weiteren Follow up Untersuchungen zeigten sich noch inhomogener. Des Weiteren interessierte uns die Einteilung der IVH. In 86,8\% der Fälle wird die "neue" Einteilung nach DEGUM und in 13,2\% die ,alte" Einteilung nach Papile mit 4 Schweregraden verwendet.

Schlussfolgerung: Unsere Ergebnisse konnten zeigen, dass es signifikante Unterschiede im Ultraschallscreening des Gehirns bei Frühgeborenen $<32+0$ SSW gibt. Zur besseren Qualitätssicherung der erhobenen Daten ist ein einheitlicher Standard in Durchführung, Verlaufskontrollen und Dokumentation sinnvoll.

\section{FT-P07}

\section{Einsatz der Thoraxkompression bei der Erstversorgung Neugeborener im Kreißsaal}

\section{Roll, F. Hornschuh, W. Pielemeier, P. Kutz}

Vestische Kinder- und Jugendklinik Datteln, Universität Witten/Herdecke, Neonatologie, Pädiatrische Intensivmedizin, Schlafmedizin, Datteln, Deutschland

Hintergrund: Leitlinien zur Reanimation des Neugeborenen empfehlen die Thoraxkompression, wenn die Herzfrequenz trotz effektiver Beatmung nicht über 60/min ansteigt.

Fragestellung: Gibt es Unterschiede in der Häufigkeit des Einsatzes der Thoraxkompression bei der Erstversorgung deprimierter Neugeborener in Abhängigkeit vom Versorgungslevel der Entbindungsklinik bzw. der medizinischen Fachrichtung des erstversorgenden Arztes.

Material und Methoden: Von 2013 bis 2016 wurden alle Neugeborenen mit einem Gestationsalter $>=34$ Wochen, die im Rahmen der Erstversorgung eine Thoraxkompression erhielten, in 3 Geburtskliniken (GK1 und GK2 ohne Kinderklinik, PZ3 = Perinatalzentrum Level 1) erfasst. Die direkt postnatale Behandlung eines deprimierten Neugeborenen erfolgte in GK1 und GK2 durch einen Anästhesisten, in PZ3 durch einen Kinderarzt/ Neonatologen. Alle Kinder aus GK1 und GK2, die eine Thoraxkompression erhalten hatten, wurden vom Neugeborenen-Notarztteam des PZ3 weiterversorgt und in PZ3 verlegt.

Ergebnisse: Im 4-Jahres Zeitraum gab es 13.382 Geburten in den 3 Kliniken, bei 22 Neugeborenen $(0,16 \%)$ wurde eine Thoraxkompression im Rahmen der Erstversorgung durchgeführt, in GK1 bei 15/3195 Neugeborenen ( $0,47 \%$ aller Geburten), in GK2 bei 5/3182 (0,16\%) und in PZ3 bei $2 / 7005(0,03 \%)$ [ $p<0,001]$. Patientenkollektiv: Sectio $18 / 22$, Jungen $13 / 22$, „late preterm“ $3 / 22$. Bei $2 / 20$ lag der Nabelarterien-pH $<7,0$, bei weiteren $6<7,15$. Sechs Kinder wurden im Verlauf der Erstversorgung intubiert und beatmet. Eine Hypothermiebehandlung wurde bei 3 Kindern begonnen. Ein Neugeborenes verstarb im Kreißsaal (Apgar 0-0-0), alle anderen überlebten bis zur Entlassung aus dem Krankenhaus.

Diskussion: Es zeigt sich eine große Spannweite in der Häufigkeit des Einsatzes der Thoraxkompression zwischen den 3 Kliniken, der nicht durch Unterschiede im Patientenkollektiv erklärt werden kann. Auch zwischen den beiden Geburtskliniken mit primärer Versorgung durch Anästhesisten besteht ein deutlicher Unterschied. Die Mehrzahl der Neugeborenen hatte einen normalen Nabelarterien-pH und eine gute weitere Adaptation. Dies spricht eher für einen zu nicht indizierten Einsatz der Thoraxkompression als für deren Effektivität. Schulung und Interpretationen der Leitlinien sind möglicherweise für die festgestellten Unterschiede verantwortlich. 


\section{FT-P08}

\section{Ist der operative Verschluss des Ductus arteriosus überflüssig?}

\section{Cornelius, H. Küster}

Universitätsmedizin Göttingen, Neonatologie, Göttingen, Deutschland

Hintergrund: Der medikamentöse Verschluss eines Ductus arteriosus Botalli gilt vielfach als nur mäßig erfolgreich. Dies trifft insbesondere auf jene Fälle zu, bei denen erst nach der 2. Lebenswoche mit der Therapie begonnen wird. Durch eine solche Operation werden nicht nur perioperative Risiken in Kauf genommen, sondern auch die der Anästhesie, deren Langzeitfolgen auf die neurokognitive Entwicklung von Früh- und Neugeborenen möglicherweise erheblich sind. [Andropoulos et al, NEJM 08.02.2017]. Somit stellt sich die Frage, ob mit einem verbesserten medikamentösen Therapieregime die Häufigkeit der Duktusligatur reduziert werden kann.

Methoden: Alle VLBW-Frühgeborenen mit einem klinisch und echokardiographisch relevanten Duktus wurden in 2 direkt aufeinander folgenden Perioden nach 2 unterschiedlichen Protokollen behandelt: In der 1. Periode verwendeten wir Ibuprofen nach Maßgabe des Herstellers (10-5 - 5 mg i. v.). War dieser Zyklus nicht erfolgreich, folgte ein zweiter Zyklus (20-10 - $10 \mathrm{mg}$ i.v.) und bei immer noch bestehendem Duktus in einigen Fällen die anschließende Indometacintherapie. In der 2. Periode verabreichten wir ausschließlich Indometacin und steigerten die Einzeldosen schrittweise bis maximal $3 \mathrm{mg} / \mathrm{kg}$. Die Therapie wurde beendet bei Verschluss des Duktus oder einem Rückgang der Ausscheidung. Dieses Schema einer individualisierten Dosisanpassung wurde von uns in der Vergangenheit mit Erfolg durchgeführt und ist die Basis einer Studie, welche von Sperandio et al [Pediatrics 2005;116:1361] veröffentlicht wurde.

Ergebnisse: In 2 aufeinanderfolgenden Perioden von je 14 Monaten behandelten wir 20 bzw. 19 Kinder mit Ibuprofen (medianes Gestationsalter 25,9 Wochen, Geburtsgewicht $789 \mathrm{~g}$ ) bzw. Indometacin (medianes Gestationsalter 25,9 Wochen, Geburtsgewicht $846 \mathrm{~g}$ ). Der Therapiebeginn lag zwischen dem 6. und 94. Lebenstag, die Therapiedauer betrug 2-25 Tage. Dabei zeigte sich keine Abhängigkeit der notwendigen Dosis vom Lebensalter. Mit Ibuprofen konnte der Duktus bei 8 von 20 Frühgeborenen (20\%) verschlossen werden. Sepsis ohne Erregernachweis und mit hohen CRPWerten war ein häufiges Abbruchkriterium unter Ibuprofen. Unter Ibuprofenmonotherapie wurde $3 \mathrm{mal}$ eine NEC beobachtet, unter Ibubrofen und anschließender Indometacintherapie 1mal, jeweils mit deutlichem Abstand zur Duktustherapie. Unter Indometacinmonotherapie trat keine NEC auf. Eine FIP trat nicht auf, kein Kind verstarb. Mit Indometacin erreichten wir einen Verschluss des Duktus bzw. eine relevante Verkleinerung bei 18 von 19 Frühgeborenen (94\%). Eine Duktusligatur aufgrund nicht erfolgreicher medikamentöser Therapie war in der 1. Periode in 4 Fällen, in der 2. Periode in 1 Fall notwendig. Erwähnenswert ist die Persistenz eines nicht hämodynamisch relevanten Duktus bei 4 Kindern unter Ibuprofen und 6 Kindern unter Indometacin, der in allen Fällen wenige Monate nach Entlassung spontan obliterierte.

Schlussfolgerung: Der chirurgische Verschluss eines Duktus konnte mit unserem individualisierten Indometacinschema in 94\% der Fälle verhindert werden. Verglichen dazu gelang dies nur bei $20 \%$ der nur mit standardisierten Ibuprofenschema behandelten Frühgeborenen. Mit einem individualisierten Dosierungsschema sind möglicherweise auch mit anderen Medikamenten wie Paracetamol ähnlich hohe Erfolgsraten erreichbar.

\section{FT-P09 \\ Echokardiographisches Screening in der Neonatologie - Mannheimer Erfahrungen}

\section{J. B. Kleber, V. Kilarski, T. Schaible}

Universitätsmedizin Mannheim, Neonatologie, Mannheim, Deutschland

Hintergrund: Angeborene kardiale Vitien sind mit 6-8/1000 die häufigsten menschlichen Fehlbildungen, kritische Herzfehlbildungen treten in 2/1000 Neugeborenen auf. Die pränatale Diagnostik erkennt je nach Qualität der Untersuchung 30-70\% dieser Fehlbildungen. Aus den meisten
Zentren werden Neugeborene nach Auskultation und Sättigungsscreening entlassen.

Fragestellung: Wir untersuchten, ob der Aufwand zur Durchführung eines standardisierten echokardiographischen Screenings gerechtfertigt ist und ob es eine sinnvolle Ergänzung zum Sättigungsscreening darstellt. Material und Methoden: Wir untersuchten 515 Neugeborene auf der Wochenbettstation zwischen Tag zwei und vier mit Hilfe von sieben standardisierten echokardiographischen Schnitten inclusive Doppler-Echokardiographie. Auf eine detaillierte Funktionsdiagnostik wurde verzichtet. PFOs wurden nur $>4 \mathrm{~mm}$ als abnormal gewertet, PDAs nur $>2 \mathrm{~mm}$. Alle nicht sofort behandlungsbedürftigen Auffälligkeiten wurden spätestens innerhalb von sechs Wochen von einem in Echokardiographie erfahrenen Neonatologen nachuntersucht oder ggf. in einem Kinderkardiologen vorgestellt.

Ergebnisse: Es fanden sich insgesamt 39 auffällige Befunde. Darunter 17 relevante PFOs (2 in langfristiger Nachkontrolle), 14 VSDs (davon 3 in Kombination mit PFO, 1 in Kombination mit quarikuspider Aortenklappe, 1 bereits pränatal bekannt, 2 in langfristiger Nachkontrolle), 1 kritische ISTA und 1 TGA. Keiner der Befunde war im postductalen Sättigungsscreening aufgefallen, nur vier waren auskultatorisch vermutet wurden.

Diskussion: Da zwei kritische Vitien vor einer Dekompensation erkannt wurden, halten wir das echokardiographische Screening für eine sinnvolle Ergänzung zum Sättigungsscreening, zumal dieses nicht alle Vitien erkennen kann. In unserem Sample zeigte sich zudem eine höhere VSD-Inzidenz als in der Literatur vermutet, was aber aufgrund der hohen Spontanverschlussrate von fraglicher klinischer Relevanz ist. Die Durchführbarkeit und Kosten-Nutzen-Effizienz halten wir in einem neonatologischen Zentrum für gegeben, eine Überlastung der Kinderkardiologien vermieden werden, wenn bei unkritischen Auffälligkeiten Kontrolluntersuchungen durch die Neonatologie selbst erfolgen. Die Sensitivität der Methode sollte vor einer generellen Einführung in Zusammenarbeit mit Kinderkardiologen überprüft werden.

\section{FT-P10}

\section{Raumluftqualität auf einer NICU}

M. Wolf', T. Diehl', S. Zanni' ${ }^{2}$, D. Singer ${ }^{1}$

'UKE, Päd. Intensivmed. und Neonatologie, Hamburg, Deutschland, ${ }^{2} \mathrm{U}$-Earth, Scientific Department, Turin, Italien

Hintergrund und Fragestellung: Die Innenraumluft ist ein wesentlicher Umgebungsfaktor gerade für Frühgeborene, die über lange Zeit der Innenraumluft ausgesetzt sind, während gleichzeitig die erste kritische postnatale Entwicklung verschiedener Organsysteme genau in diese Phase fällt. Interessant erscheinen in diesem Zusammenhang vor allem die Volatile Organic Compounds (VOC), d.h. gas- und dampfförmige Stoffe organischen Ursprungs, wie sie beispielsweise aus synthetisch hergestellten Stoffen freigesetzt werden können. Es sollte daher die VOC-Belastung im Patientenzimmer einer Neonatologischen Intensivstation (NICU) und im Innenraum eines Intensivpflegeinkubators gemessen und auf Tagesschwankungen untersucht werden.

Material und Methoden: Patientenzimmer einer NICU/PNZ Level $1 \mathrm{mit}$ 4 Behandlungsplätzen und einem Raumluftvolumen von 85 m3. Intensivpflegeinkubator (Caleo, Fa. U-Earth) mit einem Innenraumvolumen von $0,12 \mathrm{~m} 3$, eingestellt auf eine Lufttemperatur von $34^{\circ} \mathrm{C}$ und eine relative Feuchte von $60 \%$. Messperiode sechs Wochen, davon 3 Wochen mit leerem Inkubator und drei Wochen mit Standardmatratze und Bettbezug (ohne Patient/Dummy). Datenerhebung mittels je eines U-Monitors 2.0 (Fa. U-Earth) im Patientenzimmer und im Inkubator, Messintervall $5 \mathrm{~min}$, Erfassung von Temperatur, Feuchte, Feinstaub $(1,0 / 2,5 \mu \mathrm{m})$, VOC und geruchsbildenden Gasen.

Ergebnisse und Diskussion: Im Patientenzimmer zeigte sich eine zirkadiane Rhythmik mit einem Anstieg der VOC-Belastung bis auf die vierfache Höhe des Mitternachtswertes (0,4 ppm) um 9:00 Uhr, auf die dreifache Höhe um 15.00 Uhr, auf die zweifache Höhe zwischen 16:30 und 19.00 Uhr und auf die zweifache Höhe um 21.00 Uhr. Die geruchsbildenden Gase zeigten einen den VOC vollständig gleichsinnigen Verlauf. Die 
Belastung mit Feinstaub der Größe 1,0 $\mu \mathrm{m}$ zeigte parallele Anstiege deutlich geringeren Ausmaßes, die Belastung mit Feinstaub der Größe 2,5 $\mu \mathrm{m}$ keine nennenswerten Schwankungen. Im Inkubator zeigten sich gleich ausgeprägte und im Verlauf gleichsinnige Anstiege ohne wesentliche Unterschiede auch in den Absolutwerten.

Schlussfolgerung: Es ergab sich ein signifikanter Anstieg der Belastung mit VOC im Tagesverlauf sowohl im Patientenzimmer als auch im Inkubator der zeitlich mit der Anwesenheit von Personal und Besuchern bzw. ärztlichen und pflegerischen Verrichtungen korrelieren und für die im Inkubator bzw. beim Känguruhen exponierten Frühgeborenen von Bedeutung sein könnte. Da in dieser Untersuchung nur die Gesamt-VOC und nicht die Einzelsubstanzen gemessen wurden, lässt sich hieraus noch keine Aussage über eine mögliche Toxizität ableiten. Je nach Substanz könnte es aber zu echten Belastungen mit Überschreiten bzw. Annäherung an bekannte Grenzwerte in den Phasen der höchsten VOC-Peaks gekommen sein. Eine Messung der Einzelsubstanzen wäre daher zukünftig sinnvoll, um womöglich Präventionsmaßnahmen formulieren zu können.

\section{FT-P11}

\section{Versorgungswirklichkeit von ausgewählten angeborenen} Fehlbildungen in Hessen - Ergebnisse der Neonatalerhebung 2010-2015

\section{U. Rolle' , B. Wittekindt'², R. Schlösser' ${ }^{2}$ J. Grossmann ${ }^{3}$, B. Misselwitz ${ }^{3}$}

'Universistätsklinik Frankfurt, Kinderchirurgie, Frankfurt, Deutschland,

${ }^{2}$ Universitätsklinik Frankfurt, Neonatologie, Frankfurt, Deutschland,

${ }^{3}$ Geschäftsstelle Qualitätssicherung in Hessen, Eschborn, Deutschland

Hintergrund: Angeborene Fehlbildungen werden in zunehmender Häufigkeit pränatal diagnostiziert und an Perinatalzentren mit entsprechender kinderchirurgischen Expertise verlegt. Dabei ist wenig über das Outcome dieser extrem heterogenen Patientengruppe bekannt.

Fragestellung: Wie viele Neugeborene mit den Erkrankungen Duodenalatresie, Gastroschisis, Omphalocele, Zwerchfellhernie und Ösophagusatresie (mit oder ohne Fistel) werden in Hessen geboren, wo werden sie versorgt, wie ist Sterblichkeit und Behandlungsdauer.

Material und Methoden: Zwischen 2010 bis 2015 wurden 318.533 Kinder in Hessen geboren. Aus den Daten der Neonatalerhebung dieser 6 Jahre der wurden alle Fälle mit einer der gesuchten Q-Diagnosen anonymisiert und weiter ausgewertet: Q41.0, Q79.2, Q79.3, Q79.0, Q39.0, Q39.1.

Ergebnisse: 283 Patienten wiesen eine der gesuchten Fehlbildungsdiagnosen auf. Es ergeben sich für die 5 Fehlbildungen folgende Inzidenzen und (in-house) Mortalitätsraten:Dudenalatresie 1:5600/3,6\%; Gastroschisis 1:5600/1,8\%; Omphalocele: 1:6250/26\%; Zwerchfellhernie: 1: 7600/28\%; Ösophagusatresie: 1: 3750/11\%. Die stationäre Behandlung bis zur ersten Entlassung nach Hause betrug im Mittel 44 Tage, was die Komplexität der Erkrankungsgruppe unterstreicht. Das Perinatalzentrum mit den meisten Fehlbildungen, hier wurde gut ein Drittel aller Patienten behandelt, hatte dabei mit 35 Tagen eine Signifikant kürzere Behandlungsdauer $(p=0,01)$. Diskussion: Unterschiede der Inzidenzen der Fehlbildungen in Hessen im Vergleich zu den Daten großer epidemiologische Fehlbildungsregister (z.B. EUROCAT) lassen sich damit erklären, dass in der Neonatalerhebung nur Lebendgeborene erfasst werden und im Falle der Zwerchfellhernie viele Patienten pränatal beispielsweise nach Mannheim verlegt werden. Die Sterblichkeit der analysierten Patienten ist wesentlich von begleitenden Faktoren (Herzfehler, Chromosomenanomalien, Frühgeburtlichkeit) beeinflusst. Die Zahlen zur Behandlungsdauer könnten ein Argument für Bündelung der Versorgung in wenigen Zentren sein.

\section{FT-P12}

Birth weight percentiles based on maternal height are universally applicable and valid for different ethnic groups

N. Rochow' ${ }^{1}$, D. Olbertz' ${ }^{2}$ J. Däbritz ${ }^{3}$, R. Hentschel ${ }^{4}$, M. Voigt ${ }^{5}$

${ }^{1}$ McMaster University, Pediatrics, Hamilton, Canada, ${ }^{2}$ Clinic Südstadt, Neonatology, Rostock, Germany, ${ }^{3}$ University Medical Center, Pediatrics, Rostock, Germany, ${ }^{4}$ University Medical Center, Neonatology, Freiburg, Germany, ${ }^{5}$ University of Freiburg, Centre for Medicine and Society, Freiburg, Germany

Background: It had been shown that the birth weights are different between ethnic groups. As a result, birth weight percentiles have been developed for specific populations. However, there is a linear relation between the maternal height and their childs birth weight. For each unit? increase in maternal height, birth weight increases by $16.7 \mathrm{~g}$. The average maternal height has also been found to be different between ethnic groups. It could be hypothesized that birth weight percentiles adjusted for maternal height account for the ethnic effects on the size at birth.

Objective: To test whether the birth weight is different between ethnic groups when maternal body height remains similar.

Design/Methods: Data (birth weight, gestational age, sex, maternal height, ethnicity) from the German Perinatal Survey of 1995-2000 with $n=2.3$ Million. singleton neonates, gestational age ranging from 26 to 41 weeks, were analyzed. Data were stratified for maternal height $(\leq 157,158-$ $163,164-169,170-175, \geq 176 \mathrm{~cm}$ ) and ethnic origin (Germany; Central and Northern Europe, North America; Mediterranean region; Eastern Europe; Middle East and North Africa; Asia excluding Middle East). Percentiles and average birth weight were calculated and compared.

Results: The average birth weight and maternal height between the ethnic groups is significantly different. Classification of birth weight by common growth charts showed a low rate of SGA and high rate of LGA infants in tall mothers $(\geq 176 \mathrm{~cm})$, and a high rate of SGA and low rate of LGA in neonates from shorter mothers $(\leq 157 \mathrm{~cm})$. When reference birth weight charts are stratified by maternal height then average birth weight, SGA and LGA rates are similar between ethnic groups.

Conclusion: Birth weight percentile charts for maternal height seem to reflect genetic fetal growth potential in small and tall mothers and might be universally applicable for different ethnic groups.

\section{Inflammation/Hämatologie}

\section{IH-P01}

Normwerte für Normoblasten- und Serum-Laktatkonzentrationen bei Frühgeborenen mit einem Geburtsgewicht unter $1500 \mathrm{~g}$ in den ersten 6 Lebenstagen

A. Wissing', M. Poryo², A. Aygün', J. Geisel', S. Wagenpfeil', J. Schöpe4, S. Meyer ${ }^{1,5}$

'Universitätsklinikum des Saarlandes, Klinik für Allgemeine Pädiatrie und Neonatologie, Homburg, Deutschland, ${ }^{2}$ Universitätsklinikum des Saarlandes, Klinik für Pädiatrische Kardiologie, Homburg, Deutschland, ${ }^{3}$ Universitäsklinikum des Saarlandes, Institut für Klinische Chemie und Laboratoriumsmedizin, Homburg, Deutschland, ${ }^{4}$ Universitätsklinikum des Saarlandes, Institut für Medizinische Biometrie, Epidemiologie und Medizinische Informatik, Homburg, Deutschland, ${ }^{5}$ Universitätsklinikum des Saarlandes, Klinik für Pädiatrische Neurologie, Homburg, Deutschland

Hintergrund: Obwohl Normoblasten (NRBC), Vorläuferzellen der Erythrozyten, beim Gesunden nur im Knochenmark vorkommen, sind sie physiologischerweise bei Neugeborenen im peripheren Blut zu finden. Erhöhte Werte sind ein Indikator für intrauterinen Sauerstoffmangel [1-3]. In einigen Studien wurde gezeigt, dass erhöhte NRBC und Serum-Laktatkonzentrationen ( $\mathrm{Lac}$ ) im peripheren Blut mit einem schlechteren neonatalen Outcome und erhöhter Mortalität einhergehen [2-4]. 
Fragestellung: Ziel unserer Arbeit ist es, Referenzwerte für NRBC und Lac in der ersten Lebenswoche bei VLBW und ELBW (very/extremely low birth weight) - Kindern zu ermitteln und eine mögliche Korrelation zwischen diesen beiden Werten zu analysieren.

Material und Methoden: Bei dieser Studie handelt es sich um eine retrospektive Analyse, die auf der neonatologischen Intensivstation des Universitätsklinikums des Saarlandes, Homburg/Saar durchgeführt wurde. Es wurden zwischen 250 VLBW/ELBW-Neonaten in die Studie eingeschlossen. Neben Geburtsgewicht, Gestationsalter, NRBC und Lac in den ersten 6 Lebenstagen wurden weitere, für das Outcome relevante Parameter (z. B. intrauterine Wachstumsretardierung (IUGR)), analysiert.

Ergebnisse: Unter den 250 Patienten sind 123 (49,2\%) männliche und 127 $(50,8 \%)$ weibliche. Die Spanne des Geburtsgewichts reicht von $320 \mathrm{~g}$ bis 1499 g (140 (56\%) VLBW, 110 (44\%) ELBW, Mittelwert (MW) 1048 g, Standardabweichung (SD) $305 \mathrm{~g}$, Median (Md) $1080 \mathrm{~g}$, Interquartilsabstand (IQR) $503 \mathrm{~g}$ ) und das Gestationsalter von 23 bis 35 Wochen (MW 203 Tage, SD 18 Tage, Md 204 Tage, IQR 28 Tage). Es konnte gezeigt werden, dass eine inverse Korrelation zwischen NRBC-Werten und Geburtsgewicht $(p=0,000)$, sowie zwischen Lac und Geburtsgewicht $(p=0,000)$ besteht. Außerdem zeigten Kinder mit einer IUGR signifikant erhöhte NRBC-Werte an den Tagen 1-3 (Tag $1 p=0,000$, Tag $2 p=0,000$, Tag 3 $p=0,003)$ und am ersten Lebenstag erhöhte $\operatorname{Lac}(p=0,007)$. Darüberhinaus konnte eine hochsignifikante Korrelation zwischen NRBC und Lac $(p=0,000)$ festgestellt werden, sowie Normwerte für NRBC und Lac abhängig vom Geburtsgewicht und für Kinder mit und ohne IUGR ausgearbeitet werden.

Diskussion: Es ist wichtig, Normwerte für NRBC zu kennen, um eine mit erhöhten Werten einhergehende Gefahr eines schlechten Outcomes und erhöhter Mortalität bei Frühgeborenen zu erkennen [4]. Bisher wurde noch keine wie bei uns beschriebene Korrelation zwischen NRBC und Lac beschrieben. Zusätzlich konnten wir Normwerte für NRBC und Lac abhängig vom Geburtsgewicht und für Kinder mit und ohne IUGR ausarbeiten.

\section{Literatur}

1. Perrone $S$ (2005) Nucleated red blood cell count in term and preterm newborns: reference values at birth. Arch Dis Child Fetal Neonatal Ed 90:F174-F175

2. Christensen RD, Henry E, Andres RL, Bennett ST (2011) Reference ranges for blood concentrations of nucleated red blood cells in neonates. Neonatology 99:289-294

3. Phillips L, Dewhurst CJ, Yoxall CW (2011) The prognostic value of initial blood lactate concentration measurements in very low birthweight infants and their use in development of a new disease severity scoring system. Arch Dis Child Fetal Neonatal Ed 96:F275-80

4. Cremer M, Roll S, Gräf C et al (2015) Nucleated red blood cells as marker for an increased risk of unfavorable outcome and mortality in very low birth weight infants. Early Hum Dev 91:559-563

\section{IH-P02 \\ Retikulozyten-Hämoglobin fällt bei Frühgeborenen in den ersten drei Lebenstagen schneller ab als bei Reifgeborenen}

L. Lorenz ${ }^{1}$, A. Peter ${ }^{2,3,4}$, J. Arand ${ }^{1}$, F. Springer 5 , C. F. Poets ${ }^{1}$, A. R. Franz ${ }^{1,6}$

'Universitätsklinik für Kinder- und Jugendmedizin, Abteilung für Neonatologie, Tübingen, Deutschland, ${ }^{2}$ Deutsches Zentrum für Diabetesforschung, Tübingen, Deutschland, ${ }^{3}$ Institut für Diabetesforschung und Metabolische Erkrankungen des Helmholtz Zentrum München, Tübingen, Deutschland, ${ }^{4}$ Universitätsklinikum Tübingen, Abteilung für Innere Medizin, Endokrinologie und Diabetologie, Angiologie, Nephrologie und Klinische Chemie, Tübingen, Deutschland, ${ }^{5}$ Universitätsklinikum Tübingen, Abteilung für diagnostische und interventionelle Radiologie, Tübingen, Deutschland, ${ }^{6}$ Centre for Pediatric Clinical Studies, Tübingen, Deutschland

Hintergrund: Retikulozyten-Hämoglobin (Ret-He) ist aufgrund der kurzen Lebensdauer der Retikulozyten im Vergleich zum herkömmlichen Erythrozyten-Hämoglobin ein geeigneterer Parameter um einen Eisenmangel nachzuweisen. Im Vergleich mit anderen Parametern wie z. B. Ferritin, Transferrinsättigung oder Hepcidin wird Ret-He im Rahmen der
Retikulozyten-Messung mitbestimmt und verursacht somit keine zusätzlichen Kosten. Da außerdem keine zusätzliche Blutabnahme notwendig ist, erscheint dieser Parameter besonders attraktiv für die Detektion des Eisenmangels bei extrem kleinen Frühgeborenen. Ein postnataler Abfall von Ret-He ist zuvor beschrieben worden, allerdings ist unklar, ob dieser Abfall bei Frühgeborenen (FG) und Reifgeborenen (RG) gleichermaßen stattfindet.

Fragestellung: Ist der postnatale Abfall von Ret-He innerhalb der ersten drei Lebenstage bei FG stärker ausgeprägt als bei RG?

Material und Methoden: Retrospektive Analyse von Ret-He-Werten aus wiederholten klinisch indizierten Differentialblutbild-Untersuchungen durch einen automatischen hämatologischen Zellcounter (Sysmex XE2100, Sysmex GmbH, Norderstedt, Deutschland) im postnatalen Alter von 0,1 bis 74,3 Stunden mittels gepaartem T-Test und mixed-modelling. Ergebnisse: 805 Blutabnahmen von insgesamt 207 RG und 295 FG wurden analysiert. Zwischen der ersten und einer zweiten Blutentnahme zeigte sich ein Ret-He Abfall von einem Mittelwert (SD) von 31,3 $(3,2)$ pg im medianen (IQR) Alter von 1,7 (1,0-2,4) Stunden auf 29,6 (3,3) pg im medianen (IQR) Alter von 24,1 (19,4-29,6) Stunden (Differenz (95\% CI) -1,6 pg $(-2,1$ bis $-1,2), p<0,0001)$. Der Mittelwert (SD) der 3. Blutentnahme im mittleren Alter von 41,0 $(28,3-49,8)$ Stunden betrug 28,2 (3,7) pg (Differenz $(95 \% \mathrm{CI})-1,3 \mathrm{pg}(-2,1$ bis $-0,4), p<0,01)$. Insgesamt fiel der RetHe Wert um 1,5 pg pro Tag (Regressionskoeffizient $-1,5$ (95\% CI $-1,8$ bis $-1,2, p<0,0001)$. Der beobachtete Abfall war bei FG ausgeprägter (Regressionskoeffizient $-2,2(-2,6$ bis $-1,8), p<0,0001)$ als bei RG (Regressionskoeffizient $-0,8(-1,3$ bis $-0,2), p<0,01$, Interaktions $p$-Wert $<0,0001$. Diskussion und Schlussfolgerung: Der postnatale Abfall von Ret-He ist bei FG innerhalb der ersten drei Lebenstage ausgeprägter als bei RG. Bei FG fällt der Ret-He Wert um ca. 2 pg pro Tag während bei RG nur ein Abfall von ca. 1 pg pro Tag nachgewiesen werden konnte. Dieser postnatale Abfall des Ret-He sowie der hier bestehende Unterschied zwischen FG und RG muss bedacht werden, wenn der Ret-He Wert zur Diagnose eines Eisenmangels verwendet werden soll. Zukünftige Studien sind notwendig, um die Ursachen des postnatalen Abfalls und des Unterschieds zwischen Reif- und Frühgeborenen genauer zu untersuchen.

\section{IH-P03}

\section{Amphiregulin (AREG) verringert die Apoptose in neonatalen und adulten Monozyten}

\section{Platen, S. Dreschers, T. Orlikowsky}

Uniklinik Aachen, Kinder- und Jugendmedizin, Sektion Neonatologie, Aachen, Deutschland

Hintergrund: Die neonatale Sepsis führt zu einer Reihe von Folgeerscheinungen (sustained inflammation), die durch inflammatorische Mediatoren, u. a. über Monozyten vermittelt werden. Nach bakterieller Infektion ist der Phagozytose-induzierte Zelltod (PICD) von neonatalen Monozyten über die Signalkaskaden via Fas-Ligand und TNF-alpha kompromittiert. Der autokrine Wachstumsfaktor Amphiregulin (AREG) führt durch Bindung an den EGF-Rezeptor zur Aktivierung des ERK1/2-Signalweges und reguliert u. a. die Aktivierung der Matrix-Metalloprotease (MMP) 9, um über p90, BAD und BclXL die Apoptose zu beeinflussen. MMP9 kann den Fas-Liganden (CD95L) an der Zelloberfläche schneiden.

Hypothese: AREG beeinflusst durch Hoch-Regulation der MMP9 die Apoptose von Monozyten.

Material und Methoden: Phänotypisierung (CD14, CD95L, MMP9) von Monozyten aus Nabelschnurblut (CBMO) und erwachsenen Probanden (PBMO) sowie Apoptose (Niocoletti) mittels Durchflusszytometrie (FACS). Die bakterielle Phagozytose wurde mittels dsRed markierten E.coli gemessen. Caspase -3 und -8 wurden intrazellulär im FACS gemessen. AREG wurde in verschiedenen Konzentrationen zugesetzt.

Ergebnisse: Bei vergleichbaren Phagozytoseraten kam es $24 \mathrm{~h}$ nach Gabe von AREG dosisabhängig zu signifikant verringerter Apoptose bei PBMO und CBMO. AREG führt dabei zu geringerer Caspase-8- und -3-Aktivierung. Die Expression von CD95L auf der Zelloberfläche war bei infizierten CBMO geringer als bei PBMO $(p<0,05)$ und wurde bei beiden 
Populationen durch AREG um $50 \%$ inhibiert ( $p<0,05$ vs. Infektion ohne AREG). AREG führte zur erhöhten MMP9-Expression auf der Zelloberfläche.

Schlussfolgerung: AREG verringert den Phagozytose-induzierten Zelltod von Monozyten (u. a.) durch Hoch-Regulation von MMP9. Die pro-apoptotischen Mechanismen, die bei Monozyten zum PICD führen, sind bei CBMO aufgrund der geringeren CD95L-, MMP9-, Caspase-3- und -8-Aktivität vermindert. Dies kann für den schweren Verlauf einer Infektion von Früh- und Neugeborenen mitverantwortlich sein.

\section{IH-P04 \\ Blutsparende und nicht-invasive Hämoglobin-Messverfahren im Vergleich zum Goldstandard bei Früh- und Neugeborenen}

\section{E. Wittenmeier', L. Lesmeister ${ }^{2}$, I. Schmidtmann ${ }^{3}$, E. Mildenberger'}

${ }^{1}$ Klinik für Anästhesiologie, Universitätsmedizin der Johannes GutenbergUniversität Mainz, Mainz, Deutschland, ${ }^{2}$ Universitätsmedizin der Johannes Gutenberg-Universität Mainz, Mainz, Deutschland, ${ }^{3}$ Institut für Medizinische Biometrie, Epidemiologie und Informatik, Universitätsmedizin der Johannes Gutenberg-Universität Mainz, Mainz, Deutschland, ${ }^{4}$ Neonatologie, Zentrum für Kinder- und Jugendmedizin, Universitätsmedizin der Johannes Gutenberg-Universität Mainz, Mainz, Deutschland

Hintergrund: Die Bestimmung des Hämoglobin-Wertes $(\mathrm{Hb})$ ist eine wichtige Voraussetzung für den rationalen und restriktiven Umgang mit Blutprodukten („Patient Blood Management“). Zur Indikationsstellung und Kontrolle von Bluttransfusionen ist eine exakte Messung des $\mathrm{Hb}$ unerlässlich. Andererseits sollten insbesondere bei Neu- und Frühgeborenen iatrogene Anämien durch die Entnahme von Blutproben und schmerzhafte Maßnahmen vermieden werden. $\mathrm{Hb}$ - Messmethoden, bei denen wenig Blut (blutsparend invasiv) oder gar keine Punktionen nötig sind (nicht-invasiv), könnten daher für Früh- und Neugeborene ideal sein. Bisher wurde kaum untersucht, ob alternative Hb-Messmethoden in dieser Patientengruppe anwendbar und genügend genau sind.

Fragestellung: Die Studie untersucht die Güte alternativer Hb-Messmethoden (invasiv blutsparend bzw. nicht-invasiv) gegenüber dem Goldstandard (Blutbild) bei Neu- und Frühgeborenen.

Material und Methoden: Die Studie wurde nach Zustimmung der zuständigen Ethikkommission durchgeführt. Auf einer neonatologischen Intensiv- und einer Normalstation wurde bei 60 Früh- und Neugeborenen de $\mathrm{Hb}$ mittels Blutbild (labHb, Advia $2120^{\circ}$, Siemens, Referenzmethode), mittels venöser Blutgas-Analyse (BGAHb, $\mathrm{ABL} 800^{\circ}$, Radiometer), mittels bettseitiger Methode aus venösem Blut (HcHbven, HemoCue ${ }^{\infty}, \mathrm{Ra}-$ diometer) und aus kapillarem Blut (HcHbkap) und mittels nicht-invasiver Methode durch einen Sensor (SpHb, Radical-7 $7^{\circ}$ 'Masimo) gemessen. Die Übereinstimmung der alternativen Hb-Messmethoden mit der Referenzmethode (labHb) wurde mittels Bland-Altman-Analyse geprüft, die Genauigkeit der alternativen Methoden untereinander wurde mit dem mittleren quadratischen Fehler verglichen.

Ergebnisse: Der mittlere Unterschied zum Referenzwert („bias“) und die Grenzen, innerhalb derer 95\% der Abweichungen zum Referenzwert liegen („limits of agreement"), betrugen bei BGAHb $-0,1 \mathrm{~g} / \mathrm{dl}$ und $-1,2$ bis $+1 \mathrm{~g} / \mathrm{dl}$, bei HcHbven $-0,3 \mathrm{~g} / \mathrm{dl}$ und $-1,8$ bis $+1,1 \mathrm{~g} / \mathrm{dl}$, bei HcHbcap + $0,7 \mathrm{~g} / \mathrm{dl}$ und $-1,9 \mathrm{bi}+3,2 \mathrm{~g} / \mathrm{dl}$, bei $\mathrm{SpHb}-1,2 \mathrm{~g} / \mathrm{dl}$ und $-4,3$ bis $+2 \mathrm{~g} / \mathrm{dl}$. Der mittlere quadratische Fehler betrug bei BGAHb 0,6 g/dl, bei HcHbven $0,8 \mathrm{~g} / \mathrm{dl}$, bei HcHbcap 1,4 g/dl und bei SpHb 1,9 g/dl. Der Anteil an fetalem Hämoglobin hatte keinen Einfluss auf die Genauigkeit der alternativen Messmethoden. Anämie bzw. Polyglobulie beeinflussten die Genauigkeit der nicht-invasiven Hb-Messung $(r=0,7)$.

Schlussfolgerung: Auch bei Früh- und Neugeborenen kann der $\mathrm{Hb}$ mit alternativen Methoden bestimmt werden. Die nicht-invasive Hb-Bestimmung $(\mathrm{SpHb})$ und die $\mathrm{Hb}$-Bestimmung aus kapillarem Blut mittels $\mathrm{He}$ moCue weichen jedoch klinisch relevant von der Referenzmethode ab und können bei Neu- und Frühgeborenen nicht empfohlen werden. Die Blutgasanalyse aus venösem Blut ist die beste Alternative zum Goldstandard.

\section{IH-P05}

\section{Analysis of immature platelet fraction in very low birth weight} infants

L. Widler', R. Dolscheid-Pommerich' ${ }^{2}$, B. Stoffel-Wagner ${ }^{2}$, A. Müller ${ }^{3}$, S. Bagci ${ }^{3}$ ${ }^{1}$ University of Bonn, Bonn, Germany, ${ }^{2}$ University of Bonn, Department of Clinical Chemistry and Clinical Pharmacology, Bonn, Germany, ${ }^{3}$ University of Bonn, Neonatology and Pediatric Intensive Care Unit, Children's Hospital, Bonn, Germany

Background: In very low birth weight infants (VLBW, birth weight $<1500 \mathrm{~g}$ ), one of the most common haematological problems is thrombocytopenia, which is associated with increased risk of morbidity and mortality. Thrombocytopenia may arise from maternal, placental or fetal/ neonatal origins featuring decreased platelet production, increased consumption, or both mechanisms. Monitoring platelet counts can be supported by monitoring immature platelet fraction (IPF) because measurement of IPF and absolute immature platelet count (AIPC) are valuable parameters for evaluating megakaryopoietic activity.

Aim of the present study was to evaluate IPF and AIPC in AGA (appropriate for gestational age) versus SGA (small for gestational age) VLBW infants and analyze whether this parameter may be as a potentially predictive factor for morbidity and mortality.

Materials and Methods: In 140 (38 SGA, 102 AGA) VLBW infants thrombocyte count and IPF were assessed in the first 24 hours of life with the $\mathrm{XN}-1000^{\text {mix }}$ (Sysmex, Norderstedt, Germany). Descriptive parameters (gestational weeks, gender, birth weight) and blood values are presented as median and interquartile range (IQR). Because variables were not normally distributed, we used the two-tailed non-parametric Mann-Whitney U-test for group comparison. Regression analysis was performed for calculating mortality risk.

Results: Overall IPF values were negatively correlated with platelet counts (Spearman correlation"s coefficient, $\mathrm{r}=-0.341, p=0.00004$ ). This correlation is more significant in SGA VLBW infants than AGA VLBW infants $(\mathrm{r}=-0.602, p=0.00006$ vs. $\mathrm{r}=-0.283, p=0.004)$. Ten $(7.1 \%)$ of the $140 \mathrm{pa}-$ tients died. Regarding survivors versus non survivors, no significant differences were found for gestational age, birth weight, gender and AIPC, whereas thrombocyte count, IPF, surfactant therapy and intracranial hemorrhage (ICH) differed significantly. To identify the factors affecting mortality, we performed a binary logarithmic regression analysis including the following parameters that differed significantly: Thrombocytes, IPF, surfactant therapy and $\mathrm{ICH}$. Moreover, gestational age and birth weight were included as possible relevant factors for mortality. Children with elevated IPF and ICH had an increased risk for mortality $(r=0.492, p<0.001)$. Discussion and Conclusions: Thrombocyte counts and AIPC, butt not IPF, differed significantly between AGA and SGA infants. We also showed that IPF negatively correlate with platelet counts, similar as reported in children and adults. Besides ICH, elevated IPF is a predictive risk factor for mortality in VLBW infants. Future studies should focus on these observations regarding secondary outcomes.

\section{Lunge}

\section{LU-P01}

\section{Less Invasive Surfactant Administration (LISA) in der klinischen Praxis - Eine europaweite Umfrage}

D. Klotz', U. Porcaro' ${ }^{2}$, T. Fleck', H. Fuchs ${ }^{1}$

'Zentrum für Kinder- und Jugendmedizin, Universitätsklinikum Freiburg, Funktionsbereich Neonatologie und Pädiatrische Intensivmedizin, Freiburg, Deutschland, ${ }^{2}$ Second University of Naples, Department of Woman, Child and General and Specialized Surgery, Naples, Italy, ${ }^{3}$ Zentrum für Kinder- und Jugendmedizin, Universitätsherzzentrum Freiburg, Klinik für angeborene Herzfehler/Pädiatrische Kardiologie, Freiburg, Deutschland 
Hintergrund: Unter Studienbedingungen wird LISA aufgrund definierter Indikationen und mittels standardisierten Prozeduren durchgeführt. Über die Häufigkeit der Anwendung von LISA, der Indikationen und Durchführung (Prämedikation, Technik, Equipment) sowie Nebenwirkungen dieser Prozedur außerhalb klinischer Studien liegen keine Daten vor. Fragestellung: Erfassung der Häufigkeit, der Indikationen und Technik von LISA in europäischen neonatologischen Abteilungen. Evaluation der Indikationsstellung, Nebenwirkungen und subjektiv empfundener Effizienz dieser Technik in der klinischen Praxis.

Material und Methoden: Umfrage an 324 europäischen neonatologischen Abteilungen mittels eines strukturierten und stratifizierten webbasierten Fragebogens von Dezember 2016 bis März 2017.

Ergebnisse: 165 Neonatologen unterschiedlicher Abteilungen aus 33 Ländern nahmen an der Umfrage teil (51\%). LISA wurde zum Zeitpunkt der Erhebung in 86 (52\%) dieser Abteilungen durchgeführt. In $41 \%$ war LISA die Standardprozedur zur Surfactantgabe. In 10 Abteilungen wurde die Anwendung von LISA aufgrund hoher Nebenwirkungsraten $(n=4)$, fehlender Evidenz einer Überlegenheit gegenüber Intubation/Insure $(n=6)$ oder niedriger Effektivität ausgesetzt. LISA würden $49 \%$ der Teilnehmer nicht für eine prophylaktische Gabe von Surfactant erwägen, $25 \%$ nicht für eine Behandlung eines milden und $46 \%$ nicht für die Behandlung eines schweren Atemnotsyndroms. 52\% der Teilnehmer führten keine Analgosedierung für LISA durch, ansonsten wurden Atropin (29\%), Opioide (23\%), Ketamin (9\%), Propofol (8\%), Coffein (6\%), Benzodiazepine (5\%) und andere Pharmaka, darunter Muskelrelaxantien (6\%) eingesetzt. $69 \%$ der Teilnehmer beobachteten trachealen Surfactantreflux und 23\% eine einseitige Surfactantdeposition. Desweiteren wurden Bradykardien (41\%), Hypoxämien (34\%) und andere Nebenwirkungen (9\%) beobachtet. Die Effektivität wurde überwiegend als hoch (52\%) bis mittel (33\%) beschrieben, nur $2 \%$ der Teilnehmer schätzen die Effektivität von LISA als sehr niedrig ein. Bei Notwendigkeit einer neuerlichen Surfactantgabe würden $56 \%$ LISA wiederholen. $89 \%$ der Neonatologen ohne bisherige Erfahrung mit LISA würden einen Einsatz erwägen.

Diskussion: LISA ist in europäischen Abteilungen weit verbreitet und wird zunehmend angewendet. Es herrscht eine große Heterogenität in der interindividuellen Indikationsstellung zur Durchführung von LISA hinsichtlich der Ausprägung eines Atemnotsyndroms, des Gestations- und des postnatalen Alters. Ebenso uneinheitlich ist das Vorgehen hinsichtlich der Prämedikation, des praktischen Vorgehens oder des verwendeten Equipments. Die hohen Nebenwirkungsraten in der Durchführung von LISA im klinische Alltag finden sich in den publizierten Interventionsstudien zu dem Thema nicht wider, dennoch wird LISA überwiegend als effektiv bezeichnet. Die Interpretation der Wertigkeit von LISA im klinischen Alltag muss auch die höchst variable Umsetzung dieses Konzeptes berücksichtigen.

\section{LU-P02 \\ Klinische und echokardiographische Risikofaktoren für ein Extubationsversagen bei Kindern mit Kongenitaler Zwerchfellhernie (CDH)}

L. Schröder', H. Reutter', U. Gembruch'², A. Müller', F. Kipfmüller ${ }^{1}$

'Universität Bonn, Zentrum für Kinderheilkunde, Neonatologie und Pädiatrische Intensivmedizin, Bonn, Deutschland, ${ }^{2}$ Universität Bonn, Zentrum für Frauenheilkunde, Geburtshilfe und Pränatalmedizin, Bonn, Deutschland

Hintergrund: Mit einer Prävalenz von 2-4/10.000 Lebendgeburten ist die $\mathrm{CDH}$ eine seltene Fehlbildung. Die $\mathrm{CDH}$ führt zu einer Lungenhypoplasie mit sekundärer pulmonal arterieller Hypertension $(\mathrm{PH})$ und mündet meist in einem akuten neonatalen Atemversagen, mit Notwendigkeit für eine maschinelle Beatmung und evtl. eine extrakorporale Membranoxygenierung (ECMO) [1,2]. Kinder nach einer erfolgten chirurgischen $\mathrm{CDH}-$ Korrektur haben ein hohes Risiko für ein Extubationsversagen, jedoch ist wenig bekannt über die hämodynamischen Auswirkungen des Extubationsversagens auf den kardiopulmonalen Zustand.
Material und Methoden: Es wurden retrospektiv epidemiologische, klinische sowie echokardiographische Daten von 22 Kindern mit einer CDH nach erfolgter chirurgischer CDH-Korrektur im Zeitraum der Jahre 2013 bis 2015 im Uniklinikum Bonn analysiert. Einschlusskriterien waren das Vorliegen einer $\mathrm{CDH}$ und eine durchgeführte Echokardiographie innerhalb von $48 \mathrm{~h}$ vor dem ersten Extubationsversuch. Als Extubationsversagen wurde die Notwendigkeit einer Reintubation innerhalb der ersten $72 \mathrm{~h}$ nach erfolgter primärer Extubation definiert. Das Kollektiv wurde in 2 Subgruppen aufgeteilt: (A) Extubationsversagen und (B) erfolgreiche Extubation.

Ergebnisse: Neun der 22 Kinder zeigten ein Extubationsversagen (Gruppe A). Die Kinder der Gruppe A hatten ein niedrigeres Gestationsalter bei Geburt $(p=0,04)$. In der Gruppe A zeigten signifikant mehr Kinder eine intrathorakale Leberhernierung bei Geburt $(p=0,001)$ und mussten häufiger mittels einer ECMO therapiert werden $(p=0,014)$. Die Oxygenierungsindizes OI (Oxygenation Index) und die $\mathrm{P} / \mathrm{F}$ Ratio $(\mathrm{PaO} 2 \mathrm{mmHg} / \mathrm{FiO} 2)$ unterschieden sich signifikant zwischen beiden Gruppen ( $p=0,006$ bzw. $p=0,005)$. Der unter maschineller Beatmung verwendete mittlere Atemwegsdruck (MAP) lag in Gruppe A deutlich höher $(p=0,004)$ und die prä- und postduktale pulsoxymetrische Sauerstoffsättigung (SpO2) war signifikant niedriger in Gruppe A ( $p=0,003$ bzw. $p=0,014)$. In Gruppe A musste häufiger mit Sildenafil intravenös therapiert werden $(p=0,036)$ und der ,vasoactive inotropic score“ (VIS) lag signifikant höher $(p=0,046)$. Die Gesamtdauer der Beatmung und der stationäre Krankenhausaufenthalt waren signifikant verlängert in Gruppe A ( $p=0,046$ bzw. $p=0,009)$. Kinder der Gruppe A hatten ein höheres Lebensalter zum Zeitpunkt der Extubation ( $p=0,024)$. Der Echo-Parameter "time-to-peak velocity“ (TPV), gemessen in der Pulmonalarterie, zeigte sich signifikant niedriger in Gruppe A $(p=0,041)$ und Zeichen einer PH lagen signifikant häufiger vor zum Zeitpunkt der Extubation in Gruppe A $(p=0,018)$.

Zusammenfassung: Ein Extubationsversagen bei Kindern führt zu einer signifikanten Erhöhung der Morbidität [3]. Besonders Kinder mit einer $\mathrm{CDH}$ haben auf Grund einer vorbestehenden Lungenhypoplasie, einer $\mathrm{PH}$ und einer gestörten Zwerchfellaktivität ein erhöhtes Risiko für ein Atemversagen. Nach unserer Kenntnis ist dies die erste Studie, welche ein Extubationsversagen bei Kindern mit einer $\mathrm{CDH}$ untersucht. Unsere Ergebnisse zeigen auf, dass ein Extubationsversagen bei Kindern mit einer $\mathrm{CDH}$ mit mehreren klinischen und echokardiographischen Risikofaktoren assoziiert ist.

\section{Literatur}

1. McGivern MR, Best KE, Rankin J et al (2015) Epidemiology of congenital diaphragmatic hernia in Europe: a register-based study. Arch Dis Child Fetal Neonatal Ed 100:F137-144

2. Reiss I, Schaible T, van den Hout L et al (2010) Standardized postnatal management of infants with congenital diaphragmatic hernia in Europe: the CDH EURO Consortium consensus. Neonatology 98:354-364

3. Ing C, Chui I, Ohkawa S et al (2013) Incidence and causes of perioperative endotracheal reintubation in children: a review of 28,208 anesthetics. Paediatr Anaesth 23:621-626

\section{LU-P03}

\section{Gas exchange mechanisms in preterm infants on HFOV - a computational approach}

C. J. Roth' ${ }^{1}$, K. Förster ${ }^{2}$, A. Hilgendorff, ${ }^{3}$, B. Ertl-Wagner, ${ }^{4,2}$, A. W. Flemmer ${ }^{3,2}$, W. A. Wall ${ }^{1}$

'Technical University of Munich, Institute for Computational Mechanics, Munich, Germany, ${ }^{2}$ Comprehensive Pneumology Center, Helmholtz Zentrum München, Member of the German Lung Research Center (DZL), Munich, Germany, ${ }^{3}$ Ludwig-Maximilian University, Dept. of Neonatology, Perinatal Center Grosshadern, Dr. von Hauner Children's Hospital, Munich, Germany, ${ }^{4}$ Ludwig-Maximilian University Hospital, Institute for Clinical Radiology, Munich, Germany

Objective: Many preterm infants require ventilatory support due to respiratory distress syndrome during the first weeks of life. High-frequency oscillatory ventilation (HFOV) is an alternative ventilation strategy that 
is commonly used in neonatology. We aimed to assess the exact underlying mechanisms of gas exchange in HFOV in preterm infants by a computational approach.

Methods: We currently evaluate longitudinal data of preterm infants born $<32$ weeks of gestational age and/or $<1500 \mathrm{~g}$ birth weight (AIRR study cohort). Spatially and temporally highly resolved computational fluid and gas-transport dynamics modelling techniques were applied to the dataset of a neonatal lung MRI and a neonatal lung-mechanical measurement in a body plethysmograph from a former extremely preterm infant, which developed a bronchopulmonary dysplasia $\mathrm{III}^{\circ}$. In silico methods were applied to an imaging-based approach of simulated high frequency ventilation under representative ventilator settings.

Results: Our novel modelling approach supports previously suggested mechanisms of gas flow within the infants airways. In addition, we were able to provide a dynamic model with spatially distinct gas transport within different areas of the lung. We detected the following six gasflow mechanisms that facilitate gas exchange in preterm lungs during HFOV:

i) Turbulence; ii) Asymmetric in- and expiratory flow profiles; iii) Turbulent flow; iv) Laminar flow in higher generations of the respiratory tract; v) Pendelluft; vi) Direct ventilation of central alveoli.

Conclusions: In silico modelling of gas flow provides detailed insight into pulmonary airflow. By using lung imaging and lung-mechanical data from a given patient individual ventilator settings could be tested. In addition, our results advance general knowledge on HFOV applied to preterm infants after birth by detecting gas transport phenomena that have never been seen or measured before. Thus, our results lead to a better understanding of gas transport in HFOV.

\section{LU-P04 \\ Management des neonatalen Respiratory Distress Syndrome (RDS): Eine nationale Umfrage}

K. Schwalbe', H. Maul', L. Koch ${ }^{2}$

'Katholisches Marienkrankenhaus, Frauenklinik, Hamburg, Deutschland, ${ }^{2}$ Katholisches Kinderkrankenhaus Wilhelmstift, Neonatologie und Pädiatrische Intensivmedizin, Hamburg, Deutschland

Hintergrund: Das neonatale RDS macht den größten Anteil der Morbidität und Mortalität bei Frühgeborenen aus. Doch die Mortalität auch von sehr kleinen Frühchen kann signifikant gesenkt werden, wenn diese auf der Grundlage evidenzbasierter Richtlinien versorgt werden. Die European Consensus Guidelines on the Management of Neonatal Respiratory Distress Syndrome geben Klinikern Therapieempfehlungen, basierend auf aktueller wissenschaftlicher Evidenz, an die Hand, mit dem Ziel, die Chance auf Überleben sowie das Outcome für Kinder mit RDS zu optimieren. Fragestellung: Ziel der vorliegenden Arbeit war herauszufinden, inwieweit diese Empfehlungen im klinischen Alltag in deutschen Perinatalzentren umgesetzt werden

Material und Methoden: Um Informationen zur Vorgehensweise bei der Behandlung des Atemnotsyndroms Frühgeborener zu erhalten, wurde ein Fragebogen mit dem Titel Management des neonatalen RDS erstellt und zur Beantwortung an 221 deutsche Perinatalzentren verschickt.

Ergebnisse und Diskussion: Insgesamt ergibt sich eine Zahl von 105 beantworteten Fragebögen, wovon 78 (74,3\%) vollständig und 27 (25,7\%) unvollständig beantwortet wurden. Insgesamt wurden 41 Fragen gestellt, von denen hier nur eine Auswahl präsentiert werden kann.

Die Fragen 16 und 17 der Online-Umfrage thematisieren die verwendeten Surfactant-Präparate sowie deren Dosierungen. Poractant alfa ist das am häufigsten verwendete Präparat. Es wird meist in einer Dosierung von $100 \mathrm{mg} / \mathrm{kg}(61,8 \%)$, aber auch $200 \mathrm{mg} / \mathrm{kg}(32,4 \%)$ gegeben. Von Bovactant wird, wenn verwendet, meist $100 \mathrm{mg} / \mathrm{kg} / \mathrm{Dosis}(70,7 \%)$ verabreicht. Nur eine der befragten Personen gab an, Beractant zu verwenden. Dieses Ergebnis deckt sich nicht mit den Empfehlungen der European Consensus Guidelines.

Obwohl die endotracheale Intubation mit anschließender maschineller Beatmung nach wie vor die am weitesten verbreitete Technik zur Applikation von Surfactant darstellt $(41,0 \%)$, kommen weniger oder nicht- invasive Applikationsformen wie INSURE $(25,0 \%)$ oder LISA $(34,0 \%)$ zunehmend häufiger zur Anwendung (Frage 18) und spiegeln so die Empfehlungen der European Consensus Guidelines wider.

Noch vor wenigen Jahren galt die prophylaktische Surfactant-Gabe, verbunden mit Intubation und maschineller Beatmung, bei Frühgeborenen mit Risiko für ein RDS als Strategie mit den besten Überlebenschancen und war gängige Praxis. Heute, wo die Verwendung von pränatalen Kortikosteroiden zum Standard gehört, ist man zu einem anderen Therapieregime übergegangen und propagiert den frühzeitigen Einsatz von CPAP sowie die selektive Gabe von Surfactant. Immerhin noch 53,5\% geben in der Online-Befragung an, Surfactant auch prophylaktisch zu verwenden (Frage 19). Hauptgrund hierfür ist eine frühe SSW (Frage 20), obwohl in der aktuellen Literatur nicht empfohlen wird, eine prophylaktische oder selektive Applikation vom Gestationsalter abhängig zu machen.

Das durchschnittliche Alter, bis zu welchem Surfactant prophylaktisch verabreicht wird, wurde mit 27+4 SSW angegeben (Frage 21). Die FiO2Grenzwerte für rescue Surfactant wurden im Median exakt so angegeben, wie von den European Consensus Guidelines empfohlen, allerdings jeweils mit einer großen Range (Frage 23 und 24).

Schlussfolgerung: Die Behandlung des RDS ist nicht immer leitlinienkonform, doch einige der Empfehlungen der European Consensus Guidelines sind in die gegenwärtige klinische Routine integriert.

\section{LU-P05 \\ Der Einfluss von Less Invasive Surfactant Administration (LISA) auf das respiratorische Outcome von sehr kleinen Frühgeborenen}

V. Marino, L. Kirchner, K. Klebermass-Schrehof, A. Berger

Medizinische Universität Wien, Klinische Abteilung für Neonatologie, Pädiatrische Intensivmedizin und Neuropädiatrie, Wien, Österreich

Hintergrund: Das Respiratory distress syndrome, bedingt durch einen Mangel an Surfactant, gehört zu den häufigsten Problemen sehr kleiner Frühgeborener. Es gibt unterschiedliche Methoden der Surfactantverabreichung. An der neonatologischen Intensivstation der medizinischen Universität Wien wird seit 2008 die sogenannte „Less Invasive Surfactant Administration" (LISA) durchgeführt. Surfactant wird dabei unmittelbar nach der Geburt mittels einer dünnen Magensonde intratracheal appliziert, während die Frühgeborenen am nasalen CPAP spontan atmen.

Fragestellung: Ziel der vorliegenden retrospektiven Analyse war es, aufzuzeigen, inwieweit das respiratorische Outcome sehr kleiner Frühgeborener durch dieses Management verbessert werden kann.

Patienten und Methoden: In die Studie wurden alle Frühgeborenen mit einem Gestationsalter von $23+0$ bis $27+6$ SSW, die zwischen 01/2009 und $12 / 2015$ an der neonatologischen Intensivstation der medizinischen Universität Wien mit „Less Invasive Surfactant Administration“ behandelt wurden, eingeschlossen. Frühgeborene mit demselben Gestationsalter, die zwischen 01/2005 und 12/2007 nach damaligem Standard behandelt wurden, dienen als historische Kontrollgruppe.

Ergebnisse: In der Studiengruppe waren 594 Patienten, in der Kontrollgruppe 182. Die Überlebensrate betrug in der Studiengruppe $80 \%$, in der Kontrollgruppe 64,1\% ( $p<0,001)$. In der Studiengruppe wurden 58,8\% der Patienten während ihres stationären Aufenthaltes invasiv beatmet, in der Kontrollgruppe waren es $78 \%(p<0,001)$. Am 28. Lebenstag benötigten $67,2 \%$ in der Studiengruppe O2 im Vergleich zu 76,9\% in der Kontrollgruppe $(p<0,001)$. In der 36 . SSW benötigten $21,4 \%$ der Überlebenden aus der Studiengruppe O2, in der Kontrollgruppe waren es 17,5\% (n.s.). Der Anteil an schwerer Frühgeborenenretinopathie betrug in der Studiengruppe 14,3\%, in der Kontrollgruppe 12,9\% (n.s.).

Schlussfolgerung: „Less Invasive Surfactant Administration“ hat an der neonatologischen Intensivstation der medizinischen Universität Wien zu einer deutlichen Verbesserung des respiratorischen Outcomes sehr kleiner Frühgeborener geführt. 


\section{LU-P06 \\ Einfluss von Steroiden auf die Funktion von pulmonalen Surfactant}

\section{G. Stichtenoth, G. Walter, E. Herting}

Universität zu Lübeck, Kinderklinik/Neonatologie, Lübeck, Deutschland

Hintergrund: Bei extrem kleinen Frühgeborenen erfolgt zur Prävention eines Atemnotsyndroms oder einer Bronchopulmonalen Dysplasie (BPD) eine prophylaktische Gabe von exogenem Surfactant gewonnen aus Tierlungen. Dieses ist bei niedrigen Konzentrationen sensibel gegenüber Inaktivierung. Die exakte alveoläre Konzentration von Surfactant ist unbekannt. Mehrere klinische Studien untersuchten den Effekt der topischen frühen Budesonid-Aerosol- oder Surfactant-Budesonid-Gabe in Bezug auf das Outcome BPD.

Fragestellung: Welchen Effekt haben topische Steroide auf die Funktion von Surfactant.

Material und Methoden: Surfactant $(80 \mathrm{mg} / \mathrm{ml}$ Phospholipide) wurde lipidextrahiert und in der Chloroform-Phase mit Budesonid, Fluticason oder Dexamethason im Verhältnis $10 \%, 1 \%$ und $0,1 \%(\mathrm{w} / \mathrm{w})$ vermischt. Surfactant ohne Steroide diente zur Kontrolle. Nach Evaporation erfolgte eine Resuspension in $\mathrm{NaCl}$ 0,9\%. Die Oberflächenaktivität der Präparationen wurde in einem Pulsating Bubble Surfactometer (PBS) bei einer Konzentration von $2,5 \mathrm{mg} / \mathrm{ml}$ von und in einem Captive Bubble Surfactometer (CBS) bei einer Konzentration von $20 \mathrm{mg} / \mathrm{ml}$ bei $37^{\circ} \mathrm{C}$ gemessen. Ergebnisse: Im PBS zeigen sich unter zyklischer Kompression der Oberfläche einer Luftblase um $50 \%$ stets niedrige minimale Oberflächenspannungen $\left(\gamma_{\min }\right)$ bei allen Surfactant/Steroid-Präparationen im Verhältnis $1 \%$ und $0,1 \%$. Bei hohen Konzentrationen von Dexamethason und Budesonid (Surfactant/Steroid $=10 \%$ ) ist die Oberflächenspannung im Vergleich zur Kontrolle signifikant erhöht. Fluticason führt zu einer leichten, aber nicht signifikanten Erhöhung der Oberflächenspannung. Im CBS zeigen sich bei höheren Surfactantkonzentrationen keine Unterschiede zwischen den Präparationen.

Diskussion: Der Zusatz von $<10 \%$ Steroiden im Vergleich zu SurfactantPhospholipiden interferiert nicht mit der Oberflächenaktivität. Eine Surfactantfunktionseinschränkung kann nur bei Zusatz von $10 \%$ Dexamethason oder Budesonid bei niedrigen Surfactantkonzentrationen im PBS gefunden werden. Diese Inaktivierung wird durch Erhöhung der Surfactantkonzentration aufgehoben. Fluticason als lipophilste Steroidpräparation scheint einen geringeren Effekt auf die Oberflächenaktivität zu haben.

\section{LU-P07}

\section{Soluble receptor for advanced glycation endproducts als prognostischer Marker bei Neugeborenen mit angeborener Zwerchfellhernie}

F. Kipfmüller', S. Holdenrieder', K. Heindel', P. Bartmann', A. Müller ${ }^{1}$ 'Universitätskinderklinik Bonn, Neonatologie und pädiatrische Intensivmedizin, Bonn, Deutschland, ${ }^{2}$ Universitätsklinikum Bonn, Klinische Chemie und Pharmakologie, Bonn, Deutschland

Hintergrund: Neonaten mit angeborener Zwerchellhernie (CDH) entwickeln in der Regel unmittelbar postpartal ein respiratorisches Versagen unterschiedlichen Schweregrades. Neben einer hohen Mortalität besteht das Risiko einer beatmungsbedingten Lungenschädigung. In verschiedenen Studien konnte gezeigt werden, dass die Konzentration des soluble receptor for advance glycation endproducts (sRAGE) im Blut bei Erwachsenen und Kindern mit ARDS mit dem Outcome korreliert. sRAGE ist als damage-associated molecular pattern für die Detektion und Bindung u. a. von freier DNA und anderen Zellbestandteilen verantwortlich.

Fragestellung: Untersucht wurde, ob sRAGE mit der Schwere des Atemversagens bei Kindern mit $\mathrm{CDH}$ korreliert.

Methoden: Im Rahmen einer prospektiven Observationsstudie an $30 \mathrm{Neo}-$ naten mit $\mathrm{CDH}$ wurde die sRAGE Konzentration im Alter von 6, 12, 24 und 48 Stunden bestimmt (Quantikine, R\&D Systems, Abingdon, UK). Da die ECMO eine Rescue-Therapie bei schwererem Atemversagen ist, wurde das Kollektiv in eine ECMO- (Gruppe 1) und eine non-ECMO-Gruppe
(Gruppe 2) unterteilt. Berechnung der optimaler Cut-Off-Werte mit ROCAnalyse. Korrelationen wurden mittels Pearsons- oder Spearman-RankKoeffizient berechnet.

Ergebnisse: 11 Neonaten wurden der Gruppe 1 zugeordnet und mit 19 Neonaten in Gruppe 2 vergleichen. Es zeigten sich keine signifikanten Unterschiede zwischen den Gruppen in Bezug auf Gestationsalter, Geburtsgewicht, Nabelarterien-pH, betroffener Seite und Rate an pränatalen Interventionen. Kinder in Gruppe 1 hatten ein signifikant niedrigeres Lungenvolumen (o/e LHR $36 \%$ vs. $42 \%, p=0,025)$ und häufiger eine intrathorakale Leber ( $73 \%$ vs. $21 \%, p=0,018$ ). Folgende sRAGE Konzentrationen (in pg/ml) wurden für Gruppe 1 vs. Gruppe 2 gemessen: 6 h: 5923 vs. 2792 ( $p=0,001) ; 12$ h: 5564 vs. 2167 ( $p=0,004) ; 24$ h: 2579 vs. 1672 ( $p=0,066)$; 48 h: 2005 vs. $1256(p=0,032)$. Die sRAGE Konzentrationen mit 6 und 12 Stunden korrelierten signifikant mit der Dauer der maschinellen Beatmung und mit der Höhe des mittleren Atemwegdruckes (MAP), nicht aber mit dem $\mathrm{PaO} 2$ oder dem $\mathrm{PaCO} 2$. sRAGE im Alter von $6 \mathrm{~h}(\mathrm{r}=0,668$; $p=<0,001)$ und $12 \mathrm{~h}(\mathrm{r}=0,510 ; p=0,007)$ korrelierte signifikant mit der Mortalität. Zur Vorhersage der ECMO-Therapie nach $6 \mathrm{~h}$ ergab sich ein Cut-Off Wert von 3600 pg/ml (AUC 0,878; $p=0,001$ ) mit einer Sensitivität von $90 \%$ und einer Spezifität von $72,2 \%$.

Diskussion: Wir beobachteten signifikant höhere sRAGE-Werte bei Neonaten mit $\mathrm{CDH}$ die eine ECMO-Therapie benötigten. Die Werte korrelieren stark mit der Intensität der Beatmung und lassen eine prognostische Aussage bzgl. Mortalität und Beatmungsdauer zu. Dieser Unterschied ist besonders früh nach Geburt ( 6 und 12 Std.) ausgeprägt. Im Alter von 24 und $48 \mathrm{Std}$. sind basierend auf den gemessenen Konzentrationen, prognostische Aussagen nur eingeschränkt möglich. Dies könnte möglicherweise in Assoziation mit einer Reduktion der Beatmung nach ECMO-Beginn stehen. Unsere Ergebnisse bestätigen bisherige Studien, die sRAGE eine Bedeutung bei ARDS zuordnen.

Schlussfolgerung: Bei Neugeborenen mit $\mathrm{CDH}$ ist sRAGE ein prognostisch wertvoller Marker zur Beurteilung des Schweregrades der Erkrankung.

\section{Neonatologisches Outcome}

\section{NO-P01}

Feto-Fetales Transfusionssyndrom (FFTS): Langzeitentwicklung nach intrauteriner Laserkoagulation

D. Müller', B. Busch', K. Hecher', P. Bartmann'

'Universitätsklinikum Bonn, Kinderklinik, Forschungsgruppe für Langzeitstudien, Bonn, Deutschland, ${ }^{2}$ Universitätsklinikum Hamburg, Klinik für Geburtshilfe und Pränatalmedizin, Hamburg, Deutschland

Hintergrund: Intrauterine Laserkoagulation der interfetalen Gefäßanastomosen ist eine kausale Therapieoption bei FFTS. Daten bezüglich der Langzeitentwicklung über die frühe Kindheit hinaus sind dennoch rar. Fragestellung: Untersucht wurde die Langzeitentwicklung im Schulalter für Patienten nach einer zwischen 1995 und 1999 durchgeführten Lasertherapie mit besonderem Augenmerk auf die Unterschiede zwischen Donor und Akzeptor.

Material und Methoden: 193/203 Kindern konnten kontaktiert werden, um mit Hilfe von Elternfragebögen und Schulzeugnissen der 4. und 6. Klasse in die Studie einzugehen. Wir erhielten 179 Fragebögen (93\%) und 152 Zeugnisse (79\%). Wenn es möglich war, wurden die Ergebnisse mit aus verschiedenen Quellen stammenden Daten der gesamten deutschen Bevölkerung verglichen.

Ergebnisse: Im Vergleich zwischen Donor und Akzeptor fanden sich Trends ohne statistischen Signifikanzen in folgenden Bereichen: Donatoren wurden etwas häufiger verspätetet in die 1. Klasse eingeschult als Akzeptoren (18,8\% zu 16\%). Außerdem besuchten Akzeptoren in der 6. Klasse 1,6 mal häufiger ein Gymnasium als Donatoren (40,3\% zu 25\%). Des Weiteren traten bei Akzeptoren häufiger als bei Donatoren Beeinträchtigungen jeglicher Art im Sinne von Paresen, Organerkrankungen, 
Lernschwächen etc. auf (31,3\% zu 23,8\%). Bei einer Einteilung in geistige und körperliche Beeinträchtigungen fällt auf, dass Akzeptoren wesentlich häufiger rein körperliche Handikaps hatten (70\% zu 47,4\%), wohingegen Donatoren häufiger eine Kombination aus geistiger und körperlicher Beeinträchtigung aufwiesen (31,6\% zu 13,3\%). Fast keine Unterschiede fanden sich dagegen hinsichtlich des Einschulungsalters, der Förderschulquote in der 4. Klasse, der Notendurchschnitte in der 4. Und 6. Klasse, der Fächernoten, der Klassenwiederholungsquote, der Rate an ärztlich diagnostizierten Verhaltensauffälligkeiten und der Inanspruchnahme von Fördermaßnahmen.

Diskussion und Schlussfolgerung: Im Vergleich zwischen Donor und Akzeptor zeigen sich nach einer Lasertherapie in der längerfristigen Entwicklung nur geringfügige Unterschiede. Setzt man die Ergebnisse jedoch mit der deutschen Allgemeinbevölkerung in Beziehung so zeigt die Studie sowohl für Donatoren als auch für Akzeptoren einen erhöhten Anteil verspäteter Einschulungen, eine höhere Rate an Handikaps und ein nach Elterneinschätzungen häufigeres Auftreten von Verhaltensauffälligkeiten. Förderung: Unterstützt mit Mitteln der Pascher-Stiftung.

\section{NO-P02 \\ Entwicklungsprognose durch Münchener funktionelle Entwicklungsdiagnostik (MÜFED) im ersten Lebensjahr - Korrelation der Ergebnisse zur Bayley Testung mit 2 Jahren \\ S. Trepels-Kottek', K. Student ${ }^{1}$, A. Schoberer ${ }^{2}$, M. Schoberer', M. Häusler', T. Orlikowsky' \\ 'UK Aachen, Sektion Neonatologie und Pädiatrische Intensivmedizin, Aachen, Deutschland, ${ }^{2}$ UK Aachen, Sektion Neuropädiatrie und Sozial Pädiatrisches Zentrum, Aachen, Deutschland}

Hintergrund: Entsprechend des GBA Beschlusses sollen Frühgeborene unter 32 Schwangerschaftswochen oder unter 1500 Gramm Geburtsgewicht mit korrigiert 24 Monaten einer Nachuntersuchung mit Bayley Testung im Perinatalzentrum, in dem sie geborenen wurden, zugeführt werden.

Fragestellung: Wir untersuchten, inwieweit in dieser Gruppe Untersuchungen bereits im ersten Jahr einen langfristigen Aussagewert haben. Dazu werden die Ergebnisse der MÜFED mit korrigiert 3 und 12 Monaten mit den Ergebnissen der Bayley Testung mit 24 Monaten verglichen. Es sollten die Bereiche identifiziert werden, die die beste Prognosewahrscheinlichkeit für die langfristige Entwicklung bietet.

Patienten und Methoden: Eingeschlossen wurden 166 Frühgeborene unter 32 SSW oder einem Geburtsgewicht unter $1500 \mathrm{~g}$, die im ersten Lebensjahr 2 Untersuchungen mittels MÜFED erhielten aufgeschlüsselt in einen motorischen Bereich (Krabbelalter, Sitzalter, Laufalter, Greifalter) und einen nicht-motorischen Bereich (Perzeptionsalter, Sozialalter, Sprechalter, Sprachverständnisalter [nur mit 12 Monaten]). Außerdem wurde mit 2 Jahren der Psychomental Development Index (PDI, motorische Skala) und der Mental Development Index (MDI, kognitive Skala) der Bayley Scale of Infant Development II (BSIDII) erfasst.

Ergebnisse: Im Vergleich der erzielten Ergebnisse mit 3 Monaten und 24 Monaten zeigt sich, dass die erreichten Mittelwerte für den PDI wie auch für den MDI der BSID II signifikant höher sind, wenn die Kinder in allen motorischen Bereichen der Münchener funktionellen Entwicklungsdiagnostik mit drei Monaten eine altersentsprechende Entwicklung erreichen (PDI 92,59 vs. 83,92 ; MDI 93,88 vs. 85,64 ). Auf einem Signifikanzniveau von alpha $=5 \%$ ergibt sich für den PDI ein $p$-Wert von 0,0021 , für den MDI liegt der $p$-Wert bei 0,0094. Kinder. Für die Abweichung im nichtmotorischen Bereich der MFED ergibt sich ein signifikanter Unterschied ( $p=0,0040)$ für den MDI $(93,97$ vs. 85,01), ein nicht-signifikanter für den PDI ( $p=0,312$, PDI 89,62 vs. 84,91$)$.

Im Vergleich zwischen 12 und 24 Monaten erkennt man, dass die Kinder ohne Entwicklungsverzögerung im motorischen Bereich einen im Mittel signifikant höheren PDI $(92,07$ vs. 80,63) und MDI $(94,04$ vs. 82,22) erzielen als die Kinder, die Abweichungen im Entwicklungsalter der MÜFED zeigen ( $p$-Wert PDI liegt $<0,0001, p$-Wert MDI 0,0002).

Wenn mit 12 Monaten keine Entwicklungsverzögerungen im nicht-motorischen Bereich der MÜFED festzustellen sind, sind die Mittelwerten für den PDI (92,67 vs. 83,$02 ; p=0,0003)$ und den MDI (96,88 vs. 83,02 ; $p=0,0001$ ) signifikant höher, als bei Kindern mit erkannten Entwicklungsverzögerungen.

Schlussfolgerung: Die MÜFED kann im ersten Lebensjahr zur Erkennung von Risikokindern eingesetzt werden, um zusätzliche Fördermaßnahmen einzuleiten, die die weitere Entwicklung und unter Umständen das Outcome mit 24 Monaten verbessern können.

\section{NO-P03}

Frühgeborenen-Retinopathie und infantiler Hämangiome bei Frühgeborenen: Eine Analyse der Geburtenjahrgänge 2000-2015 der Universitätsklinik Bonn

\section{E. A. Alsat, A. Müller, S. Bagci}

Universitätsklinikum Bonn, Neonatologie und Pädiatrische Intensivmedizin, Bonn, Deutschland

Hintergrund: Bei Frühgeborenen mit infantilem Hämangiom wurde eine erhöhte Inzidenz von Frühgeborenen Retinopathie (ROP) festgestellt. Ob diese Assoziation eine Relevanz auf Diagnostik und Therapie einer ROP hat, ist derzeit nicht hinreichend untersucht.

Fragestellung: 1. Lassen sich unterschiedliche Risikofaktoren für eine ROP bei Patienten mit infantilem Hämangiom ermitteln? 2. Haben Patienten mit infantilen Hämangiom eine andere Verteilung von Schweregrad und somit Therapiebedürtigkeit einer ROP? 3. Ist für Patienten mit infantilem Hämangiom ein gesondertes ROP Screening indiziert?

Material und Methoden: In einer retrospektiven Analyse wurden 1680 Frühgeborene untersucht, die zwischen dem 01.01.2000 und dem 31.12.2015 vor der vollendeten 33. SSW lebend geboren und/oder als Neugeborene im Perinatalzentrum der Universität Bonn behandelt wurden. Die ermittelten Daten des gesamten Kollektivs wurden mit denen in diesem Zeitraum behandelten Patienten mit den Diagnosen neonatales infantiles Hämangiom und/oder Frühgeborenen-Retinopathie gegenübergestellt.

Ergebnisse: $55,3 \%$ ( $n=929)$ waren männliche, 44,7\% ( $n=751)$ weibliche Patienten. Das durchschnittliche (SD) Gestationsalter lag bei 29,5 $( \pm 2,6)$ SSW. Die Kinder lagen mit ihrem Geburtsgewicht durchschnittlich bei $1294 \mathrm{~g}( \pm 487 \mathrm{~g})$. Bei 8,8\% $(n=139)$ der Kinder wurde ein infantiles Hämangiom diagnostiziert. Bei 13,0\% $(n=218)$ trat eine ROP auf. Bei[SB1] $20,9 \%(n=29)$ der Kinder mit einem infantilen Hämangiom wurde auch eine ROP diagnostiziert. Im Vergleich zum Gesamtkollektiv, das Risiko einer ROP bei Vorliegen eines infantilen Hämangioms ist signifikant erhöht ( $p$-Wert: 0,0078). Für die metrischen Merkmale wie SSW, Geburtsgewicht, Alter der Mutter, 5-Minuten-APGAR und max. FiO2 gab es keinen signifikanten Unterschied zwischen Patienten mit ROP und Patienten mit infantilem Hämangiom und ROP. Bei keinem der nominalen Merkmale Geschlecht, HELLP, Hypoxie, IUGR, IVH, Mehrlingsschwangerschaft, O2 bis 28d, Präeklampsie/Eklampsie, Sepsis, SGA, Surfaktant-Gabe oder Transfusionen lag kein erhöhtes Risiko bei Patienten mit infantilem Hämangiom vor. Das Risiko an einer höhergradigen ROP ( $>$ Stadium 2) zu erkranken ist bei Kindern mit Hämangiom nicht erhöht. Das Risiko für Kinder mit Hämangiom im Vergleich zum Gesamtkollektiv eine ROP Therapie zu benötigen ist ebenfalls nicht erhöht.

Schlussfolgerung: Infantile Hämangiome sind signifikant mit einem erhöhten Auftreten einer ROP insgesamt im Vergleich zum Gesamtkollektiv assoziiert. Die erhöhte Inzidenz ist liegt bei niedrigeren ROP Stadien. Höhergradige und Therapiebedürftige ROP treten bei Kindern mit infantilem Hämangiom nicht vermehrt auf. Ein gesondertes ROP-Screening für Frühgeborenen mit intantilem Hämangiom ist somit nicht indiziert. 
NO-P04

\section{Retrospektive Datenanalyse zum neurologischen Outcome mittels Bayley Scales of Infant and Toddler Development im Alter von korrigiert 24 Monaten bei Frühgeborenen mit $1250 \mathrm{~g}$ Geburtsgewicht}

I. J. Broekaert' ${ }^{1}$ A. Sorce', J. Gilsbach', A. Mennemann', A. Ernst ${ }^{2}$, W. Fazeli', T. Keller', C. Düchting' ', B. Hero', C. Hünseler', A. Kribs'

'Universitätskinderklinik Köln, Universität zu Köln, Medizinische Fakultät, Köln, Deutschland, ${ }^{2} I M S I E$, Universität zu Köln, Köln, Deutschland

Hintergrund: Durch das verbesserte Überleben extrem Frühgeborener in den letzten Jahrzenten ist das neurologische Outcome in den Vordergrund getreten. Die Bayley Scales of Infant and Toddler Development (BSID) sind eine etablierte Methode, um das Langzeit-Outcome im korrigierten Alter von 24 Monaten zu untersuchen. Die retrospektiven Daten dieser Studie wurden im Rahmen einer geplanten Studie bei extrem Frühgeborenen, welche multizentrisch den enteralen Nahrungsaufbau und das neurologischen Outcome untersucht, erhoben.

Methode: Daten von 241 Frühgeborenen, die in den Jahren 2010-2015 an der Universitätskinderklinik Köln geboren wurden, wurden retrospektiv ausgewertet. Die BSID-II wurden bis 2011 und die BSID-III ab 2010 eingesetzt. Es wurde nach Untergruppen ausgewertet (Gruppe $1<26+0$ SSW und Gruppe $2 \geq 26+0$ SSW; Gruppe A Developmental Index (Entwicklungsalter/chronologisches Alter) für die Skala Kognition $\geq 1$; Gruppe B Developmental Index für die Skala Kognition $<1)$. Zur statistischen Auswertung wurde der X2-Test angewendet ( $\alpha=5 \%)$.

Ergebnisse: Bei 160 (70 Mädchen) von 241 ehemaligen Frühgeborenen wurden im Alter von $27 \pm 2$ Monaten die BSID-II bzw. im Alter von $28 \pm 4$ Monaten die BSID-III durchgeführt. Von den 160 Frühgeborenen zeigten 8 eine $\mathrm{ICH}^{\circ} \mathrm{III}(6<26$ SSW vs. $2 \geq 26 \mathrm{SSW}), 10$ eine $\mathrm{ICH}{ }^{\circ} \mathrm{II}(8$ vs. 2$)$, und 17 eine $\mathrm{ICH}^{\circ} \mathrm{I}\left(8\right.$ vs. 9). Frühgeborene mit einer $\mathrm{ICH}^{\circ} \mathrm{III}$ wurden aus der Analyse ausgeschlossen.

In Gruppe 1 (MW 24+3 SSW) zeigte sich ein kognitives Entwicklungsalter von 17,6 Monaten bei einem chronologischen Alter von 26,5 Monaten in den BSID-II (12 Frühgeborene) sowie ein kognitives Entwicklungsalter von 23,0 Monaten bei einem chronologischen Alter von 28,5 Monaten in den BSID-III (49 Frühgeborene). In Gruppe 2 (MW $28+3$ SSW) zeigte sich ein kognitives Entwicklungsalter von 24,6 Monaten bei einem chronologischen Alter von 27,4 Monaten in den BSID-II (30 Frühgeborene) sowie ein kognitives Entwicklungsalter von 25,7 Monaten bei einem chronologischen Alter von 28,5 Monaten in den BSID-III (50 Frühgeborene). Insgesamt zeigten 41 von 160 Frühgeborenen einen Developmental Index für die Skala Kognition $\geq 1$ (MW 1,07 in den BSID-II bzw. 1,03 in den BSID-III) (Gruppe A). Die restlichen Frühgeborenen $(n=119)$ zeigten einen Developmental Index für die Skala Kognition $<1$ (MW 0,79 in den BSID-II bzw. 0,81 in den BSID-III) (Gruppe B). Beim Vergleich von Gruppe A und B zeigt sich für Gruppe A ein Trend für ein höheres mittleres Gestationsalter ( 28,47 vs. 26,50 SSW) $(p=0,019)$, ein tendenziell höheres mittleres Geburtsgewicht ( $929 \pm 175$ vs. $818 \pm 258$ g), ein geringerer Einsatz an Antibiotika (1,4 $\pm 1,2$ vs. $2,3 \pm 1,4$ Antibiotikazyklen) $(p=0,017)$, sowie eine tendenziell höhere Rate ausschließlicher Muttermilchernährung bei Entlassung (78 vs. $64 \%)$.

Diskussion: Das neurologische Langzeit-Outcome extrem Frühgeborener wird u. a. durch das Gestationsalter und das Geburtsgewicht beeinflusst. Ein niedrigeres Auftreten postpartaler Infektionen gemessen an dem Einsatz an Antibiotika und einer höheren Rate ausschließlicher Muttermilchernährung bei Entlassung sind beeinflussbare Faktoren, die einen positiven Einfluss auf das neurologische Langzeit-Outcome haben. Ziel der prospektiv angelegten Studie ist es, den enteralen Nahrungsaufbau bei extrem Frühgeborenen zu optimieren und den Einfluss auf das neurologische Outcome zu untersuchen.
NO-P05

Korrelieren die Volumina der Seitenventrikel und der Basalganglien mit dem neurologischen Outcome von sehr unreifen Frühgeborenen?

T. Storbeck', B. Hüning ', F. Dransfeld', J. Hobrecht', S. Sirin', B. Schweiger², C. Weiss ${ }^{3}$, U. Felderhoff-Müser ${ }^{1}$, H. Müller ${ }^{1}$

'Uniklinikum Essen, Kinderheilkunde I (Neonatologie, Neuropädiatrie, päd. Intensivmedizin), Essen, Deutschland, ${ }^{2}$ Uniklinikum Essen, Institut für Diagnostische und Interventionelle Radiologie und Neuroradiologie, Essen, Deutschland, ${ }^{3}$ Uniklinikum Mannheim, Abteilung für Medizinische Statistik, Biomathematik und Informationsverarbeitung, Mannheim, Deutschland

Hintergrund: Frühgeburtlichkeit ist mit einem deutlichen Risiko für neurologische Entwicklungsauffälligkeiten assoziiert. Deshalb wäre es hilfreich, Frühmarker für Hoch-Risiko-Kinder zu identifizieren.

Fragestellung: Wir haben untersucht, ob die Volumina der Seitenventrikel und der Basalganglien im kranialen Magnetresonanztomografie (MRT) am errechneten Entbindungstermin mit dem neurologischen Outcome von sehr unreifen Frühgeborenen im korrigierten Alter von 2 Jahren korrelieren.

Patienten und Methoden: Bei 73 unreifen Frühgeborenen, die im Zeitraum März 2011 bis Dezember 2012 geboren wurden, wurde eine kraniale MRT am errechneten Entbindungstermin durchgeführt und das Volumen der Basalganglien und der beiden Seitenventrikel bestimmt. Das mittlere Gestationsalter betrug 29 \pm 3 (Bereich: 23-34) Wochen, das mittlere Geburtsgewicht $1131 \pm 369$ (Bereich: 450-2085) g. Bei 67 dieser Kinder war zum Zeitpunkt des MRTs der Kopfumfang gemessen worden. Der Mental Developmental Index (MDI) und der Psychomotor Development Index (PDI) im Rahmen der BSID II-Testung mit korrigiert 24 Monaten lag bei 50 bzw. 46 dieser Kinder vor.

Ergebnisse: Bei 23 Kindern (31,5\%) hatte der rechte Seitenventrikel ein größeres Volumen, bei 50 Kindern (68,5\%) war der linke Seitenventrikel größer. Dieses Ungleichgewicht ist signifikant $(p=0,0021)$. Die Volumina beim rechten Seitenventrikel bewegten sich zwischen 1025,9 und 6254,4 $\mathrm{mm}^{3}$, die des linken zwischen 1501,3 und 10.606,4 $\mathrm{mm}^{3}$. Das Volumen des rechten und linken Seitenventrikels korrelierte nicht mit dem Volumen der Basalganglien ( $p=0,2070$ und $p=0,5965)$ und nicht mit dem Kopfumfang beim MRT ( $p=0,1771$ und $p=0,9757)$. Zudem zeigte sich keine Korrelation zwischen dem Gesamtvolumen beider Seitenventrikel und dem MDI $(p=0,3360)$ und PDI $(p=0,6499)$ bei der BSID II-Testung.

Bei den Basalganglien waren Volumina zwischen 10.902 und $35.029 \mathrm{~mm}^{3}$ zu beobachten. Hier zeigte sich eine signifikante Korrelation zwischen den Volumina der Basalganglien und dem Kopfumfang beim MRT $(p<0,0001$; $r=0,6403)$, dem Geburtsgewicht ( $p=0,0001 ; r=0,4371)$, aber nicht dem Gestationsalter $(p=0,0751)$. Zudem war das Basalganglienvolumen signifikant mit dem MDI ( $p=0,0286 ; \mathrm{r}=0,3098)$ und dem PDI $(p=0,0015$; $r=0,4559)$ bei der BSID II-Testung assoziiert.

Schlussfolgerung: Die Volumina der Basalganglien beim MRT am errechneten Geburtstermin sind in unserem Studienkollektiv signifikant mit dem neurologischen Outcome im korrigierten Alter von 2 Jahren assoziiert.

\section{NO-P06}

Longitudinal assessment of growth using z-scores in preterm infants is confounded by systematic errors

E. Landau-Crangle', N. Rochow' 'A. Bhatia', G. Fusch', P. Muppidi', W. Göpel', C. Fusch ${ }^{3,1}$

${ }^{1}$ McMaster University, Pediatrics, Hamilton, Canada, ${ }^{2}$ Universität zu Lübeck, Klinik für Kinder- und Jugendmedizin, Lübeck, Deutschland, ${ }^{3}$ Paracelsus Medizinische Privatuniversität Klinikum Nürnberg, Klinik für Neugeborene, Kinder und Jugendliche, Nürnberg, Deutschland

Background: Growth of preterm infants is often assessed by z-score differences and it is suggested that a change in $\mathrm{z}$-score is reflected in weight gain. Current $z$-scores are calculated using references based on in-utero growth. These references are developed from cross-sectional data of birth weights 
of pregnancies with known gestational age (GA). These data include a significant proportion of pathological pregnancies leading to a skewed distribution of percentiles (\%ile) for GA which might affect the z-score calculation. Weight normalized distances between \%iles and standard deviation show an increase from 24 weeks to $\sim 30$ weeks followed by a decrease until term age. The 3rd and 97th\%ile curves show opposite acceleration and deceleration of weight gain. In particular, it is difficult to give a physiological explanation of the fluctuating course of the $3 \mathrm{rd}$ and 10 th \%ile growth rates. Objective: To test the hypothesis, in a large scale data set, that assessment of growth by z-score differences in preterm infants is affected by GA and birth weight \%ile.

Design/Methods: This observational study included 6928 VLBW infants from German Neonatal Network (2009 to 2015). For each infant, weight gain from birth to discharge was calculated and normalized using the 50th\%ile growth rate (Fenton 2013) for the corresponding observation period (normalized weight gain, NWG). For comparison, z-score differences were calculated from birth to discharge and were compared with NWG. The analysis was stratified for GA and birth weight \%ile. Primary outcome is the homogeneity in the correlation of $\mathrm{z}$-score differences vs. NWG. Results: There is a correlation between $z$-score differences and growth, however the inter-individual variation is high, up to the factor of 3 . The correlations are different between the strata. This is reflected by the observation that infants with higher weight gain than in-utero have in negative $\mathrm{z}$-scores.

Conclusions: This study confirms the hypothesis that z-score differences are confounded for certain GA and \%iles. This mostly due to fact that cross-sectional data of interrupted pregnancies with pathologies have been used to create birth weight charts. Therefore, in the extreme periods, \%iles and $\mathrm{z}$-scores should be considered with caution. Physiological values of intrauterine growth might be only assessable by using pregnancies which reach term age.

\section{Neurologische Grundlagenforschung}

\section{NEURO-P01 \\ Neonatale systemische Inflammation verändert die Myelinisierung und die mikrogliäre Besiedlung des Kleinhirns bis ins Erwachsenenalter}

L. Klein', B. Fleiss' ${ }^{2,3}$, T. Scheuer', S. Endesfelder', C. Bührer', P. Gressens ${ }^{2,3}$, T. Schmitz

${ }^{1}$ Charité Universitätsmedizin Berlin, Neonatologie, Berlin, Deutschland, ${ }^{2}$ King's College London, King's Health Partners, St. Thomas' Hospital, Centre for the Developing Brain, Department of Perinatal Imaging and Health, Division of Imaging Sciences and Biomedical Engineering, London, UK, ${ }^{3}$ Unversité Paris Diderot, Sorbonne Paris Cité, PROTECT, INSERM, Paris, France

Hintergrund: Obwohl schwere Hirnschädigungen in der perinatalen Periode seltener werden, leiden ehemalige Frühgeborene oft bis ins Erwachsenenalter an neurologischen Einschränkungen und kognitiven Defiziten. Insbesondere das Kleinhirn befindet sich bei Frühgeborenen noch in einer hoch vulnerablen Entwicklungsphase und ist anfällig für Schädigungen. Eine bekannte Ursache für Hirnschäden von Frühgeborenen stellt perinatale Infektion dar. Wir haben in einem inflammatorischen neonatalen Mausmodell den Einfluss postnataler Stimulation mit Interleukin-1 $\beta$ (IL$1 \beta$ ) auf die Entwicklung der weißen Substanz im Kleinhirn untersucht. Ziel war es, die Auswirkungen auf myelinisierende Oligodendroglia und auf Mikroglia zu definieren.

Methoden: Neugeborene Mäuse erhielten über die ersten 5 Lebenstage zweimal täglich intraperitoneale Injektionen mit IL-1 $\beta(10 \mu \mathrm{g} / \mathrm{kg})$. Die Kontrollgruppe erhielt zweimal täglich PBS. Anschließend wurden zu verschiedenen Zeitpunkten Genexpression, Proteinnachweise sowie immunhistochemische (IHC) Färbungen analysiert. Im Alter von 5 Tagen (P5) und 10 Tagen (P10) haben wir mittels Real-time PCR die Genexpression der oligodendrogliären Faktoren Olig2 und CNP quantifiziert und für die Einschätzung mikrogliärer Funktionen die mRNA Expression von MHCII, iNOS und IGF-1. Die Auswirkungen von oxidativem Stress wurden anhand der Expression der anti-oxidativen Enzym-Einheiten SOD2 und Gclc erhoben. Zu den Zeitpunkten P10 und P60 haben wir die Proteinexpression mittels Western Blot für die Myelinbestandteile MOG, MAG, MBP und PLP bestimmt. Zu den Zeitpunkten P3 und P5 haben wir mit IHC-Färbungen die Proliferation von Olig2+PCNA+ Oligodendroglia und von Iba1+PCNA+ Mikroglia analysiert; Apoptose von Oligodendroglia wurde durch Olig2/Casp3 Co-Färbung bestimmt. Die Myelinisierung der zerebellären weißen Substanz wurde zudem im adulten Alter von P45 durch Markierung mit MOG-Antikörpern ermittelt sowie die Zellzahl der Iba1+ Mikroglia.

Ergebnisse: Mit IL-1 $\beta$ behandelte Mäuse zeigten signifikante Reduktionen der Proliferationsrate der Oligodendroglia, die absolute Zahl war jedoch nicht verändert. Interessanterweise war die Apoptoserate in Olig2+ Oligodendroglia nach IL-1 $\beta$-Injektionen im Vergleich zu Kontrolltieren vermindert. Die Myelinisierung war anhand der Marker MAG und MOG im Western Blot im Alter P10 signifikant reduziert. In der Immunhistologie für MOG im Alter von P45 schien die Myelinisierung der IL-1 $\beta$ behandelten Mäuse zudem nachhaltig gestört zu sein. Die Zellzahl der Iba1+ Mikroglia war bei den behandelten Tieren bei P3, P5 und P45 massiv erhöht. Insbesondere fanden sich mehr Mikroglia des amöboiden, aktivierten Zelltyps. Passend dazu war die Genexpression von MHCII und iNOS bei P5 erhöht. Der Anteil der Co-Lokalisationen von Mikroglia mit Oligodendroglia war bei den behandelten Mäusen im Alter von P3 vermindert. Die Proliferationsrate der Mikroglia war in den untersuchten Kleinhirn-Arealen mit über $50 \%$ in beiden Gruppen auffallend hoch.

Schlussfolgerung: Die vorliegenden Daten zeigen persistierende Myelinisierungsdefizite des Kleinhirns nach neonataler systemischer Inflammation. Die Schädigung der Oligodendroglia ist vor allem an reduzierter Proliferation und Reifungsdefiziten zu sehen. Die weitreichenden Auswirkungen von postnataler Inflammation auf die weiße Substanz des Kleinhirns sind darüber hinaus an den Veränderungen der Mikroglia-Population bis ins Erwachsenenalter zu erkennen.

\section{NEURO-P02 \\ Dexmedetomidin-vermittelte Protektion des Hyperoxie- exponierten unreifen Gehirns der Ratte}

S. Endesfelder', H. Makki', C. von Haefen'², C.D. Spies², C. Bührer', M. Sifringer ${ }^{2}$

${ }^{1}$ Charité Universitätsmedizin Berlin, Neonatologie, Berlin, Deutschland, ${ }^{2}$ Charité Universitätsmedizin Berlin, Anästhesie und Operative Intensivmedizin, Berlin, Deutschland

Hintergrund: Dexmedetomidin (DEX) ist ein hochselektiver Agonist von a2-Adrenorezeptoren mit sedierenden, anxiolytischen, analgetischen und möglichen neuroprotektiven Eigenschaften. In den letzten Jahren hat DEX in der Anästhesie und Intensivmedizin an Relevanz gewonnen. In der Frühgeborenen-Intensivmedizin bietet DEX einen vorteilhaften Ersatz zu herkömmlich eingesetzten Narkotika und Sedativa. Durch die Verkürzung der Beatmungsdauer und die Minimierung gastrointestinaler Komplikationen kommt es zu einer Verminderung der Exposition der Frühgeborenen gegenüber erhöhten Sauerstoffkonzentrationen und anderen Betäubungsmitteln [1].

Fragestellung: In unserer in-vivo Studie an neugeborenen Wistar-Ratten (P6) im akuten Hyperoxie-Schädigungsmodell testeten wir die Hypothese, dass DEX $(1 \mu \mathrm{g} / \mathrm{kg}, 5 \mu \mathrm{g} / \mathrm{kg}$ und $10 \mu \mathrm{g} / \mathrm{kg})$ protektiv auf die postnatale hippocampale Neurogenese und neuronale Plastizität wirkt.

Ergebnisse: Bei 6 Tage alten Wistar-Ratten konnten wir zeigen, dass nach 24 h Hyperoxie $\left(80 \% \mathrm{O}_{2}\right)$ die Differenzierungs- und Proliferationskapazität reifender und reifer Neurone (immunhistochemische Färbungen für PCNA, Nestin, PSA-NCAM, NeuN) im Gyrus dentatus sowie die Genexpression für relevante neuronale Transkriptionsfaktoren (Realtime-PCR für Pax6, SOX2, Tbr2, Prox1, Tbr1) und Plastizitätsfaktoren (RealtimePCR und Western Blot für Nrp1, Nrg1, Syp, Sema3 a/f) signifikant reduziert wurden. Die Applikation von DEX $(5 \mu \mathrm{g} / \mathrm{kg}$ und $/$ oder $10 \mu \mathrm{g} / \mathrm{kg})$ vor dem hyperoxischen Insult führte zu einer verbesserten hippocampalen 
Neurogenese und einer Expressionszunahme der neuronalen Plastizitätsund Transkriptionsfaktoren.

Diskussion: Durch die Applikation von DEX vor der Exposition der neugeborenen Ratten mit hohen Sauerstoffkonzentrationen konnten die inhibierenden Effekte des oxidativen Stresses aufgehoben werden. DEX erhöhte die Proliferation von mitotischen neuronalen Zellen und führte zu einer höheren Anzahl reifer Neurone ohne die Apoptoserate zu verändern. Interessanterweise konnte dies auch bei Raumluft gehaltenen Ratten beobachtet werden, wohingegen die neuronalen Plastizitätsfaktoren durch die DEX-Administration unter normoxischen Bedingungen nicht beeinflusst waren. In vivo Studien zeigten bereits, dass postnatales DEX weder zu langanhaltenden Lerndefiziten führte, noch die hippocampale Plastizität beeinflusst wurde [2, 3]. Kontrovers dazu wurden sedierende DEX-Konzentrationen in adulten Ratten mit einer veränderten synaptischen Plastizität assoziiert [4]. Aufgrund der hohen Vulnerabilität des sich entwickelnden Gehirns kann kein potentiell nützliches Medikament ohne Nebenwirkungen erwartet werden, so dass weiterführende Studien zum sicheren Einsatz von DEX in der Neonatologie notwendig sind.

Schlussfolgerung: Diese Ergebnisse weisen auf neuroprotektive Effekte von DEX, die möglicherweise anti-oxidativ vermittelt sind.

\section{Literatur}

1. Mahmoud M, Mason KP (2015) Dexmedetomidine: review, update, and future considerations of paediatric perioperative and periprocedural applications and limitations. Br J Anaesth 115:171-182

2. Tachibana K, Hashimoto T, Kato R et al (2012) Neonatal administration with dexmedetomidine does not impair the rat hippocampal synaptic plasticity later in adulthood. Paediatr Anaesth 22:713-719

3. Sanders RD, Sun P, Patel S et al (2010) Dexmedetomidine provides cortical neuroprotection: impact on anaesthetic-induced neuroapoptosis in the rat developing brain. Acta Anaesthesiol Scand 54:710-716

4. Kato Rl, Tachibana K, al Hashimoto Tet (2014) Dexmedetomidine suppresses long-term potentiation in the hippocampal CA1 field of anesthetized rats. J Anesth 28:828-832

\section{NEURO-P03}

\section{Brain biometry shows impaired brain growth in neonates with intraventricular hemorrhage}

K. Goeral', B. M. Hüning', G. Kasprian' ${ }^{3}$, R. Fuiko' , B. Schweiger, ${ }^{1,4}$, U. Felderhoff-Müser' ${ }^{2}$ A. Berger', M. Olischar', K. Klebermass-Schrehof' ${ }^{1}$ Medical University of Vienna, Department of Pediatrics and Adolescent Medicine - Division of Neonatology, Intensive Care and Pediatric Neurology, Vienna, Austria, 'University Children's Hospital Essen, Department of Neonatology, Essen, Germany, ${ }^{3}$ Medical University Vienna, Department of Radiology - Division of Neuroradiology and Musculoskeletal Radiology, Vienna, Austria, ${ }^{4}$ University Hospital Essen, Institute of Diagnostic and Interventional Radiology and Neuroradiology, Essen, Germany

Background: Brain biometry at term equivalent age (TEA) has been shown to correlate with three dimensional volumetric measures. Those measures were recently used to study the degree of impaired brain growth in very preterm neonates at TEA. The aim of the present study was to evaluate the additional impact of intraventricular hemorrhage (IVH) on impaired brain growth.

Patients and Methods: Seventy-four preterm infants with IVH and a gestational age (GA) brain growth was evaluated according to Kidokoro et al. [1] by using one-dimensional measurements on MRI. Interhemispheric distance (IHD) and cerebral biparietal width (cBPW) were quantified. Z-Scores were calculated by comparing the obtained measurement to normative data of healthy age-matched controls published by either Garel (fetal MRI, data up to 38 weeks gestation [2]) or Nguyen Te Tich et al. (data at TEA [3]). Furthermore, the presence of impaired brain growth (either increased IHD or small BPW brain pattern ( $>2$ standard deviations compared to normative data) was evaluated.

Results: $56.9 \%$ of neonates showed no parenchymal defect (IVH II+III), $43.1 \%$ showed a parenchymal defect (IVH IV) $39.4 \%$ a localised and $60.6 \%$ an extensive parenchymal defect as defined by Bassan et al. [4] IHD showed a mean Z-score of $+1.9 \pm 2.0$ and cBPW a mean Z-score of
$-2.6 \pm 1.7 .95 .3 \%$ of studied neonates showed some form of impaired brain growth (37.5\% increased IHD brain pattern; $92.2 \%$ small BPW brain pattern; $34.2 \%$ impaired brain growth according to both patterns).

Conclusions: Comparing our percentages of impaired brain growth to the cohort of 325 very preterm neonates studied by Kidokoro et al. [1], a comparable percentage of increased IHD, but a three-fold increase in the percentage of small BPW pattern could be observed. This underlines the impact of IVH on brain growth. Correlation to neurodevelopmental outcome needs to be assessed.

\section{References}

1. Kidokoro H, Anderson PJ, Doyle LW et al (2014) Brain injury and altered brain growth in preterm infants: predictors and prognosis. Pediatrics 134:e444-453

2. Garel C (2004) MRI of the fetal brain. Springer Berlin, Heidelberg, $S 35-114$

3. Nguyen The Tich S, Anderson PJ, Shimony JS et al (2009) A novel quantitative simple brain metric using MR imaging for preterm infants. AJNR Am J Neuroradiol 30:125-131

4. Bassan H, Feldman HA, Limperopoulos Cet al (2006) Periventricular hemorrhagic infarction: risk factors and neonatal outcome. Pediatr Neurol 35:85-92

\section{NEURO-P04}

NDUFV2-Gen Mutation (c.704_707del) als bislang unbekannte Variante eines Leigh-Syndroms: ein Fallbericht.

\section{Schröder', E. Alsat', S. Bagci', F. Kipfmüller', J. Schmitt' , H. Schade²,} A. Müller ${ }^{1}$

'Universität Bonn, Zentrum für Kinderheilkunde, Neonatologie und Pädiatrische Intensivmedizin, Bonn, Deutschland, ${ }^{2}$ Kreiskrankenhaus Mechernich, Klinik für Kinder- und Jugendmedizin, Mechernich, Deutschland

Hintergrund: Das Leigh-Syndrom (LS) beschreibt eine genetisch verursachte Mitochondriopathie und ist die häufigste klinische Präsentation einer Mitochondriopathie im Kindesalter [1]. Das LS ist genetisch heterogen und kann autosomal-rezessiv, X-chromosomal-rezessiv oder maternal vererbt werden. Autosomal-rezessiv vererbte Mutationen im NDUFV2-Gen sind für das LS vorbeschrieben und führen zu einem Komplex-I-Defekt der Atmungskette. Die im vorliegenden Fall identifizierte Mutation war bisher nicht bekannt. Fallbericht: Wir berichten über einen zweieinhalb Monate alten Säugling konsanguiner Eltern mit unklarer Stoffwechselentgleisung. Die initiale Präsentation im externen Krankenhaus erfolgte bei zunehmender Schläfrigkeit, streng riechendem Urin sowie Gewichtsstagnation. Bei Verdacht auf eine Sepsis wurde eine antibiotische Therapie begonnen. Im Verlauf traten Krampfanfälle und Apnoen auf.

Verlauf: Es zeigte sich ein dystropher und somnolenter Säugling. Laborchemisch imponierte eine ausgeprägte Laktatazidose $(10 \mathrm{mmol} / \mathrm{l}$ i. S. und $13,8 \mathrm{mmol} / \mathrm{l}$ i. Lq.). Eine Stoffwechseldiagnostik ergab neben der Laktatazidose eine deutliche Laktaturie, mit erhöhtem 2-Methyl-2,3-DiOh-Butyrat, und eine deutlich erhöhte Alanin- sowie Prolinkonzentration im Blut. Im EEG zeigte sich eine kontinuierliche Krampfaktivität (frontal betont). Die kardiologische Abklärung ergab eine hypertrophe Kardiomyopathie, einen ASD II und Zeichen der pulmonalen Hypertonie. In zwei konsekutiven MRTs zeigte sich vor allem eine ausgeprägte und progressive supraund infratentorielle Leukodystrophie, mit Betonung der Stammganglien und weitreichender Nekrosen des rechtsseitigen Kortex. Klinisch und auf Grund der bis dahin unauffälligen Familienanamnese bei Konsanguinität der Eltern ergab sich der Verdacht auf eine autosomal-rezessiv vererbte Mitochondriopathie. In einer humangenetischen Panel-Diagnostik konnte eine homozygote Mutation im NDUFV2-Gen identifiziert werden (Variante c704_707del [pTHR235Aanfs]). Nach primärer Entlassung verstarb die Patientin im Alter von dreieinhalb Monaten nach prolongierter Reanimation mit schwerer Azidose nach erneuter Übernahme auf unsere Intensivstation. Diskussion: Erst in den letzten 5 Jahren wurden ca. 30 neue Mutationen charakterisiert [1], jedoch bleibt in vielen Fällen eines LS die genetische Ursache weiterhin unklar. Die meisten Mutationen führen zu einem Komplex-I-Defekt der Atmungskette, wie auch die Mutation im NDUFV2-Gen (kodiert das NADH Dehydrogenase (Ubichinon) Flavoprotein 2). Die Variante c704_707del stellt eine Leserasterverschiebung dar. Der Beginn des 
LS und das klinische Erscheinungsbild variieren stark von Fall zu Fall, aber typischerweise tritt die Erkrankung im Alter von 2 Jahren auf und die Prognose ist infaust [3]. Im vorliegenden Fall kam es zu einem sehr frühen Krankheitsbeginn. Das LS wird durch charakteristische neuropathologische Veränderungen gekennzeichnet, wie bilaterale symmetrische Läsionen der Basalganglien und Mitbeteiligungen des Hirnstammes, des Rückenmarks sowie eine häufig beobachtete Hirnatrophie [4]. Komplex-IDefekte sind häufig assoziiert mit einer hypertrophen Kardiomyopathie [1]. Schlussfolgerung: Es konnte eine neue Mutation des NDUFV2-Gen als Ursache eines LS identifiziert werden. Die Identifikation neuer Mutationen ist essentiell für das Verständnis der Erkrankung.

\section{Literatur}

1. Lake NJ, Compton AG, Rahman, Thorburn DR (2016) Leigh syndrome: One disorder, more than 75 monogenic causes. Ann Neurol 79:190-203

2. Hammans SR, Sweeney MG, Brockington M et al (1991) Mitochondrial encephalopathies: molecular genetic diagnosis from blood samples. Lancet 337:1311-1313

3. Sofou K, De Coo IF, Isohanni P et al (2014) A multicenter study on Leigh syndrome: disease course and predictors of survival. Orphanet J Rare Dis 9:52

4. Bonfante E, Koenig MK, Adejumo RB et al (2016) The neuroimaging of Leigh syndrome: case series and review of the literature. Pediatr Radiol 46:443-451

\section{NEURO-P05 \\ Dendritische Entwicklung kortikaler Pyramidenzellen bei juvenilen Mäusen nach postnataler Hyperoxie}

\section{Y. Sharkovska ${ }^{1,2,3}$, T. Scheuer', S. Endesfelder', S. Zaqout ${ }^{2}$, M. Rosario ${ }^{2}$,} C. Bührer', V. Tarabykin', T. Schmitz'

'Charité - Universitätsmedizin Berlin, Klinik für Neonatologie, Berlin, Deutschland, ${ }^{2}$ Charité - Universitätsmedizin Berlin, Institut für Zell- und Neurobiologie, Berlin, Deutschland, ${ }^{3}$ Berliner Institut für Gesundheitsforschung, Berlin, Deutschland

Hintergrund: Extrem unreife Frühgeboren haben ein erhöhtes Risiko für psychointellektuelle und kognitive Entwicklungsstörungen einschließlich Autismus-Spektrum-Störung, Aufmerksamkeits- und HyperaktivitätsProblemen und psychomotorische Retardierung. Neue Untersuchungen weisen auf eine kortikale Reifungsverzögerung mit lokal veränderter Dendritogenese bei Patienten mit kognitiven Entwicklungsstörungen hin. Sauerstoff ist ein wichtiger Regulator der Neurogenese. Die physiologische fetale „Hypoxie“ fördert die neuronale Proliferation, Differenzierung und Reifung während der fetalen Hirnentwicklung. Die Frühgeburt bewirkt einen drastischen Anstieg der $\mathrm{O}_{2}$-Konzentration im Vergleich zu den Bedingungen in utero, welche die natürliche Entwicklung des zentralen Nervensystems beeinträchtigen kann. Wir gehen von der Hypothese aus, dass eine relative neonatale Hyperoxie im frühen Stadium der Gehirnreifung dendritisches Wachstum von kortikalen Pyramidenzellen verändert und die Entstehung kognitiver Störungen bei ehemaligen Frühgeborenen begünstigt.

Methoden: Fünf Tage alte gesunde C57BL/6-Mäuse werden zusammen mit einem Muttertier in eine Kammer (OxyCyclerBioSpherix, Lacona, NY, USA) über einen Zeitraum von 48 Stunden einer hohen Sauerstoffkonzentration von $80 \%$ in der Atemluft (Hyperoxie) ausgesetzt. Um die dendritische Morphogenese kortikaler Pyramidenzellen zu analysieren, wurden die Gehirne juveniler Mäuse nach der Hyperoxie-Exposition an dem 30. postnatalen Tag mittels Golgi-Cox Färbung imprägniert. Die Sholl-Analyse wurde blind auf den Z-Stapelbildern durchgeführt. Es wurden um den Mittelpunkt des Zellkörpers 30 konzentrische Kreise mit einem Abstand von $10-\mu \mathrm{m}$ gezogen und dendritische Verzweigungen mittels ImageJ Software gezählt. Die Dichte von dendritischen Spines wurde auf basalen und apikalen Dendriten von Golgi-imprägnierten Pyramidenzellen hin untersucht.

Ergebnisse: Die Sholl-Analyse von Golgi-gefärbten Pyramidenzellen ergab eine signifikante Abnahme der dendritischen Verzweigung im Radius von $20-40 \mu \mathrm{m}$ in der oberflächlichen Schicht des somatomotorischen Kortexes $(p<0,05)$ und im Radius von $80-160 \mu \mathrm{m}$ in der oberflächlichen Schicht des somatosensorischen Kortexes $(p<0,05)$. Die durchschnittliche Gesamtlänge der Dendriten und die Somagröße zeigten keine signifikan- ten Unterschiede zwischen beiden Gruppen. Es ließ sich eine signifikante Verringerung von dendritischen Spines (Basaldendriten) im somatomotorischen um $25 \%$ und im somatosensorischen Kortex um $12 \%$ bei den Mäusen nach der Hyperoxie-Exposition feststellen.

Schlussfolgerung: Zusammengefasst ergibt sich, dass neonatale Hyperoxie die dendritische Entwicklung kortikaler Neurone stören kann. Dieser Schädigungsmechanismus könnte eine Grundlage für die Entstehung der bekannten kognitiven Störungen bei ehemaligen Frühgeborenen sein.

\section{NEURO-P06 \\ CEACAM1-Expression im Cerebellum}

\section{S. Prager ' ${ }^{1}$ B. B. Singer', I. Bendix', U. Felderhoff-Mueser}

'Universitätsklinikum Essen, Klinik für Kinderheilkunde 1 - Neonatologie, Essen, Deutschland, ${ }^{2}$ Universitätsklinikum Essen, Institut für Anatomie, Essen, Deutschland

Hintergrund: CEACAM1 ist ein Zelladhäsionsmolekül aus der Familie der Carcinoembryonic Antigen (CEA)-related Cell Adhesion Molecules, das in Proliferations- und Differenzierungsprozessen eine essentielle Rolle spielt. Es wird in Oligodendrozyten des Großhirns der Ratte in einem zeitlich-räumlichen Zusammenhang zur Myelinisierung exprimiert. In vitro konnte durch Stimulation von primären Oligodendrozyten mit einem CEACAM1-Liganden eine vermehrte Myelinisierung hervorgerufen werden. Das Expressionsmuster von CEACAM1 im Cerebellum ist unbekannt. Fragestellung: Wird CEACAM1 auch im Cerebellum der Ratte exprimiert? Welcher Zelltyp des Kleinhirns exprimiert CEACAM1? Besteht analog zur Expression im Großhirn ein räumlich-zeitlicher Zusammenhang zur Myelinisierung?

Material und Methoden: Paraffinschnitte von Kleinhirnen (Wistar-Ratten, P3(postnataler Tag 3)-P28) wurden immunhistochemisch mit CEACAM1-spezifischen Antikörpern gefärbt, um die ontogenetische Expression von CEACAM1 im Cerebellum zu detektieren. CEACAM1exprimierende Zelltypen wurden durch Co-Färbungen mit Zelltyp-spezifischen Markern bestimmt.

Ergebnisse: CEACAM1 wird im sich entwickelnden Cerebellum exprimiert, die CEACAM1-Expression beginnt zwischen P7 und P11. Durch Co-Färbungen mit Antikörpern gegen das basische Myelinprotein konnte nachgewiesen werden, dass die CEACAM1-Expression in Oligodendrozyten des Cerebellums in einem zeitlich-räumlichen Zusammenhang zur Myelinisierung erfolgt.

Schlussfolgerung: Wie im Großhirn wird CEACAM1 auch in Oligodendrozyten des Cerebellums exprimiert, die CEACAM1-Expressionsmuster sind dabei nahezu deckungsgleich mit der fortschreitenden Myelinisierung im untersuchten Zeitraum (P3-P28). Dies legt nahe, dass CEACAM1 analog zum Großhirn auch im Kleinhirn eine Rolle in der Myelinisierung spielt. Die genauen Mechanismen sind Gegenstand aktueller Untersuchungen.

\section{NEURO-P07}

\section{Schädelasymmetrie und Vorzugshaltung bei Frühgeborenen - Einfluss eines strukturierten Lagerungsregimes}

W. Burkhardt', H. Steglich', S. Ifflaender ${ }^{2}$

${ }^{1}$ Helios Klinikum Schwerin, Pädiatrie, Schwerin, Deutschland, ${ }^{2}$ Unikinderklinik Dresden, Neonatologie, Dresden, Deutschland

Hintergrund: Die Prävalenz von lagebedingter, nichtsynostotischer Schädelasymmetrie (SA) und Vorzugshaltung (VZ) ist im Verlauf der ersten Lebensmonate hoch. Folgeprobleme in der motorischen und auch kognitiven Entwicklung in den ersten Lebensjahren sind beschrieben (Collet et al. 2013). Bis zu $22 \%$ der Termingeborenen zeigen eine SA, Frühgeborenen bis $50 \%$. Eine VZ findet sich bei $18 \%$ der Termingeborenen und $37 \%$ der Frühgeborenen (Nuysink et al. 2013). Generell wird ein negativer Einfluss der überwiegenden Rückenlage zur SIDS-Prophylaxe diskutiert, bei Frühgeborenen auch das unreife muskulosketale und nervale System. 
Fragestellung: Kann durch Einführung einer strukturierten Lagerung von Frühgeborenen auf einer neonatologischen IMC-Station die Prävalenz von Schädelasymmetrie und Vorzugshaltung im korrigierten Alter von 3 Monaten gesenkt werden?

Methoden: Verglichen wurden insgesamt 95 Frühgeborenen, die in zwei identischen Zeiträumen aufeinanderfolgender Jahre auf der neonatologischen IMC der Universitätskinderklinik Dresden betreut wurden, eine strukturierte Lagerungsgruppe $(n=48)$ und eine ungelagerte Kontrollgruppe $(n=47)$ aus dem Vorjahr. Die strukturierte Lagerung erfolgte im 4 stündlichen Wechsel von Seitenlage (rechts/links) und Rückenlage. Parameter: SA und VZ in beiden Gruppen zur Untersuchung mit korrigierten 3 Monaten im Rahmen der Frühgeborenennachsorge; Variablen zur Geburt (GA, Gewicht, Geschlecht, Modus) und Verlauf (mechanische Atemhilfen, Dauer ITS-Aufenthalt).

Ergebnisse: Durch strukturierte Lagerung auf der IMC-Station ließ sich in dieser Studie die Häufigkeit von SA und VZ mit korrigierten 3 Monaten nicht reduzieren. So zeigten $31 \%$ der Lagerungsgruppe vs. $21 \%$ der Kontrollgruppe eine SA und 19\% der Lagerungsgruppe vs. $21 \%$ der Kontrollgruppe eine VZ zu diesem Zeitpunkt. Bei Betrachtung der gesamten Studienpopulation waren Frühgeborene, die eine SA oder VZ ausbildeten signifikant länger auf der neonatologischen ITS betreut $(9,2 \mathrm{~d} \pm 12$ vs. 4,7 $\mathrm{d} \pm 6 / p=0,042)$, bei ihnen bestand tendenziell ein längerer Bedarf an mechanischen Atemhilfen ( $90,0 \mathrm{~h} \pm 187$ vs. $39,2 \mathrm{~h} \pm 78,5)$.

Diskussion: Die Studie zeigt, dass ein strukturiertes Lagerungsregime regelmäßig kontrollierte Lagerungswechsel bei Frühgeborenen ermöglicht. Allerdings sollte das Lagerungsregime für Folgestudien modifiziert werden. Offenbar empfiehlt sich ein Beginn der strukturierten Lagerung schon auf der ITS, damit die Frühgeborenen davon profitieren. Dies gilt insbesondere für Frühgeborenen mit Bedarf an Atemunterstützung. Tägliche Bauchlagezeiten werden bei Säuglingen zur Prävention von SA und $\mathrm{VZ}$ immer wieder vorgeschlagen. Dabei sind die SIDS-Empfehlungen zu beachten. Die regelmäßige Bauchlage könnte zumindest im klinischen Alltag beim überwachten Frühgeborenen aber eine notwendige Erweiterung der strukturierten Lagerung sein.

\section{NIRS}

\section{NIRS-P01 \\ Sauerstoffversorgung des Gehirns von sehr kleinen Frühgeborenen während des Känguruhens}

L. Lorenz ${ }^{1,2}$, A. Marulli', J. A. Dawson ${ }^{2,3,4}$, S. M. Donath ${ }^{3,4}$, B. J. Manley ${ }^{2,3,4}$, L.S. Owen ${ }^{2,3,4}$, P. G. Davis ${ }^{2,3,4}$, O. F. Kamlin ${ }^{2,3,4}$

'Universitätsklinik für Kinder- und Jugendmedizin, Abteilung für Neonatologie, Tübingen, Deutschland, ${ }^{2}$ The Royal Women's Hospital

Melbourne, Newborn Research and Neonatal Services, Melbourne, Australia, ${ }^{3}$ Murdoch Childrens Research Institute, Melbourne, Australia, ${ }^{4}$ University of Melbourne, Melbourne, Australia

Hintergrund: Auf neonatologischen Intensivstationen wird die KänguruhMethode zunehmend auch bei kleinen Frühgeborenen (FG) angewandt. Besorgniserregend sind allerdings Daten, die gezeigt haben, dass FG beim Känguruhen mehr Sättigungsabfälle zeigen als im Inkubator. Außerdem ist bekannt, dass längere und häufigere Hypoxien bei FG mit einem schlechteren neurologischen Outcome assoziiert sind. Ein Grund dafür könnte sein, dass Sättigungsabfälle auch mit einer Hypoxie des Gehirnes einhergehen. Die regionale zerebrale Oxygenierung $\left(\mathrm{rcO}_{2}\right)$ kann heutzutage mittels Nahinfrarotspektroskopie (NIRS) nicht-invasiv gemessen werden und bietet zusätzliche Informationen bzgl. des zerebralen Sauerstoffangebots wie auch des Verbrauchs.

Fragestellung: Ziel dieser Studie war nachzuweisen, dass $\mathrm{rcO}_{2}$ und andere physiologische Parameter wie z. B. Sauerstoffsättigung $\left(\mathrm{SpO}_{2}\right)$ und Herzfrequenz (HF) während des Känguruhens von kleinen FG (Gestationsalter $<33$ Wochen) nicht schlechter sind als im Inkubator.
Material und Methoden: Propektive, cross-over Nicht-Unterlegenheits (non-inferiority) Studie. Der primäre Endpunkt war $\mathrm{rcO}_{2}$ und die non-inferiority margin wurde auf $-1,5 \%$ des primären Endpunktes ( $\mathrm{rcO} 2)$ festgelegt. Sekundäre Endpunkte sind $\mathrm{SpO}_{2}, \mathrm{HF}$, Körpertemperatur, Anzahl von Bradykardien ( $\mathrm{HF}<100 / \mathrm{min}$ für $>5 \mathrm{sec}$ ) und Entsättigungen $\left(\mathrm{SpO}_{2}<80 \%\right.$ für $>5 \mathrm{sec}$ ) und Anteil der Beobachtungszeit in ruhigem Schlaf. Mittelwerte der o. g. Parameter jedes FG wurden mittels gepaartem T-test verglichen. Jedes FG wurde für 90 min im Inkubator (30 min wash-out und $60 \mathrm{~min}$ Datenakquirierung) mit anschließenden 90 min während des Känguruhens (30 min wash-out und 60 min Datenakquirierung) untersucht. Mit diesem cross-over Design bildete jedes FG seine eigene Kontrolle. Pflegepersonal, Ärzte und Eltern waren für die $\mathrm{rcO}_{2}$ Messungen geblindet.

Ergebnisse: Die Studie wurde an 40 FG mit einem Gestationsalter von im Median (IQR) 30,6 (29,1-31,7) Wochen und im Alter von 14 (8-38) Tagen durchgeführt. Während des Känguruhens zeigte sich eine kleine, aber statistisch signifikante Reduktion de $\mathrm{rcO}_{2}$, wobei das untere Ende des $95 \%$ Konfidenzintervalls unterhalb der non-inferiority margin lag. Während des Känguruhens zeigte sich außerdem ein signifikanter Abfall von $\mathrm{SpO}_{2}$, ein Anstieg von HF und ein Anstieg des Anteils der Zeit, die die FG in ruhigem Schlaf verbrachten. Es konnte kein Unterschied in der axillären Körpertemperatur nachgewiesen werden. Die Anzahl der Entsättigungen war im Median (IQR) 0 (0-1) während des Känguruhens und 0 (0-3) im Inkubator. In beiden Untersuchungszeiträumen konnten im Median (IQR) nur 0 (0-0) Bradykardien gemessen werden, wobei eine maximale Anzahl von 2 Bradykardien im Inkubator und beim Känguruhen beobachtet wurde.

Diskussion und Schlussfolgerung: Die sehr geringen Unterschiede in der regionalen zerebralen Oxygenierung (Abfall um 1,3\%) wie auch in den anderen physiologischen Parametern $\left(\mathrm{SpO}_{2}\right.$ Abfall um 1,1\% und HF Anstieg um 5/min) sind zwar statistisch signifikant, sind aber so minimal, dass sie aus unserer Sicht vermutlich keine klinische Bedeutung haben. Darüber hinaus konnten keine vermehrten Entsättigungen oder Bradykardien während des Känguruhens beobachtet werden. Diese Daten geben Evidenz dafür, dass Känguruhen von sehr kleinen FG weiterhin ermutigt werden kann.

\section{NIRS-P02}

\section{Welchen Blutdruck braucht ein ELBW Frühchen?}

T. Heinzmann, S. Waldherr, N. Kuss, B. Beedgen, J. Pöschl

Zentrum für Kinder- und Jugendmedizin der Universität Heidelberg, Neonatologie, Heidelberg, Deutschland

Hintergrund: Der adäquate Blutdruck eines Frügeborenen wird kontrovers diskutiert. Nur einzelne neonatologische Zentren weltweit streben in den ersten 6 Lebensstunden einen mittleren arteriellen Druck (MAD) $\geq 30 \mathrm{mmHg}$ an. Die meisten Zentren therapieren einen MAD < Gestationsalter in Wochen [1], andere bei klinischen Zeichen einer Minderperfusion [2]. Unklar ist auch das Vorhandensein einer zerebralen Autoregulation und ob ein Fehlen dieses Schutzmechanismus zu einem erhöhten Risiko für intraventrikuläre Blutungen (IVH) führt [3]. Um eine zerebrale Autoregulation nachzuweisen, kann die mittels Nahinfrarotspektroskop (NIRS) gemessene, zerebrale fraktionierte Sauerstoffextraktion (cFTOE) mit dem MAD korreliert werden [4].

Material und Methoden: Bei 27 Frühgeborenen $<30$ SSW wurde prospektiv der arteriell/peripher gemessene Blutdruck und die zerebrale Sättigung mittels NIRS gemessen und die cFTOE, als Marker für den Sauerstoffangebot und Verbrauch, berechnet. Als Nachweis einer zerebralen Autoregulation wurde die Korrelation zwischen MAD und cFTOE bestimmt. Die arterielle Hypotension wurde definiert als ein MAD $<30 \mathrm{mmHg}$. Die Kinder wurden nach Notwenigkeit einer Therapie in 4 Gruppen eingeteilt: (i) keine Therapie $(n=3)$, (ii) Volumentherapie $(n=3)$, (iii) plus Hydrocortison $(n=8)$, (iiii) plus Katecholamine $(n=13)$, davon erhielten 11 FG Dopamin und 2 FG Suprarenin.

Ergebnisse: Innerhalb der ersten 2 Lebensstunden haben alle FG einen $\mathrm{MAD} \geq 30 \mathrm{mmHg}$ erreicht. Allerdings wird trotz Therapie das Niveau der FG ohne Therapie nicht erreicht. Auch die zerebrale Sättigung der FG ohne 
Therapie weist über $72 \mathrm{~h}$ ein höheres Niveau auf als die unter Therapie (85\% (i) vs $65 \%$ (iiii)). Die cFTOE war bei den FG ohne Therapie deutlich niedriger (0,13 (i) vs 0,3 (iiii)). Eine negative Korrelation zwischen MAD und cFTOE und damit Hinweis auf ein Fehlen einer zerebralen Autoregulation zeigte sich bei 5 der FG mit Katecholamintherapie in den ersten 6 Stunden. Darunter war das einzige Kind mit einer IVH III. Bei den anderen FG zeigte sich keine Korrelation und somit besteht der Hinweis auf eine bestehende, zerebrale Autoregulation.

Diskussion: Bei einem Ziel-MAD $\geq 30 \mathrm{mmHg}$ werden mehr Frühgeborene aufgrund einer arteriellen Hypotension therapiert. Über 5 Jahre haben $1 \%$ unserer überlebenden Frühgeborenen eine IVH $\geq$ II, so dass die Hypotensionstherapie selbst nicht die Ursache für die Entstehung einer IVH ist. Zudem konnten wir zeigen, dass gerade in den ersten Lebensstunden eine Autoregulation nicht immer nachzuweisen ist. Wir postulieren, dass die zerebrale Perfusion gerade in den ersten Lebensstunden entscheidend ist, und dass dafür stetig steigende und nicht schwankende MADs notwendig sind, um Reperfusionsschäden zu verhindern.

\section{Literatur}

1. Stranak Z, Semberova J, Barrington K, O'Donnell C, Marlow N, Naulaers G, Dempsey $E$ (2014) HIP consortium. International survey on diagnosis and management of hypotension in extremely preterm babies. Eur J Pediatr 173:793-798

2. Dempsey EM, Barrington KJ (2006) Diagnostic criteria and therapeutic interventions for the hypotensive very low birth weight infant. Perinatol 26:677-681

3. Weindling AM, Kissack CM (2001) Blood pressure and tissue oxygenation in the newborn baby at risk of brain damage. Biol Neonate 79:241-245

4. Wong F, Silas R, Hew S, Samarasinghe T, Walker A (2012) Cerebral oxygenation is highly sensitive to blood pressure variability in sick preterm infants. PLOS ONE $7: 43165$

\section{NIRS-P03}

Einfluss der Körperposition auf die zerebrale Durchblutung und Oxygenierung bei Frühgeborenen mit einem Gestationsalter $\leq 33$ Schwangerschaftswochen.

E. Loewe, D. Spengler, M. Krause

Klinik für Kinder- und Jugendmedizin des UKSH Kiel, Neonatologie, Kiel, Deutschland

Hintergrund: Frühgeborene $<33$ Schwangerschaftswochen (SSW) haben ein erhöhtes Risiko, perinatal eine Ventrikelblutung zu erleiden. Verschiedene Präventionsstrategien befürworten eine Kopfmittellage in Rückenposition, um Alterationen der zerebralen Perfusion als mögliche Ursache einer Blutung zu vermeiden.

Fragestellung: Ziel dieser Arbeit war es zu untersuchen, ob sich die Flussgeschwindigkeiten der intrakraniellen arteriellen und venösen Gefäße sowie die regionale zerebrale Oxygenierung als Parameter für die zerebrale Perfusion im Vergleich zwischen Bauch- und Rückenlage unterscheiden. Material und Methoden: 21 klinisch stabile Frühgeborene mit einem Gestationsalter $<33$ SSW wurden zu zwei Zeitpunkten (innerhalb der ersten 72 Lebensstunden und 6-7 Tage später) mit Hilfe der Dopplersonografie folgendermaßen untersucht: Die Flussprofile (maximaler und minimaler Fluss, Resistance Index) der Aa. cerebri anterior, basilaris und carotides internae und der V. galeni (sagittal und coronar) wurden jeweils in Bauchund in Rückenlage untersucht. Zusätzlich erfolgte eine zerebrale Nahinfrarotspektroskopie zur Erfassung der regionalen zerebralen Oxygenierung. Die Ergebnisse zwischen Rücken- und Bauchlage wurden mittels t-Tests für verbundene Stichproben untersucht (Signifikanzniveau $p<0,05$ ).

Ergebnisse: Es zeigte sich weder bei der dopplersonografischen Erfassung der Flussgeschwindigkeiten noch bei der Untersuchung der regionalen zerebralen Oxygenierung ein Unterschied zwischen Rücken- und Bauchlage. Schlussfolgerung: Die Körper- und Kopfposition hatte im untersuchten Kollektiv keinen Einfluss auf die dopplersonografisch erfassten Flussprofile und auf die regionale zerebrale Oxygenierung. Somit kommen möglicherweise andere Parameter als Ursache eines vermuteten Risikos für Ventrikelblutungen in der Bauchlage in Frage. Eine strenge Empfehlung zur Rückenpositionierung mit Kopfmittellage lässt sich aus den vorliegenden Ergebnissen nicht ableiten.

\section{NIRS-P04}

Untersuchungen zur Präzision der zerebralen Sauerstoffsättigung $\left(\mathrm{StO}_{2}\right)$ bei Frühgeborenen mit einem neu entwickeltem Gerät (OxyPrem v1.3)

S. Kleiser, T. Karen, H. U. Bucher, D. Bassler, M. Wolf, F. Scholkmann

Universitätsspital Zürich, Zürich, Schweiz

Hintergrund: Die Nahinfrarospektroskopie (NIRS) ist eine nicht-invasive Methode zur Messung der zerebralen Oxygenierung. Das Problem herkömmlicher NIRS-Geräte ist die geringe Präzision $\geq 5 \%$ [1], mit der Folge, dass sowohl Hypoxie als auch Hyperoxie nicht adäquat erkannt werden. Deswegen hat sich NIRS als klinisches Monitoring bei Frühgeborenen noch nicht durchgesetzt. Aus diesem Grund haben wir in unserer Abteilung ein neues NIRS-Gerät entwickelt, OxyPrem v.1.3, dass aufgrund seiner besonderen Technologie die regionale zerebrale Sauerstoffsättigung $\left(\mathrm{StO}_{2}\right)$ mit einer höheren Präzision messen soll.

Fragestellung: Das Ziel ist die Untersuchung der Präzision von OxyPrem v 1.3 durch wiederholte Messungen der zerebralen Sauerstoffsättigung $\left(\mathrm{StO}_{2}\right)$ am präfrontalen Kortex Frühgeborener.

Material und Methoden: Untersucht wurden 35 Frühgeborene mit einem mittleren Gestationalter von 31,4 bei einem mittleren postmenstruellen Alter von 35,3 Wochen. Das in unserem Hause entwickelte Oximeter OxyPrem v1.3 benützt 2 Lichtdetektoren und 4 Lichtquellen mit jeweils 4 Wellenlängen (690, 760, 805 und $830 \mathrm{~nm})$ und symmetrischen Abständen von 15, 20, 30 und $35 \mathrm{~mm}$. Der OxyPrem v1.3 Sensor wurde $5 \times$ für 1 Minute auf dieselbe Stelle auf dem linken präfrontalen Kortex (temporal) aufgesetzt. Zeitgleich wurden physiologische Parameter wie Herzfrequenz und arterielle Sättigung $\left(\mathrm{SpO}_{2}\right)$ mit einem Pulsoximeter (Sensmart-X100, Nonin) am rechten Arm und die zerebrale $\left(\mathrm{StO}_{2}\right)$ mit einem zweiten OxyPrem v1.3 Sensor über dem visuellen Kortex (okzipital) permanent aufgezeichnet. Die Variabilität innerhalb der Probanden wurde mithilfe der Statistiksoftware R und der Funktion lme mit Proband als Faktor bestimmt. Hierzu wurde der StO2 Median jeder 1-minütigen Messung verwendet.

Ergebnisse: Für alle Probanden ergeben sich Variabilitäten von 2,64\%, $3,06 \%$ und 2,35\% für temporale $\mathrm{StO}_{2}$, okzipitale $\mathrm{StO}_{2}$ und $\mathrm{SpO}_{2}$. Schliesst man Probanden mit auffällig starken physiologischen Schwankungen aus (Standardabweichung über die 1-Minuten-Mediane $>2 \%$ in $\mathrm{SpO}_{2}$ oder $>7,5 \%$ in okzipitaler $\mathrm{StO}_{2}$ ), so verringern sich diese Werte auf $1,85 \%$, $2,08 \%$ und $1,01 \%$.

Diskussion und Schlussfolgerung: Mit einer Präzision von 2,64\% ist OxyPrem v1.3 bereits besser als aktuell verfügbare Geräte. Obwohl alle Patienten klinisch stabil waren, zeigten einige jedoch starke systemisch-physiologische Schwankungen. Entsprechend ist die Variabilität in $\mathrm{SpO}_{2}$ fast gleich hoch wie die in $\mathrm{StO}_{2}$. Somit kann ein beträchtlicher Teil der beobachteten Variabilität in $\mathrm{StO}_{2}$ auf tatsächlich im Körper stattfindenden Schwankungen zurückgeführt werden. Ein unveränderter (wahrer) Zielwert ist jedoch eine Grundannahme der Präzisionsbestimmung. Daher müssen Probanden mit ausgeprägten physiologischen Schwankungen aus der Analyse ausgeschlossen werden, um den Einfluss des wiederholten Platzierens des Sensors nicht zu überschätzen. Nach Eingrenzung auf physiologisch stabile Probanden konnten wir für OxyPrem v1.3 eine Präzision von $1,85 \%$ feststellen.

\section{Literatur}

1. Greisen G, Andresen B, Plomgaard AM, Hyttel-Sørensen S (2016) Cerebral oximetry in preterm infants: an agenda for research with a clear clinical goal. Neurophotonics 3:031407 


\section{NIRS-P05}

Laktatwerte und regionale cerebrale Sauerstoffsättigung in den ersten zwölf Lebensstunden und Risiko für Hirnblutung bei sehr kleinen Frühgeborenen

\author{
P. Paul', K. Hanke', C. Wieg' ', E. Herting', W. Göpel', C. Haertel' \\ 'Universitätsklinik Schleswig-Holstein, Campus Lübeck, Klinik für \\ Kinder- und Jugendmedizin, Neonatologie, Lübeck, Deutschland, \\ ${ }^{2}$ Klinikum Aschaffenburg-Alzenau, Klinik für Kinder- und Jugendmedizin, \\ Aschaffenburg, Deutschland
}

Hintergrund: Gegenwärtig stehen keine Biomarker mit hohem prädiktivem Wert für die Entstehung von Hirnblutungen bei sehr kleinen Frühgeborenen (Geburtsgewicht < 1500 g, very-low-birth-weight infants, VLBWI) zur Verfügung. Ziel dieser Studie war es, Laktatwerte in den ersten Lebensstunden mit Risiko für Hirnblutung bei VLBWI zu korrelieren (GNN, $n=1618$ VLBWI). In einer weiteren bizentrischen Studie wurde der Zusammenhang zwischen Laktatwerten und regionaler zerebraler Sauerstoffsättigung (rSO2) mittels Nahinfrarotspektroskopie untersucht (NIRS1, $n=60$ ).

Material und Methoden: Im Geburtsjahrgang 2015 der GNN-Kohorte (Einschlusskriterium: VLBWI) wurden maximale Laktatwerte in den ersten 12 Lebensstunden bei allen VLBWI prospektiv erfasst. In der Beobachtungsstudie NIRS 1 (Einschlusskriterium: Gestationsalter 26 0/7 bis 31 6/7 SSW) wurden in den ersten 120 Lebensstunden cerebale rSO2-Werte dokumentiert und mit den Parametern der Blutgasanalysen korreliert. Ergebnisse: In der GNN-Kohorte lagen die höchstgemessenen Laktatwerte bei 4,1 $\pm 3,4 \mathrm{mmol} / \mathrm{l}$ (P25: 2, P75: 5, P90: $8 \mathrm{mmol} / \mathrm{l})$. VLBWI mit einem Laktatwert $>5 \mathrm{mmol} / \mathrm{l}$ (P75) hatten im Vergleich zu VLBWI mit einem Laktat $<2 \mathrm{mmol} / \mathrm{l}(<\mathrm{P} 25)$ eine deutlich erhöhte Hirnblutungsrate (Gesamt IVH: 27,6 vs. $13,9 \%$, IVH $3 / 4^{\circ}: 9,4$ vs. $\left.2,8 \%, p<0,001\right)$. Bezüglich PVL waren Laktatwerte > P90 mit einem erhöhten Risiko assoziiert (5,2 vs. 2,4\%), In der NIRS1-Studie wurden bei Frühgeborenen mit Laktat $\geq 5 \mathrm{mmol} / \mathrm{l}$ (erste kindliche Blutentnahme nach Geburt) erniedrigte rSO2-Werte nach 5 bzw. 10 Lebensminuten im Vergleich zu Frühgeborenen mit einem Laktat $<5 \mathrm{mmol} / \mathrm{l}$ dokumentiert (MW $\pm \mathrm{SD}, 95 \% \mathrm{CI}$; 5 min: $51 \pm 18,39-63$ vs. $67 \pm 20,61-73, p=0,02 ; 10$ min: $66 \pm 13,57-75$ vs. $76 \pm 14,71-80, p=0,04)$ Schlussfolgerung: Hohe Laktatwerte in den ersten 12 Lebensstunden können mit ungünstigem neurologischem Outcome assoziiert sein. Zukünftige Studien sollten Laktatwerte und rSO2-Werte in prädiktiven Risikomodellen prospektiv untersuchen.

\section{NIRS-P06}

\section{Resistance Index (RI) in der Arteria cerebri anterior und zerebrale Oxygenierung bei Frühgeborenen in den ersten 24 Lebensstunden}

N. Baik, B. Urlesberger, B. Schwaberger, L. Mileder, N. Höller, G. Pichler

Medizinische Universität Graz, Neonatologie, Graz, Österreich

Hintergrund: In den letzten Jahren wächst das Interesse an nicht-invasivem Monitoring des Gehirns bei Frühgeborenen insbesondere in den ersten Lebenstagen.

Zielsetzung: Das Ziel dieser Arbeit war die Untersuchung des Zusammenhanges zwischen Resistance Index (RI) gemessen in der Arteria cerebri anterior und zerebraler Gewebsoxygenierung (cTOI) bei Frühgeborenen in den ersten 24 Stunden Lebensstunden

Methode: In der vorliegenden Beobachtungsstudie wurden sekundäre Outcome-Parameter der prospektiv randomisiert-kontrollierten Studie „Vermeidung von Hypotonie bei Frühgeborenen“ (AHIP) analysiert. Innerhalb der ersten 24 Lebensstunden wurde eine kraniale Ultraschalluntersuchung einschließlich der Messung des RI in der Arteria cerebri anterior durchgeführt. cTOI wurde unter Verwendung der Nahinfrarotspektroskopie (NIRS) mittels NIRO 200-NX (Hamamatsu, Japan) gemessen, wobei der NIRS-Sensor innerhalb von sechs Stunden nach der Geburt auf der linken Stirnseite angelegt und cTOI kontinuierlich für 24 Stunden gemessen wurde. Um den Zusammenhang zwischen RI und zerebraler Gewebsoxygenierung zu untersuchen, wurde eine Korrelationsanalyse zwischen RI und cTOI - Mittelwert über eine Stunde zum Zeitpunkt der kranialen Sonographie - durchgeführt.

Ergebnis: Zwischen Oktober 2013 und Juli 2015 wurden 60 Frühgeborene eingeschlossen. Daten von 51 Frühgeborenen wurden in dieser Studie analysiert. Das mittlere Gestationsalter betrug 32,6 $\pm 1,95$ Wochen und das mittlere Geburtsgewicht 1869,9 $\pm 514,3 \mathrm{~g}$. Die Mittelwerte von cTOI und RI betrugen $70,5 \pm 8,5 \%$ und $0,75 \pm 0,09$. Es gab eine statistisch signifikante negative Korrelation zwischen RI und cTOI $(p=0,015 / \rho=-0,338)$. Schlussfolgerung: Bei Frühgeborenen innerhalb der ersten 24 Stunden nach der Geburt besteht ein signifikanter Zusammenhang zwischen RI und zerebraler Gewebsoxygenierung. Bei zunehmenden RI-Werten konnten niedrigere zerebrale Gewebsoxygenierungswerte gemessen werden.

\section{Pädiatrische Intensivmedizin}

\section{PÄD-P01 \\ Potenzial und Limitationen von Cochrane Reviews in der Pädiatrischen Kardiologie}

S. Khosrawikatoli', M. Poryo², H. Abdul-Khaliq', S. Meyer ${ }^{1,3}$

${ }^{1}$ Klinik für Allgemeine Pädiatrie und Neonatalogie,Universitätsklinikum des Saarlandes, Homburg/Saar, Deutschland, ${ }^{2}$ Universität des Saarlandes, Pädiatrische Kardiologie, Homburg/Saar, Deutschland, ${ }^{3}$ Universität des Saarlandes, Neuropädiatrie, Homburg/Saar, Deutschland

Hintergrund: Die Evidenz-basierte Medizin (EBM) hat wesentlich zur Qualität der medizinischen Versorgung im Bereich der Pädiatrischen Kardiologie beigetragen. Randomisierte, kontrollierte Studien (RCTs) und systematische Reviews/Metaanalysen bilden dabei den Goldstandard der EBM $[1,2]$. Diese generieren jedoch häufig kontroverse Ergebnisse, die nicht direkt in den klinischen Alltag übertragen werden können und damit nur von begrenztem Nutzen sind.

Fragestellung: Die Arbeit untersucht den potentiellen Nutzen und die Limitationen der Cochrane Reviews in der pädiatrischen Kardiologie.

Material und Methoden: Es erfolgte eine systematische Analyse der Cochrane Reviews im Bereich der Pädiatrischen Kardiologie, die zwischen 2001 bis 2015 publiziert wurden. Der Fokus der Arbeit war die Ermittlung des absoluten und prozentualen Anteils konklusiver, partiell konklusiver und inkonklusiver Ergebnisse sowie deren Empfehlungen und Entwicklung über drei a priori definierte Zeitintervalle.

Ergebnisse: Insgesamt wurden 69 Reviews analysiert. Am häufigsten wurden Früh- und Neugeborene (36,2\%) untersucht, wohingegen 33,3\% der Arbeiten Kinder und Erwachsene jeglichen Alters einschlossen. Führende Themen waren aus dem pharmakologischen Bereich $(70,1 \%)$, gefolgt von interventionellen $(10,1 \%)$ und operativen (2,9\%) Maßnahmen. Die Mehrzahl der Reviews lieferte inkonklusive Daten (42,0\%), während nur 36,2\% konklusiv und 21,7\% partiell konklusiv waren. Obwohl die Anzahl der Reviews im Laufe der Jahre zugenommen hatte, war der prozentuale Anteil an Reviews mit „keiner spezifischen Empfehlung“ über die drei Zeitintervalle stabil geblieben und stets führend, während der Anteil an klaren Empfehlungen für eine Intervention kontinuierlich zunahm. Hauptgründe für fehlende Empfehlungen waren die ungenügende Evidenz durch insuffiziente Daten $(n=41)$, unzureichende Studienanzahl $(n=22)$, sowie mangelhafte Studienqualität $(n=18)$ und kleine Stichproben $(n=13)$. Die meisten Reviews erhielten ein Update $(n=42 / 69)$, welches jedoch mehrheitlich ohne inhaltliche Änderung blieb ( $n=35 / 69)$; in nur zwei Fällen zeigte sich eine Verbesserung der Konklusivität.

Diskussion und Schlussfolgerung: In Übereinstimmung mit González-de Dios et al. konnten wir Defizite bei der Implementierung von Cochrane Reviews in die klinisch Praxis zeigen [3]. Es zeigte sich, dass viele Arbeiten potentiell schädliche Langzeiteffekte oder Nebenwirkungen nicht ausschließen konnten und eine Handlungsempfehlung deswegen ausblieb. Es besteht weiterhin Bedarf an hochwertigen randomisierten, kontrollierten Studien, die mit ausreichender Sicherheit eine Entscheidungshilfe liefern. 
Literatur

1. Bothwell LE, Greene JA, Podolsky SH, Jones DS (2016) Assessing the gold standard - lessons from the history of RCTs. N Engl J Med 374:2175-2181

2. Fox GN (1993) Evidence-based medicine: A new paradigm for the patient. JAMA 269:1253-1253

3. González-de Dios J, Balaguer-Santamaría A, Ochoa-Sangrador C (2005) Usefulness of Cochrane Collaboration for Pediatric Cardiology. Rev Esp Cardiol Engl Ed 58:1093-1106

\section{PÄD-P02}

\section{Extracorporeal Life Support bei pädiatrischen Patienten mit respiratorischem Versagen nach hämatopoetischer Stammzelltransplantation: Literaturübersicht anlässlich eines erfolgreichen Fallbeispiels}

\section{J. Potratz' , M. Ahlmann², C. Rössig' ${ }^{2}$ H. Omran' ', K. Masjosthusmann'}

'Universitätsklinikum Münster, Klinik für Kinder- und Jugendmedizin Allgemeine Pädiatrie, Münster, Deutschland, ${ }^{2}$ Universitätsklinikum Münster, Klinik für Kinder- und Jugendmedizin - Pädiatrische Hämatologie und Onkologie, Münster, Deutschland

Hintergrund: Extracorporeal Life Support (ECLS) hat sich zu einer wichtigen Rescue-Strategie in der pädiatrischen Intensivmedizin mit einem zunehmenden Einsatzspektrum entwickelt. Dies schließt heute Patienten mit Immundefekten und onkologischer Grunderkrankung ein. Für Patienten nach hämatopoetischer Stammzelltransplantation (HSCT) hingegen wird ihr Einsatz weiterhin kontrovers diskutiert. Allein einzelne erfolgreiche Verläufe deuten an, dass wenige ausgewählte Patienten von dieser invasiven und Ressourcen-intensiven Therapie profitieren können. Auswahlkriterien bleiben bislang jedoch unklar.

Fragestellung: Wir berichten über die erfolgreiche ECLS Therapie eines 14-jährigen Patienten mit akutem respiratorischem Versagen nach allogener HSCT aufgrund einer akuten lymphatischen Leukämie, und diskutieren diesen Fall in einem Review der Literatur.

Material und Methoden: PubMed Literaturrecherche zum Outcome respiratorischer ECLS Therapie bei pädiatrischen Patienten nach allogener HSCT.

Ergebnisse: Besondere Merkmale des klinischen Verlaufs waren (1) ein fehlender Nachweis jeglicher infektiöser Pathogene oder Virusreaktivierungen, bei bestehender klinischer und laborchemischer Inflammation; sowie (2) ein hyperakutes respiratorisches Versagen von Symptom-Beginn $\mathrm{zu}$ ECLS.

Die Literatur beschreibt 23 weitere Patienten mit respiratorischer ECLS Therapie nach HSCT. Von 6 Patienten, die vom ECLS wurden, überlebten 4 bis zur Entlassung; keiner davon bot eine unserem Fall ähnliche klinische Konstellation. Entgegen der Annahme einer schlechteren Prognose bestanden bei 3 dieser Patienten pulmonale Infektionen. Besonders erscheint der Nachweis von Respiratory Syncytial Virus, allein oder kombiniert, bei allen 3 Patienten. Dies bleibt in seiner prognostischen Wertigkeit offen. Vielmehr zeigt die Literaturübersicht, dass die spezifische Prognose einzelner infektöser wie nicht-infektöser pulmonaler Diagnosen mit respiratorischem Versagen, mit und auch ohne ECLS, in der hoch-risiko Population der HSCT Patienten bislang nicht definiert ist. Die Anzahl funktionaler neutrophiler Granulozyten ist hier ein entscheidender Parameter einerseits als rasche Regeneration im Rahmen des seltenen Engraftment Syndroms, andererseits in der Pathogenese und Beherrschung von Infektionen. Ebenso wie T-Lymphozyten-Zahlen, genaue Transplantations-Konstellationen oder Immunsuressiva sind sie aber derzeit in der Literatur unzulänglich berichtet.

Diskussion und Schlussfolgerung: Respiratorische ECLS Therapie kann für einzelne ausgewählte immundefiziente hoch-Risiko Patienten lebensrettend sein. Unser Ziel muss sein, trotz kleinster Fallzahlen diese Subgruppen zu definieren, um die schwierige klinische Entscheidungsfindung in diesem sich entwickelnden Gebiet zu lenken. Die Ätiologie des respiratorischen Versagens und der Neutrophilen- und Immunstatus verdienen Beachtung als Kriterien in diesem schwierigen Prozess.

\section{PÄD-P03 \\ Antidot Fomepizol kann Akutdialyse bei potentiell letaler Ethylenglycolintoxikation ersetzen}

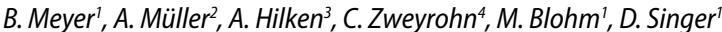

'Universitätsklinik Hamburg-Eppendorf, Kinderklinik, Sektion

Neonatologie und Pädiatrische Intensivmedizin, Hamburg, Deutschland,

2Universitätsklinik Hamburg-Eppendorf, Rechtsmedizin/Toxikologie,

Hamburg, Deutschland, ${ }^{3} U$ niversitätsklinik Hamburg-Eppendorf,

Klinikapotheke, Hamburg, Deutschland, ${ }^{4}$ Katholisches Kinderkrankenhaus Wilhelmstift, Hamburg, Deutschland

Hintergrund: Die Substanz Ethylenglycol ist Bestandteil der Kühlflüssigkeit von Kfz-Verbrennungsmotoren. Nach Ingestion verursacht die Metabolisierung zu Glycolaldehyd, Glyoxal, Ameisensäure und Oxalat eine ausgeprägte metabolischen Azidose, Hypokalzämie, renale, kardiale und zerebrale Toxizität. Die $\mathrm{LD}_{50}$-Dosis bei Ratten beträgt $4,7 \mathrm{~g} / \mathrm{kg}$ Körpergewicht. Durch kompetitive Hemmung der Alkoholdehydrogenase (mittels Alkohol, Zielspiegel 1,0\%o; oder mittels Fomepizol (4-Methylpyrazol)) kann der Abbau des Ethylenglycols und damit die Entstehung der toxischen Metabolite gehemmt werden. Der unmittelbare Beginn einer Hämodialyse wird empfohlen bei Ethylenglycol-Plasmakonzentrationen $>0,5 \mathrm{~g} / \mathrm{l}$, metabolischer Azidose, bereits vorhandenem Endorganschaden. Fallbericht: Ein 12-jähriges Mädchen hatte versehentlich eine relevante Menge Kühlerflüssigkeitskonzentrat getrunken. Bereits zu Hause war eine kleine Menge Wodka verabreicht worden. Fomepizolgaben (Aufsättigungsdosis $15 \mathrm{mg} / \mathrm{kg} \mathrm{KG}$, dann 12-stündlich $10 \mathrm{mg} / \mathrm{kg} \mathrm{KG}$ intravenös) wurden zwei Stunden nach der Ingestion begonnen und über 4 Tage fortgeführt. Abweichend von den Empfehlungen bezüglich des Beginns einer Hämodialyse wurde trotz potentiell letalen Ethylenglycolspiegels $(0,71 \mathrm{~g} /$ 1, Anionenlücke initial bis $24,8 \mathrm{mmol} / 1$ verbreitert) bei klinisch stabilem Kind ohne laborchemische Zeichen einer Organschädigung nach frühzeitigem Beginn der Fomepizolgabe unter engmaschiger klinischer und laborchemischer Überwachung aktiv auf eine Hämodialyse verzichtet. Der Ethylenglycolspiegel fiel unter forcierter Diurese $\left(3 \mathrm{l} / \mathrm{m}^{2} / \mathrm{Tag}\right)$ mit einer Halbwertzeit von ca. $26 \mathrm{~h}$ im Verlauf von 3 Tagen unter die Nachweisgrenze ab. Die Patientin konnte ohne Endorganschäden nach 5 Tagen nach Hause entlassen werden.

Diskussion und Schlussfolgerung: Der Verlauf des Falles zeigt, dass im Einzelfall bei Ethylenglycolintoxikation durch frühzeitige Gabe von Fomepizol auf eine Hämodialyse und damit möglicherweise assoziierte Sekundärkomplikationen verzichtet werden kann. Jede Krankenhausapotheke sollte Fomepizol kurzfristig vorhalten.

\section{PÄD-P04}

\section{Vena Galeni Malformation: Epidemiologie, Klinik und} Management - Ergebnisse einer 2-jährigen ESPED-Studie

F. Brevis Nuñez', C. Dohna-Schwake

'Sana-Kliniken Duisburg, Neonatologische und Pädiatrische Intensivstation, Duisburg, Deutschland, ${ }^{2}$ Universitätsklinikum, Pädiatrische Intensivstation, Essen, Deutschland

Hintergrund: Bei der Vena Galeni-Malformation (VGM) handelt es sich um eine seltene angeborene zerebrale Gefäßmalformation. Im Neugeborenenalter steht die Herzinsuffizienz im Vordergrund. Jenseits der Neonatalzeit dominieren zerebrale Symptome. Zuverlässige Angaben zur Inzidenz, klinischen Erstmanifestation, Diagnostik und Therapie lagen für Deutschland bislang nicht vor.

Ziele der Studie: 1. Ermittlung der Inzidenz der Vena Galeni Malformation in Deutschland; 2. Erfassung von Altersverteilung, Symptomatik, Diagnostik und Therapie bei Diagnosestellung

Material und Methoden: Monatliche Anfragen über ESPED-Zentrale, Fragebogen, Einschlusskriterien: Patienten unter 18 Jahren mit erstmaliger Diagnose einer VGM

Ergebnisse: Es konnten 30 Fragebögen ausgewertet werden. Die Geschlechterverteilung betrug 22:8 (m:w). Bei 11 Patienten wurde die Diagnose pränatal, bei 9 Patienten in der Neonatalzei tfestgestellt, so dass 
insgesamt 20 Kinder perinatal diagnostiziert wurden. Die primäre Diagnosestellung erfolgte in 23 der Fälle sonographisch, in 6 der Fälle durch ein zerebrales MRT, in einem Fall durch eine CT-Angiographie. Es fand sich in 18 Fällen ein choroidealer und in drei Fällen ein muraler Typ. Bei der echokardiographische Untersuchung (27 Patienten) fanden sich bei 18 Kindern Zeichen einer Rechtsherzbelastung. Von diesen 18 Patienten mussten 15 invasiv beatmet, 3x zusätzlich mit Stickstoffmonoxid (NO). In der Schädelsonographie fand sich präinterventionell bei 11 Kindern ein begleitender Hydrozephalus. Eine neuroradiologisch-interventionelle Therapie wurde bei 20 Kindern durchgeführt, 17 davon in den Sana-Kliniken Duisburg. 12 von diesen Kindern konnten ohne Komplikationen nach Hause entlassen werden. Bei 5 Patienten kam es als Komplikation zu intrazerebralen Blutungen. 4 dieser Patienten wurden in der Folge einer neurochirurgischen Operation unterzogen. Bei zwei Patienten kam es nach neuroradiologischer Intervention zu einer ausgedehnten rechtshemisphärischen Ischämie. Ein Patient verstarb nach interventioneller Behandlung. Insgesamt 3 Kinder wurden, aufgrund der bereits bei Geburt vorliegenden schweren Hirnschädigungen, keiner interventionellen Therapie unterzogen. Drei Kinder wurden in andere Kliniken zur weiteren Diagnostik und Therapie verlegt, ohne dass die weitere Therapie bekannt wurde Zwei Kinder zeigten postnatal keine Beschwerden, so dass zunächst von weiterer Diagnostik und Therapie abgesehen wurde. Ein Neugeborenes verstarb unmittelbar vor der geplanten neuroradiologischen Intervention. Schlussfolgerung: 1. Die Inzidenz liegt bei mindestens 1:48.000 bezogen auf die Geburtenrate. 2. Es findet sich ein deutliches Überwiegen des männlichen Geschlechts (2,75:1). 3. In 2/3 der Fälle wurde die Erstdiagnose der VGM in der Perinatalzeit festgestellt. Fast alle perinatal diagnostizierten Patienten zeigten die erwartete kardiale Symptomatik. 3. Bei den Patienten außerhalb der Perinatalzeit fand sich präinterventionell ausschließlich eine zerebrale Symptomatik. 4. Bei 2/3 aller Patienten wurde nach Diagnosestellung eine interventionelle Therapie durchgeführt. Trotz der geringen Letalität (1 postinterventioneller Todesfall) ist die Komplikationsrate der interventionellen Therapie nicht gering. 5. Aufgrund des Studiendesigns kann das neurologische Langzeit-Outcome nicht sicher beurteilt werden.

\section{PÄD-P05 \\ Akuter Stoffwechselnotfall - Neonatale Hyperammonämie und Burst-Suppression im amplitudenintegrierten EEG}

\section{Klepzig, J. Jochim, M. Engler}

\section{Sana Klinikum Offenbach, Kinderklinik, Offenbach, Deutschland}

Hintergrund: Bei mütterlicher Präeklampsie wurde ein männliches Frühgeborenes der $29+6$ Schwangerschaftswoche per Sectio entbunden. Nach Intubation und Surfactant-Gabe kam es zu einer guten kardiorespiratorischen Adaptation. Es erfolgte eine systemische antibiotische Therapie. Der Kostaufbau wurde zügig mittels Formulanahrung begonnen. Am 3 . Lebenstag trat eine rapide Verschlechterung des Allgemeinzustandes auf: stimulationspflichtige Bradykardien und Sättigungsabfälle, zunehmend komatöser Bewusstseinzustand, muskuläre Hypotonie, Schmatzautomatismen sowie fehlende Schutzreflexe. Laborchemisch ergab sich kein Infektionshinweis, Lactat und Blutgase waren normwertig. Auffällig war ein erhöhtes Ammoniak > $6000 \mu \mathrm{g} / \mathrm{dl}$.

Fragestellung: Welcher Genese ist die akute Hyperammonämie? Material und Methoden:

Familienanamnese: Die konsanguinen türkischen Eltern haben einen gesunden 12 jährigen Sohn. Die Mutter erlitt einen Abort, ein Geschwisterkind sei im Alter von 4 Monaten unter dem klinischen Verdacht eines Atmungskettendefektes verstorben. In der Familie häufen sich unklare Todesfälle im Säuglingsalter sowie fortschreitende psychomotorische Retardierung ab dem Kindesalter.

Stoffwechselscreening: unauffälliges Neugeborenen-Stoffwechselscreening. Organische Säuren im Urin/Aminosäuren im Plasma: erhöhte Konzentration aller Aminosäuren, die eine mitochondriale Dysfunktion anzeigen, wobei nicht zwischen einer primären und sekundären Störung (durch die Hyperammonämie) unterschieden werden kann.
Amplitudenintegriertes EEG: kontinuierliches Burst-Suppression-Muster mit Krampfäquivalenten

Schädelsonographie: zunehmende periventrikuläre zystische Strukturen Augenärztliche Untersuchung: unauffälliger Status

Ergebnisse: In der genetischen Paneldiagnostik zur Differentialdiagnostik einer Enzephalopathie im Rahmen eines Harnstoffzyklusdefektes gelang der Nachweis eines autosomal rezessiv vererbten CarbamoylphosphatSynthetase (CPS) 1 Defekts mit homozygoter Mutation im CPS 1 Gen für die Variante c.3037_3039del (p.Val1013del).

Diskussion: Harnstoffzyklusdefekte treten mit einer Inzidenz von ca. 1:8000 auf, Störungen speziell der CPS gehören mit 1:60.000 bis 1:100.000 nach dem Ornithincarbamoyltransferase-Mangel zu den häufigeren Harnstoffzyklusdefekten. Es handelt sich hierbei um einen Defekt im 1. Schritt der Harnstoffsynthese.

Bei unserem Patienten lag die schwere neonatale Verlaufsform vor, bei der innerhalb der ersten 3 Lebenstage ein nicht therapierbares hyperammonämisches Koma mit letalem Ausgang auftritt. Die von uns eingeleitete Therapie mit L-Arginin und Carnithin sowie strenger Eiweißkarenz bewirkte nur eine kurzfristige Stabilisierung des Allgemeinzustandes, der kleine Patient verstarb am 27. Lebenstag am Multiorganversagen.

Retrospektiv kann postuliert werden, dass auch das im Säuglingsalter erkrankte Geschwisterkind an diesem genetischen Defekt verstorben ist. Die Mitochondropathie-Diagnose konnte genetisch nicht bestätigt werden und hatte sich vor allem auf die Aminosäure-Profile in Urin und Plasma, sowie die klinische Symptomatik begründet. Es könnte sich hier also ebenfalls um eine sekundäre mitochondriale Dysfunktion in Zusammenhang mit einer durch den CPS-1-Dekt bedingten Hyperammonämie gehandelt haben. Eine Ammoniak-Analyse wurde nur einmalig am 2. Lebenstag vor ausreichender Eiweißzufuhr abgenommen. Der Familie wurde eine dringende humangenetische Untersuchung und Beratung empfohlen.

\section{Literatur}

1. Häberle J, Linder M (2016) Diagnostik und Therapie von Harnstoffzykulusstörungen. Monatsschr Kinderheilkd 164:883-891

\section{PÄD-P06}

Outcome of children with cancer and/or allogeneic hematopoietic stem cell transplantation in the intensive care unit: Experience at a large European Pediatric Cancer Center

C. T.M. Barking', K. Masjosthusmann ${ }^{2}$, G. Rellensmann ${ }^{2}$, K. Ehlert', S. Zöllner', S. Jocham ', B. Bohnenkamp³ , A. Kremer', E. Rieger-Fackeldey², A. Groll'

'University Children's Hospital Münster, Dept. of Pediatric Hematology and Oncology, Münster, Germany, ${ }^{2}$ University Children's Hospital Münster, Dept. of General Pediatrics, Münster, Germany, ${ }^{3}$ University Hospital Münster, Medical Controlling, Münster, Germany

Background: Pediatric cancer treatment and hematopoietic stem cell transplantation (HSCT) carry considerable risks of morbidity. We analyzed intensive care unit (ICU) admissions in children and adolescents treated for cancer or undergoing HSCT who developed life-threatening complications.

Methods: Patients $\leq 21$ years with hematological or oncological disorders or status post allogeneic HSCT receiving care at the Department of Pediatric Hematology and Oncology admitted to the ICU between 2003 and 2013 for life-threatening conditions were identified through a search of the University Hospital“s Medical Controlling database. Demographics, disease related parameters, medical course during the ICU stay and outcome of the ICU stay were analyzed. The primary endpoint of outcome was survival in the ICU; survival at discharge from the hospital, at 30,100 and 365 days post discharge, and long term survival probability were further endpoints. Causes of death (cancer vs. complications) and parameters with potential impact on outcome were analyzed by uni- and multivariate analysis. The study was reviewed and approved by the local ethics committee. Results: During the study period, 140 patients had 188 admissions to the ICU for a life-threatening medical condition, accounting for $1.6 \%$ of all 11.890 hospital admissions of patients of the Department of Pediatric Hematology and Oncology. The majority of patients (60.6\%) had a hemato- 
logical malignancy, and $38.3 \%$ were post allogeneic HSCT; the median age was 10.4 years (range, $0.0-20.5$ ). Main reasons for ICU admission were respiratory insufficiency $(85 ; 45.2 \%)$, cardiovascular insufficiency (52; $27.7 \%)$ and sepsis $(51 ; 27.1 \%)$. The median duration of ICU stay was 3 days (range, $1 \mathrm{hr}$ - -80 days); re-admission to the ICU within 7 days occurred in 23 cases (12.2\%). Mortality in the ICU was $19.1 \%$ (36) and related to organ failure and acute complications $(28 ; 77.8 \%)$ or irreversible progress of the underlying malignancy $(8 ; 22.2 \%)$. Mortality rates at 30,100 and 365 days post discharge from the ICU were $24.5 \%, 30.9 \%$, and $39.9 \%$, respectively. After a median follow-up of 1735 days (range, 404-3931), survival probabilities (Kaplan-Meyer) after five and ten years following admission to the ICU were $46.4 \%$ and $39.8 \%$. There was no trend over time regarding individual survival endpoints. Parameters associated with death in the ICU by univariate analysis included status post allogeneic HSCT, prior ICU admission(s), the number of days in the ICU, the presence of infections, occurrence and number of organ failures and the number of supported organ systems. Multivariate analysis revealed the number of failed organ systems (OR 6.21; 95\% CI: 2.55-15.120; $p<0.01$ ), the number of prior ICU stays (OR 4.66; 95\% CI: $1.20-18.02 ; p=0.025$ ), and the number of days in the ICU (OR, $1.09 ; 95 \%$ CI: $1.01-1.17 ; p=0.015)$ as parameters that were significantly associated with death in the ICU.

Conclusions: The outcome of pediatric cancer/HSCT patients admitted for acute, life-threatening conditions was not as dismal as reported for some centers in the literature. Most patients benefitted from ICU care and survival was predominantly compromised by the evolution of complications.

\section{PÄD-P07 \\ Beurteilung der Sedierungstiefe pädiatrischer Intensivpatienten mithilfe des Bispektral-Index}

\section{M.D. Jösch, F. Uhlenberg, D. Singer, P. Deindl}

UKE, Klinik für Kinder- und Jugendmedizin Sektion Neonatologie und pädiatrische Intensivmedizin, Hamburg, Deutschland

Hintergrund: Intensivmedizinisch behandelte pädiatrische Patienten sind oftmals auf eine Analgosedierung im Rahmen einer künstlichen Beatmung oder invasiver Prozeduren angewiesen. Bei zu tiefer Analgosedierung drohen eine verschlechterte Kreislaufsituation, eine verlängerte $\mathrm{Be}$ atmungsdauer, die Gefahr von beatmungsassoziierten Pneumonien, ein Entzugssyndrom oder die Entwicklung eines posttraumatischen Stresssyndroms. Bei zu flacher Analgosedierung können Stressreaktionen und auch neuroplastische Veränderungen resultieren, welche die Grundlage für eine Schmerzchronifizierung bilden können.

Zur Vermeidung einer Über- oder Untersedierung werden in der Regel klinische Parameter und spezielle Scoring-Systeme verwendet. Allerdings sind physiologische Parameter durch den Einfluss von Erkrankung und Therapie oft nur bedingt beurteilbar. Fremdbeurteilungsskalen sind durch unterschiedliche Erfahrung des Beurteilenden und den subjektiven Charakter einiger zu bewertender Variablen beeinflusst. Zudem sind Fremdbeurteilungsskalen bei tiefer Sedierung nur eingeschränkt verwendbar. Insbesondere ist keine Aussage darüber möglich, ob die aktuelle Analgosedierung für eine noch ausstehende Intervention ausreichend ist und deren Steuerung daher nur im Nachhinein erfolgen. Bei Ausbleiben einer Reaktion auf den Reiz ist es zudem nicht möglich abzuschätzen, ob es sich um eine adäquate Analgosedierung oder bereits um eine Über-Dosierung handelt. Eine Möglichkeit der objektiven Sedierungsmessung könnte ein EEG-basiertes Verfahren, der sogenannte Bispektral-Index, darstellen, der in ersten Studien zur Sedierungsmessung bei Kindern bereits vielversprechende Ergebnisse gezeigt hat.

Fragestellung: Kann der Bispektral-Index (BIS) die Sedierungstiefe pädiatrischer Intensivpatienten abbilden?

Material und Methoden: Es wurden fünfzehn beatmete analgosedierte $\mathrm{Pa}$ tienten zwischen zwei und 17 Jahren zu 42 Messzeitpunkten untersucht Der Bispektral-Index wurde kontinuierlich verblindet aufgezeichnet. Vor und während eines schmerzhaften Reizes (endotracheales Absaugmanöver) wurden sowohl die COMFORT-B Skala als auch die Behavioral Pain Scale (BPS) von der behandelnden Pflegekraft sowie einem weiteren un- abhängigen Beobachter erhoben. Eine positive Reaktion wurde als ein BPS $>5$ bzw. ein Herzfrequenzanstieg $>5$ Schläge/Min. definiert.

Ergebnisse: Der mittlere BIS \pm SD für die Kategorien Übersedierung, adäquate Sedierung und Untersedierung gemäß der COMFORT-B Skala $(\leq 10 ; 11$ bis 22 und $\geq 23)$ lag bei: $34 \pm 19 ; 59 \pm 18(p<0,001)$ und $77 \pm 8$ $(p=0,12)$. Der BIS und der COMFORT-B Score korrelierten stark miteinander (Spearman Korrelations Index $\mathrm{r}=0,59 ; p<0,001$ ). Der mittlere $\mathrm{BIS} \pm \mathrm{SD}$ der Patienten, die auf einen schmerzhaften Reiz reagierten, war signifikant höher als in der Gruppe derer, die nicht reagierten (Herzfrequenzanstieg: $33 \pm 17$ vs. $53 \pm 24$ Schläge/Min., $p=0,005$; BPS $>5: 35 \pm 19$ vs. $58 \pm 22, p=0,002)$. Die Interrater-Reliabilität der beiden Beobachter für BPS (Cronbachs Alpha 0,94) und COMFORT-B (Cronbachs Alpha 0,97) sehr gut.

Schlussfolgerung: Der Bispektral-Index korrelierte stark mit der COMFORT-B Skala. Patienten, die nicht auf einen schmerzhaften Reiz reagierten, hatten signifikant niedrigere BIS-Werte.

\section{PÄD-P08}

Akutes Leberversagen im Kindes- und Jugendalter: eine ESPEDStudie zu Inzidenz, Ätiologie und Outcome

\section{Staufner', D. Lenz', S. Kölker', D. Wenning ', H. Prokisch², I. Eckerle? , B. Heinrich', P. Burgard', G. F. Hoffmann'}

'Zentrum für Kinder- und Jugendmedizin Heidelberg, Klinik I (Allg. Pädiatrie, Stoffwechsel, Gastroenterologie, Nephrologie), Heidelberg, Deutschland, ${ }^{2}$ Institut für Humangenetik, Klinikum rechts der Isar, Technische Universität München, München, Deutschland, ${ }^{3}$ Institut für Virologie, Universitätsklinikum Bonn, Bonn, Deutschland, ${ }^{4}$ Koordinierungszentrum für Klinische Studien (KKS), Heinrich-Heine-Universität Düsseldorf, Düsseldorf, Deutschland

Hintergrund: Akutes Leberversagen im Kindes- oder Jugendalter ist ein seltenes, aber lebensbedrohliches Ereignis. Therapeutische Maßnahmen sowie Prognose sind von der zugrunde liegenden Ursache des akuten Leberversagens abhängig, welche jedoch in ca. 50 \% der Fälle ungeklärt bleibt. Fragestellung: Inzidenz, Ätiologie und Outcome von akutem Leberversagen im Kindes- und Jugendalter in Deutschland. Anteil metabolischer bzw. genetischer Krankheiten an ungeklärten Fällen.

Methoden: Mittels der Erhebungseinheit für seltene pädiatrische Erkrankungen in Deutschland (ESPED) erfolgt eine bundesweite Erfassung aller pädiatrischen Fälle akuten Leberversagens seit Januar 2016. Bei ungeklärter Ätiologie besteht das optionale Angebot kostenfreier komplettierender metabolischer Diagnostik, Exom-Sequenzierung und Detektion unerkannter und/oder unbekannter Viren. Über die ESPED-Studie hinaus werden Patienten mit ungeklärtem akutem Leberversagen zur Exom-Sequenzierung über bilaterale Kooperationen rekrutiert.

Ergebnisse: Im Zeitraum Januar-Dezember 2016 wurden 38 Fälle über die ESPED gemeldet, $31,6 \%$ davon mit Manifestation im Neugeborenenalter, 21,1 \% im Säuglingsalter (1 Monat-6 Jahre), 23,5\% im Kleinkindesalter (1-6 Jahre), 23,5\% im Schulkindesalter (>6 Jahre). Die häufigsten bekannten Ursachen sind angeborene Stoffwechseldefekte $(21 \%)$ und Infektionen (16\%), der Anteil nicht sicher geklärter Fälle beträgt $50 \%$.

Bislang wurden insgesamt 96 Patienten mit zuvor ungeklärtem akutem Leberversagen mittels Exom-Sequenzierung untersucht. In 37/96 Fällen (38\%) konnten damit angeborene Stoffwechseldefekte diagnostiziert werden, welche teils spezifische Behandlungsoptionen bieten. Die gefundenen Stoffwechselkrankheiten wurden teils erst kürzlich identifiziert, zwei Krankheiten wurden erstmals durch uns beschrieben (NBAS Defizienz, IARS Defizienz).

Schlussfolgerung: Angeborene Stoffwechseldefekte stellen die häufigste Ursache von akutem Leberversagen im Kindes- und Jugendalter dar; sie sind die häufigste Ätiologie bei geklärten Fällen, sowie für mehr als 1/3 der bislang ungeklärten Fälle verantwortlich. Die frühe und enge Zusammenarbeit mit einem Stoffwechselzentrum ist für das Management von Patienten mit akutem Leberversagen daher von großer Bedeutung. Alle Fälle akuten Leberversagens sollten bei der ESPED gemeldet werden, in 
ungeklärten Fällen bieten wir eine für den Einsender kostenfreie weitere Abklärung inklusive Exom-Sequenzierung an.

\section{PÄD-P09 \\ Speziell für polytraumatisierte Kinder konzipiertes Massentransfusionsprotokoll als Qualitätskriterium des Schockraummanagements}

C. Hülstrunk', S. Kuhn², K. Laabs', J. Harbarth', C. Oetzmann von Sochaczewski', C. Martin', R. Huth', S. O. Dietz', S. Gehring' 'Universitätsmedizin Mainz, Zentrum für Kinder- und Jugendmedizin, Mainz, Deutschland, ${ }^{2}$ Universitätsmedizin Mainz, Zentrum für Orthopädie und Unfallchirurgie, Mainz, Deutschland

Hintergrund: In den letzten Jahren zeigte sich aufgrund von Präventionskampagnen und mit der kontinuierlichen Verbesserung der Versorgungsstrukturen ein Rückgang der tödlich verunglückten Kinder und Jugendlichen. Unfälle stellen jedoch weiterhin die häufigste Todesursache bei Kindern über einem Jahr dar. Die Schwere des Schädel-Hirn Trauma und die Auswirkungen einer Massenblutung bestimmen die Mortalität und Morbidität. Die Prognose einer traumainduzierten Koagulopathie wird durch die Anwendung von Massentransfusionsprotokollen bei Erwachsenen verbessert. Diese gehen jedoch nicht auf die physiologischen Unterschiede bei Kindern ein. Massentransfusionen sind bei Kindern selten, so dass ein standardisierter Algorithmus für eine schnelle qualitativ hochwertige Therapie entscheidend ist. Dennoch besitzen viele Kliniken in Deutschland keine entsprechenden Protokolle. Im Jahr 2011 entwickelte eine interdisziplinäre Arbeitsgruppe der Universitätsmedizin Mainz ein Massentransfusionsprotokoll für polytraumatisierte Kinder. In den folgenden Jahren kam dieses bei vorher festgelegten Auslösekriterien zum Einsatz.

Fragestellung: Ziel der Evaluation war es, ob die Anwendung des Massentransfusionsprotokolls zu einer Verbesserung der Versorgung von polytraumatisierten Kindern führte und ob die festgelegten Auslösekriterien sich bewährten

Material und Methoden: Wir untersuchten retrospektiv alle Fälle von aktivierten Massentransfusionsprotokollen bei pädiatrischen Schockraumpatienten. Hierzu wurden die Daten der versorgten Kinder analysiert.

Ergebnisse: Zwei Patienten erhielten eine Massentransfusion. Beide Patienten verstarben im Verlauf aufgrund der Schwere des erlittenen Schädel-Hirn Trauma trotz stabilisierter Blutgerinnung. Bei vorliegender Indikation wurde das Protokoll aktiviert und bei Notwendigkeit Blutprodukte entsprechend des Algorithmus gegeben. Die Sensitivität für Massentransfusionen betrug $100 \%$. Die Spezifität lag bei $14,3 \%$ und für die Gabe von Blutprodukten 57,1\%. In keinem Fall war eine sekundäre Transfusion bei nicht erfolgter Aktivierung notwendig.

Eine Stabilisierung der traumainduzierten Koagulopathie war rasch zu erzielen. Die vorher festgelegten Kriterien, insbesondere das Verhältnis von Erythrozytenkonzentraten und FFPs, wurden in beiden Fällen eingehalten. Eine deutliche Zeitreduktion der Bereitstellung von Blutprodukten war zu beobachten. Jede notwendige Transfusion konnten unmittelbar bereits im Schockraum begonnen werden.

Diskussion: Unsere Untersuchung bestätigte, dass eine Massentransfusion eine seltene erforderliche Therapie bei Kindern ist. Die vorher festgelegten Auslösekriterien führten zu einer overtriage. Bei einer Massenblutung ist jedoch eine zeitnahe effektive und effiziente Therapie für die Prognose wesentlich. Eine Verzögerung führt zu einer erhöhten Morbiditäts- und Mortalitätsrate. Die Auslösekriterien haben sich bewährt und alle Patienten, die eine Transfusion zeitnah benötigten, wurden detektiert. Entgegen der wenigen publizierten Studien war die Einhaltung des vorgegebenen Erythrozytenkonzentrat und FFP Verhältnis unproblematisch. Für eine signifikante Aussage eines konsensus-basierten Massentransfusionsprotokolls ist eine multizentrische Studie erforderlich. Die klar vorgegeben Kriterien unseres Massentransfusionsprotokolle halfen, die Versorgung von verletzten Kindern in Mainz zu verbessern.
PÄD-P10

Nichtinvasive inhalative Applikation von Stickstoffmonoxid bei Früh- und Reifgeborenen mit persistierender pulmonaler Hypertension

F. Pulzer', A. Serfling', A. Möckel' ${ }^{2}$, N. Wolf', C. Gebauer', B. Ackermann', M. Knüpfer', U. Thome

${ }^{1}$ Universitätskinderklinik, Neonatologie, Leipzig, Deutschland, ${ }^{2}$ Sana Kliniken Leipziger Land GmbH, Neonatologie, Borna, Deutschland

Hintergrund: Stickstoffmonoxid (NO) wird als starker selektiver Vasodilatator zur Behandlung einer persistierenden pulmonalen Hypertension (PPHN) bei Früh- und Neugeborenen erfolgreich eingesetzt. Wir berichten über unsere Erfahrungen mit der sehr frühen nichtinvasiven inhalativen Gabe von NO (NINO) bei echokardiographisch gesicherter PPHN. Fragestellung: Ist die sehr frühe Gabe von NINO zusätzlich zur etablierten Behandlung einer PPHN bei spontan atmenden Früh- und Neugeborenen sicher und effektiv?

Material und Methoden: Während einer 6-jährigen Beobachtungszeit wurden 4297 Patienten auf unserer neonatologischen Intensivstation betreut, wovon 393 Patienten mit inhalativem NO therapiert wurden. Davon erhielten 46 Neonaten mit ausreichender Eigenatmung ausschließlich NINO mit Beginn innerhalb der ersten 12 Lebensstunden. In allen Fällen wurde eine PPHN anhand klinischer Zeichen sowie durch Messung prä- und postduktaler Sauerstoffsättigungsdifferenzen diagnostiziert und die Indikation zur Therapie mit NO durch wiederholte echokardiographische Untersuchungen gestellt. Wir führten eine Analyse aller mit NINO behandelten Kinder durch.

Ergebnisse: Die 46 mit NINO therapierten Patienten hatten im Median ein Gestationsalter von 37 Schwangerschaftswochen (SSW), [24+6 SSW $-42+4$ SSW], darunter waren 10 Frühgeborene $\leq 30$. SSW. NINO wurde im Median 24 Stunden appliziert [1,5-168 Stunden], die maximale Dosis von betrug im Mittel 20 ppm [ $10-35$ ppm]. Die supplementäre Sauerstoffgabe konnte im Median rasch von $60 \%$ [35\% - 100\%] zu Beginn auf $25 \%$ [21-40\%] nach Beenden von NINO gesenkt werden. Der stationäre Aufenthalt betrug im Median 13 Tage [1-70 Tage]. Keiner der Patienten entwickelte eine bronchopulmonale Dysplasie. Lokale oder signifikante systemische Nebenwirkungen der NO-Therapie wurden nicht beobachtet. Alle mit NINO behandelten Patienten überlebten.

Schlussfolgerung und Diskussion: Bei Neonaten mit PPHN und ausreichender Spontanatmung ist die Therapie mit NINO eine sichere und effektive Behandlungsmöglichkeit, welche zu einer verbesserten Oxygenierung beiträgt. Ob die Nebenwirkungen einer NO-Therapie oder die toxischen Wirkungen von freien Sauerstoffradikalen das Outcome der kleinen Patienten ungünstiger beeinflussen muss durch weiterführende Untersuchungen gezeigt werden.

\section{PÄD-P11}

\section{RSV-Infektion und Hyponatriämie bei einem jungen Säugling}

\section{Pommerenke, D. Windschall}

Asklepios Klinik Weißenfels, Klinik für Kinder- und Jugendmedizin, Weißenfels, Deutschland

Hintergrund: Das Syndrom der inadäquaten ADH-Sekretion (SIADH) ist ein häufiger Grund für eine Hyponatriämie, die bei ca. $30 \%$ aller hospitalisierten Patienten auffällt. Beim SIADH führt eine pathologisch erhöhte $\mathrm{ADH}-$ Sekretion mit konsekutiver überschießender Retention freien Wassers zu einer Verdünnungshyponatriämie mit der Folge einer hypotonen Hyperhydratation. Die Ursachen sind vielfältig und die genaue Pathophysiologie teils noch ungeklärt. Neben Medikamenten, ZNS-Störungen, Malignomen, Operationen, Hormonbehandlungen und hereditären Syndromen sind pulmonale Erkrankungen, wie Asthma bronchiale, Atelektasen oder ein Pneumothorax häufige Ursachen. Pathophysiologisch wird bei pulmonalen Erkrankungen angenommen, dass Überdruckbeatmung und "Air-Trapping" zu einer reduzierten Wandspannung des linken Vorhofs führen, wodurch es zur Aktivierung atrialer Niederdruckbarorezeptoren und konsekutiv überschießender ADH-Sekretion kommt. Gestützt wird 
dieser Mechanismus durch Hyperkapnie, Hypoxie und auch durch Therapie mit Betamimetika. Zerebrale Krampfanfälle können Folge der Hyponatriämie sein. Neben der kausalen Therapie der Grunderkrankung erfolgt eine symptomatische Therapie mit Ausgleich des Natriumdefizits, Flüssigkeitsrestriktion und ggf. der Gabe von Diuretika. Patient: Wir behandelten einen 7 Wochen alten Jungen (Frühgeborenes der $32+4$ SSW). Im Rahmen einer RSV-Pneumonie mit respiratorischer Insuffizienz fiel nach initial unauffälligen Serumelektrolyten am 2. stationären Behandlungstag eine Hyponatriämie mit $114 \mathrm{mmol} / \mathrm{l}$ auf.

Methode: Die Konstellation einer Serumhypoosmolalität bei fehlender Urinhypotonie sprach am ehesten für ein SIADH. Neurologische Auffälligkeiten bestanden bis auf eine Trinkschwäche nicht. Trotz einer Natriumsubstitution, mit bis zu $20 \mathrm{mmol} / \mathrm{kg} / \mathrm{Tag}$, und Flüssigkeitsrestriktion (50\%) konnte erst nach 36 Stunden ein Natrium-Wert über $125 \mathrm{mmol} / \mathrm{l}$ erreicht werden. Es erfolgte die Gabe von Furosemid. Erst am 3. Behandlungstag stabilisierte sich das Natrium vollständig.

Schlussfolgerung: Hyponatriämie bei pulmonalen Affektionen, vor allem bei RSV-Infektionen, ist eine seltene, aber relevante Komplikation. Die Bestimmung der Serumelektrolyte sollte bei allen hospitalisierungspflichtigen pädiatrischen Patienten mit pulmonalen Infektionen durchgeführt und bei komplizierten Verläufen auch wiederholt werden. Bei Krampfanfällen im Rahmen pulmonaler Infekte sollte an eine Hyponatriämie als mögliche Ursache gedacht werden.

\section{Literatur}

1. Albinski M, Gämperli L, Regamey N et al (2016) Hyponatraemia in paediatric bronchiolitis. Klin Padiatr 228:275-276

2. Rivers RP, Forsling ML, Oliver RP (1981) Inappropriate secretion of antidiuretic hormone in infants with respiratory infections. Arch Dis Child 56:358-363

3. Sahay M, Sahay R (2014) Hyponatremia: A practical approach. Ind. J Endocrinol Metab 18:760-771

\section{PÄD-P12}

\section{Early Initiated Feeding (EIF) versus Early Reached Target Enteral Nutrition (ERTEN) in critically ill children: A multicenter study in Turkey}

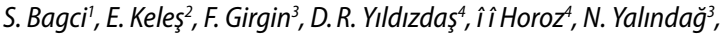
M. Tanyıldız' , B. Bayrakci ${ }^{5}$, G. Kalkan², B. N. Akyıldız ${ }^{6}$, A. Köker ${ }^{7}$, T. Köroğlu' A. B. Anıl ${ }^{8,9}$, N. Zengin ${ }^{8}$, E. î Dinleyici' ${ }^{10}$, E. Kıral ${ }^{10}$, O. Dursun ${ }^{11}$, P. Bartmann', A. Müller

'University of Bonn, Neonatology and Pediatric Intensive Care Unit, Children's Hospital, Bonn, Germany, ${ }^{2}$ University of Gazi, Pediatric Intensive Care Unit, Department of Pediatrics, Ankara, Turkey, ${ }^{3}$ University of Marmara, Pediatric Intensive Care Unit, Department of Pediatrics, Istanbul, Turkey, ${ }^{4}$ University of Cukurova, Pediatric Intensive Care Unit, Department of Pediatrics, Adana, Turkey, ${ }^{5}$ University of Hacettepe, Pediatric Intensive Care Unit, Department of Pediatrics, Ankara, Turkey, ${ }^{6}$ University of Erciyes, Pediatric Intensive Care Unit, Department of Pediatrics, Kayseri, Turkey, ${ }^{7}$ University of Dokuz Eylül, Pediatric Intensive Care Unit, Department of Pediatrics, Izmir, Turkey, ${ }^{8}$ Izmir Tepecik Hospital, Pediatric Intensive Care Unit, Department of Pediatrics, Izmir, Turkey, ${ }^{9}$ University of Izmir Katip Celebi, Pediatric Intensive Care Unit, Department of Pediatrics, Izmir, Turkey, ${ }^{10}$ University of Osmangazi, Pediatric Intensive Care Unit, Department of Pediatrics, Eskisehir, Turkey, ${ }^{1}$ University of Akdeniz, Pediatric Intensive Care Unit, Department of Pediatrics, Antalya, Turkey

Introduction: The aim of this study was to evaluate our current practice supplying enteral nutrition (EN) and to identify factors that affect both the initiation of feeding within 24 hours after PICU admission and the adequate supply of EN in the first 48 hours after PICU admission in critically ill children.

Materials and Methods: We conducted a prospective, multicenter, observational study in nine PICUs in Turkey. Inclusion criteria were: 1) patient age between 1 month and 16 years, 2) expected length of PICU stay at least 96 hours, 3) use of a nasogastric tube, and 4) no history of acute or chronic gastrointestinal disease. Of the 111 patients admitted to the PICU with a critical illness, 16 patients did not meet all inclusion criteria, leaving 95 patients to participate in the study. Any kind of tube feeding commenced within 24 hours of PICU admission was considered Early Initiated Feeding (EIF). Patients who received more than $25 \%$ of the estimated energy requirement via enteral feeding within 48 hours of PICU admission were considered to have Early Reached Target EN (ERTEN).

Results: Feeding was initiated in $47 \%$ of patients within 24 hours after PICU admission. ERTEN was achieved in 43 (45\%) of 95 patients.

To determine the factors that might have influenced the decision to initiate feeding, we compared the time of initiation after PICU admission for each patient. Feeding was initiated in $20(21 \%)$ patients within $6 \mathrm{~h}$ of PICU admission, in 25 (26\%) patients between 7 and $24 \mathrm{~h}$ of PICU admission and in 43 (45\%) patients after $24 \mathrm{~h}$ of PICU admission. Seven (7\%) patients were not fed during their PICU stay. Patients who were fed in the first $6 \mathrm{~h}$ of PICU admission had significantly lower PIM2 scores $(p=0.012)$, higher $\mathrm{pH}(p=0.006)$, higher BE $(p=0.035)$, and lower serum glucose values $(p<0.001)$ than patients who were not fed in the first $6 \mathrm{~h}$ of PICU admission $(n=75)$. However, no differences were found between patients who were fed between 7 and $24 \mathrm{~h}$ of PICU admission and patients who were fed after $24 \mathrm{~h}$ of PICU admission. In many patients, initiation of feeding seems to have been delayed without an evidence-based reason.

Patients with EIF were significantly more likely to reach ERTEN. Sixteen (17\%) of the 95 patients died within 28 days of PICU admission. ERTEN was an independent prognostic factor for survival $(p<0.001)$ in patients who reached the target enteral caloric intake on day 2 .

Conclusions: There is substantial variability among clinician"s perceptions regarding indications for delay to initiate enteral feeding in critically ill children, especially after the first 6 hours of PICU admission. ERTEN, but not EIF, is associated with a significantly lower mortality rate 28 days after PICU admission in critically ill children. To provide appropriate clinical guidance for practitioners of PICU, future studies should focus not only on timing the initiation of feeding, but also on target goals of enteral nutrition in critically ill children.

\section{PÄD-P13 \\ Hämodiafiltration als effektive Therapie der Ethylenglycol- Intoxikation}

R. Camara', G. Dworschak' , H. Kyrieleis², T. Dresbach' , A. Müller ', B. Hoppe², M. Feldkötter ${ }^{2}$

'Universität, Neonatologie/Pädiatrische Intensivmedizin, Bonn, Deutschland, ²Universität, Pädiatrische Nephrologie, Bonn, Deutschland

Hintergrund: Ethylenglycol, der einfachste zweiwertige Alkohol mit der chemischen Bezeichnung Ethan-1,2-diol, ist der Hauptbestandteil von Frostschutzmitteln. Es handelt sich um eine farb- und geruchslose, angenehm bittersüß schmeckende viskose Flüssigkeit. Bei oraler Aufnahme von $30 \mathrm{ml}$ oder mehr handelt es sich um eine schwere, bei mehr als $100 \mathrm{ml}$ um eine lebensbedrohliche Intoxikation. Das BfR gibt für Menschen eine toxische Dosis von $100 \mathrm{mg} / \mathrm{kg}$ Körpergewicht an. Ethylenglycol ist selbst ungiftig, wird aber im Körper durch die Alkoholdehydrogenase in nephrotoxische Metabolite umgewandelt, darunter auch Oxalat und Glycolat. Unbehandelt verläuft die Vergiftung in drei Stadien über erste Symptome (Schwindel, Trunkenheit, Bewusstseinsstörungen), Schäden an Herz und Leber (nach 12-24 Stunden) bis zum urämischen Koma mit akutem Nierenversagen.

Fallbericht: Wir berichten über einen 15-jährigen Patienten, der in suizidaler Absicht $600 \mathrm{ml}$ Frostschutzmittel getrunken hat. Es erfolgte die intensivmedizinische Überwachung und die Therapie mit intravenöser Ethanol Infusion. Aufgrund eines Ethylenglycol Serumspiegels von $614 \mathrm{mg} / \mathrm{l}$ erfolgte die Verlegung zur Hämodialysebehandlung in unsere Klinik. Nach Anlage eines großlumigen zentralvenösen Katheters begannen wir eine Hämodiafiltration mit dem Plasauto Sigma-System (DIAMED, Cologne). Unter der Therapie sank der Ethylenglycol-Spiegel nach 8 Stunden auf $208 \mathrm{mg} / \mathrm{l}$ und nach weiteren 20 Stunden auf $29 \mathrm{mg} / \mathrm{l}$. Zusätzlich wurde eine Ethanol-Therapie über insgesamt 60 Stunden durchgeführt, wobei die Zielspiegel zwischen 1\%o und 1,5\%o lagen. Eine Azidose, Einschränkung der Herz- oder Leberfunkton und auch der Nierenfunktion traten 
nicht auf. Neben dem Monitoring der Funktionsparameter der obengenannten Organe und des Ethylenglycols maßen wir auch die Abbauprodukte Oxalat und Glycolat. Die Spiegel im Serum waren maximal vor Beginn der Hämodiafiltration: Max. Oxalat 12,2 $\mu \mathrm{mol} / \mathrm{l}(\mathrm{Norm}<6,3 \mu \mathrm{mol} / \mathrm{l})$, max. Glycolat 507,9 $\mu \mathrm{mol} / \mathrm{l}(\mathrm{Norm}<7,4 \mu \mathrm{mol} / \mathrm{l})$. Nach vier Tagen konnte der Patient somatisch unauffällig/gesund in die Kinder- und Jugendpsychiatrie verlegt werden.

Diskussion: Ethylenglycol-Intoxikationen, ob akzidentiell oder in suizidaler Absicht, sind glücklicherweise seltene Fälle in der Pädiatrie. Ab einer Menge von $\sim 1,5 \mathrm{~g} / \mathrm{kgKG}$ Ethylengylcol kann eine Intoxikation tödlich enden. Die primäre Giftentfernung innerhalb der ersten Stunde, die AntidotTherapie mit Ethanol oder Fomepizol, sowie gegebenenfalls die Hämodialyse ab einem Ethylenglykolspiegel von $500 \mathrm{mg} / \mathrm{l}$ sind die entscheidenden Maßnahmen. Bei dem hier präsentierten Fall konnten wir erneut belegen, dass eine Hämodiafiltration effektiv zur Elimination beiträgt und Folgeschäden vermeidet. Auch das Monitorings der Oxalat- und Glycolatkonzentrationen belegt die effektive Therapie.

\section{PÄD-P14}

\section{Anwendung und Nutzen von inhalativem Stickstoffmonoxid bei angeborener Zwerchfellhernie}

\section{K. Herich, D. Süha, H. Steffen, J. Reinhard, J. B. Kleber, T. Schaible}

Universitätsmedizin Mannheim, Neonatologie, Mannheim, Deutschland

Hintergrund: Inhalatives Stickstoffmonoxid (iNO) senkt bei Neugeborenen mit hypoxämischem respiratorischen Versagen nachweislich den Bedarf an Extracorporaler Membranoxygenierung (ECMO) (1). Die Anwendung wird laut American Academy of Pediatrics für reifere Neugeborene mit schwerer erworbener Atemstörung und einem Oxygenierungsindex $>15$, nicht aber für Neugeborene mit angeborener Zwerchfellhernie $(\mathrm{CDH})$ empfohlen (2). Trotzdem ist der Einsatz von iNO auch hier, aufgrund des günstigen Nebenwirkungsprofils und der einfachen Applikation, durchaus weit verbreitet.

Fragestellung: Mit einer Fallzahl von circa 50 Patienten im Jahr, die in unserer Klinik entbunden werden oder kurz nach der Geburt zur Behandlung zu uns verlegt werden, gehört das Universitätsklinikum Mannheim zu einem der erfahrensten Zentren in der Therapie der CDH. Ziel dieser Arbeit war es, den Einsatz von inhalativem NO bei CDH anhand einer größeren retrospektiven Kohorte zu untersuchen und die Wirksamkeit zu evaluieren.

Material und Methoden: Als Datengrundlage dienten die die klinischen Aufzeichnungen von 292 CDH-Patienten, die in den Jahren 2010 bis 2015 in Mannheim therapiert wurden. Von den 175 Jungen und 117 Mädchen wurden insgesamt 246 auch im Haus geboren (inborn). Die Therapie erfolgte gemäß dem standardisierten Protokoll des CDH EURO Consortium. iNO wurde nach der Aufnahme auf die Intensivstation circa eine Stunde nach Geburt oder im Verlauf dann begonnen, wenn eine prä-postduktale Sättigungsdifferenz $>10 \%$ und/oder ein Oxygenierungsindex $>20$ vorlag. Die initiale Dosierung betrug 20 ppm und eine Stunde nach Therapiebeginn wurde der Effekt evaluiert (3).

Ergebnisse: 197 Patienten oder 67,47\% der Kohorte erhielten über eine mediane Dauer von 13,79 Tagen inhalativ NO (Min.: 0,08d; Max.: > 100d). Die Dauer der Applikation war bei CDH mit liver up im Vergleich zu liver down deutlich erhöht $(p<0,0001)$. Die Neugeborenen, die iNO erhielten, waren signifikant jünger $(37,19$ Wochen vs. 37,72 Wochen) $[p=0,0295]$ und leichter ( $2840 \mathrm{~g}$ vs. $3037 \mathrm{~g}$ ) [ $p=0,0035]$. Von ihnen konnten 104 $(52,79 \%)$ eine Verbesserung des Oxygenation Index verzeichnen, wobei eine Reduktion von $\geq 5$ Punkten als response gewertet wurde. Dies war bei 68 Patienten $(34,52 \%)$ der Fall, wobei die Mädchen tendentiell etwas besser ansprachen $(p=0,0761)$. Insgesamt verbesserte sich der mediane OI innerhalb der ersten Stunde allerdings nur um 1,7 Punkte (n. s.). Von den Respondern kamen 48,53\% dennoch an die ECMO, weil der Effekt nicht lange anhielt, bei den Non-Respondern betrug der Anteil der Patienten, welche mit ECMO behandelt wurden, 63,06\%. Damit reduziert iNO bei Respondern den Bedarf an ECMO $(p=0,0562)$. Die ECMO Rate insgesamt betrug $40 \%$.
Diskussion: Die Wirksamkeit von inhalativem NO bei CDH-Patienten ist deutlich geringer als bei Neugeborenen mit anderen erworbenen Atemstörungen. Allerdings wird iNO wegen mangelnder Alternativtherapien großzügig eingesetzt. Wie unsere Ergebnisse zeigen, scheint Reduktionspotential vorhanden. Insbesondere sollte die Indikationsstellung für iNO konsequenter begrenzt (beispielsweise nicht bei initialem OI $<10$ ) und die Therapie bei Non-Respondern mit dem Beginn der ECMO zeitnah reduziert oder beendet werden. Ausstehend sind Studien zu alternativen Handlungsansätzen bei pulmonaler Hypertension des Neugeborenen, insbesondere mit Sildenafil.

\section{Psychosoziale Betreuung}

\section{PSY-P01 \\ „Dabei sein ist alles - Online Videostreaming für Eltern in der Neonatologie" - Videopräsentation mit Live-Schaltung auf die neonatologische Intensivstation der Universitätsklinik Bonn}

T. Dresbach', P. Feuereisel ${ }^{2}$, A. Müller ${ }^{1}$

'Universitätsklinikum Bonn, Neonatologie und Pädiatrische Intensivmedizin, Bonn, Deutschland, ${ }^{2}$ Natus Europe $\mathrm{GmbH}$, Planegg, Deutschland

Hintergrund: Eine der großen Herausforderungen im Bereich der Neonatologie ist die Etablierung von familienfreundlichen Pflege- und Betreuungskonzepten. Die Erkenntnis, dass Eltern keine Besucher, sondern ein Teil des neonatologischen Behandlungskonzept sind, setzt sich zunehmend im neonatologischen Fachbereich durch. Dem Bedürfnis vieler Eltern rund um die Uhr bei ihrem Kind zu sein, steht auf vielen neonatologischen Intensivstationen ein limitiertes Raumangebot entgegen. Eine Übernachtungsmöglichkeit für Eltern ist häufig nicht gegeben. Gerade die Zeiträume in denen die Eltern nicht bei ihrem Kind sein können, werden als belastend empfunden. Moderne internetbasierte Videostream-Systeme ermöglichen Eltern ihr Kind auch dann zu sehen, wenn sie nicht persönlich am Bett ihres Kindes sein können.

Fragestellung: Wie realistisch ist die Etablierung von Videostreaming für Eltern auf neonatologischen Intensivstationen in Deutschland unter datenschutzrechlichen und betriebsrechtlichen Gesichtspunkten?

Material und Methoden: Wir berichten über das Prozedere zur Inbetriebnahme des Videostreaminsystems NicView der Firma Natus auf der Neonatologischen Pflege- und Intensivstation des Universitätsklinikums Bonn. Ergebnisse: Videostreaminsystems NicView der Firma Natus streamt LiveBilder der am Patientenbett befestigten Kamera ohne jegliche Bildspeicherung. Die Eltern erhalten ein individuelles Passwort, mit dem sie sich über eine sichere Datenleitung auf den Server (Standort Frankfurt) einloggen und den Videostream der Bettkamera ihres Kindes ansehen können. Nur eine enge und vertrauensvolle Zusammenarbeit mit der Abteilung für IT-Sicherheit am UKB ermöglichte das Einbinden in das klinikseigene Netzwerk und die Aufsetzung eines für das NICview-System notwendigen Servers. Nach einer datenschutzrechtlichen Beurteilung durch den Datenschutzbeauftragten erfolgte eine Beurteilung durch den Betriebsrat der wissenschaftlichen und nicht-wissenschaftlichen Arbeitnehmer. Durch eine frühzeitige und umfangreiche Aufklärung des pflegerischen und ärztlichen Mitarbeiter, des Datenschutzbeauftragten, der Abteilung für IT-Sicherheit, des Betriebsrates und des Klinikvorstandes konnte das Projekt „Dabei sein ist Alles - Online Videostreaming für Eltern in der Neonatologie“ in der Universitätsklinik Bonn etabliert werden. 
PSY-P02

\section{Veränderungen der Betätigungsbalance bei Eltern}

frühgeborener Kinder im Verlauf des stationären Aufenthalts, ein Zwischenbericht

\section{Dür ${ }^{1,2}$, C. Oberleitner-Leeb ${ }^{1}$, V. Herrmanns ${ }^{3}$, H. Kurz ${ }^{3}$, B. Mattner',} T. Frischer', A. Berger ${ }^{1}$

${ }^{1}$ Medizinische Universität Wien, Univ.-Klinik f. Kinder- und Jugendheilkunde, Wien, Österreich, ${ }^{2}$ IMC Fachhochschule Krems, Department Health Sciences, Krems, Österreich, ${ }^{3}$ Sozialmedizinisches Zentrum Ost - Donauspital, Kinderund Jugendheilkunde, Wien, Österreich, ${ }^{4}$ Wilhelminenspital, Abteilung für Kinder- und Jugendheilkunde, Wien, Österreich

Hintergrund: Eine als gut und befriedigend erlebte Mischung von verschiedenen Tätigkeiten hängt mit der Gesundheit zusammen und wird in den Ergotherapie und Handlungswissenschaften als Betätigungsbalance bezeichnet. Personen haben berichtet, dass sie durch verschiedene Lebensereignisse, wie zum Beispiel der Geburt eines Kindes, eine Veränderung ihrer Betätigungsbalance erlebten. Dies kann vor allem auf Eltern frühgeborener Kinder zutreffen. Es gibt bisher keine Studie, welche eine mögliche Veränderung der Betätigungsbalance prospektiv erfasst.

Fragestellung: Verändert sich die Betätigungsbalance bei Eltern frühgeborener Kinder im Verlauf der stationären Aufnahme statistisch signifikant? TeilnehmerInnen und Methoden: Im Rahmen einer multizentrischen Longitudinalstudie werden derzeit Eltern frühgeborener Kinder unmittelbar nach der Geburt und kurz vor der Entlassung gebeten ein Fragebogenset auszufüllen. Dieses Fragebogenset beinhaltet unter anderem den Fragebogen zur Betätigungsbalance für pflegende Angehörige und den Fragebogen zur Sozialen Unterstützung. Anhand des Statistik Programms SPSS wurde eine Zwischenanalyse durchgeführt. Der Wilcoxon Vorzeichen-RangTest wurde verwendet um mögliche Unterschiede zwischen der Erst- und Folgeerhebung der Betätigungsbalance und der sozialen Unterstützung zu identifizieren.

Ergebnisse: Bisher wurden 86 Teilnehmerinnen und Teilnehmer eingeschlossen. Es konnte ein statistisch signifikanter Unterschied bei der Betätigungsbalance zwischen der Erst- und Folgeerhebung festgestellt werden. Erste Analysen zeigen, dass die Zufriedenheit mit der Verschiedenartigkeit und der Abwechslung von Tätigkeiten, sowie mit der Abwechslung der Orte an denen die Eltern tätig waren, im Verlauf der stationären Aufnahme abnahm. Zusätzlich waren die Eltern kurz vor der Entlassung ihres Kindes mit dem Ausmaß an Haushaltstätigkeiten, an der Teilhabe an der Gesellschaft, an Tätigkeiten bei denen sie für ihre eigene Gesundheit und ihr Wohlbefinden sorgen, weniger zufrieden als kurz nach der Geburt ihres Kindes. Die Zufriedenheit mit der sozialen Unterstützung, einschließlich der Anerkennung, dem Verständnis und der Unterstützung in Bezug auf die Tätigkeiten der Eltern, blieb unverändert.

Diskussion und Schlussfolgerung: Erste Analysen zeigen, dass sich die Betätigungsbalance von Eltern frühgeborener Kinder während des Krankenhausaufenthaltes verschlechtert. Die Zufriedenheit der Eltern mit der sozialen Unterstützung bleibt hingegen stabil. Daraus kann gefolgert werden, dass die Einseitigkeit der Tätigkeiten, die mit einem stationären Aufenthalt einhergehen, zu Einschränkungen einer als subjektiv befriedigend erlebten Mischung an Tätigkeiten führt. Diese Ergebnisse weisen auf einen möglichen Bedarf von gezielten Interventionen zur Verbesserung der Betätigungsbalance von Eltern frühgeborener Kinder hin.

\section{PSY-P03}

Eine Studie über das Erleben von Eltern langzeitbetreuter Kinder während und nach der Betreuung an einer neonatologischen Intensivstation, am Beispiel des AKH Wien

\section{E. Smajic}

Allgemeines Krankenhaus der Stadt Wien, NICU, Wien, Österreich

Hintergrund: Bedingt durch die medizinische Komplexität der Krankheitsbilder, wurde eine Zunahme der langzeitbetreuten Kinder und ihren Eltern auf einer neonatologischen Station (Ebene 10 NICU) im Allgemeinen Krankenhaus der Stadt Wien in den letzten Jahren beobachtet, die zunehmend in den Mittelpunkt der multidisziplinären Betreuung rückte. Fehlendes institutionelles und systematisches Wissen über das Erleben dieser Patientengruppe und deren Bezugspersonen, waren Beweggründe für eine empirische Untersuchung.

Fragestellung: Wie erlebten Eltern von frühgeborenen Kinder mit unterschiedlichen Krankheitsbildern, die länger als zwei Monate im neonatologischen Setting des allgemeinen Krankenhauses der Stadt Wien betreut wurden, ihr Umfled und wie gehen sie heute mit dieser Situation um? Methodik: An dieser qualitativen Untersuchung nahmen fünf Eltern von fünf Kindern teil, die mit unterschiedlichen Krankheitsbildern geboren wurden. Zwischen 16. Juli und 10. Oktober 2015 wurde mit Ihnen im häuslichen Setting ein episodisches Interview mit einem halbstrukturierten Interviewleitfaden durchgeführt. Die zusammenfassende Inhaltsanalyse erfolgte durch eine induktive Kategorienbildung.

Ergebnisse: Fünf Schwerpunkte des elterlichen Erlebens wurden in Form von Kategorien generiert: 1. Belastungen, 2. Ressourcen, 3. Bedürfnisse, 4. Multiprofessionelle und interdisziplinäre Interaktionen, 5. Das Erleben danach.

Schlussfolgerung: Die Eltern von langzeitbetreuten Kindern sind individuellen Belastungen ausgesetzt und haben besondere Bedürfnisse während dieser Zeit, die das Erleben mit ihren Kindern beeinflussen. Ein spezielles multidisziplinäres Bezugsteam steigert das Wohlbefinden, erhöht das Vertrauen und führt zur Entlastung im neonatologischen Intensivsetting. Das kann nur gelingen, wenn Kontinuität, fachliche Kompetenz und Kommunikation von allen Beteiligten in der Betreuung gewährleistet und forciert wird. Speziell Pflegepersonen stellen eine wichtige Ressource für die Eltern dar und sind somit in der Langzeitbetreuung unverzichtbar.

\section{PSY-P04}

\section{Pilot Evaluation der FrühstartApp durch Eltern von Frühgeborenen}

M. Reimann' ', S. Sahlmen', C. Dahlmann' ${ }^{2}$ N. Hammer ${ }^{3}$, M. Bönig ${ }^{4}$, U. Felderhoff-Müser ${ }^{5}$, B. M. Hüning ${ }^{5,1}$

'Bunter Kreis, Universitätsklinikum Essen, Essen, Deutschland, ${ }^{2}$ Universitätsklinikum Essen, Pflegedirektion, Abteilung für Entwicklung und Forschung in der Pflege, Essen, Deutschland, ${ }^{3}$ Westfälische Hochschule Gelsenkirchen, Fachbereich Informatik und Kommunikation, Gelsenkirchen, Deutschland, ${ }^{4}$ Vitabook GmbH, Hamburg, Deutschland, ${ }^{5}$ Universitätsklinikum Essen, Klinik für Kinderheilkunde I, Essen, Deutschland

Hintergrund: Familienzentrierte Betreuung von Familien Frühgeborener findet derzeit überwiegend im face-to-face Kontakt oder via E-Mail, Messaging und Telefon statt. Die FrühstartApp ermöglicht eine moderne Form strukturierter Informationserfassung und interdisziplinärer, transsektoraler Kommunikation in einer geschützten Cloud, die Eltern, Ärzte und Pflegende adressiert. Sie ermöglicht strukturierte Datenerfassung zur Entwicklung des Kindes durch die Eltern bereits während des stationären Aufenthaltes (Tagebuchfunktion), mit dem Ziel, die Wahrnehmung der Eltern zu trainieren und den Übergang in die Häuslichkeit zu erleichtern. Checklisten bieten Informationen z. B. zu Ernährung und Schlaf und die Möglichkeit, Arztbesuche vorzubereiten. Reminder erinnern an Medikamentengaben und Termine. Die Verbesserung transsektoraler Kommunikation und verbesserte Fallübersicht für die beteiligen Akteure stellen weitere Ziele dar. Die Speicherung der Daten erfolgt auf einer cloudbasierten Gesundheitsplattform, so dass Inhalte geteilt werden können und auch bei Verlust des Endgerätes gesichert sind.

Fragestellung: Ziel der Pilot-Evaluation war es, die FrühstartApp hinsichtlich der Inhalte und der Bedienbarkeit durch Eltern zu testen.

Material und Methoden: Eltern von Frühgeborenen, die am Programm der familienzentrierten Betreuung teilnahmen, wurden zu einem Test der FrühstartApp eingeladen und gebeten, Fragebögen zu den Inhalten und der Bedienbarkeit der App auszufüllen. Diese beinhalteten für die Bedienbarkeit folgende Aspekte: Orientierung in der App, Funktionalität Inhalte zu teilen, Ladezeit und Absturz der App. Fragen zu den Inhalten umfassten: die App als Ganzes, einzelne Funktionen (Tagebuch, MedikamentenReminder, Checklisten, Auswertungen), und ob die App als hilfreich an- 
gesehen wurde. Die Bewertung erfolgte anhand des Schulnotensystems. Ferner wurden allgemeine Fragen zu Vorerfahrungen mit SmartphoneApps und der Nutzung sozialer Netzwerke gestellt.

Ergebnisse: 12 Eltern erklärten sich bereit, die FrühstartApp zu evaluieren; 10 nutzen die App für das Betriebssystem Android, 2 für Apple iOS. 8 Eltern gaben an $>4$ Jahre ein Smartphone zu besitzen und häufig soziale Netzwerke zu nutzen, nur ein Befragter nutzte ein Smartphone $<1$ Jahr, 4 Befragte nutzten selten soziale Netzwerke. Die Bedienbarkeit wurde von $82 \%$ der Befragten mit sehr gut oder gut bewertet, von $11 \%$ mit befriedigend; Inhalte und Funktionalität wurden von $89 \%$ mit sehr gut/gut, von $11 \%$ mit befriedigend beurteilt. $91 \%$ gaben an, die App anderen Eltern weiter empfehlen zu wollen.

Schlussfolgerung: Die FrühstartApp wurde in der ersten Pilot-Evaluation von Eltern hinsichtlich Bedienbarkeit, technischer Umsetzung und der Inhalte in hohem Maße mit sehr gut bis gut bewertet. Über $90 \%$ der befragten Eltern würden die App anderen Eltern weiter empfehlen. Dies zeigt eine hohe Relevanz und Akzeptanz dieser modernen Kommunikationsform unter den Eltern.

\section{PSY-P05 \\ ELWIS - Eltern durch Wissen stärken - Ein Elternprogramm für Eltern von frühgeborenen Kindern}

I. Menrath, M. Diestel, C. Härtel, U. Thyen

UKSH Lübeck, Klinik für Kinder- und Jugendmedizin, Lübeck, Deutschland

Hintergrund: Eine Frühgeburtlichkeit stellt für Eltern eine erhebliche Herausforderung dar. Die häufig plötzliche Geburt wird von vielen Eltern als traumatisch erlebt. Nach Geburt stehen Gefühle des Überfordertseins und des Zweifels, den Anforderungen nicht standhalten zu können, im Vordergrund (Goutaudier et al., 2001). Psychische Belastungen der Eltern können die Entwicklung der Kinder negativ beeinflussen. Daher ist es wichtig, die Eltern darin zu unterstützen, in ihre neuen Rollen hineinzuwachsen. Eine psychosoziale Unterstützung und Anleitung kann Eltern helfen, die Zeit der Krise zu überwinden und die Entwicklungschancen des Kindes zu verbessern (Jotzo et al., 2005). Am Universitätsklinikum Schleswig-Holstein, Campus Lübeck, wird seit Februar 2016 den Eltern extremer Frühgeborener (VLBW) das modulare Gruppenschulungsprogramm „ELWIS - Eltern durch Wissen stärken " 2 mal wöchentlich angeboten. Das Programm umfasst 8 Module, im Vordergrund steht die Verbesserung der Elterlichen Kompetenzen im Umgang mit der Frühgeburtlichkeit.

Fragestellung: Wie wird das Elternprogramm ELWIS von den Eltern extremer Frühchen angenommen und bewertet? Welche Faktoren spielen bezüglich der Programmteilnahme eine Rolle? Welche Besonderheiten sind bei der Programmdurchführung zu beachten?

Material und Methoden: Alle Eltern von VLBW zwischen Februar 2016 und Januar 2017 wurden eingeladen an ELWIS teilzunehmen. Es wurden die Programmteilnahme und mit standardisierten Fragen die Zufriedenheit mit dem Programm erfasst. Im Sinne einer Prozessevaluation wurden Besonderheiten der Etablierung dieser neuen Versorgungsform erhoben. Ergebnisse: Innerhalb des ersten Jahres nahmen 42 Familien an ELWIS teil. Dies entsprach ca. der Hälfte aller Eltern von VLBW. Im Durchschnitt bewerteten die Eltern ELWIS sehr gut. Von Bedeutung waren vor allem eine Anpassung der Programminhalte an die Bedürfnisse der Eltern und eine offene, wohlwollende Atmosphäre. Schwere Komplikationen bei den Frühgeborenen und mangelnde Deutschkenntnisse erschwerten eine Programmteilnahme. Auch nahmen weniger Väter als Mütter an dem Programm teil. Die Etablierung von ELWIS ging mit zahlreichen Herausforderungen auf Klinikseite einher und die Arbeit mit den Eltern bedurfte eines Höchstmaßes an Professionalität.

Diskussion oder Schlussfolgerung: Insgesamt wurde das Gruppenschulungsprogramm ELWIS von den Eltern gut angenommen und evaluiert. Zukünftig sollte die Inanspruchnahme verbessert und auch schwerer erreichbare Eltern für das Programm gewonnen werden. Hier sind inhaltliche und strukturelle Verbesserungen notwendig, um das erfolgreiche Programm auch für diese Eltern zugänglicher zu machen.

\section{Literatur}

1. Goutaudier N, Lopez A, Sejourne N, Denis A, Chabrol H (2011) Premature birth: subjective and psychological experiences in the first weeks following childbirth, a mixed-methods study. J Reprod Infant Psychol 29:364-373

2. Gross SJ, Mettelmann BB, Dye TD, Slagle TA (2001) Impact of family structure and stability on academic outcome in preterm children at 10 years of age. J Pediatr 138:169-175

3. Jotzo M, Poets ChF (2005) Helping parents cope with the trauma of premature birth: an evaluation of a trauma-preventive psychological intervention. Pediatrics 115:915-919

\section{PSY-P06}

Persönlichkeit der Mutter und Bewältigung der Frühgeburt eines Kindes im Vergleich zwischen zwei NICU-Standorten und zu Müttern kindlicher Kardiochirurgie-Patienten

\section{Wollny', L. Gortner', B. Roth ${ }^{3}$, L. Kuntz ${ }^{4}$}

'Universitätsklinikum des Saarlandes, Klinik für Allgemeine Pädiatrie und Neonatologie, Homburg, Deutschland, ${ }^{2}$ Medizinische Universität Wien, Klinik für Kinder- und Jugendheilkunde, Wien, Österreich, ${ }^{3}$ Uniklinik Köln, Kinder- und Jugendmedizin, Neonatologie, Köln, Deutschland, ${ }^{4}$ Universität Köln, Department of Business Administration and Health Care Management, Köln, Deutschland

Hintergrund: Initiiert von der Universitätsklinik Köln wurde der Zusammenhang zwischen Kommunikations-verhalten, Belastungserleben seitens der Eltern und deren Bewertung der Mitarbeiter sowie des Kliniksettings auf neonatologischen Intensivstationen (NICU) und dem Outcome untersucht.

Fragestellung: Im Rahmen dieser Untersuchung fokussierten wir ergänzend auf die Fragestellung: Wie hängen vor allem (kommunikative) Strukturdaten, elterliche Persönlichkeitsmerkmale, Bewältigung der Belastung durch eine Frühgeburt und katamnestische Daten zusammen?

Methoden:

Datenerhebung Köln

- Strukturdaten (Kommunikationsdauer, -häufigkeit etc. mit Ärzten/Pflegepersonal)

- Wahrgenommene Empathie (CARE-Fragebogens)

- Subjektive Belastung (Impact of Event Scale)

- Zufriedenheit: Kölner Patientenfragebogen (KPF)

- Sozialanamnese Eltern

\section{Daten Homburger Ergänzung}

- NEO - Fünf Faktoren Inventar (NEO-FFI)

- Palliativinventar aus dem UBV (Umgang mit Belastungen im Verlauf), Teil X, adaptiert

- Index „Bildungs- und Berufsniveau“ (aus Sozialanamnese)

- katamnestische Daten für Homburger Frühgeborene bis korr. 2 Jahre nach Geburt

- in allen Fragebogenteilen:

Datensätze: Nur vollständige und eindeutig den Müttern zuzuordnende Datensätze: 70 von 121, Zeitraum 2011 und 2012. Neonatologie Homburg $n=33$, Neonatologie Köln $n=20$, Kinder-Kardiologie Homburg $n=17$ (Kleinkinder nach kardiochirurgischer Intervention).

Katamnestische Daten waren nur aus der Klinik Homburg verfügbar. Hier konnten minimal 9, maximal 33 Datensätze verwertet werden (Schwund). Statistik: Korrelationsstatistische Analyse einschließlich explorative Faktorenanalyse (EFA)

Ergebnisse: Es zeigten sich varianzanalytisch keine Unterschiede zwischen den Untersuchungsgruppen. Einzig für die Gruppe Kardiochirurgische Patienten ergab sich eine signifikant kürzere Aufenthaltsdauer, für die Klinik Homburg signifikant häufigere Gespräche mit Ärzten.

Mütter mit höherem Bildungs- und Berufsniveau äußern weniger Vertrautheit. Mütter, deren Kind länger auf der NICU bleiben muss, fühlen sich belasteter, sprechen häufiger mit den Ärzten. Ältere sind eher zufrieden und äußern weniger die Neigung, Alkohol und Nikotin zu nutzen. Das äußern auch die, welche sich als verträglicher bezeichnen. Wer insgesamt häufiger das Gespräch sucht, sucht dies mit allen Mitarbeitern und intensiver. Das tun zumal emotional weniger belastbare Mütter. Bei 
den - allerdings wenigen - Datensätzen, welche katamnestische Daten enthalten, zeigt sich, dass zumindest bis zum Alter von korrigiert zwei Jahren Kommunikationsdaten wie Persönlichkeitsvariablen keine Bedeutung für die weitere Entwicklung haben. Entscheidend ist allein die Ausgangsmorbidität.

Schlussfolgerung: Sowohl der Verlauf der kindlichen Entwicklung nach einer Frühgeburt wie aber auch das Erleben dieses einschneidenden Ereignisses durch die Mütter sind wesentlich determiniert durch die initiale Morbiditätsbelastung der Frühgeborenen. Für eine umgekehrte Wirkungsrichtung sowohl des kommunikativen Klimas als auch der Persönlichkeitscharakteristika der Mutter gibt es keinerlei Hinweis. Aber Mütter bewältigen diese Lebenssituation unterschiedlich schwer. Emotional weniger stabile leiden mehr und verdienen daher mehr Beachtung und emotionale Stützung.

\section{Literatur}

1. Pick V, Halstenberg K, Demel A et al (2014) Staff and parents are discriminators for outcomes in neonatal intensive care units. Acta Pædiatrica 103:e475-e483

\section{PSY-P07}

Raus aus dem Inku (RADI) -Einfluss des Verlegens vom Inkubator in ein Wärmebett bei Frühgeborenen mit einem Geburtsgewicht unter $1500 \mathrm{~g}$ (VLBW) auf das Empfinden der Eltern

\section{S. Elias' ${ }^{1}$ A. Stein', U. Felderhoff-Müser ${ }^{2}$}

'Universität Essen, Klinik für Kinderheilkunde I, Klinik für Kinder und Jugendmedizin, Essen, Deutschland, ${ }^{2}$ Universitätsklinikum Essen, Zentrum für Kinder- und Jugendmedizin, Essen, Deutschland

Hintergrund: VLBW-Frühgeborene werden aufgrund der negativen Auswirkungen einer Hypothermie direkt postnatal im Inkubator versorgt. Es liegen keine Daten vor, wie sich das Verhältnis von Eltern zu Ihrem Kind verändert, wenn die Kinder bei einem geringeren Gewicht vom Inkubator ins Wärmebett umgelegt werden.

Methode: Prospektive Studie von 42 VLBW-Frühgeborenen im Zeitraum von November 2011 bis September 2014 (Geburtsgewicht $1008 \pm 272 \mathrm{~g}$, range $530 \mathrm{~g}-1440 \mathrm{~g}$, Gestationsalter 28,2 $\pm 2,3 \mathrm{SSW}$, range $23+6 \mathrm{SSW}-$ $32+2 \mathrm{SSW})$. Verlegung vom Inkubator in ein Wärmebett bei einem aktuellen Gewicht zwischen $1490 \mathrm{~g}$ und $1650 \mathrm{~g}$. Für $72 \mathrm{~h}$ nach der Umbettung wurden Vitalzeichen, Trinkverhalten und die Gewichtsentwicklung analysiert und mit einer historischen Gruppe aus 2011/2012 mit höherem Umbettungsgewicht verglichen. Im Rahmen dieser Studie wurde zur Analyse des Elternempfindens sieben bis zehn Tage vor und nach Umbettung ein Fragebogen mit je 10 Fragen und einer Skala von 0 bis 5 Punkten (von eher nein bis eher ja) an die Eltern verteilt. Die Fragen beziehen sich auf die Versorgung des Frühgeborenen im Inkubator durch Eltern und Krankenhauspersonal, die Sorge des Verlegens in das Wärmebettchen, die ElternKind-Beziehung sowie die Beziehung zwischen den Eltern.

Ergebnisse: Die Fragebögen wurden 1 bis 3 Tage nach Erhalt vom Studienpersonal eingesammelt. Die Mütter und Väter machten sich vor dem Umbettung etwas mehr Sorgen, als rückblickend (Median Mütter vorher 2 , nachher 0, Median Väter vorher 1, nachher 0,5). Die Mütter hatten vorher etwas mehr das Gefühl, dass ihr Kind im Inkubator sicherer/besser aufgehoben sei. (Median Mütter vorher 2, nachher 0), bei den Vätern gab es einen geringeren Unterscheid, der jedoch rückblickend bestand (Median Väter vorher 1, nachher 1,5). Die Mütter fühlten sich in der Versorgung des Kindes im Inkubator etwas sicherer als die Väter. Beide Eltern fühlen sich aber sicherer in der Versorgung ihres Kindes, seitdem dieses im Wärmebettchen liegt (Median Mütter vorher/nachher 5; Median Väter vorher 4, nachher 5). Sowohl vorher als auch rückblickend fühlten sich die Eltern ihrem Kind gegenüber distanziert, als es noch im Inkubator lag (Median Mütter vorher/nachher 4, Väter vorher 3, nachher 3,5). Mütter fühlten sich sicherer dabei, ihr Kind im Inkubator zu wickeln (Median Mütter vorher 5, Median Väter vorher 3,5). Im Wärmebettchen fühlen sich beide Eltern sicher dabei, ihr Kind zu wickeln (Median Mütter/Vater 5). Die Beziehung der Eltern zu ihrem Kind hat sich nach der Umbettung bei den Müttern viel verbessert, bei den Vätern gebessert. Weder vorher noch nachher wünschten sich Eltern die Zeit zurück, in der ihr Kind noch nicht auf der Welt war (Median Mütter/Väter vorher/nachher 0). Beide Elternteile finden die Situtation wenig belastend für die Beziehung zu ihrem Partner (Median Mütter/Väter vorher/nachher 0).

Schlussfolgerung: Ein Verlegen von Frühgeboren mit einem Geburtsgewicht von unter $1500 \mathrm{~g}$ vom Inkubator in ein Wärmebett bei einem aktuellen Gewicht von $1500 \mathrm{~g}$ bis $1600 \mathrm{~g}$ hat einen positiven Einfluss auf die Eltern-Kind-Beziehung.

\section{PSY-P08}

\section{Pilot study „Feasibility of the use of BABYBE $^{\oplus} 001$ Emotional} Prosthesis in hospitalized preterm infants"

I. Araya, L. Marquez, S. Estobar, R. Salinas, M. Canals

San Borja Arriaran Clinic Hospital, Santiago de Chile, Chile

Background and Scientific issue: Being premature not only affects the newborn but also his family, especially his parents who live a permanent anguish during hospitalization. The care and interventions that premature infants undergo during their hospital stay interfere with the normal process of bonding that should be generated between a newborn and his parents. $\mathrm{BABYBE}^{\oplus}$ is an emotional prosthesis for hospitalized preterm infants that emerges as a solution from the technological area in response to the impossibility of permanent contact between the parents and their child whilst hospitalized in a neonatal intensive care unit. $\mathrm{BABYBE}^{\oplus}$ is a device that consists of a sensor that is placed in the mother's chest and transmits the mother's heartbeat and breathing to be replicated in the mattress where the newborn is, in real time, and that also allows recording a cycle with information from the maternal sensor so as to maintain the premature infant with a 24 hours of the day feeling the breathing and heartbeat of its own mother in order to imitate a continuous Kangaroo.

Materials and Methods: A pilot study was carried out with 15 stable preterm infants, each patient being their own control randomized for two 48-hour periods, one period with $\mathrm{BABYBE}^{\circledast}$ functioning and another with $\mathrm{BABYBE}^{\circledast}$ not functioning. Hemodynamic, anthropometric variables as well as skin photographs were recorded for each patient, and the results were analyzed with two-way analysis of variance for repeated measures (ANOVA).

Results: When reviewing the statistical analyzes it is evident that there were no statistically significant differences between groups for any variable. Conclusions: Use of $\mathrm{BABYBE}^{\oplus}$ is safe and feasible for use in hospitalized preterm infants.

\section{Wachstum und Ernährung}

\section{WE-P01}

\section{Docosahexaensäure und Arachidonsäure werden im Plasma} Frühgeborener als Phosphatidylcholin transportiert

W. Bernhard', C. Maas', A. Shunova', M. Mathes', K. Böckmann', C. Bleeker', J. Vek', C. F. Poets' ${ }^{1}$ E. Schleicher' ${ }^{2}$, A. Franz ${ }^{1,3}$

${ }^{1}$ Klinik für Kinder- und Jugendmedizin, Universitätsklinikum Tübingen, Abt. Neonatologie, Tübingen, Deutschland, ${ }^{2}$ Universitätsklinikum Tübingen, Innere Medizin IV, Tübingen, Deutschland, ${ }^{3}$ Klinik für Kinder- und Jugendmedizin, Universitätsklinikum Tübingen, Center for Pediatric Clinical Studies, Tübingen, Deutschland

Hintergrund: Docosahexaensäure (DHA) und Arachidonsäure (ARA) sind langkettige polyunsaturierte Fettsäuren, die für die Gesamt- und insbesondere die Gehirnentwicklung Frühgeborener essentiell sind. Sie kommen in den Membranen aller Zellen vor, werden transplazentar im Feten angereichert und im 3. Trimenon zu 90\% in Fettgewebs-Triglyceriden als Reservoir gespeichert. In der grauen Hirnsubstanz sind ARA und DHA die hauptsächlichen langkettigen ungesättigten Fettsäuren und liegen in den Phospholipiden vor.

Fragestellung: Wie werden DHA und ARA in postnatalen Plasmaproben Frühgeborener im Vergleich zu Nabelschnurplasmaproben transportiert? 
Material und Methoden: Plasma von 59 Frühgeborenen mit einem Gestationsalter bei Geburt $<32$ Wochen und einem postnatalen Alter von32 (16-44) Tagen sowie 35 Nabelschnurblutproben (Gestationsalter 24-42 Wochen; 19,6 [10,7-23,6]) wurden mit Chloroform:Methanol extrahiert. Neutrallipide wurden mittels Gaschromatographie analysiert, Phosphatidylcholin (PC) mittels Massenspektrometrie. Die Daten sind als Mediane und Quartilenrange dargestellt.

Ergebnisse: (A) Die Plasma-Neutrallipide der Frühgeborenen enthielten zu 0,48\% $(0,34-0,65)$ DHA und zu 2,67\% $(2,13-3,23)$ ARA. Diese Anteile waren in Nabelschnurplasmaproben höher $(0,88 \%$ [0,73-1,23] DHA und $5,74 \%[3,67-6,45]$ ARA) (jeweils $p<0,0001$ ). Demgegenüber waren 5,7\% $(5,2-6,6)$ des Plasma-PC Frühgeborener DHA-PC und 21,2\% (19,4-23,3) waren ARA-PC. Bei Nabelschnur-Plasma waren es 10,2\% $(8,8-12,8)$ bzw. $36,1 \%(34,2-38,6)$ (jeweils $p<0,0001$ ). (B) Bezogen auf die Gesamtkonzentration im Plasma befanden sich DHA und ARA vorwiegend in der PC-Fraktion: der Anteil von DHA im Plasma-PC Frühgeborener betrug $86,1 \%(83,1-88,9)$, der von ARA $80,6 \%(77,8-83,0)$. Im Nabelschnurplasma waren es $79,2 \%(75,2-85,4)$ für DHA $(p<0,0001)$ und $71,3 \%(67,8$ $72,9)$ für ARA $(p<0,0001)$. Der Anteil der Ölsäure und Linolsäure im Plasma-PC Frühgeborener betrug 26,8\%(23,1-31,0) bzw. 58,8\%(54,6$62,9)$. Beim Nabelschnur-Plasma waren es nur 19,6\% $(10,7-23,6)$ bzw. $48,6 \%(41,6-52,2)$ (jeweils $p<0,01$ ).

Schlussfolgerung: 1 . Phosphatidylcholin ist insbesondere beim Frühgeborenen, aber auch beim Fetus der hauptsächliche Carrier von DHA und ARA im Plasma. Im Vergleich zum Fetus ist bei Frühgeborenen (wahrscheinlich ernährungsbedingt) der Anteil von DHA-PC und ARA-PC zugunsten anderer PC-Komponenten erniedrigt. 2. Die metabolische Verbindung zwischen DHA/ARA und Cholin (als Bestandteil von PC) spricht für die Notwendigkeit einer adäquaten Cholinversorgung, um die DHAund ARA-Homöostase Frühgeborener zu gewährleisten.

\section{WE-P02 \\ Laktase Persistenz und Wachstum von Frühgeborenen mit einem Geburtsgewicht unter 1500 Gramm}

\section{J. Zimmermann ${ }^{1,2}$, L. Beyssell, ${ }^{1,2}$, B. Tröger ${ }^{1,2}$, C. Härtel ${ }^{1,2}$, E. Herting ${ }^{1,2}$, W. Göpel1,2 \\ 'UKSH Lübeck, Pädiatrie, Lübeck, Deutschland, ${ }^{2}$ Universität, Lübeck, Deutschland}

Hintergrund: Die Laktase Persistenz ist eine in Europa häufige genetische Variation, die mit einer besseren Verträglichkeit von Milch und Milchprodukten assoziiert ist. Sie wird vermittelt durch den Polymorphismus rs4988235. In Studien zeigte sich bei Erwachsenen und Jugendlichen mit Laktase Persistenz ein höheres Körpergewicht und ein besseres Wachstum, insbesondere bei milchreicher Ernährung (Hum Mol Genet 2010; 19:1129-36, Food Nutr Res 2011; 55:7253). Frühgeborene mit einem Geburtsgewicht unter 1500 Gramm zeigen im Verlauf oft ein unterdurchschnittliches Wachstum. Bislang wurden keine größeren Gruppen von Frühgeborenen auf die Effekte einer genetischen Laktase Persistenz untersucht.

Fragestellung: Führt eine Laktase Persistenz bei Frühgeborenen mit einem Geburtsgewicht unter 1500 Gramm zu einem besseren Längenwachstum und/oder einer besseren Gewichtzunahme im Alter von 5 Jahren?

Material und Methoden: Nach DNA-Isolierung aus Mundschleimhautabstrichen bzw. Nabelschnurgewebe erfolgte die Genotypisierung des rs4988235 Polymorphismus mittels PCR und Diskriminierung der Allele durch Fluoreszenzmarker. Frühgeborene mit dem Genotyp TC oder TT wurden als Kinder mit Laktase Persistenz (Lak +), Frühgeborene mit dem Genotyp CC als Kinder ohne Laktase Persistenz (Lak -) kategorisiert. Die Bestimmung der Körpergröße im Alter von 5 Jahren erfolgte mittels eines Harpenden Portable Stadiometer, das Körpergewicht wurde mit einer geeichten Personenwaage (ADE M300020) bestimmt. Die klinischen Daten der Kinder wurden mittels chi-square und T-Test verglichen.

Ergebnisse: Daten von 1062 Kindern wurden analysiert. Bei 74\% der Kinder lag eine Laktase Persistenz vor. Wie erwartet war die Häufigkeit einer Laktase-Persistenz sehr stark durch die Herkunft der Kinder geprägt:
Deutschland $81 \%$, übriges Europa $60 \%$, Naher Osten/Türkei $22 \%$, Asien und Afrika jeweils $25 \%$. Kinder mit Laktase Persistenz hatten ein signifikant höheres Geburtsgewicht (Lak+ $1040 \pm 297 \mathrm{~g}$ vs. Lak- $981 \pm 303 \mathrm{~g}$ ), dieser Unterschied verschwand jedoch, wenn das Geburtsgewicht in Abhängigkeit von der Herkunft analysiert wurde (Deutsche Herkunft: Lak+ $1044 \pm 293$ g vs. Lak- $1030 \pm 279$ g). Im Alter von 5 Jahren zeigten sich weder Gewichts- noch Größenunterschiede in Abhängigkeit von der Laktase Persistenz. Körpergewicht: Lak+ 18,10 $\pm 2,97 \mathrm{~kg}$ vs. Lak- 18,38 $\pm 3,26 \mathrm{~kg}$. Körperlänge: Lak+ $111,2 \pm 5,7 \mathrm{~cm}$ vs. Lac- $111,5 \pm 5,7 \mathrm{~cm}$. Auch Auswertungen der Wachstumsgeschwindigkeit und nach der maternalen Herkunft stratifizierte Analysen ergaben keine Unterschiede.

Diskussion und Schlussfolgerung: Das Vorliegen einer genetischen Laktasepersistenz führt bei Frühgeborenen bis zum Alter von 5 Jahren nicht zu einem stärkeren Wachstum oder einer höheren Gewichtszunahme.

\section{WE-P03}

\section{Ein ungewöhnlicher Fall von Kraniotabes}

\section{F. Mohr', S. Märzheuser' ${ }^{2}$ E. Walch ${ }^{1,3}$, C. Bührer ${ }^{1}$}

${ }^{1}$ Charité Universitätsmedizin, Neonatologie, Berlin, Deutschland, ${ }^{2}$ Charité Universitätmedizin, Kinderchirurgie, Berlin, Deutschland, ${ }^{3}$ Charité Universitätsmedizin, SPZ Neuropädiatrie, Berlin, Deutschland

Hintergrund: Darmpassagestörungen sind ein bekanntes Problem sehr unreifer Frühgeborener. Die Verwendung von Movicol als Abführmittel hat sich zunehmend - ohne Evidenz - etabliert.

Fallbericht: Wir stellen hier ein Frühgeborenen-Zwillingspärchen vor, monochorial, diamniotisch, welches bei pathologischem Doppler und FetoFetalem-Transfusionssyndrom mit 28 3/7 SSW geboren wurde (Gewicht 1030 g/920 g, Apgar 6/7/9 und 8/8/8, NapH 7,28 und 7,36).

Während des Krankenhausaufenthaltes zeigten die Zwillinge eine hartnäckige, kombinierte Stuhltransport- und Stuhlentleerungsstörung, die beim ersten Zwilling (Akzeptor) mit 37 SSW in eine Subileus-Symptomatik mündete. Ein M. Hirschsprung ließ sich nicht nachweisen, die Plexuszellen des Biopsats wiesen jedoch eine auffällige Unreife (im Sinne einer Neuronalen Intestinalen Dysplasie) auf

Unter symptomatischer Therapie mit Movicol Junior (Macrogol $69 \mathrm{mg}$ / Tag) und täglichem rektalen Anspülen konnte eine gute Darmpassage, Nahrungsverträglichkeit und regelrechtes Gedeihen erzielt werden. Routine-Laboruntersuchungen vor Entlassung (41 1/7 SSW) waren unauffällig, die ambulante Medikation bestand in Vitamin D 500 IE/Tag, Eisen-2-glycinsulfat 4,3 mg/kg/Tag und Movicol Junior $69 \mathrm{~g}$, gelöst in $60 \mathrm{ml}$ Wasser. Rektale Spülungen 1-2 mal täglich wurden vereinbart.

Im korrigierten Alter von 3 Monaten wiesen beide Kinder einen Kraniotabes auf. Laborwerte zeigten eine erhöhte Alkalische Phosphatase $713 \mathrm{U} /$ $\mathrm{L}$, Phosphat 1,12 mmol/l und normale Kalzium und 25-OH-Vitamin-D3Werte. Eine Phosphaturie wurde ausgeschlossen. Nach Absetzen der Movivol-Gaben und Substitution von 1000 IE Vitamin D/Tag sowie $3 \times 4$ Kalzium-Glycerophosphatkapseln (Kalzium 1,8 mmol/kg und Phosphat $1,2 \mathrm{mmol} / \mathrm{kg}$ ) normalisierten sich Klinik und Labor nach 6 Wochen. Die Obstipationssymptomatik der Kinder ließ sich auch ohne zusätzliche Gabe von Movicol durch regelmäßige Darmspülungen beherrschen.

Diskussion: Bei dem hier beschriebenen Fall bestand eine chronische Obstipation, welche mit abführenden Maßnahmen behandelt wurde. Aufgrund der unter suffizienter Vitamin D-Substitution aufgetretenen Zeichen einer Rachitis mit Kraniotabes und entsprechenden Laborparametern stellt sich die Frage, ob die Nährstoffaufnahme durch die Macrogol-Therapie vermindert gewesen sein könnte. Insbesondere sehr unreife Frühgeborene stellen durch ihr ohnehin erhöhtes Osteopenierisiko eine Patientengruppe dar, in welcher die Therapie mit Abführmitteln mit regelmäßigen ärztlichen Kontrollen verbunden sein sollte. Fallberichte in der Literatur zeigen eine Malabsorption bestimmter Medikamente unter Macrogol-Therapie [1], auch wenn sich in einer randomisierten placebokontrollierten Studie keine Sicherheitsprobleme zeigten [2]. Eine Anpassung der Vitamin D Substitution auf 1000 IE/Tag bei VLBW-Frühgeborenen unter Macrogol-Therapie auch nach Entlassung, ist aus unserer Sicht empfehlenswert. 


\section{Literatur}

1. Del Greco SSP, Ricci F et al (2014) Hydrocortisone malabsorption due to polyethylene glycols (Macrogol 3350) in a girl with congenital adrenal insufficiency. Ital J Pediatr 40:78

2. McGraw T (2016) Safety of polyethylene glycol 3350 solution in chronic constipation: randomized, placebo-controlled trial. Clin Exp Gastroenterol 9:173-180

\section{WE-P04}

\section{The Economic Benefits of Breastfeeding Preterm Infants}

\section{J. Mahon' ${ }^{1}$ L. Claxton' , H. Wood ${ }^{1}$, R. Rychlik ${ }^{2}$ \\ ${ }^{1}$ York Health Economics Consortium, York, UK, ${ }^{2}$ Institut für Empirische Gesundheitsökonomie, Burscheid, Deutschland}

Background: The health and economic benefits of providing human milk to term infants have long been established in the medical literature, with evidence demonstrating that human milk can aid development and reduce risks of certain infections [1]. Mothers with preterm infants face further barriers to breastfeeding. For infants that are born preterm $(<37$ weeks of pregnancy), providing human milk to the infant and sustaining lactation up to and beyond hospital discharge may be challenging [2]. Feeding preterm infants with human milk has been shown to have benefits over feeding formula milk both in the short-term and the long-term, such as a lower risk of necrotising enterocolitis (NEC) [3], and development impairment and obesity $[4,5]$.

Aims: An economic analysis focusing on preterm infants was undertaken to estimate the cost savings and health benefits in the German healthcare system that could be achieved if human milk usage in neonatal intensive care units (NICUs) were increased.

Materials and methods: A systematic review established the disease areas with the strong sources of evidence of the short, medium and long-term benefits of human milk for preterm infants as opposed to the use of formula milk. The health economic analysis assessed the economic impact of reducing rates of NEC, sepsis, sudden infant death syndrome (SIDS), leukaemia, otitis media, obesity and neurodevelopmental impairment. Results: If all preterm infants were provided with human milk compared to none having human milk, the overall cost saving to the German healthcare system due to improved health outcomes after one year is estimated to be $€ 47$ million, with a further $€ 42$ million over the infants lifetime. The infants would have a total lifetime QALY gain of 12,158 . The provision of human milk would prevent 4.3 in 1,000 preterm infants dying in the first year of life due to reductions in neonatal infections and SIDS. The death of an infant means a significant loss of earnings, equating to a total of $€ 174$ million in additional lifetime earnings. Sensitivity analyses indicated that results were robust to a wide range of inputs, with the odds ratio for sepsis and NEC having the greatest impact upon the results.

Discussion and conclusions: This analysis established that increasing the use of human milk in NICUs the Germany may lead to cost savings to the German healthcare system. More research is needed on the health and economic outcomes associated with breastfeeding preterm infants, and the differences between mothers own and donor breast milk.

\section{References}

1. Victora CG et al (2016) Breastfeeding in the 21st century: epidemiology, mechanisms, and lifelong effect. Lancet 387:475-490

2. Maastrup R et al (2014) Factors associated with exclusive breastfeeding of preterm infants. Results from a prospective national cohort study. PLOS ONE 9:e89077

3. Boyd CA et al (2007) Donor breast milk versus infant formula for preterm infants: systematic review and meta-analysis. Arch Dis Child Fetal Neonatal Ed 92:F169-75

4. Horta BL, Victora CG (2013) Long-term effects of breastfeeding: A systematic review. World Health Organisation

5. Renfrew MJ et al (2009) Breastfeeding promotion for infants in neonatal units: a systematic review and economic analysis. Health Technol Assess 13:1-146

\section{WE-P05}

\section{Entlassungsnahrung von früh- und kranken reifgeborenen Kindern: Gibt es Risikofaktoren für Formula-Ernährung?}

N. Heller, M. Rüdiger, L. Mense

Klinik für Kinder- und Jugendmedizin, Universitätsklinikum Carl Gustav Carus Dresden, Fachbereich Neonatologie \& pädiatrische Intensivmedizin, Dresden, Deutschland

Hintergrund: Muttermilch ist mit wenigen Ausnahmen sowohl für Reifgeborene als auch für frühgeborene Kinder die optimale Nahrung. Die Ernährung mit Muttermilch wird durch die Aufnahme eines Neugeborenen auf die neonatologische Pflege- oder Intensivstation erschwert. Die Kenntnis weiterer Risikofaktoren ermöglicht gezielte Interventionen zur Steigerung der Muttermilch-Ernährung.

Fragestellung: Welche maternalen bzw. neonatalen Einflussfaktoren erhöhen das Risiko einer Entlassung mit Formula-Ernährung?

Material und Methoden: Erfasst wurden mögliche Einflussfaktoren auf die Art der Entlassungsnahrung der zwischen dem 01.04.2013 und 31.03.2015 entlassenen Kinder der neonatologischen Pflegestation, welche am Universitätsklinikum Dresden geboren oder innerhalb der ersten 48 Stunden in dieses verlegt worden waren. Das primäre Outcome ist die vorwiegende, d.h. mehr als $50 \%$ der Gesamtnahrung umfassende Ernährung mit Muttermilch oder Formula in den letzten 48 Stunden vor Entlassung. Gruppenunterschiede wurden mittels Mann-Whitney-U-Test bzw. Chi ${ }^{2}$-Test nach Pearson berechnet. Kinder $\geq 32$ und $<32$ SSW wurden einzeln untersucht. Ein Vorhersagemodell zur Entlassungsnahrung wurde mittels binärer logistischer Regressionsanalyse mit Berücksichtigung aller signifikant unterschiedlichen Einzelfaktoren berechnet.

Ergebnisse: $66 \%$ der 363 Kinder $\geq 32$ SSW erhielten vorwiegend Muttermilch. In der Gruppe der vorwiegend mit Muttermilch ernährten Kinder fanden sich signifikant weniger mit mütterlichem Gestationsdiabetes, $\mathrm{Ni}$ kotin-, Alkohol- oder Drogenkonsum, mit nichtakademischen oder alleinstehenden Müttern, nicht angelegte oder gebondete Kinder sowie mehr Kinder mit CPAP/Intubation im Verlauf des Aufenthaltes. Signifikante Gruppenunterschiede konnten außerdem für die Faktoren mütterliches Alter, Dauer des ITS-Aufenthaltes, Geburtsgewicht und Gestationswoche nachgewiesen werden. In der Regressionsanalyse waren die Parameter Gestationsdiabetes sowie nie angelegt mit einem signifikant höherem Risiko für Formula-Ernährung verbunden.

$69 \%$ der 250 Kinder $<32$ SSW erhielten hauptsächlich Muttermilch. Signifikant mehr mit Muttermilch ernährte Kinder fanden sich bei im Verlauf angelegten Kindern, bei Mehrlingen sowie bei akademischen Müttern und ohne Nikotin- oder Dogenkonsum. Kinder von alleinstehenden Müttern wurden signifikant häufiger mit einer Formulaernährung entlassen. Weiter signifikante Gruppenunterschiede wurden für Gesamtaufenthaltsdauer, Dauer der Sondenernährung, Tag des ersten Kangarooings und das Geburtsgewicht ermittelt. In der Regressionsanalyse war lediglich der $\mathrm{Pa}-$ rameter nie angelegt mit einem signifikant erhöhten Risiko für FormulaErnährung assoziiert.

Schlussfolgerung: Mütter, welche die Risikofaktoren eines Gestationsdiabetes aufweisen oder im Verlauf das Kind noch nicht angelegt haben, bedürfen einer besonderen Unterstützung während des Aufenthaltes, um den Kindern die bestmögliche Ernährung mit Muttermilch zu ermöglichen. 


\section{WE-P06}

Kombinierte Cholin-/Docosahexaensäure-Supplementierung bei sehr unreifen Frühgeborenen - Untersuchungen mit stabiler Isotopenmarkierung

K. Böckmann', C. Maas', A. Franz', A. Shunova', M. Mathes', J. Hövelmann', C. F. Poets ${ }^{1,2,3}$, W. Bernhard

${ }^{1}$ Klinik für Kinder- und Jugendmedizin, Universitätsklinikum Tübingen, Abt. Neonatologie, Tübingen, Deutschland, ${ }^{2}$ Klinik für Kinder- und Jugendmedizin, Universitätsklinikum Tübingen, Center for Pediatric Clinical Studies, Tübingen, Deutschland, ${ }^{3}$ Universitätsklinikum Tübingen, Center for Pediatric Clinical Studies, Tübingen, Deutschland

Hintergrund: Docosahexaensäure (DHA) ist für die Entwicklung Frühgeborener essentiell. DHA wird während des 3. Trimesters im Fötus angereichert und hauptsächlich (90\%) in den Triglyceriden des Fettgewebes gespeichert. Sein Plasmatransport geschieht jedoch hauptsächlich via Phosphatidylcholin (PC), das DHA enthält (DHA-PC). Daher ist der Metabolismus von DHA essentiell mit dem von Cholin verknüpft.

Fragestellung: Wie ist die Wirkung einer kombinierten DHA-/CholinSupplementierung auf ihren Plasmametabolismus im Vergleich zur Gabe der Einzelsubstanzen bzw. zur Behandlung nach klinischen Standards?

Material und Methoden: Randomisierte, teilverblindete monozentrische Studie der Abteilung Neonatologie, Universitätsklinikum Tübingen, an 24 Frühgeborenen <32 Wochen, Median (p25/75): 28,9 (27,3/29,8) Wochen Gestationsalter. Rekrutierung von Juni 2015 bis Januar 2017, Registrierung: Clinicaltrials.gov (identifier NCT01773902).

Interventionen: Nach oralem Nahrungsaufbau wurden die Frühgeborenen randomisiert einer von vier parallelen Gruppen $(N=6)$ zugeordnet: Standardernährung (Kontrolle) oder Supplementierung per os mit $60 \mathrm{mg} /$ $\mathrm{kg} / \mathrm{d}$ DHA, $30 \mathrm{mg} / \mathrm{kg} / \mathrm{d}$ Cholin oder beiden für jeweils 10 Tage. Nach 7,5 Tagen wurde den Frühgeborenen $3,6 \mathrm{mg} / \mathrm{kg}$ deuterium-markiertes Cholin (D9-Cholinchlorid) per os verabreicht, um den Plasma-Metabolismus von Cholin, Gesamt-PC und DHA-PC zu untersuchen. (D9-)Cholin und seine Metaboliten sowie Plasma- und Erythrocyten-(D9-)PC wurden mittels Tandemmassenspektrometrie untersucht.

Ergebnisse: Die Ergebisse der ersten 20 von 24 Patienten sind dargestellt. Cholin-Substitution erhöhte das Plasma-Cholin von 23,3(19,0-24,8) $\mu \mathrm{mol} / \mathrm{L}$ auf $36,9(31,9-39,3) \mu \mathrm{mol} / \mathrm{L}(p<0,01)$, während in Kontrollen das Cholin konstant blieb 23,5(19,4-28,4) bzw 19,3(16,1-22,3) $\mu \mathrm{mol} / \mathrm{L}$. Die Kombination von DHA mit Cholin, nicht aber DHA allein, erhöhte den Anteil von DHA-PC im Plasma-PC von 5,06(4,17-6,17)\% auf 7,75(7,10$8,81) \%(p<0,01)$.

Die-D9-Cholin-Anreicherung in cholin-haltigen Phospholipiden, d.h. PC (Kontrolle, 12 h: 0,56[0,54-0,73]\%) und Sphingomyelin $(0,11[0,11-$ $0,15] \%)$ wurde durch die Cholin-Supplementierung um $34 \%$ erniedrigt $(p<0,01)$, was die stärkere Verdünnung des D9-tracers durch die Auffüllung der Cholinpools anzeigt. Die D9-Anreicherung des Plasma-PC war nach $60 \mathrm{~h}$ um $40 \%$ niedriger als nach $12 \mathrm{~h}(p<0,001)$. Im ErythrocytenPC stieg sie kontinuierlich an. Dies zeigt einen schnellen PC-turnover des Plasma-PC und Austausch mit den Erythrocytenmembranen. Die D9Anreicherung war hoch für PC-Spezies, die Ölsäure $(0,79[0,72-0,81] \%)$ oder Linolsäure $(0,72[0,59-0,80] \%)$ enthalten, während sie für DHA-PC $(0,34[0,18-0,43] \%)$ signifikant niedriger war $(p<0,01)$.

Schlussfolgerung: 1 . Cholinsubstitution $(30 \mathrm{mg} / \mathrm{kg} / \mathrm{d})$ erhöht das PlasmaCholin auf fetale Konzentrationen und erhöht die Cholinpools. 2. Eine Erhöhung des DHA-PC, der Hauptquelle von DHA für die Entwicklung des Gehirns (und aller Gewebe) wurde nur durch die simultane Gabe von DHA (60 mg/kg/d) und Cholin erreicht. 3. Die Syntheserate von PC-Spezies mit DHA ist niedriger, als die mit Ölsäure oder Linolsäure. Das könnte auf ihre Kompetition mit DHA hinweisen. 4. Die simultane Supplementierung von DHA und Cholin erhöht möglicherweise die Bioverfügbarkeit von DHA.

\section{WE-P07 \\ Cholestase bei Früh- und Neugeborenen - trägt das Protein DMBT1 dazu bei?}

H. Müller ${ }^{1}$, M. Renner ${ }^{2}$, J. Mollenhauer ${ }^{3}$, U. Felderhoff-Müser ${ }^{1}$

'Uniklinikum Essen, Kinderheilkunde I, Neonatologie, Essen, Deutschland, ${ }^{2}$ Uniklinikum Heidelberg, Institut für Pathologie, Heidelberg, Deutschland, ${ }^{3}$ University of Southern Denmark, Molecular Oncology and Lundbeckfonden Center of Excellence NanoCAN, Odense, Denmark

Hintergrund: DMBT1 ist eine Glykoprotein und hat Funktionen bei der angeborenen Immunabwehr, der epithelialen Differenzierung und bei der Angiogenese. Im Rahmen von Infektionen wird DMBT1 hochreguliert. Bei Erwachsenen wurde gezeigt, dass DMBT1 bei verschiedenen Erkrankungen der Gallengänge (Obstruktion, primär sklerosierende Cholangitis, chronische virale Hepatitis, Gallensteine) vermehrt in den Gallengängen exprimiert wird. Der Anteil an Cholesterol in den intrahepatischen kleinen Gallengängen war bei Patienten mit DMBT1-positiver Galle signifikant höher. Die vermehrte Expression und Sekretion von DMBT1 in die intrahepatischen großen Gallenwege bei Hepatolithiasis macht eine Rolle von DMBT1 bei der Gallensteinentstehung wahrscheinlich.

Fragestellung: Es ist bekannt, dass eine durch Endotoxine verursachte Sepsis (z. B. nekrotisierende Enterokolitis) und andere Infektionen (z. B. aus dem Harntrakt) zu einer neonatalen Cholestase beitragen können. Deshalb soll untersucht werden, ob verstorbene Früh- und Neugeborenen eine DMBT1-Expression in den Gallengängen aufweisen.

Patienten und Methoden: Wir haben das Lebergewebe von 10 Früh- und Neugeborenen untersucht, die mit einem Gestationsalter von 23-46 Wochen verstorben waren. Die Kinder hatten ein postnatales Alter zwischen 1 Tag und 6 Wochen erreicht. Im Lebergewebe wurde das Protein DMBT1 mittels Immunhistochemie detektiert, indem zwei verschiedene Antikörpern gegen DMBT1 (Anti-DMBT1p84 und Anti-DMBT1h12) verwendet wurden.

Ergebnisse: DMBT1 konnte in den Gallengängen von 5 der 10 untersuchten Kindern nachgewiesen werden. Dabei war eine hohe DMBT1-Expression in den Gallengängen der Kinder mit höherem postnatalen Alter und Sepsis oder Cholestase zu beobachten. Die Zellen des Gallengangsepithels zeigten eine luminale, laterale und basale Färbung. Ebenso zeigte der Gallenblaseninhalt eine intensive Färbung.

Schlussfolgerung: DMBT1 ist in den Gallengängen von manchen Frühund Neugeborenen nachweisbar und könnte zu einer neonatalen Cholestase beitragen.

\section{WE-P08}

Einfluss eines umfassenden Pflege- und Ernährungskonzepts auf das Trinkverhalten von Frühgeborenen bei Entlassung

\section{K. Rudofsky, J. Höfer, A. Holubovsky, A. Berger, L. Kirchner}

Medizinische Universität Wien, Klinische Abteilung für Neonatologie,

Pädiatrische Intensivmedizin und Neuropädiatrie, Wien, Österreich

Hintergrund: Ein großes Problem bei der Betreuung sehr kleiner Frühgeborener stellt die orale Nahrungsaufnahme dar. Vor der 32. Schwangerschaftswoche ist auf Grund der neurologischen, kardiorespiratorischen und oral-muskulären Unreife sowie des herabgesetzen Muskeltonus und der fehlenden Koordination mit der Atmung ein aktives Saugen und Schlucken kaum möglich. Besonders wichtig ist während dieser Zeit jedoch die indirekte Vorbereitung auf die orale Nahrungsaufnahme. An der Intermediate Care Station Ebene 15B der Abteilung für Neonatologie der Medizinischen Universität Wien wurde von März bis Juni 2015 ein intensives Schulungsprogramm zur Optimierung des Saugverhaltens durchgeführt, an dem alle dort tätigen Pflegepersonen teilnahmen. Auch die Eltern wurden einbezogen. Dabei wurde neben einer logopädischen Betreuung der Frühgeborenen vor allem auf positive orale Erfahrungen sowie verstärkte soziale und kommunikative Interaktionen Wert gelegt.

Fragestellung: Ziel der Studie war es, das Trinkverhalten der Frühgeborenen vor und nach Durchführung dieses Schulungsprogramms zu vergleichen. 
Patienten und Methoden: In die Studie wurden alle Frühgeborenen $<37$. SSW eingeschlossen, welche im Zeitraum vom 01.01.2014 bis 31.12.2014, also vor Durchführung dieses Schulungsprogramms, und vom 01.10.2015 bis 30.09.2016, also nach Etablierung des neuen Ernährungskonzepts, an dieser Abteilung behandelt wurden. Die Daten wurden dem computergestützten Patientendokumentationssystem AKH PDMS entnommen.

Ergebnisse: In der Studiengruppe befanden sich 84 Patienten (32 Pat. $<28$ SSW, 52 Patienten $>28$ SSW), in der Kontrollgruppe 75 (36 Pat. <28 SSW, 39 Patienten $>28$ SSW ). 54,8\% der Kinder aus der Studiengruppe waren bei Entlassung ausschließlich mit Muttermilch ernährt, in der Kontrollgruppe waren es 36\%. 22,6\% der Patienten aus der Studiengruppe wurden bei der Entlassung ausschließlich gestillt, in der Kontrollgruppe waren es 13,3\%. Die Zeit bis zum vollständig selbständigen Trinken betrug in der Studiengruppe bei den Patienten <28. SSW im Mittel 100 Tage, bei den Patienten $>28$. SSW 30 Tage. In der Kontrollgruppe tranken die Patienten $<28$ SSW im Mittel nach 73 Tagen, > 28 SSW nach 28 Tagen selbständig. Schlussfolgerung: Ein konsequentes entwicklungsförderndes Schulungsprogramm zur Verbesserung des Saugverhaltens konnte die Zeit bis zum vollständig selbständigen Trinken nicht verkürzen, es waren aber mehr Patienten bei Entlassung ausschließlich gestillt und mehr Patienten ausschließlich mit Muttermilch ernährt.

\section{WE-P09}

Beurteilung der parenteralen Ernährung bei Frühgeborenen unter $1500 \mathrm{~g} \mathrm{~m}$ Vergleich zu publizierten Leitlinien: Eine retrospektive, systematsiche Analyse

\section{Sirch, M. Butte, L. Gortner, U. Lindner, M. Poryo, S. Meyer Universität des Saarlandes, NICU, Homburg, Deutschland}

Hintergrund: Ein wichtiger Aspekt für das Wachstum sowie die körperliche Entwicklung von Frühgeborenen ist eine adäquate Nahrungszufuhr. Basierend auf der Ergebnissen zahlreicher Studien werden sowohl die Geschwindigkeit des Nahrungsaufbaus als sowie die Substratmengen zum Teil kontrovers diskutiert.

Zielsetzung: Ziel dieser Arbeit war es, das parenterale Ernährungsregime bei sehr unreifen Frühgeborenen (Very low birth weight Neonaten (VLBW) mit einem Geburtsgewicht $<1500$ Gramm) systematisch zu untersuchen, die zugeführten Substratmengen zu berechnen und mit publizierten Leitlinien zu vergleichen.

Methodik: Retrospektive Studie bei VLBW-Neonaten der neonatologischen Intensivstation der Universitätskinderklinik des Saarlandes (Homburg) über einen Zeitraum von zwei Jahren (01.01.2009-31.12.2010)

Ergebnisse: In die Studie wurden insgesamt 100 Frühgeborene mit einem Geburtsgewicht $<1500 \mathrm{~g}$ eingeschlossen. Das mittlere Gestationsalter lag bei $29+4$ SSW [Spannweite: $24+3-34+1$ SSW]. Das Geburtsgewicht aller Frühgeborener lag im Mittel bei 1118,8 g $\pm 260 \mathrm{~g}$ (570-1490 g).

Bei der Analyse der zugeführten parenteralen und enteralen Nahrungsmengen für Flüssigkeit, Glukose, Aminosäuren, Fette und Kalorienzufuhr zeigte sich, dass bis auf die verabreichte Glukosemenge, die in den Leitlinien geforderten Substratmengen für parenterale Ernährung von Frühgeborenen der DGEM unterschritten wurden. Die Wachstumsperzentilen bezüglich Körpergewicht, -länge und Kopfumfang waren in den ersten drei Lebenswochen deutlich abfallend. Hingegen zeigte sich in der Nachuntersuchung im Alter von 2 Jahren ein aufgeholtes Wachstum, dass sich dem eines termingerecht Geborenen annähert. Bei der Nachuntersuchung mittels Bayley II im Alter von 2 Jahren waren 77,8 \% der untersuchten Kinder im Normbereich.

Schlussfolgerung: Die von uns durchgeführte Analyse zeigt, dass die Verabreichung der parenteralen Ernährung auf unserer neonatologischen Intensivstation ehrheitlich nicht leitlinienkonform durchgeführt wurde und mit inadäquaten Wachstumsparametern assoziiert war. Inwiefern ein leitlinienkonformes Vorgehen neben einer veränderten Wachtstumscharakteristik auch mit positiven Langzeitfolgen bezüglich der neurologischen Entwicklung einhergehen kann, bleibt ungeklärt.

\section{WE-P10}

Spendermilch vs. Formulanahrung - Analyse der neonatalen Morbidität von extremen Frühgeborenen vor und nach Einführung von Spendermilch am Perinatalzentrum Großhadern

V. Lieftüchter, A. H. Schulze, A. W. Flemmer, S. Herber-Jonat

Dr. von Haunersches Kinderspital, Ludwig-Maximilians-Universität, Perinatalzentrum Großhadern, München, Deutschland

Hintergrund: Die Effekte von Muttermilch bzw. gespendeter Frauenmilch auf die Entwicklung des extrem unreifen Frühgeborenen sind komplex. Vermutet werden eine positive Beeinflussung der Entwicklung und Reifung des Immunsystems und Gastrointestinaltrakts. In verschiedenen Studien konnte eine Reduktion nosokomialer Infektionen und nekrotisierender Enterokolitiden (NEC) bei Frühgeborenen (FG) nach Nahrungsaufbau mit pasteurisierter Frauenmilch und Vermeidung von Formulanahrung gezeigt werden. Pasteurisierung verändert jedoch die Zusammensetzung und Qualität der Frauenmilch. Ein Nahrungsaufbau mit unpasteurisierter Frauenmilch anstelle von Formulanahrung verstärkt möglicherweise die positiven Effekte, ist aber bisher in der Literatur wenig untersucht. Seit Einführung der Frauenmilchbank (FMB) am PNZ Großhadern im Februar 2012 wird auf der Station für Kinder $<32$ SSW ein exklusiver Nahrungsaufbau mit unpasteurisierter Frauen- bzw. eigener Muttermilch angestrebt. Methode: Retrospektiver Vergleich aller FG $<32$ SSW und $<1500 \mathrm{~g}$, die in zwei Zeiträumen $(02 / 2010-02 / 2012$ vor Einführung der FMB und 02/2012-03/2013 nach FMB) am PNZ Großhadern geboren wurden. Ausschlusskriterien waren Tod $<7 d$, schwere Fehlbildungen sowie Stoffwechseldefekte. Verglichen wurden initial Formula-ernährte Kinder mit initial Spendermilch-ernährten Kindern, Während des gesamten Beobachtungszeitraums wurden bis auf die Art der Milchnahrung keine grundlegenden Änderungen des Nahrungsregimes eingeführt. Erfasst wurden Gestationsalter (GA), Amnioninfektion, orale Nahrung in den ersten Lebenstagen (Lt.), Lt. bei Erreichen des vollen Nahrungsaufbaus, Gewichtsentwicklung und neonatale Morbidität (Sepsis, NEC, BPD, ROP, Tod). Primäre Zielkriterien waren die Inzidenz von NEC und sekundärer Sepsis während der beiden Beobachtungszeiträume.

Ergebnisse: Vor Einführung der FMB erfüllten 142/174 Frühgeborene die Einschlusskriterien. Nach Einführung der FMB wurden 250 FG $<32$ SSW und $<1500 \mathrm{~g}$ auf der Station betreut. Bei 121/250 Frühgeborenen erfolgte der Nahrungsaufbau mit Spendermilch (74\% unpasteurisiert). 115/250 Kinder erhielten auch nach Etablierung der FMB in den ersten Lebenstagen Formulanahrung. Die Zusammensetzung beider Gruppen unterschied sich in Bezug auf das mittlere Gestationsalter (GA) und Geburtsgewicht (vor FMB: GA $28,2 \pm 2,6 \mathrm{SSW} ; 1053 \pm 300 \mathrm{~g}$ vs. nach FMB: $26,9 \pm 2,1 S S W ; 885 \pm 258$ g; $p<0,0001$ ). 22/121 (18\%) Kinder mit Spendermilch erlitten eine Sekundärsepsis. In der Gruppe der Formula-ernährten Kinder lag die Häufigkeit bei $21 / 142$ (15\%, n. s.; $p=0,62$ ). Bei jeweils einem Kind in beiden Beobachtungszeiträumen wurde eine beginnenden NEC (Bell Stadium 1) diagnostiziert. FG mit Formulanahrung waren im Mittel nach 11,2 $\pm 4,4$ Tagen voll enteral aufgebaut; FG mit Spendermilch nach $10,4 \pm 4,2$ Tagen $(p=0,09)$. In beiden Gruppen haben die FG im Mittel am 19,3 Lt. $120 \%$ ihres Geburtsgewichts erreicht.

Schlussfolgerung: In den ersten 2 Jahren nach Aufbau der FMB am PNZ Großhadern konnten $50 \%$ aller Frühgeborenen $<32$ SSW mit Spendermilch versorgt werden, davon drei Viertel mit unpasteurisierter Milch. Bei geringer Ausgangs-NEC Rate bereits vor Start der FMB $(<1 \%)$ ist in unserer Kohorte keine weitere Reduktion der NEC-Inzidenz zu beobachten. Der Nahrungsaufbau mit Spendermilch gelingt tendenziell schneller als mit Formulanahrung und ist mit einem vergleichbaren Wachstum verbunden. 


\section{WE-P11}

\section{Messung der optischen Eigenschaften des Mekoniums von Frühgeborenen mittels Nah-Infrarotspektroskopie}

H. Stachel', D. Schenk', J. Bernhard', F. Scholkmann', S. Kleiser', D. Ostojic', D. Bassler', M. Wolf', T. Karen'

'Universitätsspital, Klinik für Neonatologie, Zürich, Schweiz, ${ }^{2}$ Carag AG, Baar, Schweiz

Hintergrund: Die nekrotisierende Enterokolitis ist die häufigste gastrointestinale Notfallerkrankung in der Neugeborenenperiode. Betroffen sind vor allem Frühgeborene mit einem Gewicht von $<1500 \mathrm{~g}$ (Inzidenz $12 \%)$. Die Pathophysiologie ist multifaktoriell. Die primäre Störung ist eine mesenteriale Ischämie und damit verbundene Hypoxie des Darmes mit sekundärer Invasion enteropathogener Keime in die Darmmukosa. Bisher gibt es kein etabliertes diagnostisches Messinstrument, welches eine Minderperfusion des Darmes frühzeitig erkennt. Die Nah-Infratospektroskopie (NIRS) ermöglicht eine kontinuierliche Messung der Sauerstoffversorgung von Gewebe und damit auch des Bauches. Das Problem herkömmlicher NIRS-Geräte ist, dass sie bei der Messung des Abdomens die optische Absorption des Mekonium, bzw. Stuhls sowie die optischen Eigenschaften des Abdomens, nicht berücksichtigen. Dies führt zu einer Verfälschung der Messwerte des abdominellen Sauerstoffgehalts.

Fragestellung: Das Ziel unserer Forschungsarbeit war die Erfassung der optischen Eigenschaften des Abdomens bei Frühgeborenen. Hierfür wurden die Absorptionsspektren der ersten Stuhlgänge bestimmt. Die Hypothese war, dass ein für alle Frühgeborene gültiges Absorptionsspektrum des Stuhls ermittelt und somit der Stuhl als zusätzlicher Absorber in die Datenanalyse bei der Messung des Sauerstoffgehalts berücksichtigt werden kann.

Material und Methoden: 25 Frühgeborene mit einem Gestationsalter $<35$ SSW wurden untersucht. Die ersten 5 abgesetzten Stuhlproben jedes Kindes wurden spektroskopisch analysiert (Shimadzu UV 1600') und auf ihre optische Absorption hin untersucht.

Ergebnisse: Zwei unterschiedliche Absorptionsspektren konnten identifiziert und mit den Stuhltypen Mekonium und Übergangsstuhl assoziiert werden. Die Stuhlproben zeigen eine starke Absorption im Nah-Infraroten auf. Der Verlauf der Absorptionsspektren beider Stuhltypen verhält sich im Wesentlichen entgegengesetzt zu oxidiertem Hämoglobin. Folglich führt die Präsenz von Stuhl im Abdomen zu einer Unterschätzung der Konzentration an oxidiertem Hämoglobin und dementsprechend zu einer Unterschätzung des abdominalen Sauerstoffgehalts.

Diskussion und Schlussfolgerung: Anhand der erhaltenen Daten soll zukünftig ein auf NIRS basierendes Gerät zur nicht invasiven und kontinuierlichen Messung des abdominalen Sauerstoffgehaltes von Frühgeborenen entwickelt werden, welches den Stuhl als Absorber berücksichtigt und abdominale Sauerstoffwerte entsprechend korrigiert. Damit könnte frühzeitig eine Darmischämie in der Risikopopulation kleiner Frühgeborener erkannt werden.

\section{WE-P12}

Primäres Abstillen als Stillhindernis - Erfahrungen eines Level I-Perinatalzentrums

E. Neumann', F. Markfeld-Erol', M. Kunze ${ }^{2}$, R. Hentschel', H. Fuchs' ${ }^{1}$ D. Klotz ${ }^{1}$

'Zentrum für Kinder- und Jugenmedizin, Uniklinik Freiburg, Neonatologie, Freiburg, Deutschland, ${ }^{2}$ Uniklinik Freiburg, Abteilung für Frauenheilkunde und Geburtshilfe, Freiburg, Deutschland

Hintergrund: Die vielfältigen Ursachen für Laktationshindernisse bei Stillwunsch sind bekannt und gut beschrieben. Die Häufigkeit des primären Abstillens und die Ursachen hierfür sind bisher weniger untersucht.

Fragestellung: Inzidenz und Gründe des primären Abstillens. Evaluation mütterlicher Beratung vor Abstillen von geburtshilflicher und neonatologischer Seite.

Methode: Retrospektive Auswertung von Patientendaten der Geburtenjahrgänge 2011 bis 2016 eines universitären Level-I-Perinatalzentrums.
Ergebnisse: Im Untersuchungszeitraum fanden 9145 Entbindungen statt, $7 \%$ dieser Frauen $(n=645)$ stillten primär ab $(2 \times 0,5 \mathrm{mg}$ Cabergolin, im Abstand von 12 Stunden). In $31 \%$ der Fälle $(n=204)$ war ein Spätabort, in 16 Fällen das postnatale Versterben des Kindes, in 39 Fällen eine mütterliche HIV-Infektion und in drei Fällen ein Mamma-Karzinom die Indikation zum Abstillen. Die Abstillgründe der übrigen 383 Fälle lauteten mütterliche Hepatitis-C-Infektion $(n=3)$ und Hepatitis-B-Infektion $(n=2)$, Methadon-Substitution $(n=5)$, intensivmedizinischer Aufenthalt der Mutter $(n=3)$, vorangegangene Brustoperationen $(n=15)$, Einnahme verschreibungspflichtiger Medikamente (darunter Carbamazepin, Modafinil, Amitriptylin, Opripramol, Paraxetin, Sildenafil) $(n=23)$. In 251 Fällen war der mütterliche Wunsch Grund für das Abstillen. Häufig wurden dabei Fortsetzung eines Nikotinabusus, Brustschmerzen und schlechte Stillvorerfahrungen genannt, meistens jedoch ließen sich die Gründe nicht eruieren. In 77 von 320 Fällen waren es Mütter frühgeborener Kinder, die primär abstillten (mittleres Gestationsalter 32 Schwangerschaftswochen). Alle 383 Mütter erhielten vor dem Abstillen eine geburtshilfliche, vier der Mütter zusätzlich eine neonatologische Beratung.

Schlussfolgerung: Eine relevante Anzahl von Müttern stillt medikamentös im frühen Wochenbett ab, ein Teil der dokumentierten Abstillgründe stellt kein medizinisch relevantes Stillhindernis dar. Während alle Mütter eine geburtshilfliche Beratung erhielten, fand eine neonatologische Intervention praktisch nicht statt. Bei Müttern mit Abstillwunsch sollte möglichst schon vor Entbindung, besonders im Falle einer drohenden Frühgeburtlichkeit, eine Still- und Laktationsberatung erfolgen und versucht werden, die Gründe eines Abstillwunsches zu eruieren. Es sollte evaluiert werden, ob eine gemeinsame Beratung von geburtshilflicher und neonatologischer Seite die primären Abstillraten reduzieren kann.

\section{Poster DGPI}

\section{Antibiotika/Antibiotic Stewardship}

\section{ANT-P01 \\ Analyse des Antibiotikaverbrauchs am Kinderklinikum der Technischen Universität München: Angriffspunkte für ein Antibiotic Stewardship Programm}

M. Burggraf', J. Geisperger', K. Kreitmeyr ${ }^{2}$, M. Steinhauser', J. Berndt ${ }^{3}$, N. Rieber ${ }^{1}$, U. Behrends ${ }^{1}$, J. Hübner ${ }^{2}$

'Technische Universität München, Kinderklinik, München, Deutschland, ${ }^{2}$ Ludiwg-Maximilians-Universität, Abteilung für Infektiologie, Dr. von Haunersches Kinderspital, München, Deutschland, ${ }^{3}$ Städtisches Klinikum Schwabing, Kinderchirurgie, München, Deutschland

Hintergrund: Die Errungenschaften der modernen Medizin werden zunehmend von multiresistenten Keimen bedroht, die unter anderem durch unkritischen Einsatz von Antibiotika entstehen. Es konnte gezeigt werden, dass der Verbrauch von Antibiotika durch Antibiotic Stewardship (ABS) Programme reduziert werden kann. Zusätzlich werden Kosten eingespart und ein besseres Outcome erreicht. In der Pädiatrie fehlen jedoch Daten zur effektiven Implementierung solcher ABS Maßnahmen.

Fragestellung: Wie hoch ist der Verbrauch von Antibiotika am Kinderklinikum der Technischen Uinversität München und entspricht die antibiotische Therapie den Leitlinien? Welche ABS Interventionen könnten die aktuelle Situation verbessern?

Material und Methodik: Im Zeitraum von 01.08 .16 bis 30.11 .16 wurden alle Patienten dokumentiert, die eine systemische antibiotische Therapie erhielten. Insbesondere wurden das Antibiotikum, die Dauer der Therapie und die Dosierung aufgenommen. Die Daten wurden auf pädiatrischen und chirurgisch-pädiatrischen Normalstationen erhoben, Intensivstation und Onkologie wurden nicht untersucht. Patienten mit Tuberkulose (2), mit Zystischer Fibrose (4) und longterm Patienten (2) wurden ausgeschlossen. Die prophylaktische Gabe von Antibiotika wurde außer Acht 
gelassen, wenn es keine perioperative Antibiotikaprophylaxe (PAP) war. Um den Verbrauch der Antibiotika zu beurteilen, wurden Days of Therapy (DoT) und Length of Therapy (LoT) berechnet. Insgesamt wurden 331 Patienten (190 pädiatrische, 141 pädiatrisch-chirurgische) mit 2308 DoT und 1653 LoT erfasst.

Ergebnisse: Von allen stationären Patienten auf den untersuchten Stationen erhielten $19 \%$ der pädiatrischen und $30 \%$ der pädiatrisch-chirurgischen Patienten eine antibiotische Therapie. Cephalosporine machten $48 \%$ und Penicilline $31 \%$ aller applizierten Antibiotika aus. Innerhalb der Cephalosporine betrug der Anteil von Ceftazidim 20\%. Die häufigsten Indikationen waren Harnwegsinfektion (HWI, 20\%) und ambulant erworbene Pneumonie (CAP, $14 \%$ ) bei den pädiatrischen und PAP bei den pädiatrisch-chirurgischen Patienten (63\%). Bezüglich Wundklassifikation und Risikofaktoren war die Indikation für eine PAP in $17 \%$ der Fälle nicht klar. Die Dauer der PAP überschritt in $48 \%$ der Fälle 24 Stunden. Die in den Leitlinien empfohlene Initialtherapie der CAP mit Ampicillin wurde nur in 9 von 28 Patienten mit CAP durchgeführt (32\%). Dosierungen der Antibiotika variierten erheblich: die Dosierungen von intravenösem Cefuroxim für Kinder $\geq 12$ Monate schwankten im Bereich von 30 bis $150 \mathrm{mg} / \mathrm{kg} / \mathrm{d}$.

Schlussfolgerung: Die Daten liefern eine Grundlage für die Entwicklung von ABS Interventionen und zeigen, dass die Wahl des Antibiotikums und die Dosierung verbessert werden können. Die fehlenden Leitlinienadhärenz und der große Anteil an Cephalosporinen, insbesondere Ceftazidim, sollten durch ein Antibiotic Stewardship Programm adressiert werden. Lokale Leitlinien mit spezifischen Empfehlungen für die wichtigsten Infektionen im Kindesalter würden den Einsatz von Antibiotika optimieren.

\section{ANT-P02 \\ Perioperative Infektionsprophylaxe mittels unterschiedlicher Antibiotikaregime nach kardiochirurgischen Eingriffen in der Pädiatrie: Ergebnisse einer randomisierten, prospektiven Pilotstudie}

\section{H. Sauer', S. Koster ${ }^{2}$}

'Universitätsklinikum des Saarlandes, Klinik für Pädiatrische Kardiologie, Homburg (Saar), Deutschland, ${ }^{2}$ Marienhaus Klinikum Saarlouis-Dillingen, Kinder- und Jugendmedizin, Saarlouis, Deutschland

Hintergrund: Vergleichende Studien zur perioperativen Infektionsprophylaxe mittels Antibiotika im Rahmen von kardiochirurgischen Eingriffen sind rar und meist nicht prospektiv durchgeführt worden - zusätzlich sind insbesondere Studien für pädiatrisches Patientengut selten. Die optimale Dauer einer perioperativen antibiotischen Infektionsprophylaxe ist bislang unklar.

Fragestellung: Eine perioperative Infektionsprophylaxe mit Cephalosporinen der 2. Generation für eine postoperative Dauer von 24 oder 48 Stunden ist einer längeren Prophylaxe mit Cepahalosporinen der 3. Generation mindestens ebenbürtig und führt nicht zu einer erhöhten Rate an postoperativen Infektionen.

Material und Methoden: Im Rahmen einer randomisierten, prospektiven Studie verglichen wir unser bisheriges Prophylaxeregime - Cefotaxim für 5 Tage postoperativ (Gruppe 1) - mit zwei anderen Prophylaxeregimen Cefuroxim für 24 (Gruppe 2) oder 48 Stunden (Gruppe 3) postoperativ. Primäre Endpunkte waren: Auftreten von oberflächlichen (SSWI) oder tiefen Wundinfektionen (DSWI) inkl. Endokarditits. Sekundäre Endpunkte: Relevante Keimnachweise an entfernten Fremdkörpern (ZVK, Tubus, Schrittmacherdrähte, Pleuradrainage) sowie Notwendigkeit einer antibiotischen Behandlung während des stationären Aufenthaltes nach Ende der Prophylaxe.

Ergebnisse: Im Untersuchungszeitraum zwischen dem 1. Oktober 2012 und dem 31. Dezember 2014 konnten insgesamt 82 Patienten in die Pilotstudie eingeschleust werden: Gruppe 1 26, Gruppe 2 26, Gruppe 330 Patienten. Bzgl. der präoperativen Parameter (Alter, ASA-Einteilung der Patienten, Gewicht, Geschlechtsverteilung, Leukozyten, CrP und Procalcitonin) ergaben sich keine signifikanten Unterschiede. Bzgl. der postop. Parameter (Leukozyten, CrP und Procalcitonin an jeweils drei verschiede- nen Tagen abgenommen, relevante Keimnachweise an ZVK, Drainagen, Schrittmacherdrähten und Tubusspitze, höchster postop. BZ-Spiegel und Bedarf für eine Insulindauertropf-Infusion sowie Auftreten von DSWI und SSWI bis sechs Monate nach OP) ergaben sich ebenfalls keine signifikanten Unterschiede. Auch bzgl. der Notwendigkeit einer antibiotischen Behandlung nach Absetzen der Prophylaxe während des stationären Aufenthaltes konnten keine signifikanten Unterschiede nachgewiesen werden. Diskussion und Schlussfolgerung: In einer Zeit, in der Therapien und Prophylaxen mittels Antibiotika immer mehr in den Fokus rücken, da Resistenzen gegen diese Wirkstoffe zunehmen, kommt dem rationalen Einsatz von Antibiotika eine immer größere Bedeutung bei. Mit unserer Pilotstudie konnten wir eindrucksvoll nachweisen, dass die Verkürzung einer perioperativen antibiotischen Infektionsprophylaxe nicht zu einer Zunahme von postoperativen Wundinfektionen führt. Im Rahmen einer randomisierten, prospektiven Multicenter-Studie wollen wir bei einem Hochrisiko-Patientenkollektiv (pädiatrische Patienten mit Operationen an der Herz-Lungen-Maschine) diese Erkenntnisse verfestigen und eine weitere Absenkung der Infektionsprophylaxe mittels Antibiotika etablieren.

\section{ANT-P03}

\section{Antibiotic Stewardship in der pädiatrischen Intensivmedizin}

J. Holle', A. Wendt', M. Stegemann', C. Isner ${ }^{2}$, A. Gratopp ${ }^{1}$

${ }^{1}$ Charité-Universitätsmedizin Berlin, Klinik für Pädiatrie m. S. Pneumologie

und Immunologie, Berlin, Deutschland, ${ }^{2}$ Charité-Universitätsmedizin

Berlin, Medizinische Klinik m. S. Infektiologie und Pneumologie, Berlin,

Deutschland

Hintergrund: Weltweit nimmt die Häufigkeit von Infektionen mit multiresistenten Erregern zu. Antibiotic Stewardship (ABS) beinhaltet verschiedene Strategien, um den rationalen Einsatz von Antiinfektiva zu gewährleisten. Ziele sind hierbei neben der bestmöglichen antiinfektiven Behandlung der Patienten die Eindämmung des unangemessenen Verbrauchs sowie der langfristige Erhalt des therapeutischen Potenzials von Antiinfektiva. Auf der pädiatrischen Intensivstation der Charité- Universitätsmedizin Berlin gibt es seit 2015 ein ABS-Programm. Dieses beinhaltet regelmäßige Visiten sowie die konsiliarische Mitbetreuung der Patienten durch die Kollegen des internistischen ABS-Teams.

Fragestellung: Darstellung von Effektivität, Sicherheit und Potenzial eines ABS-Programms auf einer pädiatrischen Intensivstation.

Material und Methoden: Strukturierte Darstellung unseres ABS-Programms mit retrospektiver Auswertung von klinischen Daten, Antiinfektivaverbrauch sowie lokalen Resistenzstatistiken. Verglichen werden das Halbjahr vor Einführung des ABS-Programms mit dem Halbjahr nach Einführung des Programms.

Ergebnisse: Unsere Station hat 15 Betten und deckt das gesamte Spektrum der pädiatrischen Intensivmedizin ab. Etwa die Hälfte der Patienten wird postoperativ betreut. Fallzahlen, Case-Mix Punkte und Mortalität waren in beiden Gruppen vergleichbar. In den Jahren vor Einführung des ABSProgramms zeigte sich eine stetige Zunahme der Besiedlung- und Infektionsraten mit multiresistenten, gram-negativen Erregern.

Nach Einführung des ABS-Programms zeigt sich ein Rückgang der Verbrauchsdaten für Antibiotika. Insbesondere kam es im untersuchten Zeitraum zu einer Abnahme im Verbrauch von Carbapenemen und Cephalosporinen. Schmalspektrumantibiotika wurden im zweiten Halbjahr häufiger verordnet.

Schlussfolgerung: Nach Einführung des ABS-Programms zeigte sich ein Rückgang insbesondere im Verbrauch von Carbapenemen und Cephalosporinen. Schmalspektrumantibiotika wurden häufiger verordnet. Ein Rückgang der Resistenzrate konnte innerhalb eines Jahres noch nicht beobachtet werden. Weitere Maßnahmen wie die Standardisierung perioperativer antibiotischer Prophylaxe und die Vereinheitlichung von Dosierungen sollen die Effektivität unseres ABS-Programms künftig noch verbessern. 


\section{ANT-P04 \\ Kolonisationsscreening und Antibiotikaverbrauch bei VLBW der Jahrgänge 2009-2014 - Daten aus Homburg/Saar}

M. Schöndorf', S. Meyer'², M. Geipel', A. Simon', B. Gärtner', Z. Takacs', L. Gortner' ${ }^{2}$, M. Zemlin'2, D. Schöndorf'

'Universitätsklinikum des Saarlandes, Pädiatrische Onkologie und Hämatologie, Homburg, Deutschland, ${ }^{2}$ Universitätsklinikum des Saarlandes, Allgemeine Pädiatrie und Neonatologie, Homburg, Deutschland, ${ }^{3}$ Universitätsklinikum des Saarlandes, Medizinische Mikrobiologie und Hygiene, Homburg, Deutschland, ${ }^{4}$ Universitätsklinikum des Saarlandes, Frauenheilkunde, Geburtshilfe und Reproduktionsmedizin, Homburg, Deutschland

Hintergrund: Seit der KRINKO-Empfehlung von 2012 [1] wird für Frühund Neugeborene mit einem Geburtsgewicht unter $1500 \mathrm{~g}$ (VLBW), die auf neonatologischen Intensivstationen (NICU) behandelt werden, ein wöchentliches Kolonisationsscreening (KoS) empfohlen. Das KoS hat individualmedizinische und krankenhaushygienische Bedeutung: Ziele sind die Vermeidung nosokomialer Übertragungen und die Auswahl geeigneter Antibiotika. Der Nutzen des KoS wird jedoch auch aufgrund des erheblichen Aufwands kontrovers diskutiert. Da es bei der praktischen Umsetzung deutliche Unterschiede zwischen verschiedenen NICUs gibt, sind monozentrische Daten von Interesse.

Fragestellung: Wie häufig sind Mütter mit multiresistenten Erregern (MRE) kolonisiert? Wie häufig sind perinatale Übertragungen von MRE? Wie häufig kommt es zu Clustern (Nachweisen der gleichen Erregerspezies mit ähnlichem Antibiogramm) bei den betreuten VLBW? Beeinflusst der Nachweis bestimmter Erreger im KoS die Auswahl der Antibiotika zur Therapie von Late-onset Infektionen? Führen die Nachweise von MRE im KoS zu einem vermehrten Einsatz von Reserveantibiotika?

Patienten und Methoden: Nach Zustimmung der Ethikkommission zu einem retrospektiven Audit wurden in unserer NICU (Level 1) die klinischen Verlaufsdaten von insgesamt 390 VLBW der Jahrgänge 2009-2014 und alle zugehörigen mikrobiellen Untersuchungen (8544) inklusive des ab Januar 2012 durchgeführten KoS erhoben. Erfasst wurden neben Basischarakteristika wie Geburtsgewicht, Gestationsalter, postnatale Adaptation, NEC, IVH, Operationen, BPD und Verweildauer insbesondere: Perinatale Transmissionen von MRE, Anwendungsrate von Devices (ZVK, PVK, Tubus), nosokomiale Infektionen durch MRE und Nicht-MRE, Spezies und Resistenzprofil aller nachgewiesenen Erreger sowie alle Antibiotikaanwendungen während des stationären Aufenthaltes.

Ergebnisse: Zum Zeitpunkt der Einreichung findet die Datenauswertung statt.

Diskussion: Die retrospektiv erhobenen monozentrischen Daten dienen der Qualitätssicherung und geben Hinweise auf Probleme und Herausforderungen des KoS. Neben krankenhaushygienischen Aspekten stehen dabei Überlegungen zu einer restriktiven, leitlinienkonformen Antibiotikatherapie im Vordergrund. Das Screening als Teil der Infektionsprävention sollte mit einem Antibiotic Stewardship Hand in Hand gehen.

\section{Literatur}

1. Kommission für Krankenhaushygiene und Infektionsprävention beim Robert Koch-Institut (2012) Ergänzende Empfehlung (2011) zur Prävention nosokomialer Infektionen bei neonatologischen Intensivpflegepatienten mit einem Geburtsgewicht unter 1500g (2007). Epidemiologisches Bulletin Nr. 2, Robert-Koch-Institut, S 13-15

\section{ANT-P05 \\ Therapie des Erythema migrans bei Kindern und Jugendlichen: systematische Übersichtsarbeit und Metaanalyse}

G. Torbahn', H. Hofmann'2, K. Bischoff', M. H. Freitag ${ }^{3}$, V. Fingerle4, P. Rücker', R. Dersch ${ }^{6}$, H. I. Huppertz' , J. J. Meerpohl', C. Schmucker ${ }^{1}$

'Universitätsklinikum Freiburg, Cochrane Deutschland, Freiburg,

Deutschland, ${ }^{2}$ Klinikum rechts der Isar, TU München, Klinik und Poliklinik für Dermatologie, München, Deutschland, ${ }^{3}$ Universität Oldenburg, Department für Versorgungsforschung, Oldenburg, Deutschland, ${ }^{4}$ Landesamt $\mathrm{f}$. Gesundheit u. Lebensmittelsicherheit, Nationales Referenzzentrum für Borrelien, Oberschleißheim, Deutschland, ${ }^{5}$ Universitätsklinikum Freiburg, Institut für Medizinische Biometrie und Statistik, Freiburg, Deutschland, ${ }^{6}$ Universitätsklinikum Freiburg, Klinik für Neurologie und Neurophysiologie, Freiburg, Deutschland, ${ }^{7}$ Klinikum Bremen-Mitte, Prof.-Hess-Kinderklinik, Bremen, Deutschland

Hintergrund: Zur Behandlung des Erythema migrans (EM) bei Kindern und Jugendlichen variieren die klinischen Empfehlungen zwischen den zur Verfügung stehenden antibiotischen Wirkstoffen und Behandlungsstrategien.

Fragestellung: Die systematische Übersichtsarbeit soll klären, ob sich anhand der vorliegenden Studien eine eindeutige Empfehlung für die am besten geeigneten Antibiotika einschließlich der jeweils notwendigen Therapiedauer ableiten lässt.

Methoden: Die systematische Übersichtsarbeit basiert auf einer systematischen Literaturrecherche (November 2015) in den Datenbanken Medline, Embase und der Cochrane Library. Für Studien, die die Einschlusskriterien erfüllen, wurde das Biasrisiko anhand der Cochrane Methoden bewertet. Um den Therapieerfolg und unerwünschte Arzneimittelwirkungen (UAW) zwischen den verschiedenen Antibiotika (AB; in Abhängigkeit von Dosis und Behandlungsdauer) zu evaluieren, wurden Netzwerkmetaanalysen (NMA) durchgeführt. Abschließend erfolgte die Einschätzung der Qualität der Evidenz in Anlehnung an GRADE (Grading of Recommendations, Assessment, Development and Evaluation) für NMA.

Ergebnisse: Die systematische Übersichtsarbeit basiert auf 5 Studien: 4 RCTs, 1 quasi-RCT, die insgesamt 524 Kinder bzw. Jugendliche im Alter von 0,5 bis 14,5 Jahren behandelten. In den Studien kam entweder Amoxicillin (166 Pat., 3 Studien), Cefuroxim axetil (77 Pat., 2 Studien), Azithromycin (126 Pat., 2 Studien), Clarithromycin (66 Pat., 1 Studie) oder Penicillin V (89 Pat., 2 Studien) in unterschiedlicher Dosierung und Therapiedauer zur Anwendung.

Bzgl. des Therapieerfolgs (Response (definiert sowohl durch vollständige Abheilung des EM und grippeähnlicher Symptome als auch einer unvollständigen Abheilung von grippeähnlichen Krankheitssymptomen bei vollständiger Abheilung des EM) vs Non-Response (Persistenz oder Dissemination des EM oder Entwicklung von Spätmanifestationen der Lyme Borreliose) besteht kein statistisch signifikanter Unterschied zwischen den verschiedenen Antibiotika. Auch für den Therapieerfolg, definiert nur durch eine vollständige Abheilung aller berichteten Symptome als Response im Vergleich zu einem Non-Response (Persistenz oder Dissemination des EM, Entwicklung von Spätmanifestationen der Lyme Borreliose oder unvollständiger Abheilung grippeähnlicher Krankheitssymptome), zeigen sich keine signifikanten Unterschiede.

Hinsichtlich der UAW und einer Jarisch-Herxheimer-ähnlichen Reaktion zeigten sich keine signifikanten Unterschiede.

Die interne Qualität der identifizierten Evidenz ist mit einem mittleren bis hohem Biasrisiko behaftet. Geringe Fallzahlen führen bei manchen Vergleichen zu einer unzureichenden Präzision. Auch bestehen häufig Mängel hinsichtlich der Berichtsqualität. Publikationsbias konnte bisher nicht nachgewiesen werden.

Schlussfolgerung: Die detaillierten Ergebnisse werden in die geplante AWMF S3-LL Kutane Lyme Borreliose implementiert. 
ANT-P06

\section{Antibiotic stewardship auf der interdisziplinären}

Kinderintensivstation - Implementierung eines lokalen Antibiotikaleitfadens

C. Hülstrunk', K. Laabs', A. Nebgen', K. Bohn', C. Martin', R. Huth', T. Schwanz ${ }^{2}$, M. Dennebaum², S. Gehring ${ }^{1}$

'Universitätsmedizin Mainz, Zentrum für Kinder- und Jugendmedizin, Mainz, Deutschland, ${ }^{2}$ Universitätsmedizin Mainz, Institut für Medizinische Mikrobiologie und Hygiene, Mainz, Deutschland

Hintergrund: In den letzten Jahren wurden immer weniger Antibiotika neu zugelassen, dies führt bei anhaltend hohem Antibiotikaeinsatz insbesondere im stationären Bereich zu einer zunehmenden Resistenzentwicklung. Dies erfordert einen umsichtigen kontrollierten und angemessenen Einsatz von Antiinfektiva. Im Jahr 2010 wurde den EU-Mitgliedstaaten ein Überwachungssystem für die Verschreibung von Antibiotika empfohlen. AntiBiotic Stewardship (ABS) Programme sollen dies in Kombination mit Maßnahmen zur Infektionsprävention sicherstellen. Ziel ist eine Verbesserung der Behandlungsqualität, eine Vermeidung der Entwicklung von Resistenzen und sekundär eine Reduktion der gesamtwirtschaftlichen Kosten. Dieser Nutzen konnte in verschiedenen Studien belegt werden. Die AntiBiotic Stewardship Programme geben Empfehlungen zur Auswahl, Dosierung, Applikation und Anwendungsdauer der eingesetzten Antiinfektiva. Eine der ABS-Kernstrategien ist die Entwicklung und Etablierung lokaler Antibiotikaleitlinien für die kalkulierte Initialtherapie von Infektionserkrankungen. Diese sollen die lokalen Erreger - und Resistenzlage mitberücksichtigen.

Fragestellung: Mit der Einführung eines Leitfadens, der sich an dem lokalen Keim- und Resistenzspektrum orientiert, soll eine Verbesserung der antibiotischen Therapie entsprechend den Empfehlungen des AntiBiotic Stewardship erzielt werden.

Material und Methoden: Eine Arbeitsgruppe bestehend aus pädiatrischen Intensivmedizinern und Mikrobiologen der Universitätsmedizin Mainz legten anhand des lokalen Keim- und Resistenzspektrums für verschiedene intensivmedizinisch zu betreuende Erkrankungen (Sepsis, Herz, Unfälle, ZNS, Bauch und Lunge) kalkulierte antibiotische Therapien fest.

Ergebnisse: Die häufigsten Infektionserkrankungen wurden identifiziert und jeweils kalkulierte antibiotische Therapien festgelegt. Der Leitfaden beinhaltet u. a. Empfehlungen bezüglich möglicher notwendiger Spiegelkontrollen, alternative Behandlungsvorschläge und weitere generelle Empfehlungen zum Einsatz von Antiinfektiva, Therapiedauer, und Interaktionen. Wir legten die jeweilige durchzuführende Diagnostik (z.B. das Procedere der Abnahme von Blutkulturen) fest. Pharmakokinetische Überlegungen bzgl. der Applikationsdauer - und Intervalle fanden ebenfalls Berücksichtigung. Nach Implementierung des Leitfadens erfolgten regelmäßig mikrobiologische Visiten, um die Umsetzung der ABS-Maßnahmen zu validieren und die Qualität der Verordnungen kontinuierlich zu verbessern. Fortbildungen zur Schulung der ärztlichen Mitarbeiter fanden statt, um eine möglichst hohe Adhärenz zu gewährleisten.

Diskussion: Viele Abteilungen besitzen Leitfäden zur kalkulierten Antibiotikatherapie, die jedoch nicht an das lokale Keim- und Resistenzspektrum adaptiert sind. Kernstrategien des ABS werden in vielen Fällen nur teilweise erfüllt. In einem nächsten Schritt soll daher für die gesamte Kinderklinik ein entsprechender Leitfaden erarbeitet werden. Eine transsektorale kalkulierte antibiotische Therapie nach den Maßgaben des ABS ist anzustreben. Eine Analyse der Verbrauchsdaten, der Entwicklung von Resistenzen und der individuellen Behandlungsergebnisse vor und nach Einführung des Leitfadens liefert Informationen bzgl. der Umsetzung im klinischen Alltag. Die Ausbildung von weiteren ABS-Experten ist zur Erfüllung der Qualitätsziele des ABS unabdingbar.

\section{ANT-P07 \\ Validierung der empirischen Antibiotikatherapie bei hospitalisierten Kindern mit fieberhaftem Harnwegsinfekt an einer großen Bremer Kinderklinik}

U. Schulze-Sturm', P. Kaiser-Labusch², H. I. Huppertz ${ }^{2}$

${ }^{1}$ Universitätsklinikum Hamburg-Eppendorf, Klinik für Kinder- und Jugendmedizin, Hamburg, Deutschland, ${ }^{2}$ Klinikum Bremen-Mitte, ProfessorHess-Kinderklinik, Bremen, Deutschland

Hintergrund: Eine frühe und passende Antibiotikatherapie bei fieberhaften Harnwegsinfekten (HWI) reduziert Nierenparenchymschäden und ist bei septischen Verläufen lebensrettend. Lokale Daten zur Resistenzlage sind nötig, um die hauseigene empirische Therapie immer wieder zu überprüfen.

Fragestellung: Vergleich der Antibiotikaresistenzraten uropathogener Erreger bei hospitalisierten Kindern mit fieberhaften HWI aus 2 Studienphasen (Zeitraum A: 2007-2009, Zeitraum B: 2013-2015), vor und nach Umstellung der empirischen Therapie fieberhafter HWI von Cefotaxim auf Ampicillin+Gentamicin.

Material und Methoden: Anhand der ICD-10-Kodierungen wurden alle Akten aus den genannten Zeiträumen von stationär aufgenommenen Kindern und Jugendlichen (0-17 Jahre) mit fieberhaftem HWI analysiert. Patienten, von denen eine Urinkultur vorlag, die aus Katheterurin, Blasenpunktion, Mittelstrahl- oder „clean catch“-Urin angelegt wurde, wurden eingeschlossen. Daten zu Uropathologien, antibiotischen Vorbehandlungen/Metaphylaxen und zurückliegenden HWI wurden aufgenommen und verglichen.

Ergebnisse: 290 hospitalisierte Kinder (137 in Zeitraum A, 153 in Zeitraum B) mit einer Gesamtzahl von 308 Episoden fieberhafter HWI wurden eingeschlossen. E.coli war jeweils der häufigste Erreger, $(78,5 \% / 72,5 \%)$ gefolgt von Klebsiellenspezies (4,7\%/6,5\%) und Enterokokken (3,4\%/9,5\%). Die Resistenzrate gegenüber empirischer Therapie mit Cefotaxim betrug 16,8 \%/15,6\%; für Ampicilin+Gentamicin 7,4\%/1 \%. Resistenzraten waren höher bei antibiotisch vorbehandelten Kindern und bei Rezidiv-HWI mit und ohne Uropathologie. In Zeitraum B kam es bei mehr "clean catch“Proben zu mehr Mischkulturen. In 12 Fällen wurden die Erreger auch in der Blutkultur nachgewiesen, es gab keine Todesfälle.

Schlussfolgerung: Ampicillin+Gentamicin war unverändert die optimale empirische Therapie bei fieberhaften Harnwegsinfektionen hospitalisierter Kinder. Im Vergleich der beiden Beobachtungszeiträume gab es eine Abnahme der Antibiotika-Resistenzen. Dazu haben möglicherweise auch örtliche Maßnahmen von Antibiotic Stewardship und die hier vorgestellte Validierung der empirischen Therapie von fieberhaften HWI beigetragen.

\section{Antimykotika/Pilzinfektionen}

\section{MYK-P01}

Posaconazole delayed release tablets: Plasma exposures and safety in pediatric cancer patients

H. Herbrüggen', M. Ahlmann', O. Makarova', B. Fröhlich', S. München², H. Thorer' ${ }^{1}$ C. Müller ${ }^{3}$, A. Groll ${ }^{1}$

'University Children's Hospital Münster, Dept. of Pediatric Hematology and Oncology, Münster, Germany, ${ }^{2}$ University of Münster, Dept. of Pharmaceutical and Medical Chemistry, Münster, Germany, ${ }^{3}$ University Hospital Cologne, Dept. of Pharmacy, Cologne, Germany

Background: Posaconazole is a recommended option for antifungal prophylaxis in pediatric patients $>12$ years of age and approved for this indication in the United States. The novel delayed release tablet formulation has been shown to provide improved oral bioavailability in adults. Little is known, however, about the exposures following administration of the DR tablets in older children and adolescents.

Patients and methods. In a retrospective descriptive fashion, we analyzed trough concentrations at steady state of posaconazole in all pediatric 
patients who had received the delayed release tablet formulation between January 2015 and August 2016 for primary or secondary prophylaxis. Dosing was guided by an early population pharmacokinetic model (Neely \& Gentry, ICAAC 2015), and drug concentrations in plasma were measured by a validated HPLC method. Laboratory parameters of hepatic function while on treatment and the rate of drug discontinuations due to adverse effects were also assessed.

Results: 20 patients (16 m/4 f) with high-risk leukemia (7), recurrent leukemia (6), bone marrow failure (3), non-Hodgkin lymphoma (NHL) or relapsed NHL (2) central nervous system histiocytosis (1) and chronic granulomatous disease (1) of whom 11 were status post allogeneic HSCT were identified. The median age was 14.8 years ( $r, 5-18 ; 6<13$ years), and the median body weight was $49 \mathrm{~kg}(\mathrm{r}, 21-85)$. Posaconazole delayed release tablets were administered at the approved dosage in 16 and at a modified dose in 4 patients for a median duration of 40 days (r, 20-303). A total of 30 trough levels were obtained; 7 patients had at least 2 levels. The median trough plasma concentration was $1661+/-1459$ ug/L (r, 512-5701); through concentrations were above the dosing target of $700 \mathrm{ug} / \mathrm{l}$ in 28/30 occasions. Posaconazole was well-tolerated without AE- related discontinuations or signals of laboratory hepatic toxicity (baseline vs. end of therapy, mean +/-SD; serum bilirubin: $0.85+/-0.67$ vs $0.81+/-0.72 \mathrm{mg} / \mathrm{dL}$; SGOT: $66+/-81$ vs. $44+/-20 \mathrm{U} / \mathrm{L}$ ).

Conclusions: In this small case series, administration of posaconazole delayed-release tablet guided by a population-PK derived dosing algorithm resulted in predictable and potentially effective exposures and was well-tolerated over prolonged time periods.

\section{MYK-P02}

\section{Pulmonale Aspergillose bei einem immungesunden Kind}

\section{A. Avila', A. Polednia' ${ }^{2}$ S. Borte ${ }^{1,3}$, M. Zurek', M. Borte ${ }^{1,3}$}

${ }^{1}$ Klinikum St. Georg Leipzig gGmbH, Klinik für Kinder- und Jugendmedizin, Leipzig, Deutschland, ${ }^{2}$ Klinikum Sankt Georg Leipzig gGmbH, Klinik für Diagnostische und Interventionelle Radiologie, Leipzig, Deutschland, ${ }^{3}$ Klinikum Sankt Georg Leipzig gGmbH, ImmunDefektCentrum Leipzig, Leipzig, Deutschland

Hintergrund: Aspergillus spp. sind weltweit und ubiquitär verbreitet. Schätzungen gehen davon aus, dass der Mensch dutzende bis hunderte Aspergillus-Sporen pro Tag einatmet. Aspergillus spp. gehören zu den vorherrschenden Erregern invasiver Mykosen. Die invasive Aspergillose manifestiert sich am häufigsten in den Atemwegen und den Nebenhöhlen. Invasive Aspergillosen treten fast ausschließlich bei Patienten mit geschwächtem Immunsystem auf.

Kasuistik: Wir berichten über einen 10 Jahre alten Knaben, der sich mit Fieber, leichtem Husten und Abgeschlagenheit vorstellte und über leichte linksseitige Schmerzen bei tiefer Inspiration klagte. In der ambulanten Diagnostik (Röntgen-Thorax und CT) zeigten sich Hinweise auf eine Pneumonie sowie einen linksthorakalen Abszess. Die Zusammenschau dieser Befunde mit sonografischen Untersuchungen bei stationärer Aufnahme ergab den Verdacht auf ein Aspergillom, welcher sich bei positiver Aspergillus-Serologie und Antigen-Nachweis im Sputum bestätigte. Unter intravenöser Voriconazol-Therapie kam es zur vollständigen Regredienz. Die immunologische Diagnostik ergab keinen Hinweis auf eine Immundefekterkrankung oder auf eine allergisch-bronchopulmonale Aspergillose. Schlussfolgerung: Obwohl invasive Aspergillosen beinahe ausschließlich bei immungeschwächten Patienten oder Patienten mit pulmonalen Vorerkrankungen beschrieben sind, sollten sie differentialdiagnostisch bei immunkompetenten Patienten in Erwägung gezogen werden.

\section{MYK-P03}

\section{Schwere early-onset Candida-Sepsis bei 2 Frühgeborenen ohne vorausgegangenen Blasensprung}

E. Tsianaka, S. Dettmers, T. Lücke, N. Teig

Universitätskinderklinik Bochum, Neonatologie, Bochum, Deutschland
Hintergrund: Konnatale Pilzinfektionen sind selten und werden vorwiegend durch Candida albicans, seltener durch andere Candida spp. verursacht. Es handelt sich um aszendierende Infektionen begünstigt durch vorzeitigen Blasensprung, Cerclage oder vorangegangene antibiotische Therapie der Mutter. Hier berichten wir über zwei Fälle invasiver earlyonset Candida Infektionen bei extrem kleinen Frühgeborenen, denen jeweils kein Blasensprung vorausgegangen ist..

Fallberichte: Patient 1; Mutter in der 24+4 SSW wird stationär mit vaginaler Blutung und Muttermunderöffnung ohne Blasensprung aufgenommen. Es wurden eine antibiotische Therapie mit Ampicillin/Sulbactam und Metronidazol sowie eine i.v. Tokolyse eingeleitet. Bei ansteigenden Entzündungsparametern wurde die Tokolyse beendet und erfolgte eine einmalige Betamethasongabe. Aus dem Cervixabstrich wurden Klebsiellen und Enterococcus feacalis aber keine Pilze isoliert. Bei pathologischem CTG erfolgte eine Sectio caesarea.. Unmittelbar postnatal wurde beim Frühgeborenen (Gewicht $650 \mathrm{~g}$ ) mit einer antibiotischen Therapie mit Ampicillin und Gentamycin bei erhöhtem CRP begonnen. Nach 12 Stunden erfolgte eine endotracheale Intubation bei respiratorischer Erschöpfung. Sonographisch ließ sich eine IVH III links nachweisen. 20 Stunden nach Geburt entwickelte sich ein foudroyanter Schock, sodass die antibiotische Therapie auf Meropenem und Vancomycin umgestellt wurde, und mit Fluconazol eskaliert wurde. Trotz maximaler Katecholamintherapie sowie Volumengabe verstarb das Neugeborene am Multiorganversagen. In 2 Blutkulturen wurde C. albicans nachgewiesen. Im Placenta-Abstrich wurde Candida albicans nachgewiesen, in der Plazenta-Histologie zeigte sich eine floride Chorioamnionitis mit Funisitis.

Patient 2: Frühgeborenes $23+3$ SSW (Geburtsgewicht $550 \mathrm{~g}$ ). Beim Fruchtblasenprolaps in der 21. SSW wurden eine Notfall-Cerclage und eine intravenöse Tokolyse durchgeführt und eine antibiotische Therapie mit Ampicillin und Meropenem eingeleitet. Mikrobiologisch wurden aus dem Cervixabstrich Enterokokken, koagulase-negative Staphylokokken und Candida glabrata isoliert. Es kam zu einem Spontanpartus bei vorzeitigen Wehen in intakter Fruchtblase. Unmittelbar postnatal wurde die antibiotische Therapie mit Ampicillin und Gentamycin sowie Fluconazol in prophylaktischer Dosis eingeleitet. Am 3. Lebenstag entwickelte sich ein septischer Schock. Bei Nachweis von Staph.haemolyticus in der Blutkultur wurde die Therapie auf Meropenem und Vancomycin umgestellt. Im Plazentaabstrich wurde Staph. xylosus und Corynebakterium tuberculostearicum nachgewiesen. Im Abdomenabstrich, im Nasenabstrich und in den Blutkulturen im Verlauf wurde Candida glabrata nachgewiesen. Unter umfassender antimykotischer Therapie wurden die Blutkultur erst am 9. Behandlungstag steril. Das Kind verstarb im Rahmen einer begleitenden Herzfehlbildung am 30. Lebenstag.

Schlussfolgerung: Early-onst-Infektionen mit Candida müssen bei sehr unreifen Frühgeborenen, die im Rahmen einer Chorioamnionitis geboren werden, auch dann in Betracht gezogen werden, wenn kein vorzeitiger Blasensprung bestanden hat und an der Cervix keine Candida spp nachweisbar sind, Es stellt sich die Frage, ob eine pränatale antimykotische Therapie die Schwangerschaften hätten verlängern und den Verlauf bei unseren beschrieben Patienten hätte abmilldern können.

\section{MYK-P04}

Micafungin Therapie bei invasiver Candida-Infektion von extrem unreifen Frühgeborenen - ein 5 -jähriger Erfahrungsbericht einer tertiären Neugeborenenstation

\section{S. Schüller, C. Bauer, L. Unterasinger, A. Berger}

Medizinische Universität Wien, Abteilung für Neonatologie, Pädiatrische Intensivmedizin und Neuropädiatrie, Wien, Österreich

Hintergrund: Die Inzidenz von invasiven Candida-Infektionen (ICI) bei extrem kleinen Frühgeborenen $(<1,000 \mathrm{~g})$ schwankt zentrumsabhängig zwischen ein und neun Prozent. Die Morbiditäts- und Mortalitätszahlen bei ICI sind hoch, weshalb eine schnelle Diagnose sowie der prompte Behandlungsbeginn entscheidend für die Prognose sind. Micafungin, ein Echinocandin, findet in der Behandlung von ICIs aufgrund seines günsti- 
gen Nebenwirkungsprofils zunehmend Anwendung, obwohl die Datenlage bei extrem kleinen Frühgeborenen noch unzureichend ist.

Fragestellung: Die vorliegende Studie untersucht Wirksamkeit und $\mathrm{Ne}-$ benwirkungen von Micafungin bei extrem kleinen Frühgeborenen, um die Therapie von extrem kleinen Frühgeborenen bei ICI weiter zu verbessern. Material und Methoden: In einer retrospektiven monozentrischen Studie wurde zwischen 2012 und 2016 bei 19 extrem kleinen Frühgeborene mit bestätigter oder suszipierter ICI, welche $\geq 3$ Tage mit Micafungin behandelt wurden, die Nebenwirkungen und Wirksamkeit von Micafungin analysiert.

Ergebnisse: Unter einer mittleren Tagesdosis von 7,5 $\pm 2,0 \mathrm{mg} / \mathrm{kg}$ (jeweils $\mathrm{MW} \pm \mathrm{SD}$ ) und einer mittleren Therapiedauer von $16,6 \pm 7,9$ Therapietagen lag die kumulative Dosis von Micafungin bei 21,2 $\pm 13,7 \mathrm{mg} / \mathrm{kg}$ Körpergewicht. 9,760 Laborwerte wurden für die Studie analysiert. Unter Micafungin-Therapie wurde ein signifikanter Anstieg der Leberenzymen AspartatAminotransaminase (AST) und Alanin-Aminotransaminase (ALT) sowie des konjugierten Bilirubin-Wertes beobachtet. Die Werte von Alkalischer Phosphatase, Gamma-Glutamyltransferase und der Retentionsparameter Kreatinin und Harnstoff sowie der gemessenen Elektrolyte zeigten hingegen keine signifikanten Änderungen unter einer Therapie mit Micafungin. Bei keinem Patienten wurde die Therapie mit Micafungin aufgrund von Nebenwirkungen beendet, es wurde kein Fall von Therapieversagen beobachtet.

Schlussfolgerung: Micafungin führt bei extrem kleinen Frühgeborenen zu einem transienten Anstieg von AST-, ALT- und Bilirubin-Werten. Vor dem Hintergrund möglicher weiterer Einflussfaktoren (nekrotisierende Enterokolitis, parenteraler Ernährung, Verabreichung anderer hepatotoxischer Medikamente) in dieser Patientengruppe wird eine engmaschige Kontrolle der Leberenzyme und Cholestaseparameter unter Micafungin Therapie empfohlen.

\section{MYK-P05}

Empirische antimykotische Therapie von VLBWI Frühgeborenen und assoziiertes Outcome - Daten des Deutschen Frühgeborenennetzwerks

\section{I. Fortmann}

UKSH Lübeck, Klinik für Kinder und Jugendmedizin, Lübeck, Deutschland

Hintergrund: Das Ziel unserer Studie war es, die Rate an empirisch antimykotisch behandelten Kindern in einer großen Kohorte von sehr kleinen Frühgeborenen (Very Low Birth Weight Infants, VLBWI) des Deutschen Frühgeborenennetzwerkes (German Neonatal Network, GNN) zu bestimmen und assoziierte Risikofaktoren und Outcomes zu ermitteln.

Methoden: Der epidemiologische Datensatz bestand aus $n=13,343$ VLBW Frühgeborenen, die zwischen 2009 und 2015 in den 54 Zentren des GNN geboren wurden. Definiert wurde antimykotische Therapie als unter dem klinischen Verdacht auf eine Pilzinfektion begonnene intravenöse Behandlung mit mindestens einem der folgenden Medikamente: Fluconazol, Amphotericin B, Voriconazol und Caspofungin (Denomination: Anzahl der im GNN eingeschlossenen Kinder). Wir verwendeten univariate Analysen und binomiale logistische Regressionen, um Risikofaktoren einer antimykotischen Behandlung zu ermitteln sowie mit der Therapie assoziierte Komplikationen und Langzeitmorbiditäten (5-Jahres-Nachuntersuchungen) zu bestimmen. Ergebnisse: Die Rate an antimykotisch behandelten Kindern in unserer Kohorte betrug 5,4\% (724/13,343 VLBWI), während bei 0,3 \% (44/13,343 VLBWI) eine systemische Infektion mit Candida spp. nachgewiesen wurde. Die wichtigsten Risikofaktoren für eine antimykotische Behandlung waren niedriges Gestationsalter, zentralvenöse Katheter, abdominelle Operationen und Therapien mittels Reserveantibiotika. Die Exposition gegenüber Antimykotika war dabei mit ungünstigen Outcomes, wie z.B. mit Bronchopulmonaler Dysplasie (BPD) assoziiert (adjustierte OR 2,3, $95 \%$ CI 1,9-2,7, $p<0,001)$. In der Subkohorte von Kindern, die im Alter von fünf Jahren bereits nachuntersucht wurden $(n=895)$, zeigte sich weiterhin ein mit einer antimykotischen Therapie assoziiertes Risiko für einen IQ $<85$ (für Gestationsalter, SGA und IVH adjustierte OR 2,2, 95\% CI 1,1$4,5, p=0,02)$, was tendenziell ebenfalls für Cerebralparese (CP; adjustierte
OR 2,3, $95 \%$ CI 0,95-4,7, $p=0,06$ ) und für das kombinierte Outcome aus IQ < 85, CP, Blindheit und/oder Hörgerätversorgung beobachtet wurde (adjustierte OR 1,8, $95 \%$ CI 0,9-3,7, $p=0,09$ ).

Schlussfolgerung: Ein nicht unerheblicher Anteil VLBWI wird antimykotisch behandelt, insbesondere Kinder mit einem Gestationsalter $<26$ Wochen. Exponierte Kinder haben ein erhöhtes Risiko für ungünstige Outcomes. Allerdings bleibt ungeklärt, in welchem Maße potentielle Nebenwirkungen einer antimykotischen Therapie selbst zur Langzeitmorbidität beitragen. Weitere Studien werden benötigt, um mittels risikobasierter Behandlungsstrategien und mit Hilfe von Stewardship Programmen die Anwendung antimykotischer Medikamente bei Frühgeborenen zu limitieren.

\section{Atemwegsinfektionen}

\section{ATEM-P01}

Ribavirin als Therapie bei Respiratory Syncytial Virus Infektionen bei Kindern nach Leber- und/oder Darmtransplantationen Auswertung der Jahre 2011-2014

J. Armann', S. Wollersheim², K. Khan ${ }^{2,3}$

'Universitätsklinikum Carl Gustav Carus, Klinik und Poliklinik für Kinder und Jugendmedizin, Dresden, Deutschland, ${ }^{2}$ Georgetown University Medical Center, Infektiologie, Washington, DC, USA, ${ }^{3}$ Georgetown University Medical Center, Transplantationsintitut, Washington, DC, USA

Hintergrund: Respiratory Syncytial Virus (RSV) ist einer der häufigsten Erreger für Erkrankungen der unteren Atemwege im Kindesalter. Die Therapie ist symptomatisch und besteht aus Flüssigkeitszufuhr, Sauerstoffgaben und Sekretmobilisation. Als kausale antivirale Therapie steht Ribavirin zur Verfügung, welches in vitro eine virostatische Wirkung zeigt. In klinischen Studien konnte allerdings kein eindeutig günstiger Effekt nachgewiesen werden, so dass die Anwendung nicht empfohlen wird. Immunkomprimierte Patienten haben häufiger schwere Verläufe einer RSV Infektion und eine erhöhte Letalität im Vergleich zur Normalbevölkerung. Eine Ribavirin-Therapie ist für Patienten nach Lungen- oder Stammzelltransplantation beschrieben. Allerdings gibt es bisher keine Daten für die Effektivität einer Ribavirin-Therapie für Kinder nach Leber- und/oder Darmtransplantation.

Methoden: Es erfolgte eine retrospektive Analyse einer Ribavirin-Therapie in pädiatrischen Patienten mit Organtransplantation. Dafür wurden die Krankenakten aller Patienten der Transplantationseinheit des Georgetown University Medical Center (Washington, DC) mit einem positivem RSV Antigen oder PCR Test zwischen Oktober 2011 und April 2014 untersucht. Patientencharakteristika, Gebrauch und Dosis von Ribavirin, immunsuppresive Therapie, Ko-Infektionen, klinische und paraklinische Veränderungen wurden analysiert ().

Ergebnisse: 15 Patienten mit RSV Nachweis wurden insgesamt 18-mal mit Ribavirin behandelt. 8 Patienten mit RSV Nachweis erhielten keine Therapie mit Ribavirin. Die Ribavirindosis lag zwischen $15-20 \mathrm{mg} / \mathrm{kg} / \mathrm{Tag}$ und die Behandlung wurde für 5-14 Tage durchgeführt. Die Behandlung musste in einem Fall aufgrund einer Panzytopenie abgebrochen werden. Im Hinblick auf die Notwendigkeit einer Aufnahme auf die Intensivstation, Sauerstoffbedarf oder Notwendigkeit einer maschinellen Beatmung zeigten sich keine signifikanten Unterschiede. 1 Patient in jeder Gruppe erhielt eine Prophylaxe mit Palivizumab in der entsprechenden Saison. Schlussfolgerung: Die Ribavirin-Therapie wurde im Allgemeinen von den Patienten gut vertragen. Allerdings zeigte sich auch in der untersuchten Population kein günstiger Effekt. Eine Ausweitung der RSV-Prophylaxe mit Palivizumab auf diese Patienten ist zu diskutieren. 


\section{ATEM-P02 \\ Die schwere akute virale Bronchiolitis: Vergleich zweier Regionen mit unterschiedlicher Versorgung}

C. Dohna-Schwake', K. Mücher', D. Phillipe ${ }^{2}$, T. Rothoeft', C. Roll' ${ }^{4}$, F. Stehling ${ }^{5}$, A. Stein ${ }^{6}$, A. Jacobs ${ }^{7}$, D. Essing ${ }^{8}$, F. Brevis Nunez ${ }^{9}$, P. Seifert ${ }^{10}$, P. Heister ${ }^{17}$, M. Hofmann ${ }^{12}$, T. Zuzak ${ }^{13}$, U. Felderhoff-Müser ${ }^{6}$, P. Tissières ${ }^{2}$

${ }^{1}$ Kinderklinik I, Pädiatrische Intensivmedizin, Essen, Deutschland, ${ }^{2}$ Université Paris Sud, Service de Réanimation Pédiatrique et Médecine Néonatale, Le Kremlin-Bicêtre, France, ${ }^{3}$ Universitäts-Klinikum, Kinderklinik, Bochum, Deutschland, ${ }^{4}$ Vestische Kinderklinik, Abteilung für Neonatologie und Pädiatrische Intensivmedizin, Datteln, Deutschland, ${ }^{5}$ Kinderklinik III, Pädiatrische Pneumologie, Essen, Deutschland, ${ }^{6}$ Kinderklinik I, Neonatologie, Essen, Deutschland, ${ }^{7}$ Marien-Hospital, Kinderklinik, Wesel, Deutschland, ${ }^{8}$ Marienhospital, Kinderklinik, Gelsenkirchen, Deutschland, ${ }^{9}$ Sana-Klinikum, Kinderklinik, Duisburg, Deutschland, ${ }^{10} \mathrm{Helios}-K$ linikum, Kinderklinik, Duisburg, Deutschland, ${ }^{11}$ Helios-klinikum, Kinderklinik, Krefeld, Deutschland, ${ }^{12}$ Städtisches Klinikum, Kinderklinik, Dortmund, Deutschland, ${ }^{13}$ Gemeinschaftskrankenhaus, Kinderklinik, Herdecke, Deutschland

Hintergrund: Die akute virale Bronchiolitis ist einer der häufigsten Gründe für Hospitalisationen im Säuglingsalter. Das Ziel der vorliegenden Studie war der Vergleich einer zentralisierten mit einer dezentralisierten Versorgung von schwerer kranken Patienten.

Methoden: Retrospektive Auswertung der Daten von November 2015 bis April 2016 stationär aufgenommenen Säuglingen mit akuter viraler Bronchiolitis, die eine Atemwegs-Unterstützung mit High Flow Nasal Canula (HFNC), nasalem CPAP (Continuous Positive Airway Pressure), NIV (Nicht-Invasive Beatmung) oder invasive Beatmung erhielten. Verglichen wurde die zentralisierte Versorgung auf einer Intensivstation im Süden der Region Großraum Paris (Gruppe 1) mit der von 10 Krankenhäusern im Ruhrgebiet (Gruppe 2). Das primäre Zielkriterium war die Anzahl der Tage mit Atemwegs-Unterstützung.

Ergebnisse: Säuglinge in Gruppe $1(n=96)$ waren jünger, hatten seltener neurologische Grunderkrankungen und hatten niedrigere Atemfrequenzen als diejenigen in Gruppe $2(n=50)$. Atemarbeit und CO2-Werte sowie der Anteil an RSV unterschieden sich nicht. Patienten in Gruppe 1 wurden in $90 \%$ mit nasalem CPAP behandelt; Patienten in Gruppe 2 hingegen in $80 \%$ mit HFNC. Die Dauer der Atemunterstützung war signifikant kürzer in Gruppe 1: 3,6 2,6 versus 7,6 $\pm 9,7$ Tage; $p<0,01$. Dieses Ergebnis blieb so bestehen, auch nach Adjustierung für zugrundeliegende Herz-, Lungenoder neurologische Erkrankungen. Säuglinge der Gruppe 2 erhielten häufiger Infusionen ( $84 \%$ versus $4 \%$ ), häufiger Inhalationen ( $88 \%$ versus $3 \%$ ) und häufiger Antibiotika (56\% versus $10 \%$; alle $p<0,01$ ).

Schlussfolgerung: Säuglinge mit schwerer akuter viraler Bronchiolitis erhielten in Frankreich bei zentralisierter Versorgung für kürzere Zeit Atemunterstützung und weniger medikamentöse Therapie als in Deutschland mit dezentralisierter Versorgung. Diese Daten können dazu anregen, Therapie-Regime zu überdenken wie den häufigeren Einsatz von nasalem CPAP statt HFNC sowie den Verzicht auf symptomatische Therapien wie Infusionen und Inhalationen. Auch die Rolle der antibiotischen Therapie sollte kritisch hinterfragt werden.

\section{ATEM-P03 \\ Ausbreitung und Schweregrad des neuen RSV-A Genotypen (ON1) In Kinderarztpraxen und Kinderkliniken in Bayern, 2010-2016}

\section{Lehmann', A. Streng', C. Krempl', C. Prifert², B. Weißbrich', J. Liese'}

${ }^{1}$ Kinderklinik und Poliklinik Würzburg, Infektionsepidemiologie, Würzburg, Deutschland, ${ }^{2}$ Institut für Virologie und Immunbiologie, Universität Würzburg, Würzburg, Deutschland

Hintergrund: 2010 wurde in Ontario (Kanada) erstmalig ein neuer Genotyp ON1 des Respiratorischen Syncytial Virus (RSV) entdeckt, der ab 2012 auch in Deutschland nachgewiesen wurde. Für RSV-A ON1 wurde ein schwererer Krankheitsverlauf vermutet (Prifert et al., Emerging Infectious Diseases 2013).
Fragestellung: Wie rasch breitet sich RSV-A ON1 in den Jahren nach seinem ersten Auftreten aus, und führt dieser neue Genotyp bei Kindern zu schwereren Erkrankungen als die bisher zirkulierenden RSV Sub- oder Genotypen?

Material und Methoden: Im Zeitraum 2010 bis 2016 wurden in Bayern klinische Daten von Kindern mit PCR-bestätigter RSV-Infektion erfasst, die wegen der RSV-Erkrankung in Kinderarztpraxen (KAP), stationär (KKL) oder intensivstationär (KITS) behandelt wurden. Die jeweilige Verteilung der Sub-/Genotypen wurde bestimmt. Innerhalb der Behandlungseinrichtungen wurden klinische Daten (u. a. Behandlungsdauer, Komplikationsrate, Outcome) von Kindern mit RSV-A ON1 innerhalb jedes Settings mit anderen RSV-Erkrankungen verglichen.

Ergebnisse: Insgesamt wurden 116 Kindern aus KAP (50\% RSV-A ON1, $10 \%$ andere RSV-A Genotypen, $40 \%$ RSV-B), 142 Kinder aus der KKL (56\% RSV-A ON1, 18\% andere RSV-A Genotypen, 27\% RSV-B) und 138 Kinder von KITS (23\% RSV-A ON1, 39\% andere RSV-A Genotypen, $38 \%$ RSV-B) in die Datenanalyse eingeschlossen. der Anteil von RSV-A ON1 an allen RSV-A Genotypen nahm in KAP von $88 \%$ bis $83 \%$ (2012/13 bis 2014/15) ab, in KKL von $13 \%$ bis $100 \%$ (2011/12 bis 2014/15) zu und in KITS von $24 \%$ bis $100 \%$ (Saison 2011/12 bis 2013/14) zu. Der noch 2011/12 dominierende Genotyp RSV-A GA2 wurde seit der Saison 2013/14 nicht mehr nachgewiesen.

Bei den KAP-Kindern gab es hinsichtlich demografischer und klinischer Charakteristika keine signifikanten Unterschiede von RSV-A ON1 zu anderen RSV-Genotypen (z. B. ON1 vs. andere RSV: mediane Erkrankungsdauer 11 Tage; $p$-Wert: 0,940; chronische Vorerkrankungen $12 \%$ vs. $19 \%$; $p$-Wert: 0,305). Bei den KKL Kindern gab es ebenfalls keine signifikanten Unterschiede (z. B. mediane Krankenhausaufenthaltsdauer 3 vs. 4 Tage; $p$ Wert: 0,200; chronischen Vorerkrankungen $38 \%$ vs. $35 \%$; $p$-Wert: 0,761). Auch bei KITS Kindern unterschied sich die mediane Krankenhausaufenthaltsdauer nicht ( 7 vs. 7 Tage, $p=0,266$ ). Jedoch war der Anteil der Frühgeborenen bei KITS Kinder mit RSV A ON1 (38\%) grösser als bei Kindern mit anderen RSV Genotypen (21\% p-Wert 0,054).

Beim Vergleich zwischen den Behandlungseinrichtungen (88 Kinder mit RSV-A ON1, 59 Kinder mit anderen RSV-Erkrankungen) war der Anteil von ON1 bei KKL Kindern höher $(n=40,71 \%)$ als bei KAP Kindern $(n=48 ; 53 \% ; p=0,025)$. Eine binär logistische Regression zur Assoziation von RSV-A ON1 mit einer stationären Aufnahme ergab nach Adjustierung für Grunderkrankungen eine OR von 2,14 ( $p=0,053)$.

Schlussfolgerung: Innerhalb von zwei Saisons hat der neue RSV-A Genotyp ON1 den vorhergehenden Genotyp GA2 ersetzt. RSV-A ON1 wurde besonders in der Saison 2012/13 bei hospitalisierten Kindern häufiger nachgewiesen. Dies deutet auf einen zumindest initial höheren Schweregrad hin, der mit Zunahme der Zirkulation abgenommen hat.

\section{ATEM-P04 \\ Therapeutisches Management bei 994 Kindern mit parapneumonischen Pleuraergüssen (PPE) und Pleuraempyemen (PE) im Kindesalter - ESPED-Studie 2010-2015}

D. Kemmling ', F. Segerer', A. Streng' ', M. Rose', L. Lehmann', J. Liese'

'Kinderklinik und Poliklinik, Universitätsklinikum Würzburg, Infektionsepidemiologie, Würzburg, Deutschland, ${ }^{2}$ Klinikum St. Georg Leipzig, Klinik für Kinder- und Jugendmedizin, Leipzig, Deutschland

Hintergrund: Die Behandlung des PPE und die Entscheidung für ein konservatives und/oder operatives Management bleibt Gegenstand kontroverser Diskussion.

Methoden: Prospektive, deutschlandweite Surveillancestudie von 10/2010 bis 06/2015 an Kindern < 18 Jahren mit Pneumonie und drainagepflichtigem oder $>7$ Tage persistierendem PPE/PE mittels der Erhebungseinheit für seltene pädiatrische Erkrankungen in Deutschland“ (ESPED). Klinische, diagnostische und therapeutische Daten sowie Outcome wurden erhoben und die Patienten anhand der invasivsten Initialtherapie (innerhalb 3 Tagen nach Diagnosestellung) in 5 Gruppen eingeteilt: nicht-invasive Therapie (NIT), Pleurapunktion (PKT), Pleuradrainage (PD), intrapleu- 
rale Fibrinolyse (FIB) sowie die operativen Maßnahmen videoassistierte Thorakoskopie (VATS) und offene Thorakotomie (TT).

Ergebnisse: Insgesamt wurden 994 Kinder mit PPE/PE eingeschlossen (504 (50,7\%) männlich). Der Altersmedian lag bei 4 Jahren (IQR 3-9), die mediane Hospitalisationsdauer bei 17 Tagen (IQR 13-24) und bei 16 Tagen (IQR 12-23) ab dem Zeitpunkt der Diagnosestellung. 610 (61,4\%) Kinder wurden intensivstationär betreut (mediane Dauer 7 Tage (IQR 3-14)). 179 (18,0\%) Patienten hatten mögliche (158) oder gesicherte (21) Folgeschäden. $11(1,1 \%)$ Kinder sind verstorben.

Insgesamt wurden 205 (20,6\% von 994) Patienten ausschließlich durch eine nicht-invasive Therapie (NIT) und $789(79,4 \%)$ mit invasiver Therapie (IT; Eröffnung des Pleuraraumes) behandelt: PKT 499 (50,2\%); PD 692 (69,6\%); FIB 243 (24,4\%); VATS 197 (19,8\%); TT 89 (9,0\%). Als initiale Therapie innerhalb 3 Tagen nach Diagnosestellung erfolgte eine NIT bei 456 ( $45,9 \%$ von 994$)$ und eine IT bei 538 ( $54,1 \%$ von 994$)$ Kindern: PKT 94 (17,5\% von 538); PD 235 (43,7\% von 538); FIB 147 (27,3\% von 538); VATS/TT 62 (11,5\% von 538).

Unter den Patienten mit einer invasiven Initialtherapie ergaben sich keine Unterschiede bzgl. der Hospitalisationsdauer nach Diagnosestellung (PKT 16 Tage (IQR 12-26); PD 17 Tage (IQR 12-25); FIB 17 Tage (IQR13-24); VATS/TT 17 Tage (IQR 13-26); $p=0,782$ ) und der Dauer der Intensivbehandlung (PKT 8 Tage (IQR 2-20); PD 7 Tage (IQR 3-16); FIB 8 Tage (IQR 5-14); VATS/TT 8 Tage (IQR 4-15); $p=0,775$ ). Die Rate an Intensivaufenthalten zeigte einen Anstieg mit zunehmender Invasivität der Therapie (PKT 55,3\%; PD 81,3\%; FIB 79,6\%; VATS/TT 93,5\%; $p<0,001$ ). Die Rate an Folgeschäden ergab keine signifikanten Unterschiede zwischen Kindern mit invasiver Initialtherapie (PKT 21,3\%; PD 19,6\%; FIB 18,4\%; VATS/TT 29,0 \%; $p=0,349$ ). Auch nach Stratifizierung der PPE/PE nach sonographischen Stadien zeigten sich keine Unterschiede bzgl. der Aufenthaltsdauer zwischen den invasiven Therapiemaßnahmen.

Diskussion: Die vorliegende retrospektive Studie zeigt anhand einer großen Zahl eingeschlossener Kinder mit PPE/PE keine Unterschiede zwischen den verschiedenen invasiven initialen Maßnahmen hinsichtlich der Krankheitsdauer und Komplikationen. Solange keine prospektiven, randomisierten Studien vorliegen, sollten die relativ häufig initial angewendeten Maßnahmen wie FIB, VATS und TT für Kinder reserviert bleiben, die auf eine initiale nicht-invasive Therapie bzw. eine initiale Behandlung mit Pleurapunktion oder Pleuradrainage allein nicht ausreichend ansprechen.

\section{ATEM-P05}

Erhöhtes Procalcitonin bei Kindern und Adoleszenten mit akutem Leberversagen durch Paracetamolintoxikation

K. Alfen', E. Tschiedel', R. Assert'², S. Kathemann ${ }^{3}$, P. Hoyer', U. FelderhoffMüser', C. Dohna-Schwake

'Uniklinikum Essen, Klinik für Kinderheilkunde I, Essen, Deutschland, ${ }^{2}$ Uniklinikum Essen, Zentrallabor, Essen, Deutschland, ${ }^{3}$ Uniklinikum Essen, Klinik für Kinderheilkunde II, Essen, Deutschland

Hintergrund: Das Procalcitonin dient v.a. als Biomarker zur Unterscheidung zwischen einer bakteriellen Infektionen und einer systemischen Inflammationen anderer Genese. Bei Patienten mit Leberzellschädigung durch Paracetamolintoxikation fiel ein deutlich erhöhter Procalcitoninwert auf ohne dass eine bakterielle Infektion vorlag.

Fragestellung: Findet sich die Erhöhung des Procalcitoninwertes konstant bei Patienten mit Leberzellschaden durch Paracetamolintoxikation und wie verhält sich der Procalcitoninwert dazu im Vergleich bei Patienten mit akutem Leberversagen durch eine andere Genese?

Methode: Retrospektiv wurden die Procalcitoninwerte von Patienten unserer Klinik, die zwischen 2009 und 2016 mit Leberzellschaden durch Paracetamolintoxikation behandelt wurden, untersucht. Verglichen wurden die Ergebnisse mit denen von Kindern im akuten Leberversagen anderer Genese ohne Infektion.

Ergebnisse: Verglichen wurden 12 Patienten mit akutem Leberzellschaden durch Paracetamolintoxikation mit 29 Patienten mit akutem Leberversagen anderer Genese. Die Gruppe der Kinder mit Paracetamolintoxikation zeigte deutlich höhere Procalcitoninwerte, als die Gruppe der Kinder mit akutem Leberversagen anderer Genese (Median: 23,7+/- 17,3 ng/ml vs. $4,3+/-8,7 \mathrm{ng} / \mathrm{ml}$ ), obwohl sie eine bessere Leber- und Nierenfunktion (gemessen am INR und Serum-Kreatinin-Wert)vorweisen konnten. Der Leberzellschaden (gemessen an Alanin Aminotransferase (ALT), Aspartat Aminotransferase (AST) und Laktatdehydrogenase (LDH)) war in beiden Gruppen ähnlich. Analysiert man das Outcome, gemessen an dem Überleben ohne Lebertransplantation, zeigte sich ein etwas besseres Outcome in der Paracetamolintoxikation- Gruppe (10/12 vs. 15/29). Bei beiden Gruppen korrelierte das Procalcitonin signifikant mit ALT und AST, jedoch nicht mit dem INR und dem Paracetamol- Spiegel im Blut.

Diskussion: Bei Leberzellschaden durch Paracetamolintoxikation kommt es im Vergleich zum akuten Leberversagen anderer Genese zu einem signifikant höheren Anstieg des Procalcitoninwertes. Der zugrundeliegende Mechanismus kann weder durch eine Infektion noch alleine durch den Leberzellzerfall erklärt werden. Es bedarf weiterer prospektiver Studien zu diesem Thema, um die Beziehungen von Paracetamol zum Procalcitonin zu untersuchen.

\section{Literatur}

1. Rey C, Arcos ML, Concha A et al (2007) Procalcitonin and C-reactive protein as markers of systemic inflammatory response syndrome severity in critically ill children. Intensive Care Med 33:477-484

2. Cies JJ, Chopra A (2014) Procalcitonin use in a pediatric intensive care unit. Pediatr Infect Dis J 33:984-986

3. Zant R, Melter M, Knoppke B, Ameres M, Kunkel J (2014) Kinetics of interleukin-6, procalcitonin, and C-reactive protein after pediatric liver transplantation. Transplant Proc 46:3507-3510

4. Rule JA, Hynan LS, Attar N, Sanders C, Corzun WJ, Lee WM (2015) Acute liver failure study group. Procalcitonin Identifies Cell Injury, Not Bacterial Infection, in Acute Liver Failure. PLOS ONE 10:e0138566

5. Jackson N, Batouche S, Shrewood R, Wendon J (2000) Serial plasma procalcitonin levels in patients requiring admission to liver ICU with paracetamol induced acute liver failure. Br J Anesthesia 84:692

6. Szabo G, Petrasek J (2015) Inflammasome activation and function in liver disease. Nat Rev Gastroenterol Hepatol 12:387-400

\section{Epidemiologie}

\section{EPI-P01}

\section{Molecular epidemiology of Staphylococcus aureus from} Lambaréné, Gabon

K. V. Okuda ', N. Toepfner', A. S. Alabi ${ }^{2,3}$, B. Arnold', S. Bélard ${ }^{2,4}$, U. Falke', L. Menschner', S. Monecke ${ }^{5,6}$, A. Ruppelt-Lorz ${ }^{6}$, R. Ehricht ${ }^{5}$, P. Slickers ${ }^{5}$, F. Schaumburg ${ }^{7}$, R. Berner ${ }^{7}$

${ }^{1}$ Technische Universität Dresden, Klinik und Poliklinik für Kinder- und Jugendmedizin, Universitätsklinikum Carl Gustav Carus, Dresden, Deutschland, ${ }^{2}$ Deutsches Zentrum für Infektionsforschung, Tübingen, Deutschland, ${ }^{3}$ Centre de Recherches Médicales de Lambaréné (CERMEL), Lambarene, Gabun, ${ }^{4}$ Charité-Universitätsmedizin Berlin, Berlin, Deutschland, ${ }^{5}$ Alere technologies $\mathrm{GmbH}$, Jena, Deutschland, ${ }^{6}$ Technische Universität Dresden, Institut für Medizinische Mikrobiologie und Hygiene, Dresden, Deutschland, ${ }^{7}$ Universitätsklinikum Münster, Institut für Medizinische Mikrobiologie, Münster, Deutschland

Background: While there is an abundance of data on epidemiology and molecular typing of Staphylococcus aureus especially those carrying PVL genes or mecA from Europe, Northern America and Australia, comparably few studies target African strains.

Methods: We genotyped by microarray hybridisation S. aureus isolated from healthy carriers and outpatients from Lambaréné, Gabon. In total, 103 isolates from 96 study participants were characterised (EJCMID, 2016).

Results: Three isolates carried mecA. However, only a CC8-MRSA-IV [ACME/PVL+] USA300 was found to be phenotypically oxacillin-resistant while two CC88-MRSA-IV isolates appeared to be oxacillin-susceptible. PVL genes were common, being detected in 44 isolates (43\%). 
CC15-MSSA [PVL+] $(n=29)$ and CC152-MSSA [PVL +$](n=9)$ were the predominant clones among the PVL-positives. Among PVL negative isolates, CC5-MSSA $(n=12)$, CC101-MSSA $(n=10)$ and CC15 $(n=9)$ were most frequent. Staphylococcus schweitzeri was detected twice, in two unrelated children. These isolates were subjected to genome sequencing. Both isolates were identical to each other. Both yielded S. schweitzeri-like MLST profiles (206-307-304-142-195-235-193) and harboured several genes or gene clusters that can also be observed in S. aureus such as seh, egc-genes, edinB, cna and sas $G$. They closely resembled known $S$. schweitze$r i$ genomes. However, they were not identical to those suggesting that $S$. schweitzeri could - as S. aureus - be split into distinguishable clonal lineages.

Conclusions: These observations emphasise a need for further studies on the role of S. aureus and S. schweitzeri in African populations, on the phylogenetic position of $S$. schweitzeri as well as on the possibility of horizontal gene transfer between these two staphylococcal species.

\section{EPI-P02}

\section{Entwicklung der nasopharyngealen Besiedlung bei unter sechsjährigen Kindern seit Einführung der Pneumokokken- Konjugatimpfung in Deutschland}

\section{A. Rose ${ }^{1,2}$, M. Imöhl' ${ }^{3}$, M. Laurenz $z^{4}$, R. Sprenger', M. van der Linden ${ }^{3}$}

${ }^{1}$ Klinikum St. Georg, Leipzig, Deutschland, ${ }^{2}$ Goethe Universität, Frankfurt am Main, Deutschland, ${ }^{3}$ Nationales Referenz Zentrum für Streptokokken, Aachen, Deutschland, ${ }^{4}$ Pfizer Pharma GmbH, Berlin, Deutschland

Hintergrund: Seit Juli 2006 werden in Deutschland nach StIKo-Empfehlung Säuglinge systematisch mit Pneumokokken-Konjugatimpfstoffen (PCVs) geimpft. Die Immunisierung erfolgte anfangs mit PCV-7, welcher später durch PCV-10 und PCV-13 ersetzt wurde. Nach WHO-Empfehlung sollen Impfprogramme von Surveillance begleitet werden, was in dieser multizentrischen prospektiven Studie anhand des Einfluß auf die nasopharyngeale Besiedlung erfolgt.

Methoden: Untersuchung nasopharyngealer Abstriche vor der 1. PCVGabe (V1), nach der 3. (Alter 9-12 Monate, V2), nach der 4. (Alter 17-19 Monate, V3) und im sechsten Lebensjahr (V4) auf Streptococcus pneumoniae, Moraxella catarrhalis, Haemophilus influenzae und Streptococcus pyogenes. Die Serotypisierung von S. pneumoniae erfolgte durch die Neufeldsche Quellungsreaktion.

Ergebnisse: Von 242 mit den ersten Abstrichen eingeschlossen gesunden Kindern konnten 154 (65,3\%) bis ins 6. Lebensjahr verfolgt werden. Mit jeglichen Bakterien besiedelt war 27,2 \% bei V1, 55,1 \% bei V2, 57,7\% be V3 und 70,1 \% bei V4. S. pneumoniae war in V 1 in $42,5 \%$ der Fälle und bei V4 in 38,0\% nachweisbar. Für M. catarrhalis, $H$. influenzae und S. pyogenes waren die Nachweise bei V1 jeweils 30, 25 und 2,5\%, bei V4 22,2, 35,7 und 4,1\%. Bei V4 waren keine PCV-7-, PCV-10- und PCV-13 Serotpen mehr nachweisbar bis auf Serotyp 3 (6,2\%) und 19A (3,1\%). Der Anteil Antibioitika-resistenter PnCs sank mit der Kolonisierungsrate, vor allem für Clarithromyin ( $21 \%$ bei V1, $11 \%$ bei V4).

Schlussfolgerung: Unsere Surveillance-Studie zeigt durch PCV eine erfolgreiche Schleimhaut-Eradikation der in den PCVs enthaltenen Pneumokokken (PnC)-Serotypen. Obwohl erwartungsgemäß auch nicht-Vakzine-Serotypen nachgewiesen wurden, liegt die PnC-Kolonisierungsrate im 6. Lebensjahr (38\%) nicht nur unter dem Ausgangswert vor Impfung $(42,5 \%)$, sondern deutlich unter dem Wert bei ungeimpften Kindern (ca. $60 \%$ ). Die PCV-Immunisierung zeigte positive Nebeneffekte mit abnehmenden Nachweisen Antibiotika-resistenter PnCs. Unsere Daten bestätigen die gute Dekolonisierungswirkung von PCVs auch unter hiesigen Versorgungsbedingungen, was gleichsam die Basis für Schutz vor invasiven Pneumokkken-Erkrankungen im entsprechenden Altersgipfel darstellt.

\section{EPI-P03}

Veränderungen der Malaria Epidemiologie bei Kinder und Jugendlichen in Deutschland, 2001-2015

S. Vygen-Bonnet, K. Stark

RKI, Infektionsepidemiologie, Berlin, Deutschland

Hintergrund: Seit Einführung des Infektionsschutzgesetzes im Jahr 2001 in Deutschland, lag, nach initial 110 Meldungen, in den Folgejahren die Zahl gemeldeter Malariaerkrankungen bei Kindern und Jugendlichen konstant um 60 Fälle/Jahr. In den Jahren 2014/15 beobachteten wir einen 1,6-fachen Anstieg der Malariameldungen in der Gesamtbevölkerung und einen mehr als 3-fachen Anstieg bei Kindern und Jugendlichen.

Methoden: Um ein besseres Verständnis der Malariaepidemiologie im Kindes- und Jugendalter zu erhalten und den Fallzahlanstieg der Jahre 2014/15 besser einordnen zu können, führten wir eine Zeitreihenanalyse der Malariadaten der vergangenen 15 Jahre durch. Ziel war es demographische Charakteristika und geographische Herkunft der Fälle, Verteilung der Plasmodien Spezies und Infektionsländer zu beschreiben.

Ergebnisse: Für Malaria besteht eine nicht namentliche Labormeldepflicht. Das Robert Koch-Institut versendet Erhebungsbögen an die Labore, auf denen Angaben zum Geburtsmonat und -jahr, Geschlecht, Monat und Jahr der Malariadiagnose, Plasmodium Spezies, geographischer Herkunft und Reiseanamnese gemacht werden. Der behandelnde Arzt ergänzt die anamnestischen Daten. Mittels eines Algorithmus werden Doppelmeldungen ermittelt. Ein Fall ist definiert als Person $<18$ Jahre mit einem direkten Nachweis von Malariaparasiten im Blut und deutschem Wohnsitz. Ein kürzlich Geflüchteter war definiert als eine Person, die innerhalb eines Jahres vor Malariadiagnose nach Deutschland gekommen war und die Angabe „Asylsuchender" hatte oder aus einem der 10 häufigsten vom Bundesamt für Migration und Flüchtlinge als Herkunftsland für Geflüchtete angegebenen Land stammte. Eine Zeitreihenanalyse der Meldedaten von 2001-15 wurde mittels STATA SE14 durchgeführt.

Insgesamt wurden in den Jahren 2001-15 bei Kindern und Jugendlichen 1211 Fälle von Malaria (M.) gemeldet (Spanne: 48-192/Jahr). Der Anteil der < 18-Jährigen an der Gesamtfallzahl lag 2001-13 konstant um 10\% (n durchschnittlich pro Jahr $(\mathrm{nd})=64$ ) und $2014 / 15$ bei $18 \%(\mathrm{nd}=188)$. Der Anteil von männlichen Kindern und Jugendlichen lag 2001-13 konstant um $59 \%$ (nd=37) und 2014/15 bei 79\% (nd=147). Am häufigsten wurde M. tropica diagnostiziert, mit Ausnahme von 2014/15. 549 Fälle (49\%) hatten einen Migrationshintergrund, 384 Fälle (32\%) deutsche Herkunft, bei 233 (19\%) fehlten Informationen zur Herkunft. 2014/15 stieg der Anteil von kürzlich Geflüchteten von durchschnittlich $5 \%(n d=3)$ in den Vorjahren auf $51 \%(n d=193)$ an. Unter den kürzlich Geflüchteten waren $75 \%(n d=174)>15$ Jahre alt gegenüber $20 \%(n d=195)$ der übrigen Fälle. Für 801 Fälle lagen Angaben zum Infektionsland vor: 559 (70\%) mal wurde West- oder Zentralafrika genannt, 172 mal (22\%) übriges Afrika, $63 \mathrm{mal}$ (8\%) Asien und 7 mal (1\%) Mittel- und Südamerika. Unter den kürzlich Geflüchteten aus den Jahren 2014/15 kamen $71 \%$ (nd=136) aus Eritrea, $9 \%(\mathrm{nd}=18)$ aus Afghanistan, $4 \%$ aus Pakistan $(\mathrm{nd}=7)$ und $3 \%$ aus Somalia (nd =5).

Schlussfolgerung: Während für alle Charakteristika die Verteilung in den Jahren 2001-13 recht konstant war, beobachteten wir 2014/15 einen starken Anstieg von M. tertiana Fällen unter vorwiegend männlichen Jugendlichen, die als Flüchtlinge aus Ländern vom Horn von Afrika, Afghanistan und Pakistan nach Deutschland gekommen waren. In dieser Gruppe ist bei unklarem Fieber auch bei mehrere Monate zurückliegender Flucht immer eine Malaria auszuschließen. Die Surveillance liefert wertvolle Daten zur epidemiologischen Bewertung der importierten Malaria. 


\section{EPI-P04}

\section{Causes of acute febrile diseases in hospitalized children in Mwanza, Tanzania}

\section{P. Koliopoulos', F. Huth', T. Daniel', N. Kayange', A. Hokororo², B. Gröndahl', C. Schmidt ${ }^{3}$, A. Zürchner', S. Ulbert', S. Mshana', S. Gehring' \\ 'Universitätsmedizin Mainz, AG Pädiatrische Infektiologie, Mainz, Deutschland, ${ }^{2}$ Bugando Medical Centre, Department of Pediatric and Adolescent Medicine, Mwanza, Tanzania, ${ }^{3}$ St. Vinzenz-Hospital, Abteilung für Kinder- und Jugendmedizin, Dinslaken, Deutschland, ${ }^{4}$ Fraunhofer Institut, Institut für Zelltherapie und Immunologie (IZI), Leipzig, Deutschland, ${ }^{5}$ Catholic University of Health and Allied Sciences (CUHAS), Mwanza, Tanzania}

Background: Acute mosquito-transmitted febrile diseases are serious threats for children in Sub-Sahara-Africa (SSA). Unfortunately, an increasing number of malaria-like infections have gained a considerable relevance within the last number of years including Dengue (DENV) and Chikungunya (CHKV; [1]). Over $50 \%$ of the world"s population are living at risk to be infected by DENV [2]. Arboviruses like CHKV already have proved that they inherit the potential to spread to Europe as recent outbreaks in Italy (2007) and autochthonous transmissions in France (2010) documented. Their prevalence in entire SSA is very likely, but to date reliable epidemiologic data are lacking. Due to the lack of diagnostic tools distinguishing between the various pathogens, inadequate treatment decisions become unavoidable [3]. Consequently, a significant health, financial, and logistic burden for countries of SSA-communities becomes inevitable.

Specific Aim: The aim of the project is to find and identify the prevalent pathogens at the Lake Victoria Region that are responsible for acute malaria-like febrile diseases in children.

Material und Methods: In 2016 a hospital based prospective explorative cohort study was conducted at two study sites in Mwanza, Tanzania. From April to December 2016 a total of 266 patients presenting with Malaria-like symptoms were included at the Bugando Medical Center (BMC) and the Sekou Toure Regional Referral Hospital (STRRH). Medical history, clinical measurements and lab results were obtained and analyzed statistically. Additionally, blood and sera samples were distributed on tubes and Filter Cards for each patient. Samples were analyzed using a Multiplex-PCR-ELISA diagnostic tool that can delineate between Malaria and several arboviral infections. Additionally, a highly sensitive serology for arboviruses was performed.

Results: A 7 valent Multiplex-PCR detecting Malaria, DENV, CHKV, Zika, Yellow Fever, Rift-Valley-Fever and West-Nile Virus was established. Only $26 \%$ (BMC) and $11 \%$ (STRRH) of the presumptive Malaria-cases had a positive Malaria finding. A 32\% overlap between Blood Smear and MRDT positive results reveal incongruent Malaria diagnostics. At least $51 \%$ (BMC)/35\% (STRRH) received unnecessary anti-malaria treatment and a very high rate of antibiotic treatment (95\% BMC/78\% STRRH). The up-to date analyzed samples did not reveal any positive PCR despite Malaria. In contrast, serology detected $18 \%$ positive Dengue IgM, $14 \%$ positive Dengue IgG and 26\% positive Chikungunya IgG within our cohort. Discussion: Incongruent Malaria diagnostics inherit a significant limitation in daily clinical routine. Additionally, a very high rate of antibiotic and anti-malaria treatment in our cohort displays the need of suitable diagnostic tools. Serum samples analysis revealed that arboviruses are prevalent in the Lake Victoria region. We intend to evaluate the use of Dried Blood Spot for preserving pathogen"s constituents.

\section{References}

1. Devaux CA (2012) Emerging and re-emerging viruses: A global challenge illustrated by Chikungunya virus outbreaks. World J Virol 1:11-22

2. Murray NE, Quam MB, Wilder-Smith A (2013) Epidemiology of dengue: past, present and future prospects. Clin Epidemiol 5:299-309

3. D'Acremont V, Kahama-Maro J, Swai N, Mtasiwa D et al (2011) Reduction of antimalarial consumption after rapid diagnostic tests implementation in Dar es Salaam: a before-after and cluster randomized controlled study. Malar J 10:107

\section{EPI-P05}

NTM Kids - Ergebnisse einer prospektiven, multizentrischen epidemiologischen Fall-Kontroll-Studie zur NTM-Lymphadenitis im Kindesalter

\section{Kuntz' ${ }^{1}$, M. Seid2 ${ }^{2,3}$, A. Nieters' ${ }^{3}$, P. Henneke ${ }^{1,3}$}

${ }^{1}$ Universitätsklinikum Freiburg, Zentrum für Kinder- und Jugendmedizin, Klinik für Allgemeine Kinder- und Jugendmedizin, Freiburg, Deutschland, ²Universitätsklinikum Freiburg, Institut für Klinische Pathologie, Freiburg, Deutschland, ${ }^{3}$ Universitätsklinikum Freiburg und Universität Freiburg, Centrum für Chronische Immundefizienz (CCl), Freiburg, Deutschland

Hintergrund und Fragestellung: Risikofaktoren, die immunkompetente Kinder für eine Lymphadenitis durch nicht-tuberkulöse Mykobakterien (NTM) prädisponieren, sind weitgehend unverstanden. Ferner fehlt Evidenz, die eine risikoadaptierte Therapiestratifizierung erlauben würde. Methoden: Wir rekrutierten Kinder mit lokalisierten Lymphadenitiden durch NTM und eine entsprechende Kontrollkohorte, die für Alter, Geschlecht und Zentrum kontrolliert war. Erhoben wurden die medizinische Anamnese, sozioökonomische Faktoren und Daten, die die Exposition gegenüber NTM abschätzen ließen. In der Patienten-Kohorte wurde ferner der Krankheitsverlauf, die entsprechende Therapie und mögliche Komplikationen oder Residuen erfasst. Sofern verfügbar, wurde außerdem die Histologie des betroffenen Lymphknotens standardisiert untersucht. Serum und EDTA-Blut von Patienten und Kontrollen (sofern verfügbar) wurden für weitergehende Analysen asserviert. Die Patienten wurden mindestens bis zum Erreichen von Symptomfreiheit nachverfolgt.

Ergebnisse und Diskussion: 128 Patienten konnten eingeschlossen werden. Das mediane Erkrankungsalter lag bei 29 Monaten. Es zeigte sich eine Mädchenwendigkeit mit $62 \%$ der Fälle. Mycobacterium avium war die am häufigsten isolierte NTM-Spezies (75\%). In ca. der Hälfte der Fälle gelang der Keimnachweis nur mittels PCR, während die Kultur negativ blieb. Unsere Analyse ergab keine signifikanten Unterschiede zwischen Patienten und Kontrollen bzgl. sozioökonomischem Status, Infekthäufigkeit, Allergien, Impfungen und Kontakt zu Tieren oder Erdreich. Diese Daten widersprechen früheren Thesen einer wesentlich vom Lebensstil abhängigen Erkrankung. Zu beachten ist allerdings, dass über $90 \%$ der Patienten in unserer Kohorte eine chirurgische Intervention erhielten (Biopsie, Inzision und Drainage, Extirpation etc.). Möglicherweise sind Patienten mit milder Erkrankung und rascher Spontanregression unterrepräsentiert. In einem weiteren Schritt werden klinische Daten mit histologischen und molekularbiologischen Markern korreliert werden.

\section{EPI-P06 \\ Hypoxien, Bradykardien und Impfantwort bei Frühgeborenen nach 6+1-fach-Impfung}

S. Gottlob, C. Gille, M. Quante, K. Büchner, K. Gründler, C. F. Poets

'Universitätsklinik für Kinder- und Jugendmedizin Tübingen, Neonatologie, Tübingen, Deutschland

Hintergrund: Hypoxien und Bradykardien sind Symptome im Rahmen der Immunisierung Frühgeborener. Daher wird die erste Impfung bei Frühgeborenen $(\mathrm{FG})<29$ Wochen unter stationären Bedingungen empfohlen. Daten von Erwachsenen zeigten, dass Impfreaktion und Impferfolg tageszeitlichen Einflüssen unterliegen. Als Ursache wird die zirkadiane Regulation des Immunsystems angenommen. In einer randomisierten, verblindeten Pilotstudie an 10 Kindern konnten wir zeigen, dass bei in den Morgenstunden geimpften Frühgeborenen vermehrt Hypoxien und Bradykardien auftraten. Diese Ergebnisse wurden für eine Fallzahlberechnung verwendet, die für eine erneute Prüfung zu Grunde gelegt wurde. Fragestellung: Untersucht werden sollte, ob es bei ehemals sehr unreifen FG Unterschiede in der Hypoxie-/Bradykardiehäufigkeit nach Impfung morgens vs. abends gibt.

Material und Methoden: Der Einschluss der Patienten erfolgte nach ausführlicher Aufklärung und schriftlicher Einwilligung der Eltern. In die Hauptstudie wurden 16 FG zwischen $26+1$ und 29+4 Schwangerschaftswochen eingeschlossen. Davon wurden jeweils acht morgens und acht 
abends geimpft. Die Randomisierung erfolgte mittels verschlossener Umschläge. Rekrutiert wurde aus dem Patientenkollektiv der Neonatologie der Universitäts-Kinderklinik Tübingen.

Zur Detektion von Hypoxien und Bradykardien wurden im Zeitraum 24 Stunden vor bis 24 Stunden nach Impfung Pulsoxymetrie-Daten aufgezeichnet. Zudem wurde ein Schlaftagebuch geführt. Ausgewertet wurden nur Hypoxien und Bradykardien während des Schlafs. 24 Stunden nach Impfung wurden Interleukin-6 (IL-6) und C-reaktives Protein (CrP) als Marker für eine Immunreaktion bestimmt. Ausgeschlossen wurden schwer beeinträchtigte Kinder (BPD, PVL, IVH $>^{\circ} 2$, schwere Fehlbildungen), sowie Kinder HBV-positiver Mütter.

Zur Kontrolle des Impferfolges wurden vor Impfung sowie beim Kontrolltermin in der neonatologischen Ambulanz im korrigierten Alter von vier Monaten Impftiter für Pertussis und Haemophilus influenzae B bestimmt. Ausgewertet wurden die Differenzen zwischen der Anzahl der Ereignisse 24 Stunden vor und nach Impfung. Die Ereignishäufigkeit in Morgen- vs. Abendgruppe wurde mittels Mann-Whitney-Test verglichen.

Ergebnisse: In den 24 Stunden nach Impfung traten nach abendlicher Impfung mehr Hypoxien und Bradykardien auf: 1,5 (-1,75; 4,75) (Median (25\%-; 75\%-Perzentile)) zusätzliche Ereignisse morgens vs. 15,5 (3,25; $20,75)$ zusätzliche Ereignisse abends $(p=0,046)$. Nahezu alle FG zeigten in den 24 Stunden nach Impfung tageszeitunabhängig einen geringen Temperaturanstieg sowie einen Anstieg der laborchemischen Entzündungsparameter IL-6 und CrP. Ferner fand sich ein Anstieg der Impftiter, der jedoch nicht mit der Häufigkeit von Hypoxien/Bradykarien korrelierte. Schlussfolgerung: Wir konnten die Ergebnisse der Pilotstudie hier nicht bestätigen, sondern kamen zu einem gegenteiligen Ergebnis. Dies zeigt eine hohe Variabilität in den Impfreaktionen. Daher scheint eine Abhängigkeit vom Zeitpunkt der Impfung in der hier geprüften Patientenkohorte nicht gegeben zu sein.

\section{EPI-P07 \\ Mikrobiologische Atemwegsflora bei Kindern mit Mukoviszidose im ersten Lebensjahr}

\section{Hübsch', J. Hammermann', R. Berner ${ }^{2}$ \\ 'Universitätsklinikum Carl Gustav Carus an der TU Dresden, UniversitätsMukoviszidoseCentrum, Klinik und Poliklinik für Kinder- und Jugendmedizin, Dresden, Deutschland, ${ }^{2}$ Universitätsklinikum Carl Gustav Carus an der TU Dresden, Klinik und Poliklinik für Kinder- und Jugendmedizin, Dresden, Deutschland}

Hintergrund: Bei Kindern mit Mukoviszidose sind die pulmonale Keimbesiedelung und Infektion wichtige prognostische Faktoren. Da es bis vor Kurzem kein flächendeckendes Neugeborenenscreening auf Mukovizidose in Deutschland gab, fehlen auch Daten zur Keimbesiedelung im ersten Lebensjahren.

Methoden: In Dresden gibt es seit 1996 ein regionales Neugeborenenscreening-Programm für Ostsachsen. Bei den Kindern, welche über das Neugeborenenscreening detektiert wurden, wurde ab Diagnosestellung ein mikrobiologisches Monitoring durchgeführt und uns liegen Daten ab 1997 vor. Ergebnisse: Im Folgenden zeigen wir die Keimbesiedelung von 55 Patienten aus unserem Mukoviszidose-Zentrum in ihrem ersten Lebensjahr. Be fast allen Patienten wurden neben der normalen Mund- und Rachenflora noch weitere Bakterien gefunden. Am häufigsten wurden Staphylococcus aureus, Haemophilus influenzae und Escherichia coli nachgewiesen, aber auch eine große Zahl anderer Bakterien wie Klebsiellen, Serratien, Streptokokken, Enterobacter, Enterokokken und Acinetobacter-Spezies. Pseudomonas aeruginosa und andere Pseudomonas-Arten wurden ebenso bereits bei einem Teil dieser jungen Patienten gefunden. Bei mehreren Patienten waren Pilze im Rachenabstrich nachweisbar, wie Aspergillus- und Candida-Spezies. Die meisten Patienten benötigten aufgrund von pulmonalen Exazerbationen eine antibiotische Therapie im ersten Lebensjahr, wobei die klinischen Symptome in vielen Fällen nicht mit den mikrobiologischen Befunden korrelierten.

Schlussfolgerung: Die Einführung eines nationalen Neugeborenenscreening-Programms auf Mukoviszidose konnte 2016 umgesetzt werden. Mit den dadurch gewonnenen Daten muss der Einfluss einer Keimbesiedelung der Atemwege im ersten Lebensjahr auf Prognose und Notwendigkeit einer Behandlung reevaluiert werden.

\section{Hygiene}

\section{HYG-P01}

Implementation of surveillance cultures and targeted decolonization reduced methicillin-susceptible Staphylococcus aureus infections of very low birth weight infants

L. Wisgrill', L. Unterasinger', T. Waldhör ${ }^{2}$, A. Makristathis ${ }^{3}$, A. Berger ${ }^{1}$

${ }^{1}$ Medizinische Universität Wien, Abteilung für Neonatologie, Pädiatrische Intensivmedizin und Neuropädiatrie, Wien, Österreich, ${ }^{2}$ Medizinische Universität Wien, Abteilung für Epidemiologie, Institut für Public Health, Wien, Österreich, ${ }^{3}$ Medizinische Universität Wien, Abteilung für Medizinische Mikrobiologie, Wien, Österreich

Background: Methicillin-susceptible staphylococcus aureus (MSSA) is a major contributor to infectious episodes of very low birth weight infants (VLBWI) resulting in high morbidity and mortality.

Objective: To examine the efficacy and safety of surveillance cultures and decolonization of MSSA-colonized VLBWI.

Methods: VLBWI admitted to our neonatal wards during 2012-2015 were analyzed. Rates of MSSA-attributable infections were compared before and after implementation of surveillance cultures and decolonization protocol of MSSA-colonized VLBWI. Mupirocin susceptibility of isolated MSSA strains was routinely proofed.

Results: A total of 743 VLBWI were included in the study, 406 in the preintervention phase (14.342 patient-days) and 337 (13.083 patient-days) in the postintervention phase. A reduction of incidence rates per $1000 \mathrm{pa}-$ tient-days of MSSA-attributable invasive infections was observed after implementation of surveillance cultures and decolonization (1883 (95\% CI $1.266-2.701)$ vs 1070 (95\% CI 0.609-1.753)). Side effects of the decolonization protocol with mupirocin and octenidin were not observed. Mupirocin-resistant MSSA strains were not detected in the study.

Conclusions: Decolonization of MSSA-colonized VLBWI reduces rates of of MSSA-attributable invasive infections.

\section{HYG-P02}

\section{Validierung Muttermilch-Pasteurisator - Sinnvoll oder unnötig?!}

E. Vogelgesang', C. Schwinn'2, U. Geipel ${ }^{3}$, M. Eggers ${ }^{4}$

'Klinikum Saarbrücken, Neonatologie Level 1, Saarbrücken, Deutschland, ${ }^{2}$ Klinikum Saarbrücken, Krankenhaushygiene, Saarbrücken, Deutschland, ${ }^{3}$ Bioscientia MVZ, Mikrobiologie, Saarbrücken, Deutschland, ${ }^{4}$ Labor Prof. Gisela Enders, Virologie, Stuttgart, Deutschland

Hintergrund: Ungeachtet der Fragen, ob Muttermilch für das eigene Kind bei einer Cytomegalievirus-Infektion der Mutter pasteurisiert werden muss und wie lange, müssen wir üblicherweise die Frauenmilchspende nach den Leitlinien der Muttermilchbanken pasteurisieren.

Fragestellung: Woher wissen wir, dass die Pasteurisatoren auf den Neonatologien korrekt arbeiten? Die Gabe von pasteurisierter Milch mit deutlich reduzierter immunologischer Wertigkeit (durch den Pasteurisierungsvorgang) und nicht komplett inaktivierten Cytomegalieviren wäre fatal für die kleinen Patienten.

Methoden: Die Pasteurisierung wurde durch die Verwendung von CMVgespikten Muttermilchproben validiert. Dafür wurde uns ein CMV-Laborstamm, mit bekannter Viruslast, zur Verfügung gestellt. Neben den CMV-gespikten Milchproben wurde auch ein Aliquot der Virussuspension pasteurisiert, um eine mögliche viruzide Aktivität der Muttermilch zu erfassen, die als Pasteurisierungserfolg missinterpretiert werden könnte. Ergebnisse: Im Ergebnis zeigt sich eindeutig, dass unser Pasteurisator korrekt arbeitet. Der Prozess dient einer optimalen internen Qualitätssicherung. 
Schlussfolgerung: Macht es Sinn, dieses Validierungsverfahren deutschlandweit einzusetzen?!

\section{HYG-P03}

Internetplattform MRSA-Kinder.net - ein internetbasiertes Informations- und Beratungsangebot zum Thema MRSA bei Kindern für Ärzte, Eltern, Gesundheitsämter

\section{T. Dresbach, S. Poralla, A. Müller}

Universitätsklinikum Bonn, Neonatologie und Pädiatrische Intensivmedizin, Bonn, Deutschland

Mit der Internetplattform MRSA-Kinder.net hat die Sektion Pädiatrische Infektiologie am Universitätsklinikum Bonn mit der Unterstützung der Deutschen Gesellschaft für Pädiatrische Infektiologie (DGPI) ein niedrigschwelliges, internetbasiertes Informations- und Beratungsangebot zum Thema MRSA bei Kindern für Ärzte, Eltern, Gesundheitsämter und Betreuungseinrichtungen etabliert.

Die Sektion Pädiatrische Infektiologie, am Zentrum für Kinderheilkunde am Universitätsklinikum Bonn, betreut seit sieben Jahren intensiv Familien mit Kindern, bei denen MRSA-Infektionen oder MRSA-Kolonisationen nachgewiesen wurden. Dem zunehmenden Beratungsbedarf wurde 2013 mit der Gründung der ersten MRSA-Ambulanz für Kinder in Nordrhein-Westfalen Rechnung getragen. In den letzten Jahren nahm der Beratungsbedarf stetig zu. Neben einer zunehmenden Zahl an ambulanten Betreuungen von Kindern mit MRSA-Infektionen/Besiedlung, wurden auch stetig mehr Beratungsanfragen von niedergelassenen Kinderärzten, Klinikärzten und Gesundheitsämtern verzeichnet.

Über 100 schriftliche und telefonische Anfragen von Eltern und Ärzten bezüglich MRSA im Kindesalter werden pro Jahr durch die Arbeitsgruppe Pädiatrische Infektiologie am Universitätsklinikum Bonn beantwortet. Eine Leistungserfassung der ärztlichen Beratung ist nicht möglich, so dass die Beratungszeit nicht gegenfinanziert werden kann. Die Auswertung der Anfragen der MRSA-Ambulanz für Kinder in Bonn ergab, dass sich 70\% der Anfragen um allgemeine Informationen bezüglich MRSA, Dekolonisationsbehandlungen, allgemeines Vorgehen bei Nachweis von MRSA-Besiedlung, sowie Fragen zu MRSA und Gemeinschaftseinrichtungen beziehen. Um weiterhin niederschwellig Informationen zur Thematik „MRSA bei Kindern" und Beratungen bei speziellen Fragen anbieten zu können, hat die Sektion Pädiatrische Infektiologie am Universitätsklinikum Bonn das „Kinder-MRSA-Netzwerk“ gegründet. Die Internetplattform „www. kinder-mrsa.net" stellt Informationen zum Thema „MRSA bei Kindern“ bereit. Für die unterschiedlichen Zielgruppen (niedergelassene und klinisch tätige Pädiater, Eltern, Gesundheitsämter und Betreuungseinrichtungen) erfolgt ein barrierefreier Zugang zu den bedarfsangepassten Informationsinhalten. Spezielle Beratungen können auf elektronischem Wege erfolgen, und werden anonymisiert auf der Internetplattform veröffentlicht, um redundante Fragestellungen zu vermeiden. Die Koordination des Netzwerkes MRSA-Kinder.net erfolgt federführend durch die Sektion Pädiatrische Infektiologie am Universitätsklinikum Bonn. Ein wissenschaftlicher Beirat, bestehend aus Pädiatrischen Infektiologen, Fachärzten für Mikrobiologie sowie Krankenhaushygienikern, ermöglicht eine umfangreiche und zeitnahe Beratung auch von komplexen Fragestellungen.

\section{HYG-P04}

\section{Kolonisationsausbruch auf einer neonatologischen Intensivstation: 3MRGN E. coli versus Klebsiella pneumoniae: same but different?}

T. Artelt' ${ }^{1}$ I. Bley' ${ }^{1}$, H. Eiffert' ${ }^{2}$, A. Mellmann ${ }^{3}$, S. Scheithauer ${ }^{1}$ 'Universitätsmedizin Göttingen UMG, Zentralabteilung Krankenhaushygiene und Infektiologie, Göttingen, Deutschland, 'Universitätsmedizin Göttingen UMG, Institut für Medizinische Mikrobiologie, Göttingen, Deutschland, ${ }^{3}$ Universitätsklinikum Münster UKM, Institut für Hygiene, Münster, Deutschland
Hintergrund: Über die aktuellen RKI-Empfehlungen hinaus wurde ein universelles Aufnahmescreening auf Multiresistente Erreger MRE (MRSA, VRE, 4MRGN, 3MRGN und 2MRGN NeoPäd) für stationäre Patienten mit zeitnaher längerdauernder Auslandsanamnese eingeführt. Dieses wird in Risikobereichen wie der kombinierten neonatologisch-pädiatrischen Intensivstation durch eine präemptive Einzelzimmerisolierung ergänzt. Hintergrund dieser Maßnahme waren die Definition des MRE-Risikos und die Risikominimierung von Transmissionsereignissen. Prävalenzraten konnten auf der Jahrestagung der DGHM 09/2016 präsentiert werden. Ausgangssituation: Die Intensivstation verfügt insgesamt über 20 Betten (10 Betten Neonatologie, 10 Betten pädiatrische Kardiologie). Nach präemptiver Isolierung (11/2015) eines Patienten mit Flüchtlingsanamnese erfolgte im Aufnahmescreening der Nachweis von 3MRGN Klebsiella pneumoniae und 3MRGN E. coli (19.11.2015). Die räumliche Isolierung wurde für die gesamte Dauer des stationären Aufenthaltes (19.11.201509.01.2016) aufrechterhalten.

Kasuistik und Verlauf: Am 13.12., 15.12. und 27. 12.2015 wurden im Rahmen des neonatologischen Kolonisationsscreenings bei drei weiteren Patienten, die im Nachbarzimmer zum Indexpatienten untergebracht waren, eine Kolonisation mit dem identischen 3MRGN Klebsiella pneumoniae-Stamm, jedoch nicht $E$. coli (auch nicht im weiteren Verlauf) gefunden werden. Der molekulare Verwandtschaftsnachweis (Stammidentität) wurde mittels Next Generation Sequencing (NGS) geführt. Kein Kind erkrankte während des stationären Aufenthaltes an einer Infektion. Alle durchgeführten Umgebungsuntersuchungen auf der Station (Geräte und Instrumente einschließend) waren unauffällig mit Ausnahme des Zimmers des Indexpatienten. Wenige Tage vor dem Nachweis des ersten Transmissionsereignisses war es zu einer Notfallsituation parallel in beiden Zimmern gekommen; mehrere Mitarbeiter wurden in beiden Zimmern benötigt. Es wurde für die gesamte Dauer des stationären Aufenthaltes eine ggf. als Kohortenisolierung durchgeführte räumliche Isolierung aller drei 3MRGN Klebsiella pneumoniae-positiven Kinder und auch aller direkten Kontaktkinder durchgeführt.

Trotz der primär erfolgten Isolierung des Indexpatienten sowie entsprechenden Hygienemaßnahmen kam es nach ca. 4 Wochen zu einer Transmission eines MRE. Bei der retrospektiven Analyse fiel eine vorausgegangene Notfallsituation als Hypothese eines einmaligen Transmissionsereignisses auf. In der Folge wurden weitere konsequente Isolierungsmaßnahmen über drei Monate aufrechterhalten. Dies führte zu Bettensperrungen in relevantem Ausmaß und zu Umterminierungen vieler elektiver Aufnahmen. Es kam zu keiner weiteren Transmission.

Schlussfolgerung: Bemerkenswert bei dem dargestellten Fall ist - auch wenn es sich um ein einzelnes Cluster handelt - dass i. das Klebsiella pneumoniae-Isolat, nicht das E. coli-Isolat übertragen wurde, ii. trotz über offizielle Vorgaben gesteigerte Hygienemaßnahmen Transmissionsereignisse nicht vollständig zu vermeiden mögen, iii. vollumfängliche Isolierung auch von Kontaktkindern die Routineversorgung von Patienten beeinflusst.

\section{HYG-P05}

Infektionshygienische Begehung der öffentlichen Gesundheitsbehörden auf einer neonatologischen und einer pädiatrischen Intensivstation aus der Perspektive der Krankenhaushygiene

\section{Baier', E. Ebadi', C. Lassahn', S. Ebeling², F.C. Bange}

'Medizinische Hochschule Hannover, Institut für medizinische Mikrobiologie und Krankenhaushygiene, Hannover, Deutschland, ${ }^{2}$ Medizinische Hochschule Hannover, Referentin des Vorstandes für Krankenversorgung, Hannover, Deutschland

Hintergrund: Die infektionshygienische Überwachung (IHÜ) von Kliniken durch die lokalen Gesundheitsbehörden begründet sich im $\$ 23$ Abs. 6 des Infektionsschutzgesetzes (IfSG). In unserer Klinik erfolgte die Begehung der neonatologischen und pädiatrischen Intensivstationen im Rahmen des Projektes „Infektionshygienische Überwachung von Intensivstati- 
onen und Intermediate-Care-Stationen“ des Fachbereichs Gesundheit der Region Hannover.

\section{Fragestellungen:}

- Wie ist eine IHÜ durch das Gesundheitsamt vorzubereiten und in praxi durchzuführen bzw. zu begleiten?

- Welche Inhalte werden behandelt?

- Welchen Stellenwert nimmt eine solche Begehung ein?

Methoden: Für die Vor- und Nachbereitung der IHÜ wurde eine Arbeitsgruppe gebildet, die sich aus der Krankenhaushygiene $(\mathrm{KH})$, den hygienebeauftragten sowie den leitenden Ärzten und Pflegekräften der jeweiligen Stationen und der Referentin des Vorstandes für Krankenversorgung zusammensetzte. Seitens des Gesundheitsamtes nahmen eine Fachärztin für Hygiene und Umweltmedizin sowie zwei Hygieneinspektoren teil. Die IHÜ erfolgte an einem Tag, der sich in eine etwa 1,5 stündige Vorbesprechung und die sich anschließende Begehung vor Ort auf den Stationen gliederte. Die Strukturierung der Vorbesprechung ergab sich aus einem vorab zugesendeten Fragebogen, der wichtige Strukturparameter und das Hygienemanagement detailliert abfragte. Die relevanten Strukturparameter, wie z. B. Personalschlüssel oder Aussagen zum betreuten Patientengut, wurden von den klinischen Abteilungen zur Verfügung gestellt. Die Fragen zum infektionspräventiven Konzept auf den Stationen wurden vor$\mathrm{ab}$ von der KH beantwortet. Die Begehung der jeweiligen Station wurde dann im Wesentlichen durch die leitenden Ärzte und Pflegekräfte gestaltet Ergebnisse: Wichtige Kernfragen der IHÜ zielten insbesondere auf die Umsetzung der im IfSG festgelegten Vorgaben zur Surveillance von nosokomialen Infektionen sowie zu der Erfassung von multiresistenten Krankheitserregern ab. Ein zentraler Aspekt war auch die Adhärenz zu den Vorgaben in den relevanten Empfehlungen der Kommission für Krankenhaushygiene und Infektionsprävention (KRINKO). In Hinblick auf den komplexen Einsatz von Medizinprodukten wurde auch der zentrale medizinproduktebeauftragte Arzt unserer Klinik mit hinzugezogen. Die praktische Begehung umfasste neben der Inspektion baulicher Gegebenheiten die Begutachtung ausgewählter Patientenzimmer und der Funktionsräume. Dabei wurden vom dort tätigen Personal Erläuterungen zu Prozessabläufen und zu strukturellen Festlegungen getätigt. Die Ergebnisse der Überwachung wurden uns von dem Fachbereich Gesundheit in einem ausführlichen Katalog mit entsprechenden Empfehlungen übermittelt. Diskussion: Der Stellenwert der IHÜ durch die lokalen Gesundheitsbehörden ist unserer Meinung nach als hoch einzuschätzen. Die Vor- und Nachbereitung der Begehung bietet die anlassbezogene Gelegenheit, wesentliche Aspekte des infektionspräventiven und hygienischen Managements mit allen tatsächlichen Entscheidungsträgern zu reflektieren und zu optimieren. Zudem bietet die IHÜ die Möglichkeit den Kontakt mit der zuständigen Aufsichtsbehörde zu intensivieren.

\section{HYG-P06 \\ Mikrobiologische, hygienische und epidemiologische Untersuchungen bei einem Todesfall eines Neugeborenen durch Legionellen \\ C. Lück', P. Markus', O. Bock-Hensley² \\ 'TU Dresden, Institut medizinische Mikrobiologie, Dresden, Deutschland, ${ }^{2}$ Gesundheitsamt Heidelberg, Heidelberg, Deutschland}

Hintergrund: Legionellen sind weitverbreitete gramnegative Wasserbakterien, die nach Eintrag in Warmwassersysteme bei $30-45^{\circ} \mathrm{C}$ optimale Vermehrungsbedingungen vorfinden. Werden Legionellen aus der Umwelt auf den Menschen übertragen, können leichte respiratorische Infektionen (Pontiac Fieber) oder Pneumonien unterschiedlichen Schweregrades entstehen. Bei Erwachsenen werden 2-4\% aller ambulant erworbenen Pneumonien durch Legionellen verursacht. Erkrankungen bei Neugeborenen sind im Zusammenhang mit Wassergeburten beschrieben. Insgesamt ist die gemeldete Inzidenz in dieser Altersgruppe sehr niedrig.

Fragestellung: Konnte mittels mikrobiologischer, hygienischer und molekularbiologischer Untersuchungen die Infektionsquelle bei einer Infektion eines Neugeborenen eindeutig belegt werden?
Material und Methode: Fallbericht: Ein gesundes, normal entwickeltes Neugeborenes wird sieben Tagen nach der Geburt im schwerkranken Zustand in die Klinik aufgenommen und stirbt drei Tage später an einer schweren Pneumonie mit Multiorganversagen. Die Diagnose Legionella Pneumonie wurde mittels PCR gestellt und erst wenige Stunden vor dem Tode auf die Station übermittelt.

Legionellen-Erkrankungen sind meldepflichtig. Das Gesundheitsamt führte daraufhin eine umfangreiche epidemiologische Untersuchung durch. In diesem Zusammenhang wurden Wasserproben aus der Geburtsklinik und aus dem häuslichen Umfeld auf Legionellen untersucht und die Isolate im Konsiliarlabor in Dresden typisiert. Hierzu wurden monoklonale Antikörper, sowie DNA-basierte Typisierungsmethoden (Sequence Based Typing, DNA Chip Hybridisierung und Gesamtgenomssequenzierung) eingesetzt.

Ergebnisse: Aus einer noch zu Lebzeiten des Kindes gewonnenen respiratorischen Probe konnte L. peumophila DNA mittels PCR nachgewiesen werden. Der kulturelle Nachweis von L. peumophila, Sg 1, monoklonaler Subtyp OLDA, Sequenztyp 1 gelang aus der gleichen Probe sowie aus bei der Autopsie gewonnenem Lungengewebe.

Aus Wasserproben der Hausinstallation konnten drei Kolonien isoliert werden, die in den allen o. g. Markern mit den klinischen Isolaten übereinstimmten. Damit konnte die Hausinstallation eindeutig als Infektionsquelle identifiziert werden. Zehn weitere Kolonien aus der Hausinstallation gehörten zu anderen Serogruppen bzw. anderen Spezies. Von insgesamt 16 Kolonien, die aus der Geburtsklinik typisiert worden, war keine mit dem klinischen Isolat übereinstimmend.

Diskussion und Schlussfolgerung: Durch den molekularbiologischen Vergleich von Patienten und Umweltisolaten konnte die Hausinstallation in der Wohnung als Infektionsquelle eindeutig bestimmt werden. Alle Isolate aus der Geburtsklinik waren hingegen vom Patientenisolat sicher abzugrenzen.

Eine Infektionsdosis ist bei Legionellainfektionen bisher nicht bekannt. Es gibt Stämme die häufig mit Erkrankungen assoziiert sind. Der Krankheitsverursachende Stamm war in unserem Fall in der Minderheit der analysierten Kolonien. Damit besteht grundsätzlich die Möglichkeit, dass der verursachende Stamm bei der Analyse übersehen wird.

Die in der Trinkwasserverordnung vorgesehene prophylaktische Untersuchung auf Legionellen in Hausinstallationen war in unserem Fall unauffällig. Daher wurden keine technischen Maßnahmen zur Verbesserung der Installationstechnik vorgenommen. Dies illustriert jedoch, dass geringe Legionella-Keimzahlen unterhalb des technischen Maßnahmewertes (100 Legionella-Kolonien in $100 \mathrm{ml}$ ) keine absolute Sicherheit bieten. Sind Legionellen im System vorhanden, können Sie sich unter bestimmten Bedingungen, auch lokal begrenzt, stark vermehren und so gegebenenfalls Ausgangspunkt von Infektionen werden.

\section{HYG-P07}

Methicillin-resistente Staphylococcus aureus (MRSA) Transmission bei zwei ELBW-Frühgeborenen durch Muttermilch von Frauen ohne Mastitis und ohne MRSA-Keimnachweis im Nasen- und Rachenabstrich

H. Buxmann', D. Fischer', A. Allendorf', C. Reinheimer', V. Kempf', R. L. Schlößer', S. Göttig ${ }^{2}$

'Universitätsklinikum Frankfurt, KKJM - Neonatologie, Frankfurt am

Main, Deutschland, ${ }^{2}$ Universitätsklinikum Frankfurt, Zentrum für Hygiene, Frankfurt am Main, Deutschland

Hintergrund: Der Nachweis von Erregern mit besonderer Resistenzlage bei Frühgeborenen (FG) induziert neben infektiologischen Überlegungen auch die Frage nach dem Ursprung dieser Keime. In den KRINKOEmpfehlungen zur Prävention und Kontrolle von Methicillin-resistenten Staphylococcus aureus-Stämmen (MRSA) in medizinischen und pflegerischen Einrichtungen wird Muttermilch als potentielle Quelle für MRSA nicht genannt. Die Empfehlung zur Prävention nosokomialer Infektionen bei neonatologischen Intensivpflegepatienten mit einem Geburtsgewicht unter $1500 \mathrm{~g}$ enthält den Hinweis, dass: möglicherweise [...] ein bakte- 
riologisches Monitoring der Muttermilch [...] im Rahmen von gezielten Ausbruchsuntersuchungen von Nutzen sein kann.

Fallbeschreibungen: Bei zwei mit Muttermilch ernährten extremely low birth weight (ELBW)-FG wurden in Routine-Rachenabstrichen im zeitlichen Abstand von einer Woche MRSA nachgewiesen. Die Sequenzanalyse des Protein A kodierenden Gens von S. aureus (spa -Typisierung) beider MRSA-Stämme ergab den seltenen spa-Typ t2518. In den Nasen- und Rachenabstrichen der Eltern beider FG war kein MRSA nachweisbar. Dagegen wurde in der Muttermilch von beiden Frauen MRSA (jeweils spa-Typ t2518) nachgewiesen ohne dass klinische Zeichen einer Mastitis bestanden. Alle weiteren Screening-Abstriche der anderen Patienten auf Station, umfangreich Umgebungsuntersuchungen, sowie ein Mitarbeiterscreening auf freiwilliger Basis, welches von 14 Personen (Reinigungskräfte, Pflegende, Ärzte) wahrgenommen wurde, blieben sämtlich MRSA negativ. Beide ELBW-Frühgeborene wurden auf Formula-Milch umgesetzt und mit Hilfe von verdünnten Polyhexan-Waschungen, Mupirocin-Nasensalbe und Vancomycin enteral von MRSA dekolonisiert. Eine der Mütter entschied sich für eine eigene Dekolonisations-therapie, die ebenfalls erfolgreich war. Anschließend erhielt ihr Kind wieder Muttermilch. In den wöchentlichen Routineabstrichen wurde nachfolgend kein MRSA mehr nachgewiesen.

Diskussion: Die zeitliche Koinzidnez der MRSA-Nachweise im Rachen zweier ELBW-FG induzierte umfangreiche Untersuchungen zur Identifikation des Ursprungs und Reservoirs der MRSA-Keime. Nasen- und Rachenabstriche beider Eltern und Mitarbeiter, sowie alle Umgebungsuntersuchungen (inklusive Kühl- und Gefrierschränke, in denen die abgepumpte Muttermilch aufbewahrt wurde) waren MRSA-negativ. Einzig in der frischen Muttermilch der Mütter beider Kinder war MRSA mit identischem spa - Typ nachweisbar. Bei einer der Mütter bestanden durch ihre eigene Grunderkrankung (Transposition der großen Arterien mit Trikuspidalatresie, Z.n. totaler Cavo-pulmonaler Konnektion [TCPC]) und den damit verbundenen häufigen stationären Aufenthalten medizinische und bei der anderen Mutter sozialanamnestische Risikofaktoren für die Akquise des MRSA.

Schlussfolgerung: Muttermilch ist eine potentielle Quelle von MRSA. Findet sich dieser Keim in den bakteriologischen Routineabstrichen eines mit Muttermilch ernährten Frühgeborenen, so erscheint es sinnvoll, in den sich anschließenden Untersuchungen zur Klärung der Frage nach dem Ursprung des MRSA, die Muttermilch für diese Kinder direkt mit einzubeziehen.

\section{Pathogenese}

\section{PAT-P01}

Die Wasserstoffperoxid-Produktion von Gruppe-A-Streptokokken - ein weiterer Virulenz-Mechanismus?

\section{Menschner, U. Falke, N. Toepfner, R. Berner}

Universitätsklinikum Carl Gustav Carus, Pädiatrische Infektiologie, Dresden, Deutschland

Hintergrund: Gruppe-A-Streptokokken (GAS) sind potenziell humanpathogene Erreger mit einem breiten Spektrum an Wirtsinteraktion. Dieses reicht vom asymptomatischen Trägerstatus über lokale Haut- und Schleimhautinfektionen zu Scharlach, Toxic-Shock-Syndrom und Sepsis. Zur Adhäsion, Invasion und Immunmodulation verfügen GAS über ein Repertoire an Virulenzfaktoren. Neben gut bekannten Virulenzfaktoren, wie z. B. den Scharlach-Toxinen und dem Emm-Protein können auch Stoffwechselprodukte und die Teilungsrate zur GAS-Pathogenität beitragen. Ganzgenom-sequenzierte GAS Referenzstämme haben mit hoher Gensequenzhomologie das Gen für die Laktat-Oxidase (lctO). Durch IctO wird Laktat unter Wasserstoffperoxid-Produktion $\left(\mathrm{H}_{2} \mathrm{O}_{2}\right)$ zu Pyruvat umgesetzt. Die Rolle dieses konservierten Proteins bei GAS ist bisher unbekannt. Eine ähnliche Funktion wie die der Pyruvat-Oxidase bei Pneumokokken ist vorstellbar. Durch die $\mathrm{H}_{2} \mathrm{O}_{2}$-Produktion von Pneumo- kokken wird das Wachstum anderer Bakterien im Mund-Rachen-Raum gehemmt [1] und bei Pneumonie führt diese zu Apoptose von Lungenepithelzellen [2].

Fragestellung: Unterscheiden sich klinische GAS-Isolate unter gleichen Wachstumsbedingungen hinsichtlich ihrer $\mathrm{H}_{2} \mathrm{O}_{2}$-Produktion? Gibt es eine Korrelation zu bereits bekannten GAS-Virulenzgenen?

Material und Methoden: Das Wachstum und die $\mathrm{H}_{2} \mathrm{O}_{2}$-Produktion von 677 klinischen GAS-Isolaten wurden mittels 24 Stunden-Kultur bei $37^{\circ} \mathrm{C}$ und $5 \% \mathrm{CO}_{2}$ auf Preußisch-Blau-Agar charakterisiert. Durch $\mathrm{H}_{2} \mathrm{O}_{2}$-Produktion wird das Hexacyanoferrat und Eisen im Agar zu dem Farbstoff Preußisch Blau (PB) reduziert. Die Menge an $\mathrm{H}_{2} \mathrm{O}_{2}$-Produktion wurde anhand der PB-Farbintensität für alle Isolate mittels semiquantitativer Charakterisierung repräsentativer Einzelkolonien (CFU) erfasst [3]. Durch Gensequenzierung wurde der emm-Typ aller GAS nach internationalem Konsensus-Protokoll bestimmt [4]

Ergebnisse: Bei 1,3\% (9/677) der GAS war eine starke und bei 2,8\% (19/677) der GAS war eine schwache $\mathrm{H}_{2} \mathrm{O}_{2}$-Produktion nachweisbar. 95,9\% (649/677) der GAS zeigten keine $\mathrm{H}_{2} \mathrm{O}_{2}$-Produktion.

Diskussion und Schlussfolgerung: Die untersuchten klinischen GAS-Isolate wiesen eine unterschiedliche $\mathrm{H}_{2} \mathrm{O}_{2}$-Produktion auf. Diese kann bei vorhandenem $1 c t O$ Gen durch eine unterschiedliche Aktivität der LaktatOxidase bedingt sein. Da unter gleichen Nährstoffbedingungen bei 4,1 \% der GAS-Isolate phänotypisch durch Nachweis der $\mathrm{H}_{2} \mathrm{O}_{2}$-Produktion eine aktive Laktat-Oxidase gefunden wurde, liegt neben dem Glukose-Repressor CcpA [5] ein weiterer Regulationsmechanismus der $\mathrm{H}_{2} \mathrm{O}_{2}$-Produktion bei GAS nahe. Da dieser Phänotyp mit bestimmten emm-Typen assoziiert ist (GAS-Typ emm75, emm12, STG485, emm3, emm6, emm28, emm36), kann eine pathogenetische Rolle dieses Regulationsmechanismus angenommen werden, die stammspezifisch zu sein scheint und in weiteren Untersuchungen zu charakterisieren wäre.

\section{Literatur}

1. Pericone CD, Overweg K, Hermans PW, Weiser JN (2000) Inhibitory and bactericidal effects of hydrogen peroxide production by Streptococcus pneumoniae on other inhabitants of the upper respiratory tract. Infect Immun 68:3990-3997

2. Rai P, Parrish M, Tay IJ et al (2015) Streptococcus pneumoniae secretes hydrogen peroxide leading to DNA damage and apoptosis in lung cells. Proc Natl Acad Sci U SA 112:E3421-3430

3. Saito M, Seki M, lida K et al (2007) A novel agar medium to detect hydrogen peroxide-producing bacteria based on the prussian blue-forming reaction. Microbiol Immunol 51:889-892

4. http://www.cdc.gov/streplab/protocol-emm-type. Zugegriffen: 01.12.2014

5. Kietzman CC, Caparon MG (2009) CcpA and LacD.1 affect temporal regulation of Streptococcus pyogenes virulence genes. Infect Immun 78:241-252

\section{PAT-P02 \\ Phagozytose von E. coli führt bei granulozytären MDSC zu einer verstärkten Expression von antiinflammatorischen Zytokinen}

J. Schwarz, A. Leiber, N. Köstlin, B. Spring, C. Poets, C. Gille

Universitätsklinkum Tübingen, Kinderklinik Neonatologie, Tübingen, Deutschland

Hintergrund: Neonatale bakterielle Infektionen bestimmen wesentlich Morbidität und Mortalität von Früh- und Neugeborenen. Pathophysiologisch spielen die begleitende Entzündungsreaktion und die nachfolgende Gewebsschädigung in Lunge und Gehirn eine wichtige Rolle. Über welche Mechanismen die Entzündungsreaktion kontrolliert wird ist unklar. Myeloide Suppressorzellen (MDSC) sind Vorläuferzellen von Granulozyten, die antiinflammatorisch wirken. Unsere Vorergebnisse zeigten, dass MDSC in erhöhter Zahl im Nabelschnurblut (NSB) vorkommen und die Fähigkeit besitzen, Bakterien zu phagozytieren.

Fragestellung: Haben MDSC aus Nabelschnurblut (NSB) nach Infektion mit Escherichia coli (E.coli) antiinflammatorische Effekte?

Material und Methoden: In einem in-vitro-Modell mit E. coli wurden granulozytäre MDSC und reife Granulozyten aus NSB durchflusszytometrisch auf die Expression von IL-8, IFN-gamma, IL-10, IL-4, IL-13, TGFbeta, sowie der beiden programmed cell death Liganden 1 und 2 (PD-L1 und PD-L2) untersucht. 
Ergebnisse: MDSC produzierten sowohl basal als auch nach Infektion mit E. coli mehr der antiinflammatorischen Zytokine TGF-beta und IL-13 im Vergleich zu Granulozyten. Gleichzeitig wurde die Expression des proinflammatorischen Zytokins IL- 8 bei MDSC weniger stark induziert als bei reifen Granulozyten. MDSC produzierten weniger IL-4, IL-10 und IFNgamma als Granulozyten. Infektion mit E. coli steigerte die Expression des co-inhibitorischen Moleküls PD-L1 in MDSC, nicht jedoch bei Granulozyten, während PD-L2 bei beiden Zellarten hochreguliert wurde.

Schlussfolgerung und Diskussion: Insgesamt zeigte sich hier bei MDSC ein Überwiegen der anti-inflammatorischen Zytokine im in-vitro-Modell. Dies unterstreicht eine wichtige Rolle von MDSC in der neonatalen Infektion. Zum einen unterstützen sie das noch unreife Immunsystem durch ihre Fähigkeit, Phagozytose zu betreiben, aktiv bei der Abwehr von bakteriellen Erregern, andererseits scheinen sie durch ihr antiinflammatorisches Profil auch ein wichtiger Schutzmechanismus gegen überschießende Immunreaktionen zu sein. Die Rolle der MDSC in der akuten neonatalen Infektion sowie in der Entwicklung von chronisch-entzündlichen Erkrankungen (z. B. BDP, PVL) soll im Weiteren mithilfe eines Sepsis-Mausmodells geklärt werden.

\section{PAT-P03}

Dosisabhängige Reduktion der Varizella-Zoster-Virus (VZV)spezifischen T-zellulären Immunantwort nach in vitro Behandlung mit Tofacitinib

\section{F. Kienle, G. Almanzar, M. Prelog}

Universitäts-Kinderklinik Würzburg, Würzburg, Deutschland

Hintergrund: Autoimmunarthritiden (AIA) sind lymphozytär vermittelte chronisch-entzündliche Erkrankungen, die in verschiedenen Formen be Kindern und Erwachsenen vorkommen. Tofacitinib, ein JAK-Inhibitor, wurde als neue Substanzklasse zur Therapie von Autoimmunarthritiden zugelassen. Es hemmt die Isotypen JAK-3 und JAK-1 und vermindert dadurch die Expression von Zytokinen, welche bei Lymphozytendifferenzierung und -funktion eine Rolle spielen. Einige Studien zeigten jedoch eine Erhöhung der Inzidenz eines Herpes Zoster bei AIA-Patienten, welche mit Tofacitinib (Zosterfälle 44-77/1000 Patientenjahre) behandelt wurden gegenüber der Behandlung mit Biologika (Infliximab/Adalimumab: 11,1/1000 Patientenjahre) oder DMARDs (5,6/1000 Patientenjahre).

Fragestellung: Ziel dieser Studie ist es, den Einfluss von Tofacitinib auf die proliferative und funktionale VZV-spezifische T-Zell-Immunantwort zu untersuchen.

Methoden: Die IFN $\gamma$-Produktion und die Proliferation VZV-spezifischer T-Zellen wurde in 500.000 Peripheral Blood Mononuclear Cells (PBMCs) nach Stimulation mit VZV-Lysat und verschiedenen Konzentrationen Tofacitinib mittels Elispot $(n=35)$ bzw. Zellkultur $(n=6)$ bestimmt. Für die Zellkultur wurden PBMCs mit CFSE markiert und deren Proliferation durchflusszytometrisch bestimmt. Ohne Stimulus bzw. antiCD3/antiCD28 wurden als Negativ- bzw. Positivkontrolle verwendet.

Ergebnisse: Tofacitinib vermindert dosisabhängig die T-Zell-spezifische IFN $\gamma$-Produktion nach Stimulation mit VZV-Lysat (0 mM: $197 \pm 33$ spot forming units/1x106 PBMCs; $1 \mathrm{mM}$ : 139 $\pm 17 ; 10 \mathrm{mM}$ : 76 $\pm 12, p=0,004)$ bzw. nach unspezifischer T-Zell-Stimulation mit antiCD3/antiCD28 (0 $\mathrm{mM}: 1332 \pm 552,1 \mathrm{mM}$ : 913 $\pm 424, p<0,001 ; 10 \mathrm{mM}$ : 506 $\pm 404, p<0,001)$. Darüber hinaus vermindert Tofacitinib dosisabhängig die Proliferationsrate VZV-spezifischer T-Zellen nach Stimulation mit VZV-Lysat (0 mM Tofacitinib: $6,58 \% ; 1 \mathrm{mM}: 3,76 \%, 10 \mathrm{mM}: 3,38 \%)$. Interessanterweise zeigten sich diese Effekte auch nach unspezifischer T-Zell-Stimulation mit antiCD3/antiCD28 (0 mM: 78,4\%; 1 mM: 58,4\%, $p=0,006,10 \mathrm{mM}: 26,4 \%, p<0,001$ ). Diskussion: Unsere Ergebnisse zeigen, dass Tofacitinib nicht nur die allgemeine proliferative und IFN $\gamma$-Antwort vermindert, sondern auch jene auf VZV Antigene. Die bereits bei gesunden Probanden gezeigten Resultate betonen die Notwendigkeit einer besonderen Aufmerksamkeit für die Reaktivierung von VZV durch den Einsatz von JAK-Inhibitoren bei der Behandlung von AIA.

\section{PAT-P04}

Neugeborenen-Screening für schwere angeborene Immundefekte - Umsetzung in die Praxis

\section{S. Borte ${ }^{1}$, A. Pöge ${ }^{2}$, R. Zetterström ${ }^{2,3}$, L. Hammarström ${ }^{2,3,4}$, M. Borte $^{1}$}

${ }^{1}$ Klinikum St. Georg Leipzig, ImmunDefektCentrum Leipzig, Leipzig,

Deutschland, ${ }^{2}$ Klinikum St. Georg Leipzig gGmbH, Zentrum für

Mikrobiologie, klinische Chemie und Laboratoriumsmedizin, Leipzig,

Deutschland, ${ }^{3}$ Karolinska Institutet, Centre for Inherited Metabolic Disorders, Stockholm, Sverige, ${ }^{4}$ Karolinska Institutet, Division of Clinical Immunology, Huddinge, Sverige

Hintergund: Schwere angeborene Immundefekte sind durch das Fehlen von T- und/oder B-Lymphozyten (SCID, XLA) bei Geburt gekennzeichnet und stellen einen pädiatrischen Notfall dar, der unbehandelt mit einer hohen Morbidität und Mortalität belastet ist. Betroffene Neugeborene sind zumeist klinisch unauffällig, so dass diese Erkrankungen erst bei Eintreten schwerster infektiologischer Komplikationen bedacht werden. Obwohl genaue Inzidenzdaten fehlen, wird von einer Häufigkeit von mindestens 1:40.000 Lebendgeborene in der BRD ausgegangen. Die frühzeitige Diagnose, präventive postnatale Maßnahmen und eine Stammzelltherapie bei SCID und eine Immunglobulin-Substitutionstherapie bei XLA stellen etablierte und wirksame therapeutische Maßnahmen dar. Die aktuelle Bewertung durch das Institut für Qualität und Wirtschaftlichkeit im Gesundheitswesen (IQWiG) zeigt hierbei einen positiven Nutzen ein Neugeborenen-Screening für schwere angeborene Immundefekte.

Fragestellung: Die Praktikabilität eines kombinierten T-cell receptor exicision circle (TREC) und kappa-deleting recombination circle (KREC) qPCR-Tests sollte mit regulären Neugeborenenproben aus Leipzig/BRD und Stockholm/Schweden prospektiv untersucht werden. Weiterhin sollten Verfahrenswege erarbeitet werden, die Screening, Tracking, Therapie und Follow-up für schwere angeborene Immundefekte strukturieren.

Material und Methoden: Zwischen 2013 und 2015 wurden insgesamt 65.320 Neugeborene in Leipzig und Stockholm mit diesem kombinierten TREC/KREC-Screeningtest untersucht. Die diagnostischen Grenzwerte des Tests wurden im Verlauf gezielt alteriert, um Testcharakteristika zu ermitteln. Das weitere diagnostische Procedere bei positiven Erstscreening (Wiederholungsmessungen, Bestätigungstests, klinische Vorstellung) wurde im Verlauf erprobt.

Ergebnisse: Das kombinierte TREC-KREC-Neugeborenscreening weist Testcharakteristika auf, die mit etablierten Screeningtests vergleichbar sind. Es wurden 3 Patienten mit schwerem kombiniertem Immundefekt (SCID) identifiziert, so dass in dieser urbanen Kohorte von einer Häufigkeit von 1:22.000 Lebendgeborene ausgegangen werden muss. Alle SCID Patienten wurden erfolgreich bei minimaler Konditionierung stammzelltransplantiert. Die erarbeiteten klinischen Verfahrenswege halfen wirksam, Neonaten mit sekundären Defekten der Immunentwicklung (Frühgeburtlichkeit, syndromale Entwicklungsstörungen) von Patienten mit schweren angeborenen Immundefekten zu unterscheiden.

Diskussion oder Schlussfolgerung: Ein Neugeborenen-Screening für schwere angeborene Immundefekte kann effektiv die Früherkennung betroffener Neonaten und deren zeitnahe kurative Therapie ermöglichen. Aufgrund der aktuellen positiven Nutzenbewertung muss mit einer Empfehlung des Gemeinsamen Bundesausschusses (GBA) zur Einführung ins Routine-Neugeborenenscreening gerechnet werden. Die Arbeitsgemeinschaft Pädiatrische Immunologie (API) hat hierzu bereits praxisnahe Verfahrenswege für die klinische Diagnostik und Therapie erarbeitet, die auch auf internationalen Erfahrungen beruhen und somit eine rasche Implementierung ermöglichen können. 
PAT-P05

\section{Untersuchungen zur Rolle des Tumor Necrosis Factor Related Apoptosis Inducing Ligand (TRAIL) bei E.coli-Infektion von Neugeborenen}

\author{
N. U. Hartmann, S. Dreschers, T. Orlikowsky \\ Uniklinik RWTH Aachen, Neonatologie, Aachen, Deutschland
}

Hintergrund: Virale und bakterielle Infektionen führen bei Frühgeborenen häufig zu inflammatorischen Folgeerkrankungen. Im Vergleich zu Erwachsenen zeigen neonatale Monozyten (CBMO) deutlich weniger Apoptose nach bakterieller Infektion als adulte Monozyten (PBMO). Ursächlich hierfür sind Unterschiede in der pro-apoptotischen Signalübertragung von FAS-L und TNF-alpha, welche zur TNF-Superfamilie gehören. Ebenfalls dazu zählt TRAIL (Tumor Necrosis Factor Related Apoptosis Inducing Ligand) mit seinen Rezeptoren DR1-DR5. DR4 und DR5 vermitteln Todessignale über zwei Wege (extrinsisch sowie intrinsisch). Der Apoptosemechanismus von TRAIL kann von Viren (Cytomegalie, Herpes simplex, Influenza) und Bakterien (S. aureus, E. coli) dazu benutzt werden, die T-Lymphozyten Antwort gegen infizierte Zellen zu regulieren.

Hypothese: Die TRAIL-abhängige Apoptose bei CBMO ist ebenso wie bei FAS-L und TNF-alpha im Vergleich zu PBMO reduziert. Dies lässt sich auf unterschiedliche Expression von DR4 und DR5 sowie Unterschiede im extrinsischen und intrinsischen Apoptoseweg zurückführen.

Methoden: PBMO und CBMO wurden mit E.coli $(\mathrm{MOI}=20)$ infiziert. Inkubation mit TRAIL ( $1 \mu \mathrm{g} / \mathrm{ml}$ ) und phänotypische Bestimmung von Monozyten, durchflusszytometrische Analyse von Caspase-Konzentrationen sowie zellulärer Apoptose (FACS).

Ergebnisse: Die basale DR4/DR5-Rezeptorexpression bei PBMO und CBMO war identisch. $24 \mathrm{~h}$ nach $E$. coli-Infektion zeigte sich bei DR4 auf PBMO eine Zunahme der Rezeptorexpression ( $p<0,05$ vs. CBMO). PBMO zeigen nach $48 \mathrm{~h}$ Inkubation mit TRAIL signifikant Apoptose, diese war bei CBMO deutlich reduziert $(p<0,05)$. Gleiches Verhalten zeigte sich nach Infektion mit E.coli. Ein additiver apoptotischer Effekt von TRAIL und E. coli zeigte sich nicht. Die Caspase- 8 war bei PBMO sowohl in der TRAIL- als auch in der Infektionsgruppe im Vergleich zu CBMO deutlich erhöht ( $p<0,05$ vs. CBMO). Intrazellulär zeigte sich durchweg eine höhere Expression des anti-apoptotischen Proteins bcl-2 bei CBMO. Schlussfolgerung: Die Apoptose neonataler Monozyten durch TRAIL ist im Vergleich zu Erwachsenen reduziert. Ursachen hierfür zeigen sich im extrinsischen sowie intrinsischen Apoptosesignalweg. Die geringere neonatale Apoptose von Monozyten unter inflammatorischen Bedingungen kann in einer verlängerten Entzündungsreaktion bei Früh- und Neugeborenen resultieren.

\section{PAT-P06}

\section{Outcome von Kindern und Jugendlichen mit Hämolytisch- urämischem Syndrom: Eine Single-Center-Analyse von 312 Fällen}

L. Vaterodt' ${ }^{1}$ J. Holle' ${ }^{2}$, J. Thumfart' ${ }^{1}$, D. Hüsemann ${ }^{3}$, D. Müller ${ }^{1}$

${ }^{1}$ Charité-Universitätsmedizin Berlin, Klinik für Pädiatrie m. S. Nephrologie, Berlin, Deutschland, ${ }^{2}$ Charité-Universitätsmedizin Berlin, Klinik für Pädiatrie m.S. Pneumologie und Immunologie, Berlin, Deutschland, ${ }^{3}$ Klinikum Barnim, Barnim, Deutschland

Hintergrund: Das Hämolytisch-urämische Syndrom (HUS) ist bei Kindern die häufigste Ursache des akuten intrarenalen Nierenversagens. $90 \%$ der Erkrankungen im Kindesalter sind auf Infektionen mit Shigatoxinproduzierenden E. coli (STEC-HUS) zurückzuführen. Ferner werden nach pathophysiologischen Erkenntnissen Komplement-assoziierte Erkrankungen sowie weitere Formen unterschieden. In dieser Single-Center-Analyse präsentieren wir Daten zum kurz- und langfristigen Verlauf des HUS zwischen 1976 und 2014

Fragestellung: Klinische Präsentation, Therapie und Outcome von Kindern mit HUS

Material und Methoden: Retrospektive Single-Center-Analyse klinischer und laborchemischer Parameter der Akutphase und der 1- bis 10-JahresNachuntersuchungen von an einem HUS erkrankten Kindern aus dem
Zeitraum 1996-2014 (Gruppe 1). Vergleich mit einer historischen Kohorte von 1976-1996 (Gruppe 2).

Ergebnisse: Im Zeitraum zwischen 1976 und 2014 wurden 312 Kinder mit einem HUS in die Auswertung eingeschlossen, davon 92 Patienten im Zeitraum von 1996-2014. In Gruppe 1 wurde bei 76 Patienten ein STECHUS und bei 16 Patienten ein Komplement-assoziiertes oder eine andere HUS-Form diagnostiziert. Im STEC-HUS-Kollektiv wurden zunehmend andere Erreger als EHEC O157 nachgewiesen. Bei mehr als $75 \%$ der Patienten war eine Nierenersatztherapie notwendig, wobei am häufigsten Peritonealdialyse eingesetzt wurde. Extrarenale Manifestation kamen in 35\% der STEC-HUS Patienten und in $68 \%$ der sonstigen HUS-Formen vor. Die Mortalität lag bei 1,3\% beim STEC-HUS und bei 6,3\% bei sonstigen HUS-Formen. Im Vergleich zur historischen Kohorte war die Mortalität rückläufig. Im Langzeitverlauf zeigten mehr als $40 \%$ der STEC-HUS-Patienten renale Residuen (Proteinurie, arterielle Hypertonie, GFR $<90 \mathrm{ml} /$ min). Alle Patienten mit sonstigen HUS-Formen zeigten renale Folgeschäden. Es zeigte sich eine Korrelation zwischen arterieller Hypertonie in der Akutphase und Anuriedauer $>7 \mathrm{~d}$ mit persistierender Nierenfunktionseinschränkung. Das Alter der Patienten, Geschlecht, Ausmaß der Thrombozytopenie und Leukozytose zeigten keinen Einfluss auf das Outcome der Patienten. Es zeigte sich ein frühes Ausscheiden von mehr als $50 \%$ der Patienten aus der regelmäßigen ambulanten Nachbetreuung.

Schlussfolgerung: Die Mortalität des HUS ist im Laufe der Jahre rückläufig und beim STEC-HUS geringer als beim Komplement-assoziierten HUS. Renale Spätfolgen sind häufig und korrelieren mit arterieller Hypertonie in der Akutphase und einer Anuriedauer von mehr als 7 Tagen.

Die Nachsorge von Kindern und Jugendlichen nach Erkrankung an einem HUS sollte verbessert werden.

\section{PAT-P07}

\section{Myeloide Suppressorzellen (MDSC) aus der Muttermilch hemmen} die T-Zell-Antwort beim Neugeborenen

N. Köstlin, J. Schwarz, C. Schoetensack, B. Spring, R. Goelz, C. F. Poets, C. Gille Universitäts-Kinderklinik Tübingen, Neonatologie, Tübingen, Deutschland

Hintergrund: Die nekrotisierende Enterokolitis (NEC) ist eine der wichtigsten Todesursachen von Frühgeborenen. Sie tritt bei ca. $7 \%$ aller VLBW-Kinder auf und hat eine Mortalität von 20-30\%. Wichtige Risikofaktorenfür eine NEC sind Formula-Ernährung statt Muttermilch und ein verändertes Darm-Mikrobiom. Myeloide Suppressorzellen (MDSC) sind myeloide Zellen mit hemmender Wirkung auf Zellen des angeborenen und des erworbenen Immunsystems. MDSC kommen in Schwangerschaft und Fetalzeit in erhöhter Zahl vor und sind wahrscheinlich wichtig für die Aufrechterhaltung der feto-maternalen Toleranz. Die wichtigsten Effektormechanismen, über die MDS ihre suppressive Wirkung ausüben sind die Expression der Enzyme ArginaseI (ArgI), induzierbare NO-Synthase (iNOS), Indolamin-2,3-Dioxygenase (IDO) und auf die Produktion reaktiver Sauerstoffspezies (ROS). Ob MDSC auch in der Muttermilch vorhanden sind und die Immunantwort im Darm des Neugeborenen beeinflussen ist bisher nicht untersucht.

Fragestellung: Sind MDSC in der Muttermilch enthalten und beeinflussen sie die intestinale Immunantwort des Neugeborenen?

Methoden: Mononukleäre Zellen (MNC) wurden aus der Muttermilch gesunder Mütter und aus dem peripheren Blut gesunder Erwachsener (PBMC) mittels Dichtegradientenzentrifugation isoliert und der Anteil CD66b+/CD33+/CD14-/HLA-DRlow/- MDSC durchflusszytometrisch quantifiziert. Darminhalt neugeborener Mäusefeten wurde entnommen und der Anteil Gr1+/CD11b+ MDSC an darin enthaltenen CD45+ Leukozyten durchflusszytometrisch quantifiziert. MDSC aus der Muttermilch wurden durchflusszytometrisch auf die von ArgI, iNOS, IDO und auf die Produktion von ROS analysiert. MDSC aus der Muttermilch wurden mittels magnetic activated cell sorting angereichert und zu CFSE-markierten und mit OKT3/IL-2 stimulierten PBMC gegeben. Nach 96 Stunden wurde die T-Zell-Proliferation durchflusszytometrisch ermittelt.

Ergebnisse: MDSC waren bei Mensch und Maus in der Muttermilch enthalten. Der Anteil von MDSC an in der Muttermilch enthaltenen MNC 
lag zwischen $21 \%$ und $97 \%(n=10)$. MDSC aus der Muttermilch exprimierten die Effektorenzyme ArgI, iNOS und IDO und produzierten ROS. Zugabe von MDSC aus der Muttermilch zu stimulierten PBMC führte zu einer Hemmung der T-Zell-Proliferation um $63 \%$ (CD4+) bzw. $45 \%$ (CD8+, je $n=5, p<0,05)$. Die hemmende Wirkung von MDSC aus der Muttermilch auf die T-Zell-Proliferation war konzentrationsabhängig. Schlussfolgerung: MDSC sind in der Muttermilch enthalten und hemmen die T-Zell-Antwort. Die immunsuppressiven Eigenschaften von MDSC aus der Muttermilch könnten eine wichtige Rolle bei der Etablierung des intestinalen Mikrobioms von Neugeborenen spielen und damit das Auftreten der NEC günstig beeinflussen.

\section{Sepsis}

\section{SEP-P01 \\ Epidemiology of Blood Culture-proven Sepsis in Children in Switzerland - a Prospective Population-based Cohort Study}

U. Heininger', P. Agyeman', L. Schlapbach', E. Giannoni'3, M. Stocker', K. M. Posfay-Barbe ${ }^{5}$, M. Schindler 6 , G. Konetzny ${ }^{7}$, A. Niederer-Loher ${ }^{8}$, C. Kahlert ${ }^{8}$, A. Donas ${ }^{4}$, A. Leone ${ }^{9}$, P. Hasters ${ }^{9}$, C. Relly' ${ }^{10}$, W. Baer ${ }^{11}$, C. Kuehni', C. Aebi ${ }^{1}$, C. Berger ${ }^{10}$ For the Swiss Pediatric Sepsis Study Group

'Department of Pediatrics, Inselspital, Bern University Hospital, University of Bern, Switzerland, ${ }^{2}$ Paediatric Critical Care Research Group, Mater Research Institute, University of Queensland, Brisbane, Australia, ${ }^{3}$ Service of Neonatology, Lausanne University Hospital and University of Lausanne, Lausanne, Switzerland, ${ }^{4}$ Department of Pediatrics, Childrens Hospital Lucerne, Lucerne, Switzerland, ${ }^{5}$ Pediatric Infectious Diseases Unit, Childrens Hospital of Geneva, University Hospitals of Geneva and University of Geneva, Geneva, Switzerland, ' $I$ nstitute of Social and Preventive Medicine, University of Bern, Bern, Switzerland, ${ }^{7}$ Childrens Hospital Aarau, Aarau, Switzerland, ${ }^{8}$ Childrens Hospital of Eastern Switzerland St. Gallen, St. Gallen, Switzerland, ${ }^{9}$ Department of Neonatology, University Hospital Zurich, Zurich, Switzerland, ${ }^{10}$ Division of Infectious Diseases and Hospital Epidemiology, and Childrens Research Center, University Childrens Hospital Zurich, Switzerland, ${ }^{11}$ Childrens Hospital Chur, Chur, Switzerland

Background: Sepsis is among the leading causes of childhood mortality worldwide. We assessed population-based incidence and outcomes of blood culture-proven sepsis in children in Switzerland.

Methods: Multicenter national prospective cohort study including children with blood culture-proven sepsis

Findings: Among 1085 children with blood culture-proven sepsis, 199 (18\%) presented with septic shock. The incidence of sepsis was 22.1/100'000 children (95\% CI 20.9-23.4), with highest rates in neonates (126.0/100'000; 95\% CI 114.1-138.8). The case fatality rate was $6.8 \%$ increasing to $26 \%$ in septic shock, and was significantly higher in neonates (11\%) and children with comorbidities $(6.8 \%)$ compared to previously healthy children (2.4\%; OR 2.7, 1.1-7.6; and OR 2.5, 1.1-6.2). Central line-associated blood stream infection $(259,24 \%)$ and primary bloodstream infection $(223,21 \%)$ were the most common manifestations. E. coli $(230,21 \%)$, S. aureus $(162,15 \%)$, coagulase-negative staphylococci (117, $11 \%)$, and S. pneumoniae $(115,11 \%)$ accounted for $58 \%$ of sepsis cases. Interpretation: This population-based study defines the burden of bacterial sepsis on child health in the era of widespread vaccinations and reveals key differences pertinent to predominant organisms, severity, and outcome between neonates, previously healthy children and those with comorbidities, which may help to guide future targeted interventions.

Funding: This study was funded by grants from the Swiss National Science Foundation (342730_153158/1), the Swiss Society of Intensive Care, the Bangerter Foundation, the Vinetum and Borer Foundation, and the Foundation for the Health of Children and Adolescents.

\section{SEP-P02}

Erhöhte Sterblichkeit bei gramnegativer Bakteriämie durch 3oder 4-MRGN: Ergebnisse einer retrospektiven Analyse positiver Blutkulturen einer Kinderklinik über 8 Jahre

\section{Erdogan', J. Steinmann', U. Felderhoff-Müser', P. M. Rath²,} C. Dohna-Schwake'

${ }^{1}$ Kinderklinik I, Pädiatrische Intensivmedizin, Essen, Deutschland, 2Universitätsklinikum, Insitut für Medizinische Mikrobiologie, Essen, Deutschland

Hintergrund: Blutstrominfektionen durch gramnegative Stäbchen-Bakterien gehen mit erheblicher Morbidität und Mortalität einher. In den letzten Jahren ist es zu einem zunehmenden Auftreten von multi-resistenten Bakterien gekommen. Der Einfluss auf das Outcome vor allem im Kindesalter ist bisher nicht ausreichend untersucht.

Fragestellung: Wie ist der Einfluss von Multi-Resistenz auf das Outcome von Kindern mit gram-negativer Bakteriämie?

Methoden: Retrospektive Untersuchung aller positiven Blutkulturen mit gramnegativen Stäbchen von 2008 bis 2015 einer Universitäts-Kinderklinik.

Ergebnisse: Von insgesamt 888 positiven Blutkulturen wurden bei 222 Blutkulturen gramnegative Stäbchen nachgewiesen. Als häufigste Erreger konnten E. coli (30\%), Klebsiella species (19\%) und Enterobacter spp. (16\%) isoliert werden. 172 (77\%) Patienten galten zum Zeitpunkt der positiven Blutkultur als immunsupprimiert. 103/222 Patienten waren bereits auf der Intensivstation oder wurden dorthin verlegt. Insgesamt starben 12 Patienten (5\%). Diese zeigten im Vergleich zu den Überlebenden ein signifikant erhöhtes Procalcitonin $(p=0,02)$ sowie vergleichbare CrP-Werte und Leukozyten-Zahlen. In den Blutkulturen von 42 der Patienten fanden sich gram-negative Stäbchen mit Resistenzen gegen 2 der 4 definierten Antibiotika-Klassen (2-MRGN), und in 27 Blutkulturen fanden sich 3- oder 4-MRGN. Die Mortalität stieg von $3 \%$ bei nicht-MRGN-Keimen über $7 \%$ bei 2-MRGN auf $15 \%$ bei 3- und 4-MRGN (statistisch signifikant für den Vergleich von sensibel zu 3- oder 4-MRGN).

Schlussfolgerung: In dieser retrospektiven Untersuchung positiver Blutkulturen mit gramnegativen Stäbchen bestätigte sich die klinische Relevanz von multi-resistenten Stämmen. Prospektive Studien zur Überprüfung dieser Ergebnisse und zur Erkennung von Patienten mit erhöhtem Risiko für multiresistente Bakterien sind dringend erforderlich.

\section{SEP-P03}

5-Jahres- Häufigkeit und molekulare Diversität invasiver ß-hämolysierender Streptokokken am Universitätsklinikum Dresden

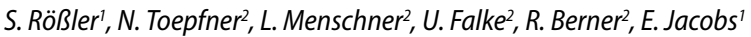
${ }^{1}$ Institut für Medizinische Mikrobiologie und Hygiene, Technische Universität Dresden, Dresden, Deutschland, ${ }^{2}$ Klinik und Poliklinik für Kinder- und Jugendmedizin, Carl Gustav Carus Universitätsklinikum, Dresden, Deutschland

Hintergrund: S. dysgalactiae (Lancefieldgruppe C oder G) gehören wie $S$. pyogenes (Lancefieldgruppe A) und S. agalactiae (Lancefieldgruppe B) zur morphologischen Gruppe der ß-hämolysierenden Streptokokken (BHS; [1]) und werden in zunehmender Häufigkeit bei invasiven Infektionen nachgewiesen [2]. Als Virulenzfaktoren wurden Emm-Proteine und Superantigene für beide Spezies beschrieben [3].

Fragestellung: (i) 5-Jahres-Prävalenz von S. dysgalactiae als Erreger invasiver Infektionen an einem 1295- Betten-Universitätsklinikum der Maximalversorgung und Vergleich zur Prävalenz anderer invasiver Erreger. (iiiv) Charakterisierung der molekulargenetischen Diversität von invasiven S. dysgalactiae und S. pyogenes-Isolaten.

Material und Methoden: ( $i$ ) Retrospektive Auswertung des jeweils ersten positiven Nachweises in eingesandter Blutkultur (BK) oder Liquor pro Patient und 90 Tage Aufenthaltsdauer im Zeitraum 2012-2016. Die (ii) Isolatanzucht auf $5 \%$ Columbia Schafsblutagar, Identifizierung mittels VITEK2/MALDI-TOF und Lancefield- Latexagglutination, (iii) moleku- 
largenetische Typisierung nach etablierten Protokollen [5, 6]. (iv) Berechnung der emm- Typ-Diversität mittels Simpson-Index, statistische Analyse mittels Fisher"s Exact Test.

Ergebnisse: (i) Von 7044 (13\%) positiven aus 55.839 BK waren 6,2\% BK Streptokokken-positiv. E. coli und S. aureus wurden in 1011 (14,4\%) bzw. 676 (10\%) BK nachgewiesen. Die Streptokokken-Differenzierung in den BK ergab 134 (1,9\%) BHS (33 S. pyogenes, 56 S. agalactiae, 45 S. dysgalactiae), $64(0,9 \%)$ S. pneumoniae und 236 (3,4\%) Viridans- Streptokokken. In 205 (2,4\%) positiven von 8412 Liquores waren 11,7\% Streptokokkenpositiv. E. coli und S. aureus wurden in $10(4,9 \%)$ und 17 (8,3\%) Liquores nachgewiesen. Die Differenzierung in den Liquores ergab 6 BHS- Isolate (2S. pyogenes, 4 S. agalactiae), jeweils 9 S. pneumoniae und ViridansStreptokokken.

Diskussion: (i) Mit einer positiven BK-Rate von 1,9\% war die Prävalenz von BHS doppelt so hoch wie die Prävalenz von S. pneumoniae. Dieses Ergebnis unterstreicht, dass BHS eine bedeutende Rolle als invasive Erreger zukommt $\{2\}$. (iv) Besonders interessant erscheint, dass sich die Biodiversität von $S$. dysgalactiae der Lancefieldgruppe C (GCS) von der Biodiversität von $S$. dysgalactiae der Lancefieldgruppe G (GGS) unterschied. Alle GCS waren vom $\mathrm{emm}$-Sequenztyp stG62647.0, (Biodiversität=0), während GGS und S. pyogenes (GAS) eine höhere Biodiversität mit 7 bzw. $10 \mathrm{emm}$-(Sequenz)-Typen aufwiesen. (iii) Das Virulenzfaktorprofil von $S$. dysgalactiae (GCS und GGS) unterschied sich deutlich vom Virulenzfaktorprofil der GAS $(p<0,0001)$. Da bei invasiven S. dysgalactiae keine (GCS) bzw. nur sehr vereinzelt (GGS) Superantigene auftraten, ist anzunehmen, dass die Pathogenese invasiver $S$. dysgalactiae Infektionen nicht primär Superantigen-getriggert ist.

\section{Literatur}

1. Thompson CC, Emmel VE, Fonseca EL et al (2013) Streptococcal Taxonomy Based on Genome Sequence Analyses F1000. Research 2:67

2. Rantala S (2014) Streptococcus dysgalactiae subsp. equisimilis bacteremia: an emerging infection. Eur J Clin Microbiol Infect Dis 33:1303-1310

3. Brandt CM, Spellerberg B (2009) Human infections due to Streptococcus dysgalactiae subspecies equisimilis. Clin Infect Dis 49:766-772

4. Sendi P, Johansson L, Norrby-Teglund A (2008) Invasive group B Streptococcal disease in non-pregnant adults: a review with emphasis on skin and soft-tissue infections. Infection 36:100-111

5. http://www.cdc.gov/streplab/protocol-emm-type. Zugegriffen: 01. 12. 2014

6. Borek AL, Obszańska K, Hryniewicz W, Sitkiewicz I (2012) Detection of Streptococcus pyogenes virulence factors by multiplex PCR. Virulence 3:529-533

\section{SEP-P04}

Unterschiede initialer klinischer und laborchemischer SepsisZeichen bei Reif- und Frühgeborenen: Ergebnisse einer retrospektiven Untersuchung

\section{T. Visser ', H. Ehrhardt' ${ }^{2}$, K. P. Zimmer ${ }^{2}$, M. Heckmann ${ }^{3}$, D. Faas ${ }^{4}$}

'St. Josefs Krankenhaus Balserische Stiftung, Chirurgie, Giessen, Deutschland, ${ }^{2}$ Universitätsklinikum Giessen und Marburg, Abteilung Allgemeinpädiatrie und Neonatologie, Giessen, Deutschland, ${ }^{3}$ Universitätsmedizin Greifswald, Zentrum für Kinder- und Jugendmedizin, Abteilung Neonatologie und Pädiatrische Intensivmedizin, Greifswald, Deutschland, ${ }^{4}$ Klinik Bavaria Zscheckwitz, Neurologisches Rehabilitationszentrum für Kinder, Jugendliche und junge Erwachsene, Kreischa, Deutschland

Hintergrund: Neugeboreneninfektionen (NG) sind schwerwiegende Erkrankungen und in der Neugeborenenperiode einer der häufigsten Gründe für eine Hospitalisation. Mit einer Letalität von bis zu $2 \%$ ist das rasche Erkennen und die Einleitung einer Therapie sehr wichtig [3, 6]. Bei nur geringem Probenmenge für die Blutkulturen sowie deren oftmals falsch negativen Ergebnissen kommt der Erkennung einer NG durch klinisch präsentierte Symptome ein hoher Stellenwert zu $[1,2,4,5]$.

Fragestellung: In dieser Studie wurden klinische Symptome und laborchemische Sepsismarker von an Neugeboreninfektion erkrankter Patienten erfasst und in Abhängigkeit des Gestationsalters (GA) ausgewertet.
Methoden: In einer retrospektiven Analyse wurden die laborchemische Sepsismarker (Differentialblutbild, CRP, IL6) aus den Patientenakten aller Neugengeborenen unseres Zentrums mit der Entlassdiagnose NG registriert (2007-2012). Die Patienten wurden hinsichtlich 15, für eine NG charakteristischen Symptome untersucht $[1,4,5]$. Aufgrund der primären Fragestellung (Sepsis-Relaps) wurden nur Patienten im unmittelbaren Einzugsgebiet eingeschlossen (315 von 558 Neugeborenen). Von den eingeschlossenen Patienten waren 219 (69,5\%) Reifegeborene (GA $37+0$ bis $42+0$ Schwangerschaftswochen (SSW), term TE), bei $54(17,1 \%)$ lag das GA zwischen $32+0$ und $36+6$ SSW (late preterm LP) und bei $42(13,3 \%)$ unter der $32+0$ SSW (preterm PT).

Ergebnisse: Die initialen IL-6 Werte lagen im Median bei den TE bei $30,1 \mathrm{pg} / \mathrm{ml}$ (Inter Quartile Range, IQR: 0,0-197,8), bei den LP bei $128,5 \mathrm{pg} / \mathrm{ml}(16,8-320,0)$ und bei den PT bei $10,0 \mathrm{pg} / \mathrm{ml}(0,0-52,0)$. Die initialen CRP Werte unterschieden sich ebenfalls: TE $15,2 \mathrm{mg} / \mathrm{l}(0,0-32,8)$, LP $0,0 \mathrm{mg} / \mathrm{l}(0,0-4,5)$ und PT $0,0 \mathrm{mg} / \mathrm{l}(0,0-10,3)$. Bezüglich der klinischen Symptome zeigten sich unterschiede in der Anzahl: TE 2 (IQR 1-3), LP 4 (2-4) und PT 5 (3-5) Die drei häufigsten Symptome bei TE und LP waren Atemstörungen (TE 51,1\%/LP 77,8\%), Apnoe und Sättigungsabfälle $(33,8 \% / 68,5 \%)$ und Trinkschwäche $(27,4 \% / 27,4 \%)$. Bei PT waren Apnoen/Sättigungsabfälle am häufigsten (95,2\%), vor Atemstörungen (83,3\%) und Trinkschwäche (73,8\%).

Schlussfolgerung: Im untersuchten Kollektiv waren die laborchemischen Sepsiszeichen bei TE häufiger positiv als bei LP und PT, aber im Gegensatz dazu zeigten LP und PT mehr und einheitlichere klinische Sepsiszeichen als die TE. Dies sollte bei Entscheidung zum Beginn einer antibiotischen Therapie berücksichtigt werden.

\section{Literatur}

1. Bekhof J, Reitsma JB, Kok JH et al (2013) Clinical signs to identify late-onset sepsis in preterm infants. Eur J Pediatr 172:501-508

2. Gerdes JS (2004) Diagnosis and management of bacterial infections in the neonate. Pediatr Clin North Am 51:939-959

3. Geschäftsstelle Qualitätssicherung Hessen (2016) Externe Qualitätssicherung in der stationären Versorgung Neonatologie. http://www.gqhnet.de/auswertungenstrukturierter-dialog/auswertungen/jahresauswertungen-2012/2012_neonatologie_basis. Zugegriffen: 19. Sept. 2016

4. Lim WH, Lien R, Huang YC et al (2012) Prevalence and pathogen distribution of neonatal sepsis among very-low-birth-weight infants. Pediatr Neonatol 53:228-234

5. Lutsar I, Chazallon C, Carducci Fl et al (2014) Current management of late onset neonatal bacterial sepsis in five European countries. Eur J Pediatr 173:997-1004

6. World Health Organization (2014) World Health Statistics 2014. World Health Organisation, Geneva

\section{SEP-P05}

Korrelation von klinischen und laborchemischen Variablen bei Reifgeborenen mit Neugeboreneninfektion/Early-onset Sepsis

C. H. Reber, J. Lubig, N. Gratzki, P. Morhart, T.M. K. Völkl

Universitätsklinikum Erlangen, Kinder- und Jugendklinik, Erlangen, Deutschland

Hintergrund und Fragestellung: Eine Neugeboreneninfektion oder Earlyonset Sepsis (EOS) betrifft bis zu 10\% aller Neugeborenen. Ziele der Untersuchung waren Analyse der Verlässlichkeit und wechselseitigen Korrelation klinischer und laborchemischer Standardparameter sowie die Frage, ob nach Abschluss eines Therapiezyklus eine (ambulante) Laborkontrolle notwendig ist.

Patienten und Methoden: Insgesamt wurden $n=531$ Reifgeborene (ab der 37.+0 SSW; 63,5\% Jungen), die innerhalb der ersten Lebenswoche wegen (V.a.) eine Neugeboreneninfektion/EOS stationär behandelt wurden, retroperspektiv untersucht. Extern geborene Kinder wurden nicht eingeschlossen. Alle Kinder erhielten eine intravenöse antibakterielle Therapie. Ergebnisse: Es fielen 264 (49,7\%) Kinder mit klinischen Infektzeichen (reduzierte RKZ, irritabel, berührungsempfindlich u. ä.) auf. Eine Leukozytose zeigte sich bei 359 Kindern (67,6\%); ein CrP > 5 mg/l bei 419 (78,9\%), davon nur bei 179 (33,7\%) mit klinischen Zeichen. Insgesamt zeigte sich sogar ein negativer signifikanter $(p<0,0001)$ Zusammenhang zwischen 
klinischen Zeichen und einem $\mathrm{CrP}>5$ bzw. $>10 \mathrm{mg} / \mathrm{l}$, was auf die Indikationsstellung einer Therapie zurückzuführen ist: entweder ein erhöhter CrP-Wert oder klinischer V. a. eine Infektion. Selbst Kinder mit einem initialen $\mathrm{CrP}>60 \mathrm{mg} / \mathrm{l}$ hatten in 45,5\% der Fälle keine typischen Symptome. Reifgeborene 40. SSW hatten ein signifikant niedrigeres CrP (Median 7,8 vs $16,2 \mathrm{mg} / \mathrm{l} ; p<0,0001$; Spearman (SSW vs CrP) $\mathrm{r}=0,208, p<0,0001$ ), bei gleicher Gesamt-Leukozytenzahl. Auch der maximale CrP-Peak im Verlauf war bei jüngerem Gestationsalter niedriger (Median 14,2 vs 16,9; $p=0,0026)$. CrP war nicht mit der Gesamt-Leukozytenzahl, aber positiv mit Neutrophilen $(\mathrm{r}=0,122, p=0,0056)$ und negativ mit Lymphozyten $(r=-0,190, p<0,0001)$, also einer relativen Linksverschiebung korreliert. Abgang von „grünem Fruchtwasser“ zeigte sich bei 187 (35,2\%) Neonaten, ein GBS-positver Abstrich bei 81 (15,3\%), eine PROM bei 92 (17,3\%). Eine Sectio caesarea war nicht signifikant mit dem Auftreten einer EOS assoziiert (35,5\% versus 36,3\%), wohingegen eine VE als signifikanter $(p<0,0001)$ Risikofaktor identifiziert wurde $(17,4 \%$ versus $7,2 \%)$.

Nach Abschluss des regulären Therapiezyklus kam es bei nur einem Kind zur Wiederaufnahme (reduzierte RKZ, CrP 10,2 mg/l), das für weitere 4 Tage therapiert wurde.

Schlussfolgerung: Es gibt keinen verlässlichen Zusammenhang zwischen CrP, Leukozytose und klinischen Zeichen bei Neugeboreneninfektion/ EOS. Die klinische Signifikanz eines erhöhten CrP-Wertes bei Neugeborenen ist unklar, ein reines Beobachten nicht zu rechtfertigen, so dass eine möglichst kurze antibakterielle Therapie mit frühzeitigem Absetzen der ratsame Mittelweg scheint. Eine (ambulante) Routinekontrolle nach abgeschlossenem antibakteriellen Therapiezyklus ist nicht notwendig.

\section{Virologie}

\section{VIR-P01}

The role of multiplex PCR analysis in children with febrile seizures

J. Naric, J. Rissland, A. Simon, L. Gortner, M. Poryo, S. Meyer

Universität des Saarlandes, NICU, Homburg, Deutschland

Background: To assess multiplex PCR analysis in detecting causative viruses in children with febrile seizures.

Patients and methods: Retrospective data analysis at a tertiary hospital comparing data from a pre-multiplex era (2009) with a period after introduction of routine respiratory multiplex analysis (2010-2013) in children with febrile seizures.

Results: 200 children with febrile seizures (mean age: $29.5 \pm 1.4$.months; 104 male) were included. Sites of infections were: respiratory $(89 ; 44.5 \%)$, gastroenteritis $(22 ; 11 \%)$, tonsillitis $(21 ; 10.5 \%)$, otitis media $(15 ; 7.5 \%)$, urinary tract infection $(2 ; 1 \%)$, and vaccination-related fever $(2 / 200 ; 1 \%)$. In $23(11.5 \%)$ children a combination of different foci was seen while in 26 (13\%) children no definite site of infection could be established. In 2009 in 10 out of 49 (20\%) children microbiology testing (bacterial/fungal) was positive compared to a rate of 74 out of 151 (49\%) children in 2010-2013 $(p<0.01)$. The number of children treated with antibiotics increased from $17(34.6 \%)$ to 73 (48.3\%). The rate of positive virological studies increased from $10(20 \%)$ in 2009 to $73(48.3 \%)$ in $2010-2013(p<0.01)$. Multiplex PCR analysis confirmed viral infections in 52 of 73 cases $(71.2 \%)$. The most common detected viruses (multiple entries possible) by multiplex PCR were: adenovirus (12), human bocavirus (10), enterovirus (9), rhinovirus (7), RSV (7), corona virus (7), parechovirus (5), parainfluenza virus (5), and human metapneumovirus (3).

Conclusions: Routine multiplex PCR analysis fosters the detection of respiratory viruses in children with febrile seizure. The precise role of multiplex analysis in the management of these children awaits further clarification.

\section{VIR-P02}

Enterovirus-Meningitiden bei Säuglingen in einer retrospektiven Analyse nach Einführung der Multiplex-PCR-Diagnostik des Liquors in die klinische Routine

\section{A. Eichinger, J. Hübner, U. von Both}

Dr. von Haunersches Kinderspital, Immunologie, München, Deutschland

Hintergrund: In der Literatur werden Enterovirus-Meningitiden als eine wichtige, aber häufig nicht diagnostizierte Ursache für fieberhafte Infektionen bei Säuglingen beschrieben.

Methoden: Es erfolgte eine retrospektive Analyse der mit Multiplex-PCR aus Liquor bestätigten Enterovirus-Meningitiden bei Säuglingen (incl. Neugeborene) über einen Zeitraum von knapp acht Monaten (Juni 2016Januar 2017).

Ergebnisse: In dem oben genannten Zeitraum wurden 50 Liquorpunktionen bei Säuglingen mit klinischem Verdacht auf Meningitis, unklaren neurologischen Symptomen oder Fieber ohne Fokus durchgeführt. Insgesamt lag in 15 Fällen ein positives Ergebnis vor, wobei sich bei acht Patienten ein positiver Enterovirus-Nachweis ergab. Bei diesen Säuglingen war das durchschnittliche Alter $32 \pm 18$ Tage, ein Großteil der Fälle trat in den Sommermonaten auf (75\%). Das führende Symptom war erhöhte Temperatur $\left(>38^{\circ} \mathrm{C} ; 100 \%\right)$; gefolgt von Trinkschwäche, Unruhe/Irritabilität sowie Schlappheit (je 50\%). Gelegentlich traten auch dünnere Stühle (40\%) und in einem Fall Erbrechen auf. In der Blutentnahme zeigten sich bei sieben der Kinder nur leicht erhöhte Entzündungswerte (CrP 0,7 $\pm 0,6 \mathrm{mg}$ / dl); des Weiteren lag zum Teil eine Leukopenie (25\%) vor. Bei einem Kind lagen ein im Vergleich deutlich höheres $\mathrm{CrP}(3,2 \mathrm{mg} / \mathrm{dl})$ sowie eine Neutrophilie vor. Die laborchemische Untersuchung des Liquors zeigte einen breiten Schwankungsbereich, bei der Hälfte der Kinder lag eine Pleozytose vor $(154 \pm 226$ Zellen/ $\mu$ l), wobei sich unterschiedliche Differentialzellverteilungen zeigten.

Bei einem Großteil der Kinder (88\%) erfolgte eine empirische intravenöse antibiotische Behandlung, die über maximal zwei Tage (bzw. bis zum Vorliegen des PCR Ergebnisses) fortgeführt wurde. Je nach Anamnese sowie Allgemeinzustand des Kindes (insgesamt bei $75 \%$ der Fälle) erfolgte die zusätzliche Therapie mit Aciclovir i.v. bis zum Erhalt des PCR-Ergebnisses (spätestes nach 24 Stunden). Aufgrund von Trinkschwäche und Fieber sowie zur Verlaufsbeurteilung nach Beendigung der antibiotischen Therapie erfolgte eine weitere stationäre Überwachung, so dass die Patienten 5,4 \pm 1,3 Tage in unserer Klinik verweilten. Bei keinem Patienten kam es zu schweren Komplikationen, kein Kind wurde intensiv-pflichtig oder zeigte akute neurologische Folgeschäden.

Schlussfolgerung: Durch die Einführung der Multiplex-PCR in die Routine der Liquor-Diagnostik bei klinischem Verdacht auf Meningitis kam es zu einem deutlichen Anstieg der diagnostizierten Enterovirus-Meningitiden (im Vorjahr im selben Zeitraum Diagnose von drei Fällen). Durch die nun schneller verfügbare Diagnostik konnte eine rasche Deeskalation bzw. Beendigung der antiviralen sowie antibiotischen Therapie bei den Kindern erfolgen. Allerdings war aufgrund von Trinkschwäche bzw. persistierendem Fieber jeweils eine weitere stationären Überwachung erforderlich. Alle Fälle verliefen gutartig. Es sollte im Rahmen der weiteren Datenanalyse geprüft werden, ob es bei den betroffenen Kindern im Verlauf zu neurologischen Auffälligkeiten kommt und ob eine spezielle Nachsorge empfohlen werden sollte.

\section{VIR-P03}

Virus-host interplay of HBV and host nuclear architecture: $\mathrm{HBx}$ directs cccDNA localization in transcribed open chromatin regions

\section{K. Hensel, F. Cantner, S. Wirth, J. Postberg}

Helios Universitätsklinikum Wuppertal, Zentrum für Kinder- und Jugendmedizin, Wuppertal, Deutschland

Background: In hepatocyte nuclei the hepatitis B virus (HBV) genome occurs episomally as covalently closed circular DNA (cccDNA). The HBV $\mathrm{X}$ protein $(\mathrm{HBx})$ is required to initiate and maintain $\mathrm{HBV}$ replication and on the long-term acts as a weak oncogene. However, the functionally rel- 
evant spatiotemporal localization and interactions of both cccDNA and HBx remain to be understood.

Aim of the study: We studied the nuclear localization of the HBV cccDNA and correlated the results with analyses of the genomic, epigenomic and transcriptomic nuclear landscape of HBV-infected hepatocytes.

Material and Methods: This is the first study utilizing circularized chromosome conformation capture (4C) to identify regional interactions of a viral genome, i. e. cccDNA, and a host genome. We combined this technology with RNA-seq and ChIP-seq to determine the nuclear landscape associated with cccDNA and nuclear HBx. Moreover, we functionally studied HBx-binding to cccDNA.

Results: ChIP and 4C revealed specific nuclear localization of $\mathrm{HBx}$ and cccDNA associated with actively transcribed nuclear domains. Strikingly, we found that $\mathrm{HBx}$ alone is sufficient to occupy transcribed chromatin domains and its binding to cccDNA dependends on its C-terminus. We thus provide evidence that the $\mathrm{HBV}$-encoded protein $\mathrm{HBx}$ might act as a nuclear marshaller directing HBV genomes to host cell nuclear sites of active transcription. In this role $\mathrm{HBx}$ directly interacts with the $4 \mathrm{D}$ epigenome ensuring the tethering of HBV genomes within functional nuclear compartments.

Discussion and conclusions: $\mathrm{HBx}$ directs cccDNA to transcriptionally active chromatin regions, thus contributing to its long-term episomal stability and ensuring the durability of HBV infection. This mechanistic explanation for the persistence of cccDNA and $\mathrm{HBx}$ expression might cohere with the weak oncogenic nature of $\mathrm{HBx}$.

\section{VIR-P04}

\section{Circulating microRNAs in the course of pediatric chronic hepatitis B}

\section{K. Hensel, P. Menge, S. Wirth, J. Postberg}

Helios Universitätsklinikum Wuppertal, Zentrum für Kinder- und Jugendmedizin, Wuppertal, Deutschland

Background: Hepatocellular carcinoma (HCC) belongs to the 10 most common malign tumors with increasing mortality and morbidity. Currently, more than 350 million people are chronically infected with the hepatitis $\mathrm{B}$ virus (HBV), comprising one of the most important risk factors for liver cirrhosis and the development of HCC. While only $5-10 \%$ of adult patients infected with HBV become chronic cases, chronification rates among paediatric patients are as high as $90 \%$. Children are most susceptible to develop chronic hepatitis B and serious subsequent sequelae when infected early in life. Diagnostic improvements for the early detection of the disease are urgently needed in order to improve quality of life and life expectancy for the affected people. Chronic infection of a cell by a virus appears to induce a change in the production of microRNAs (miR). It is known that in many diseases viral-induced miRs are secreted into the peripheral blood stream where they are easily accessible for molecular diagnostic purposes.

Aim of the study: Up to date, most previous studies that have focused on the influence of $\mathrm{HBV}$ on de-regulated non-coding RNAs took into account a limited pre-selection of already known miRs only. Here, we performed analyses of miR-profiles in cell-free serum on a holistic level utilizing massive parallel sequencing technology in order to generate $\mathrm{miR}$ libraries comprising of the entirety of all miRs, including those not being in focus previously.

Material and methods: Therefore, we utilized a biobank containing blood/ serum samples and clinical parameters such as history of symptoms, physical examination results, laboratory chemistry and serologic parameters of more than 900 pediatric patients suffering from chronic hepatitis $B$, documented over a period of more than two decades. We utilized $120 \mathrm{sam}-$ ples, including longitudinally collected sera from the same donors suffering from chronic hepatitis B at several time-points: 1 . At first diagnosis; 2. Briefly before $\mathrm{HBeAg} /$ anti-HBeAg seroconversion was detected; 3 . After seroconversion. Further we could distinguish patients treated with nucleoside analogs and untreated cases.
Results: We determined differential miR profiles comprising of up to 431 miRs between first diagnosis of chronic HBV infection and stages representing longer courses of the disease. Following $\mathrm{HBeAg} / \mathrm{anti}-\mathrm{HBeAg}$ seroconversion, we observed restitution of those longer-course miR-profiles in many patients, particularly if they were treated with nucleoside analogs. Discussion and conclusions: Our study highlights the possibility that miR-profiling could be utilized for the complementation of standard serological diagnostics in order to improve personalized molecular diagnostics of paediatric patients with chronic hepatitis $\mathrm{B}$, which might in future improve monitoring of disease progression and the success of treatment for children infected with HBV.

\section{VIR-P05}

Zerebrale Magnetresonanztomographie am errechneten Geburtstermin zeigt bei Frühgeborenen $<32$ Schwangerschaftswochen mit postnatal erworbener Cytomegalievirusinfektion keine erhöhte Rate an

\section{Gehirnschädigung}

\section{Wurnitsch, K. Stock, M. Biermayr, V. Neubauer, R. Trawöger}

Medizinische Universität Innsbruck, Department für Kinder- und Jugendheilkunde, Univ.-Klinik für Pädiatrie II (Neonatologie, NICU, Frühgeborenen-Nachsorge, Risikokinder), Innsbruck, Österreich

Hintergrund: Frühgeborene von Cytomegalievirus (CMV)-positiven Müttern können sich über unpasteurisierte Muttermilch infizieren. Postnatal erworbene CMV-Infektionen verlaufen bei Frühgeborenen häufig asymptomatisch, können sich aber auch als Sepsis-ähnliches Krankheitsbild manifestieren. Zudem berichten einzelne Studien über einen negativen Effekt auf die neurologische Entwicklung von ehemaligen Frühgeborenen. Bisher gibt es nur wenige Daten zu den anatomischen bzw. mikrostrukturellen Korrelaten für dieses Phänomen.

Fragestellung: Das Ziel dieser Studie war es, Frühgeborene $<32$ Schwangerschaftswochen am errechneten Geburtstermin mittels zerebraler Magnetresonanztomographie (MRT) zu untersuchen und die Rate an zerebralen Auffälligkeiten von Kindern mit und ohne postnatal erworbene CMV-Infektion zu vergleichen.

Patienten und Methoden: Für alle Frühgeborenen $<32$ Schwangerschaftswochen, die zwischen Oktober 2010 und Jänner 2016 in Tirol geboren wurden, wurden der CMV-Status bei Geburt und bei Entlassung erhoben. Die Muttermilch wurde unabhängig vom mütterlichen CMV-Status während der gesamten Studienperiode unpasteurisiert verabreicht. Die Kinder wurden am errechneten Geburtstermin mittels MRT untersucht. Die MRT-Bilder wurden mit einem etablierten Schema in 3 Kategorien ausgewertet (intraventrikuläre Blutung, Schädigung der weißen Substanz, Kleinhirnblutung).

Ergebnisse: Es wurden insgesamt 277 Kinder in die Studie eingeschlossen, davon wurde bei 11 Kindern (4\%) eine postnatal erworbene CMV-Infektion diagnostiziert. Mittels MRT zeigte sich bei 24,9\% aller Frühgeborenen eine Gehirnschädigung, wobei 5,8\% aller Kinder eine höhergradige Schädigung aufwiesen. Am häufigsten zeigte sich eine intraventrikuläre Blutung (16,8\%). Bei 10,1\% wurde eine Schädigung der weißen Substanz festgestellt. Zudem wurde bei 8,7\% aller Kinder eine Kleinhirnblutung diagnostiziert. Es zeigte sich kein statistisch signifikanter Zusammenhang zwischen einer postnatal erworbenen CMV-Infektion und dem häufigeren Auftreten einer Gehirnschädigung.

Diskussion und Schlussfolgerung: Mittels konventioneller MRT wiesen Frühgeborenen mit postnatal erworbener CMV-Infektion vergleichbare Raten an Gehirnschädigung auf wie Frühgeborene ohne CMV-Infektion. Dies zeigt erneut, dass Frühgeborene mit postnatal erworbener CMV-Infektion am errechneten Geburtstermin keine markanten zerebralen Auffälligkeiten aufweisen. Es erscheint sinnvoll, Frühgeborene mit postnatal erworbener CMV-Infektion mittels differenzierterer MRT-Verfahren zu untersuchen und potentielle Auffälligkeiten mit der Langzeitentwicklung dieser Kinder zu korrelieren. 


\section{Fallpräsentationen GNPI}

\section{GNPI-FP01 \\ Hypercalcämie nach Asphyxie, Hypothermie und ECMO

\author{
A. C. Longardt, C. Bührer \\ Universitätsmedizin Berlin - Charité, Neonatologie, Berlin, Deutschland
}

Hintergrund: Eine Hypercalcämie bei Neonaten nach Asphyxie ist eine seltene Komplikation im Rahmen einer subkutanen Fettgewebsnekrose (SCFN). Bei der SCFN handelt sich um eine benigne Inflammation und Nekrose des subkutanen Fettgewebes unklarer Pathogenese [1], die nach Schockzuständen mit oder ohne und therapeutischer Hypothermie beobachtet wird.

Fallbericht: Wir berichten von einem männlichen Neugeborenen $(40+0$ Schwangerschaftswochen, $4620 \mathrm{~g}$ Geburtsgewicht), das per Sectio aus dick-grünem Fruchtwasser (Nabel-pH 6,9) geboren wurde. Es erfolgte eine therapeutische Hypothermie bei Asphyxie. Bei unzureichender Oxygenierung im Rahmen des Mekoniumaspirationssyndrom trotz maximaler Beatmung und NO-Therapie erfolgte eine extrakorporale Membranoxygenierung (ECMO) vom 3. - 9. Lebenstag. Am 35. Lebenstag fielen erstmals deutlich erhöhte Calcium-Werte (Ca++ ionisiert $1,95 \mathrm{mmol} / \mathrm{l}$, $\mathrm{Ca}++$ gesamt 3,95 mmol/l), außerdem fanden sich derbe rötlich-livide Verhärtungen im Schulter-Nackenbereich und palpable Verkalkungen auf dem Rücken und beiden Wangen. Sonographisch stellte sich eine beidseitige Nephrokalzinose dar (rechts $3^{\circ}$, links $2^{\circ}$ ). Im Rahmen der Hypercalcämie traten Übelkeit, Erbrechen, Irritabilität und Unruhephasen, Gewichtsverlust sowie muskuläre Hypotonie auf, keine Herzrhythmusstörungen. Die Symptome waren nach Pausieren von Vitamin D und Hyperhydratation rückläufig. Über 3 Wochen zeigte sich kein Anstieg der Calciumwerte (maximal $\mathrm{Ca}++2,2 \mathrm{mmol} / \mathrm{l}$, Ca ges. $4,24 \mathrm{mmol} / \mathrm{l}$ ), jedoch auch keine Normalisierung - daher erfolgte eine calciumarme Diät im Wechsel mit Muttermilch. Die Calciumpräzipitatablagerungen blieben unverändert. Als weiteres Symptom der SCFN trat eine Thrombopenie (minimal 69/ nl) ohne Blutungszeichen auf. Das Kind wurde am 54. Lebenstag entlassen. Die Kontrolle am 70. Lebenstag zeigte ein Ca++ ges. von 2,76 mmol/l. Diskussion: Eine Hypercalcämie tritt in rund 25\% der SCFN-Fälle auf, sie ist in der Regel benigne und selbstlimitierend [1,2].40\% der Hypercalcämien im Rahmen einer SCFN zeigen sich in den ersten 6 Lebenswochen [1]. Als Pathomechanismus werden eine gesteigerte Prostaglandinaktivität, Freisetzung von Calcium aus nekrotischem Fettgewebe und erhöhte Sekretion von 1,25-Dihydroxyvitamin D3 aus subkutanen Läsionen mit erhöhter intestinaler Aufnahme von Calcium diskutiert [1,3]. Mögliche Komplikationen sind Nephrokalzinose, Nephrolithiasis bis zum Nierenversagen, Verkalkungen der Falx cerebri, der Haut, des Myokards und der gastralen Mukosa [1]. Die Therapie beinhaltet Hyperhydratation, calciumarme Ernährung und ein Sistieren der Vitamin D-Gabe.

\section{Literatur}

1. Rubin $G$, Spagnut $G$, Morandi $F$ et al (2015) Subcutaneous fat necrosis of the newborn. Clin Case Rep 3:1017-1020

2. Del Pozzo-Magaña BR, Ho N (2016) Subcutaneous fat necrosis of the newborn: a 20-year retrospective study. Pediatr Dermatol 33:e353-e355

3. Farooque A, Moss C, Zehnder D, Hewison M, Shaw NJ (2009) Expression of 25-hydroxyvitamin D3-1alpha-hydroxylase in subcutaneous fat necrosis. Br J Dermatol 160:423-425

\section{GNPI-FP02 \\ "Duplication of the Pituitary Gland-Plus Syndrome" bei einem Neugeborenen mit Epignathus}

E. A. Alsat', S. Bagci', M. Born'², T. Dresbach', M. Martini' ${ }^{3}$, J. Schmitt ${ }^{1}$, A. Müller 'Universitätsklinikum Bonn, Neonatologie und Pädiatrische Intensivmedizin, Bonn, Deutschland, '2Univeristätsklinikum Bonn, Radiologische Klinik, Bonn, Deutschland, ${ }^{3}$ Univeristätsklinikum Bonn, Mund-, Kiefer- und Plastische Gesichtschirurgie, Bonn, Deutschland
Hintergrund: Das Duplication of the Pituitary Gland-Plus Syndrome (DPG-Plus Syndrom) ist ein seltenes Fehlbildungssyndrom mit einer Geburtenprävalenz von <1:1.000.000. Das klinische Hauptmerkmal ist eine doppelt angelegte Hypophyse. Des Weiteren können zum Beispiel ein Hypertelorismus, ein Epignathus, eine Gaumenspalte, überzählige Zahnanlagen, eine Lingua bifida, ein hypothalamische Hamartom, eine Duplikation der Basilararterie, Wirbelkörperfehlbildungen, eine Balkenhypoplasie oder -agenesie vorkommen. Das Syndrom ist Folge einer Entwicklungsstörung während der Blastogenese.

Fallbericht: Mittels Ultraschalluntersuchung wurde bei einem weiblichen Fetus in der 21. SSW ein Epignathus diagnostiziert sowie im Verlauf der V.a. eine Arachnoidalzyste gestellt. Das eutrophe Mädchen wurde mit $37+4 / 7$ SSW spontan entbunden. Die postnatale Anpassung verlief komplikationslos. Es zeigten sich ein Hypertelorismus, ein gestielter, weicher, von Haut mit feiner Behaarung bedeckter Epignathus sowie eine Hartund Weichgaumenspalte mit gespaltener Uvula. Initial wurde der Säugling über Magensonde ernährt, aufgrund komplikationsloser Trink- und Stillversuche konnte auf eine orale Nahrungszufuhr umgestellt werden. In der präoperativen MRT-Untersuchung zeigte sich eine $2,1 \times 1,6 \times 3,5 \mathrm{~cm}$ messende, teils fetthaltige Raumforderung, die rechts paramedian im harten Gaumen endet. Angrenzend fanden sich mehrere medial im harten Gaumen gelegene Zahnanlagen. Aufgrund des in der Sonographie auffälligen Hirnbefundes wurde ergänzend eine MRT des Gehirns durchgeführt. Hier zeigte sich eine Megacisterna magna, ein hypothalamisches median gelegenes Hamartom, ein Cavum septi pellucidi und eine doppelt angelegte Hypophyse. Zusätzlich wurde eine vertikale Spalte im 2. Halswirbelkörper gesehen. Eine Anomalie der Basilararterie lag nicht vor. Laborchemisch zeigten sich im Verlauf unauffällige Werte für $\beta$-HCG, $\alpha$-Fetoprotein, TSH, freies T3, freies T4, ACTH, Cortisol, LH, FSH, Östradiol, Prolaktin, Wachstumshormon, IGF-1 und IGFBP-3. Der orale Tumor, Zysten sowie die akzessorischen Zahnanlagen wurde aus dem Oberkiefer entfernt und die Gaumenspalte verschlossen. Die Histologische Untersuchung ergab keinen Anhalt für Malignität. Postoperativ wurde der Säugling 4 Tage beatmet und dann komplikationslos extubiert. Ab dem 6. postoperativen Tag konnte erneut mit der oralen Nahrungsaufnahme begonnen werden. Zusammenfassung: DPG-Plus Syndrom ist eine seltene Störung der Blastogenese mit sehr unterschiedlicher Ausprägung von Mitteliniendefekten im Mund-, Kiefer-, Gesichts- und Halsbereich sowie strukturellen Auffälligkeiten des Gehirns. Das gemeinsame Merkmal des DPG-Plus Syndrom ist die doppelte Hypophyse. Die neurokognitive Entwicklung ist fast ausnahmslos unauffällig, eine Hormonstörung liegt im Allgemeinen nicht vor. Der Fall betont die Bedeutung der Bildgebung des Gehirns bei Patienten mit Mittellinien Gesichtsanomalien und die Rolle der MRT.

\section{GNPI-FP03}

\section{Fallpräsentation: Plötzlicher Herzstillstand bei einem Säugling während der OP}

N. Ahyai, G. Finster

Orthopädisches Spital Speising, Anästhesie und Intensivmedizin, Wien, Österreich

Fallbericht: In unserem Fall handelt es sich um einen elektiven Eingriff am Fuß mit der Resektion einer atypischen akzessorischen Großzehe. Der Eingriff wird in Vollnarkose mit einer anschließenden Wundinfiltration durch den Operateur durchgeführt.

Der Patient ist ein zehn Monate alter männlicher Säugling mit einem Gewicht von $11 \mathrm{~kg}$. Die Eigen- und Familienanamnese sind unauffällig. Es ist dies seine erste Operation und Narkose: Der Säugling erhält eine rektale Prämedikation und wird anschließend per Maske eingeleitet. Nach Legen eines iv.-Zuganges wird die Narkose vertieft und es erfolgt eine orale Intubation. Die Narkose wird als balancierte Intubatiosnarkose aufrechterhalten und verläuft zunächst komplett unauffällig. Nach ca. 25 min tritt plötzlich eine Bradykardie von ca. 60/min auf, die mit kurzfristigen deformierten Kammerkomplexen jedoch ohne primären Sättigungsabfall imponiert. Die sofortige Atropingabe ist erfolglos. Der Säugling wird reanimationspflichtig. Was ist passiert? 


\section{GNPI-FP04}

Pulmonales interstitielles Emphysem bei nicht-invasiv beatmeten Gemini (VLBW) -ein Fallbericht

\section{J. Gronbach', M. Waitz', K. P. Zimmer' ${ }^{2}$, H. Ehrhardt ${ }^{1}$}

'Universitätsklinikum Gießen, Zentrum für Kinderheilkunde und Jugendmedizin, Neonatologie, Gießen, Deutschland, ${ }^{2}$ Universitätsklinikum Gießen, Zentrum für Kinderheilkunde und Jugendmedizin, Allgemeine Pädiatrie und Neonatologie, Gießen, Deutschland

Hintergrund: Die frühe Entwicklung eines interstitiellen pulmonalen Emphysems (PIE) bei Frühgeborenen mit sehr niedrigem Geburtsgewicht (VLBW) ist in der Regel mit zwei Komponenten assoziiert: dem Krankheitsbild des Atemnotsyndroms (ANS) und dem Einfluss von mechanischer Ventilation. Aktuelle Behandlungsstrategien bei respiratorischem Versagen in Folge eines PIE sind konservative nicht-invasive und invasive Beatmung (z.B. konventionelle und/oder Hochfrequenzoszillation (HFOV) unter niedrigen Tidalvolumina), selektive Intubation, spezielle Lagerungsformen und falls notwendig Entlastung relevanter Pneumothoraces.

Fragestellung: Welchen Verlauf kann das PIE bei Frühgeborenen (VLBW) unter nicht-invasiver Beatmung nehmen und welche individuellen Therapieansätze ergeben sich daraus.

Material/Methoden: Klinischer Fallbericht zweier weiblicher diamniot-dichorialen Gemini aus der $28+5$ SSW

Ergebnisse: Eine 34-jährige Mutter (GI/PI) wurde bei Cervixinsuffizienz (CI), vorzeitigem Blasensprung (4 Std. vor Entbindung) und letztendlich unstillbarer Wehentätigkeit sekundär sektioniert. Präpartal wurde sie unter stets negativen Entzündungsparametern bei zunehmender CI für 7 Tage antibiotisch behandelt (Clindamycin). Die Lungenreifeinduktion über antenatale Steroidgaben war 2 Wochen vor Entbindung bereits abgeschlossen. Sowohl klinisch, als auch histologisch (Plazenta), laborchemisch und mikrobiologisch zeigten sich keine Hinweise für eine Chorioamnionitis. Das Geburtsgewicht des ersten Geminus lag bei $1350 \mathrm{~g}$ (Geminus A), des zweiten durch intrauterine Wachstumsrestriktion bedingt nur bei $900 \mathrm{~g}$ (Geminus B). Beide Frühgeborene erhielten bei klinisch und radiologisch diagnostiziertem ANS und steigendem O2-Bedarf nicht-invasiv Surfactant (LISA) und nicht-invasive Atemunterstützung über CPAP unter niedrigen Beatmungsdrücken. Der Sauerstoffbedarf war darunter bei Geminus A rückläufig, Geminus B profitierte davon weniger. Anschließend entwickelten beide Zwillinge das radiologische Bild eines PIE mit konsekutivem Pneumothorax. Geminus A konnte unter konservativer Therapie und CPAP-Unterstützung erfolgreich behandelt werden, Geminus $B$ wurde nach Intubation und Thoraxdrainage des Spannungspneumothorax Hochfrequenz-beatmet (HFOV). Beide erhielten eine empirische antibiotische Therapie (Cefotaxim und Gentamycin) über 5 Tage bei stets negativen Entzündungsparametern. In beiden Fällen zeigte sich klinisch und radiologisch eine vollständige Rückbildung des PIE. Eine nativradiologische Bilderserie stellt beide Verläufe ergänzend bildmorphologisch dar. Diskussion: Die Entwicklung eines PIE unter nicht-invasiver Beatmung bei VLBW-Gemini ist eine äußerst seltene Konstellation und in der Literatur nur spärlich beschrieben. Dieser Fallbericht beschreibt mögliche Verlaufsformen mittels konservativer Behandlung unter nicht-invasiver Beatmung und Entlastung unter intermittierend druckkontrollierter und HFO- Beatmung.

\section{GNPI-FP05}

\section{Cogenital CLN10 disease in two siblings}

S. Meyer, M. Poryo, L. Gortner, A. Baghai, G. Löffler

Universität des Saarlandes, NICU, Homburg, Deutschland

Background: Neuronal ceroid lipofuscinoses (NCL) is characterised by a combination of retinopathy, dementia, and epilepsy. As a group, they encompass 10 distinct biological and clinical entities and are the most common type of childhood neurodegenerative disease.

Patients and methods: Case reports.
Results: We demonstrate the clinical course of two neonates (brother and sister) with infantile NCL (CLN 10 disease) presenting with intractable seizures and respiratory insufficiency immediately after birth. Characteristic clinical, radiological and pathological findings of this form of NCL are presented.

Conclusions: We conclude that the diagnosis of CLN10 should be kept in mind as a differential diagnosis in newborns presenting with respiratory insufficiency and severe epilepsy that is largely refractory to AED treatment. Because of the severity of CLN10 disease and futility of treatment, important ethical issues arise when caring for children with this clinical entity.

\section{GNPI-FP06}

\section{Fetal akinesia as a diagnostic challenge}

R. Kothari, R. Arlettaz Mieth

Universitätsspital Zürich, Neonatologie, Zürich, Schweiz

Introduction: We report our management of a newborn with fetal akinesia, severe hypotonia, muscle weakness and congenital chylothorax.

Case Description: The infant was born to healthy parents by cesarean section at 30 weeks of gestation. There was no consanguinity. Family history was remarkable due to a sister, who died due to asphyxia and had a mutation of Exon5CFHR4, possibly responsible for various diseases. The older brother is healthy. Pregnancy was complicated with decreased fetal movements, polyhydramnion, pleural effusion, edema and the same heterozygote mutation (Exon5CFHR4). Apgar score were 4-3-4 at 1, 5, and 10 minutes respectively. At birth, the baby had muscular hypotonia and showed no respiratory effort, so intubation was required. Weight, crownheel-length and head circumference were normal.

The first clinical examination showed missing vigilance, absence of active movements, absent reflexes, arthrogryposis, and dysmorphic features with expressionless triangular low-set ears, an inverted v-shaped upper lip and bilateral cryptorchidism. The infant remained intubated and ventilated. Extubation was failed three times. Further course was complicated by a congenital chylothorax managed by chest tube drainage and fat free nutrition. At present, the infant is 3 months old and still hospitalized.

Regarding neuromuscular diseases, we ruled out central causes of muscular hypotonia by brain MRI showing no obvious morphological abnormalities or signs of hypoxic ischemic encephalopathy and whole-exome sequencing where chromosomal disorders could be excluded, besides the mutation mentioned above. Concerning peripheral causes, genetic and laboratory investigations did not verify anterior horn cell diseases, neuromuscular junction diseases or metabolic diseases. Electromyography and nerve conduction velocity were normal, so any congenital muscular dystrophies, metabolic myopathies and congenital myopathies are unlikely. Thus, the etiology of the symptoms presented is still unclear.

Conclusions: When caring for an infant with a fetal akinesia syndrome one has to rule out abnormalities of the central nervous system as well as neuromuscular and metabolic diseases. Identifying the specific etiology is crucial for both treatment and prognosis, but can be a very challenging task especially when a genetic disorder is suspected. In approximately half of affected individuals, a diagnosis cannot be found in the newborn period.

\section{References}

1. Hall JG (2014) Arthrogryposis (multiple congenital contractures): Diagnostic approach to etiology, classification, genetics, and general principles. Eur J Med Genet $57: 464-472$ 


\section{GNPI-FP07}

Neonatale muskuläre Hypotonie und Trinkschwäche. Häufig abzuklärende Diagnose - seltenes Krankheitsbild: Neugeborene mit Prader-Willi-Syndrom

B. de Potzolli', S. Breindl', J. Stoffels', G. Srobl-Wildemann'3 , S. Seeliger', S. Hnevkovsky'

${ }^{1}$ Kliniken St. Elisabeth, Kinderklinik,Neonatologie, Neuburg an der Donau, Deutschland, ${ }^{2}$ Kliniken St. Elisabeth, Sozialpädiatrisches Zentrum, Neuburg, Deutschland, ${ }^{3}$ Humangenetik Ulm, Ulm, Deutschland

Hintergrund: Die muskuläre Hypotonie und Trinkschwäche im Neugeborenenalter ist eine häufige Diagnose auf der Neu- und Frühgeborenenstation. Oft besteht eine respiratorische Anpassungsstörung. Wir stellen 2 Neugeborene vor, bei denen in den ersten Lebensmonaten ein PraderWilli-Syndrom diagnostiziert wurde.

Fallvorstellung 1: Neugeborenes $40+2$ SSW, Spontanpartus, Apgar 7/10, pH 7,35, GG $3480 \mathrm{~g}$; KL $53 \mathrm{~cm}$; KU 33,5 cm. Postnatal Trinkschwäche, ausgeprägte muskuläre Hypotonie, keine fazialen Dysmorphien, kaum Saugreflex, Klitorishypoplasie, Kontrakturen der Hände und Füße. Übriger körperlicher Untersuchungsbefund regelrecht. Teilsondierung der Nahrung über 3 Wochen. Bei Hypopnoen erfolgte eine Sauerstoffvorlage. Es fanden sich weder Hinweise für Störungen im Aminosäurestoffwechsel, der Fettsäure-Oxidation noch Defekte im Carnitinzyklus. Kein Anhalt für ein CDG- Syndrom oder Mitochondropathien. Schon neonatal wurde eine genetische Diagnostik hinsichtlich eines Prader-Willi-Syndroms in der differentialdiagnostischen Abklärung durchgeführt, was dann rasch zur Klärung führte.

Fallvorstellung 2: Neugeborenes aus $40+1$ SSW, Spontanpartus, Apgar 2/5/6, pH 7,33, GG $3100 \mathrm{~g}$; KL 48,5 cm; KU 36,5 cm. Postnatal insuffiziente Eigenatmung. Eine CPAP-Atemhilfe war für $24 \mathrm{~h}$ erforderlich. Auffallende muskuläre Hypotonie, Trinkschwäche. Es bestanden Fehlhaltungen und Kontrakturen der Hände und Beine. Eine Zuordnung zu einer kongenitalen Arthrogryposis oder Myopathie erschien in den ersten zwei Lebenswochen möglich. Die Abklärung inklusive Myastheniebehandlungsversuch und genetischem Muskelpanel blieb ohne Zuordnung, so dass im Alter von 5 Monaten eine Diagnostik auf das Prader-Willi-Syndrom durchgeführt wurde. Es zeigte sich ein paternaler Methylierungsdefekt 15q11-13. Ausschluss einer Imprinting-Center-Mutation.

Das Prader-Willi-Syndrom ist ein komplexes neurogenetisches Krankheitsbild, das schon früh mit einer Muskelhypotonie, extreme Trinkschwäche und einer Hypoplasie des äußeren Genitales klinisch auffällig wird. Die typischen fazialen Dysmorphien mit schmalem Kopf, Mikrostomie und Mandelaugen sind bei Neugeborenen nicht immer augenscheinlich. Die Trinkschwäche und Gedeihstörung wird im Alter von 2-4 Jahren durch eine Hyperphagie, welche regelhaft in eine Adipositas mündet, abgelöst. Ein hypothalamer Gonadotropinmangel führt zu einer zentralen Hypothyreose, zu einem Wachstumshormonmangel und zu einer Pubertas tarda. Zusätzlich besteht eine motorische und kognitive Entwicklungsverzögerung. Durch den frühen Beginn einer Wachstumshormontherapie kommt es zu einer positiven Beeinflussung der kognitiven und motorischen Entwicklung sowie der Körperzusammensetzung. Eine Polysomnographie ist aufgrund der Gefahr der obstruktiven Apnoen unter der Therapie in regelmäßigen Abständen erforderlich.

Schlussfolgerung: Bei Neugeborenen, die mit Trinkschwäche und einer isolierten muskulären Hypotonie auffällig werden, kommt differentialdiagnostisch immer auch das Prader-Willi-Syndrom in Frage.

\section{Literatur}

1. Goldstone AP (2008) Recommandations for diagnosis and management of Prader Willi Syndrom. J Clin Endocrinol Metab 93:4183-4197

2. Whittington J, Holland A (2017) Cognition in people with Prader-Willi-Syndrom. Neurosci Biobehav Rev 72:153-167

3. Berini J, Spica Russotto V, Castelnuovo P et al (2013) Growth hormone therapy and respiratory disorders in PWS. J Clin Endocrin Metab 98:E1516-1523

\section{GNPI-FP08}

Infantile Pyknozytose: Eine seltene Ursache hämolytischer Anämien bei Neugeborenen

S. Schmidt ', A. Treptow ${ }^{1}$, O. Andres', G. Heubner ${ }^{1}$

'Städtisches Klinikum Dresden, Dresden, Deutschland,

${ }^{2}$ Universitätskinderklinik Würzburg, Würzburg, Deutschland

Fallbericht: Ein preterm-hypotrophes Neugeborenes der 34. SSW fällt nach ungestörter postnataler Adaptation im Verlauf der ersten Lebenswochen mit einer transfusionspflichtigen hämolytischen Anämie auf. Es bestehen anhand der Blutgruppenkonstellation und des direkten Agglutinationstests keine Hinweise für eine immunologisch vermittelte Hämolyse. Nach Ausschluss von Eryhtrozytenmembran- und -enzymdefekten sowie Hämoglobinopathien fallen im Blutausstrich Pyknozyten und hyperdense Zellen auf. Nach Normalisierung des Blutbildes nach Transfusion kommt es zu einem erneuten Abfall des roten Blutbildes, das sich erst mit 6 Monaten stabilisiert.

Diskussion: Das Vorkommen von Pyknozyten als eine erythrozytäre Stressform ist in den ersten Lebenswochen physiologisch (Frühgeborene 0,3-5,6\%, Termingeborene 0,3-1,9\% der Erythrozyten). Die infantile Pyknozytose wurde erstmals 1959 durch Tuffy [1] beschrieben. Die Diagnose wird bei einem Anteil hyperdenser Zellen $\geq 3 \%$ bzw. von Pyknozyten (irregulär geformte Erythrozyten mit multiplen Zellmembranausläufern) $\geq 4 \%$ gestellt und soll für 9,4\% der nicht-immunologischen hämolytischen Anämie ursächlich sein [2]. Die Ausprägung der Anämie korreliert mit der Pyknozytenzahl. Familiäre und ethnische Häufungen sowie Knabenwendigkeit sind beschrieben [3]. Icterus (praecox, gravis oder prolongatus) sowie meist transfusionspflichtige hämolytische Anämien (Nadir mit 3-4 Wochen mit inadäquater Retikulozytose) können klinisch hinweisend sein. Fälle von intrauteriner Hämolyse wurden beschrieben [4]. Die Ursache der Pyknozytose ist unklar, wenngleich ein transienter extrakorpuskulärer Faktor vermutet wird. Spendererythrozyten wandeln sich teilweise ebenfalls in Pyknozyten um [5, 6]. Nach 4-6 Monaten kommt es zur spontanen Normalisierung.

Schlussfolgerung: Der Nachweis von Pyknozyten in geringer Zahl ist in der Neonatalperiode altersphysiologisch. Die infantile Pyknozytose ist für knapp $10 \%$ der unklaren hämolytischen nicht-immunologisch vermittelten Anämien verantwortlich und stellt eine Ausschlussdiagnose dar. Die qualifizierte Beurteilung des Blutausstrichs ist für die Diagnosestellung essentiell. Aufgrund der familiären Häufung besteht ein Wiederholungsrisiko. Die Erkrankung ist binnen 6 Monaten selbstlimitierend.

\section{Literatur}

1. Tuffy P, Brown AK, Zuelzer WW (1959) Infantile Pyknocytosis: A common erythrocyte abnormality of the first trimester. AMA J Dis Child 98:227-241

2. Eyssette-Guerreau S, Bader-Meunier B, Garcon L et al (2006) Infantile pyknocytosis: a cause of haemolytic anaemia of the newborn. Br J Haematol 133:439-442

3. Limme B, Dresse MF, Ketelslegers $O$ et al (2008) La pyknocytose infantile: une anémie néonatale mal connue à propos des 5 cas. Arch Pediatr 15:1765-1768

4. Maxwell DJ, Seshadri R, Rumpf DJ, Miller JM (1983) Infantile pyknocytosis: a cause of intrauterine haemolysis in 2 siblings. Aust N Z J Obstet Gynaecol 23:182-185

5. Keimowitz R, Desforges JF (1965) Infantile pyknocytosis. N Engl J Med 273:11521155

6. Ackerman BD (1969) Infantile pyknocytosis in Mexican-American infants. Am J Dis Child 117:417-423

7. El Nabouch M, Rakotoharinandrasana I, Ndayikeza A, Picard V, Kayemba-Kay's S (2015) Infantile pyknocytosis, a rare cause of hemolytic anemia in newborns: report of two cases in twin girls and literature overview. Clin Case Rep 7:535-538 


\section{GNPI-FP09}

Bullöse Hautläsionen nach Fototherapie bei einem

Frühgeborenen mit hämolytischer Anämie und Thrombozytopenie: seltener Fall einer kongenitalen erythropoetischen Porphyrie

M. Strammiello, R. Hellwig, F. Fischer, J. Link, K. Siedler, A. Bosk Diakonissen-Stiftungskrankenhaus Speyer, Speyer, Deutschland

Fallbericht: Ein männliches Frühgeborenes (29+1 SSW, GG 1830 g) syrischer Abstammung konsanguiner Eltern mit intrauterinem und kongenitalem Aszites, Hepatomegalie sowie hämolytischer Anämie (Hämoglobin 9,5 g/dl) und Thrombopenie (Thrombozyten 22/nl) wurde bei Ikterus praecox (Gesamtbilirubin max. $16 \mathrm{mg} / \mathrm{dl}$ ) trotz initial schon hohen Anteils an direktem Bilirubin fototherapiert. Es erfolgten Transfusionen von Erythrozyten- und Thrombozytenkonzentraten. Ab Tag 2 trat eine ausgeprägte Bronzefärbung der Haut mit kutaner Blasenbildung an Handrücken, Knöcheln und Oberarmen, insbesondere an den Ableitungsstellen der transkutanen Sauerstoffsättigung, und schließlich am gesamten Integument mit Dunkelfärbung des Urins auf.

Ergebnisse: Im Fluoreszenz-Scan des Urins zeigte sich eine intensive Emissionsbande bei $618 \mathrm{~nm}$ und eine exzessive Erhöhung der Gesamtporphyrinausscheidung mit hohen Anteilen von Uro- und Koproporphyrin als Zeichen einer Uroporphyrinogen-III-Cosynthase-Defizienz. In Zusammenschau der Befunde musste von einer kongenitalen erythropoetischen Porphyrie (CEP) ausgegangen werden [1].

Diskussion: Die CEP ist eine seltene autosomal-rezessiv vererbte Störung des Porphyrinstoffwechsels. Ursache ist eine Defektmutation des Gens, welches für die Uroporphyrinogen-III-Synthase (UROS) codiert [2]. Die reduzierte UROS-Aktivität führt zum erhöhten Anfall von Porphyrinmetaboliten der Isomerenreihe I, welche in Erythrozytenvorläuferzellen und Erythrozyten akkumulieren und zu einer ineffektiven Erythropoese, Hämolyse und Splenomegalie führen [3]. Die Abbauprodukte lagern sich in Geweben an und führen bei Lichtexposition zu Verbrennungen der Haut mit Blasenbildung, Ikterus und Erythrodontie.

Schlussfolgerung: Unter Vermeidung von Lichtexposition, auch der tcSO2-Messung, heilten die bestehenden Blasen ab, neue traten nicht mehr auf. Wir transfundierten wiederholt Erythrozyten zur Senkung der Porphyrinproduktion durch Suppression der Erythropoese [4]. Eine kausale Therapie bietet die Stammzelltransplantation [5]. Derzeit führen wir eine HLA-Typisierung des Patienten und der Familienmitglieder durch. Aufgrund der kardialen Vitien (ISTA, PDA) erhält das Kind eine antikongestive Therapie und wird auf einen kardiochirurgischen Eingriff vorbereitet.

\section{Literatur}

1. Labor Volkmann, Karlsruhe

2. Egan D, Yang Z, Phillips J, Abkowitz J (2015) Inducing iron deficiency improves erythropoiesis and photosensitivity in congenital erythropoietic porphyria. Blood 126:257-261

3. Desnick R, Astrin K (2002) Congenital erythropoietic porphyria: advances in pathogenesis and treatment. Br J Haematol 117:779-795

4. Piomelli S, Poh-Fitzpatrick M, Seaman C, Skolnick L, Berdon W (1986) Complete suppression of the symptoms of congenital erythropoietic porphyria by long-term treatment with high-level transfusions. N Engl J Med 314:1029-1031

5. Shaw PH, Mancini AJ, McConnell JP, Brown D, Kletzel M (2001) Treatment of congenital erythropoietic porphyria in children by allogeneic stem cell transplantation: a case report and review of the literature. Bone Marrow Transplant 27:101-105

\section{GNPI-FP10}

\section{Trachealstenose eines Neugeborenen durch ektopes} intratracheales Schilddrüsengewebe

\section{G. Stichtenoth', P. Jung ', K. Reddemann'ㄹ, E. Herting}

'Universität zu Lübeck, Kinderklinik/Neonatologie, Lübeck, Deutschland, ²Universität zu Lübeck, Institut für Pathologie, Lübeck, Deutschland

Fallbericht: Eine Erstgravida stellt sich in der $38+0$ Schwangerschaftswoche zur Geburtseinleitung in unserem Perinatalzentrum vor. In der Frühschwangerschaft war es zur Erstdiagnose eines Morbus Basedow gekom- men, der im 1. Trimenon mit Propycil und im 2. Trimenon mit Thiouracil behandelt wurde. Die maternalen Schilddrüsenparameter normalisierten sich rasch, so dass die Medikation reduziert werden konnte. Beim Fetus entwickelte sich eine Schilddrüsenhyperplasie. In unserer Pränataldiagnostik war eine Trachealkompression ausgeschlossen worden. Trotzdessen raten wir nach inzwischen stattgehabtem Blasensprung zu einer sekundären Sectio in Intubations- und Tracheotomiebereitschaft. Nach Entwicklung des Kindes zeigt sich kein makroskopisch auffälliges Struma. Unter assistierter Beatmung steigen die $\mathrm{SaO} 2$ Werte $>90 \%$ und die Herzfrequenz $>100 / \mathrm{min}$, so dass keine Tracheotomie erfolgt. Das Kind zeigt eine beidseits belüftete Lunge und normale initiale Atemanstrengungen. Es erfolgen die Abnabelung und der Transport auf unsere Erstversorgungseinheit. Hier verfällt das Neugeborene rasch, wird zyanotisch, zeigt Dyspnoe und entwickelt trotz Atemunterstützung eine schwere respiratorische Azidose. Beatmungstuben 3,0 und 2,5 können nicht über den subglottischen Bereich vorschieben. Das Kind muss kardiopulmonal reanimiert werden. En Cook-Stab lässt sich tracheal platzieren, über den ein Beatmungstubus $3,0 \mathrm{~mm}$ per Seldinger-Technik gelegt wird. Hierüber erfolgt die Beatmung. Es zeigt sich ein klarer Farbumschlag im colorimetrischen $\mathrm{CO}_{2}$-Detektor. Die Herzfrequenz steigt an. Herzdruckmassage kann eingestellt werden. Kurz darauf kommt es zur massiven Blutung aus dem Tubus und erneuten Verfall. Zudem zeigt sich ein massiv geblähtes Abdomen. Per Kaltlicht-Transillumination kann kein Pneumothorax festgestellt werden. Es besteht erneute Reanimationspflicht. Nach Adrenalin- und Surfactantgabe über den Tubus besteht eine zunehmend kombinierte respiratorische und metabolische Azidose. Im Röntgen Thorax zeigt sich ein Spannungspneumothorax, der sofort entlastet wird. Nach initial wieder einsetzender Herzfrequenz kommt es erneut zur Bradykardie. Aufgrund der schweren Asphyxie nach langer intermittierender Reanimation bei weiterhin schwerer kombinierter Azidose erfolgt die Einstellung der Maßnahmen. In der Obduktion findet sich neben dem die Trachea ummauernden Struma ektopes tracheal gelegenes submuköses Schilddrüsengewebe, das zu einer ausgeprägten Stenosierung des Tracheallumens geführt hat. Der Befund erklärt die Passage mittels Cook-Stabes. Nach Intubation hat der Tubus vermutlich funktionell wie ein Ventil gewirkt und die Entstehung des Pneumothorax begünstigt.

Schlussfolgerung: Ursache der Problematik ist am ehesten eine Unterfunktion der Schilddrüse während der Fetalzeit, die zur Hyperplasie geführt hat. Ektopes Schilddrüsengewebe kann aufgrund des embryonalen Deszensus lingual, sublingual, thyroglossal und intralaryngotracheal gefunden werden.

\section{GNPI-FP11}

\section{Salzverlustsyndrom bei einem Neugeborenen durch} Pseudohypoaldosteronismus

\section{E. Fink-Leinweber' ', B. Köster' ${ }^{1}$ P. M. Holterhus ${ }^{2}$}

${ }^{1}$ Märkische Kliniken, Kinderklinik Lüdenscheid, Lüdenscheid, Deutschland, 2Universität Kiel, Kiel, Deutschland

Fallbericht: Es handelt sich um ein weibliches Neugeborenes, das am 11. Lebenstag mit Notarzt wg. Cyanoseanfall beim Stillen zu Hause abgeholt wurde. Auf dem Weg zur Klinik wurde das reanimationspflichtig mit Braycardie $<60$ bpm und Ateminsuffizienz. Bei Eintreffen in der Klinik HF ca. $60 \mathrm{bpm}$, insuffiziente Spontanatmung, livide-blass-marmoriertes Hautkolorit mit massiv eingeschränkter Mikrozirkulation. Notfallmäßige orotracheale Intubation und Anlage eines intraossären Zugangs zur Volumenund Epinephrinapplikation.

Ergebnisse: Im EKG waren massive Herzrhythmusstörungen mit hohem spitzem $\mathrm{T}$ erkennbar. In der 1 . Blutanalyse ausgeprägte Acidose mit pH 6,96 und Base excess -23 mmol/l, Natrium 105 mmol/l, Kalium $11,8 \mathrm{mmol} / \mathrm{l}$. Nach Asservierung von Blut und Urin Beginn mit Notfalltherapie zur Senkung des Serumkaliums mit Calciumapplikation, Glucose-Insulin-Infusion, Natriumbicarbonatinfusion, Sabutamolinhalation, forcierter Diurese mit Furosemid und Ionenaustauscherharz per os und rektal, zudem Natriumsubstitution. Spiegel für Aldosteron mit 26,050 pg/ ml massiv erhöht, Renin mit 11,300 ng/l ebenfalls stark erhöht. Ein adre- 
nogenitales Syndrom konnte bei massiver Steigerung der Mineralocorticoidsynthese ausgeschlossen werden. Unter Weiterführung der Therapie und Vermeidung jeglicher Kaliumzufuhr konnte eine Stabilisierung erreicht werden. Im Alter von 4 Monaten erhält das Kind weiterhin Natriumchlorid, Natriumbicarbonat und ionenaustauscherharz per os unter Ernährung mit zunächst nahezu kaliumfreier Spezialmilch, im Verlauf Umstellung auf adaptierte Säuglingsmilch.

Diskussion: Am ehesten handelt es sich um einen generalisierten Pseudohypoaldosteronismus 1B mit massivem Verlauf, eine Mutation im NR3C2Gen, das für den Mineralocorticoidrezeptor kodiert, konnte molekulargenetisch ausgeschlossen werden, die Untersuchung auf Mutationen des $\mathrm{ENaC}$ ist in die Wege geleitet.

\section{GNPI-FP12 \\ GATA-6 Gen Mutation als Ursache für eine konnatale Pankreasinsuffizienz}

I. Petkova, H. Aktas, J. Jochim, M. Engler

Sana Klinikum, Pädiatrie, Offenbach, Deutschland

Fallbericht: Wir berichten über ein hypotrophes, reifes Neugeborenes der 37.+3 SSW (GG: $1730 \mathrm{~g}(<<\mathrm{P} 3)$, Geburtslänge: $44 \mathrm{~cm}(<\mathrm{P} 3)$, Kopfumfang: $33 \mathrm{~cm}(\mathrm{P} 13)$ ). Bei guter postpartaler Adaptation zeigte sich im Verlauf eine träge Gewichtszunahme. Im Rahmen des stationären Aufenthaltes entwickelte das Kind zunächst Symptome einer exokrinen und im weiteren Verlauf auch einer endokrine Pankreasinsuffizienz mit neonatalem Diabetes mellitus. Molekulargenetisch ließ sich als Ursache für die Pankreasinsuffizienz eine Mutation des GATA-6 Gens feststellen, welche mit einer partiellen Pankreasagenesie einhergeht.

\section{GNPI-FP13 \\ Kongenitaler Hyperinsulinismus. Diagnose und Verläufe einer seltenen pädiatrischen Stoffwechselerkrankung}

\section{U. Seyfarth', A. Teti ${ }^{2}$}

${ }^{1}$ Kongenitaler Hyperinsulinismus e.V., Berlin, Deutschland, ${ }^{2}$ Robert KochInstitut, Epidemiologie und Gesundheitsmonitoring, Berlin, Deutschland

Hintergrund: Kongenitaler Hyperinsulinismus (HI) ist eine seltene Erkrankung der insulinproduzierenden Zellen (ß-Zellen) der Bauchspeicheldrüse. Generell kann $\mathrm{HI}$ in jedem Alter auftreten aber vor allem davon betroffen sind Kinder, die bereits bei der Geburt unter unvorhersehbaren Hypoglykämien infolge einer zu hohen Insulinausschüttung leiden. Ein zunächst unerkannter bzw. inadäquat behandelter HI kann gegebenenfalls Entwicklungsverzögerung, Pflegebedürftigkeit oder Behinderung als Folge haben. Für Mitteleuropa wird die HI-Inzidenz auf etwa 1:40.000 geschätzt. In Abhängigkeit vom Grad der Konsanguinität (binnen einer Bevölkerung) kann die Inzidenz in bestimmten Regionen bis auf 1:2.500 steigen [1].

Am Tag der seltenen Erkrankungen (29.02.) im Jahre 2011 wurde der Selbsthilfeverein Kongenitaler Hyperinsulinismus e.V. in Berlin gegründet. Derzeit zählt dieser 61 Vereinsmitglieder, darunter erkrankte Kinder, deren Familienangehörige sowie die behandelnden Ärzte (Endokrinologen und Pädiater). Die betroffenen Kinder leben größtenteils in Deutschland; der Verein zählt allerdings Mitglieder aus Österreich, Schweiz, Schweden, Slowakei und Portugal. Der Verein verbindet neu betroffene Eltern mit Eltern, die auf jahrelange Erfahrung mit einem HI-Kind zurückblicken, und wissenschaftlichen Fachgruppen sowie Spezialisten auf diesem Gebiet.

Im Fokus dieses Beitrages steht die Vorstellung des HI-Erkrankung-Bildes, deren Diagnose und Behandlungsprofile. Ferner werden exemplarisch die Krankheitsverläufe von $n=27$ erkrankten Kindern über ihre Lebenszeit dargestellt.

Methoden: Seit 2014 führt der Verein eine standardisierte Befragung deren betroffenen Mitglieder zu den Themen Diagnose, Medikation, Behandlung und Pflegebedarf. Bisher konnten die Hälfte der betroffenen Famili- en mittels Fragebogen (Response 44\%) erfasst werden. Die quantitativen Ergebnisse der Befragung werden deskriptiv dargestellt.

Ergebnisse: Bei den 27 erkrankten Kindern (15 W/12 M; Altersdurchschnitt 14 Jahre) wurde im Mittel 160 Tage nach der Geburt eine HI-Erkrankung diagnostiziert. Lediglich bei fünf Fällen war HI bereits in der Familie aufgetreten. Bei 5 erkrankten Kindern wurde eine fokale und bei 15 Kindern eine diffuse HI-Form diagnostiziert. Sieben Fälle sind der atypischen HI-Form zuzuordnen. 14 von 27 Kinder erhielten eine Operation, jedoch nur 6 haben eine Heilung erfahren. 19 von 27 wurden zeitweise mit PEG-Sonde ernährt. 20 Kinder bzw. Jugendliche erhalten täglich Medikamente (z.B. Diazoxid und Lanreotid). 15 Kindern sind dauerhaft einer Pflegestufe zugeordnet.

Schlussfolgerung: Eine rechtzeitige Diagnose sowie eine kompetente Behandlung der HI-Erkrankung kann den Maß an Entwicklungsverzögerungen, Pflegebedürftigkeit oder Behinderungen bei den betroffenen Kindern positiv beeinflussen und somit deren Lebensqualität der Betroffenen verbessern. Dafür sind Kenntnisse über die Krankheit, Behandlungsprofile und Krankheitsverläufe unter Professionellen (Neonatologen, Hebammen, Pädiater und Endokrinologen) unabdingbar.

\section{Literatur}

1. Meissner T, Mayatepek E (2015) Kongenitaler Hyperinsulinismus: Diagnose und Behandlung. Monatsschr Kinderheilkd 153:483-494

\section{GNPI-FP14}

\section{Spontane Milzruptur bei zwei eutrophen reifen Neugeborenen}

C. Wieg, J. Keck, K. Stuchlik, F. Seitz, C. Bösche

Klinikum Aschaffenburg, Neonatologie und pädiatrische Intensivmedizin, Aschaffenburg, Deutschland

Hintergrund: Milzrupturen bei Neugeborenen sind extrem seltene, mit einer sehr hohen Mortalität assoziierte, Ereignisse. Wir berichten von zwei reifen Neugeborenen, die jeweils spontan aus Schädellage ohne Komplikationen geboren wurden. Es gab keine Auffälligkeiten in der Schwangerschaft, insbesondere keine mütterlichen Traumata, Infektionen oder irreguläre Antikörper. Ebenso konnten anamnestisch keine geburtshilflichen Risiken für eine intraabdominelle Verletzung eruiert werden.

Fall 1: Eutrophes weibliches Neugeborenes. Spontanpartus nach $40+4$ SSW aus Schädellage in einer externen Geburtsklinik. Am 3. Lebenstag zufällig entdeckt, reduzierter AZ, blasses Hautkolorit und deutlich vorgewölbtes Abdomen. Aufnahme über unseren NNAD. Laktatazidose $(\mathrm{pH}$ 7,245, Laktat 18 mmol/l, BE -20 mmol/l, BZ 190 mg/dl, Hb 6,2 g/dl). Sonographisch intraabdominell massiv freie Flüssigkeit, sowie ein echogenes Areal im linken Oberbauch. Bei klinischer Dekompensation und $\mathrm{Hb}-\mathrm{Ab}-$ fall bis auf $3,4 \mathrm{mg} / \mathrm{dl}$ explorative Laparotomie. Intraoperativ fand sich ein traumatischer Ausriss der Milz aus ihrer Aufhängung. Mit einer TachoSil ${ }^{\circ}-$ Packung Stillen der Blutung erfolgreich. Prä-, Peri- und postoperativ waren mehrmalige Gaben von Erythrozyten-Konzentrat und FFP notwendig. Hinweise für einen hypoxischen Hirnschaden waren im durchgeführten MRT und in den Follow-up Kontrolle nicht nachweisbar. Entlassung nach unkompliziertem postoperativem Verlauf am 12. Tag.

Fall 2: Eutrophes männliches Neugeborenes mit $40+3$ SSW nach unkompliziertem Spontanpartus extern. Nach 33 Stunden Blässe, im Blutbild Anämie ( $\mathrm{Hb} 7,6 \mathrm{~g} / \mathrm{dl})$. Aufnahme über unseren NNAD, hier Laktatazidose (pH 7,275, Laktat $11 \mathrm{mg} / \mathrm{dl}, \mathrm{BE}-11 \mathrm{mmol} / \mathrm{l}, \mathrm{BZ} 161 \mathrm{mg} / \mathrm{dl}$ ), schwere Gerinnungsstörung. (Quick 46\%, Fibrinogen 116 mg/dl, AT III 59\%). Sonographisch hochgradige V.a. auf eine Milzruptur mit Hämatoperitoneum. Notfalllaparatomie und Massentransfusion bei weiter abfallenden $\mathrm{Hb}$ Werten ( $\mathrm{Hb} \mathrm{4,9} \mathrm{g/dl)} \mathrm{sowie} \mathrm{Entwicklung} \mathrm{einer} \mathrm{DIC.} \mathrm{Intraoperativ} \mathrm{konnte}$ die Blutung mittels Elektrokauterisation und TachoSil ${ }^{\circ}$-Packung gestoppt werden. Peri- und postoperativ mehrfache Transfusionen von Erythrozyten-, Thrombozyten-, Prothrombinkomplexkonzentrat und FFP. Entlassung erfolgte nach unkompliziertem postoperativem Verlauf am 10. Tag. Diskussion: Die erste Publikation zur spontanen Milzruptur erschien 1958, seitdem gibt es nur knapp 50 Fallbeschreibungen in der Literatur. Die meisten Ereignisse sind mit maternalem präpartalen Trauma bzw. perinatalem Trauma assoziiert. Tiboni et al beschrieben in einem Case-Report 
2015 ein Neugeborenes mit einer plötzlich einsetzenden Schocksymptomatik, aber nur wenig ausgeprägten Zeichen einer abdominellen Ursache, ähnlich wie in unserem zweiten Fall. Hier gelang aber, im Gegensatz zu unseren Fällen nicht die Milz mittels TachoSil ${ }^{\circ}$-Packing zu erhalten. Die Pathogenese zur spontanen Milzruptur ist unklar, es gibt Spekulationen über ein transdiaphragmales Druck-Zug-Trauma bei der Initiierung der Lungenbelüftung sub partu. Möglicherweise gibt es eine Dunkelziffer, da diese Diagnose erst bei der Autopsie nach frühem plötzlichen Kindstod gestellt wird.

Schlussfolgerung: Eine spontane Milzruptur sollte bei wenige Tage alten Neugeborenen mit hämorrhagischem Schockgeschehen differenzialdiagnostisch in Betracht gezogen werden, da eine umgehende Diagnose für ein Überleben erforderlich ist.

\section{GNPI-FP15}

\section{Seltene Ursache hartnäckiger Hypoglykämien bei einem Frühgeborenen}

\section{S. Stutte, S. Bagci, A. Müller}

Zentrum für Kinderheilkunde der Universität Bonn, Neonatologie, Bonn, Deutschland

Fallbericht: Wir berichten über ein männliches Frühgeborenes von $32+2$ Schwangerschaftswochen. Die Geburt erfolgte per Spontanpartus nach Einleitung aufgrund zunehmender Präeklampsie der Mutter. Pränatal beschrieben war eine auffällig große Plazenta wie auch eine Hemihypertrophie der linken unteren Extremität des Kindes.

Ergebnisse: Die Primärversorgung verlief komplikationslos. Makroskopisch bestand eine ausgeprägte Plazentamegalie. Die pränatal vermutete Hemihypertrophie links bestätigte sich postnatal. In den ersten Lebenstagen bestand ein Atemnotsyndrom mit pulmonaler Hypertension, SIRS und Kapillarleck, welches eine intensive Beatmung mit iNO und Katecholaminbehandlung zur Kreislaufstabilisierung erforderlich machte.

Im Abdomen-Ultraschall am 3. Lebenstag fiel eine ausgeprägte Hepatomegalie sowie ein aufgetriebenes Pankreas auf. Ein MRT einen Monat später zeigte mehrere kontrastmittelanreichernde Leberläsionen. In engmaschigen sonographischen Verlaufskontrollen waren die Leberläsionen zunächst größenprogredient, zuletzt blieb der Befund konstant. Das AFP lag stets im Normbereich.

Rezidivierende Hypoglykämien unter voll- wie teilparenteraler Ernährung machten eine Glucosezufuhr von maximal $30 \mathrm{~g} / \mathrm{kgKG} / \mathrm{d}$ notwendig. In Hypoglykämiephasen bestand wiederholt ein Hyperinsulinismus. Der Zuckerbedarf reduzierte sich sukzessive mit Steigerung der enteralen Nahrungszufuhr. Bei Entlassung wurde das Kind ausschließlich mit Muttermilch ernährt.

Diagnose: Aufgrund des Vorhandenseins von je zwei Haupt- und Nebenkriterien eines Beckwith-Wiedemann-Syndroms (BWS - Hepatomegalie, Hemihypertrophie, Plazentahypertrophie, Hypoglykämien) führten wir zur Diagnosesicherung eine molekulargenetische Untersuchung durch. Diese ergab das Vorliegen einer paternalen uniparentalen Diploidie (paternale UPD 11p15.5).

Diskussion: Die Inzidenz des BWS wird in der Literatur mit 1:13.700 angegeben. Es sind mittlerweile viele (epi)genetische Veränderungen des Chromosoms 11p15.5 bekannt, die mit charakteristischen Genotyp-Phänotyp Ausprägungen bei Patienten mit BWS einhergehen [1]. Eine UPD liegt bei etwa $20 \%$ der sporadisch auftretenden BWS-Fällen vor. Diese führt häufig zu einer vermehrten Expression des Wachstumsfaktors IGF2 und damit in ca. $70 \%$ der Fälle zu einer Hemihypertrophie bei den Patienten. Gleichzeitig kommt es zu einer verringerten Expression zweier Tumorsuppressorgene (CDKN1C und H19), weshalb sich bei BWS-Patienten mit UPD häufig und auch über die ersten acht Lebensjahre hinaus Leber- und Nieren-Tumore entwickeln können [2].

Schlussfolgerung: Bei Frühgeborenen mit großer Plazenta, hartnäckigen Hypoglykämien sowie einer Hemihypertrophie/Organomegalie sollte ein BWS in Erwägung gezogen werden.

\section{Literatur}

1. Weksberg R, Shuman C, Beckwith JB (2010) Beckwith-Wiedemann syndrome. Eur J Hum Gen 18:8-14

2. Cooper WN, Luharia A, Evans GA et al (2005) Molecular subtypes and phenotypic expression of Beckwith-Wiedemann syndrome. Eur J Hum Genet 13:1025-1032

\section{GNPI-FP16}

Hyperleukozytose mit Leukostase als Folge einer akuten myeloischen Leukämie - eine intensivmedizinische und onkologische Herausforderung

\section{H. Schneider', C. Flotho' ${ }^{2}$, H. Fuchs'}

'Zentrum für Kinder- und Jugendmedizin Uniklinikum Freiburg, Funktionsbereich Neonatologie und päd. Intensivmedizin, Freiburg, Deutschland, ${ }^{2}$ Zentrum für Kinder- und Jugendmedizin, Klinik f. pädiatrische Hämatologie und Onkologie, Freiburg, Deutschland

Hintergrund: Eine Leukostase stellt einen schwerwiegenden medizinischen Notfall dar, der als Folge einer Hyperleukozytose (>100.000 Leukozyten/ $\mu \mathrm{l}$ ) auftreten kann. Hyperleukozytosen sind typische Komplikationen bei Patienten mit akuter myeloischer Leukämie, werden aber auch bei solchen mit akuter lymphoblastischer Leukämie beobachtet.

Fallbericht: Dieser Vortrag soll den Fall eines 6-jährigen Mädchens mit akuter myeloischer Leukämie und schwerer Hyperleukozytose darstellen. Die Patientin wurde uns mit dem V. a. eine akute Leukämie, mit einer stark erhöhten Leukozytenzahl von maximal 494.000/ $\mu$ l, zugewiesen.

Bei Aufnahme stand zu einem eine deutliche Vigilanzminderung sowie wiederholte generalisierte Krampfanfälle und zum anderen ein zunehmendes respiratorisches Versagen im Vordergrund. Trotz umgehender Austauschtransfusion kam es im Verlauf zu einer Verschlechterung der respiratorischen Situation sowie einer katecholaminpflichtigen Kreislaufinsuffizienz als Folge der Leukostase. Zudem bestand ein Nierenversagen sowie eine schwere Gerinnungsstörung mit intraventrikulären und intraparenchymatösen Hämorrhagien. Durch invasive Beatmung, Hinzunahme von inhalativem NO, wiederholter Austauschtransfusion und Hämodialyse konnte eine klinische Stabilisierung der Patienten erreicht werden. Eine Chemotherapie wurde umgehend nach Diagnosestellung und erster Austauschtransfusion begonnen.

Nach Diagnosestellung der intrakraniellen Blutungen erfolgte die Anlage einer externen Ventrikeldrainage. Bei steigendem intrakraniellen Druck entschlossen wir uns eine intraventrikuläre Lysetherapie mit Urokinase durchzuführen, um die Liquorpassage zu verbessern und einem Verschlusshydrocephalus vorzubeugen.

Diskussion: Diese Fallvorstellung richtet sich an Kolleginnen und Kollegen auf pädiatrischen Intensivstationen und soll zum einen sensibilisieren gegenüber der Wichtigkeit der raschen Diagnosestellung einer Leukostase, sowie die Möglichkeiten der Therapie aufzeigen. Gefürchtete Folgen einer Leukostase sind das akute Lungenversagen, Gerinnungsstörungen mit schweren Blutungen und neurologische Ausfälle. Im Vorliegenden Fall erschwerte neben diesen Hauptkomplikationen insbesondere ein Rechtsherzversagen infolge der Hyperleukozytose die intensivmedizinische Therapie.

Wir möchten im Vortrag insbesondere die Echokardiografiebefunde direkt vor und nach Start der inhalativen NO-Therapie zeigen, mit der für uns erstaunlich raschen Besserung der rechtsventrikulären Funktion. Darüber hinaus möchten wir auch die Ergebnisse der zerebralen Bildgebung und die korrelierenden klinisch neurologischen Befunde, mit der fast vollständigen Erholung der Patientin, darstellen. 


\section{GNPI-FP17}

Pylorusatresie (PA) bei Epidermolysis bullosa junctionalis (EBJ) verursacht durch eine bisher in der Literatur nicht beschriebene Mutation im ITGB4-Gen: Wahl des Operationszeitpunktes und weiteres Procedere

\section{E. M. Mair, H. Hummler, M. R. Mendler}

Universitätsklinikum Ulm, Neonatologie, Ulm, Deutschland

Hintergrund: EBJ ist eine klinisch heterogene Gruppe von erblich bullösen Dermatosen, die neben Beteiligung der Haut u. angrenzender Schleimhäute in seltenen Fällen auch mit dem Auftreten von PA assoziiert sein kann. Pathogenetisch bedingen Strukturproteine der Basalmembran eine Fragilität dieser Zone, so dass minimale Traumata zur Blasenbildung führen. Das klinische Bild einer EBJ ist äußerst variabel.

Fallbericht: Wir berichten von einem weibl. Frühgeborenen der $33+2$ SSW; Kind konsanguiner Eltern $\left(\mathrm{C} / \mathrm{C} 1^{\circ}\right)$, 36-jährige Mutter, 1. Gravida. Vorbekannt war ein Polyhydramnion, welches zweimalig intrauterin entlastet wurde (insg. ca. 41 drainiert). Zum Blasensprung kam es $48 \mathrm{~h}$ nach der letzten Punktion u. $124 \mathrm{~h}$ vor Geburt. Es erfolgte eine eilige Sectio bei patholog. CTG und Blutungen der Mutter.

Das Kind kam septisch mit unzureichender Eigenatmung zur Welt (APGAR 2/7/8) und wurde im Verlauf der ersten Lebensstunde intubiert und antibiotisch mit Piperacillin/Tazobactam und Gentamycin therapiert: Noch im Kreißsaal fielen großflächige Hautlösungen an allen Extremitäten mit Beteiligung der Schleimhäute auf. Zudem zeigte sich anhand von corneal ubiquitär gelblichen Einlagerungen eine Mitbeteiligung der Augen. Radiologisch ergab sich bei luftgefüllter Magenblase und ansonst luftleerem Abdomen der Verdacht auf eine Pylorusatresie.

Wir entschieden uns bzgl. einer OP - nach Rücksprache mit versch. EBZentren (Freiburg, Salzburg, Cincinnati) - zunächst für ein abwartendes Verhalten zur Sicherung der Verdachtsdiagnose EBJ und zur Stabilisierung des Kindes. Eine entnommene Hautbiopsie ergab mittels Immunfluoreszenzmapping den Befund einer EBJ mit einer Integrin a6 34 -Defizienz. Zur genaueren molekulargenetischen Abklärung führten wir eine Mutationsanalyse der Gene ITGA6 u. ITGB4 durch, dabei wurde die homozygote Variante c.2020delC in Exon 17 des ITGB4-Gens nachgewiesen. Diese Variante ist bisher in der Literatur nicht beschrieben.

Am 35. LT führten wir via medianer Laparotomie eine Gastroduodenostomie mit Pylorusbypass u. End-zu-End-Anastomose durch. Intraoperativ zeigte sich eine PA Typ I mit intraluminalem Web. Die OP verlief komplikationslos, der Hautbefund zeigte sich nach dem Eingriff stabil. Aktuell befindet sich die Patientin im Nahrungsaufbau. Die weitere Entwicklung bleibt abzuwarten.

Schlussfolgerung: Die meisten Fälle von EBJ mit PA gehen mit einer reduzierten Lebenserwartung einher, allerdings gibt es einzelne Fallberichte mit günstigeren Verläufe u. mit im Verlauf abnehmender Tendenz zur Blasenbildung. Da die gefundene Mutation im ITGB4-Gen bisher nicht beschrieben ist, kann keine genaue Prognose abgeschätzt werden. Rasante molekulargenetische Fortschritte bzgl. der Pathogenese von EBJ ermöglichen eine frühe präzise Diagnostik, die für die weitere Therapieplanung u. die genet. Beratung unverzichtbar ist. Die Entwicklung gentherapeutischer Verfahren legt die Basis für zukünftige kausale Therapien. Bis dahin bleibt die symptomatische Behandlung und die interdisziplinäre Betreuung der Ansatz der Wahl.

\section{GNPI-FP18 \\ Fallbericht: Neugeborenes mit einer schweren kongenitalen Nemalin-Myopathie}

L. Meyer-Dobkowitz', U. Blümlein', W. Heinritz', U. Wetzel', G. C. Schwabe' ${ }^{1}$ Carl-Thiem-Klinikum Cottbus, Klinik für Kinder- und Jugendmedizin, Cottbus, Deutschland, '2̈̈berörtliche Berufsausübungsgemeinschaft für Humangenetik Oberelbe/Spree, Cottbus, Deutschland

Hintergrund: Die Nemalin-Myopathie (NM) umfasst ein weites Spektrum seltener genetischer Muskelerkrankungen bei denen Nemalinkörper in der Muskelbiopsie nachweisbar sind. Die Prävalenz einer schweren kon- genitalen NM unter Lebendgeborenen lässt sich auf 1:250.000 zu 1:500.000 schätzen. Betroffene Kinder versterben meist in den ersten Lebenswochen bis -monaten in Folge der respiratorischen Insuffizienz bzw. aufgrund von Aspirationspneumonien.

Fallbericht: Bei einem betroffenen Neugeborenen der $33+6$. Schwangerschaftswoche zogen wir bei einer schweren muskulären Hypotonie mit respiratorischer Insuffizienz, Arthogryposis multiplex congenita und einem Mangel an Spontanbewegungen ein (neuro-)muskuläres Krankheitsbild mit konsekutiver Akinesie/Hypokinesie in Betracht. Wegen fetal-sonografischen Auffälligkeiten (clenched fingers bds.) wurde bereits pränatal unter dem Verdacht einer Trisomie 18 eine Amniozentese zur zytogenetischen Diagnostik durchgeführt. Diese ergab einen unauffälligen männlichen Karyotyp 46,XY. Zielführend konnte molekulargenetisch mittels Trio-ExomAnalyse eine de novo Mutation im ACTA1-Gen (c.90G >C (p.Arg30Ser), heterozygot) identifiziert werden. Das ACTA1-Gen codiert für das skelettmuskelspezifische Strukturprotein $\alpha$-Aktin. De novo Veränderungen in diesem Gen sind mit den schweren kongenitalen Verlaufsformen der NM assoziiert. Als ungünstige Prognosemarker wies der Patient einen bilateralen Chylothorax und (für das Krankheitsbild eher untypisch) einen zunehmenden Hydrozephalus internus auf.

Schlussfolgerung: Für die schwere kongenitale NM gibt es derzeit keine kurative Therapie. Im Fokus bei der palliativ ausgerichteten Versorgung betroffener Kinder stehen die maschinelle (Heim-)Beatmung, die symptomatische Behandlung weiterer Symptome bzw. auftretender Komplikationen und die psychologische Mitbetreuung der gesamten Familie.

\section{GNPI-FP19}

Kongenitaler intrahepatischer portokavaler Shunt und Hypoglykämie aufgrund eines sekundären Hyperinsulinismus: Ein Fallbericht

\section{A. Weigert ${ }^{1}$, H. Reutter ${ }^{2}$, J. Wölfle', R. Ganschow', M. Jankofsky', A. Müller ${ }^{2}$}

'Universität Bonn, Abteilung für Allgemeine Pädiatrie, Bonn, Deutschland, ${ }^{2}$ Universität Bonn, Abteilung für Neonatologie und Pädiatrische Intensivmedizin, Bonn, Deutschland

Hintergrund: Angeborene portosystemische Shunts sind seltene Fehlbildungen des portokavalen Gefäßsystems (Inzidenz ca. 1 auf 30.000 Neugeborene). Vielfältige assoziierte Fehlbildungen und Komplikationen wurden bisher beschrieben.

Fallbericht: Wir beschreiben den Fall eines Neugeborenen, der neben einem intrahepatischen Shunt persistierende Hypoglykämien, aufgrund eines sekundären Hyperinsulinismus, aufwies. Der Patient wurde, nachdem bereits pränatal die Diagnosen einer Ductus venosus Agenesie und zweier intrahepatischer Shunts im linken Leberlappen gestellt wurden, komplikationslos in unserer Klinik entbunden.

Die Diagnose konnte postnatal bestätigt werden. Neben einer nicht behandlungsbedürftigen Kardiomegalie, einer Cholestase, Hyperbilirubinämie, einer reduzierten Gerinnungsfaktoren-Produktion und einer leichten Hyperammonämie zeigte unser Patient $\mathrm{ab}$ dem 2. Lebenstag relevante Hypoglykämien, die zunächst mit einer intravenösen Glucosesubstitution behandelt wurden. Auch unter einer oralen Glucose-Zufuhr von max. $25 \mathrm{~g}$ Glucose/kgKG/Tag traten weiterhin Hypoglykämien auf. Laborchemisch zeigte sich in einer Hypoglykämie ein erhöhtes Insulin-Level. Daher begannen wir eine Therapie mit Diazoxid und die Nahrung des Patienten wurde mit Stärke angereichert. Hierunter stabilisierten sich die Blutzucker, es traten jedoch weiterhin Hypoglykämien auf.

Diskussion: Intrahepatische Shunts können anatomisch in intra- und extrahepatische Shunts aufgeteilt werden. Intraheptische Shunts, wie bei unserem Patienten, haben eine hohe Spontan-Verschluss Rate. So wird in der Regel von einem Verschluss abgesehen. Wir entschieden uns jedoch aufgrund der weiterhin bestehenden Hypoglykämien und der verringerten Synthese von Gerinnungsfaktoren für einen interventionellen Verschluss der Shunts. Als der Patient 2 Monate alt war konnte einer der beiden Shunts mit einem Coil verschlossen werden, während der andere bereits spontan verschlossen war. Hiernach stabilisierten sich die Blutzucker Werte weiter und die Produktion der Gerinnungsfaktoren normali- 
sierte sich. Warum es zu den Hypoglykämien unseres Patienten kam, ist letztlich noch nicht ausreichend geklärt.

Es gibt Hinweise, dass es bei Patienten mit portokavalen Shunts einerseits zu einem vermehrten Speicher von Insulin den pankreatischen B-Zellen und andererseits zu einer verminderten Synthese von sekretorischen Proteinen für Insulin kommt. Da bei unserem Patienten jedoch in einer Hypoglykämie ein erhöhtes Insulin-Serum-Level nachgewiesen wurde, denken wir, dass es aufgrund des verminderten Blutflusses durch die Leber zu einem deutlich verminderten Abbau des Insulins ebendort kommt und somit das sezernierte Insulin länger wirksam ist.

Schlussfolgerung: Auch wenn persistierende Hypoglykämien, wie bei unserem Patienten, eine sehr seltene Komplikation einer portokavalen Shunts ist, so schlagen wir ein konsequentes Screening auf Hypoglykämien bei diesen Patienten vor.

\section{GNPI-FP20}

\section{Seltene Ursachen von Krampfanfällen bei reifen Neugeborenen - 3 Fallbeispiele}

\section{J.P. Streidl', F. W. Hirsch², K. Gröger'}

${ }^{1}$ Muldentalkliniken gGmbH, Kinder- und Jugendmedizin, Wurzen, Deutschland, ${ }^{2}$ Universitätsklinikum Leipzig - AöR, Abteilung für Kinderradiologie, Leipzig, Deutschland

Hintergrund: Krampfanfälle im Neugeborenenalter treten mit einer Häufigkeit von $0,7-2,7 / 1000$ auf und betreffen meist Frühgeborene $<1500 \mathrm{~g}$ Geburtsgewicht. In ca. $90 \%$ der Fälle finden sich bei reifen Neugeborenen ursächlich Hypoxisch-ischämische Enzephalopathie, ZNS-Infektionen, Intrakranielle Blutungen, Hypokalzämie und Hypoglykämie.

Fragestellung: Wir präsentieren 3 seltene Ursachen als Kasuistiken. Patienten und Methoden: In unserem Krankenhaus der Grund- und Regelversorgung mit perinatalem Schwerpunkt betreuten wir 3 Fälle von zerebralen Krampfanfällen bei reifen Neugeborenen mit ungewöhnlichen Ursachen innerhalb von 3 Jahren.

Fallbericht 1: Neugeborenes (NG) $38+0$ Schwangerschaftswoche (SSW) Spontangeburt; Apgar 7/8/8; pH 7,37; Gewicht 2820 g/Länge 49 cm/Kopfumfang $33 \mathrm{~cm}$. Im Alter von ca. $1 \frac{1}{2}$ Stunden wird der Kinderarzt hinzugezogen, da das Kind krampfen würde. Er findet ein eutrophes NG mit eingeschlagenen Daumen bds. und intermittierend generalisierten Kloni vor. Im Rahmen der Diagnostik z.A.o.g. häufiger Ursachen mittels Blutentnahme und Lumbalpunktion, zeigen sich in der Schädelsonografie strukturelle Auffälligkeiten. Es werden eine pontocerebelläre Hypoplasie sowie eine GM1-Gangliosidose diagnostiziert.

Fallbericht 2: NG 40+5 SSW; Geburt mittels Vakuumextraktion; Apgar 9/10/10; pH 7,26; Gewicht 3490 g/Länge 54 cm/Kopfumfang 35 cm. Ab 3 Lebenstag deutlicher Ikterus, zunehmende Schläfrigkeit, muskuläre Hypotonie, in den nächsten Stunden rasche AZ-Verschlechterung mit flacher Atmung, reduzierten Schmerzreizen. Bei Übernahme auf Kinderstation Temperatur $34,5^{\circ} \mathrm{C} /$ Sauerstoffsättigung $80 \% /$ Herzfrequenz $145 / \mathrm{min}$ /auffälliger Singultus. Nach Stabilisierung der Vitalparameter inclusive Intubation und Beatmung bestätigt sich in Plasma und Liquor die Verdachtsdiagnose nicht-ketotische Hyperglycinämie.

Fallbericht 3: NG 40+6 SSW, Spontangeburt aus Schädellage; Apgar 9/10/10; pH 7,34. In der Nacht zum 3. Lebenstag seien wiederholt Krampfanfälle beobachtet worden $(1 \times$ ca. $1 \mathrm{~min}$. andauernde linksseitige Kloni von Arm und Bein, Augenbewegungen normal, $1 \times \mathrm{ca} .2 \mathrm{~min}$. andauernd beidseitig sichtbar). Abholung aus einer externen Geburtsklinik auf unsere Kinderstation. Im Rahmen der Diagnostik zunächst Verdacht auf intrazerebrale Blutung, jedoch bei Kontrollen Nachweis eines Teilinfarktes im Versorgungsgebiet der Arteria cerebri media rechts.

Diskussion: Krampfanfälle bei Neugeborenen erfordern eine rasche und zielgerichtete Diagnostik und Therapie. Nach Ausschluss o.g. häufigerer Ursachen, können mittels Bildgebung und Stoffwechseltests auch Raritäten diagnsotiziert und ggf. behandelt werden.

Schlussfolgerung: Auch kleine Kliniken, die Neugeborene betreuen, sollten darauf vorbereitet sein, dass bei reifen Neugeborenen Krampfanfälle auftreten können. Bei der Diagnostik helfen Ansprechpartner im zustän- digen LEVEL-1-Zentrum, der Kinderradiologie auch über Telemedizin und dem zuständigen Stoffwechselzentrum.

\section{GNPI-FP21}

\section{Fallpräsentation Sternumspalte - Sternal Cleft}

M. Klinke' ', M. Boettcher', S. Apostolidou'², D. Singer ${ }^{2}$, K. Reinshagen

'Universitätsklinikum Hamburg Eppendorf, Klinik für Kinderchirurgie, Hamburg, Deutschland, ${ }^{2}$ Universitätsklinikum Hamburg Eppendorf, Neonatologie und Pädiatrische Intensivmedizin, Hamburg, Deutschland

Hintergrund: Die Sternumspalte ist eine seltene, idiopathische Thoraxfehlbildung, welche mit einer Prävalenz von 1:50.000 Geburten auftritt und ca. $0,15 \%$ aller kongenitalen Thoraxwandfehlbildungen ausmacht. Es erfolgt eine Klassifikation in komplette und partielle Formen, wobei weiterführend eine superiore von eine inferioren Sternumspalte unterschieden wird. Mit $67 \%$ stellt die superiore Sternumspalte die häufigste Form dar. Eine operative Korrektur in der Neonatalzeit sollte angestrebt werden, um einen primären Verschluss zu erreichen. Mit zunehmendem Alter steigt die Rigidität des knöchernen Thorax, so dass häufig der Einsatz eines Interponates mit erhöhtem Operations- und Infektionsrisiko notwendig wird. Bei ausbleibender chirurgischer Korrektur steigt das Risiko für Verletzungen mediastinaler Organe sowie langfristig für schlechte kosmeticher Ergebnisse. Eine operative Korrektur ist entsprechend dringend empfohlen und sollte möglichst frühzeitig erfolgen.

Fallbericht: Im referierten Fall handelt es sich um ein reifes Neugeborenes der $38+5$. Schwangerschaftswoche, welches mit einem Geburtsgewicht von $3235 \mathrm{~g}$ spontan vaginal entbunden wurde. Schwangerschaft und Geburt verliefen unauffällig, die postnatale Adaptation gestaltete sich unkompliziert, APGAR 9/10/10.

In der U1 fielen eine Fehlbildung des Sternums mit hochthorakalen inspiratorischen Einziehungen, eine supraumbilicale Raphe sowie eine präkordiale Hautmarke auf. Palpatorisch zeigte sich ein breiter, nach kaudal spitz zulaufender Defekt des knöchernen Thorax. Weitere Auffälligkeiten bestanden nicht. Radiologisch bestätigte sich der klinische Verdacht auf eine Sternumspalte.

Im Alter von 7 Wochen erfolgte die operative Korrektur mittels Thorakoplastik und Keilosteotomie. Intraoperativ zeigten sich kranial weit auseinander klaffende Sternumhälften, welche kaudal über eine Knochenbrücke verbunden waren. Unter probatorischer Adaptation blieb das Kind kardiorespiratorisch stabil. Zur Prävention einer oberen Einflussstauung wurde eine Thymusteilresektion durchgeführt. Der knöcherne Verschluss erfolgte mittels Drahtcerclage. Postoperativ bestanden passagere Belüftungsstörungen, welche unter adäquater Beatmungs- und diuretischer Therapie rasch sistierten. Drei Wochen postoperativ konnte das Kind in gutem Allgemeinzustand nach Hause entlassen werden.

\section{GNPI-FP22}

\section{Expect the unexpected: letale Hyperkaliämie als Folge einer Mitochondriopathie}

\section{R. Roßmann', J. Mayr', C. Uhrig', S. Wortmann-Hagemann' ${ }^{2}$, R. Rossi'}

${ }^{1}$ Klinik für Kinder- und Jugendmedizin, Klinikum Neukölln, Berlin, Deutschland, ${ }^{2}$ Universitätsklinik für Kinder- und Jugendheilkunde, Salzburg, Österreich

Hintergrund: Neonatale Hyperkaliämien treten vor allem bei Frühgeborenen auf, sie können neben Herzrhythmusstörungen zu einem Kreislaufversagen mit Lactatazidose führen.

Fallbeschreibung: In der Schwangerschaft lange bekannte IUGR mit Oligohydramnion. Geburt per Sectio bei $37+5$ SSW, Apgar 6/6/6. Rasche Entwicklung eines schweren Lungenversagens mit ausgeprägter pulmonaler Hypertonie, aber ohne strukturelles oder funktionelles kardiales Versagen. Praktisch keine positive Reaktion auf NO, Surfactant ohne Effekt, kein Infektionshinweis, auch wenn das Kind in der kritischen Situation mit multiplen Gefäßzugängen und invasiven Maßnahmen antibiotisch behandelt wurde. Trotz hochdosierter Katecholamintherapie bleib das Kind 
im protrahierten Schock. Am 3. LT nach einer Puffertherapie Nachweis einer zunächst als iatrogen befürchteten Hyperkaliämie $(11,3 \mathrm{mmol} / \mathrm{l}) \mathrm{mit}$ Kreislaufstillstand, wiederholten Reanimationen und fortgesetzter Kreislaufinsuffizienz mit Lactatazidose von $>300 \mathrm{mg} / \mathrm{dl}$, die auch nach einer Multivitamintherapie unverändert fortbestand. Tod am 5. LT im therapierefraktären Schock.

Ergebnisse: Nachdem den Eltern zunächst ein vermuteter Infusionsfehler kommuniziert worden war, wurde später die Lactatazidose als Ausdruck eines möglichen Stoffwechseldefektes interpretiert. Die Eltern stimmten einer Obduktion nicht zu, aber der Entnahme einer Hautprobe zur Anzucht von Fibroblasten. In diesen wurde eine Verminderung der ATPSynthase auf $5 \%$ sowie molekularbiologisch eine homozygote Mutation c.217-2A>G im TMEM70 Gen gefunden und somit eine Mitochondriopathie nachgewiesen. Die gefundene Mutation ist eine Founder-Mutation in der Roma-Population. Erst in der wiederholten Anamnese wurden seitens der Familie die Konsanguinität und die ethnische Herkunft aus der Roma-Population bestätigt.

Schlussfolgerung: Auch letale Hyperkaliämien können Ausdruck einer Mitochondriopathie sein. Der Defekt ist zudem als Ursache von sowohl einer pränatalen Dystrophie als auch einer pulmonalen Hypertonie beschrieben, bei allerdings sehr variabler neurologischer Prognose [1]. Die Fallbeschreibung macht deutlich, dass es Sinn macht zu versuchen, unklare Todesfälle unter Nutzung biochemischer und molekularbiologischer Möglichkeiten zu klären.

\section{Literatur}

1. Magner M, Dvorakova V, Tesarova M et al (2015) TMEM70 deficiency: long-term outcome of 48 patients. J Inher Metab Dis 38:417-426

\section{GNPI-FP23}

Letaler Verlauf eines generalisierten Hirnödems durch multiple zerebrale Abszesse in der Folge einer komplizierten ambulant erworbenen Pneumonie durch Methicillin-sensiblen Stapylococcus aureus

M. V. Dewan', E. Tschiedel', P. Liedgens', E. Lemonas', P.M. Rath', U. Felderhoff-Müser', C. Dohna-Schwake'

'Universitätsklinikum Essen, Kinderklinik I, Essen, Deutschland, ${ }^{2}$ Elisabeth-Krankenhaus Essen, Kinderchirurgie, Essen, Deutschland, ${ }^{3}$ Universitätsklinikum Essen, Neurochirurgie, Essen, Deutschland, ${ }^{4}$ Universitätsklinikum Essen, Medizinische Mikrobiologie, Essen, Deutschland

Hintergrund: Die Inzidenz von Pneumonien bei Kindern <5Jahre liegt in den westlichen Ländern bei etwa 33/10.000. Trotz einer hohen Morbidität mit Hospitalisationsraten von bis zu $42 \%$ ist die Prognose gut. Die Mortalität liegt bei $<0,1 \%$. Ein Methicillin-sensibler Staphylococcus aureus (MSSA) ist als Erreger einer ambulant erworbenen Pneumonie zwar selten, zählt allerdings neben Streptococcus pneumoniae zu den häufigsten Erregern eines komplizierten Verlaufes. Zerebrale Abszesse im Kindesalter sind ebenfalls sehr selten. Risikofaktoren sind zyanotische Herzvitien, Immundefekte und Infektionen im Hals-Nasen-Ohren-Bereich.

Fallbericht: Wir berichten über einen 14 Monate alten Jungen, der als Komplikation einer ambulanten Pneumonie mit Pleuraempyem multiple zerebrale septische Embolien entwickelte. Das Pleuraempyem wurde initial thorakoskopisch gespült, und im Anschluss eine Thoraxdrainage gelegt. Bei Nachweis von MSSA im Pleurasekret wurde die Therapie mit hochdosiertem Cefuroxim und Gentamicin fortgeführt. Zehn Tage nach stationärer Aufnahme wurde der Junge zunehmend schläfrig und zeigte fokale Krampfanfälle mit sekundärer Generalisation. Ein MRT des Schädels zeigte sowohl infra- als auch supratentoriell multiple zerebrale Abszesse. Bei einem Glasgow Coma Scale von 8 erfolgten die Intubation und die Anlage einer externen Ventrikel-Drainage zur Messung des Hirndruckes. Im Liquor konnte kein Keim nachgewiesen werden. Die antibiotische Therapie wurde auf Meropenem und Fosfomycin umgestellt. Zwei Tage später kam es zu einem akuten Hirndruckanstieg und im zerebralen CT konnte eine massive Zunahme des Hirnödems dokumentiert werden. Trotz sofortiger dekompressiver Kraniotomie nahm die Schwellung weiter zu, so dass weitere drei Tage später der Hirntod festgestellt wurde. Hinweise auf einen Immundefekt fanden sich nicht.

Schlussfolgerung: Dieser Fall soll für die mögliche Komplikation einer zerebralen Abszedierung im Rahmen einer Pneumonie sensibilisieren, insbesondere, weil die initiale Symptomatik unspezifisch, aber rapide progredient sein kann. Die Behandlung erfolgt multidisziplinär zwischen Pädiatern, Neurochirurgen, Neuroradiologen und Mikrobiologen. Trotz adäquater und progressiver Therapie sind wie im vorliegenden Fall disseminierte Hirnabszesse im Kindesalter mit einer hohen Morbidität und Mortalität verbunden.

\section{GNPI-FP24}

Syndromatische Diarrhoe oder Tricho-Hepato-Enterisches Syndrom als Ursache einer kongenitalen Diarrhoe. Ein Fallbericht.

\section{Reuter, I. Broekaert, A. Kribs, C. Hünseler}

Klinik für Kinderheilkunde und Jugendmedizin der Uniklinik Köln, Neonatologie, Köln, Deutschland

Hintergrund: Eine kongenitale Diarrhoe ist eine seltene Erkrankungsentität mit hoher Morbidität und Mortalität. Die Ursachen sind vielfältig, die Diagnostik oft schwierig. Das Tricho-Hepato-Enterische Syndrom (THE-S) oder Syndromatische Diarrhoe ist eine wiederum seltene Ursache der kongenitalen Diarrhoe mit molekulargenetisch gesicherter Ursache [1]. Wir präsentieren einen Fall eines THE-S und beschreiben den diagnostischen Algoritmus.

Fallbeschreibung: Es handelt sich um ein weibliches Frühgeborenes der 34,0 SSW, Geburt per Sectio bei IUGR (Geburtsgewicht $1370 \mathrm{~g}(85 \mathrm{~g}<3 . \mathrm{P})$. Die initiale Anpassung war bis auf einen verzögerten Nahrungsaufbau mit Muttermilch unkompliziert. Nach 4 Wochen zeigten sich zunehmend voluminöse, wässrige Diarrhoen, welche eine erneute i.v. Flüssigkeitssubstitution und orale Bicarbonat-Substitution erforderten. Nahrungskarenz führte nicht zum vollständigen Sistieren der Diarrhoe, therapeutische Versuche mit kohlenhydratfreier Nahrung, aminosäurebasierter Nahrung, Loperamid, Kreon, Racecadotril etc. brachten keine Verbesserung, das Kind blieb dauerhaft abhängig von parenteraler Ernährung. Die auffällige Facies mit hoher Stirn, die wolligen, schnell ausfallenden Haare (mikroskopisch Pili torti) und der histologsche Nachweis einer nodulären Leberzirrhose führten zur Verdachtsdiagnose eines THE-S. Auffällig waren zusätzlich eine bikuspide Aortenklappe und eine links-persistierende obere Hohlvene. Laborchemisch fiel v. a. ein erniedrigtes IgG bei normalem A1AT im Stuhl auf. Die Verdachtsdiagnose THE-S konnte molekulargenetisch gesichert werden, es fanden sich zwei Punktmutationen c.1162C $>\mathrm{T}$ an Position 388 und c.3187C $>$ T an Position 1063 im SKIV2L-Gen (superkiller viralicidic activity 2) auf Chromosom 6p21.33. Die DünndarmHistologie zeigte keine Auffälligkeiten.

Im weiteren Verlauf wurde das Kind muttermilchernährt bei normalen Trinkmengen und es benötigte weiterhin eine vollständige parenterale Ernährung (ca. $150 \mathrm{ml} / \mathrm{kg}$ ) mit der es nach hause entlassen wurde. Die Gewichts- und Längenentwicklung verläuft aktuell perzentilenparallel unterhalb der 3. Perzentile. Die Leberenzyme und Syntheseparameter sind bislang normal.

Diskussion: In der Diagnostik der kongenitalen Diarrhoe empfiehlt sich ein strukturiertes Vorgehen [2]. Ein Sistieren der Diarrhoe unter Nahrungskarenz spricht für eine osmotische Ursache (z.B. KohlenhydratMalabsorptionen), besteht die Diarrhoe fort handelt es sich um eine sekretorische Komponente. Je nach Vorliegen zusätzlicher Symptome kann ggf. eine entsprechende Verdachtsdiagnose gestellt werden (z.B. THE-S, IPEX-Syndrom, Tufting-Enteropathie, Autoimmun-Enteritis, Microvillus-Inclusion Disease etc). Viele der in Frage kommenden Erkrankungen sind molekulargenetisch gesichert und können durch entsprechende $\mathrm{Pa}$ nel-Untersuchungen abgeklärt werden, so dass im Prinzip auf invasive Untersuchungen in vielen Fällen verzichtet werden könnte. Dies ist auch für das THE-S möglich. Die pathophysiologische Ursache der Diarrhoe und weiteren Auffälligkeiten beim THE-S sind noch nicht komplett verstanden, eine ursächliche Therapie ist nicht möglich. Ein Teil der Kinder bleibt 
im Verlauf abhängig von parenteraler Ernährung, die dadurch bedingten Komplikationen sind vor allem für die erhöhte Mortalität verantwortlich.

\section{Literatur}

1. Chong JH et al (2015) Tricho-hepato-enteric syndrome (THE-S): two cases and review of the literature. Eur J Pediatr 174:1405-1411

2. Terrin $\mathrm{G}$ et al (2012) Congenital diarrheal disorders: an updated diagnostic approach. Int J Mol Sci 13:4168-4185

\section{GNPI-FP25}

\section{Akute Bilirubinencephalopathie und Kernikterus, - ein Gespenst aus alten Tagen? Ein aktueller Fall}

\author{
M. Martin, H. Reutter, A. Müller \\ Universitätsklinikum Bonn, Kinderklinik, Neonatologie/Pädiatrische \\ Intensivmedizin, Bonn, Deutschland
}

Hintergrund: Der Neugeborenenikterus ist sehr häufig. Etwa $60 \%$ aller Neugeborenen werden innerhalb der ersten Lebenswoche sichtbar ikterisch. Durch die Möglichkeit der Phototherapie bleiben langfristige Schäden aus. Die Häufigkeit eines extrem hohen Bilirubinwertes $(>30 \mathrm{mg} / \mathrm{dl})$ bzw. einer chronischen Bilirubin-Enzephalopatie ist mit 1 in 10-4 bzw. 1 in 10-5 sehr gering. In Deutschland erkranken pro Jahr 2-7 Neugeborene an einem Kerinkterus. Um so wichtiger ist das Erkennen eines Neugeborenen mit einem hohen oder rasch ansteigenden Bilirubin Wert.

Fallbericht: Am 5. Lebenstag stellt eine Mutter ihr Kind in der Notaufnahme unserer Klinik bei zunehmend ikterischem Hautkolorit vor. Die Geburt erfolgte in einem Geburtshaus mit $38+0$ Schwangerschaftswochen. In der am Vortag der Aufnahme durchgeführt U2-Untersuchung wurde ein Neugeboreneninkterus beschrieben. Die in unserer Notaufnahme durchgeführte kapilläre Blutgasanalyse zeigte einen Bilirubinwert von $45 \mathrm{mg} / \mathrm{dl}$. Es erfolgte die sofortige Verlegung auf unsere neonatologische Intensivstation. Auf dem Weg dorthin zeigte das Neugeborene kurz andauernde wiederkehrende Krampfanfälle mit Apnoen.

Wir begannen umgehend eine Phototherapie. Zur Vorbereitung einer Austauschtransfusion und bei anhaltenden Anfallsäquivalenten wurde das Kind rasch intubiert und eine Austauschtransfusion begonnen. Vor Beginn der Austauschtransfusion und während der Vorbereitung der Erythrozytenkonzentrate durch die Blutbank verabreichten wir eine Immunglobulingabe. Unter den genannten Maßnahmen fiel der Bilirubinwert rasch ab.

Hirnsonographisch zeigten sich vor und nach der Austauschtransfusion keine Auffälligkeiten. Auch ein EEG blieb ohne pathologischen Befund. In einer Kernspintomographie am 10. Lebenstag fielen mesencephale Signalanhebungen und Veränderungen der Stamganglien, insbesondere im Globus pallidus und der Substantia nigra auf, die mit einer zentralen Hyperbilirubinämie vereinbar sind. Das Hörscreening (AABR) zeigte einen pathologischen Befund. Ursächlich lag der Hyperbilirubinämie eine $\mathrm{ABO}$ Inkompatibilität zu Grunde. Unser Patient ist das zweite Kind der Mutter, die die Blutgruppe $0 \mathrm{Rh}$ negativ besitzt und nach der ersten Schwangerschaft mit Anti-D Immunglobulin behandelt wurde. Der Patient hat die Blutgruppe A Rh positiv. Laborchemisch zeigte sich ein positiver direkter Coombstest. Eine Infektion als weitere Ursache konnte ausgeschlossen werden.

Schlussfolgerung: Unser Fall demonstriert den seltenen, jedoch schweren Verlauf eines Neugeborenenikterus. Eine frühere Erkennung des hohen Bilirubinwertes bzw. eine frühere Zuweisung im Rahmen der U2 hätte zur Vermeidung des Kernikterus geführt. Der Kernikterus, auch wenn extrem selten, kommt immer wieder vor. Bei einem ikterischen Neugeborenen mit einer Rhesus- oder ABO-Inkompatibilität sollte leitliniengerecht eine transkutane oder je nach Lebensalter eine blutige Messung des Bilirubins erfolgen.

\section{GNPI-FP26}

\section{Drayer Syndrom - seltene Ursache einer intrauterinen Wachstumsretardierung}

J. Weinknecht' ${ }^{1}$ C. Walter, A. von der Wense', H. Wiedemann', P. Gudowius', W. H. Becker' ${ }^{2}$, U. Peters ${ }^{2}$

${ }^{1}$ Altonaer Kinderkrankenhaus, Neonatologie und Pädiatrsche Intensivmedizin, Hamburg, Deutschland, ${ }^{2}$ Praxis für Pränatalmedizin im PNZ Altona, Hamburg, Deutschland

Fallbericht: Mit 26+5 Schwangerschaftswochen, einem Geburtsgewicht von $470 \mathrm{~g}(<3$.Perzentile), einem Kopfumfang von $21 \mathrm{~cm}(<3$. Perzentile) und einer Körperlänge von $27 \mathrm{~cm}(<3$. Perzentile) wurde ein hypotrophes Mädchen bei bekannter intrauteriner Wachstumsretadierung als 2 . Kind einer 23-jährigen Viertgravida via Sectio caesarea aus Beckenendlage geboren.

Die Eltern sind konsanguin. Zwei Feten verstarben intrauterin, das dritte Kind in der Neonatalperiode. Die pränatal durchgeführte Amniozentese zeigt eine Deletion am Chromosom 15q26.

Bereits im Kreißsaal werden folgende Stigmata beobachtet: ein symmetrisch hypotrophes Frühgeborenes, Brachydaktylie der Hände und Füße, eine Vier-Finger-Furche an der linken Handinnenfläche sowie Klumpfüße beidseits. Die Brachydaktylie ist postaxial betont. Im Gesicht stellt sich eine breite Nasenwurzel und eine Blepharophimose beidseits sowie tiefsitzende Ohren dar.

Verlauf: Postnatale Surfactantgabe bei Atemnotsyndrom ${ }^{\circ}$ III. NIPPVAtemunterstützung. Am 12. Lebenstag entwickelt das Mädchen eine fulminante nekrotisierende Enterocolitis, an welcher es am 14. Lebenstag verstirbt. Eine Obduktion des Kindes wird von den Eltern abgelehnt. Eine Microarray-basierte komparative genomische Hybridisierung (Array-CGH) der Eltern wurde diesen zur weiteren genetischen Abklärung angeraten. Das Ergebnis liegt noch nicht vor.

Diskussion: Drayer (1977) und später Rump (2008; [3]) beschrieben kleinwüchsige Geschwister (1 Mann, 1 Frau) mit einer sehr seltenen Deletion am Chromsom 15(q26.2-qter). Deren Eltern wiesen die Deletion nicht auf. Das lokalisierte, für die Wachstumsretadierung verantwortliche Gen ist das insulin-like growth factor 1 receptor Gen (IGF1R, OMIM 147370; [2]). Bhakta et al. [1] beschreiben 2005 ein Frühgeborenes der 34. SSW mit einer Deletion am Chromosom 15q26.1 und den von Drayer beschriebenen phänotypischen Stigmata. Diese Patientin erkrankte nach Korrektur eines unterbrochenen Aortenbogens ebenfalls an einer nekrotisierenden Enterocolitis.

Zusammenfassung und Hypothese: Da IGF-1 die Mukosazellen vor Hyperoxie induzierter Apoptose schützt und IGF-1 Mangel mit einem erhöhten Risiko für NEC assoziiert ist [4], liegt es nahe, dass das DrayerSyndrom durch fehlende IGF-1-Rezeptor-vermittelte Mechanismen ein besonders hohes Risiko für eine NEC mit sich bringt.

\section{Literatur}

1. Bahkta KY, Marlin SJ, Shen JJ, Fernandes CJ (2005) Terminal deletion of chromosome 15q26.1: Case report and brief literature review. J Perinatol 25:429-432

2. Rudaks LI, Nicholl JK, Bratkovic D, Barnett CP (2011) Short stature due to 15q26 microdeletion involving IGF1R: Report of an additional case and review of the literature. Am J Med Genet Part A 155:3139-3143

3. Rump P, Dijkhuizen T, Sikkema-Raddatz B et al (2008) Drayer's syndrome of mental retardiation, microcephaly, short stature and absent phalanges is caused by a recurrent deletion of chromosome 15(q26.2-qter). Clin Genet 74:455-462

4. Baregamian N, Song J, Jeschke MG et al (2006) IGF-1 protects intestinal epithelial cells from oxidative stress-induced apoptosis. J Surg Res 136:31-37 


\section{GNPI-FP27}

\section{Erythrodermie und hypotone Hypernatriämie beim} Neugeborenen - eine Fallbeschreibung des Netherton-Syndroms

V. Adam', M. Teubner', L. J. M. Herrmann', P. Suhl', F. Müller', F. Wild', D. Metzte ${ }^{2}$, H. Schneider ${ }^{3}$, M. Steinhoff ${ }^{4,5}$, S. Seeliger ${ }^{1}$

${ }^{1}$ Klinik für Kinder- und Jugendmedizin, Kliniken St. Elisabeth, Neuburg an der Donau, Deutschland, ${ }^{2}$ Dermato-Histologisches Labor, Universität Münster, Münster, Deutschland, ${ }^{3}$ Kinder- und Jugendklinik des Universitätsklinikums Erlangen, Erlangen, Deutschland, ${ }^{4}$ Dept. of Dermatology \& Venerology, Hamad Medical Corporation, Qatar University, Doha, Qatar, ${ }^{5}$ Dept. of Dermatology and Venerology, UCD Charles Institute of Dermatology, Dublin, Ireland

Hintergrund: Das Netherton-Syndrom (NS) ist eine kongenitale ichthyosiforme Erythrodermie (CIE), verbunden mit einem charakteristischen Defekt des Haarschaftes (Trichorrhexis invaginata, TI) und einer ausgeprägten Atopieneigung. Seine Prävalenz wird mit 1:200.000 angegeben [1]. Ursache sind Mutationen im Gen SPINK5 (5q31-q32), das für den Serinprotease-Inhibitor LEKTI kodiert. Die Vererbung erfolgt autosomal-rezessiv. Betroffene Neugeborene zeigen eine generalisierte Eythrodermie mit Schuppung sowie eine durch die unzureichende Barrierefunktion der Haut hervorgerufene hypernatriämische Dehydratation. Später kommt es zu rezidivierenden Infekten, Atopien, Diarrhoe und intestinaler Malabsorption und einer damit verbundenen Gedeihstörung [1].

Fallbeschreibung: Ein weibliches Neugeborenes fiel postpartal durch eine ausgeprägte Erythrodermie mit beginnender Schuppung auf. Wegen einer respiratorischen Anpassungsstörung benötigte es am ersten Lebenstag eine Atemunterstützung. Im weiteren Verlauf kam es zu ausgeprägtem Flüssigkeitsverlust über die gestörte Hautbarriere mit hypernatriämischer Dehydratation und Natriumwerten von max. $165 \mathrm{mmol} / \mathrm{l}$. Über Wochen war ein Ausgleich des Flüssigkeitsverlusts erforderlich. Bei Verdacht auf NS wurde eine mikroskopische Untersuchung des Haarschafts durchgeführt. Hier zeigte sich keine TI. In der Hautbiopsie konnte jedoch das Fehlen des LEKTI-Proteins sicher nachgewiesen und so der klinische Verdacht auf ein NS bestätigt werden. Die Neigung zu - teils infektgetriggerter - hypernatriämischer Dehydratation blieb wochenlang bestehen, führte zu mehreren Krankenhausaufenthalten und war mit einer erheblichen Gedeihstörung verbunden.

Diskussion: Bei Neugeborenen mit Erythrodermie muss auch an das sehr seltene Krankheitsbild eines NS gedacht werden, da betroffene Kinder durch Elektrolytentgleisungen lebensbedrohlich gefährdet sind und diese mit einer hohen Letalität einhergehen. Die Diagnose sowie die Therapie des NS erfordern eine sehr gute interdisziplinäre Zusammenarbeit, auch nach der Neugeborenenzeit. Eine engmaschige Weiterbetreuung der $\mathrm{Pa}-$ tienten besonders während des Säuglings- und Kleinkindalters ist wichtig.

\section{Literatur}

1. Zambruno G (2008) Netherton-Syndrom, ORPHA 634, Stand Oktober 2008. http:// www.orpha.net/consor/cgi-bin/OC_Exp.php?Lng=DE\&Expert=634. Zugegriffen: 05. Januar 2017

\section{GNPI-FP28}

Congenitale Cutane Candidose mit konsekutiver Candida-Sepsis zwei unabhängige Fälle

A. Werner' , M. Steidl ', C. Jakubowicz', R. Wolf ${ }^{2}$, C. Müller ${ }^{3}$, S. Herber-Jonat ${ }^{\text {', }}$ M. Klemme' ${ }^{1}$ K. Förster ${ }^{1}$, A. W. Flemmer ${ }^{1}$

${ }^{1}$ Klinikum der Universität München, Neonatologie Perinatalzentrum Großhadern, München, Deutschland, ${ }^{2}$ Universitätsklinikum Marburg, Dermatologie und Allergologie, München, Deutschland, ${ }^{3}$ Klinkum der Universität München, Dr. von Haunersches Kinderspital, München, Deutschland

Hintergrund: Die Congenitale Cutane Candidose (CCC) ist eine seltene Erkrankung der Neonatalperiode mit $<100$ beschriebenen Fällen in der englischsprachigen Literatur. Sie umfasst ein weites Krankheitsspektrum von isoliertem kutanem Befall, bis hin zu schweren systemischen Infektionen mit neonataler Mortalität und Spätschäden. Noch seltener ist die aus ihr hervorgehende Candida-Sepsis. Bei reifen Neugeborenen gibt es bisher keine beschriebenen Fällen einer CCC mit im Blut nachgewiesener invasiver Candidiasis.

Methode: Wir präsentieren zwei unabhängige Fälle mit dem kombinierten Krankheitsbild aus CCC und Candida-Sepsis: Ein Neugeborenes mit $39+5 / 7$ SSW sowie eine Frühgeborenes mit 28 + 4/7 SSW.

Fallbericht 1: Der reifgeborene Junge wurde komplikationslos per Spontanpartus entbunden. Bei der Erstinspektion fiel ein generalisiertes monomorphes Exanthem mit disseminiert verteilten Papulopusteln auf. Am 2. Lebenstag zeigte sich ein Anstieg der Entzündungsmarker (CrP max. $18,4 \mathrm{mg} / \mathrm{dl}$, IL-6 $1193 \mathrm{pg} / \mathrm{ml}$ ). Es wurde eine Antibiotikatherapie begonnen. Die Mutter berichtete über eine vaginale Mykose in der Schwangerschaft. Im Pustel-Abstrich des Neugeborenen konnte Candida albicans nachgewiesen werden, sodass eine intravenöse Fluconazol-Therapie ergänzt wurde. In der Urinkultur, im Pustelinhalt und im Nabelschnurblut konnte ebenfalls Candida albicans nachgewiesen werden. Auch der Candida-Antigen-Nachweis erwies sich positiv und bestätigte somit eine CCC mit konsekutiver Candida-Sepsis. Unter der Therapie stabilisierte sich das Kind und das Exanthem heilte unter Schuppung vollständig ab.

Fallbericht 2: Der frühgeborene Junge wurde bei Amnioninfektionssyndrom per Sectio entbunden. Im Direktpräparat des Fruchtwassers zeigten sich mikroskopisch Hyphen. Die Mutter hatte eine vaginale Besiedelung mit Candida albicans. Im initialen Labor bestanden erhöhte Infektparameter (CrP 1,5 mg/dl, IL-6 204 pg/ml). Es wurden eine Antibiotikatherapie und eine systemische Therapie mit Fluconazol gestartet. Am 2. Lebenstag zeigte sich ein pustulöser Hautausschlag im Bereich des Abdomens und der Genitalien. Am Rücken bestand eine ausgeprägte Schuppung auf erythematösem Untergrund. Im Fruchtwasser, im Ohrabstrich, im Pustelabstrich, im Magensaft und im Trachealsekret konnte Candida albicans nachgewiesen werden. Das Candida-Antigen im Serum war positiv. Dies bestätigte die Verdachtsdiagnose einer CCC mit begleitender CandidaSepsis. Unter der genannten Therapie zeigte sich eine komplette restitutio ad integrum.

Schlussfolgerung: Die Congenitale Cutane Candidose mit konsekutiver Candida-Sepsis ist eine sehr seltene Erkrankung der Neonatalperiode, welche das Früh- und Reifgeborene akut und langfristig schwer schädigen und im schlimmsten Fall zum neonatalen Tod führen kann. Es gilt das Bewusstsein für dieses Krankheitsbild zu schärfen. Eine unmittelbare Diagnosestellung und die frühe Einleitung einer systemischen antimykotischen Therapie sind entscheidende Faktoren für das Outcome dieser Patienten.

\section{GNPI-FP29}

\section{Hepatopathie: Ursache der konnatalen CMV-Infektion oder Nebenwirkung der Therapie?}

D. Stavropoulou', P. Franck', J. C. Krause', P. Henneke', P. Gerner' ${ }^{3}$, R. Hentschel' ${ }^{1}$ Universitätsklinikum Freiburg, Neonatologie und pädiatrische Intensivmedizin, Freiburg, Deutschland, 'Universitätsklinikum Freiburg, $\mathrm{CCl}$, Zentrum für Chronische Immundefizienz, Freiburg, Deutschland, ${ }^{3}$ Universitätsklinikum Freiburg, Funktionsbereich Kindergastroenterologie, Freiburg, Deutschland

Hintergrund: Die konntale CMV-Infektion ist die häufigste konnatale Infektion. Sie kann verschiedene Organe betreffen. Eine Hepathopathie wird in $15 \%$ der Fälle. Trotz der z. T. gravierenden Auswirkungen einer symptomatischen konnatalen CMV-Infektion fehlen offizielle Screening-Empfehlungen, sowohl während der Schwangerschaft als auch postnatal.

Fallbericht: Wir berichten über ein hypotrophes NG der 38 + 3/7 SSW mit einem GG von $2335 \mathrm{~g}(\mathrm{P}<3)$, KU $27 \mathrm{~cm}(\mathrm{P}<3), \mathrm{KL} 43 \mathrm{~cm}(\mathrm{P}<3)$ und pränatal bekannter Hirnventrikelerweiterung rechts. Die erst im 5 . Monat erkannte Schwangerschaft verlief bis auf einen grippalen Infekt mit Abgeschlagenheit und Gliederschmerzen in der 24. SSW komplikationslos. Toxoplasmose- und Lues-Serologien waren unauffällig. Für CMV wurde nicht getestet. Die Amniozentese ergab keine Pathologien. Die postnatalen Befunde der Schädelsonographie und des MRT zeigten eine bilaterale open-lip Schizenzephalie mit Polymikrogyrie sowie Verkalkungen frontobasal, periventrikulär und links temporal. Es bestand keine Thrombo- 
zytopenie. Die CMV-PCR aus Plasma(7500IE/ml) und Urin waren hoch positiv. Bei symptomatischer konnataler CMV-Infektion erfolgte eine intravenöse Ganciclovir-Therapie mit raschem Abfall der Viruslast. Die CMV-PCR aus Plasma, Urin und Liquor waren nach 9 Tagen negativ. Daraufhin wurde die Therapie auf Valganciclovir oral umgestellt. Diese musste nach 3 Wochen bei Zeichen einer Therapietoxizität mit Cholestase und Leberzelllyse für 2 Wochen pausiert und schließlich 1 Woche nach Wiederaufnahme endgültig beendet werden (Transaminasen max. 800U/l). Bereits 4 Monate nach Erstdiagnose und ohne antivirale Therapie zeigten sich im Verlauf stetig steigende Transaminasen ohne nachweisbare CMV-Viruslast. 5 Monate nach Erstdiagnose kam es zur Reaktivierung der CMV-Infektion und im Rahmen dessen zur Verschlechterung der bestehenden Hepatitis. Bis zum jetzigen Zeitpunkt bestehen erhöhte Transaminasenwerte mit guter Syntheseleistung. Sonographisch besteht kein Hinweis auf eine Leberfibrose. Ein Alagille-Syndrom, ein alpha1-AT-Mangel, eine Autoimmunhepatitis, virale Hepatitiden, eine HIV-Infektion, Zöliakie und Stoffwechselerkrankungen wurden ausgeschlossen. Die persistierende Hepatopathie bleibt weiterhin ungeklärt.

Das Outcome des aktuell 2-jährigen Jungen zeigt eine schwere globale Entwicklungsverzögerung, eine Cerebralparese sowie Fütterungsprobleme und Dystrophie.

Diskussion und Schlussfolgerung: Retrospektiv stellt sich die Frage, ob der vermutete grippale Infekt nicht eine fehlgedeutete primäre CMV-Infektion darstellen könnte, und ob eine CMV-Serologie bei ähnlichen Symptomen nicht sinnvoll wäre. Hepatitis und Cholestase wurden im vorliegenden Fall als mögliche Therapienebenwirkungen von Ganciclovir gedeutet, können aber auch durch die Grunderkrankung ausgelöst werden. Der diskordante Verlauf von Viruslast und Transaminasenerhöhung bei dem Fall erlaubt keine Klärung. Aus der Literatur wissen wir, dass die Hepatitis bei einer konnatalen CMV-Infektion weiter persistieren kann und beim Neugeborenen bis hin zum Leberversagen fortschreiten kann

\section{GNPI-FP30 \\ Fallpräsentation: Katheterassozierte Perikardtamponade - eine lebensbedrohliche Komplikation bei der intensivmedizinischen Betreuung von sehr unreifen Frühgeborenen}

S. Goretzki' , K. Pieper' ${ }^{2}$, J. Küter ${ }^{3}$, U. Neudorf ${ }^{3}$, U. Felderhoff-Müser', H. Müller'

${ }^{1} K$ linik für Kinderheilkunde I des Universitätsklinikums Essen, Neonatologie, Pädiatrische Intensivmedizin und Neuropädiatrie, Essen, Deutschland, ${ }^{2}$ Klinik für Kinderheilkunde II des Universitätsklinikums Essen, Pädiatrische Gastroenterologie, Essen, Deutschland, ${ }^{3}$ Klinik für Kinderheilkunde III des Universitätsklinikums Essen, Pädiatrische Kardiologie und Rheumatologie, Essen, Deutschland

Hintergrund: Ein Extravasat im Perikard durch Infusionslösung ist eine bekannte lebensbedrohliche Komplikation der parenteralen Ernährung über zentralvenöse Katheter. Es kann beim Legen der Katheter zu einer akuten und direkten Perforation kommen oder der liegende Katheter verursacht durch eine chronische Drucknekrose eine Perforation. In beiden Fällen sind eine zügige Diagnose und eine entlastende Punktion essentiell. Fallbericht: Ein weibliches Frühgeborenes kam per Notsectio bei Plazentalösung in der 26+0 SSW nach inkompletter Lungenreife (1. Gabe kurz vor der Geburt) und einem Geburtsgewicht von $800 \mathrm{~g}$ zur Welt (APGAR 4/7/8, NapH 7,32). Die Anlage von NAK und NVK erfolgten in der 4. Lebensstunde komplikationslos und diese wurden nach Röntgenbild in der Lage korrigiert. Bei V. a. AIS erfolgte eine antibiotische Therapie und eine antimykotische Prophylaxe. Die pulmonale Situation (RDS $3^{\circ}$ ) erlaubte keine frühe Extubation, sondern erforderte weitere Surfactantgaben. Im Alter von 20 Lebensstunden, kurz nach der 2. Surfactantgabe, kam es zu einer akuten Verschlechterung des Hautkolorits mit Tachykardie und Tachydyspnoe, welche innerhalb von Minuten in eine reanimationspflichtige Bradykardie überging. Eine Reanimation mit Herzdruckmassage, Kontrolle der Tubuslage und Ausschluss eines Pneumothoraxes mittels Kaltlichtquelle und Röntgen-Thorax, sowie ein Stopp der Infusionslösungen über den NVK (damit sollte einer möglichen iatrogenen Hyperkaliämie entgegengewirkt werden) folgten. Nach Überdenken der sogenannten
„HITS“ (Herzbeuteltamponade, Intoxikation, Thromboembolie, Spannungspneumothorax) folgte eine orientierende Echokardiographie. Diese zeigte eine Herzbeuteltamponade. Unter sofortiger Perikardpunktion mit Ablassen von chylus- oder fettähnlicher weißlicher Flüssigkeit kam es zur klinischen Stabilisierung. Bei dem Nachweis der Perikardtamponade mit weißlicher Flüssigkeit gingen wir von einer Myokardperforation durch den NVK aus. Nach initialer Besserung kam es schnell erneut zu einer kardiokompressionsbedürftigen Phase, worauf die Anlage einer dauerhaften Perikarddrainage (ultraschallgesteuert, mit 24 G-Katheter für art. Zugänge) erfolgte und sich das Kind endgültig stabilisierte. Eine Echokardiographie durch den Kinderkardiologen zeigte in der Folge eine uneingeschränkte Kontraktilität mit minimalem Erguss und korrekt einliegender Drainage; die NVK- Spitze projizierte sich in den linken Vorhof. Der NVK konnte komplikationslos, ohne Nachbluten, gezogen werden und am 3. Lebenstag wurde die Drainage komplikationslos entfernt. Eine nach der akuten Phase durchgeführte Schädelsonographie zeigte eine IVH I-II ${ }^{\circ}$ li und IVH II$\mathrm{III}^{\circ}$ re ohne Parenchymbeteiligung oder Hydrozephalus bei klinisch neurologisch unauffälligem Kind. Zum eigentlichen Geburtstermin wird ein cMRT durchgeführt werden (Bestandteil unseres neurologischen Monitorings der Frühgeborenen $<32$. SSW $/<1500 \mathrm{~g}$ ) und SPZ-Kontrollen werden die neurologische Entwicklung überwachen.

Schlussfolgerung: Zusammenfassend zeigt dieser Fall, dass in einer unklaren Reanimationssituation das strukturierte Durchgehen der „HITS“ lebensrettend sein kann, da auch seltene Ursachen wie eine Perikardtamponade schnell und leicht per Sonographie diagnostizierbar sind und ihre zügige Therapie lebensrettend sein kann.

\section{GNPI-FP31}

\section{Methämoglobinämie als Ursache einer Zyanose bei einem Neugeborenen}

G. Avrami, A. Ledermann, T. Hofmann, M. Endmann

EVK Lippstadt, Kinderklink, Lippstadt, Deutschland

Hintergrund: Der zyanotische Säugling nach Geburt ist ein häufig anzutreffender Kasus. Bleibt die Zyanose auch nach Erhöhung des Sauerstoffsupplements in der Einatemluft des Babys bestehen, sind zügig ernstzunehmende Krankheiten auszuschließen, da die Desaturation des Blutes an ,sauerstoffintensiven“ Geweben (Herz, Hirn) schwere Schäden verursachen kann.

Fallbericht: Ein reifes Neugeborenes der 39. SSW wurde ca. 8 Stunden postnatal im Babybett einer auswärtigen Geburtsklinik zyanotisch vorgefunden. Die gemessene Sauerstoffspannung im Blut betrug $85 \%$. Trotz unmittelbarer O2-Vorlage trat keine Besserung des $\mathrm{SaO} 2$-Wertes ein. Es wurde von unserem Neo-Team nasotracheal intubiert für den Transport in unsere Klinik bei Verdacht auf ein Vitium cordis. Auch nach Intubation und Erhöhung der Sauerstoffkonzentration trat keine Besserung der gemessenen Sauerstoffsättigung ein; diese betrug bei einem $\mathrm{FiO} 2$ von 0,7 nur $90 \%$. Es erfolgte ein Echokardiografie, die jedoch keinen zyanotischen Herzfehler zeigte. Auch die Röntgenuntersuchung des Thorax war unauffällig wie die Ultraschalluntersuchung des Schädels. Die erhobenen Laborbefunde (Blutbild, CrP, IL-6 und Elektrolyte) waren im Normbereich, so dass auch eine Infektion ausgeschlossen werden konnte.

Im Zusammenhang mit der grau-lividen Hautfarbe des Kindes und der dunkel-braunen Farbe des Blutes vom Kind wurde die Diagnose einer Met-Hb-ämie durch eine BGA gestellt. Das Met-Hb betrug max. $34 \% \mathrm{am}$ Tag der Geburt. Am 3. Lebenstag kam es zur kompletten Normalisierung $(1,5 \%)$, so dass sowohl auf weitere Diagnostik bezüglich der angeborenen Form einer Methämoglobinämie, als auch auf eine medikamentöse Behandlung verzichtet werden konnte. Auf dezidiertes Nachfragen bei den Entbindungshelfern und den Eltern haben wir von einer unmittelbar vor Entbindung applizierten Lokalanästhetikagabe bei der Mutter erfahren. Es wurden $10 \mathrm{ml}$ Prilocain im Bereich des Perineums appliziert, woraufhin die Mutter unmittelbar Übelkeit empfand.

Diskussion: Die neonatale Methämoglobinämie durch Lokalanästhesieapplikation bei der Mutter ist eine Rarität [4] aber zu bedenken. Wesentlich häufiger finden sich Methämoglobinämien im späteren Säuglingssalter, 
wobei auch einige in der Kinderheilkunde benutzen Antibiotika sowie Nitrat im Wasser (Milchzubereitung) diese auszulösen vermögen [3].

Schlussfolgerung: Bei der Zyanose des Neugeborenen ist die Met-Hb-ämie als Ursache zu bedenken. Unerwünschte Arzneimittel-Nebenwirkungen sollten der AkdÄ gemeldet werden. Deren Erkenntnisse werden regelmäßig veröffentlicht, wovon alle Behandler profitieren und Schaden vom $\mathrm{Pa}$ tienten abgewendet werden kann.

\section{Literatur}

1. Greiling H, Gressner AM (1995) Lehrbuch der Klinischen Chemie und Pathobiochemie, 3. Aufl. Schattauer Verlagsgeschellschaft, Stuttgart, S 1015-1025

2. Umbreit J (2007) Methemoglobin - It's not just blue: a concise review. Am J Hematol 82:134-144

3. Methämoglobinämie durch Gifte. http://toxcenter.org/stoff-infos/m/methaemoglobinaemie.pdf

4. arznei-telegramm (1997) Prilokain (XYLONEST)-Anästhesie der Mutter - Zyanose beim Neugeborenen? a-t 2:24

\section{GNPI-FP32}

\section{,Right Ventricular Diverticuloma' als Zufallsbefund bei einem Neonaten mit Trisomie 21, komplettem AVSD und Digoxinintoxikation}

\section{B. Wannenmacher, M. Weidenbach, J. Hambsch, I. Dähnert, R. Wagner Herzzentrum Leipzig GmbH, Klinik für Kinderkardiologie, Leipzig, Deutschland}

Hintergrund: Ventrikuläre Aneurysmen und Divertikel sind eine seltene angeborene kardiale Anomalie. Das klinische Erscheinungsbild der überwiegend im Bereich des Apex vorkommenden Aussackungen ist variabel und reicht von asymptomatischen Verläufen über Arrhythmien und Hydrops fetalis aufgrund der erhöhten Volumenlast des fetalen Herzens bis hin zu Spontanrupturen und intrauterinem Fruchttod.

Fallbericht: Wir berichten über den Fall eines Mädchens mit komplettem atrioventrikulären Septumdefekt (AVSD) bei Trisomie 21 und Digoxinintoxikation, bei welchem ein Divertikel des rechten Ventrikels als $\mathrm{Zu}$ fallsbefund diagnostiziert wurde. Bereits pränatal war der Verdacht auf eine Trisomie 21 mit AVSD gestellt und eine Entbindung in einem großen Perinatalzentrum geplant worden. Aus logistischen Gründen kam es zur spontanen Entbindung in einem Haus mit Perinatalzentrum Level II. Nach unkomplizierter Anpassung des reifen und eutrophen Neugeborenen wurde die Diagnose klinisch und echokardiographisch bestätigt und eine antikongestive Therapie mit Digoxin und Furosemid begonnen. Aufgrund einer akzidentiellen Digoxin-Überdosierung kam es zu einer akuten Reanimationssituation und in der Folge nach Antidot-Gabe zur Verlegung in unsere Klinik. Eine Hypothermiebehandlung war bei allzeit stabilen hämodynamischen Parametern nicht indiziert worden. Die Patientin konnte am Folgetag extubiert werden und zeigte sich im weiteren Verlauf ohne hämodynamische oder neurologische Residuen. Eine passagere Niereninsuffizienz war unter konservativer Therapie rückläufig. Wir führten eine antikongestive Therapie mit Hydrochlorothiazid und Spironolacton fort. Echokardiographisch fiel eine ca. $1,4 \times 1,0 \mathrm{~cm}$ große muskelstarke und gute kontraktile Aussackung im Bereich der lateralen Wand des rechten Ventrikels auf, welche in Übereinstimmung mit der publizierten Literatur als Divertikel klassifiziert werden konnte. Fallberichte über eine Assoziation dieser seltenen kardialen Anomalie mit AVSD oder Trisomie 21 sind bislang nicht publiziert. Es ist daher von einer unabhängigen Fehlbildung auszugehen.

Schlussfolgerung: Zusammenfassend berichten wir über den Fall eines Neonaten mit Trisomie 21, AVSD und einem rechtsventrikulären Divertikel, welches uns im Zuge einer Digoxin-Intoxikation zuverlegt wurde. Eine Korrektur-Operation unter Belassung des Divertikels ist im Alter von 3 bis 4 Monaten geplant.

\section{GNPI-FP33}

\section{Frühgeborenes mit komplexem Verlauf nach maternaler Nekrotisierender Fasziitis}

\section{A. Joachim, A. Kribs}

\section{Uniklinik Köln, Kinderklinik, NICU, Köln, Deutschland}

Hintergrund: Die Nekrotisierende Fasziitis ist eine seltene Erkrankung mit hoher Mortalität [2]. Schwangere Frauen haben ein erhöhtes Risiko [3]. Daten zum Outcome der betroffenen Feten sind sehr rar. Wir berichten erstmals über ein überlebendes Frühgeborenes der 29. SSW mit komplexem Verlauf nach maternaler nekrotisierender Fasziitis.

Fallbericht:

Schwangerschaft: Ab 28+0 SSW Schmerzen im rechten Knie. Klinisch rasch progrediente Rötung und Schwellung, CRP 212,3 mg/l. Im MRT/ CT massive Entzündungsreaktion und Nekroseherde in der rechten unteren Extremität. Bei septischem Schock Notsectio und anschließend operative Versorgung der Extremität. Bestätigung einer Nekrotisierenden Fasziitis mit $\mathrm{S}$. pyogenes.

Erstversorgung: $28+6$ SSW, 1235 g, APGAR 3/6/8. Intubation und SIMVBeatmung. Keine Erhöhung der Entzündungszeichen im Blut, trotzdem klinisches Bild eines septischen Patienten.

Verlauf: Persistierender Ductus Arteriosus (PDA) mit hämodynamischer Relevanz am 2.LT. Erfolgloser medikamentöser Verschluss. Bei fortbestehender Symptomatik und gleichzeitiger Kontraindikation für einen medikamentösen Verschluss bei blutigem Trachealsekret und IVH ${ }^{\circ}$ III bds. operative Ductus-Ligatur am 11. LT. Bei respiratorischem Versagen komplizierte Beatmung über insgesamt 43 Tage. Nach Extubation noch Highflow-Unterstützung für weitere 4 Wochen. In Folge der IVH Entwicklung eines posthämorrhagischen Hydrocephalus, Anlage Rickham-Reservoirs am 17. (re) und 61. (li) LT., Anlage VP-Shunt am 138. LT. Klinisch-neurologisch gute Entwicklung.

$\mathrm{Ab}$ dem 4. LT persistierende Anurie. Ab dem siebten Lebenstag Peritoneal-Dialyse. Nach drei Wochen Wiedereinsetzen der Urinproduktion mit Harnstau bei perirenalen Hämatomen. Nach operativer Ausräumung der Hämatome und nekrotischem perirenalen Gewebe am 32.LT rechts weiterhin Harnstau und urinöser Aszites, daher Nephrostoma-Anlage. In der weiteren Diagnostik Ureterabgangsstenose mit Nekrose, die im Verlauf durch eine Ureterplastik behoben werden konnte.

Gastrointestinal zunächst schlechte Nahrungsverträglichkeit bei Mekoniumileus. Im Rahmen der Hämatomausräumung explorative Laparotomie und protektive Ileostomaanlage. Im Anschluss unproblematischer Nahrungsaufbau. Entlassung nach 159 Tagen.

Schlussfolgerung: Insgesamt bot das Kind einen hochkomplexen Verlauf, wie er für septische Frühgeborene typisch ist. Da weder CRP noch IL-6 postpartal erhöht waren, könnten weitere Zytokine hier eine Rolle gespielt haben, wie zuvor beschrieben [1]. In jedem Fall stellt eine maternale nekrotisierende Fasziitis eine erhebliche Bedrohung auch für das Kind dar, bei der mit zahlreichen Komplikationen zu rechnen ist.

\section{Literatur}

1. Chaudhry H, Zhou J, Zhong Y et al (2013) Role of cytokines as a double-edged sword in sepsis. Vivo Athens Greece 27:669-684

2. Kaul R, McGeer A, Low DE, Green K, Schwartz B (1997) Population-based surveillance for group $A$ streptococcal necrotizing fasciitis: Clinical features, prognostic indicators, and microbiologic analysis of seventy-seven cases. Ontario Group A Streptococcal Study. Am J Med 103:18-24

3. Oud L, Watkins P (2014) Necrotizing Fasciitis Associated with Pregnancy: a Population-Based Cohort Study. Infect Dis Ther 3:307-320 


\section{GNPI-FP34}

Integraauflage und Spalthauttransplantation - Eine sinnvolle Therapiestrategie zur Behandlung der Epidermolysis Bullosa junctionalis und der Aplasia Cutis Congenita bei Carmi-Syndrom?

J. Trah' I. I. Haußer' ${ }^{2}$ C. Has ${ }^{3}$, H. Kutzner', K. Reinshagen ${ }^{5}$, M. Fattouh ${ }^{5}$, I. Königs ${ }^{5}$ ${ }^{1}$ Univeristätsklinikum Hamburg Eppendorf, Neonatologie und päd. Intensivmedizin, Hamburg, Deutschland, ${ }^{2}$ Universität, Hautklinik, Heidelberg, Deutschland, ${ }^{3}$ Universität, Hautklinik, Freiburg, Deutschland, ${ }^{4}$ Dermatopathologie Friedrichshafen, Dermatopathologie, Friedrichshafen, Deutschland, ${ }^{5}$ Universitätsklinikum Hamburg Eppendorf, Klinik und Poliklinik für Kinderchirurgie, Hamburg, Deutschland

Fallbericht: Wir berichten über eine Patientin mit dem klinischen und immunhistologischen Bild eines Carmi-Syndrom (OMIM 226730). Bei dieser wurde (nach Korrektur der Pylorusatresie) mittels Integraauflage und Spalthauttransplantation der Versuch einer frühen Therapie der syndromal bedingten Hautdefekte unternommen, um das hohe Letalitätsrisiko durch Infektion zu senken. Zudem sollte diese Therapie als möglicher kurativen Ansatz zur Behandlung der Aplasia Cutis Congenita und der junktionalen Epidermolysis Bullosa dienen.

Das Carmi-Syndrom wurde erstmals 1982 von R. Carmi beschrieben. Es handelt sich dabei um das klinische Erscheinungsbild einer junktionalen Epidermolysis Bullosa (EB), einer Pylorusatresie (PA) und einer Aplasia Cutis Congenita (ACC), welches in einer Veröffentlichung von Maman et al. 1998 systematisch untersucht wurde [3]. Die Prognose dieser Erkrankung ist sehr schlecht. Die meisten Patienten versterben im/in den ersten Lebensmonat/en infolge septischer Komplikationen [4].

Bei der ACC wird in der Literatur die Hauttransplantation als kurative Möglichkeit beschrieben [2]. Gostynski et al. 2014 beschreiben in mehreren Fällen eine erfolgreiche Therapie der EB mittels Spalthauttransplantation mit modifizierter Keratinozyten [1].

Im Falle unserer Patientin konnten wir mittels Dermisersatzverfahren (Integra) und der nachfolgenden Spalthauttransplantation ein sehr gutes klinisches Ergebnis erreichen. Die Integraauflage zeigte makroskopisch einen suffizienten zeitgerechten Umbau und die Transplantation zeigte einen vollständigen Take. Die Patientin verstarb im Verlauf wider erwarten an den Folgen einer Lungenembolie. Post mortem ließ sich ein Hemidesmosomendefekt i.S. einer junktionalen Epidermolyse nachweisen und somit Elektronenmikroskopisch kein Heilungserfolg im Sinne einer Korrektur der EB.

Diskussion: Mit dem Schwerpunkt auf die frühe Deckung der Hautdefekte zur Vermeidung septischer Komplikationen zusammen mit den klinisch guten Ergebnissen und aufgrund einzelner Berichte aus der Literatur halten wir die Therapie der ACC beim Carmi-Syndrom mittels Integraauflage und Spalthauttransplantation für eine mögliche Behandlungsstrategie zur Verbesserung des Langzeitüberlebens.

Schlussfolgerung: Weitere Untersuchungen bezüglich der Beeinflussung der EB erscheinen notwendig, um Langzeitergebnisse zu erhalten. Zusätzlich stellt sich die spannende Frage, ob die Neodermis mit der Spalthaut eine günstigere (da leicht narbige) Struktur bildet, die eine Blasenbildung erschwert.

\section{Literatur}

1. Gostyński A, Pasmooij AM, Jonkman MF (2014) Successful therapeutic transplantation of revertant skin in epidermolysis bullosa. J Am Acad Dermatol 70:98-101

2. Liu Y, Qiu L, Fu Y et al (2015) Large defects in aplasia cutis congenita treated by large-sized thin split-thickness skin grafting: long-term follow-up of 18 patients. Int J Dermatol 54:710-714

3. Maman E, Maor E, Kachko L, Carmi R (1998) Epidermolysis bullosa, pyloric atresia, aplasia cutis congenita: histopathological delineation of an autosomal recessive disease. Am J Med Genet 78:127-133

4. Marjanovic Z, Slavkovic A, Djordjevic I (2013) Syndromic association of pyloric atresia and epidermolysis bullosa (Carmi syndrome) - a case report. West Indian Med J 62:149-151

\section{GNPI-FP35}

Neugeborenes mit Zellweger-Spektrum-Störung, eine wichtige Differentialdiagnose bei Floppy-Infant-Syndrom

\section{S. Stein', A. Hahn², A. Weber ${ }^{3}$, K. P. Zimmer', H. Ehrhardt ${ }^{1}$}

${ }^{1}$ Universitätsklinikum Gießen, Allgemeine Pädiatrie und Neonatologie, Gießen, Deutschland, ${ }^{2}$ Universitätsklinikum Gießen, Zentrum für Kinderheilkunde und Jugendmedizin, Abt. Kinderneurologie, Sozialpädiatrie und Epileptologie, Gießen, Deutschland, ${ }^{3}$ Universitätsklinikum Gießen, Institut für Humangenetik, Gießen, Deutschland

Hintergrund: Zellweger-Spektrum-Störungen sind seltene Erkrankungen, die auf Grund eines Peroxisomendefektes vielfältige klinische Ausprägungen aufweisen.

Fallbericht: Wir beschreiben den Fall eines männlichen reifen Neugeborenen, symmetrisches SGA, erstes Kind konsanguiner Eltern (Verwandschaftsgrad 4) aus Syrien. Postpartal imponieren eine ausgeprägte Muskelhypotonie mit Beeinträchtigung der Atmung sowie Dysmorphiezeichen (große Fontanellen, Hypertelorismus, Hornhauttrübung, gotischer Gaumen Kryptorchismus, Pes equinovarus).

In der kraniellen MRT sind diffuse Polymicrogyrie, T2-Signalerhöhung im Nucleus Dentatus sowie bandförmige Heterotopien darstellbar. Sonografisch finden sich zystendurchsetzte Nieren sowie eine Hepatomegalie. Augenärztlich ist eine Hornhautdystrophie mit Micropapille darstellbar. In der weiterführenden Diagnostik zeigen sich linksseitige Taubheit und röntgenologisch kalkspritzerartige Gelenkauffälligkeiten, die rezidivierenden Hypoglykämien sind Folge adrenaler Insuffizienz.

In der Stoffwechseldiagnostik bestätigt sich der Verdacht auf eine Zellweger-Spektrum-Störung mit deutlich erhöhten überlangkettigen Fettsäuren im Serum, sowie Gallensäurenmetaboliten und Epoxysäuren im Urin als Ausdruck peroxisomaler Störung. Zusätzlich werden deutlich verminderte Plasmalogene in Erythrozyten nachgewiesen.

Die humangenetische Untersuchung ergibt eine unauffällige Chromosomenanalyse, jedoch in der Array-CGH auf vielen Chromosomen große Bereiche mit fehlender Herterozygotie, unter anderem auf Chr 7q21 im Bereich des PEX 1 Genes. Dieses gehört zu den häufigsten Mutationsorten für das Zellwegersyndrom. Die Sequenzierung des betroffenen Genabschnittes ist noch ausstehend.

Im weiteren klinischen Verlauf tiefe SpO2-Abfälle und konsekutive Bradykardien, bedingt sowohl durch zerebrale Anfälle, als auch durch Obstruktion der Atemwege im Rahmen der muskulären Hypotonie. Während einer Neugeboreneninfektion erfolgt die kurzzeitige Schienung der Atemwege mittels Rachentubus und CPAP-Atemtherapie sowie, auf expliziten Wunsch der Eltern, Beatmungen mittels Beatmungsbeutel in Akutsituationen. Epileptische Anfälle werden zunächst mit Phenobarbital, auf Grund der hierdurch verstärkten muskulären Hypotonie mit Ateminsuffizienz, dann mit Levetiracetam behandelt. Die Familie wird bei Entlassung durch einen $24 \mathrm{~h}$-Pflegedienst sowie durch das lokale ambulante SAPVTeam betreut.

Zusammenfassung: Zellweger-Spektrum-Störungen sind seltene, autosomal rezessiv vererbte Störungen der peroxisomalen Enzyme, auch als Zerebrohepatorenales Syndrom bezeichnet, und stellen eine wichtige Differentialdiagnose bei Floppy-Infant-Syndrom dar. Die Häufigkeit beträgt geschätzt ca. 1:50.000 Neugeborene, die Erkrankung manifestiert sich in der Regel postnatal und verläuft früh letal. Die Fallvorstellung beinhaltet Bildmaterial und eine genaue Darstellung der Diagnostik im oben beschriebenen Fall mit Vollbild einer Zellweger-Spektrum-Störung.

\section{GNPI-FP36}

Kongenitaler Hyperinsulinismus - Angeboren, oder nicht immer?

L. Kallmayer ${ }^{1}$, T. Rohrer ${ }^{2}$, K. Fritsche ${ }^{1}$, T. Kriebel ${ }^{1}$

'Westpfalz-Klinikum Kaiserslautern, Kaiserslautern, Deutschland,

2Universitätsklinikum des Saarlandes, Homburg, Deutschland

Hintergrund: Der kongenitale Hyperinsulinismus beschreibt ein Krankheitsbild verschiedener genetischer Mutationen der $\beta$-Zellen des Pankre- 
as. Man unterscheidet neben der transienten Form den fokalen und diffusen Typ.

Fallbericht: Ein reifes Neugeborenes (GG $2620 \mathrm{~g}$, KL $47 \mathrm{~cm}$ ) fiel am 1. Lebenstag mit rezidivierenden Hypoglykämien auf. Am 2. Lebenstag trat ein Zyanoseanfall im Rahmen einer Hypoglykämie (19 mg/dl) auf. Bei gleichzeitiger Thrombozytopenie und Verdacht auf Infektion begannen wir die Therapie mit Ampicillin und Tobramycin. Im Verlauf traten erneut tiefe Hypoglykämien trotz Intensivierung der Kohlenhydratzufuhr auf.

Der Verlauf legte den Verdacht eines Hyperinsulinismus nahe, der durch Nachweis von Insulin ( $>3 \mathrm{mU} / \mathrm{l})$ während der Hyopoglykämie $(<35 \mathrm{mg} / \mathrm{dl}$ $(2,0 \mathrm{mmol} / \mathrm{l}))$ bestätigt wurde. Infektparameter blieben im Verlauf unauffällig und die antibiotische Therapie wurde nach 5 Tagen beendet. Durch Nachweis maternaler HPA-/HLA-Allo-Antikörper bestätigte sich eine Neonatale Allo-Immun-Thrombozytopenie (NAIT).

Nach Rücksprache mit der endokrinologischen Ambulanz in Homburg begannen wir mit der spezifischen Therapie. Unter Eindosierung von Diazoxid p.o. war eine Kohlenhydratzufuhr bis max. $25,7 \mathrm{mg} / \mathrm{kg} / \mathrm{min}$ notwendig, wir begannen zusätzlich eine Glucagon-Dauerinfusion. Das Blutzucker-Niveau stieg, einzelne Hypoglykämien waren weniger tief. Ab einer Diazoxid-Dosis von $10 \mathrm{mg} / \mathrm{kg} / \mathrm{d}$ ergänzten wir um des synergistischen Effektes Spironolacton. Mit Erreichen der Maximaldosis von $15 \mathrm{mg} / \mathrm{kg} / \mathrm{d}$ Diazoxid wurde die Glucagonzufuhr beendet. Die Muttermilch wurde mit 15\% Maltodextrin angereichert, Stillen wurde neben Teilsondierung bei stabilen Blutzuckern gefördert. Die Eltern wurden früh in Blutzuckermessungen und Medikamentengabe einbezogen. Des weiteren wurde eine sozialmedizinische Nachsorge initiiert. Die weitere Entwicklung war regelrecht, so dass die Entlassung am 53. Lebenstag ohne Teilsondierung möglich war.

Glucagonpflichtige Hypoglykämien traten im weiteren Verlauf bei häuslichen Blutzuckerkontrollen alle 4-6 h nicht mehr auf. Die Diazoxid-Dosis wurde bei stabilen Blutzuckern mit zunehmendem Gewicht nicht angepasst und zuletzt bei stabilen Blutzuckern auf $5 \mathrm{mg} / \mathrm{kg} / \mathrm{d}$ reduziert. Aufgrund der Assoziation mit der NAIT besteht die Möglichkeit einer transienten Form. Eine Reduktion des Diazoxid wird aktuell im Alter von 3 Monaten begonnen, die Ergebnisse der Molekulargenetik sind ausstehend, ein PET-MRT des Pankreas ist nur bei Persistenz geplant.

Schlussfolgerung: Bei anhaltenden Hypoglykämien im Neugeborenenalter unter hoher Kohlenhydratzufuhr sollte der Ausschluss eines kongenitalen Hyperinsulinismus erfolgen, um frühzeitig eine spezifische Therapie zu beginnen. Priorität hat die Stabilisierung der Hypoglykämien für die neurologische Entwicklung. Die Klassifizierung des Hyperinsulinismus erfolgt sekundär. Der frühe Kontakt zu einem endokrinologischen Zentrum, sowie die Anbindung sind essentiell. Die enge Einbindung der Eltern, sowie eine sozialmedizinische Nachsorge sollten angestrebt werden. Die Neonatale Allo-Immun-Thrombozytopenie ist möglicherweise mit dem transienten Hyperinsulinismus assoziiert.

\section{GNPI-FP37}

\section{Case-Report: Seckel-Syndrom und Moya-Moya}

J. Trah', S. Apostolidou' ', M. Blohm', J. Denecke', P. Emami', F. S. Fritzsche ${ }^{3}$, D. Singer

'Univeristätsklinikum Hamburg Eppendorf, Neonatologie und päd. Intensivmedizin, Hamburg, Deutschland, ${ }^{2}$ Universitätsklinikum Hamburg Eppendorf, Neuropädiatrie, Hamburg, Deutschland, ${ }^{3}$ Universitätsklinikum Hamburg Eppendorf, Klinik für Neurochirurgie, Hamburg, Deutschland

Fallbericht: Wir beschreiben den Fall eines 13-jährigen Patienten mit Seckel-Syndrom, der mit einer links cerebellären Blutung und klinischen Hirndruckzeichen zur weiteren neurochirurgischen Mitbetreuung zuverlegt wurde. Die initiale Vorstellung erfolgte Aufgrund zunehmender Vigilanzminderung mit Krampfanfällen. Anamnestisch bestand bereits zuvor eine mentale Retardierung ohne motorische Einschränkungen.

Die Übernahme in unsere Klinik erfolgte intubiert und beatmet. Aufgrund klinischer Einklemmungs- und sonographischer Zeichen intrakranieller supratentorieller Minderperfusion wurde umgehend die Anlage einer externen Ventrikeldrainage und im Anschluss die operative Entfernung eines
Hämatoms mit einer möglicherweise kleinen AV-Malformation links im Bereich des Kleinhirns durchgeführt. Postoperativ erfolgte eine neuroprotektive Intensivtherapie über 9 Tage. Nach erfolglosem Weaning kam es zur Anlage einer Trachealkanüle mit anschließender suffizienter Spontanatmung. Bis zur Entlassung auf die periphere Station bestanden zahlreiche neurologische Einschränkungen wie Fehlen einer gezielten Spontanmotorik, beinbetonte Tetraspastik und Rumpfhypertonie.

In den durchgeführten zerebralen Bildgebungen fanden sich multiple alte sowie neue Infarktareale. Radiologisch wurde zusätzlich eine okklusive Vaskulopathie im Sinne einer Moya-Moya-Erkrankung als mögliche Erklärung beschrieben. Aufgrund der klinischen Gesamtsituation wurde in der aktuellen Situation von weiteren neurochirurgischen und/oder gefäßchirurgischen Behandlungsoptionen abgesehen.

Diskussion: Das Seckel-Syndrom ist eine autosomal-rezessive Erkrankung, welche durch Wachstumsretardierung, Mikrozephalie, mentale Retardierung und faziale Dysmorphien gekennzeichnet ist. In der Literatur gibt es zahlreiche Berichte über typische zerebrovaskuläre Läsionen, z.B. Aneurysmata, die dabei auftreten können [2].

Moya-Moya ist eine idiopathische, chronische zerebrovaskuläre Erkrankung, welche sich typischerweise durch Stenosen der intrakraniellen Karotisarterien manifestiert und üblicherweise nicht mit dem Seckel-Syndrom in Verbindung gebracht wird [1]. Bislang gibt es nur zwei Beschreibungen des gemeinsamen Auftretens von Moya-Moya mit dem Seckel-Syndrom $[4,5]$.

Schlussfolgerung: Bei neurologischen Auffälligkeiten beim Seckel-Syndrom sollte immer an zerebrovaskuläre Veränderungen oder Läsionen gedacht werden. Das gemeinsame Auftreten mit Moya-Moya erscheint sehr selten, sollte jedoch in Betracht gezogen werden und stellt aufgrund des erhöhten Blutungsrisikos eine besonders beachtenswerte und kontrollbedürftige Variante des Seckel-Syndroms dar [3].

Literatur

1. Suzuki J, Kodama N (1983) Moyamoya disease - a review. Stroke 14:104-109

2. D'Angelo VA, Ceddia AM, Zelante L, Florio FP (1998) Multiple intracranial aneurysms in a patient with Seckel syndrome. Childs Nerv Syst 14:82-84

3. Krishna AG, Scrimgeour EM, Zawawi TH (1994) Seckel syndrome in a Yemini family in Saudi Arabia. Am J Med Genet 51:224-227

4. Codd P, Scott R, Smith E (2009) Seckel syndrome and moyamoya. J Neurosurg Pediatr 3:320-324

5. Rahme R, Crevier L, Dubois J, Mercier C (2010) Moyamoya-like vasculopathy and Seckel syndrome: just a coincidence? Childs Nerv Syst 26:983-986

\section{GNPI-FP38}

\section{Zwei Fallberichte: Die Hämoglobinanomalie „Hb Bassett“ als Ursache einer erniedrigten SpO2 in der Pulsoxymetrie}

U. Blümlein' ' D. Schneider-Kulla' , L. Geerdts', L. E. Meyer-Dobkowitz', G. C. Schwabe', W. Heinritz ${ }^{2}$

${ }^{1}$ Carl-Thiem-Klinikum, Cottbus, Deutschland, ${ }^{2}$ Praxis für Humangenetik, Cottbus, Deutschland

Hintergrund: Das Pulsoxymetrie-Screening bei Neugeborenen dient der frühzeitigen Erkennung kritischer Herzfehler, die nicht in der Pränataldiagnostik festgestellt wurden. Die betrifft etwa 4 von 10.000 Neugeborenen. Im November 2016 wurde es vom Gemeinsamen Bundesausschuss (G-BA) für Deutschland bindend festgelegt.

Das Screening erfolgt mittels Pulsoxymetrie am Fuß zwischen der 24. und 48. Lebensstunde. Bei etwa 13 von 10.000 Neugeborenen ist das Pulsoxymetrie-Screening auffällig. Davon haben drei Neugeborene einen kritischen Herzfehler, die restlichen zehn haben eine andere Erkrankung, die mit einer erniedrigten $\mathrm{SpO} 2$ einhergeht. Bei etwa einem von $10.000 \mathrm{Neu}-$ geborenen wird ein kritischer Herzfehler mittels Pulsoxymetrie nicht erkannt.

Fallpräsentation: Wir berichten über zwei Säuglinge mit Auffälligkeiten in der Pulsoxymetrie:

Der erste Patient ist ein reifes Neugeborenes, das im Pulsoxymetrie-Screening durch eine erniedrigte $\mathrm{SpO} 2$ von $82-85 \%$ auffiel und unter dem Ver- 
dacht auf das Vorliegen eines kritischen angeborenen Herzfehlers in unser Perinatalzentrum verlegt wurde.

Das Kind wirkte trotz niedriger $\mathrm{SpO} 2$ klinisch unbeeinträchtigt. Unter Sauerstoffvorlage über eine Nasenbrille besserte sich die SpO2 (max. 92\%). Eine Anämie, eine Infektion, ein Pneumothorax, anatomische Anomalien von Gehirn, Lunge und Herz, eine Choanalstenose und eine Mukoviszidose konnten ausgeschlossen werden. Unter dem Verdacht auf eine Hämoglobinanomalie wurde eine Hb-Elektrophorese durchgeführt: diese ergab neben $\mathrm{HbF}$ und $\mathrm{HbA}$ eine zusätzliche Fraktion. In der arteriellen Blutgasanalyse war der $\mathrm{PaO} 2$ ohne Sauerstoffvorlage normwertig, die $\mathrm{SaO} 2$ erniedrigt.

Der zweite Patient wurde im Alter von drei Monaten unter dem Verdacht auf eine Harntraktinfektion stationär eingewiesen und zeigte im Pulsoxymetrie-Monitoring eine auffällig niedrige $\mathrm{SpO} 2$ von $80 \%$. Nach Ausschluss einer pulmonalen oder kardialen Erkrankung stellten wir den Verdacht auf das Vorliegen einer Hämoglobinanomalie, der sich in der Hb-Elektrophorese bestätigte. Mittels molekulargenetischer Diagnostik wurde bei beiden Patienten die Hämoglobinanomalie „Hb Bassett“ heterozygot nachgewiesen.

Diskussion: Anomale Hämoglobine sind eine Unterform der Hämoglobinopathien mit einer veränderten Aminosäuresequenz des Hämoglobinmoleküls aufgrund einer Genmutation. $\mathrm{Hb}$ Bassett ist eine sehr seltene $\mathrm{Hb}$-Anomalie und betrifft die $\alpha$-Globinkette (Austausch von Asparaginsäure gegen Alanin an Position 94). In der Literatur sind bisher drei Fälle von „Hb Bassett“ publiziert. Diese Hb-Anomalie ist durch eine erniedrigte $\mathrm{O}_{2}$-Affinität gekennzeichnet. Die Sauerstoffbindungskurve ist daher nach rechts verschoben.

Schlussfolgerung: Bei unklaren Hypoxämien in der Pulsoxymetrie ohne sonstige klinische Auffälligkeiten sollte eine Hämoglobinanomalie differentialdiagnostisch erwogen werden. Die frühzeitige Diagnose kann auch zur Entscheidung über die Notwendigkeit einer Sauerstofftherapie und zur Begrenzung unnötiger diagnostischer/therapeutischer Maßnahmen bedeutsam sein.

\section{GNPI-FP39}

Mekoniumileus und Darmnekrose als Erstmanifestation einer zystischen Fibrose mit Compound-Heterozygotie des CFTR-Gens

\section{E. Kampmann', A. Uebler', S. Rohleder' ${ }^{2}$ K. Poplawska ${ }^{3}$, G. Staatz',} E. Mildenberger ${ }^{1}$

'Universitätsmedizin Mainz, Zentrum für Kinder- und Jugendmedizin, Neonatologie, Mainz, Deutschland, ${ }^{2}$ Universitätsmedizin Mainz, Klinik für Kinderchirurgie, Mainz, Deutschland, ${ }^{3}$ Universitätsmedizin Mainz, Zentrum für Kinder- und Jugendmedizin, Pulmologie, Mainz, Deutschland, ${ }^{4}$ Zentrum für Kinder- und Jugendmedizin, Klinik für Radiologie, Kinderradiologie, Mainz, Deutschland

Hintergrund: Mekoniumileus als Frühmanifestation der zystischen Fibrose ist in der Literatur gut beschrieben. Eine assoziierte Pannekrose von Jejunum und Ileum mit resultierendem Kurzdarmsyndrom ist eine seltene Komplikation.

Fallbeschreibung: Ein reifes männliches Neugeborenes wurde am zweiten Lebenstag bei zunehmender abdomineller Distension sowie Mekoniumverhalt aus einem externen Krankenhaus übernommen. Radiologisch fand sich eine ileustypische massiv dilatierte Darmschlinge. Ein Megacolon congenitum wurde ausgeschlossen. Intraoperativ fand sich ein bis in das Jejunum reichender Mekoniumileus mit vorgeschalteter, stark dilatierter Dünndarmschlinge. Nach Enterotomie und Evakuation von zähem Mekonium Anlage einer doppelläufigen Jejunostomie proximal der Dilatation. Weiterhin bestand eine teils eingeschränkte Durchblutung des dilatierten Darmabschnittes, welche sich nach Entlastung deutlich besserte. Im weiteren Verlauf war kein Kostaufbau möglich, es blieben die Entzündungsparameter deutlich erhöht und die Beatmung zunehmend erschwert. Am 10. postoperativen Tag erfolgte die Re-Laparotomie. Hier zeigte sich ausgehend vom aboralen Jejunostoma eine ausgeprägte Dünndarmnekrose auch des ehemals dilatierten Darmabschnittes, so dass eine ausgedehnte Resektion (verbleibendes Jejunum und Ileum: 14 bzw. $7 \mathrm{~cm}$ ) und erneute Jejuno-Ileostomie erfolgten. Histologisch zeigte sich eine Nekrose vom ischämischen Typ. Postoperativ war der Kostaufbau erst nach Verabreichung von Kontrastmittel über den oralen und aboralen Schenkel ab dem 32. Lebenstag möglich und durch eine hohe Abflussmenge begrenzt. Über den Krankheitsverlauf zeigte sich eine zunächst deutlich zunehmende Cholestase, welche nach Beginn der enteralen Ernährung rückläufig ist. Im Alter von sieben Wochen wurde der Anus praeter zurückverlagert sowie ein Broviackatheter und ein Gastrostoma angelegt.

Untersuchungen im Rahmen des Neugeborenenscreenings sowie danach untersuchte Proben erbrachten eine unauffällige Konzentration des immunreaktiven Trypsins. Trotz des unauffälligen Screenings führten wir eine Iontophorese durch, welche eine deutlich erhöhte Chloridkonzentration zeigte $(>110 \mathrm{mmol} / \mathrm{l})$. In der genetischen Untersuchung wurde eine Compound-Heterozygotie für die Mutationen N1303K/W1282X des CFTR-Gens identifiziert.

Diskussion: Trotz negativer Screeningergebnisse liegt bei dem Patienten eine Compound-Heterozygotie des CFTR-Gens (N1303K/W1282X) vor. Diese Mutationen werden jeweils als „schwer“ eingestuft. Trotz Assoziation beider Mutationen mit Mekoniumileus liegen ausführliche Fallberichte zum spezifischen Genotyp unseres Patienten und der aufgetretenen Komplikation bisher nicht vor.

Die Erstmanifestation der Erkrankung stellte sich mit kompliziertem Mekoniumileus und der seltenen Komplikation der schweren Darmnekrose mit resultierendem Kurzdarmsyndrom dar. Es bleibt abzuwarten, ob sich Zeichen einer CF assoziierten Lebererkrankung zeigen.

\section{GNPI-FP40}

\section{Persistierende Apnoe bei wachem Kind}

\section{Vlajnic}

GFO Kliniken Bonn, St. Marien-Hospital Bonn, Pädiatrie, Bonn, Deutschland

Fallbericht: Notruf durch den Notarzt. 1,5 Jahre altes Mädchen mit respiratorischer Insuffizienz. Der Notarzt benötigt zusätzliche pädiatrische Kompetenz. Es erfolgte die Abholung unseres Kindernotfallteams in der Klinik und Transport in die häusliche Umgebung.

Bei Ankunft waches Kind am Boden liegend, Beutel-Masken-Beatmung durch Notarzt. Kind wach, Kopf und Augenbewegung vorhanden. Während Unterbrechung der Beutel-Masken-Beatmung Kind ansprechbar, Augenbewegung vorhanden, Kind fixiert, lächelt, aber weiterhin andauernde Apnoe. Notarzt unsicher bezüglich des Procedere, da das Kind wach. Anamnestisch bekanntes Kind mit Leigh-Syndrom. In letzter Zeit etwas vermehrte Krampfanfälle.

Es erfolgte die Anlage einer peripheren Verweilkanüle. Entschluss nach Beratung mit dem Team den Transport unter Beutel-Masken-Beatmung durchzuführen. Keine Narkose vor Ort, keine Intubation. Unproblematischer Transport mittels 2-Helfer Technik. Erste BGA ausgeglichen, Lactat $8,1 \mathrm{mmol} / \mathrm{l}$.

Intubation im Schockraum, es erfolgte die weitere Behandlung in Absprache mit dem betreuenden Zentrum. Nach 24 Stunden Extubation möglich. Schlussfolgerung: Respiratorische Störungen mit unregelmäßiger Atmung, Apnoen (Atempausen) sind beim Leigh-Syndrom häufig. Diese können auch zu kritischen Situationen führen. Präklinisch kann bei stabiler Maskenbeatmung auf eine Intubation verzichtet werden, vor allem bei schwerer Grunderkrankung und unklarer Stoffwechselsituation. 


\section{GNPI-FP41}

\section{Stüve-Wiedemann Syndrom bei einem Neugeborenen}

U. Wanz', J. Pansy' ', C. Binder-Heschl', F. Lindbichler', P. Kroisel', B. Urlesberger', B. Resch'

${ }^{1}$ Klinische Abteilung für Neonatologie, Universitätsklinik für Kinder- und Jugendheilkunde, Medizinische Universität, Graz, Österreich, ${ }^{2}$ Klinische Abteilung für Kinderradiologie, Universitätsklinik für Radiologie, Medizinische Universität, Graz, Österreich, Institut für Humangenetik, Medizinische Universität, Graz, Österreich

Hintergrund: Das Stüve-Wiedemann-Syndrom ist eine sehr seltene kongenitale Skelettdysplasie mit Minderwuchs, angeborener Verbiegung der langen Knochen, Deformitäten der Gelenke und Kamptodaktylie. Die Krankheit geht mit schweren Komplikationen wie respiratorischer Insuffizienz, Schluck- bzw. Ernährungsschwierigkeiten und rezidivierenden Fieberschüben, einher. Ursache sind Null-Mutationen im leukemia inhibitory factor receptor (LIFR) Gen für den Rezeptor des Leukämie-Hemmfaktors der Chromosomenregion 5p13.

Fallbericht: Bei der 3. Schwangerschaft einer 20-jährigen Frau ergab sich nach pränataler Sonographie und Magnetresonanzuntersuchung der Verdacht einer fetalen Anomalie mit kürzerem Femur rechts, multizystische Niere rechts und einem relativ großen Magen mit eventueller Passagebehinderung. Anamnestisch war ein Säugling postnatal am 2. Lebenstag verstorben, ein weiteres Kind ist gesund. Die aus Afghanistan stammenden Eltern sind konsanguin.

In der 39+0 SSW erfolgte eine Resectio. Das männliche Neugeborene (Gewicht: $3270 \mathrm{~g}=30$. Perzentile (P.), Länge: $47 \mathrm{~cm}$, 3.P, Kopfumfang: $36,5 \mathrm{~cm}=60 . P$; Apgar 7/7/9, Nabelarterien-ph 7,25) zeigte postnatal bei Mekoniumaspirationssyndrom eine unzureichende Spontanatmung, weshalb es intubiert und beatmet wurde. Die Beatmung war bei pulmonalem Hypertonus mit Rechts-links-Shunt über den persistierenden Ductus arteriosus sehr schwierig. Insgesamt war das Neugeborene 13 Tage invasiv beatmet und erhielt für 5 Tage eine inhalative NO-Therapie. Nach Extubation erfolgte eine Atemunterstützung mittels NCPAP.

Das Neugeborene zeigte folgende Dysmorphiezeichen: nach innen gebogene untere Extremitäten, Schädelasymmetrie mit spitzem Kinn, tiefsitzende Ohren, mongolide Lidachse und Nackenfalte.

In der Röntgenuntersuchung zeigten sich starke Biegungsdeformitäten der Ober- und Unterschenkel, weshalb an eine Campomele Dysplasie und differentialdiagnostisch an ein Stüve-Wiedemann Syndrom gedacht wurde. Mit diesem Wissen konnte eine gezielte genetische Untersuchung durchgeführt werden, welche eine Mutation im LIFR-Gen (C1744_1745delCA,p. Gln582ValfsTer4 homozygot) zeigte und somit die Diagnose eines StüveWiedemann Syndroms sicherte.

Am NCPAP kam es zu schweren Apnoeanfällen mit starker Sekretproblematik und respiratorischer Erschöpfung, mit nur langsamer Erholung. Im ärztlichen Team und mit den Eltern wurde aufgrund der infausten Prognose der Grunderkrankung ein palliatives Vorgehen vereinbart. Unser Patient verstarb mit 4 Wochen schließlich an einem Atem- und Kreislaufversagen.

Schlussfolgerung: Der schwere Verlauf des Stüve-Wiedemann-Syndroms ist vor allem durch die respiratorische Insuffizienz bedingt. Oft kommt es zu Sepsis-ähnlichen Fieberschüben mit Katecholaminbedarf und Ernährungsschwierigkeiten mit Aspirationen. Da nur eine symptomatische Behandlung möglich ist, ergibt sich eine geringe Lebenserwartung und die meisten Patienten versterben früh.

\section{GNPI-FP42}

Octreotid-Therapie eines Frühgeborenen mit Chylothorax nach Hydrops fetalis bei Chorangiose Typ 1

\section{A. Höche, A. Schlesinger, H. Graffstädt, C. Utech, B. Schmidt}

St. Joseph-Krankenhaus, Zentrum für Kinder- und Jugendmedizin, Berlin, Deutschland

Fallbericht: Wir präsentieren den Fall eines weiblichen Frühgeborenen $(35+2$ SSW $)$ mit nicht-immunologischem Hydrops fetalis und Chylothorax bei plazentarer Chorangiose Typ 1. Die Patientin wurde umgehend nach Vorstellung der Mutter in unserer Klinik wegen eines ambulant durchgeführten pathologischen CTGs per eiliger Sectio entbunden (Nabelarterien-pH 7,14, Apgar 1/3/5). Bei fehlenden Lebenszeichen des massiv ödematösen Kindes erfolgte die erfolgreiche kardiopulmonale Reanimation sowie nach sonografischem Nachweis von Pleuraergüssen und Aszites die Anlage von Pleura- und Aszitesdrainagen. Der erste venös nachgewiesene $\mathrm{pH}$ des Kindes betrug 6,92. Es erfolgte eine HypothermieTherapie als Heilversuch über 72 Stunden. Unter maschineller Beatmung und Katecholamintherapie konnte die Patientin in den folgenden Tagen stabilisiert werden. Es könnten immunologische, primär kardiale, infektiöse und genetische Ursachen für den Hydrops ausgeschlossen werden. In der Plazentahistologie wurde eine Chorangiose Typ 1 diagnostiziert. Während sich die kariozirkulatorische und respiratorische Situation in den ersten 7 Lebenstagen rasch besserte, bestanden anhaltende Pleuradrainageverluste von bis zu $500 \mathrm{ml} / \mathrm{d}$ sowie nach Ernährungsaufbau mit Muttermilch ein Chylothorax. Bei ausbleibender Besserung trotz fettfreier oraler Diät begannen wir eine Octreotid-Therapie mit $1 \mu \mathrm{g} / \mathrm{kg} / \mathrm{h}$ an Lebenstag 17. Die Pleurasekret-Menge halbierte sich zunächst, stagnierte jedoch in den Folgetagen, so dass eine fraktionierte Dosiserhöhung auf $3 \mu \mathrm{g} / \mathrm{kg} / \mathrm{h}$ erfolgte, worunter die Pleuraergüsse sistierten. Die Octreotid-Therapie wurde nach 3 Wochen beendet. Die Patientin konnte an Lebenstag 38 entlassen werden. Ein Rezidiv trat nicht auf, neurologisch waren bislang (Lebensalter 75 Tage) keine Auffälligkeiten zu verzeichnen.

Diskussion: Während insbesondere tumoröse vaskuläre Anomalien der Plazenta wie die Chorangiomatose als Ursache für den nicht-immunologischen Hydrops fetalis bekannt sind, ist ein Zusammenhang mit der Chorangiose als Hypervaskularisation der Plazentazotten unserer Literaturrecherche zufolge nur in Einzelfällen beschrieben worden. Die Chorangiose tritt vermehrt bei mütterlichem Diabetes mellitus auf (bei der Mutter unserer Patientin nicht bekannt) und ist vermutlich hypoxisch bedingt. Wir vermuten, dass in dem Fall unserer Patientin ein Kausalzusammenhang besteht. Die Octreotid-Therapie ist eine häufig verwendete, jedoch unzureichend evaluierte Therapieoption bei kongenitalem Chylothorax mit widersprüchlichen Daten bezüglich Zeitpunkt, Dosis, Therapiedauer und Effektivität. In unserem Fall konnte in zeitlichem Zusammenhang von Therapiestart und Dosiserhöhungen eine Verminderung bzw. ein Sistieren der Pleurasekretion verzeichnet werden.

\section{GNPI-FP43}

Präklinische Reanimation eines 2-jährigen Jungen mit einer Mitochondropathie

D. Vlajnic, E. Klein

GFO Kliniken Bonn, St. Marien-Hospital Bonn, Pädiatrie, Bonn, Deutschland

Fallbericht: Notruf durch den Notarzt. Seit 25 Minuten Reanimation bei einem 2-jährigen Kind. Ankunft unseres Notfallteams 15 Minuten nach Notruf.

Kind hat eine bekannte Mitochondropathie (durch SPZ der benachbarten Kinderklinik betreut). Das Kind hatte einen leichten Infekt, am gleichen Tag waren die Eltern beim Kinderarzt gewesen. Kind war vor zwei Stunden ins Bett gelegt worden, von Eltern leblos aufgefunden. Liegedauer unklar. Erstversorgung durch den Notarzt. Anlage einer intraossären Nadel sowie endotracheale Intubation, dabei viel Erbrochenes endotracheal abzusaugen. Reanimation nach ERC-Kriterien.

Bei Ankunft unseres Notfallteams Kind auf Kommode im Badezimmer. Übernahme der Leitung des Reanimationsteams. Unter Reanimation er- 
folgte die Überprüfung der Tubuslage und der intraossären Nadel ohne Beanstandung. Einmalige Gabe von Adrenalin. Weiterhin Asystolie. In einem Teamgespräch erfolgte der Entschluss zur Beendigung der Reanimation und Betreuung der Familie im häuslichen Umfeld. Unter Begleitung der Eltern erfolgte die Beendigung der Reanimationsmaßnahmen. Auf dem Arm der Eltern Abschiednahme im Wohnzimmer. Ruf des Kriseninterventionsteams und Begleitung der Eltern. Aufgrund der Grunderkrankung und des Nachweises der Aspiration Bescheinigung einer natürlichen Todesursache. Betreuung der Eltern und Gespräche in den nächsten 2 Stunden, dann weitere Betreuung durch den Notfallseelsorger. Schlussfolgerung:

1. Entscheidungsfindung für den Notarzt zur Beendigung der Maßnahmen deutlich erleichtert durch Hinzukommen des zweiten Teams

2. Entscheidung zur familienzentrierten Betreuung und Verabschiedung im häuslichen Setting gerechtfertigt und zu Verarbeitung besser

\section{GNPI-FP44}

\section{Kann eine intermittierend nicht lagekorrekte Magensonde ein möglicher Hinweis auf ein erhöhtes Risiko für einen Volvulus sein?}

H. Müller', A. Stein', R. van den Bruck', A. Sahloul', G. Krawzak', U. Felderhoff-Müser ${ }^{1}$

'Uniklinikum Essen, Kinderheilkunde I, Neonatologie, Essen, Deutschland, ${ }^{2}$ Uniklinikum Essen, Klinik für Allgemein-, Viszeral- und Transplantationschirurgie, Sektion Kinderchirurgie, Essen, Deutschland

Hintergrund: Der Volvulus ist ein seltenes, aber sehr akutes Krankheitsbild in der Neonatologie. Meist finden sich keinerlei Vorzeichen, dass dieses Krankheitsbild auftreten könnte.

Fallbericht: Ein männliches Frühgeborenes kam per Notsectio bei Plazentalösung in einem peripheren Krankenhaus ohne Kinderklinik mit einem Geburtsgewicht von $935 \mathrm{~g}$ zur Welt und wurde dort von der Anästhesie oral intubiert. Der Mutter war nicht aufgefallen, dass sie schwanger war (geschätztes Gestationsalter: 27 Wochen). Der neonatologische Transportdienst der Uni-Kinderklinik Essen wurde hinzugerufen, der das Kind zunächst nasotracheal intubierte, Surfactant applizierte und dann in die Kinderklinik der Uni Essen brachte. Auf dem Röntgenbild des 1. Lebenstages war der Verlauf der Magensonde regelrecht. Am 4. Lebenstag erfolgte ein Röntgen nach Silastikanlage. Dabei fiel auf, dass der distale Teil der Magensonde nach rechts zeigte. Da das Kind gleichzeitig gallige Magenreste bei weichem Abdomen hatte, wurde bei V.a. eine Magenperforation Kontrastmittel über die Magensonde appliziert. In der danach erfolgten Röntgenaufnahme (ca. 1,5 Stunden nach dem vorherigen Röntgenbild) zeigte sich ein regelhafter Verlauf der distalen Magensonde sowie keinerlei Kontrastmittelaustritt, sodass eine Magenperforation ausgeschlossen werden konnte. Am 5. und 9. Lebenstag wurden nochmals Röntgenaufnahmen durchgeführt, die jeweils eine regelrechte Lage der Magensonde und am 5. Lebenstag auch einen Weitertransport des nochmals applizierten Kontrastmittels zeigten. Im Verlauf des 13. Lebenstages kam es plötzlich zu Erbrechen und einem akuten und gespannten Abdomen (BGA: $\mathrm{pH}$ 6,98; Co2 66, BE -17,5, Lactat 16 mmol/l; CRP $<0,5 \mathrm{mg} / \mathrm{dl}$, IL6 726 pg/ml, Leukos 30/nl, Thrombos 199/nl). Eine Karenz, Antibiose, Intubation, ein Röntgen des Abdomens (keine freie Luft, Ileus), eine Sonographie des Abdomens (kein portales Gas, wenig freie Flüssigkeit, Darmschlingen sehr dilatiert, Darmwände nicht verdickt, Gefäße nicht darstellbar) wurden sofort durchgeführt und die Kinderchirurgie für eine OP ins Perinatalzentrum gerufen. Bei der sehr zeitnah erfolgten Laparatomie zeigte sich bei Eröffnung des Peritoneums ein trübes, grünes Sekret. Der distale Dünndarm war schwarz/nekrotisch. Der proximale Dünndarm wies segmentale langstreckige Wandischämiezonen (weißimponierend) auf, beginnend ca. $15 \mathrm{~cm}$ hinter dem Duodenum. Als Ursache fand sich ein Volvulus mit einer Darmverdrehung um $360^{\circ}$ bei schmaler Mesenterialwurzel. Nach Detorsion wurde der Darm für ca. 15 Minuten in warme Bauchtücher gepackt. Dies führte nicht zur Besserung der Durchblutung. Es zeigte sich zudem ein mobiles Duodenum mit fehlendem Treitzschen Band; im linken Oberbauch war keine Darmfixierung bei normal gelegenem und fixiertem Zökum. Ergänzend zum oben geschilderten Dünndarmbefund zeigte sich die Appendix teilnekrotisch. Die antimesenteriale Seite des Zökums, das Colon ascendens sowie $2 / 3$ des Transversums waren dunkellivide bis nekrotisch verändert. Lediglich Magen und distaler Dickdarm/ Rektum waren gut durchblutet. Aufgrund der infausten Situation wurden keine weiteren Maßnahmen mehr durchgeführt und das Kind verstarb nach palliativer Therapie.

Schlussfolgerung: Zusammenfassend zeigt dieser Fall, dass eine pathologische Darmfixierung ursächlich für eine intermittierend nicht lagekorrekte Magensonde sein kann. Dies geht mit einem erhöhten Risiko für einen Volvulus einher.

\section{GNPI-FP45}

\section{Fataler Verlauf einer chaotischer Vorhofarrhythmie bei einem Frühgeborenen der 23. Schwangerschaftswoche durch ein Costello Syndrom}

B. Kuehne', K. Becker ${ }^{2,3}$, E. Heine', K. Langhammer', R. Irvin ${ }^{2,3}$, N. Hindrichs', U. Bangen ${ }^{4}$, R. Heller', A. Kribs', S. Cirak ${ }^{2,3}$, A. Oberthür ${ }^{1}$

${ }^{1}$ Uniklinik Köln, Klinik und Poliklinik für Kinder- und Jugendmedizin, Abteilung für Neonatologie und pädiatrische Intensivmedizin, Köln, Deutschland, ${ }^{2}$ Universität zu Köln, Zentrum für Molekulare Medizin, Köln, Deutschland, ${ }^{3}$ Uniklinik Köln, Klinik und Poliklinik für Kinder- und Jugendmedizin, Köln, Deutschland, ${ }^{4}$ Uniklinik Köln, Klinik und Poliklinik für Kinderkardiologie, Köln, Deutschland, ${ }^{5}$ Uniklinik Köln, Institut für Humangenetik, Köln, Deutschland

Hintergrund: Das Costello Syndrom (CS) ist eine seltene angeborene Erkrankung infolge konstitutioneller heterozygoter Neumutationen im Harvey rat sarcoma viral oncogene homolog gen (HRAS). Der klinische und diagnostische Phänotyp im Kleinkindes- und Jugendalter wird bestimmt durch initiale Gedeihstörung, reduzierten Muskeltonus, Herzerkrankungen, dermatologische und kraniofaziale Charakteristika, erhöhtem Risiko für Tumoren, besonders von Rhabdomyosarkomen, sowie geistiger Behinderung. Wir berichten erstmalig über ein CS bei einem Frühgeborenen (FG) der 23. Schwangerschaftswoche (SSW), das infolge einer therapierefraktären chaotischen Arrhythmie verstarb.

Fallbericht: Das männliche FG wurde als diamniot-dichorialer Zwilling im Alter von 23 0/7 SSW per Sectio caesarea aufgrund eines Amnioninfektionssyndroms bei Cervixinsuffizienz und Fruchtblasenprolaps entbunden. Die Mutter war eine 40-jährige G2P0, die Konzeption erfolgte nach Fremd-Eizellspende und ICSI. Auffällig waren ein Polyhydramnion in der 22. SSW sowie ein moderater Hydrops fetalis bei unauffälligem fetalsonographischem Organbefund. Das FG war postnatal eutroph: Gewicht $710 \mathrm{~g}$ (Perc. 70), Länge $30 \mathrm{~cm}$ (Perc. 40), Kopfumfang $22 \mathrm{~cm}$ (40 Perc.). Auffällig waren jedoch eine generalisierte Hypokinesie sowie eine große, flüssigkeitsgefüllte subkutane Zyste am linken Oberarm. Weitere Befunde waren Anasarka, eine auffällige Facies mit Hypertelorismus, vollen Lippen, dünnem, lichtem Haar, sowie lange dünne Finger mit breiten Endphalangen. Im weiteren Verlauf mit multisystemischen Komplikationen dominierte die Beatmungspflichtigkeit bei unzureichendem Atemantrieb sowie ab der 2. Woche ein renaler Elektrolyt- und Eiweißverlust mit hohem Substitutionsbedarf ( $\mathrm{Na}+/ \mathrm{Ca} 2+/ \mathrm{Mg} 2+/ \mathrm{PO} 43-)$. Die Zyste am linken Oberarm rupturierte nach Größenprogredienz in der 6. Woche spontan. Histopathologisch präsentierte sich ein Lymphangiom. Problematisch ab der 2. Woche waren hämodynamisch relevante, massive multifokale ektope atriale Tachykardien, die eine hochdosierte Therapie mit Amiodaron, Flecainid und Bisoprolol erforderten. Dennoch kam es zu rezidivierenden low-cardiac output Situationen, in deren Folge das Kind am 72. LT verstarb. Die zuvor eingeleitete genetische Diagnostik erbrachte einen normalen Karyotyp sowie den Ausschluss einer myotonen Dystrophie Typ 1. Aufgrund der unklaren genetischen Diagnose erfolgte eine Exomsequenzierung mittels next generation sequencing-Technologie, wodurch eine heterozygote denovo Mutation im HRAS Gen (c.35G>C (p.Gly12Ala)) entdeckt und die Diagnose eines CS gestellt werden konnte.

Diskussion: Wir berichten erstmalig über ein CS bei einem FG der 23. SSW. Obwohl retrospektiv für das Syndrom einige charakteristische klinische Zeichen vorlagen, gelang die Diagnosestellung erst mittels Exomsequen- 
zierung. Für ein Costello Syndrom richtungsweisend waren therapie-refraktäre, chaotische atriale Tachykardien, die letztlich den fatalen Verlauf bedingten. Bei FG mit komplexen Rhythmusstörungen in Kombination mit pränatalem Polyhydramnion und ausgeprägter postnataler Hyokinesie sollte differentialdiagnostisch auch ein CS in Betracht gezogen werden.

\section{GNPI-FP46 \\ Frühgeborenes mit kongenitaler RYR1-assoziierter Myopathie und beidseitigem kongenitalen Chylothorax}

\section{A. Wirth, J. Salzburg, T. Maiberger, A. von der Wense AKK Altonaer Kinderkrankenhaus $\mathrm{gGmbH}$, Neonatologie und Pädiatrische Intensivmedizin, Hamburg, Deutschland}

Hintergrund: Kongenitale Myopathien weisen eine große phänotypische Variationsbreite auf. Patienten mit schwerster Muskelschwäche können direkt nach der Geburt beatmungspflichtig werden. Bei verschiedenen hereditären Myopathien sind kongenitale Chylothoraces beschrieben, für die hier vorliegende Form gibt es bisher keine Berichte. Wir berichten von einem Fall mit beidseitigen Chylothoraces bei einer kongenitalen Myopathie, die mit einer Ryanodin-Rezeptor-Mutation assoziiert ist.

Fallbericht: $1830 \mathrm{~g}$ (P5) schweres männliches FG der 34 +5 SSW Entbindung per Notsektio bei Bradykardie. Polyhydramnion. APGAR 1/3/7, Nabel-pH 7,37. Primäre Reanimation und Intubation bei fehlender Spontanmotorik und Atemtätigkeit. Im Verlauf fielen klinisch eine schwere muskuläre Hypotonie, eine myopathische Fazies, Ptosis, externe Ophthalmoplegie und eine Schluckstörung auf. Weiterhin entwickelte sich eine auffällige Ödemneigung und beidseitige Pleuraergüsse, die sich als Chylus herausstellten und bis jetzt drainagepflichtig blieben. Die anfangs hohen Flussraten von bis zu $400 \mathrm{ml} / \mathrm{d}$ reduzierten sich im Verlauf auf ca. $100 \mathrm{ml} /$ d. Parenterale Ernährung und hochdosiertes Octeotrid (s.c. und i.v.) über 4 Wochen zeigten keinen Effekt. Klinisch zeigte sich im Verlauf bisher keine Veränderung. Auf Wunsch der Eltern, die eine Verlegung in die Heimat anstreben, erfolgte die Anlage einer Trachealkanüle im Alter von 3 Monaten bei anhaltender Abhängigkeit von der maschinellen Beatmung. Diagnostik: Histologie der Muskelbiopsie: zentronukleäre Myopathie mit Faseratrophie und desorganisierten Sarkomeren. Next Generation Sequencing (NGS): Nachweis von zwei pathogenen Varianten im RYR1-Gen jeweils im heterozygoten Zustand [c.5989G >A (p.Glu1997Lys), missense Mutation; c.1441-2A >G (p.?), Zerstörung der Spleißakzeptorstelle]. Annahme einer compound-heterozygoten Konstellation der beiden Varianten und damit höchstwahrscheinlich molekulargenetische Bestätigung einer RYR1-assoziierten Myopathie.

Diskussion: Das RYR1-Gen auf Chromosom 19q13.1. kodiert für den Ryanodin-Rezeptor. Bei Eintreffen eines Aktionspotentials transportiert der ligandengesteuerte Calciumkanal Calciumionen aus dem sarkoplasmatischen Retikulum in das Zytosol. Die erhöhte Calciumkonzentration löst an den Sarkomeren die Muskelkontraktion aus. Nach unserem Wissen wurde bisher kein Fall eines kongenitalen beidseitigen Chylothorax als Symptom einer RYR1-assoziierten Myopathie bei einem Lebendgeborenen berichtet. Beschrieben ist ein nicht-immunologischer Hydrops bei einem in der 26. SSW intrauterin verstorbenem Kind, das ebenfalls eine heterozygote RYR1-Genmutation an anderem Genort aufwies. Der pathogenetische Zusammenhang zwischen schweren kongenitalen Myopathien und Chylothorax ist ungeklärt.

\section{GNPI-FP47 \\ Fetale Akinesie assoziiert mit einer heterozygoten Mutation im RYR1-Gen}

\section{Kennerknecht, H. Hummler, M. Mendler}

Universitätsklinik Ulm, Neonatologie und pädiatrische Intensivmedizin, Ulm, Deutschland

Anamnese: 31-j. Erstgravida, ab der 24 SSW V.a. fetale Akinesie, Querlage. Hüfte mit konstanter Beugung, Finger fixiert. Zudem Thoraxhypoplasie mit auffällig lang gestreckten Rippen. Generalisiertes Hautödem und feh- lende Magenfüllung mit Polyhydramnion. Fruchtwasserpunktion $2 \times$ mit $31+5$ SSW bzw. $33+6$ SSW. Die Pränataldiagnostik ergab einen unauffälligen, weiblichen Chromosomensatz 46XX. Die Fruchtwasseruntersuchung auf TORCH war unauffällig. Zudem Next-Generation-Sequencing (NGS)- Panel angelegt. Blasensprung $24 \mathrm{~h}$ vor Geburt. Primäre Sektio bei unhemmbarer Wehentätigkeit.

Klinischer Befund: Geboren wurde ein eutrophes weibliches FG $34+4$ SSW, GG: 2160 g (Perz.:25), Länge: $48 \mathrm{~cm}$ (Perz.:75), Kopfumfang: $35 \mathrm{~cm}$ (Perz.: 97). APGAR 1“:1, 5“:3, 10“:5, Nabelarterien-pH 7,39. Das Kind präsentierte sich mit zyanotischem Hautkolorit, ohne Muskeltonus, ohne Eigenatemtätigkeit und einer Bradykardie $<100 / \mathrm{min}$. . Es bestand ein ausgeprägtes generalisiertes Ödem und disseminierte Petechien/Hämatome. Weiterer Verlauf: Versuch der respiratorischen Stabilisierung mittels Noninvasiver Beatmung über einen Rachentubus (PIP max. $30 \mathrm{cmH}_{2} \mathrm{O}$ ) gelang nicht. Bei anhaltender Bradykardie Intubation in LM 4, zeitgleich Beginn Herz-Druck- Massage (Dauer ca. 30 Sek.). Erst bei Beatmungsdrücken ab $50 \mathrm{cmH}_{2} \mathrm{O}$ wenig Thoraxexkursionen, Umstellung auf HFO-Beatmung (MAP 15-20 $\mathrm{cmH}_{2} \mathrm{O}$ ). $\mathrm{FiO}_{2}$-Bedarf dauerhaft 1,0 um $\mathrm{SpO}_{2}$-Werte $>90 \%$ zu erzielen. Gabe von Surfactant. Unter o. g. Maßnahmen kardiorespiratorische Stabilisierung. Anlage Nabelgefäße. Bei erneut fallenden $\mathrm{SpO}_{2}$-Werten Sedierung und Relaxierung und Beginn einer inhalativen NO-Therapie ( $20 \mathrm{ppm}$ ) bei V.a. eine pulmonale Hypertonie, welche sich echokardiographisch bestätigte.

Im Verlauf hohe Beatmungsdrücke nötig (MAP unter HFO max. $30 \mathrm{~cm}$ $\mathrm{H}_{2} \mathrm{O}$ ). Radiologisch sahen wir das Bild komplette „white lung" bds., bei V.a. auf Lungenhypoplasie. In Lebensstunde 6 akuter Blutdruck- und Herzfrequenzabfall $<60 / \mathrm{min}$.. Koordinierte kardiopulmonale Reanimation und wiederholte Gabe von Suprarenin. Ausgeprägtes klinisch sichtbares Hautemphysem. Wiederholte Entlastungspunktionen bei V.a. Pneumothorax bds. und sonographisch V.a. Pneumoperikard. Nach 15 Min. kardiopulmonaler Reanimation Maßnahmen eingestellt.

Postmortale Diagnostik: Ein postmortem durchgeführtes Babygramm bestätigte den klinischen Verdacht des ausgeprägten Emphysems, sowie den V.a. eine Lungenhypoplasie (Radial Alveolar Zellcount 3,2 Ref. 3,7-4,1). Eine Obduktion und histologische Untersuchung einer Muskelbiopsie zeigte einen hochgradig umgebauten Skelettmuskel mit rundatrophen Muskelfalsern und massivem Fett- und Bindegewebsersatz. Das NGS- Panel konnte in der DNA aus kultivierten Fruchtwasserzellen eine compound heterozygote Mutation im RYR 1- Gen (c.14928C $>$ G und c.13013 130332del20) nachweisen. In der Literatur und in der Mutationsdatenbank (HGMD) sind diese Veränderungen im Ryanodin-1-Rezeptor als Pathogen aufgeführt und mit einer fetalen Akinesie assoziiert. Damit konnte die molekulare Ursache für die klinische Symptomatik beim verstorbenen Kind identifiziert werden.

\section{Literatur}

1. Bharucha-Goebel DX, Santi M, Medne L et al (2013) Severe congenital RYR1-associated myopathy. Neurology 80:1584-1549

2. Romero NB, Monnier N, Viollet L et al (2003) Dominant and recessive central core disease associated with RYR1 mutations and fetal akinesia. Brain 126:2341-2349

\section{GNPI-FP48}

\section{Kongenitales Halsteratom - ein Beispiel für erfolgreiches} interdisziplinäres Handeln

S. Poralla', J. Schmitt ', M. Martini', U. Gembruch ${ }^{3}$, T. Dresbach ', A. Müller ${ }^{1}$

'Universitätsklinikum Bonn, Neonatologie und Pädiatrische Intensivmedizin, Bonn, Deutschland, ${ }^{2}$ Universitätsklinikum Bonn, Mund-, Kiefer- und Plastische Gesichtschirurgie, Bonn, Deutschland, ${ }^{3}$ Universitätsklinikum Bonn, Geburtshilfe und Pränatalmedizin, Bonn, Deutschland

Hintergrund: Kongenitale Tumore sind mit einer Inzidenz von ca. 7:100.000 Lebendgeborene selten. Unter ihnen finden sich am häufigsten Lymphangiome und Teratome. Innerhalb der Teratome stellen die des Kopf- und Halsbereichs mit ca. $4 \%$ aller Teratome wiederum eine sehr seltene Form von Keimzelltumoren dar. Aufgrund ihrer Lage und teils ausgeprägten Größe kann es zur Kompression der Luftwege kommen, die eine Entbindung per EXIT = ex-utero intrapartum treatment, mit entspre- 
chender Bereitschaft verschiedener Fachdisziplinen notwendig machen kann. Auch in der langfristigen postnatalen Betreuung der Patienten mit Halsteratom ist zur optimalen Betreuung der Patienten ein gutes interdisziplinäres Handeln erforderlich.

Fallbericht: Hypertrophes weibliches Neugeborenes (Geburtsgewicht $3785 \mathrm{~g}, \mathrm{P} 91$ ), Geburt per EXIT in der $38+2$ SSW bei in der 22. SSW erstmals diagnostiziertem zervikalem Tumor links. Nach initial frustranem Versuch der fiberendoskopischen Intubation konnte das Kind in Lebensminute 12 mit einem 3,0er Portex-Tubus oral intubiert und im weiteren Verlauf konventionell beatmet werden. Am 2. Lebenstag erfolgte eine MRT-Untersuchung, bei der sich ein $8,7 \times 9,3 \times 8,8 \mathrm{~cm}$ großer, ventral vom Hals ausgehender, links betonter, teils zystisch, teils solider, kranial bis nach submental, kaudal bis zur apikalen Thoraxwand reichender, den Ösophagus und die Trachea verdrängender Tumor zeigte. Am 3. Lebenstag erfolgte die vollständige operative Entfernung durch die Kollegen der Mund-, Kiefer-, Gesichtschirurgie. Histologisch erwies sich der Tumor als $115 \mathrm{~mm}$ messendes Teratom mit unreifen $(<10 \%)$ und reifen Anteilen, Gonzales-Crussi Grad I.

Regelmäßige postoperative sonographische Verlaufskontrollen zeigten keinen Hinweis auf Tumorreste. Die Patientin konnte am 5. postoperativen Tag auf eine CPAP-Atemunterstützung extubiert werden und war ab dem 6. postoperativen Tag ohne Unterstützung allzeit respiratorisch stabil Im Verlauf entwickelte sie einen in Aufregung hörbaren inspiratorischen Stridor. Der orale Kostaufbau erfolgte zunächst via Magensonde, im Verlauf komplikationslos oral.

Das alpha-Fetoprotein war initial im altersentsprechenden Normbereich und fiel im weiteren Verlauf adäquat ab. Aktuell erhält die Patientin aufgrund einer postoperativ diagnostizierten Hypothyreose bei sonographisch nur rechtsseitig sichtbarem Schilddrüsengewebe L-Thyroxin sowie Amlodipin bei Hypertonie unklarer Genese.

Schlussfolgerung: Patienten mit Halsteratom benötigen eine sowohl prä-, peri-, als auch postnatal gut abgestimmte interdisziplinäre Betreuung und sollten an dementsprechend aufgestellten Zentren behandelt werden.

\section{GNPI-FP49}

Intravenöse Insulintherapie bei einem ELBW mit transientem neonatalen Diabetes mellitus - eine Herausforderung

\section{K. Roefke, A. Lemmer, A. Sauerbrey \\ ${ }^{1}$ Helios Klinikum Erfurt, Klinik für Kinder- und Jugendmedizin, Erfurt, Deutschland}

Fallbericht: Ein extrem unreifes Frühgeborenen, GA $23+5$ SSW, Geb.gew. $530 \mathrm{~g}$, zeigt nach der zweiten Lebenswoche anhaltend hohe Blutzuckerwerte bis $20 \mathrm{mmol} / \mathrm{l}$ trotz reduzierter Glukosezufuhr $<5 \mathrm{~g} / \mathrm{kg} / \mathrm{d}$ und enteraler Nährstoffzufuhr von ca. $65 \%$. Aufgrund der stagnierenden Gewichtszunahme wurde eine Insulintherapie unumgänglich. Bei einem Insulinbedarf von $1 \mathrm{IE} / \mathrm{kg} / \mathrm{d}$ und einem Körpergewicht von $600 \mathrm{~g}$ ergaben sich mehrere Probleme. Die Medikamentenlösung musste in Volumen und Konzentration minimal sein. Die Herstellung einer derart verdünnten Medikamentenlösung ist fehlerbehaftet und gängige Spritzenpumpen garantieren bei Laufgeschwindigkeiten $<1 \mathrm{ml} / \mathrm{h}$ keine exakte kontinuierliche Zufuhr mehr. Sicherer war die Verwendung einer Insulinpumpe (Animas $^{\odot} V_{i b e}{ }^{\oplus}$. Die intravenöse Insulintherapie erstreckte sich über einen Zeitraum von 5 Wochen, Nährstoffzufuhr und Gewichtsentwicklung waren adäquat, Hypoglykämien traten nicht auf.

\section{GNPI-FP50}

\section{Carboanhydrase-VA Defizienz- Ein neonatologischer Notfall}

A. Knoll', D. Haas', J. Häberle', P. Neuberger', M. Holder ${ }^{1}$

'Olgahospital Stuttgart, Pädiatrie2, Stuttgart, Deutschland,

2Universitätsklinikum Heidelberg, Dietmar-Hopp Stoffwechselzentrum, Heidelberg, Deutschland, ${ }^{3}$ Kinderspital Zürich, Stoffwechsel-und Forschungszentrum für das Kind, Zürich, Schweiz

Hintergrund: Die Carboanhydrase VA Defizienz (CAVAD) ist eine seltene autosomal-rezessive Stoffwechselerkrankung die zu einem Defekt der hepatischen Bicarbonatsynthese führt. Klinisch kommt es in der ersten Lebenswoche zu einer lebensbedrohlichen Hyperammonämie mit Laktatazidose und Ketonurie. Bislang wurden weltweit weniger als 15 Fälle publiziert.

Fallbericht: $H$. ist das 2. Kind indischer Eltern. Unkomplizierte Geburt, Familienanamnese leer. Ab 5. LT Allgemeinzustandsverschlechterung, am 6. LT Somnolenz.Aufnahmebefund ITS: Laktat 4,6 mmol/l und Ammoniak $260 \mu \mathrm{mol} / \mathrm{l}$. Weitere Diagnostik und Befunde nicht richtungsweisend. V.a. Harnstoffzyklusdefekt und Therapiebeginn mit hochkalorischer parenteraler Glucose, Natrium-Benzoat, Argininhydrochlorid und L-Carnitin. Stopp der Proteinzufuhr. Darunter Rückgang des Ammoniaks auf $160 \mu \mathrm{mol} / \mathrm{l}$ innerhalb von 6 h. In der Stoffwechseldiagnostik deutlich erhöhte Glutaminkonzentration, bei normalen Citrullin, Argininosuccinat und Orotsäure. Aufgrund des Musters der organischen Säuren im Urin Verdacht auf CAVAD und Therapiebeginn mit Carbamylglutamat. Nach 3 Wochen ausgeglichenes Aminosäurenprofil im Plasma und Urin. Molekulargenetische Bestätigung der Diagnose (Mutationen c.619-10G $>A$ und c.721G $>A$ p. (Glu241Lys) in CA5A Gen). Bei Entlassung Ernährung mit 1,0 g/kg/d Aminosäurenzufuhr über Muttermilch und $0,8 \mathrm{~g} / \mathrm{kg} / \mathrm{d}$ synthetisches Eiweiß über Combi Nahrung (Comida UrC A Formula + LPC). Regelmäßige Vorstellungen in der Stoffwechselambulanz mit stabilen Ammoniakwerten, auch nach Absetzen von Carbamylglutamat im 6. Lebensmonat. Komplikationsloser Kostaufbau und regelrechtes Erreichen der Meilensteine.

Diskussion: Bei einer lebensbedrohlichen Hyperammonämie in den ersten Lebenstagen sollte auch an die bisher noch sehr seltenen Carboanhydrase VA-Defizienz gedacht werden. Nach überstandener Akutphase ist der weitere klinische Verlauf insgesamt recht gut.

\section{GNPI-FP51}

\section{Kombinierte Leber- und Nierentransplantation (CLKT) bei} schwerer Primärer Hyperoxalurie Typ 1 (PH1)

J. Trah', S. Apostolidou', M. Blohm', J. Oh', E. Grabhorn ${ }^{3}$, F. Brinkert ${ }^{3}$, L. Fischer', D. Singer ${ }^{1}$

'Univeristätsklinikum Hamburg Eppendorf, Neonatologie und päd. Intensivmedizin, Hamburg, Deutschland, ${ }^{2}$ Universitätsklinikum Hamburg Eppendorf, Pädiatrische Nephrologie, Hamburg, Deutschland, ${ }^{3}$ Universitätsklinikum Hamburg Eppendorf, Pädiatrische Gastroenterologie und Hepatologie, Hamburg, Deutschland, ${ }^{4}$ Universitätsklinikum Hamburg Eppendorf, Hepatobiliäre Chirurgie und Transplantationschirurgie, Hamburg, Deutschland

Hintergrund: Die Primäre Hyperoxalurie (PH) ist eine seltene autosomalrezessive Stoffwechselstörung mit bislang drei bekannten Subtypen. Beim häufigsten Typ 1 ist aufgrund eines Enzymdefekts in der Leber der Metabolismus von Glyoxylat zu Glycin gestört. Damit kommt es zu einem massiven Anfall von Glyoxylaten, die als Oxalat zusammen mit Kalzium zu Kristallen ausfallen. Das Oxalat wird insbesondere bei Niereninsuffizienz im Rahmen der Nephrokalzinose in multiplen Organen abgelagert (systemische Oxalose; [2]).

Fallbericht: Wir präsentieren den Fall eines Patienten, welcher im vierten Lebensmonat mit terminaler Niereninsuffizienz auffällig wurde. Bei ihm wurde molekulargenetisch die Diagnose einer PH1 gesichert. Aufgrund technischer Schwierigkeiten im Heimatland konnte keine Hämodialyse etabliert werden. Deshalb erfolgte die Therapie, trotz der bekannt schlechteren Oxalatclearence, über eine Peritonealdialyse (PD). Bei Erstvorstellung in unserer Klinik im Alter von 8 Jahren zeigte der Patient alle Zeichen 
einer schweren systemischen Oxalose mit minimalem Restvisus, Schwerhörigkeit und schwerer Osteopathie mit deutlich erhöhten Plasmaoxalatwerten. Zur Vorbereitung auf eine CLKT wurde eine tägliche Hämodialyse zusätzlich zur PD etabliert.

Im Alter von 9 Jahren wurde die CLKT mit einem Rechtssplit-Lebertransplantat und singulärer NTx vorgenommen. Bei Größenmismatch erfolgte ein temporärer Bauchdeckenverschluss mittels Patchplastik. Im Verlauf kam es zu einzelnen postoperativen Komplikationen wie Galle-Leckage, Kinking und Hämatombildung, welche korrigiert werden konnten. Die Beatmungszeiten konnten mit jeweils ein bis zwei Beatmungstagen postoperativ sehr kurz gehalten werden. Es wurde eine dreifache immunsuppressive Therapie begonnen, und die Antikoagulation erfolgte PTT-gesteuert mit Heparin und Acetylsalicylsäure.

Die Transplantatfunktionen beider Organe setzten zeitgerecht ein. Überlappend zur Operation erfolgte zur Protektion der Transplantatniere eine Fortsetzung der Hämodialyse über weitere 14 Tage. Nach endgültigem Bauchdeckenverschluss sowie sonographisch und laborchemisch sicherer Transplantatfunktion beider Organe konnten wir den Patienten nach 16 Tagen auf eine periphere Station verlegen. Die endgültige Entlassung erfolgte 40 Tage nach CLKT. Trotz erfolgreicher Transplantation ist aufgrund des ausgeprägten Oxalat-Loads mit einer pathologischen Hyperoxalurie über Monate bis Jahre zu rechnen. Daher ist es wichtig, dass weiterhin eine konsequente Hyperhydratation und Harnalkalisierung zum Schutz der Transplantatniere gegen eine fortschreitende Nephrokalzinose erfolgt. Schlussfolgerung: Wir präsentieren den seltenen Fall einer schweren Form der Oxalose. Im Krankheitsverlauf kam es nach langer Therapie mit zahlreichen Komplikationen zu massiven Multiorganschäden durch hohe Oxalatspiegel im Blut. Zur Korrektur des Stoffwechseldefekts und Behebung der Niereninsuffizienz erfolgte eine kombinierte Leber- und Nierentransplantation [1]. Besondere Beachtung verdient aus intensivmedizinischer Sicht die perioperative Therapie mit Hämodialyse und unmittelbarem Beginn der Hyperhydratation und Harnalkalisierung zum Schutz des Nieren-Transplantats vor erneuter Oxalose.

\section{Literatur}

1. Bacchetta J, Mekahli D, Rivet C et al (2015) Pediatric combined liver-kidney transplantation: a 2015 update. Curr Opin Organ Transplant 20:543-549

2. Strauss SB, Waltuch T, Bivin W et al (2017) Primary hyperoxaluria: spectrum of clinical and imaging findings. Pediatr Radiol 47:96-103

\section{GNPI-FP52}

\section{Rezidivierende ileozökale Invaginationen bei einem 9-jährigen Patienten mit Y.enterocolica Infektion}

\section{S. Kenntner}

Universitätsklinikum Würzburg, Würzburg, Deutschland

Fallbericht: Ein 9 Jahre alter Junge stellte sich mit seit dem Vortag bestehenden rechtsseitigen Unterbauchschmerzen vor. Sonographisch zeigte sich eine ileozökale Invagination mit ausgeprägter mesenterialer Lymphadenopathie. Es erfolgte die komplikationslose hydrostatische Desinvagination. Im Stuhl wurde Yersinia enterocolica nachgewiesen. Nach drei und nach sieben Wochen stellte sich der Patient mit der gleichen Symptomatik jeweils erneut vor. Wieder konnte sonographisch eine ileozökale Invagination bei mesenterialer Lympahdenopathie dargestellt werden, welche erneut hydrostatisch desinvaginiert wurde. Bei der zweiten Episode konnte weiterhin Y. enterocolica im Stuhl nachgewiesen werden. Bei unauffälligem Stuhlbefund gelang bei der dritten Episode jedoch serologische Nachweis. Nach Ausschluss einer intraabdominellen Raumforderung mittels MRT war von einer persistierenden Y. enterocolica Infektion mit Lymphadenitis mesenterialis als Ursache der rezidivierenden Invaginationen auszugehen; es erfolgte die antibiogrammgerechte antibiotische Therapie mit Cotrimoxazol. In einer Verlaufskontrolle nach 4 Wochen bestand bei klinischem Wohlbefinden sonographisch und serologisch kein Hinweis mehr auf eine akute Yersinieninfektion.

Schlussfolgerung: Die Fallpräsentation dieses untypischen Verlaufs in einem ungewöhnlichen Alter für das häufige pädiatrische Krankheitsbild wird unterstützt durch die sonographischen Bilder und ist interessant für alle allgemeinpädiatrischen Kollegen.

\section{Fallpräsentationen DGPI}

\section{DGPI-FP01 \\ Kerion Celsi durch Trichophyton quinckeanum}

P. Nenoff', S. Uhrlaß', A. Bethge ${ }^{2}$, A. Pöge ${ }^{2}$, C. Krüger ${ }^{1,2}$, M. Koh³, M. Borte ${ }^{3,4}$ 'Labor für medizinische Mikrobiologie, Partnerschaft Prof. P. Nenoff \& Dr. Constanze Krüger, Rötha, Deutschland, ${ }^{2}$ Klinikum St. Georg gGmbH, Zentrum für Klinische Chemie, Mikrobiologie und Transfusionsmedizin, Leipzig, Deutschland, ${ }^{3}$ Klinikum St. Georg gGmbH, Klinik für Kinderchirurgie, Leipzig, Deutschland, ${ }^{4}$ Klinikum St. Georg gGmbH, Klinik für Kinder- und Jugendmedizin, Leipzig, Deutschland

Hintergrund: Die Tinea capitis ist eine hierzulande zwar seltene Dermatomykose, jedoch muss schon seit einigen Jahren mit einer Zunahme dieser Dermatophyten-Infektion gerechnet werden. Der Zeitraum vom Auftreten der ersten Symptome bis zum Beginn einer konsequenten innerlichen antimykotischen Therapie ist insbesondere bei eitrig-abszedierenden Formen der Tinea capitis nahezu immer viel zu lang, egal ob sich die Kinder mit ihren Eltern in einer Kinder- oder in einer Hautarztpraxis vorstellen. Bei nässenden, putriden Infektionen der Kopfhaut wird auf Verdacht hin fast immer erst einmal antibiotisch behandelt, eine mikrobiologische und insbesondere mykologische Diagnostik erfolgt zu spät, so wie auch beim hier vorgestellten Kind.

Fallbericht: Ein 7jähriger Junge hatte im Urlaub auf Mallorca kurzzeitig Kontakt zu einer Katze. 14 Tage nach dem Urlaub entwickelten sich bei dem Kind mehrere eitrig-abszedierende und verkrustete sowie schmerzhafte und alopezische Läsionen parietookzipital. Lymphknotenschwellungen waren zervikal, nuchal und submandibulär palpabel. Unter Cefuroxim-Axetil per os über 7 Tage trat keine Besserung ein. Im Grampräparat vom mikrobiologischen Abstrich sah man mäßig viele Leukozyten, bakteriologisch war kein Wachstum zu verzeichnen. Es wuchs jedoch ein Pilz, welcher als Schimmelpilz und eher als Kontamination oder Anflugkeim angesehen wurde. Eine weitere Identifizierung des Isolates erfolgte nicht. Erst ca. 6 Wochen nach Auftreten der ersten Symptome wurde unter dem klinischen Verdacht auf eine Tinea capitis profunda (Kerion Celsi) eine systemische antimykotische Therapie initiiert. Es kam Fluconazol $100 \mathrm{mg} / \mathrm{d}$ für eine Woche, danach $50 \mathrm{mg} / \mathrm{d}$ - zum Einsatz. Zur topischen Therapie wurden Terbinafin-Creme sowie Clotrimazol-Lösung aufgetragen. Fluconazol wurde über insgesamt 9 Wochen gegeben.

Die Sequenzierung der Pilz-DNA des Isolates erbrachte die Dermatophyten-Spezies Trichophyton (T.) schoenleinii. Für diesen anthropophilen Dermatophyten gab es jedoch weder anamnestisch (kein Aufenthalt im Nahen Osten/Kleinasien), noch mikroskopisch (keine hirschgeweihartigen Hyphen) einen Anhalt. Aus einem zweiten Pilzisolat wurde eine erneute Sequenzierung der rDNA (ITS-Region: ITS1, 5.8S rRNA, ITS2) durchgeführt. Es handelte sich definitiv um T. quinckeanum, den Erreger des sog. Mäusefavus.

Diskussion: Eitrig-abszedierende Infektionen an der Kopfhaut von Kindern sollten immer auch Anlass sein, an Pilze zu denken und eine mikrobiologische Diagnostik durchzuführen. Abstriche, Exsudat, Kopfschuppen und vor allem epilierte Haarwurzeln sollten entnommen werden. Die Untersuchung erfolgt auf Bakterien, jedoch unbedingt auch auf Dermatophyten. Die mykologische Diagnostik umfasst heute fluoreszenzoptisches Präparat, Kultur und die Dermatophyten-PCR sowie Sequenzierung zum schnellen und spezifischen DNA-Nachweis der Erreger.

Schlussfolgerung: Mit neuen zoophilen Dermatophyten muss aktuell gerechnet werden. T. quinckeanum ist wenig bekannt. In Deutschland wird T. quinckeanum immer häufiger isoliert, Infektionsquelle für diesen zoophilen Dermatophyten sind hierzulande z. B. Pferde, aber auch Hunde und Katzen. Die von Katzen erworbenen Infektionen durch T. quinckeanum betreffen sowohl Deutschland, als auch Südeuropa, u. a. Mallorca. Bei Kindern verursacht T. quinckeanum die Maximalvariante der Tinea capitis, das Kerion Celsi.

Die Tinea capitis profunda bzw. ein Kerion Celsi muss systemisch antimykotisch behandelt werden. Die Therapie kann im Einzelfall auch empirisch aufgrund des klinischen Bildes sofort initiiert werden. Bei Tinea 
capitis durch Trichophyton-Arten kommt - immer im Off-Label-Use mit dem Einverständnis der Eltern - entweder Terbinafin, alternativ Fluconazol oder Itraconazol zur Anwendung.

\section{DGPI-FP02}

\section{Auf Umwegen zur Diagnose Tuberkulose}

S. Koop' ', H. Lode', S. Otto' ', P. C. Krüger', S. Fleck ${ }^{2,3}$, R. Bruns ${ }^{1}$

'Universitätsmedizin Greifswald, Zentrum für Kinder- und Jugendmedizin, Greifswald, Deutschland, ${ }^{2}$ Universitätsmedizin Greifswald, Institut für Diagnostische Radiologie und Neuroradiologie, Greifswald, Deutschland, ${ }^{3}$ Universitätsmedizin Greifswald, Klinik und Poliklinik für Neurochirurgie, Greifswald, Deutschland

Hintergrund: Tuberkulose-Erkrankungen steigen in Deutschland wieder an. 2016 wurden dem RKI 5329 Fälle gemeldet. Vor allem die extrapulmonale Tuberkulose bereitet häufig diagnostische Schwierigkeiten.

\section{Fallbericht:}

Familienanamnese: 4.von 4 Kindern, FA zunächst leer.

Eigenanamnese: deutsches Kind 23 Monate, motorisch retardiert (steht und läuft nicht) und Fußfehlhaltung (Gips in auswärtiger Praxis angelegt). Vorstellung beim Kinderchirurgen aufgrund des u. g. Lokalbefundes. Status praesens: Patientin mit stabilem AZ, dystroph, kombinierte Entwicklungsverzögerung, geringe Pharyngotonsillitis.

Lokalbefund: livide, überwärmte Schwellung von prall elastischer Konsistenz am Malleolus medialis rechts $\mathrm{ca} .3 \times 1 \mathrm{~cm}$.

Abszessspaltung (intraoperative Wundabstriche ohne Erregernachweis) i. v. Cefuroxim (Kinderchirurg). Im Verlauf jedoch rezidivierend subfebrile Temperaturen, reduzierter AZ bei reizlosen Wundverhältnissen.

MRT: V.a. eine Osteomyelitis des Epiphysenkernes der distalen Tibia und Gelenkempyem. (Verlegung in die Pädiatrie)

Aufgrund der protrahierten Verschlechterung des AZ mit Nahrungsverweigerung, Erbrechen, Gewichtsverlust und rezidivierendem Fieber trotz unterschiedlicher Antibiotikaregime weitere Diagnostik.

Labor: Rachenabstrich: Entero- und Rhinoviren-PCR positiv, Quantiferontest positiv

Lumbalpunktion: im Liquor erhöhtes Eiweiß, erniedrigte Glukose, erhöhtes Laktat, leichte Pleozytose, lymphomonozytäres Sediment, IgA/-IgM intrathekale Synthese.

Kultur: positiv für M. tuberculosis aus Magenaspirat und Liquor.

$c M R T$ : Liquoraufstau mit Druckkappen- und Membranbildung sowie Zeichen einer Meningitis betont rechts fronto-parietal bei arachnoidalem Enhancement.

MRT (Wirbelsäule): tuberkulöser LWK 1 und meningeale Entzündung auf Höhe des Os sacrum.

Thorax- Röntgen: Hilusverdichtung, rechtes OF flaue umschriebene Verdichtung.

Histologie (Knochen): floride granulomatöse Entzündung mit käsigen Nekrosen und geordneten Riesenzellen, DNA- Nachweis von Mykobakterien. Therapie und Verlauf: Nach LP Behandlung mit INH, RMP, PZA und EMB sowie Vitamin-B6- Gabe in Kombination mit Dexamethason. Im Verlauf zeigte das cMRT eine Zunahme des Hydrocephalus internus. Erweiterung der tuberkulostatischen Therapie um Protionamid und Amicacin und Einsatz eines Rickham-Reservoirs. Bei ausbleibendem Erfolg der Liquordrainage wurde nach Liquorsanierung ein VP-Shunt angelegt.

Allmähliche Zustandsbesserung und deutliche Verbesserung der motorischen Fähigkeiten, jedoch persistierende intracerebrale Granulome deshalb Zusatz von Thalidomid, die tuberkulostatische Therapie wurde reduziert und Dexamethason langsam ausgebaut.

Schlussfolgerung: Dieser Fall soll die Schwierigkeiten der Diagnostik der Tbc bei nicht typischer Anamnese sowie die Probleme der Therapie bei Meningitis tuberculosa zeigen.

\section{DGPI-FP03}

\section{Seltene (?) Ursache eines Medulla oblongata Infarktes}

\section{Pilz-Klement, B. Korinth}

Helios Klinikum Berlin Buch, Berlin, Deutschland

Hintergrund: Der kindliche Schlaganfall ist ein seltenes Ereignis mit einer Inzidenz von 3-5:100.000. Sehr häufig (70-80\%) tritt dabei eine Hemisymptomatik auf. Jedoch werden nur $1 / 3$ der Infarkte in den ersten 6 Stunden diagnostiziert. Dabei zeigen $40 \%$ der kindlichen Schlaganfallpatienten neurologische Residualsymptome. Die häufigste Ursache eines Schlaganfalles im Vorschulalter ist parainfektiös oder infektiös bedingt. Falldarstellung: Die Verlegung des 7 jährigen Mädchens erfolgte mit Verdacht auf Meningitis bei seit dem Vortag bestehender frontaler Cephalgie, rezidivierendem Erbrechen, Schwindel, breibasigem Gang, Doppelbildern, Nystagmus und Anisokorie (re>li), leichter Horner, Somnolenz, kein Meningismus, kein Fieber, voll orientiert, leichte Heiserkeit. Erstes MRT als unauffällig beschrieben, kein Hinweis auf bakterielle Infektion. Keine schweren Vorerkrankungen, vollständig geimpft. Migräne in der Familie, Mutter aktuell Herpes labialis. Unter dem Verdacht Enzephalitis Beginn der Therapie mit Aciclovir, weiter symptomatische Therapie und ASS. Erneutes MRT $80 \mathrm{~h}$ nach Symptombeginn, dort Darstellung eines Medulla oblongata Infarktes links (Wallenberg Syndrom); kein Hinweis auf Vertebralisdissektion. Gerinnungsstörung, Autoantikörperenzephalitis oder Intoxikation. Am 6. Tag nach Aufnahme Nachweis einer Borellieninfektion und Beginn einer intravenösen Ceftriaxontherapie für 3 Wochen, ASS 100 mg weiter für 6 Monate. Regelmäßige Dopplersonographien der Halsgefäße und MRT-Kontrollen zeigen im Verlauf keinen Hinweis auf eine Stenosierung, Vaskulitis oder Rezidiv. Neurologische Rehabilitation bereits in der 2. Krankheitswoche begonnen. Im Verlauf alle neurologischen Defizite rückläufig.

Diskussion: Der kindliche Schlaganfall ist ein schwerwiegendes Ereignis mit hoher Morbidität. Die Diagnosefindung wird durch die Vielzahl der pädiatrischen Differentialdiagnosen erschwert. Bei familiärer Belastung und zunächst unauffälliger Bildgebung ist eine Migräne mit neurologischer Begleitsymptomatik häufiger. Die Zusammenschau aus Infarkt und positivem Borelliennachweis macht eine Neuroborreliose mit Vasculitis sehr wahrscheinlich. Problematisch stellt sich dar, dass die Vaskulitis häufig zu einem protrahierten und rezidivierenden Verlauf führt. Daher ist eine suffiziente antientzündliche und antibiotische Therapie zur Bekämpfung der Infektion, frühzeitige neurologische Rehabilitation sowie regelmäßige bildgebende Kontrollen zum rechtzeitigen Erkennen einer Stenosierung oder eines Rezidives obligat.

\section{DGPI-FP04}

\section{Jugendlicher mit protrahiertem Krankheitsverlauf bei parapharyngealem Abszess}

\section{B. Tröger, C. Härtel, E. Herting}

Universität Lübeck, Pädiatrie, Lübeck, Deutschland

Fallbericht: Die Übernahme des 17-jährigen männlichen Patienten aus dem HNO-OP erfolgte intubiert und beatmet auf unsere Intensivstation nach Spaltung eines paraphyryngealen Abszesses links. Vorangegangen waren seit 4 Tagen Halsschmerzen mit beginnender Schon- und Schiefhaltung des Kopfes, Schluckunfähigkeit und eine reduzierte Nahrungsaufnahme.

Im Verlauf zeigte der Patient zunächst die klinischen Zeichen eines systemic inflammatory response syndromes mit Fieber, Neutro- und Thrombopenie und respiratorischer Insuffizienz. Bei arterieller Hypotonie war eine differenzierte Katecholamintherapie erforderlich. Die initial begonnene antibiotischen Therapie mit Ampicillin/Sulbactam wurde auf Meropenem und Teicoplanin umgestellt und bei anhaltendem Fieber und Neutropenie um Amphotericin B erweitert.

Der pathologische Befund der operativ entfernten Lymphknoten erbrachte eine abszedierende Lymphadenitis. Im intraoperativen Wundabstrich ließ sich Streptokokkus pneumoniae nachweisen. Eine bei anhaltend reduzier- 
tem klinischen Zustand durchgeführte Computertomographie des Halses erbrachte den thrombotischen Verschluss der V. jugularis interna links. Mit dieser Befundkombination konnte die Diagnose des Lemierre Syndroms gestellt werden, welches folgende Charakteristika aufweist:

1. Primäre Infektion im Bereich des Oropharynx

2. Systemic inflammatory response syndrome oder Sepsis

3. Thrombose der V. jugularis

4. Septische Embolien

Das Lemierre-Syndroms beginnt meist mit Hals- und Nackenschmerzen und zeigt einen zweiphasigen Verlauf mit

1. Oropharyngealer Infektion, Lymphadenopathie, evtl Abszessformation

2. Infektion des parapharyngealen Raumes mit Thrombophlebitis und Sepsis

Das Lemierre Syndrom betrifft 1/1.000.000 Personen/Jahr. Meist sind Patienten ohne Vorerkrankungen im Alter zwischen 10-20 Jahren betroffen. In der Hälfte der Fälle gelingt der Nachweis von Fusobacterium necrophorum, in den übrigen $50 \%$ der Fälle gelingt mikrobiologisch der Nachweis von Streptokokken, Staphylokokken, Bacteroides oder es finden sich Mischinfektionen. Das Lemierre Syndrom weist eine signifikante Morbidität auf. Mehr als 50\% der Patienten weisen einen langen Krankenhausaufenthalt, septische Arthritiden/Osteomyelitiden oder eine Sinusvenenthrombose auf. Septische Embolien der Lunge, Milz, Leber und des ZNS können ebenfalls auftreten. Die Mortalität liegt bei ca. 5-20\%. Die Thrombosen entstehen durch eine inflammationsbedingte Hyperkoaguabilität, venöse Stase und Verletzungen des Endothels. Eine Antikoagulation wird bei ca $50-80 \%$ der Patienten mit einer mittleren Dauer von 3 Monaten durchgeführt.

Der klinische Verlauf unseres Patienten gestaltete sich kompliziert mit dreimaliger Notwendigkeit eines intraoperativen Wunddebridements. Der Patient erlitt unter Vollheparinisierung eine Hb-wirksame gastrointestinale Blutung und konnte letztendlich nach 4-wöchiger stationärer Therapie mit ambulanter Physiotherapie und psychologischer Betreuung nach Hause entlassen werden.

\section{DGPI-FP05}

\section{Influenza A-assoziierte akute nekrotisierende Enzephalopathie} bei einem Mädchen mit Autismus und Epilepsie

\section{F. Roche', M. Born'², B. Wiebe ${ }^{3}$, P. Nitsch-Felsecker', A. Müller}

'Kinderklinik Universitätsklinikum Bonn, Neonatologie und pädiatrische Intensivmedizin, Bonn, Deutschland, ${ }^{2}$ Universitätsklinikum Bonn, Radiologie, Bonn, Deutschland, ${ }^{3}$ Asklepios Kinderklinik, Neonatologie und pädiatrische Intensivmedizin, Sankt Augustin, Deutschland

Hintergrund: Die akute nekrotisierende Enzephalopathie (ANE) ist eine verheerende und rasch progrediente Erkrankung des Vorschulalters, die durch das plötzliche Auftreten von gravierenden neurologischen Symptomen charakterisiert wird. Diagnostisch hinweisend sind symmetrische Läsionen (Nekrosen) in Thalamus, Pons oder anderen cerebralen Strukturen im cMRT ohne Nachweis einer primär infektiösen oder metabolischen Ursache. Die exakte Ätiologie ist unklar. Meist tritt sie im Gefolge einer viralen Infektion bei gesunden, jedoch gehäuft bei neurologisch vorerkrankten Kindern auf. Neben Mykoplasmen und Herpesviren sind Influenza-Viren die am häufigsten assoziierten Pathogene im Rahmen der Erkrankung. Wir berichten über den Verlauf einer ANE bei einem 5-jährigen Mädchen Fallbericht: Eine 5-jährige aus dem Irak stammende Patientin wurde bei Zustand nach prolongiertem febrilem Krampfanfall, hoch fiebernd, komatös und im akutem Nierenversagen aus einer peripheren Klinik auf die Intensivstation der Universitätskinderklinik in Bonn verlegt. Seit mehreren Tagen bestand ein hochfieberhafter, pulmonaler Infekt, der trotz antibiotischer und antiviraler Therapie keine Besserung zeigte. Die Patientin war seit mehreren Tagen komatös. Anamnestisch waren ein Krampfleiden und eine autistische Persönlichkeitsstörung bekannt, die motorische Entwicklung sei bislang normal verlaufen. Die laborchemische Diagnostik zeigte keinen Hinweis auf eine bakterielle Infektion. Die neurometabolische, toxikologische sowie infektiologische Diagnostik des Liquors blieb unauffällig. Die virologische Diagnostik des Trachealsekrets erbrachte ei- nen positiven PCR-Befund für Influenza A H1N1 Variante 2009. Im cMRT zeigten sich ein generalisiertes Hirnödem, bilaterale Signalanhebungen in den Stammganglien und flächige Signalanhebungen im Corpus callosum, hinweisend auf eine Nekrotisierung der weißen Substanz. Unter der Verdachtsdiagnose einer Influenza-assoziierten ANE begannen wir die Therapie mit Oseltamivir und führten eine supportive intensivmedizinische Therapie durch.

Immunglobuline zeigten keinen Einfluss auf den Verlauf der Erkrankung. Im Verlauf zeigte sich nur eine geringe Besserung der neurologischen Symptomatik. Das Mädchen wies nach 3-monatigem Aufenthalt in der Klinik, bei der Verlegung in eine Pflegeeinrichtung, ein schweres neurologisches Residualsyndrom auf.

Schlussfolgerung: Influenza-assoziierte ANE ist eine seltene, jedoch dramatische Erkrankung, die gravierende Folgen für die betroffenen Patienten nach sich ziehen kann. Eine genetische Prädisposition, sowie familiäre Formen sind bekannt. Diagnostisch wegweisend sind neuroradiologische Untersuchungen. Die Prognose ist meist schlecht, wobei auch Verläufe mit völliger Erholung beschrieben werden.

Die ANE stellt eine wichtige Differenzialdiagnose bei Vorliegen einer progredienten Enzephalopathie im Rahmen einer fieberhaften Erkrankung dar. Die therapeutischen Möglichkeiten beschränken sich zur Zeit auf die antivirale und antiinflammatorische Therapie, jedoch ohne wesentliche Verbesserung des Outcomes. Lediglich eine Prävention der Influenza-Infektion durch eine Impfung kann möglicherweise diese schwere Komplikation verhindern.

\section{DGPI-FP06}

\section{Fallpräsentation: Pertussis mit letalem Ausgang, eine seltene Komplikation - auch in Deutschland}

A. Kunze, A. von Knoop, M. Knuf

Helios HSK Wiesbaden, Klinik für Kinder und Jugendliche, Wiesbaden, Deutschland

Hintergrund: Pertussis gilt in der Bevölkerung gemeinhin als harmlose Kinderkrankheit. Eine Impfprävention ist möglich. Die Impfquoten bei Eintritt in die Schule liegen in Deutschland bei 95\%. Eine lang anhaltende Immunität, sei es nach abgeschlossener Impfung oder durchgemachter Infektion, ist jedoch nicht gegeben, so dass Auffrischungsimpfungen nötig sind. Pertussis Erkrankungen nehmen in den letzten Jahren zu. Durch einzelne Nukleotidpolymorphismen scheint eine Adaptation des Erregers Bordetella Pertussis an die Umgebung zu erfolgen. Zudem sind vermehrt Stämme mit einer erhöhten Produktion von Pertussistoxin nachweisbar. Die Erkrankung von Säuglingen an Keuchhusten ist mit einer hohen Morbidität und sogar einer nicht zu vernachlässigenden Letalität behaftet, dies betrifft in besonderem Maße Risikokinder wie z. B. Frühgeborene. Seltenere Komplikationen der Pertussis, wie beispielsweise die Entwicklung einer Hyperleukozytose, sind auch unter Pädiatern nicht hinreichend bekannt. Fallbericht: Ehemaliges hypotrophes $(<2$. Perzentile) Frühgeborenes der $32+2$. SSW, Wiederaufnahme im Alter von 6 Wochen bei seit 5 Tagen bestehendem Husten. Insgesamt kranker Allgemeinzustand des Kindes, bestehender Sauerstoffbedarf und bereits im häuslichen Umfeld Hustenattacken mit Zyanoseanfällen. Beim Vater des Kindes war ein schon seit einigen Monaten bestehender Husten anamnestisch zu eruieren, der als Nebenwirkung von ACE Hemmern gewertet wurde.

Nachweis von Bordetella Pertussis über eine MultiplexPCR bei dem Frühgeborenen. Von Beginn an erfolgte eine Isolation und Behandlung mit Erythromycinestolat. Übernahme auf die Kinderintensivstation wegen Hyperkapnie. Beginn einer High-Flow Therapie über Nasenmaske. Protrahierter Verlauf und nach kurzfristiger Stabilisierung sekundäre Verschlechterung mit Hyperleukozytose (Leukozyten max. 126/nl) und Entwicklung eines ARDS (acute respiratory distress syndrome) mit Notwendigkeit der Intubation mit invasiver Beatmung. Eine Austauschtransfusion wurde durchgeführt. Zu diesem Zeitpunkt bestand bereits ein Multiorganversagen infolge des SIRS (systemic inflammation response syndrom). Das Kind wurde an ein ECMO-Zentrum verlegt, verstarb jedoch dort innerhalb weniger Stunden. 
Schlussfolgerung: Keuchhusten ist eine Infektionserkrankung mit relevanten Komplikationen, zu denen eine Hyperleukozytose gehört. Ein $\mathrm{Zu}-$ sammenhang zwischen Hyperleukozytose mit negativem Outcome ist bei Neugeborenen und Kindern bekannt, auch wenn der zugrundeliegende Mechanismus weiterhin nicht abschließend geklärt scheint. Eine Austauschtransfusion sollte frühzeitig angestrebt werden.

Bei Frühgeborenen und Hochrisikokindern sollte der Kokon-Strategie, d.h. Impfung des direkten familiären Umfeldes und der Kontaktpersonen zur Vermeidung von Krankheiten, ein deutlich höherer Stellenwert eingeräumt werden. Eine Tetanus-Impfung Erwachsener i. R. von Notfällen sollte auch im ambulanten Setting mit dem Td-aP (Tetanus, Diphtherie, Pertussis) Impfstoff erfolgen. Häufig wird der Kombinationsimpfstoff in den Notfallambulanzen nicht vorgehalten und ist auch bei Hausärzten nicht hinreichend bekannt, obwohl dieser in den STIKO Empfehlungen enthalten ist.

\section{DGPI-FP07}

\section{Subakute pulmonale Nocardiose bei immungesundem Kind}

\section{P. Kaiser-Labusch, H. I. Huppertz}

Prof. Hess Kinderklinik, Bremen, Deutschland

Fallbericht: Anamnese: Ein 4jähriger deutscher übergewichtiger, psychomotorisch entwicklungsverzögerter Junge wurde in unsere Klinik verleg mit seit 4 Monaten bestehendem Husten; keine B- Symptomatik, kein Fieber. Verschiedene orale und iv antibiotische Therapien waren ohne Effekt geblieben. Inhalative Steroide, Salbutamol und Montelukast führten zu keiner Veränderung. Der Junge lebte weitgehend beim Vater auf einem Bauernhof in desolaten hygienischen Verhältnissen; Familienanamnese unauffällig.

Befunde: Im Röntgenbild parakardiale Infiltrate bds; die Lungenfunktion zeigte eine mittellschwere kombinierte Ventilationsstörung. CrP und gr. BB unauffällig, BSG und Immunglobuline mäßig stimuliert. Schweißtest, allergologische Diagnostik, spez. AK bzgl exogen-allergischer Alveolitis, Ziliendiagnostik, Lymphozytendifferenzierung, -subpopulationen, ImpfAK: normwertig.

CT Thorax: ausgedehnte Konsolidierungen und Traktionsbronchiektasen v.a. im re. OL und ML, und im li. OL sowie mediastinale Verbreiterung. Sonographisch Hepatomegalie, ansonst keine Auffälligkeiten. Knochenmark o. B.

$B A L$ : reichlich sehr zähes Sekret mit vielen Granulozyten; konventionelle Kultur, Virologien, PcJ, Tbc Kultur sowie PCR auf NTM/TB: negativ. Transbronchiale Biopsien: unspez. Alveolitis. Die spezifische Kultur aus der BAL auf Nocardien war positiv. Die Subspeziesbestimmung gelang nicht; Cotrimoxazol und Amoxicillin/Clavulan wurden als resistent getestet. Nach diesem Befund erweiterte immunologische Diagnostik mit HIV-Serologie und T-Zellproliferation - oB.

Therapie und Verlauf: Unter einer 2-wöchigen iv Therapie mit Imipenem+Amikacin, parallel Sekretolyse mit 3\% $\mathrm{NaCl}$ und in der Folge monatelanger oraler Therapie mit Doxycyclin kam es erst nach Herausnahme des Jungen aus der väterlichen Betreuung (monatelang fragliche Compliance) nach letzlich 6 Monaten gesicherter oraler Medikamenteneinnahme zu einer durchgreifenden Besserung des AZ. Traktionsbronchiektasen des re OL verbleiben, die Lungenfunktion hat sich vollständig normalisiert.

Diskussion: Eine subakute pulmonale Nocardiose ist bei Immungesunden und v. a.bei Kindern eine Rarität, und wird eher bei HIV Patienten oder älteren, anderweitig immunsupprimierten Menschen gesehen. Nocardien sollten eigentlich auch in der Tuberkulosekultur identifizierbar sein; in unserem Fall war die gezielte gesonderte Anforderung in der mikrobiologischen Diagnostik essentiell für die Auflösung des Falles. Ansonst ist die Identifizierung in der bakteriellen 16S rRNA- PCRmöglich. Außer den schwierigen sozialen und hygienischen Lebensbedingungen fand sich kein Risikofaktor für diese schwere Erkrankung. Bei chronischer Pneumonie muss die mikrobiologische Diagnostik breit sein und auch unwahrscheinliche Erreger mit erfassen.

\section{DGPI-FP08}

Todesfall eines Neugeborenen durch Legionellen- MDRTuberkulose eines 6 Mo alten Säuglings. Aktive Ermittlung und Maßnahmen des Gesundheitsamtes

O. Bock-Hensley', A. Möhlenbruch', J. Meyburg', O. Sommerburg ${ }^{4}$, C. Lück 'ehem. Gesundheitsamt Heidelberg, Abt. Infektionsschutz, Dossenheim, Deutschland, ${ }^{2}$ Gesundheitsamt Heidelberg, Abt. Infektionsschutz, Heidelberg, Deutschland, ${ }^{3}$ Universitätsklinikum Heidelberg, Kinderklink, Abt. Allgemeine Pädiatrie, Heidelberg, Deutschland, ${ }^{4}$ Universitätsklinikum Heidelberg, Kinderklinik, Abt. Onkologie, Hämatologie, Immunologie und Pneumologie, Heidelberg, Deutschland, ${ }^{5}$ Universität, Institut für Hygiene und Mikrobiologie, NRZ Legionellen, Dresden, Deutschland

Hintergrund: Rechtsgrundlage ist das Infektionsschutzgesetz (IFSG). Infektionserkrankungen sind nach dem IFSG durch einen Arzt (\$6) oder das Labor $(\$ 7)$ meldepflichtig. Das Gesundheitsamt ist nach $₫ 25$ IFSG verpflichtet, bestimmte Ermittlungen und Maßnahmen einzuleiten. Dies soll an 2 Fallbeispielen (Legionellen, Tuberkulose) erläutert werden.

Fragestellung: Wäre der Tod eines Neugeborenen durch Legionellen vermeidbar gewesen oder wäre die MDR-Tuberkulose eines Säuglings zu verhindern gewesen sind Fragen, die anhand des Vorgehens des Gesundheitsamtes ausführlich diskutiert und, mit Hintergrunddaten belegt, beantwortet werden.

Material und Methode: Legionellen-Erkrankungen und Tuberkulose sind meldepflichtig. Für beide Erkrankungen liegen Therapieempfehlungen der Fachgesellschaften vor. Beide Kinder wurden in einer Kinderklinik versorgt. Die Behandlung der Kinder obliegt den Kliniken und den niedergelassenen Ärzten. Außer in Ausnahmefällen ist das Gesundheitsamt in die Therapie nicht involviert. Das Gesundheitsamt wurde vom Labor und der Klinik über die o. g. Kinder informiert. Das Gesundheitsamt muss bei diesen Erkrankungen nach $\$ 25$ IFSG ermitteln und handeln. Damit liegen klare Handlungsanweisen der Ermittlungen vor. Anhand der beiden Beispiele werden das Vorgehen und die Hintergründe des Handelns des Gesundheitsamtes erläutert.

1. Fall: Ein gesundes Neugeborenes wird nach 1 Wo in moribundem $\mathrm{Zu}$ stand in die Klinik gebracht und stirbt nach 3 Tagen an einer schweren Pneumonie. Der Befund einer Legionellen-Pneumonie wurde vom Labor übermittelt. Fragen für das Gesundheitsamt sind: Wo war die Quelle der Infektion? Sind weitere Fälle vorhanden? Liegt eine Überschreitung der empfohlenen Richtwerte in Wasserleitungen vor? Das NRZ Legionellen in Dresden wurde eingeschaltet.

2. Fall: Ein 6 Mo alter Säugling ausländischer Eltern (EU-Bürger) erkrankt an einer MDR-Lungentuberkulose. Fragen für das Gesundheitsamt: Wo ist die Quelle der Infektion? Wer ist Kontaktperson? Wie kann das 6 Mo alte Kind (Katheter bei i.v.-Therapie) altersgerecht durch seine Mutter versorgt werden? Ambulant oder stationär? Wer trägt die Kosten? Wie ist die weitere ambulante Betreuung durch die mittellosen Eltern zu gewährleisten? Wie kann Compliance mit den erforderlichen Maßnahmen erreicht werden?

Ergebnisse: In beiden Fällen erfolgte nach ausführlichen Gesprächen mit den Eltern eine gute und effektive Zusammenarbeit mit der Klinik, den Hausbesitzern, den anderen zuständigen Behörden und den Nationalen Referenzzentren. Die jahrelange gute Zusammenarbeit der Kliniken mit dem Gesundheitsamt hatte sich auch in diesen beiden sehr unterschiedlichen Fällen sehr bewährt.

Diskussion und Schlussfolgerung: Die Ergebnisse der Maßnahmen des Gesundheitsamtes beider Fälle werden erläutert. Die Tbc-Erkrankung des 6 Mo alten Säuglings mit einer MDR-Tbc wäre vermeidbar gewesen, wenn in den wirtschaftlich schlechter gestellten Ländern in Europa Risikogruppen gezielt gescreent werden könnten und eine adäquate Therapie zur Verfügung stehen würde. Der Todesfall des Neugeborenen wäre zu vermeiden gewesen, wenn alle Wasserleitungen in Hausinstallationen frei von Legionellen wären. Dies ist jedoch illusorisch. Die empfohlenen Technischen Maßnahmewerte waren in der betreffenden Hausinstallation nicht überschritten. Beide Fälle zeigen, dass Prävention und gute Aufklärung der Bevölkerung intensiviert werden müssen. Daran hat der ÖGD einen wichtigen Anteil. 


\section{DGPI-FP09}

\section{Die schwere Weichteilinfektion: Ein Neonat mit ausgedehnter PVL-MRSA Phlegmone}

\section{A.S. Schaper', P. A. Hoppe², R. Krüger ${ }^{2}$ \\ ${ }^{1}$ Charité Berlin, Neonatologie, Berlin, Deutschland, ${ }^{2}$ Charité Berlin, Berlin, Deutschland}

Hintergrund: Ist ein Staphylococcus aureus durch spezielle Bakteriophagen infiziert, die den Virulenzfaktor des porenbildenen Zytotoxins Panton-Valentine-Leukozidin (PVL) transferieren [1], können schwere Hautund Weichteilinfektion die Folge sein [2, 3]. Die MRSA-Besiedlung von Patienten auf neonatologischen Intensivstationen nimmt im Rahmen der steigenden Prävalenzahlen für nosokomiale Erreger zu [4], eine schwere Weichteilinfektion durch ambulant erworbene PVL-MRSA hingegen bleibt bisher eine Rarität auf deutschen NICUs.

Fallbericht: Wir berichten über ein reifes Neugeborenes einer Hepatitis Cpositiven und mit Polamidon-substituierten Mutter, das zur Behandlung eines neonatalen Drogenentzugssyndroms auf die NICU aufgenommen wurde. Mittels PCR im Urin wurde eine konnatale CMV-Infektion nachgewiesen, die bisher asymptomatisch und nicht therapiert ist. Im Verlauf des stationären Aufenthaltes entwickelte der Patient eine bilaterale purulente Konjunktivitis, die mit antibiotischen Olfloxacin Augentropfen behandelt wurde. Des Weiteren traten multiple dolente Panaritien auf, die nicht auf lokal-antiseptische Maßnahmen ansprachen. Bei Nachweis einer MRSA-Besiedlung erfolgte eine Sanierung. Währenddessen entwickelte sich jedoch ein nekrotisierender Abszess in der linken Achselhöhle, der sich in der Thoraxwand bis in die Interkostalmuskulatur ausbreitete und von einer einschmelzenden Lymphadenopathie begleitet wurde. Das maximale CRP betrug $186 \mathrm{mg} / \mathrm{dl}$. Es erfolgte eine systemische antibiotische Therapie mit Clindamicin gemäß Resistogramm und eine chirurgische Ausräumung. Zur Prophylaxe toxinbedingter Komplikationen erfolgte präoperativ die einmalige Gabe von Immunglobulinen. Die durchgeführte Basisdiagnostik zum Ausschluss eines Immundefektes war unauffällig. Postoperativ konnte der PCR-Nachweis eines hochpathogenen PVLMRSA im Haut- und Wundabstrich erbracht werden, der eine erneute MRSA-Sanierung von Mutter und Kind nach sich zog, unter deren Anwendung sich der klinische Zustand des Kindes zusätzlich besserte. Bis zur Entlassung traten keine weiteren Hauteffloreszenzen auf.

Schlussfolgerung: PVL-MRSA-Weichteilinfektionen können sich aggressiv ausbreiten, ein früher Nachweis des PVL-Virulenzgens mittels PCR erscheint deshalb sinnvoll.

\section{Literatur}

1. Panton PN, Valentine FCO (1932) Staphylococcal toxin. Lancet 1:506-508

2. Shallcross LJ, Fragaszy E, Johnson AM, Hayward AC (2013) The role of the PantonValentine leucocidin toxin in staphylococcal disease:a systematic review and metaanalysis. Lancet Infect Dis 13:43-54

3. Demos M, McLeod MP, Nouri K (2012) Recurrent furunculosis: a review of the literature. Br J Dermatol 167:725-732

4. Carey AJ, Duchon J, Della-Latta P et al (2010) The epidemiology of methicillinsusceptible and methicillin-resistant Staphylococcus aureus in a neonatal intensive care unit, 2000-2007. J Perinatol 30:135-139

\section{DGPI-FP10}

\section{Rezidivierende Abszesse in einer Familie - Infektion oder Immundefekt?}

\section{Faßhauer, N. Kellner, S. Borte, A. Bethge, T. Grünewald, B. R. Ruf, M. Borte} Klinikum St. Georg, Leipzig, Deutschland

\section{Fallbericht:}

Anamnese: 17 Jahre altes Mädchen, seit vier Jahren rezidivierend Abszesse an wechselnden Lokalisationen (Oberschenkel, Axillae, Unterarme, Bauchdecke, Gesicht) mit mehrfach Nachweis von Staphylococcus (Staph.) aureus. Wiederholte Abszess-Spaltungen, z.T. antibiotische Sanierungsversuche und multiple stationäre Aufenthalte ohne Therapieerfolg. Davor nie ernsthaft erkrankt, keine Pneumonien, keine Pilzinfektionen, keine Ekzeme, keine Fehlbildungen. Vorstellung der Jugendlichen in der Immundefektambulanz am Klinikum St. Georg bei V.a. Hyper-IgESyndrom (HIES).

Laborbefunde: Leicht erhöhtes IgE, Blutbild und Differenzierung unauffällig, keine Eosinophilie. Subpopulationen mononukleärer Zellen mit leichter Erniedrigung der TH17-Zellen. Auch beim Vater seit einigen Monaten rezidivierende Abszesse.

Verlauf: Ambulanter Versuch der Prophylaxe mit Cefuroxim und Minocyclin. Hierunter erneut Rezidive. HIES und chronische Granulomatose (CGD) ausgeschlossen. Nachweis von Staph. aureus mit Panton-Valentin Leukozidin (PVL)-Gen positiv (lukSS-lukF,c-MRSA, spa-Typ t044, klonaler Komplex 80) im intraoperativen Abstrich der rechten Axilla. In Folge PVL-positiver S. aureus auch beim Vater nachweisbar. Stationäre Aufnahme der Jugendlichen, Isolation und 1 Woche antimikrobielle Therapie mit Cefazolin i.v. Dann ambulante Folgetherapie mit Azithromycin über 3 Monate sowie täglich antiseptischen Haar- und Körperwaschungen. Seither keine Rezidive. Testung der Haustiere erforderlich, um eine Rekolonisierung über diese zu verhindern.

Diskussion und Schlussfolgerung: Aus dem Abszess der Patientin wurde ein PVL-positiver Staph. aureus isoliert. Dieses Toxin ist plasmidkodiert und verursacht einen Untergang von Granulozyten, so dass es zu klinisch relativ anergen rezidivierenden Abszessen kommt. Die Toxinbildner lassen sich nicht vom Resistogramm herleiten. Eine PCR-Untersuchung mit entsprechender Fragestellung ist erforderlich. Die Erkrankung sollte bei entsprechender Klinik differenzialdiagnostisch von HIES und CGD abgegrenzt werden.

\section{DGPI-FP11}

\section{Vertikale HIV-1 Infektionen bei asymptomatische Jugendlichen}

\section{Kohns, H. J. Laws, A. Borkhardt, J. Neubert}

Universitätsklinikum Düsseldorf, Kinder Hämato-, Onkologie, Immunologie, Düsseldorf, Deutschland

Hintergrund: Ca. $15 \%$ aller vertikal HIV infizierten Kinder zeigen unbehandelt eine rasche Progression und sterben vor dem ersten Lebensjahr. Nicht frühzeitig diagnostizierte Kinder entwickeln zu $40 \%$ vor dem Grundschulalter AIDS, $90 \%$ zeigen bis zur Einschulung auf eine HIV-Infektion hinweisende Symptome [1]. Ein geringer Anteil der Kinder bleiben asymptomatisch und werden erst nach dem 13 Lebensjahr diagnostiziert. Es besteht die Empfehlung, Kinder HIV-positiver Mütter unabhängig vom Alter zu testen, allerdings zeigte sich beispielsweise in England, dass Jugendliche häufig nicht getestet werden, mutmaßlich da ihr Risiko nach langem asymptomatischem Verlauf nur noch als gering eingeschätzt wird [2]. Ein erhöhtes Risiko für eine späte Diagnose in Deutschland besteht vermutlich insbesondere für Kinder, bei deren Müttern erst lange nach der Geburt die HIV-Infektion diagnostiziert wurde oder die aus Ländern einwandern, in denen nach der Geburt eine routinemäßige Testung nur lückenhaft erfolgt.

Fragestellung: Lassen sich bei Jugendlichen mit Erstdiagnose einer vertikal übertragenen HIV-Infektion durch sorgfältige Anamnese Symptome identifizieren, die bereits früher Anlass zu einer HIV-Testung hätten geben können?

Material und Methoden: Drei Jugendliche mit Erstdiagnose einer vertikalen HIV-Infektion und ihre Familien wurden zu früheren Symptomen, die Anzeichen einer HIV-Infektion sein könnten, befragt. Neben den demographischen Daten wurden Laborparameter u.a. die CD4 Zahl und die quantitativen HIV-1 RNA bestimmt. In 2 von 3 Patienten wurden die HIV-1 Stämme von Mütter und Jugendlichen verglichen.

Ergebnisse: Zwei Patienten waren bei Diagnosestellung 13 Jahre, eine Patientin 16 Jahre alt. Die 16jährige Patientin zeigte eine CD4-Zahl von 101/ $\mu \mathrm{l}(9 \%)$, die beiden 13 jährigen Jungen hatten CD4-Zellwerte von 378/ $\mu \mathrm{l}$ $(21,6 \%)$ und $254 / \mu \mathrm{l}(17 \%)$. Die Viruslast der Patienten lag zwischen 2885 und 38.750 Kopien pro ml. Alle drei Jugendlichen stammten aus afrikanischen Ländern und waren erst im Alter von über 10 Jahren nach Deutschland gezogen. In keinem der Fälle ergaben sich aus der Anamnese und Untersuchung Hinweise für einen anderen Infektionsweg als eine vertika- 
le Infektion. In den beiden Fällen in denen die Mutter noch lebte wurde dieser Übertragungsweg durch die Virusgenetik unterstützt.

Eine Patientin hatte Dermatom bezogene Narben am Thorax, die hinweisend für einen Herpes zoster waren. Die beiden anderen hatten bis ins Jugendalter keine schweren oder untypischen Infektionen. Gewicht und Längenentwicklung waren bei allen drei Kindern im altersentsprechenden Bereich. Nur bei einem der Patienten führten letztlich Untersuchungen im Rahmen der Differentialdiagnose einer Fazialisparese zur HIV-Diagnose. Die beiden anderen Patienten wurden lediglich auf Grund der Familienanamnese getestet.

Schlussfolgerung: Eine vertikale HIV-Infektion lässt sich auch durch sorgfältige Anamnese und klinischer Untersuchung nicht ausschließen. Da eine frühzeitige antiretrovirale Therapie mit einer deutlichen Mortalitätssenkung einhergeht, muss eine HIV-Testung aller Kinder HIV-positiver Mütter unabhängig vom Alter und Symptome erfolgen.

\section{Literatur}

1. Gray L, Newell ML, Thorne C, The European Collaborative Study et al (2001) Fluctuations in Symptoms in Human Immunodeficiency Virus-Infected Children: The First 10 Years of Life. Pediatrics 108:116-122

2. Briggs A, Bond K, Rogstad KE (2011) Testing the children of HIV-positive mothers. Int J STD AIDS 22:348-350

\section{DGPI-FP12}

\section{Eine komplizierte Pneumokokkenmeningitis}

V. Lieftüchter', F. Hoffmann', F. Hey' , J. Hübner' ${ }^{2}$, K. Reiter ${ }^{1}$

'Dr. von Haunersches Kinderspital, Kinderintensivstation KIPS, München, Deutschland, ${ }^{2}$ Dr. von Haunersches Kinderspital, Pädiatrische Infektiologie, München, Deutschland

Hintergrund: Die Letalität einer invasiven Infektion mit Streptococcus pneumoniae ist in Deutschland immer noch sehr hoch und es können Residuen wie Hörverlust oder andere neurologische Schäden persistieren. Eine diagnostische und therapeutische Herausforderung ist die Entwicklung eines ZNS-Empyems als seltene, aber vital bedrohliche Komplikation. Fallbericht: Wir berichten über ein 11 Monate altes Mädchen, welches uns nach stattgehabtem 1. kompliziertem Fieberkrampf auf unsere Kinderintensivstation gebracht wurde. Das Mädchen hatte nach einer zweitägigen Infektanamnese mit Fieber und Erbrechen begonnen, linksseitig mit Arm und Bein tonisch-klonisch zu krampfen. Der Anfall sistierte erst nach mehrmaliger Benzodiazepin- und Phenobarbitalgabe. Das Mädchen zeigte postiktal eine Hemiparese links. In der Folge kam es bei Fieberanstieg zu weiteren Krampfereignissen mit jeweils reversibler linksseitiger Hemisymptomatik. Im cMRT demaskierte sich in der Folge ein Empyem über der gesamten Hemisphäre rechts. Klinische Hirndruckzeichen fanden sich nicht, so dass keine Drainage oder Kraniektomie erfolgen musste. Das Mädchen wurde für 6 Wochen zunächst mit Ceftriaxon (i.v.), im Anschluss für weitere 2 Wochen mit Linezolid (p. o.) behandelt. Antikonvulsiv erhielt es eine Therapie mit Levetiracetam. Eine PneumokokkenImpfung war im Vorfeld vom Kinderarzt nicht empfohlen worden.

Methoden: In der Liquoranalyse (37 Zellen/ $\mu$ l) konnten sofort Pneumokokken mittels Multiplex-PCR nachgewiesen werden, später auch im Nasenabstrich und in der Blutkultur. Im ersten cCT zeigte sich eine plumpe Gyrierung hoch parietal rechts im Vergleich zur linken Großhirnhemisphäre. Im 3 Tage später durchgeführten cMRT wurde der Verdacht auf eine pyogene Meningitis rechts gestellt, welche sich in der Kontroll-cMRT eine Woche später in Form eines Empyems bestätigte. Im EEG zeigte sich eine reduzierte Amplitude über der Großhirnhemisphäre rechts und in der Folge eine leichte Asymmetrie zentral.

Schlussfolgerung: Die Schwere und Ausprägung dieser invasiven Pneumokokken-Infektion mit unilateralem Haubenempyem einer Gehirnhälfte erklärt die lange Therapiedauer und verdeutlicht einmal mehr die Dringlichkeit einer Immunprophylaxe mit einem Pneumokokken(Konjugat)-Impfstoff bei Kindern. Frühe Hirndruckzeichen sind bei schwerer Meningitis oft schwer differenzierbar, daher ist eine Schnittbildgebung frühzeitig zu erwägen.

\section{DGPI-FP13}

\section{Subdurales Empyem als Komplikation einer Pansinusitis}

\section{A. Schlesinger, K. Gröger, Y. Vorwerg, J. P. Streidl}

Muldentalklinik Krankenhaus Wurzen, Kinder- und Jugendabteilung, Wurzen, Deutschland

Hintergrund: Ein subdurales Empyem ist eine Eiteransammlung zwischen Dura mater und Arachnoidea und tritt z. B. in Folge einer Sinusitis, Otitis oder hämatogen auf. Häufig liegt der Ursprung des subduralen Empyems in einer akuten Sinusitis. Da die Symptome (Schnupfen, Husten, Fieber etc.) einer akuten Sinusitis im Kindesalter denen einer viralen Infektion sehr ähnlich sind, wird die akute Sinusitis häufig spät diagnostiziert oder nicht erkannt. Ursächlich für die Entstehung einer bakteriellen Sinusitis sind die Minderbelüftung der Nasennebenhöhlen, der Sekretstau und eine bakterielle Besiedlung durch die Standortflora der Nase.

Fallbericht: Wir berichten über einen 13 8/12- jährigen Patienten mit einem subduralem Empyem bei akuter Pansinusitis, Sepsis durch Streptokokken der Gruppe A und bakterieller Meningoenzephalitis. Aufnahme des Patienten bei rez. Erbrechen $(6-7 \times / \mathrm{d})$ und zunehmender Schläfrigkeit. Es bestand seit 1,5 Wochen ein Infekt mit Husten, Schnupfen, Fieber und Kopfschmerzen. Bei Aufnahme fiel der Junge durch Somnolenz mit wechselnd Abwehr/Aggressivität, starken Kopfschmerzen und angedeutetem Meningismus auf.

Ergebnisse: Initial Lumbalpunktion bei sehr aggressivem abwehrigen $\mathrm{Pa}-$ tienten nicht durchführbar. Beginn einer kalkulierten Therapie mit Ceftriaxon bei VD Meningitis. Die Eltern schätzten das Verhalten als nicht auffällig ein (Pat. hatte mehrere Aufenthalte in KJP, nahm Risperidon bei ADHS). Im Verlauf gut führbar aber verzögernd reagierend, retrospektiv war das Verhalten auffällig.

Paraklinik: CrP max. 239, Leuko 14,3 mit Linksverschiebung, Verbrauchskoagulopathie, Transaminasenerhöhung, Blutkultur: Streptokokken Gr. A. Liquorbefund am 3. BT: Leuko $361 \mathrm{Mptl} / \mathrm{l}$, Eiweiß $703 \mathrm{mg} / \mathrm{l}$, Lactat 2,26 mmol/l. Schrankenstörung. Rachenabstriche auf Viren/Bakterien und Urin+ Drogenscreeing unauffällig.

Bei Nachweis Sinusitis im Röntgen und auffälligem EEG mit Herdbefund re - Durchführung cMRT (Abbildungen siehe Poster). Befund: Nachweis eines subduralem Empyems mit Begleitmeningitis frontobasal rechts, offenbar per continuitatem ausgehend von einer rechtsseitigen Sinusitis/ Pansinusitis. Nach Erhalt dieses Befundes Verlegung HNO Uniklinik Leipzig.

Diskussion/Schlussfolgerung: In unserem Fall zeigten sich mehrere komplizierende Faktoren. 1. Die Einschätzung eines Patienten mit psychiatrischer Anamnese fällt schwer und stützt sich häufig auf die Fremdanamnese. Jedoch stuften die Eltern das Verhalten als „normal“ ein und sahen erst auf wiederholtes Nachfragen ein auffälliges Verhalten des Sohnes. 2. Anfänglich VD bakt. Meningitis ohne Erregernachweis (da LP erst am 3. BT möglich) und kalkulierte Antibiotikatherapie. 3. Erst im Verlauf Feststellung der Sinusitis und Erhalt der positiven Blutkultur und somit verzögerte Diagnose des subduralen Empyems am 10. Behandlungstag.

\section{DGPI-FP14}

\section{Malaria Tertiana bei einem Flüchtling aus Pakistan}

\section{T. Strömer, K. Gröger, J. P. Streidl, A. Schlesinger}

Muldentalkliniken, Krankenhaus Wurzen, Kinder- und Jugendmedizin, Wurzen, Deutschland

Hintergrund: Die Malaria ist eine der bedeutendsten Infektionskrankheiten weltweit. Die Anzahl der nach Deutschland importierten Fälle ist in den letzten Jahren angestiegen; 2016 wurden 1068 Malaria-Fälle in Deutschland gemeldet. Die Inzidenz in Sachsen ist im bundesweiten Vergleich niedrig. Betroffen sind insbesondere Jugendliche (männlich $>$ weiblich) zwischen 15 und 19 Jahren. Die Infektionsländer sind hauptsächlich afrikanische Länder, außerhalb von Afrika ist Pakistan das häufigste Infektionsland. Wir berichten über einen seit 2 Monaten in Deutschland lebenden, jugendlichen Flüchtling aus Pakistan mit seit einer Woche bestehendem, rhythmisch auftretendem Fieber unklarer Ursache. 
Fragestellung: Relevanz der Herkunftsländer von Flüchtlingen im medizinischen Kontext

Patient und Methode: Vorstellung des Patienten durch den Rettungsdienst in der Notfallambulanz. Es zeigte sich ein 16 7/12 jähringer, allein reisender Flüchtling aus Pakistan. Anamn. seit 7 Tagen Fieber, grippeähnliche Allgemeinsymptome, kein Durchfall, kein Erbrechen. Klinisch reduzierter Allgemeinzustand (AZ), blass, Temp. $40,2^{\circ} \mathrm{C}$, Schmerzen am Rücken; durch Antipyretika deutliche AZ Besserung, nach 48 h erneuter Fieberanstieg und Verschlechterung.

Ergebnisse: Paraklinik: Sonographie Abdomen, Echokardiographie, EKG, Röntgen-Thorax unauff., im Labor (SI): Thrombozytopenie, CRP max. 97, PCT 14. Aufgrund der Symptomatik und der Herkunft aus einem Malariaendemiegebiet erfolgte ein Blutausstrich und Dicker Tropfen mit dem Nachweis von Plasmodien vivax (Ringformen, Gametozyten) als Zeichen einer Malaria Tertiana. Auch in der Differenzierung mittels Durchflusszytometrie (FACS) fand sich ein Malaria Scattergramm als Hinweis einer Malaria. Es wurde eine dreitägige Therapie mit Malarone durchgeführt, der anschließende Kontrollausstrich war unauffällig. Auf den stationären Aufenthalt folgte eine 14-tägige Prophylaxe mit Primaquin.

Diskussion: Es bestanden bei dem Patienten multiple Faktoren wie Klinik, Geschlecht und Alter, die an eine Malaria (in Deutschland) denken ließen; insbesondere jedoch sein Herkunftsland, ein Malariaendemiegebiet, führte zu der Einleitung einer Malaria-Diagnostik durch einen mikroskopischen Nachweis.

Schlussfolgerung: Malaria ist eine in Deutschland und insbesondere in Sachsen seltene Erkrankung. Wichtig ist es, bei einem klinischen Bild mit episodischem Fieber unklarer Genese und entsprechender Anamnese (Herkunftsland), Malaria als mögliche Ursache in Betracht zu ziehen und entsprechende diagnostische Schritte einzuleiten. Ein Scattergramm kann bereits in einem Krankenhaus der Grund- und Regelversorgung den Hinweis auf eine Malaria geben.

\section{DGPI-FP15}

\section{Ausschließlich MR-morphologisch nachweisbare intracerebrale septische Herde im Falle einer durch E. coli verursachten Early onset Sepsis - eine häufig nicht diagnostizierte Komplikation?}

R. van den Bruck', A. Stein', H. Müller', G. Krawzak², B. Schweiger ${ }^{3}$ U. Felderhoff-Müser ${ }^{1}$

'Universitätsklinikum Essen, Perinatalzentrum/Kinderheilkunde I, Essen, Deutschland, ${ }^{2}$ Universitätsklinikum Essen, Klinik für Allgemein-, Viszeralund Transplantationschirurgie, Essen, Deutschland, ${ }^{3}$ Universitätsklinikum Essen, Institut für Diagnostische und Interventionelle Radiologie und Neuroradiologie, Essen, Deutschland

Hintergrund: E.coli ist nach Gruppe-B-Streptokken der häufigste Erreger von Early onset Septitiden (EOS) beim Neugeborenen. Eine E.coli Infektion ist mit einer hohen Mortalität von bis zu $25 \%$ assoziiert, das Risiko einer Beteiligung des ZNS liegt um das 1,5 fache höher als bei anderen bakteriellen EOS Erregern (4,2 vs. 6,2\%) [1].

Fallbericht: Ein weibliches eutrophes Neugeborenes der $37+2$ SSW präsentierte sich nach Spontanpartus mit einer pulmonalen Adaptationstörung, Hypoglykämien $(20 \mathrm{mg} / \mathrm{dl})$ und einer verzögerten Rekapillarisierungszeit. Bei Verdacht aufEOS wurde eine empirische Therapie mit Ampicillin und Gentamycin initiiert. Das postnatale IL-6 war massiv erhöht (16.526 pg/ $\mathrm{ml})$. An pränatalen Risikofaktoren bestand eine in der 25.SSW angelegte prophylaktische Cerclage, zum Blasensprung kam es 2 hpräpartal. Im maternalen Vaginalabstrich bestand eine Besiedlung mit Klebsiella pneumoniae, E.coli und E.faecalis. Im Alter von 12 Stunden setzte das Mädchen rektal blutigen Schleim ab. Die Therapie wurde auf Meropenem und Vancomycin umgestellt. Es dominierte klinisch ein Ileus mit akutem Abdomen. Eine am 3. Lebenstag durchgeführte explorative Laparotomie zeigte ein nekrotisches Areal ohne Perforation im Bereich des terminalen Ileums, $4 \mathrm{~cm}$ Darm wurden reseziert und ein Santulli-Stomas angelegt. Mikrobiologisch wurde in den postnatalen Routineabstrichen eine vertikale E.-coli-Übertragung nachgewiesen. Weitere Nachweise desselben Erregers gelangten in der initialen Blutkultur und den intraoperativen Abstrichen.
Nach Nachweis von E.coli in der Blutkultur wurde die Therapie mit Vancomycin am 2. Lebenstag beendet und nach Erhalt des Resistogramms am 6. Lebenstag auf Ampicillin/Sulbactam umgestellt. Postoperativ besserte sich der Zustand der Patientin rasch, das $\mathrm{CrP}$ war zügig rückläufig ( $\mathrm{CrP}$ max. 7,1 mg/dl am 2.Lebenstag) und erstmals am 6. Post-OP Tag negativ. Wegen des mit E.coli assoziierten statistischen Risikos einer ZNS-Beteiligung führten wir am 10. Lebenstag ein cMRT durch, welches mehrere septische Embolien im Bereich des periventrikulären Marklagers zeigte. Diese waren auch unter Kenntnis der genauen Lokalisation sonographisch nicht fassbar. Eine initiale Lumbalpunktion war nicht erfolgt. Eine Untersuchung des Liquors nach Erhalt des MRT-Befundes zeigte einen unauffälligen Liquorstatus (IL6 3 pg/ml), ein Nachweis von E.coli im Liquor gelang weder kulturell noch PCR-basiert. Die antibiotische Therapie wurde auf Cetotaxim $200 \mathrm{mg} / \mathrm{kg} / \mathrm{d}$ umgesetzt und über 6 Wochen durchgeführt. Schlussfolgerung: In dem hier beschriebenen Kasus konnte die prognostische und therapeutisch relevante Komplikation intracerebraler septischer Herde im Falle einer EOS durch E.coli ausschließlich per cMRT nachgewiesen werden. $\mathrm{Ob}$ die intraparenchymatös gelegenen Herde jemals Anschluss an das Liquorsystem hatten und über eine frühzeitige Liquorpunktion hätten detektiert werden können, bleibt spekulativ. Eventuell kam es erst im Rahmen der chirurgischen Intervention zu einer Aussaat ins ZNS und eine primär unauffällige Liquoruntersuchung hätte zu einem zurückhaltenden Procedere bezüglich weiterer Bildgebung geführt. Aus dem beschriebenen Verlauf lässt sich das Fazit ziehen, dass bei einer Sepsis mit Nachweis von E.coli in der Blutkultur unabhängig vom Liquorbefund die Durchführung eines cMRT's großzügig erfolgen sollte.

\section{Literatur}

1. Schrag SJ, Farley MM, Petit S et al (2016) Epidemiology of Invasive Early-Onset Neonatal Sepsis, 2005 to 2014. Pediatrics 138:e20162013

\section{DGPI-FP16}

\section{Komplizierte Malaria tropica mit multipler Organbeteiligung}

L. Schlemmer', U. von Both', M. Alberer', H. Johannes', B. Lange-Spirandio', K. Reiter ${ }^{1}$

'Ludwig Maximilians Universität, Pädiatrie, München, Deutschland, ${ }^{2}$ Ludwig Maximilians Universität, Abteilung für Infektions- und Tropenmedizin, München, Deutschland

Hintergrund: Malaria ist eine der häufigsten Erkrankungen weltweit. Mit der zunehmenden Mobilität der Weltbevölkerung (sei sie freiwillig im Sinne von Tourismus oder erzwungen durch Flucht) sehen sich auch die Subtropen immer häufiger mit diesem Krankheitsbild konfrontiert.

Fragestellung: Präsentation der Pathophysiologie, der Erscheinungsbilder und der Behandlung der komplizierten Malaria im Kindesalter, anhand des Falls eines 11 Jahre alten Mädchens, die sich mit einer komplizierten Malaria in unserer Behandlung befand.

Fallbericht: Ein elfjähriges Mädchen nigerianischer Abstammung, jedoch in Deutschland geboren und aufgewachsen, stellte sich mit seit einer Woche bestehendem Fieber bis $39^{\circ} \mathrm{C}$ sowie Husten und Schnupfen vor. Eine zuvor eingeleitete antibiotische Therapie hatte zu keiner Besserung geführt. Die Patientin war vor einer Woche aus einem dreiwöchigen Urlaub in Nigeria zurückgekehrt. Eine Malariaprophylaxe war nicht eingenommen worden. Das Mädchen war bei Aufnahme in deutlich reduziertem Allgemeinzustand mit einer ausgeprägten Tachydyspnoe und Fieber bis $40^{\circ} \mathrm{C}$. Der weitere Untersuchungsbefund war unauffällig ohne Hepatosplenomegalie. Laborchemisch bestand eine Anämie ( $\mathrm{Hb} \mathrm{8,0} \mathrm{mg/l)} \mathrm{mit}$ erhöhter LDH, erniedrigtem Haptoglobin und Hyperbilirubinämie, sowie eine Thrombopenie (70 G/l). Im Röntgenbild zeigte sich eine basal betone Transparenzminderung beider Lungen. Die Malaria-Diagnostik ergab den Nachweis von Plasmodium falciparum mit einer initialen Parasitämie von $3 \%$, so dass die Verlegung auf unsere Intensivstation zur i.v.-Therapie mit Artesunat, sowie bei weiterer respiratorischer Verschlechterung eine Atemunterstützung mit NIV-Beatmung erfolgte. Die Parasitämie stieg innerhalb der ersten zehn Stunden der Therapie auf max. $10 \%$ an. 36 Stunden nach Therapiebeginn waren keine Trophozoiten mehr nachweisbar. Dennoch verschlechterte sich die respiratorische Situation des Mädchens 
zunehmend. Auch das Röntgenbild zeigte eine deutliche Zunahme des Lungenödems mit neu aufgetretenen Pleuraergüssen, so dass eine i. v.-Therapie mit Furosemid begonnen wurde. Der $\mathrm{Hb}$ von 6,4 g/dl erforderte die Gabe eines Erythrozytenkonzentrats. Nach 72 Stunden war die respiratorische Symptomatik gebessert und das Mädchen konnte auf Normalstation verlegt werden. Am fünften Tag zeigte sich bei Mikrohämaturie im Sammelurin zusätzlich eine große glomeruläre Proteinurie $(3,11 \mathrm{~g} / \mathrm{m} 2 /$ d, $\mathrm{N}<0,1)$. Auf eine Nierenbiopsie wurde bei Reduktion der Proteinurie im Verlauf verzichtet. Bei hohen IgG-Spiegeln im Serum gehen wir davon aus, dass es sich am wahrscheinlichsten um eine ImmunkomplexGlomerulonephritis handelt. Zur Reduktion der Proteinurie wurde eine Therapie mit einem ACE-Inhibitor begonnen. Elf Tage nach Diagnosestellung konnte das Mädchen nach Hause entlassen werden. In der Verlaufskontrolle fünf Tage nach Entlassung waren im Blut der Patientin noch Gametozyten nachweisbar; eine Woche später zeigte das Mädchen in der nephrologischen Verlaufskontrolle immer noch eine glomeruläre Proteinurie $(0,9 \mathrm{~g} / \mathrm{m} 2 / \mathrm{d})$.

Diskussion: Dieser Fall ist auch deswegen interessant, da das Mädchen neben dem ausgeprägten Lungenödem eine Glomerulonephritis entwickelte. Diese ist bei Kindern vornehmlich bei Infektionen mit Pl. malariae beschrieben und nur selten bei Pl. falciparum. Eine post-Pl.-falciparumGN ist vor allem bei erwachsenen Patienten beschrieben. Eine Co-Infektion mit Pl. malariae wurde in unserem Fall mittels PCR ausgeschlossen.

\section{DGPI-FP17}

\section{Novel TB immune-diagnostic test (TAM-TB) allows for treatment monitoring in a rare case of extra-pulmonary TB}

\section{Ahmed ${ }^{1,2}$, I. Dubinsky ${ }^{3}$, K. Held ${ }^{1,2}$, C. Geldmacher ${ }^{1,2}$, U. von Both ${ }^{3,1}$ 'DZIF, Standort München, Deutschland, ${ }^{2}$ Abteilung für Infektions- und Tropenmedizin, LMU München, München, Deutschland, ${ }^{3}$ Pädiatrische Infektiologie, Dr von Hauner'sches Kinderspital, LMU München, München, Deutschland}

Background: Childhood tuberculosis (TB), particularly in its extra-pulmonary form, is very challenging to diagnose, let alone to monitor treatment response. Predictive markers to differentiate between active disease and cure are lacking. Thus, clinicians of both adult and paediatric specialties acknowledge and an urgent need for improved diagnostic tests. Here we report a rare case of extra-pulmonary TB with a novel immune-diagnostic test allowing for both accurate diagnosis and treatment Monitoring. Case Presentation \& Results: A 16 year-old male refugee from Afghanistan presented to our tertiary care hospital with a 3-months history of worsening left-sided hip pain, but generally being stable and well otherwise. $\mathrm{He}$ did not report any episodes of high temperature. Previous conventional diagnostics, including a microbiological culture of the joint fluid aspirate yielded negative results. On presentation he showed a mildly raised CRP $(26 \mathrm{mg} / \mathrm{l})$ with normal FBC and chemistry. Conventional radiography and subsequent MRI scan of the hip joints revealed significant narrowing of joint space and destructive erosions of the left hip. IGRA testing was positive and $M$. tuberculosis could be detected from joint effusion using microscopy, PCR and culture. He was started on anti-TB treatment, gradually showing clinical improvement.

The novel TAM-TB assay previously demonstrated accurate differentiation between active TB and latent TB infection (LTBI) in different age groups [1]. We collected whole blood for TAM-TB assay at time of diagnosis (T0), 4 weeks (T4w) and 6 months (T6 m) into treatment. As expected, the test result at $\mathrm{T} 0$ accurately classified the patient as active TB. Of particular note, the samples collected at T4w and T6 m showed a clear trend towards the previously established LTBI-signature, thus mirroring the clinical response to anti-TB treatment.

Discussion: TB of the hip is a very rare event in Germany, but a common presentation of arthro-skeletal tuberculosis worldwide. It is an important differential diagnosis in migrant children from TB-high endemic countries presenting with prolonged episodes of joint pain. The TAM-TB assay is a very promising new tool with great potential to improve TB diagnostics. It may even be the only quantitative test allowing for treatment monitoring.
Large-scale validation studies are already underway and will soon inform about test sensitivity and specificity when applied in the field.

\section{Literatur}

1. Portevin D, Moukambi F, Clowes P et al (2014) Assessment of the novel T-cell activation marker-tuberculosis assay for diagnosis of active tuberculosis in children: a prospective proof-of-concept study. Lancet Infect Dis 14:931-938

\section{DGPI-FP18}

Lungen- und Leberabszess bei einem 1 Jahr alten Jungen immunologische Differentialdiagnose

\section{J. Böhm, A. Wroblewski, B. Schmidt}

St. Joseph Krankenhaus Berlin-Tempelhof, Klinik für Kinder- und Jugendmedizin, Berlin, Deutschland

Hintergrund: Patienten mit pulmonalen Infektionen - auch mit schwereren Verlaufsformen und dem Bedarf einer highflow nasal cannula (HFNC)- oder CPAP-Atemhilfe - begegnen dem Kinderarzt im klinischen Alltag auf einer pädiatrischen Intensivstation vor allem in den Wintermonaten mit hoher Frequenz, häufiger Erreger ist u. a. Streptokokkus pneumoniae. Abszedierungen gehören zu den Komplikationen einer schwer verlaufenden Pneumonie. In solchen Fällen sind bei der Suche nach Grunderkrankungen im Säuglings- und Kleinkindalter differentialdiagnostisch unter Anderem immunologische Erkrankungen in Betracht zu ziehen. Der folgende Fall soll einen möglichen Verlauf einer komplizierten Pneumonie illustrieren.

Fallbericht: Wir berichten den Fall eines 1 Jahr alten Jungen, der sich in den Wintermonaten mit seit einigen Wochen rezidivierend auftretendem Fieber sowie einer seit 2 Tagen zunehmenden Luftwegssymptomatik und Schlappheit mit ausbleibender Besserung nach antibiotischer Therapie mit Amoxicillin in unserer Klinik vorstellte. Bei Aufnahme reduzierter AZ blasses Kolorit, Tachydyspnoe mit Einziehungen und feinblasige RG bei sonst unauffälligem Status sowie deutlich erhöhte laborchemische Infektionsparameter und eine ausgeprägte Anämie. Sonographisch stellten sich ein großer pulmonaler Abszess $(7 \times 5 \times 4 \mathrm{~cm})$ im rechten Unterlappen sowie mehrere intrahepatische Abszesse dar. Es erfolgte umgehend die Umstellung der antibiotischen Therapie auf Ampicillin/Sulbactam, Metronidazol und Erythromycin sowie die chirurgische Abszessdrainage im Lungenunterlappen rechts, hierbei entleerte sich reichlich putrides Sekret. Nachfolgend war bei respiratorischem Versagen nCPAP-Therapie via HFNC notwendig. Kulturell wurden im Punktat sowie im Trachealsekret Streptokokkus pneumoniae und Haemophilus influenzae nachgewiesen. Wir erweiterten die antibiotische Therapie um Cefotaxim und Clindamycin, nach Erhalt des Antibiogramms wurde resistogrammgerecht auf letztere Antibiotika eingeengt. Unter diesem Therapieregime zeigten die laborchemischen Infektionsparamter eine rückläufige Tendenz. Im weiteren Verlauf gelang nur eine langsame Entwöhnung von der HFNC-Therapie, auch der Allgemeinzustand besserte sich nur zögerlich. Auch sonographisch zeigte sich nach initial rascher Befundregredienz der hepatischen Herde, die im Verlauf z.T. Schallschatten gebend imponierten, dann eine nur unzureichende Besserung des hepatischen und pulmonalen Befundes. Radiologisch stellte sich rechts-pulmonal nach Drainage anhaltend eine pneumatisierte Abszesshöhle mit bronchialer Fistel dar.

Aufgrund der multiplen abszedierenden Läsionen in mehreren Organen wurde weitere Diagnostik bzgl. einer möglichen Grunderkrankung durchgeführt. Infektiologisch ergaben sich bis auf den o.g. Nachweis von $\mathrm{S}$. pneumoniae und $\mathrm{H}$. influenzae keine weiteren pathologischen Befunde. Laborchemisch zeigten sich erniedrigte Spiegel der Immunglobuline und erniedrigte Impftiter der Antikörper gegen S. pneumoniae bei ausreichenden AK-Titern gegen $\mathrm{H}$. influenzae (Bisher waren 2 Impfdosen gegen Pneumokokken- und 3 gegen $\mathrm{H}$. influenzae appliziert worden.). In der weiterführenden immunologischen Diagnostik ergaben sich Erkenntnisse, die für die folgenden Behandlungsschritte von entscheidender Bedeutung sein sollten. 


\section{Poster Pflege GNPI}

\section{Pflege-P01 \\ Entwöhnung von der High-Flow Therapie - die pflegerischen Aspekte}

C. Werner, R. Hanusch

Gesundheits -und Kinderkrankenpflegerin, Station KIK S6, Uniklinik

Dresden, Dresden, Deutschland

Bei der Entwöhnung von einer High-Flow Therapie bei Frühgeborenen obliegt der Pflege besonders die Aufgabe einer intensiven Krankenbeobachtung und einer sanften Frühchenpflege. Die gesamte Einschätzung des Kindes kann oft sehr gut von den Pflegenden gegeben werden, da erheblich mehr Zeit am und um das Kind herum zur Beobachtung zur Verfügung steht. So wird in unserer Klinik versucht nach einem Schema die FlowRate zu senken. Dazu werden verschiedene Aspekte betrachtet, die den Atemzustand und Gesamtzustand des Kindes beurteilen.

\section{Pflege-P02 \\ Implementierung und Reliabilität eines Sedierungsscores (Comfort-B Scale) auf einer Neonatologischen (NICU) bzw. Pädiatrischen Intensivstation (PICU) \\ T.M. K. Völkl, J. Lubig, U. Stein, K. Ott \\ Kinder- und Jugendklinik, Universitätsklinikum Erlangen, Erlangen, Deutschland}

Hintergrund und Fragestellung: Die Erfassung der Güte der Analgosedierung gestaltet sich aufgrund verschiedener Faktoren (z. B. maschinelle Beatmung, Alter des Kindes mit mangelnder Krankheitseinsicht und fehlender verbaler Kommunikationsmöglichkeit) auf einer NICU/PICU oft schwierig. Auch wird die Steuerung der Sedierung und Analgesie bislang zumeist anhand einer subjektiven Einschätzung durchgeführt, die je nach Beurteiler entsprechend unterschiedlich ausfallen kann. Eine Möglichkeit dies zu objektivieren, ist die Verwendung geeigneter Scores.

Das Ziel dieser Intervention war die Implementierung der Comfortbehavior(B) Scale (van Diijk et al., 2005) auf der NICU bzw. PICU und die Erhebung der Interrater-Reliabilität sowie eine Evaluation nach Einführung.

Methoden: Jede Pflegekraft der NICU/PICU wurde von einer speziell geschulten Instruktorin theoretisch und anhand von 3 Videobeispielen in der Erhebung des Comfort-B Scale angeleitet. Anschließend wurden 10 Erhebungen des Scores am Patientenbett bei verschiedenen Kindern durchgeführt. Die Erhebungen erfolgten unabhängig ohne Einsicht auf das Ergebnis der Instruktorin und ohne die Möglichkeit von Rückfragen.

Für jedes Paar (Pflegekraft/Instruktorin) wurde das Maß der Übereinstimmung der 10 Erhebungen, die Interrater-Reliabilität, erhoben. Hierfür wurde der gewichtete Cohens Kappa Koeffizient ( $\kappa$ ) errechnet. Ein $\kappa \geq 0,6$ wurde als starke Übereinstimmung angenommen.

Nach einjähriger Implementierung des Scores erfolgte die Evaluation im Pflegeteam anhand eines anonymisierten Fragebogens.

Ergebnisse: Es wurden 127 Score-Erhebungen ausgewertet. 46 Erhebungen fanden an invasiv beatmeten Patienten statt, die übrigen waren ohne Atemhilfe bzw. hatten CPAP oder HFNC. Das mittlere Alter der Kinder lag bei 28 Tagen (Quartilen 7 und 53); die invasiv beatmeten Kinder waren signifikant älter (Median 45 vs 19 Tage; $p<0,0001$ ). Es konnte ein medianes Cohens $\kappa$ von 0,67 (Quartilen 0,65 und 0,69) aus allen Erhebungen erzielt werden. Zwischen der Gruppe der invasiv beatmeten Kindern und CPAP/HFNC bzw. nicht beatmeten Kindern fand sich kein Unterschied. Auch das Lebensalter des zu scorenden Kindes hatte keinen Einfluss auf das Maß der Übereinstimmung beider Untersucher. Pflegekräfte mit Berufserfahrung $\geq 10$ Jahren erzielten eine signifikant bessere Interrater-Reliabilität als Kollegen/-innen mit 0-5 Jahren Berufserfahrung (median 0,67 vs 0,$65 ; \mathrm{p}=0,0068$ ).

Die Evaluation des Scores nach einem Jahr ergab u. a., dass sich die Mehrheit der befragten Pflegekräfte ausreichend sicher in der Anwendung des
Scores fühlten $(71 \%)$ und dessen Erhebung gut in den Routineablauf zu integrieren ist (71\%). Ebenfalls $71 \%$ der Befragten gab an, sich vorstellen zu können, die Sedierung in einem vorgegebenen Dosisrahmen mittels Erhebung des Scores selbständig zu steuern.

Schlussfolgerung: Die Comfort-B Scale ist eine gute Möglichkeit, die Erfassung der Sedierung zu vereinheitlichen und zu objektivieren. Im Rahmen einer aufwändigen Schulung kann eine ausreichend gute Interrater-Reliabilität erzielt werden. Es zeigte sich in unserer Klinik eine gute Akzeptanz im Team, sodass dieser Score Grundlage für eine teil-selbständige Sedierungssteuerung durch Pflegekräfte sein kann.

\section{Pflege-P03}

Eine Studie über das Erleben von Eltern langzeitbetreuter Kinder während und nach der Betreuung an einer neonatologischen Intensivstation, am Beispiel des AKH Wien

\section{E. Smajic}

Neonatologische Intensivstation (NICU), Universitätsklinik für Kinder- und Jugendheilkunde, AKH - Med. Universitätscampus, Wien, Österreich

Hintergrund: Bedingt durch die Komplexität der Krankheitsbilder, wurde eine Zunahme der langzeitbetreuten Kinder und ihren Eltern auf einer neonatologischen Station (Ebene 10 NICU) im Allgemeinen Krankenhaus der Stadt Wien in den letzten Jahren beobachtet, die zunehmend in den Mittelpunkt der multidisziplinären Betreuung rückte. Fehlendes institutionelles und systematisches Wissen über das Erleben dieser Patientengruppe und deren Bezugspersonen, waren Beweggründe für eine empirische Untersuchung.

Fragestellung: Wie erlebten Eltern von frühgeborenen Kindern mit unterschiedlichen Krankheitsbildern, die länger als zwei Monate im neonatologischen Setting des allgemeinen Krankenhauses der Stadt Wien betreut wurden, ihr Umfeld und wie gehen sie heute mit dieser Situation um? Methodik: An dieser qualitativen Untersuchung nahmen fünf Eltern von fünf Kindern teil, die mit unterschiedlichen Krankheitsbildern geboren wurden. Zwischen 16. Juli und 10. Oktober 2015 wurde mit Ihnen im häuslichen Setting ein episodisches Interview mit einem halbstrukturierten Interviewleitfaden durchgeführt. Die zusammenfassende Inhaltsanalyse erfolgte durch eine induktive Kategorienbildung.

Ergebnisse: Fünf Schwerpunkte des elterlichen Erlebens wurden in Form von Kategorien generiert: 1. Belastungen, 2. Ressourcen, 3. Bedürfnisse, 4. Multiprofessionelle und inter- disziplinare Interaktionen, 5. Das Erleben danach.

Schlussfolgerung: Die Eltern von langzeitbetreuten Kindern sind individuellen Belastungen ausgesetzt und haben besondere Bedürfnisse während dieser Zeit, die das Erleben mit ihren Kindern beeinflussen. Ein spezielles multidisziplinäres Bezugsteam steigert das Wohlbefinden, erhöht das Vertrauen und führt zur Entlastung im neonatologischen Intensivsetting. Das kann nur gelingen, wenn Kontinuität, fachliche Kompetenz und Kommunikation von allen Beteiligten in der Betreuung gewährleistet und forciert wird. Speziell Pflegepersonen stellen eine wichtige Ressource für die Eltern dar und sind somit in der Langzeitbetreuung unverzichtbar.

\section{Pflege-P04}

\section{Das Passwort findet den Weg auf die Kinderintensivstation}

\section{Bergers, S. Spahl}

Kinderintensivstation, UKE, Hamburg, Deutschland

Projekt: Bei der Aufnahme eines urteils- oder handlungsunfähigen Patienten erfragt die Pflegefachperson bei den engsten Angehörigen des Patienten (Eltern od. weitere nähere Verwandte falls keine Eltern vorhanden) ein sogenanntes Pass- oder Codewort. Dieses Passwort wird in den Akten notiert und signalisiert den Mitarbeitern der Station ob eine nachfragende Person auskunftsberechtigt ist oder nicht. Bei Volljährigen sowie urteils- und handlungsfähigen Patienten wird das Passwort direkt beim Patienten erfragt. 
Wichtig: Der Vorname als auch der Nachname sind für die Passwortverwendung NICHT geeignet.

Beispiel: Die Eltern eines Kindes teilen der Pflegefachperson das Passwort „Sternchen79“ mit. Sternchen hat dabei vielleicht eine spezielle Bedeutung für die Eltern in Zusammenhang mit Ihrem Kind und 79 kann beispielsweise ein Geburtsjahr eines der Elternteile sein. Von nun an werden jegliche Informationen ausschließlich an Personen abgegeben, welche über dieses Passwort verfügen. Dies wird vor jeder Informationsauskunft (beispielsweise telefonische Auskunft) von der Pflegefachperson erfragt.

Zielsetzung:

1. Gewährleistung des Datenschutzes

2. Wahrung der Privatsphäre

3. Unterstützung der Vertrauensbildung

4. Sicherheitsvermittlung

Urteils- und handlungsfähige Patienten erhalten auf einfache Art und Weise eine Möglichkeit die Weitergabe Ihrer Informationen zu regulieren. Schutz vor den Medien in Fällen, welche öffentliches Interessen erwecken Umsetzung in der Praxis: Aufgrund seiner Einfachheit in der Anwendung ist eine schnelle Integration dieser Maßnahme auf der Station möglich. Die alltäglichen Arbeitsprozesse werden nicht gestört oder behindert und es fallen keine komplexen Veränderungen für die Mitarbeiter an. Lediglich die Pflegeanamnese wird um einen Punkt erweitert.

Benefit für die Patienten: Bei lückenfreier Umsetzung dieser Maßnahme, ist es nahezu unmöglich, dass Informationen des Patienten ungewollt nach außen dringen. Der Patient kann sich gewiss sein, dass seine Daten sicher verwahrt werden. Dies stärkt die Vertrauensbildung zwischen der Station und dem Patienten (oder seinen nächsten Angehörigen) und ermöglicht dem Patienten eine Genesung in sicherer Umgebung. Dabei ist das Ganze schnell und rasch umsetzbar, ohne dass für den Patienten oder dessen Angehörigen ein wesentlicher Mehraufwand besteht.

Übertragbarkeit des Projektes: Aufgrund seiner einfachen Struktur lässt sich die Maßnahme ohne weiteres auf jegliche Station übertragen. Dies beweist die Früh- und Neugeborenen-Intensivstation des UKE, welche die Passwortnutzung seit geraumer Zeit ebenfalls umsetzt.

Benefit für die Klinik: Der große Vorteil der Maßnahme ist, dass die Umsetzung des Projektes kaum Ressourcen der Klinik einfordert. Weder zusätzliches Personal noch ein zusätzlicher zeitlicher Aufwand ist von Nöten. Weiterhin ist das Projekt komplett kostenfrei umsetzbar. Zudem schützt die Maßnahme vor möglichem Fehlverhalten bzgl. Datenschutz und erspart ggf. juristische Folgen. Das Projekt überzeugt durch einen hohen Beitrag zur Patientensicherheit mittels extrem geringer Ressourcennutzung.

\section{Pflege-P05}

Pflegerische Aspekte bei Meningokokkenmeningitis mit Waterhouse Friederichsen Syndrom

S. Riedel

Kinderintensivstation, Uniklinikum Dresden, Dresden, Deutschland

„Fallbeispiel Egon H.“

Eine bakterielle Meningitis ist immer ein medizinischer Notfall.

Am Fallbeispiel eines 11 Monate alten Kindes wird das Vorgehen bei der Notfallversorgung, insbesondere unter pflegerischen Aspekten, dargestellt. Von der Anmeldung des Patienten, über die Vorbereitung des Patientenplatzes, Personalmanagement und Erstversorgung, bis zum Verlauf, soll dieses Beispiel ein Fazit für die Pflege erbringen.

\section{Pflege-P06}

Aktualisierung eines Stillkonzeptes nach den Richtlinien von WHO und BfR und Vorbereitung seiner Umsetzung am UniversitätsKinder- und Frauenzentrum Dresden mit Perinatalzentrum Level 1

C. Menzel, R. Pfeifer, E. Kersten

Universitäts- Kinder- und Frauenzentrum Dresden, Dresden, Deutschland

Hintergrund: In der Stillberatung ist es unser Ziel, fachlich kompetent und möglichst einheitlich in Empfehlung und praktischer Umsetzung zu bera- ten und anzuleiten. Seit 2001 gibt es am Universitäts- Kinder- und Frauenzentrum Dresden (UKF) ein Stillkonzept, welches den Standard festlegt und bis 2012 kontinuierlich aktualisiert und nach den aktuellen Stillrichtlinien angepasst wurde. Ein Feedback der Eltern zeigte, dass die erhaltenen Stillempfehlungen sehr unterschiedlichen waren. Das Ergebnis waren verunsicherte Eltern mit nicht befriedigenden Stillerfolgen, die sich nicht fachkompetent beraten fühlten. Zusätzliche Herausforderung stellen die unterschiedlichen Arbeitsabläufe auf den einzelnen Stationen des UKF dar. Zur Optimierung und Verbesserung der Stillsituation war eine grundlegende Überarbeitung des bestehenden Stillkonzeptes erforderlich. Umsetzung: Zur Überarbeitung des Stillkonzeptes wurde eine fachübergreifende Projektgruppe gebildet. In monatlichen Abständen fanden Treffen zum direkten Austausch sowie zur Diskussion und Kontrolle der bereits erarbeiteten Teilkonzepte statt. 2015 konnte ein umfassendes und evidenzbasiertes Stillkonzept am UKF fertiggestellt und genehmigt werden, das für die Mitarbeiter in allen Bereichen bindend ist. Herausforderungen bei Akzeptanz und Umsetzung des Stillkonzepts als Standard ergaben sich auf unterschiedlichen Ebenen und in den verschiedenen Arbeitsbereichen.

Zur Umsetzung des Stillkonzeptes war es demnach erforderlich, für die Hebammen und Kinderkrankenschwestern- und -pfleger zusätzliche Handlungsanweisungen zu erarbeiten. Diese beziehen sich auf allgemeine Still- und Beratungssituationen, aber auch auf die Frage des Hinzuziehens von Stillberaterinnen IBCLC bei speziellen Stillsituationen. Darüber hinaus wurden Indikationen zur Anforderung der speziellen Stillberatung konsentiert, im Stillkonzept hinterlegt und als Grundlage für die konsiliarische Beiziehung der speziellen Stillberatung definiert. Korrekturen und Anpassungen sind unter Beachtung der internationalen Stillstandards/ Leitlinien und der Prüfung der Umsetzbarkeit in der praktischen Anwendung im Arbeitsalltag im Verlauf notwendig.

Schlussfolgerung: Die Umsetzung eines neu erarbeiteten Stillkonzeptes ist eine Herausforderung für alle Beteiligten auf allen Arbeitsebenen. Die alleinige Existenz eines gültigen Stillkonzepts mit Handlungsanweisungen verändert die Beratungsqualität für die Eltern nur unzureichend. Um die einheitliche und umfassende Beratung und Anleitung der Eltern stillkonzeptkonform zu gewährleisten, sind im Stillkonzept auch Umsetzungsanweisungen zu definieren, die neben Argumentationsgrundlagen z. B. auch die Schulung der MitarbeiterInnen einschließen müssen. Eine Evaluation zur Umsetzung des Stillkonzepts ist geplant.

\section{Pflege-P07 \\ Erstellung eines Schulungskonzeptes zur Umsetzung des Stillkonzeptes am Universitäts- Kinder- und Frauenzentrum Dresden mit Perinatalzentrum Level 1}

C. Menzel, R. Pfeifer, E. Kersten

Universitäts- Kinder- und Frauenzentrum Dresden, Dresden, Deutschland

Hintergrund: Um die Stillergebnisse, die Qualität der Stillberatung und die Bindungs- und Entwicklungsförderung zu optimieren wurde $2015 \mathrm{im}$ Universitäts-Kinder-und Frauenzentrum (UKF) ein Stillkonzept entwickelt. Zur Sicherung der Umsetzung der neu erarbeiteten Stillstandards im Stationsalltag ist es notwendig, dass alle MitarbeiterInnen der gynäkologischen, neonatologischen und pädiatrischen Stationen einen einheitlichen Wissensstand erreichen und zur Umsetzung befähigt werden.

Umsetzung: Um einen einheitlichen Wissensstand aller MitarbeiterInnen zu erreichen, wurde ein modulares Schulungskonzept entwickelt. Der Schulungsinhalt ist nach theoretischen und praktischen Modulen gegliedert. Der Zeitrahmen der Gesamtschulung umfasst insgesamt 7-8 Stunden. Die Teilnahme an der Schulung ist für die MitarbeiterInnen der Pflege der entsprechenden Bereiche verpflichtend und wird als Arbeitszeit angerechnet; für das ärztliche Personal ist die Teilnahme fakultativ.

Der Schulungsplan für 2016 sah eine Schulung von 240 MitarbeiterInnen der einzelnen Stationen vor; die Vermittlung des Schulungsinhalts erstreckte sich über 4 Module a 120 Minuten Dauer, die im Abstand von vier Wochen angeboten wurden. Diese Vorgehensweise sollte den Arbeitsbedingungen in der stationären Routineversorgung von Schwangeren, Müt- 
tern und Neugeborenen am ehesten entsprechen. Angezielt war, insgesamt ca. 50\% der MitarbeiterInnen 2016 zu erreichen; tatsächlich wurden nur etwa $19 \%$ in allen Modulen geschult. Hinderungsründe waren hohes Arbeitsaufkommen, Schulungsbeginn zum Schichtwechsel sowie auch Widerstände gegen eine Schulung.

Für 2017 ergab sich hieraus die Konsequenz, die Schulungen als Ganztagsschulungen anzulegen, um dadurch der Dienstplanung der einzelnen Stationen besser entsprechen zu können. Erwartet wird eine deutliche höhere Erreichbarkeit der MitarbeiterInnen.

Schlussfolgerung: Damit ein Konzept nachhaltig eingesetzt werden kann, bedarf es einer langfristig orientierten Umsetzungsstrategie. Dabei sind die Aktualisierung des Konzeptes und die Planung von an den Bedarfen der Mitarbeiter orientierten Schulungen entscheidend für den Erfolg. Klar formulierte Zielkriterien erleichtern ggf. erforderliche Anpassungen der Umsetzungsstrategie.

\section{Pflege-P08}

Geschwister und Freunde zu Besuch auf der Kinderintensivstation

\section{K. Biernath}

Universitätsklinikum Essen, Essen, Deutschland

Die Handhabung der Besuchszeiten auf der pädiatrischen Intensivstation hat sich in den letzten Jahren stark zum Positiven verändert. Durften die Eltern früher ihre Kinder nur zu festen und zeitlich stark begrenzten Zeiten besuchen, ist heutzutage ein dabei-sein rund um die Uhr möglich. Allerdings gibt es immer noch starke Einschränkungen für die Besuche von Geschwisterkindern und guten Freunden der kleinen Patienten.

Dieses Poster beschäftigt sich im Rahmen einer ausführlichen Literaturrecherche mit den positiven Auswirkungen durch den Besuch von Geschwisterkindern und Freunden. Desweiteren zeigt es mögliche Ursachen auf, warum auch noch heutzutage die Besuchsmöglichkeiten von Intensivstation zu Intensivstation unterschiedlich offen oder eingeschränkt sind. Abschließend werden die daraus resultierenden Vor- und Nachteile erörtert.

Ziel des Posters ist es, Pflegekräfte zum Nachdenken anzuregen, um so den Patienten auf den pädiatrischen Intensivstationen den Besuch von ihren Geschwistern und Freunden zu ermöglichen.

\section{Pflege-P09}

\section{"Auch wenn der Anfang schwer war ..."}

\section{S. Männchen}

Klinik für Kinder- und Jugendmedizin, Universitätsklinikum Dresden, Dresden, Deutschland

1. Vorstellung einer perinatologischen Station

2. Situation, bevor die Station KIK-S8 eröffnet wurde

3. Vorteile der frühen Mutter-Kind-Bindung

4. Schwerpunkt Stillen

5. Vorstellung Patientenklientel

6. Interprofessionelle Zusammenarbeit für ein gutes Outcome

\section{Gutachter der Abstracts der GNPI}

Angelika Berger, Prof. Dr. (Wien/AT)

Wolfram Burkhardt, Dr. (Schwerin)

Georg Frey, Dr. (Darmstadt)

Matthias Heckmann, Prof. Dr. (Greifswald)

Roland Hentschel, Prof. Dr. (Freiburg)

Florian Hoffmann, Dr. (München)

Thomas Höhn, Prof. Dr. (Düsseldorf)

Helmut D. Hummler, Prof. Dr. (UIm)

Philipp Jung, Dr. (Lübeck)

Matthias Keller, Prof. Dr. (Passau)

Angela Kribs, Priv.-Doz. Dr. (Köln)

Helmut Küster, Dr. (Göttingen)

Eva Mildenberger, Prof. Dr. (Mainz)

Jens Möller, Prof. Dr. (Saarbrücken)

\section{Gutachter der Abstracts DGPI}

Christian Gille, Dr. (Tübingen)

Christoph Härtel, Dr. (Lübeck)

Christian Hedrich, Priv.-Doz. Dr. (Dresden)

Ulrich Heininger, Prof. Dr. (Basel/CH)

Johannes Hübner, Prof. Dr. (München)

Markus Hufnagel, Prof. Dr. (Freiburg)

Markus Knuf, Prof. Dr. (Wiesbaden)

Fabian Lander (Dresden)

Andreas Müller, Prof. Dr. (Bonn)

Matthias Nelle, Priv.-Doz. Dr. (Bern/CH)

Felix Neunhoeffer, Dr. (Tübingen)

Johannes Pöschl, Prof. Dr. (Heidelberg)

Irwin Reiss, Priv.-Doz. Dr. (Rotterdamm/NL)

Rainer Rossi, Prof. Dr. (Berlin)

Thomas Schaible, Dr. (Mannheim)

Rolf L. Schlößer, Prof. Dr. (Frankfurt a. M.)

Lothar Schrod, Priv.-Doz. Dr. Dr. habil. (Frankfurt a. M.)

Burkhard Simma, Dr. (Feldkirch/AT)

Dominique Singer, Prof. Dr. (Hamburg)

Guido Stichtenoth, Dr. (Lübeck)

Ulrich Thome, Prof. Dr. (Leipzig)

Johannes G. Liese, Prof. Dr. (Würzburg)

David Nadal, Prof. Dr. (Zürich/CH)

Horst Schroten, Prof. Dr. (Mannheim)

Arne Simon, Prof. Dr. (Homburg/Saar)

Volker Strenger, Ass. Prof. Priv.-Doz. Dr. univ. (Graz/AT)

Tobias Tenenbaum, Prof. Dr. (Mannheim)

Nicole Toepfner, Dr. (Dresden)

Fred Zepp, Prof. Dr. (Mainz) 